UNIVERSIDAD DE SALAMANCA

Departamento de Geología

\title{
ASTROBIOCRONOLOGÍA Y ESTRATIGRAFÍA DE ALTA RESOLUCIÓN DEL NEÓGENO DE LA CUENCA DEL GUADALQUIVIR-GOLFO DE CÁDIZ
}

Santiago Ledesma Mateo

TESIS DOCTORAL

Salamanca, 2000 

DEPARTAMENTO DE GEOLOGÍA

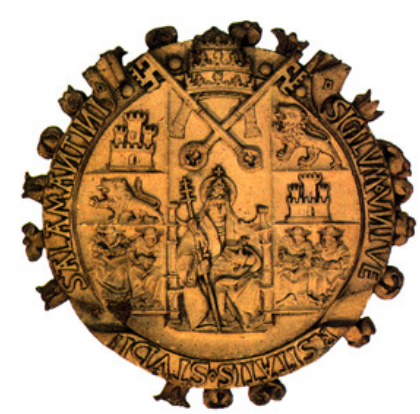

\section{ASTROBIOCRONOLOGÍA Y ESTRATIGRAFÍA DE ALTA RESOLUCIÓN DEL NEÓGENO DE LA CUENCA DEL GUADALQUIVIR-GOLFO DE CÁDIZ}

MEMORIA PARA ASPIRAR AL GRADO DE DOCTOR EN CIENCIAS GEOLÓGICAS POR LA UNIVERSIDAD DE SALAMANCA

$\mathrm{DE}$

SANTIAGO LEDESMA MATEO

Trabajo realizado bajo la dirección de los Profesores

D. FRANCISCO JAVIER SIERRO SÁNCHEZ

D. JOSÉ ABEL FLORES VILLAREJO

Salamanca, noviembre de 2000 


D. FRANCISCO JAVIER SIERRO SÁNCHEZ y
D. JOSÉ ABEL FLORES VILLAREJO,

PROFESORES TITULARES DE PALEONTOLOGÍA

DE LA UNIVERSIDAD DE SALAMANCA

CERTIFICAN

Que SANTIAGO LEDESMA MATEO ha realizado, bajo nuestra dirección, en el Departamento de Geología de la Universidad de Salamanca el trabajo:

\section{ASTROBIOCRONOLOGÍA Y ESTRATIGRAFÍA DE ALTA RESOLUCIÓN DEL NEÓGENO DE LA CUENCA DEL GUADALQUIVIR-GOLFO DE CÁDIZ}

Y para que conste, firmamos el presente certificado

Salamanca, noviembre de 2000
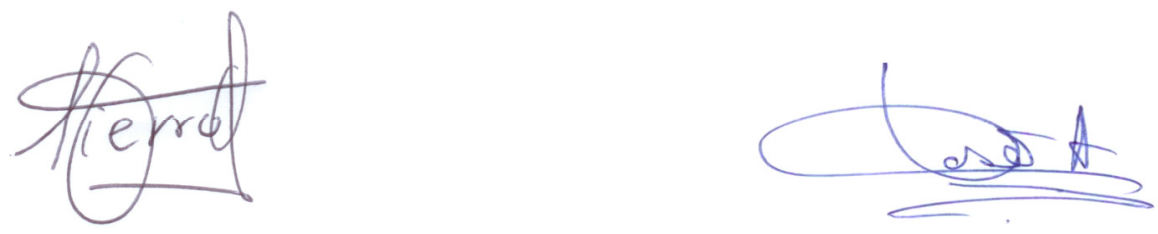

Francisco Javier Sierro Sánchez

José Abel Flores Villarejo 

Esta Tesis Doctoral ha sido financiada por la FUNDACIÓN REPSOL mediante una beca de investigación.

Los proyectos DGCYES PB98-0288 y FEDER 1FD97-1148, la Fundación Ramón Areces y el Programa Fulbright también han contribuido en la financiación de este trabajo.
FUNDACION REPSOL YPE

Departamento de Geología

Área de Paleontología

Facultad de Ciencias

UNIVERSIDAD DE SALAMANCA

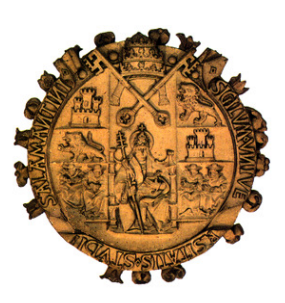





\section{AGRADECIMIENTOS}

En primer lugar quisiera expresar mi profunda gratitud y reconocimiento a mis directores de Tesis, Dr. D. FRANCISCO JAVIER SIERRO SÁNCHEZ y Dr. D. JOSÉ ABEL FLORES VILLAREJO.

Mención destacada merece la estrecha colaboración realizada con mis directores. Así, el doctor F.J. Sierro realizó en los años 80, análisis micropaleontológicos previos en algunos de los sondeos estudiados en este trabajo, dicha información no publicada, ha sido incorporada y fundida con los datos obtenidos en esta Tesis. Así mismo, los conocimientos del doctor Sierro sobre la geología general y la micropaleontología en particular del área estudiada, han supuesto una inagotable fuente de información. Por otro lado, el doctor J.A. Flores ha supuesto el otro pilar imprescindible en este trabajo, realizando los análisis de nanoplancton calcáreo así como un continuo seguimiento y asesoramiento en todos los aspectos de esta Tesis. La dilatada experiencia de ambos investigadores y su profesionalidad, han sido fundamentales en la consecución de los objetivos que nos habíamos planteado.

Quisiera dar las gracias a REPSOL EXPLORACIÓN S.A. que por medio de una franca y eficaz colaboración por parte de SUSANA TORRESCUSA y WENCESLAO MARTÍNEZ DEL OLMO ha contribuido significativamente en la ejecución de este proyecto. Quisiera agradecer personalmente a ambos, el apoyo que me han brindado y la celeridad con que han resuelto nuestra ingente demanda de documentación, así como su participación directa en la discusión y análisis de los resultados. También quisiera dar las gracias al geólogo JULIO HERNÁN-GÓMEZ por su interés, ayuda y comentarios. A JUAN LASTAGARAY (geólogo) y ÁNGELA ECHANOVE (geofísica) de Repsol, quisiera agradecerles su interés y colaboración durante la perforación del Sondeo Santa Clara-1. También quiero acordarme de JULIO y AVELINO (Técnicos de Geoservices) con los que conviví esos días rodeado de cables, sensores y pantallas de ordenador. Así mismo, al personal de los almacenes de Repsol en Daganzo-Madrid (Miguel y Vicente), gracias por echarme una mano y facilitarme el muestreo durante las interminables horas que pasé entre muestras de subsuelo, estanterías y cajas de madera.

Debo agradecer particularmente al director de la FUNDACIÓN REPSOL, D. JOSÉ LUIS DÍAZ FERNÁNDEZ su gestión y colaboración en este proyecto. Así mismo, a D. JOSÉ LUIS RAMOS y al resto de componentes de la Fundación, les agradezco su interés y apoyo para que este proyecto siguiera adelante. Quisiera subrayar la importancia que ha tenido para mí la adjudicación de esta beca de la FUNDACIÓN REPSOL y apoyar incondicionalmente este tipo de inversiones en investigación por parte de las empresas privadas. Espero y deseo que los inversores y todos aquellos que depositaron en mí su confianza, vean satisfechas sus expectativas. 
Por otra parte quiero expresar mi gratitud a las compañías LOCS y CEPSA por permitir el uso de la información sísmica y de sondeos en los permisos de exploración de hidrocarburos de su titularidad.

Debo dar las gracias a D. LUIS GRANADOS, que hace más de una década solicitó a la entonces Empresa Nacional Adaro los levigados de varios sondeos que fueron depositados en el Departamento de Geología de la Universidad de Salamanca, y cuyas muestras han sido estudiadas en este trabajo.

Quisiera dar las gracias al Dr. F. J. HILGEN de la Universidad de Utecht, sus comentarios y puntualizaciones en la calibración astronómica de algunos bioeventos utilizados.

Quiero agradecer el apoyo recibido por la Dra. Ma ÁNGELES BÁRCENA, MARTA PÉREZ, ELENA COLMENERO, ISABEL REGUERA y CARMEN ÁLVAREZ. También la ayuda de JESÚS RONCERO y J. IGNACIO MARTÍN en la preparación de las muestras.

A los Drs. D. JORGE CIVIS LLOVERA y D. JOSÉ ÁNGEL GONZÁLEZ les agradezco la oportunidad que me brindaron para estudiar los foraminíferos planctónicos del sondeo continuo "Huelva". Aunque no he podido invertir todo el tiempo que me hubiera gustado, agradezco la confianza que depositaron en mi. También a la Dra. Dña. MARUJA VALLE HERNÁNDEZ y a Dña. ROSARIO RIVAS CARBALLO les agradezco su apoyo.

Mi gratitud a JOSÉ M. GRAVALOSA y J. MANUEL RODRÍGUEZ por su inestimable colaboración y su compañía durante estos años.

Quiero dedicar esta Tesis a mi mujer, que es el soporte sobre el que se apoya todo mi trabajo. Gracias Carmen por tu ayuda y apoyo incondicional. 
ÍNDICE 
2.1. MARCO GEOGRÁFICO-GEOLÓGICO

2.1.1. La cordillera Bética 22

2.1.2. La cuenca del Guadalquivir-golfo de Cádiz 24

2.1.3. Evolución del margen Suribérico 27

2.1.4. Estratigrafía del Neógeno de la cuenca del Guadalquivir-golfo de Cádiz $\quad 30$

2.1.5. Exploración de hidrocarburos 35

2.2. PALEOCEANOGRAFÍA 39

2.2.1. Contexto oceanográfico actual del golfo de Cádiz 41

3.1. SONDEOS Y MUESTRAS

3.1.1 Sondeos de exploración de hidrocarburos 47

3.1.2 Tipos de muestra recuperada $\quad 52$

3.2. METODOLOGÍA DEL ANÁLISIS BIOESTRATIGRÁFICO 55

3.2.1. Preparación de las muestras $\quad 55$

3.2.2. Análisis micropaleontológico 56

3.2.3. Técnicas informáticas de apoyo 57

3.3. RESULTADOS

3.3.1. Bioeventos de globorotálidos carenados 63

3.3.2. Bioeventos de globorotálidos no carenados 64

3.3.3. Bioeventos de neogloboquadrínidos 65

3.3.4. Bioeventos de nanoplancton calcáreo 66

3.3.5. Sucesión bioestratigráfica 66

3.3.6. Astrobiocronología de los eventos del plancton calcáreo:

Correlación con otras áreas $\quad 76$

3.3.7. Unidades bioestratigráficas $\quad 82$

\section{PERFILES SISMOBIOESTRATIGRÁFICOS Y UNIDADES}

UNIDADES LITOSÍSMICAS

4.1. PERFILES SÍSMICOS $\quad 89$

4.2. METODOLOGÍA Y PERFILES SISMOBIOESTRATIGRÁFICOS 101

4.3. UNIDADES LITOSÍSMICAS 115 
5.1. INTRODUCCIÓN A LA CICLICIDAD EN EL REGISTRO GEOLÓGICO 125

5.1.1. Ciclos climáticos 126

5.1.2. Causas de la ciclicidad. Factor orbital en los cambios climáticos

5.1.2.1. Registro geológico de los ciclos climáticos orbitales

5.1.3. Sapropeles del Mediterráneo y la escala astronómica de tiempo

5.1.3.1 Desarrollo de la APTS

5.1.4. Ciclicidad orbital en registros geofísicos

5.2. SONDEOS Y DIAGRAFÍAS UTILIZADAS

5.3. METODOLOGÍA DEL ANÁLISIS CICLOESTRATIGRÁFICO

5.3.1.Ciclicidad orbital en diagrafías de sondeos de la cuenca del Guadalquivir-golfo de Cádiz

5.4. CALIBRACIÓN DE LOS LOGS CON LA SOLUCIÓN ASTRONÓMICA. CORRELACIONES

5.4.1. Messiniense inferior

5.4.2. Messiniense superior

5.4.3. Límite Mio-Plioceno

5.5. IMPLICACIONES PALEOCLIMÁTICAS Y

PALEOCEANOGRÁFICAS

6.1.1.Carmona-2

6.1.2. Santa Clara-1

6.1.3. Carmona-4

6.1.4. Carmona-1

6.1.5. Ciervo-1

6.1.6. Sevilla-2

6.1.7. San Juan V-6

6.1.8. San Juan V-2

6.1.9. San Juan R-1

6.1.10. San Juan Z-1

6.1.11. Salteras-1

6.1.12. Castilleja-1 
6.1.16. Isla Mayor-1 256

6.1.17. Melo-1 260

6.1.18. Marismas-2 264

6.1.19. Marismas-4 268

6.1.20. Marismas A-1 272

6.1.21. Asperillo-1 276

6.2. GOLFO DE CÁDIZ 280

6.2.1. Golfo de Cádiz D-1 280

6.2.2. Golfo de Cádiz C-4 284

6.2.3. Golfo de Cádiz C-2 285

6.2.4. Golfo de Cádiz B-2 288

6.2.5. Golfo de Cádiz B-4 292

6.2.6. Atlántida-2 292

6.2.7. Golfo de Cádiz C-3 294

6.2.8. Golfo de Cádiz B-6 300

6.2.9. Golfo de Cádiz B-3 304

6.2.10. Atlántida-3 308

$\begin{array}{ll}\text { 6.2.11. } 6 \mathrm{x} 1 & 312\end{array}$

7. MODELO SEDIMENTARIO 319

7.1. LA CUENCA TORTONIENSE-MESSINIENSE 321

7.2. EL RELLENO SEDIMENTARIO 332

7.2.1 Unidad litosísmica A 333

7.2.2 Unidad litosísmica B 338

7.2.3. Unidad litosísmica C 342

7.2.3.1. Depósitos turbidíticos en la cuenca
del Guadalquivir-golfo de Cádiz

7.2.4. Unidad litosísmica D 353

7.2.4.1. Límite Mio-Plioceno 354

7.2.5. Unidad litosísmica E 355

7.2.6. Posición relativa del nivel del mar 356

8. RELACIÓN CON LAS SERIES MEDITERRÁNEAS Y CON

LA CRISIS DE SALINIDAD MESSINIENSE $\quad \mathbf{3 6 1}$

8.1. LÍMITE TORTONIENSE-MESSINIENSE 363

8.2. MESSINIENSE PREEVAPORÍTICO 364

8.3. MESSINIENSE EVAPORÍTICO 367

8.4. LÍMITE MIO-PLIOCENO. La inundación pliocena 371

8.5. PLIOCENO 374

\begin{tabular}{lr} 
9. CONCLUSIONES & 377 \\
\hline
\end{tabular}

\begin{tabular}{lr} 
BIBLIOGRAFÍA & 383 \\
\hline
\end{tabular} 
TABLAS DE RESULTADOS CUANTITATIVOS PARCIALES

MATRICES DE LA TOPOGRAFÍA DE LA CUENCA

DURANTE EL TORTONIENSE-MESSINIENSE

“MICROPALEO-2000”, TÉCNICAS INFORMÁTICAS DE APOYO

GLOSARIO

ABREVIATURAS

\section{ANEXO}

POSTER resumen con la correlacción cicloestratigráfica de los sondeos estudiados

CD ROM: Versión digital de la Tesis Doctoral (incluye el programa

"Micropaleo-2000"). 


\section{ÍNDICE DE FIGURAS}

1.1. Localización general del área de estudio. $\quad 14$

1.2. Procedimiento seguido en la consecución de los objetivos propuestos. 16

2.1. Mapa general de la cordillera Bética y sus dominios. 21

2.2. Principales cuencas neógenas del sur de España. 23

2.3. Proyección cónica del suroeste peninsular.

2.4. Cuencas hidrográficas que drenan sus aguas al golfo de Cádiz. 25

2.5. Desplazamiento hacia el oeste del dominio de Alborán. 28

2.6. Modelo litosecuencial propuesto por Riaza y Martínez del Olmo (1996). 32

2.7. Secuencias de depósito establecidas por Sierro et al. (1996). 35

2.8. Localización de los principales descubrimientos y reservas de gas. 37

2.9. Evolución de la extracción de gas natural en España. 38

2.10. Distribución de las principales masas de agua mediterráneas. 40

2.11. Dinámica oceanográfica del golfo de Cádiz. 42

3.1. Sondeos en los que se han realizado análisis bioestratigráficos. 46

3.2. Esquema de funcionamiento de un sondeo mecánico de exploración. 48

3.3. Distintos aspectos de un sondeo de exploración de hidrocarburos. 49

3.4. Contaminación vertical de partículas en muestras tipo "ripio" (cutting). 54

3.5. Esquema de preparación de las muestras procedentes de ripios y testigos. 55

3.6. Sondeos estudiados y principales bioeventos localizados. 62

3.7. Relación de los principales foraminíferos planctónicos identificados. 63

3.8. Globorotálidos carenados utilizados en la datación. $\quad 64$

3.9. Globorotálidos no carenados utilizados en la datación. 65

3.10. Neogloboquadrínidos utilizados en la datación. 65

3.11. Escala temporal con los bioeventos y sucesos bioestratigráficos significativos. $\quad 67$

3.12. Distribución de las biozonas propuestas en los sondeos estudiados. 83

3.13. Panel de correlación tridimensional de las biozonas propuestas. 85

4.1. Posición de las líneas sísmicas utilizadas. $\quad 89$

4.2. Perfiles sísmicos utilizados.

4.3. Metodo de elaboración de los perfiles sismobioestratigráficos. 102

4.4. Perfiles sismobioestratigráficos. 107

4.5. Relación entre las unidades litosísmicas, bioestratigráficas y modelos previos. $\quad 116$

5.1. Tipos y rangos de ciclos en materiales pelágicos. 126

5.2. Ciclos climáticos de Milankovitch. 127

5.3. Teoría de Milankovitch. $\quad 129$

5.4. Solución astronómica de Berger para una latitud de $65^{\circ} \mathrm{N}$. 131

5.5. Registro isotópico de oxígeno en foraminíferos bentónicos (Broecker, 1992). 133 
5.6. Varianza espectral del isótopo de oxígeno de 0 a 800.000 años (Imbrie, 1985). 134

5.7. Ejemplo de sapropeles en un testigo del Mediterráneo. 135

5.8. Posibles procesos que conducen a la formación de los sapropeles. 136

5.9. Clásica sección cíclica de Punta di Maiata al sur de Sicilia. 139

5.10. El registro geofísicos como herramienta en la detección de ciclos climáticos. $\quad 142$

5.11. Posición de los sondeos empleados en el análisis cicloestratigráfico. 145

5.12. Metodología del análisis cicloestratigráfico. 149

5.13. Ejemplo de correlación y datación astronómica de dos de los sondeos. 153

5.14. Análisis espectral del registro de velocidad sónica del sondeo Atlántida-3. 158

5.15. Cicloestratigrafía y calibración astronómica de los sondeos Vim-1 y Can-1. 161

5.16. Correlación del sondeo Casanieves-1 con las series cíclicas mediterráneas. $\quad 167$

5.17. Cicloestratigrafía y calibración astronómica, sondeos C2, Vim-1 y Can-1. 169

5.18. Cicloestratigrafía y calibración astronómica de los sondeos C3, C2 y C4. 173

5.19. Cicloestratigrafía y calibración astronómica de los sondeos B2 y C2. 177

5.20. Cicloestratigrafía y calibración astronómica de los sondeos At-3 y 6x1. 179

5.21. Cicloestratigrafía y calibración astronómica, sondeos B2, C2, 6x1 y At-3. 181

5.22. Cicloestratigrafía y calibración astronómica de los sondeos C3 y D4. 183

5.23. Cicloestratigrafía y calibración astronómica de los sondeos B5, C5 y At-3. 185

5.24. Cicloestratigrafía y calibración astronómica de los sondeos C4, D1 y D4. 187

5.25. Respuesta sedimentaria a la ciclicidad orbital. $\quad 190$

6.1. Leyenda de las figuras sintéticas de cada sondeo. 199

6.2. Leyenda de los perfiles sismobioestratigráficos incluidos en este capítulo. 200

6.3. Sondeo Carmona-2. 203

6.4. Sondeo Santa Clara-1. 205

6.5. Sondeo Carmona-4. 211

6.6. Sondeo Carmona-1. 215

6.7. Sondeo Ciervo-1. 219

6.8. Sondeo Sevilla-2. 221

6.9. Sondeo San Juan V-6. 225

6.10. Sondeo San Juan V-2. 227

6.11. Sondeo San Juan R-1. 231

6.12. Sondeo San Juan Z-1. 235

6.13. Sondeo Salteras-1. 239

6.14. Sondeo Castilleja-1. 241

6.15. Sondeo Palancares-1. 245

6.16. Sondeo Villamanrique-1. 249

6.17. Sondeo Casanieves-1. 253

6.18. Sondeo Isla Mayor-1. 257 
6.19. Sondeo Melo-1. 261

6.20. Sondeo Marismas-2. 265

6.21. Sondeo Marismas-4. 269

6.22. Sondeo Marismas A-1. 273

6.23. Sondeo Asperillo-1. 277

6.24. Sondeo D1. 281

6.25. Sondeo C2. 286

6.26. Sondeo B2. 289

6.27. Sondeo At-2. 293

6.28. Sondeo C3. 295

6.29. Sondeo B6. 301

6.30. Sondeo B3. 305

6.31. Sondeo At-3. 309

6.32. Sondeo $6 \times 1$. 313

6.33. Figura resumen con los bioeventos y sucesos estratigráficos significativos. $\quad 317$

7.1. Mapa de isobatas de la isócrona correspondiente a 8 Ma. 324

7.2. Mapas tridimensionales de la isócrona correspondiente a 8 Ma. 325

7.3. Mapa de isobatas de la isócrona correspondiente a 7.24 Ma. 326

7.4. Mapas tridimensionales de la isócrona correspondiente a 7.24 Ma. 327

7.5. Mapa de isobatas de la isócrona correspondiente a 6.35 Ma. 328

7.6. Mapa tridimensional de la isócrona correspondiente a 6.35 Ma. 329

7.7. Mapa de isobatas de la isócrona correspondiente a 6.05 Ma. 330

7.8. Mapa tridimensional de la isócrona correspondiente a 6.05 Ma. 331

7.9. Panel de correlación tridimensional basado en las unidades litosísmicas. $\quad 334$

7.10. Sucesión estratigráfica en dos cortes transversales a la cuenca. 336

7.11. Borde norte de la cuenca del Guadalquivir, afloramientos de campo. 339

7.12. Formación “arcillas de Gibraleón” y nivel de glauconita. 340

7.13. Evolución del relleno sedimentario basado en el perfil sísmico $\mathrm{n}^{\circ} 1$. 345

7.14. Aparatos turbidíticos messinienses en la cuenca del Guadalquivir-golfo de Cádiz. 348

7.15. Contacto discordante entre las unidades C y D en la cabecera de la cuenca. 351

7.16. Unidades bioestratigráficas, cicloestratigráficas y litosísmicas del perfil $\mathrm{n}^{\circ} 10 . \quad 352$

7.17. Esquema sintético de la disposición de las unidades litosísmicas en la cuenca. $\quad 357$

8.1. Diferentes interpretaciones respecto a la datación de la Crisis de Salinidad. 368

8.2. Datación y correlación de los sondeos Vim-1 y Can-1 con la Crisis de Salinidad. 372 



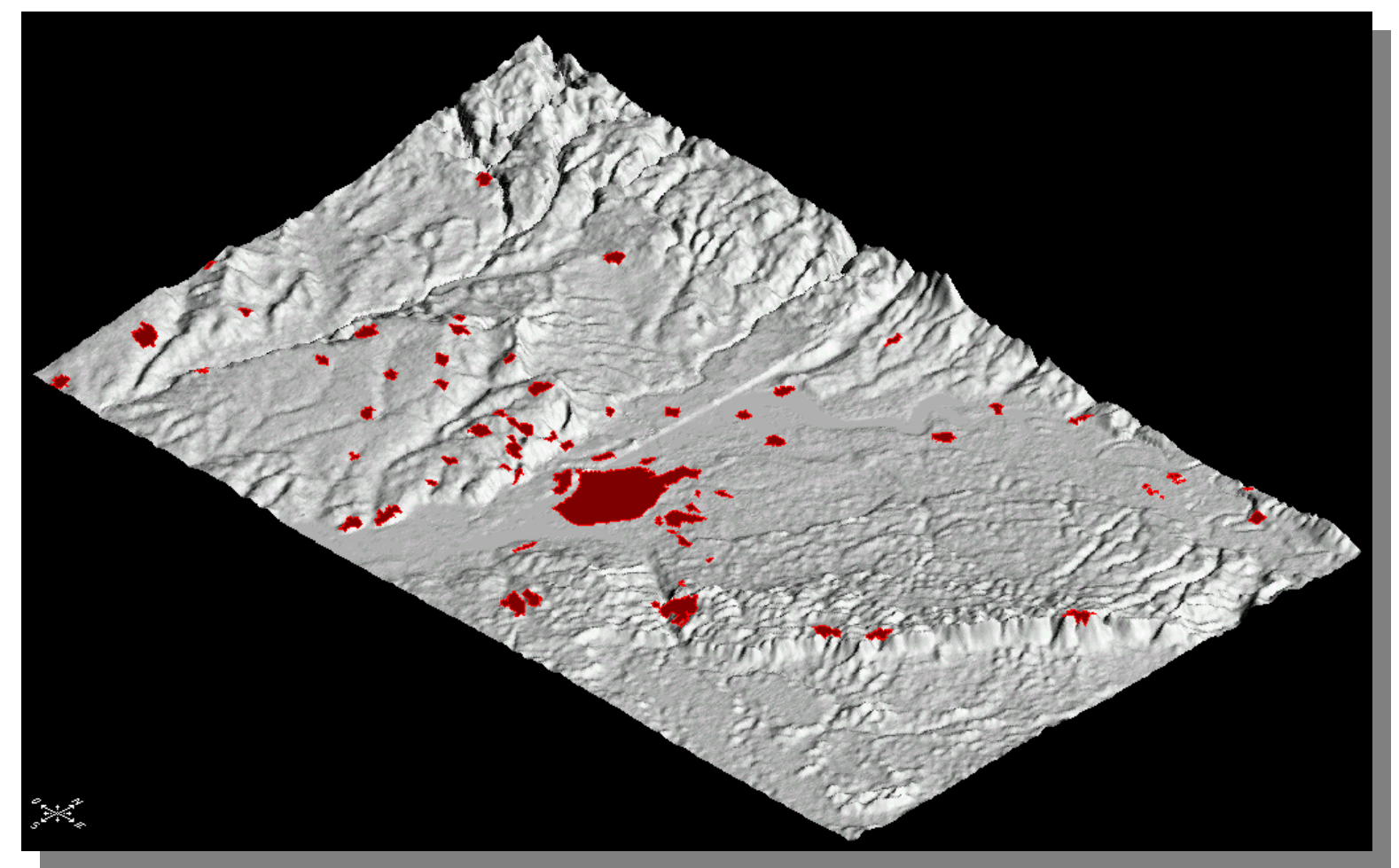

1. OBJETIVOS 
Página anterior: Mapa topográfico tridimensional de los alrededores de la ciudad de Sevilla. En la zona inferior derecha de la imagen se observa el relieve de la calcarenita de Carmona, con esta localidad en el extremo nororiental. Cartografía digital del Ejército de Tierra (basado en el mapa topográfico 1:200.000). 
La industria petrolera ha dedicado grandes inversiones a la investigación del subsuelo en España. Desde mediados de la década de los años 50, la actividad de las compañías petroleras ha sido importante. No obstante, en los últimos años la exploración petrolífera se ha reducido considerablemente, habiéndose extinguido o renunciado a la mayoría de los permisos de exploración otorgados por la Administración. El origen de las compañías prospectoras ha sido muy diverso, además del español, también han operado compañías de nacionalidad norteamericana, canadiense, francesa, belga, holandesa, italiana, británica y alemána. Según datos del ITGE (1990), entre las compañías petroleras que invirtieron considerables esfuerzos en la exploración de hidrocarburos en nuestro país destacan Repsol (y sus predecesoras Hispanoil-Auxini...), las francesas Enpasa, Enpensa y Coparex, las americanas Amospain (Texaco-Chevron), Valdebro (General American), Phillips y Esso.

La cuenca del Guadalquivir, enmarcada en una localización tectónica compleja próxima a un límite de placas, fue una de las principales áreas de interés para estás compañías. Actualmente la mayor parte de los presupuestos se destinan a la exploración offshore, en el golfo de Cádiz. Esta Tesis Doctoral se encuadra entre ambas áreas, concretamente en la zona que aparece recuadrada en la figura 1.1.

La Tesis contiene tres líneas de investigación bien definidas e íntimamente relacionadas:

- Por un lado, la investigación se centrará en el análisis bioestratigráfico de las muestras procedentes de ripios, testigos continuos y testigos laterales de sondeos comerciales perforados tanto onshore en el Guadalquivir, como offshore en el golfo de Cádiz. Con la información obtenida se determinarán una serie de unidades bioestratigráficas que van a constituir el marco de referencia para los otros dos apartados.

- Por otro lado, el análisis de los perfiles sísmicos permitirá obtener una serie de unidades litosísmicas que permitirán contrastar el actual modelo de secuencias de depósito y avanzar en la reconstrucción del relleno sedimentario de la cuenca.

- Finalmente, se pretende realizar un exhaustivo estudio cicloestratigráfico basado en el análisis de diagrafías de diferentes sondeos del área de estudio. En este punto se tratará de potenciar la correlación de sondeos mediante diagrafías, apoyándose en los dos puntos anteriores y en la investigación cicloestratigráfica de las frecuencias astronómicas de Milankovitch. 

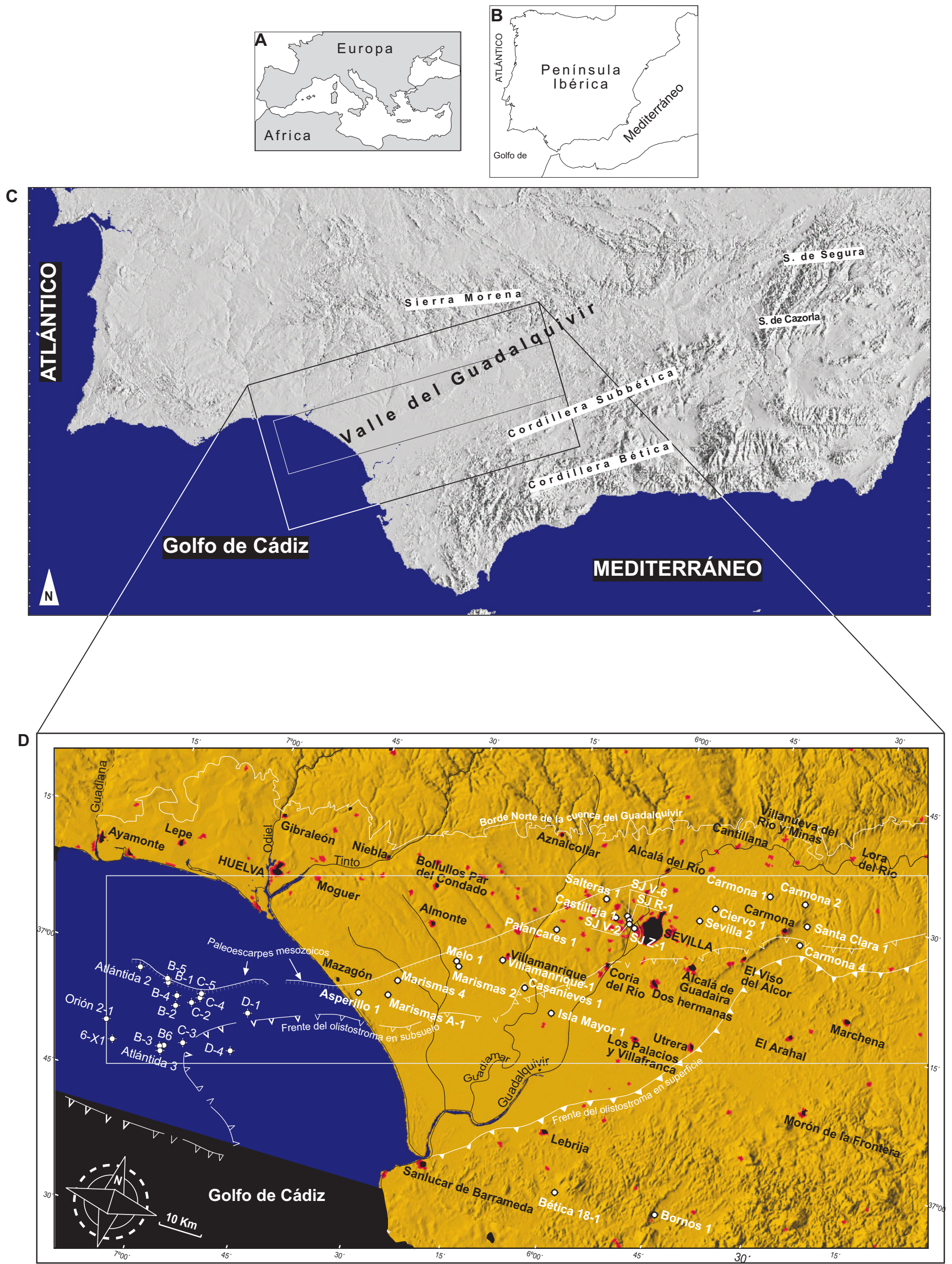

Figura 1.1. A, B y C, localización general del área de estudio. D, localización de los sondeos de exploración utilizados en este trabajo; recuadrado en blanco el principal área de interés. 
Concretamente la Tesis Doctoral pretende abordar los siguientes objetivos:

1. Realizar el análisis de foraminíferos planctónicos procedentes de muestras de sondeos de diferentes puntos de la cuenca del Guadalquivir-golfo de Cádiz. Para ello se seleccionarán aquellos sondeos que puedan ser de mayor interés y que atraviesen las principales unidades del relleno sedimentario. Se utilizarán tanto sondeos recientes llevados a cabo por Repsol SA, como antiguos sondeos realizados por otras compañías multinacionales.

2. Proponer una nueva bioestratigrafía de alta resolución para el área de estudio basada en el análisis de foraminíferos planctónicos (excepcionalmente en nanofósiles calcáreos). Para ello se compararán los datos obtenidos con las secciones de referencia en la escala de tiempo astronómica tanto del Mediterráneo occidental (cuencas del SE de España) como del Mediterráneo oriental (Sicilia y Creta). Así mismo se considera de particular interés la relación existente entre las dos zonas que constituyen la cuenca: el área del Guadalquivir y el del golfo de Cádiz. En la actualidad existe cierta desconexión entre ambas áreas debido a la ausencia de líneas sísmicas que conecten ambos dominios.

3. Obtener una datación precisa de los sondeos mediante la bioestratigrafía de alta resolución y comparar los resultados con las series mediterráneas arriba mencionadas. Calibrar los eventos biogénicos identificados en la cuenca del Guadalquivir con la escala magnetoestratigráfica de Cande y Kent (1992) y con la escala de tiempo de polaridad astronómica (APTS, Astronomical Polarity Time Scales) actualmente en proceso de elaboración para el Mioceno superior (ver Hilgen et al. 1995, 1999, Krijgsman et al., 1995).

4. En particular se va a dedicar especial atención a los cuerpos turbidíticos (objeto de la exploración de hidrocarburos en el área) y a la datación de la discontinuidad intramessiniense identificada en la cuenca por Martínez del Olmo et al. (1996). La correlación de esta discontinuidad con los eventos acaecidos en el Mediterráneo durante ese momento proporcionará sin duda novedosa información a la evolución ambiental del Mediterráneo y de las zonas adyacentes durante la Crisis de Salinidad Messiniense.

5. Se pretende calibrar por primera vez los sondeos de exploración de la cuenca del Guadalquivir y golfo de Cádiz con la escala astronómica de Tiempo. Los estudios estratigráficos de series cíclicas en tierra han procurado en los últimos años una enorme cantidad de información estratigráfica y han mostrado la utilidad de la cicloestratigrafía. La escala de tiempo de polaridad astronómica (APTS) fue establecida en series actualmente expuestas en el Mediterráneo (como son Metochia en la isla de Creta, Falconara en la de 
Sicilia, o Sorbas en Almería) y ha sido utilizada en las campañas de ODP (Ocean Drilling Program) en sedimentos marinos a lo largo del Mediterráneo oriental (ODP, Leg 160) y en el Mediterráneo occidental (ODP, Leg 161). La utilización de esta escala de tiempo de alta resolución ha sido uno de los pilares fundamentales en la evaluación de la reconstrucción paleontológica, paleoceanográfica y paleoclimática de la cuenca mediterránea.

6. Como complemento de la investigación bioestratigráfica se pretende realizar una aplicación informática que permita automatizar el recuento de microfósiles, que agilice el recuento y sea intuitiva. La base de datos resultante deberá ser compatible con las habituales hojas de cálculo.

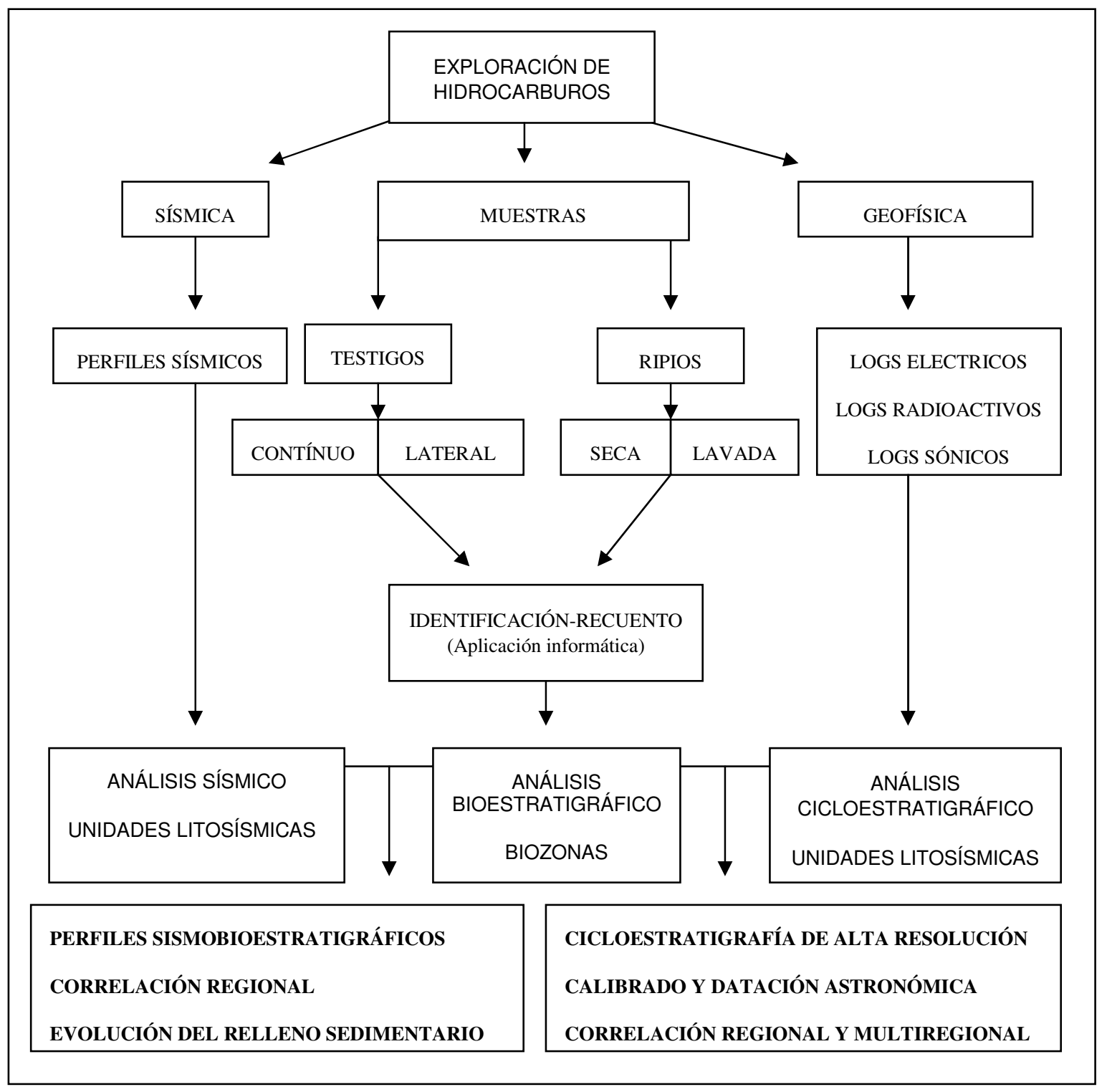

Figura 1.2. Proceso seguido para la consecución de los objetivos propuestos. 
La Tesis Doctoral pretende completar los resultados micropaleontológicos obtenidos con toda aquella información estratigráfica, sísmica y geofísica que sea posible, con el fin de establecer un modelo integral basado en un estudio pluridisciplinar de la evolución de la cuenca. Resumiendo los principales objetivos, pretendemos proporcionar nueva información micropaleontológica, plantear una interpretación del relleno sedimentario a través del análisis de los perfiles sísmicos y obtener una cicloestratigrafía de alta resolución basada en el análisis de las diagrafías de sondeos profundos. En la figura 1.2 se resumen los pasos seguidos para alcanzar los objetivos propuestos.

Palabras clave: astrobiocronología, bioestratigrafía, ciclicidad, cicloestratigrafía, cuenca del Guadalquivir, exploración de hidrocarburos, gamma ray, golfo de Cádiz, Messiniense, Milankovitch, Plioceno, Tortoniense; sonic. 


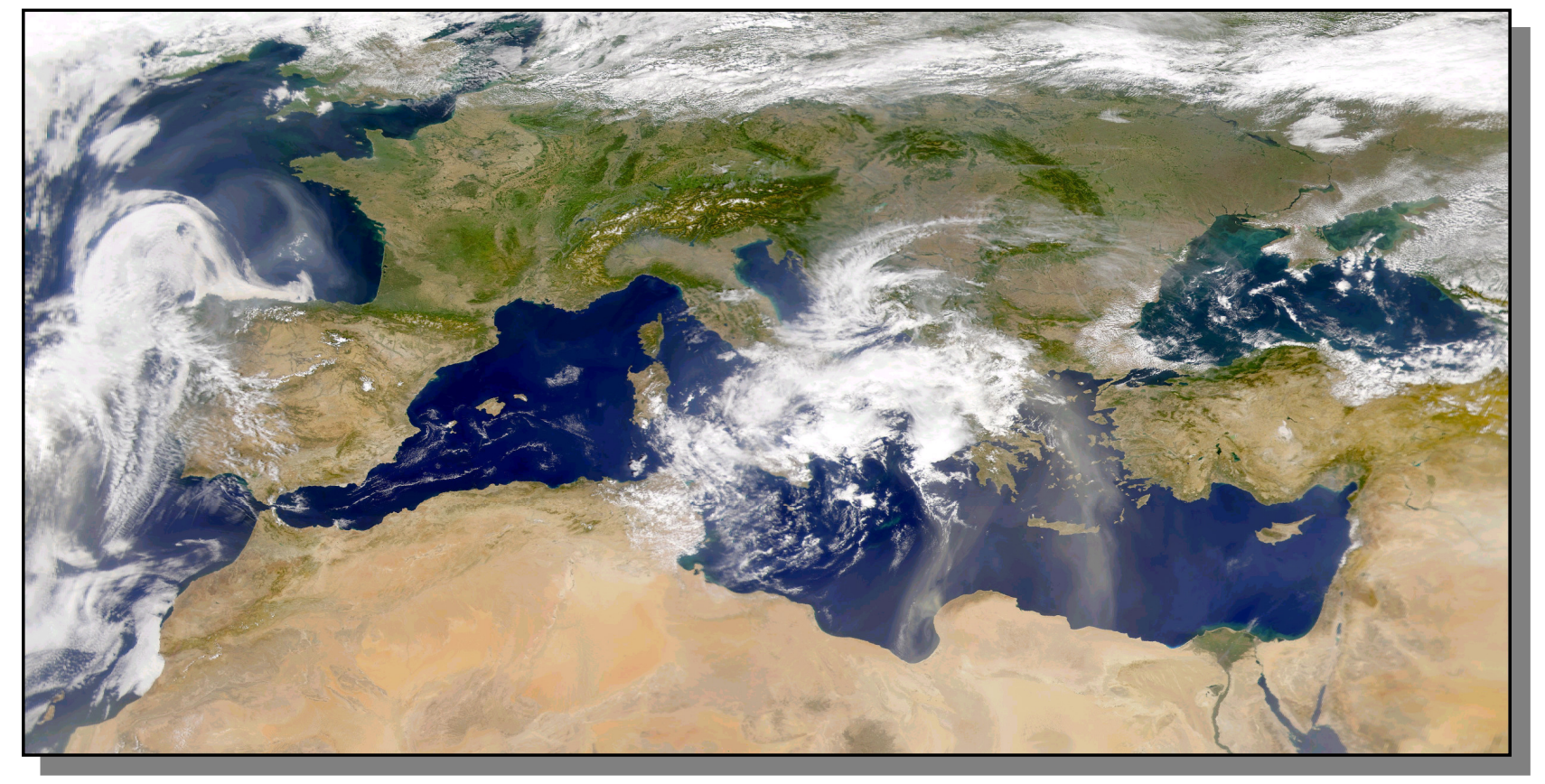

\section{CONTEXTO GEOLÓGICO Y OCEANOGRÁFICO}


Página anterior: Europa desde el espacio. Imagen obtenida en http://visibleearth.nasa.gov/ 


\subsection{MARCO GEOGRÁFICO-GEOLÓGICO}

La cuenca del Guadalquivir representa la cuenca de antepaís del orógeno Bético y constituye la mayor cuenca terciaria del sur peninsular.

En la figura 2.1 podemos observar el complejo contexto tectónico del sur peninsular. En el marco regional en el que se encuadra la cuenca del Guadalquivir-golfo de Cádiz destacan tres dominios fundamentales:

- I. La cordillera Bética que representa el orógeno, con sus respectivos dominios.

- II. La cuenca del Guadalquivir (-golfo de Cádiz) como cuenca de antepaís.

- III. El macizo ibérico (antepaís), que queda al norte, fuera de nuestro área de interés y al que no dedicaremos ningún capítulo en particular.

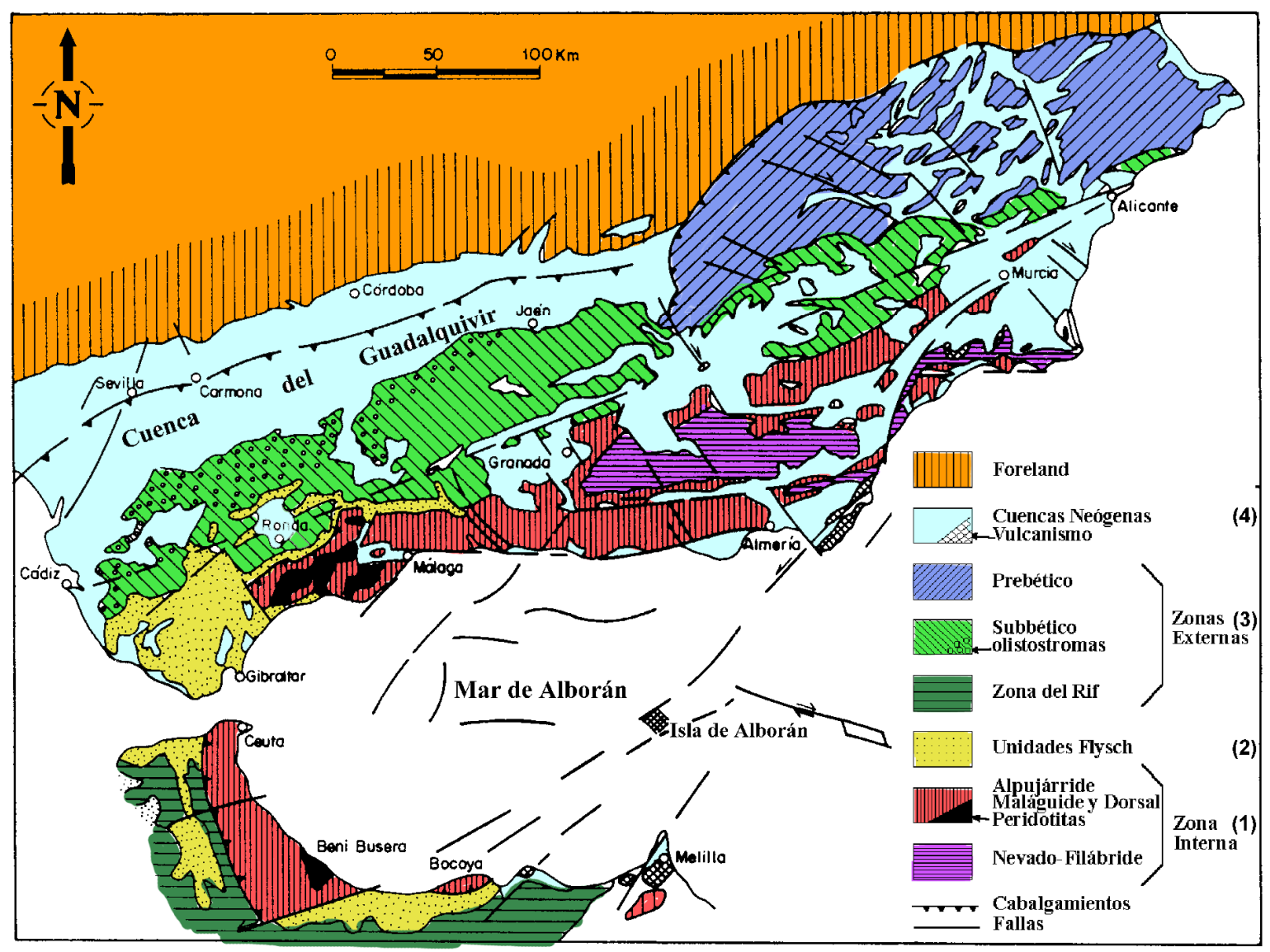

Figura 2.1. Mapa general de la cordillera Bética y sus dominios (modificado de Sanz de Galdeano y Rodríguez-Fernández, 1996). Explicación en el texto. 


\subsubsection{La cordillera Bética}

Las cordilleras Béticas atraviesan durante $650 \mathrm{~km}$ el sur de la Península Ibérica, desde el cabo de la Nao al este, hasta el golfo de Cádiz al oeste. Junto con el Rif (Marruecos), la cordillera Bética forma parte de las cadenas alpinas mediterráneas occidentales y está compuesta de los siguientes dominios:

1.- Dominio de Alborán (Zona Interna) (1 de la figura 2.1). Está formado por tres complejos superpuestos tectónicamente, cuyos materiales están más o menos metamorfizados. Los complejos, en orden ascendente en el apilamiento, se denominan: Complejo Nevado-Filábride, complejo Alpujárride y complejo Maláguide. El dominio de Alborán forma las Zonas Internas de la cordillera Bética y constituye el basamento del mar de Alborán (García-Dueñas y Martínez-Martínez, 1988).

2.- Complejo del Surco de Flyschs (2 de la figura 2.1). En una posición tectónica algo más compleja, intermedia entre los dominios de la zona Interna (1) y de la zona Externa (3) se sitúan unas secuencias rítmicas muy potentes, de arenisca y arcilla, de carácter turbidítico, denominadas "complejo del Surco de Flyschs". Son rocas de edades mesozoicas y terciarias, que se depositaron sobre una corteza continental atenuada y/o sobre corteza oceánica en medios marinos profundos (Biju-Duval et al., 1978; Decourt et al., 1986; Vera, 1988; Sánchez-Almazo, 1999). Concretamente, el "complejo del Campo de Gibraltar" forma parte de las unidades alóctonas originalmente depositadas desde la cuenca de Flysch norteafricana al sur del dominio Sur-Sárdico (Sanz de Galdeano y Rodríguez-Fernández, 1996).

3.- Dominio Suribérico (zona Externa) (3 de la figura 2.1). Fue el paleomargen meridional mesozoico y cenozoico del Macizo Ibérico y lo forman las Zonas Externas de la cordillera. Está constituido por sedimentos mesozoicos y terciarios muy deformados, ya que están afectados por cabalgamientos (García-Hernández et al., 1980; Vera, 1988).

La zona Externa incluye dos dominios: el plegado dominio Prebético autóctono, enlazado al norte con la Meseta, y las unidades alóctonas subbéticas que cabalgan el Prebético hacia el norte. El Prebético y el Subbético están formados de series sedimentarias que van desde el Triásico al Mioceno. Las últimas evaporitas triásicas actúan como un gran 
nivel de despegue y han jugado un importante papel en el desarrollo tectonosedimentario (Vera, 1986; Montenat, 1996).

\section{4.- Las cuencas neógenas (4 de la figura 2.1)}

Diversas cuencas con sedimentos neógenos marinos aparecen tanto en la zona Interna como en la Externa (fig. 2.2). Las cuencas subbéticas contienen sedimentos sinorogénicos y postorogénicos. Estas cuencas que se formaron durante el Mioceno inferior y medio presentan caracteres típicamente sinorogénicos. Las últimas cuencas están deformadas y en ocasiones localmente, con un alto grado de deformación (Sanz de Galdeano y Rodríguez-Fernández, 1996).

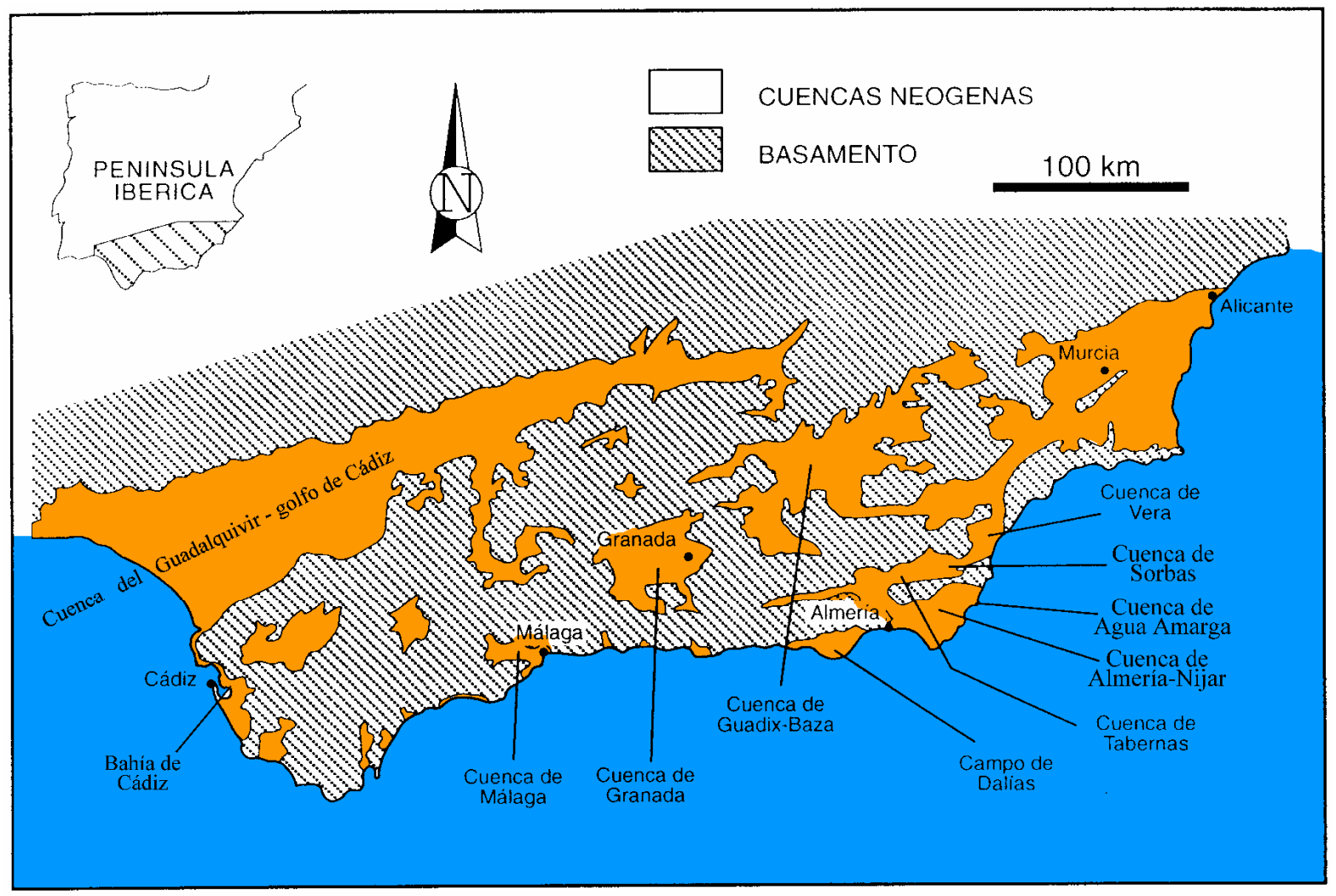

Figura 2.2. Principales cuencas neógenas del sur de España (Modificado de Sánchez Almazo, 1999). 


\subsubsection{La cuenca del Guadalquivir-golfo de Cádiz}

Actualmente, el valle del Guadalquivir es una depresión topográfica orientada en dirección ENE-WSW, flanqueada septentrionalmente por Sierra Morena y al sur por la cordillera Bética (fig. 2.3.). La Meseta Ibérica al norte presenta una altitud media de unos $500 \mathrm{~m}$, que aumenta hasta $\operatorname{los} 650 \mathrm{~m}$ al aproximarse a Sierra Morena y disminuye conforme avanzamos sobre la depresión del Guadalquivir. Ya en la cuenca, la altitud oscila entre unos $500 \mathrm{~m}$ en el extremo NE y el nivel del mar en el extremo SW de la misma. Al sur, en la cordillera Bética, se alcanzan altitudes máximas superiores a $3000 \mathrm{~m}$, si bien, no suelen sobrepasarse los $1500 \mathrm{~m}$. La cordillera disminuye en elevación hacia el oeste y, tras orientarse en dirección norte-sur junto al estrecho de Gibraltar, enlaza con el Rif en el continente africano (García Castellanos, 1998).

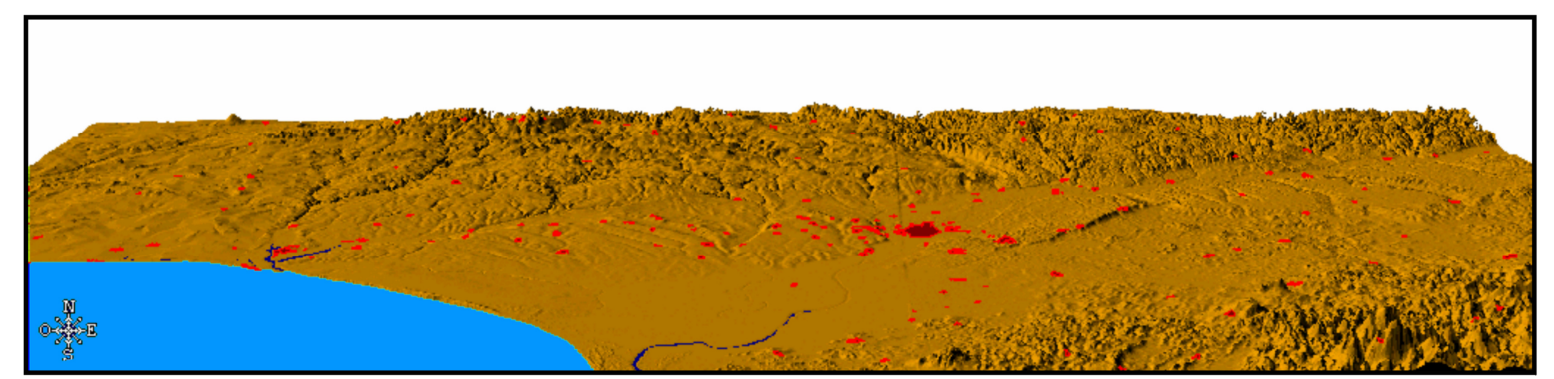

Figura 2.3. Proyección cónica del suroeste peninsular. Cartografía digital del Ejército de Tierra (1:200.000). Al norte, Sierra Morena bordea la cuenca del Guadalquivir. En el sur destaca la cordillera Bética en el extremo inferior derecho de la imagen. En el centro de la figura se encuentra la ciudad de Sevilla con la calcarenita de Carmona al este de la capital andaluza.

El drenaje de la depresión del Guadalquivir, así como el del extremo sur de la Meseta y de la mayor parte de las béticas se canaliza en dirección longitudinal ENE-WSW a través del río Guadalquivir. Si unimos a esta cuenca de drenaje la cuenca del Guadiana, y la de los ríos menores que desembocan en el golfo de Cádiz, nos encontramos con que la mayor parte de la mitad sur peninsular vierte sus aguas al golfo de Cádiz (fig. 2.4). 


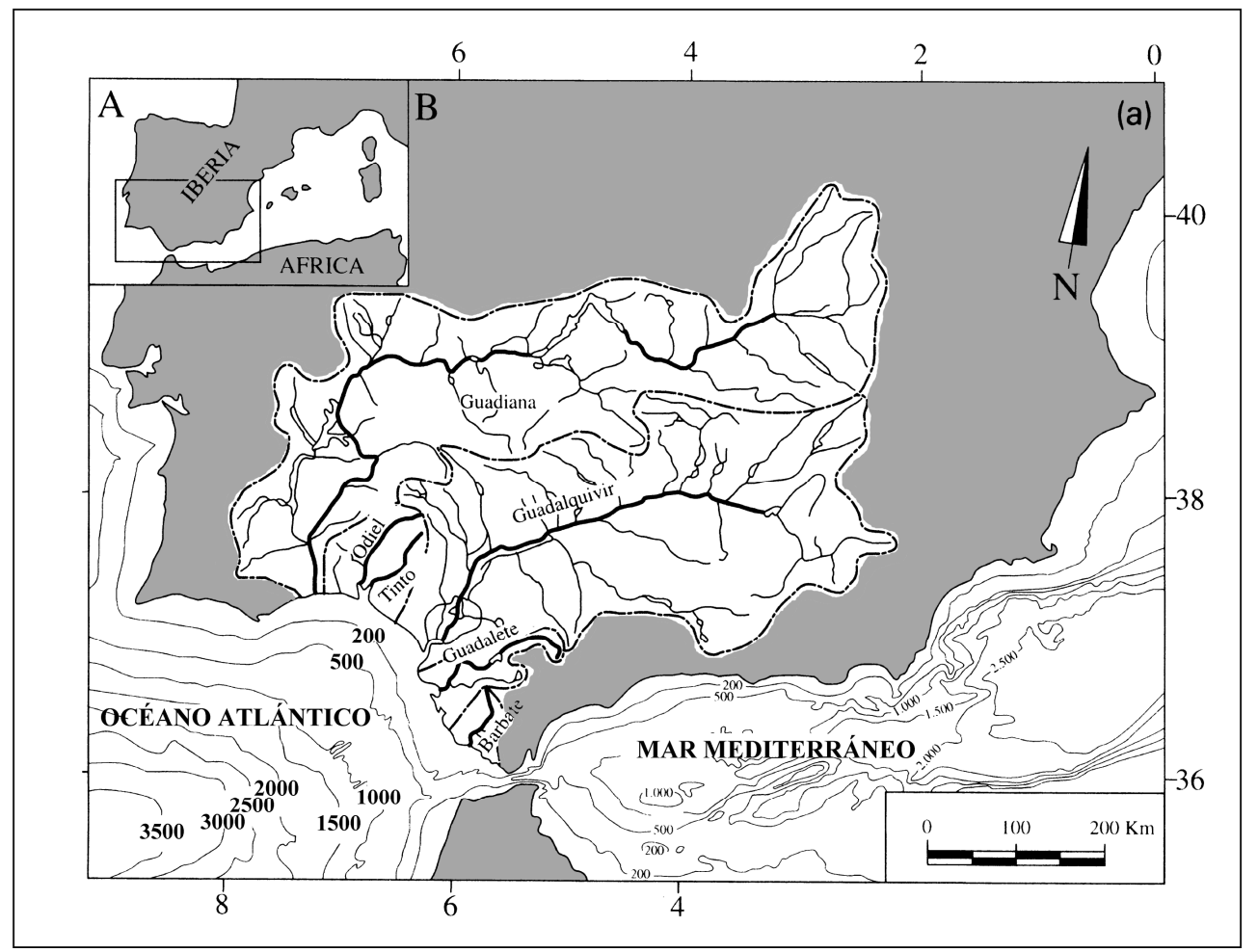

Figura 2.4. Cuencas hidrográficas que drenan sus aguas al golfo de Cádiz (modificado de Nelson y Maldonado, 1999).

La cuenca del Guadalquivir constituye la unidad geológica más joven del sur de España (Mioceno superior - Cuaternario). La cuenca se halla situada entre los afloramientos meridionales (paleozoicos y mesozoicos) del Macizo Hespérico al norte (borde pasivo, foreland), y el frente del olistostroma al sur de la cuenca (borde activo) procedente de las cordilleras Béticas (Mesozoico y Cenozoico). El extremo oriental viene determinado por los afloramientos mesozoicos de la Sierra de Cazorla (Mesozoico Prebético) y por la sierra de Segura, mientras que hacia el oeste pasamos al dominio del golfo de Cádiz (fig. 1.1).

Denominamos como cuenca del Guadalquivir-golfo de Cádiz al área que engloba la cuenca del Guadalquivir sensu stricto (entre las provincias de Huelva, Cádiz, Sevilla, Córdoba y Jaén) y a la zona marina frente a la costa de las provincias de Huelva y Cádiz. El estudio conjunto de la cuenca del Guadalquivir y el golfo de Cádiz viene determinado por la continuidad geológica entre ambas zonas, separadas únicamente por la línea de costa actual.

El margen continental del suroeste de la Península Ibérica es un área sumamente interesante para numerosas disciplinas científicas debido a la compleja historia tectónica entre las placas Ibérica y Africana, al importante aporte de sedimentos y a que supone hoy 
en día, la única puerta de entrada y salida del Mediterráneo. Abundan los estudios tectónicos (Nelson y Maldonado, 1999; Maldonado et al., 1999; Dañobeitia et al., 1999; Maldonado y Nelson, 1999), estratigráficos (Somoza et al., 1996; López-Galindo et al., 1999; Nelson et al., 1999; Rodero et al., 1999; Lee y Baraza, 1999), de circulación marina (Bainger y Price, 1999), de depósitos contouríticos (Sierro et al., 1999a) y riesgos geológicos (Baraza et al., 1989; Baraza et al., 1999) o de recopilación (Vera, 2000).

La cuenca neógena del Guadalquivir-golfo de Cádiz comenzó a desarrollarse a finales de la fase compresiva del Mioceno inferior. Tiene unas características y una historia geológica íntimamente relacionada con la de la cordillera Bética, de la cual constituye la extremidad noroeste de la alargada fosa marginal bética. La morfología de la cuenca es la de un semigraben con gradiente de hundimiento más o menos continuo, suave y uniforme, desde las posiciones morfológicamente más altas al N, NW y E-NE, hacia las más deprimidas localizadas al S y W-SW (García y López, 1984). En el golfo de Cádiz se produce el potente desarrollo de las series neógenas postorogénicas, no solo en continuación con la cuenca del Guadalquivir, sino cubriendo las unidades alóctonas meridionales de una forma prácticamente generalizada. Así mismo se observa un mayor desarrollo de las series mesozoicas supra-triásicas y del Terciario inferior (ITGE, 1990). La cuenca es relativamente somera, con sólo $500 \mathrm{~m}$ de profundidad hasta el basamento en el este; si bien se incrementa hacia el oeste hasta los $1200 \mathrm{~m}$ bajo la línea de costa actual, introduciéndose más profundamente a medida que nos adentramos en el golfo de Cádiz. Su relleno es principalmente clástico, procedente de la Meseta al norte, y también desde los mantos cabalgantes béticos al sur (Meléndez y Álvarez, 1996).

La cuenca del Guadalquivir es una cuenca de antepaís formada sobre un basamento paleozoico que supone la prolongación hacia el sur del Macizo Ibérico (García y López, 1984; Tortella et al., 1996). La inclinación hacia el sur del sustrato podría deberse a una deformación por flexura de la corteza hercínica (González et al., 1992), relacionada con la sobrecarga provocada por la cuña de Alborán, que cabalga sobre el Macizo Ibérico en el arco de Gibraltar (Maldonado, 1992). Por su parte, la cordillera Bética constituye el extremo occidental del cinturón orogénico alpino que se extiende desde el Himalaya al Mediterráneo occidental, y que marca el borde sur de la cuenca del Guadalquivir. La cordillera Bética denota el carácter activo del margen sur de la cuenca que contrasta con el carácter pasivo del margen norte. Una imagen similar se observa en el Rif marroquí, donde dominios geológicos equivalentes se disponen aproximadamente en simetría especular respecto al mar de Alborán. La formación del "arco de Gibraltar" es consecuencia del emplazamiento en dirección E-W del dominio de Alborán sobre los dominios continentales ibérico y magrebí (Comas et al., 1992, 1993, García-Dueñas et al., 1992, García Castellanos, 1998). 


\subsubsection{Evolución del margen Suribérico}

La evolución del margen suribérico fue más compleja que la de la mayoría de los márgenes del Atlántico Norte debido a que comprende varias fases de rifting, convergencia y movimientos de strike-slip (Maldonado et al., 1999).

La cordillera Bética se formó en una orogenia colisional inducida por el movimiento relativo de las placas Africana, Euroasiática e Ibérica (Andrieux et al., 1971; Vera, 1988; García-Dueñas y Martínez-Martínez, 1988; Sanz de Galdeano, 1990; Srivastava et al., 1990). Las placas Africana y Euroasiática pasaron de un régimen extensivo durante el Mesozoico, a un régimen compresivo hacia el Cretácico superior. La convergencia N-S entre la placa Africana e Iberia se hizo más pronunciada hacia el Oligoceno inferior. Asociada a este contexto tectónico compresivo, comenzó la formación de la cordillera Bético-Rifeña, en el extremo occidental del sistema Alpino Mediterráneo (Sánchez-Almazo, 1999). Boccaletti et al. (1987) distinguen tres sistemas de fallas transcurrentes responsables de la estructuración de la cordillera y la zona externa y del origen del arco de Gibraltar. Aseguran así mismo que la génesis de las cuencas intramontañosas neógenas pueden ser interpretadas en un contexto compresivo regional de dirección N-S.

La deriva de África hacia el norte causó el cierre progresivo de las cuencas del Thetis y la rápida propagación del cinturón del "arco de Gibraltar" hacia el área del golfo de Cádiz en el oeste (Maldonado et al., 1999). En la figura 2.5 se muestra como el "dominio de Alborán" se superpone sobre la unidad del "surco de Flyschs" y, a su vez, sobre los márgenes Suribérico y Africano (García-Dueñas et al., 1986; Sanz de Galdeano, 1990; García-Dueñas et al., 1992; Martínez-Martínez y Azañón, 1997). Simultáneamente al avance del "frente de cabalgamientos", se generaron procesos de "rifting" y despegues extensionales en la parte trasera del dominio de Alborán, provocando extensión y adelgazamiento de la corteza (Comas et al., 1992; García-Dueñas et al., 1992; SánchezAlmazo, 1999).

La cuenca de Flysch destruida y sus fragmentos fueron emplazados en las Zonas Externas, particularmente en el sector situado al oeste de la zona Interna adelantada (el área del Campo de Gibraltar y el golfo de Cádiz) sufriendo también retrocabalgamientos (Sanz de Galdeano y Rodríguez Fernández, 1996; Sánchez-Almazo, 1999).

Durante el Burdigaliense medio el Subbético fue altamente deformado como resultado de la colisión de la zona Interna. El Subbético se desplazó hacia el oeste y formó grandes masas de olistostromas (figura 2.1), particularmente en los sectores más 
occidentales, siendo superpuesto en parte por el Prebético (Sanz de Galdeano y Rodríguez Fernández, 1996).

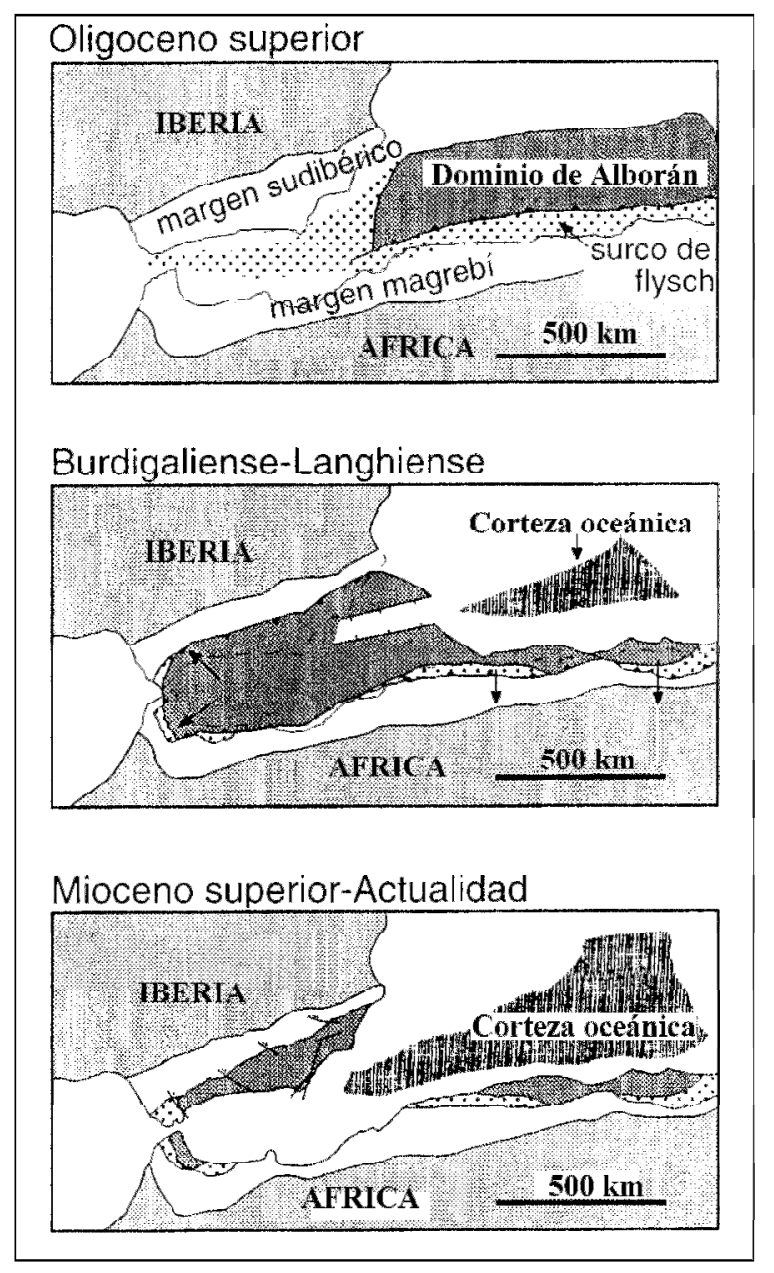

Figura 2.5. Desplazamiento del dominio de Alborán hacia el oeste y su relación con la creación de corteza oceánica en el Mediterráneo occidental. Modificada de Martínez-Martínez y Azañón, 1997.

La cuenca del Guadalquivir correspondía en el Mesozoico a un margen pasivo en el que los materiales de las actuales Zonas Externas se depositaban sobre el basamento paleozoico al sur de la cuenca actual (García-Hernández et al., 1980; Maldonado et al., 1999). Esta situación se mantiene hasta el Langhiense (Sanz de Galdeano y RodríguezFernández, 1996), momento en que se desarrolla un profundo foredeep entre el orógeno Bético en el sur y el foreland Ibérico al norte (Montenat, 1996). Este surco va a constituir uno de los estrechos de comunicación estre el océano Atlántico y el mar Mediterráneo durante el Tortoniense, el estrecho Norbético. Como otras cuencas tipo foreland, el margen pasivo (al norte) está caracterizado por una profundización gradual del basamento hacia el sur debido a la flexión del substrato, localizándose en el sur la parte más profunda del 
estrecho, próximo al orógeno Bético. Este margen es muy pronunciado debido a su posición al frente del cinturón cabalgante Subbético, al tiempo que los olistostromas de materiales caóticos mesozoicos y cenozoicos (Roldán García, 1988) se deslizan pendiente abajo para ser incorporados a los depósitos (Sanz de Galdeano y Rodríguez-Fernández, 1996; Sierro et al., 1996; Maldonado et al., 1999). A lo largo de la mayor parte del Mioceno, tuvo lugar un desplazamiento de los sucesivos depocentros del foreland hacia el norte, debido al emplazamiento del cinturón cabalgante Subbético en la misma dirección.

Un gran cambio paleogeográfico tuvo lugar en el "Tortoniense" (6.5 Ma) (García Castellanos, 1998) momento en el que el estrecho Norbético se cerró debido al plegamiento y levantamiento de las zonas central y oriental del foredeep. El bloqueo del estrecho causó erosión de la cobertera sedimentaria en esta zona. La parte occidental del viejo foredeep evolucionó hacia una cuenca foreland de forma triangular que separaba la cadena plegada (y sus cuencas intramontañosas) del emergente foreland, formando la actual configuración geográfica de la cuenca del Guadalquivir (García y López, 1984; Sanz de Galdeano y Rodríguez-Fernández, 1996; Sierro et al., 1996; Maldonado et al., 1999).

Durante el Messiniense la tendencia al levantamiento continuó, de manera que la ausencia de contacto entre Atlántico y Mediterráneo en la cordillera Bética fue constante. A finales del Messiniense se interrumpen totalmente las comunicaciones entre el mar Mediterráneo y el océano Atlántico, coincidiendo un descenso eustático con un levantamiento tectónico (Sáenz de Galdeano, 1983; Sanz de Galdeano y Rodríguez Fernández, 1996). La incomunicación del mar Mediterráneo provocó la Crisis de Salinidad y el depósito de las conocidas series evaporíticas.

La situación paleogeográfica del suroeste peninsular durante el Plioceno fué muy similar a la del presente. Algunos sectores de la vertiente atlántica en las provincias de Cádiz y Huelva que ahora están expuestas, estaban cubiertas por un mar somero. Destaca la aparición del estrecho en el arco de Gibraltar hacia el límite Messiniense-Plioceno. Esto supuso la restauración definitiva de las comunicaciones marinas y provocó el final de los depósitos de evaporitas en el Mediterráneo. En la vertiente mediterránea, se desarrollaron en este momento algunas cuencas subsidentes costeras como las de Fuengirola, Málaga y Almería (Sanz de Galdeano y Rodríguez Fernández, 1996).

En el Cuaternario las diferencias con la posición de la actual línea de costa fueron muy pequeñas. La plataforma noroeste del golfo de Cádiz está caracterizada por rasgos extensionales, subparalelos a la costa, que están asociados con fallas subsidiarias de componente predominantemente strike-slip. Estas fallas facilitaron la subsidencia hacia mar abierto de la plataforma y el desarrollo de potentes series de depósito. Muchas de las 
fallas activas durante el Cuaternario son interpretadas como fracturas miocenas y pliocenas reactivadas (Maldonado et al., 1999).

\subsubsection{Estratigrafía del Neógeno de la cuenca del Guadalquivir-golfo de Cádiz}

La cuenca del Guadalquivir se formó durante el Mioceno como consecuencia de la colisión entre las placas Ibérica y Africana, desarrollándose sincrónicamente a la evolución de la cadena montañosa bética. La cuenca actuó como conexión entre los océanos Atlánticos y Tethys durante la mayor parte del Neógeno, y finalmente comenzó a cerrarse durante el Mioceno superior.

El fondo de la cuenca está formado por un zócalo paleozoico, que desciende suavemente hacia el sur desde la flexura del Guadalquivir (Boccaletti, et al., 1987). La configuración geométrica de la cuenca sería por lo tanto la de un semigraben, siendo esta morfología fundamental para la interpretación de un modelo de relleno sedimentario de la cuenca del Guadalquivir.

El sector sur de la cuenca está caracterizado por la presencia de fenómenos de deslizamiento de gran escala, particularmente olistostromas provenientes de los mantos béticos a lo largo del borde sur de la cuenca. Los olistostromas se formaron durante el Serravalliense cuando los mantos subbéticos se emplazaron en la cuenca Prebética. En el golfo de Cádiz, una característica destacable es la evolución diapírica del Trías que afecta incluso a la zona ocupada por el olistostroma, pudiendo llegar a afectar al Terciario superior-Plioceno (ITGE, 1990).

Para Suárez et al., (1989) los rasgos más importantes de la cuenca neógena pueden resumiese en la existencia de dos bordes de naturaleza muy diferente: uno al norte, formado por la flexura del Guadalquivir, de carácter pasivo y sobre el que se instala una plataforma siliciclástica estable, y otro al sur, con el olistostroma de carácter activo y móvil y sobre el que se instalan unas plataformas inestables de carácter carbonatado. En general se consideran fundamentales las siguientes características (Suárez et al., 1989; Riaza y Martínez del Olmo, 1996).

- Un margen pasivo al norte, resto de un basamento Paleozoico y de una plataforma Mesozoica.

- Un margen activo al sur, que es compresivo y gravitacional, con una gran masa olistostrómica rellenando esta cara de la cuenca durante el Tortoniense superior, 
y que destruye parcialmente y enmascara los sedimentos previos de este margen. Algunos eventos olistostrómicos han sido registrados antes de este momento, pero son mucho menos importantes que los avances gravitacionales del Tortoniense superior.

- Sedimentos desde el Langhiense al Cuaternario rellenando una cuenca de dirección WSW-ENE que se abre y profundiza hacia el oeste.

Algunas investigaciones se han basado en el empleo de métodos de prospección eléctrica (Grada Sanz, 1984), pero los mayores avances se han basado en la utilización de la sísmica de reflexión como método geofísico básico en la investigación de hidrocarburos en la cuenca (Martínez del Olmo, 1984; Suárez et al., 1989, Riaza y Martínez del Olmo, 1996). Desde un punto de vista estratigráfico, Martínez del Olmo et al., (1984) distinguen cuatro unidades Ttectosedimentarias (UTS, TSU) y/o secuencias sedimentarias basadas en datos sísmicos y sondeos profundos de los depósitos marinos del Mio-Plioceno de la cuenca del Guadalquivir. Las secuencias sedimentarias en orden estratigráfico son las siguientes:

- Grupo Atlántida, de edad Langhiense-Serravalliense.

- Grupo Bética, de edad Tortoniense 2 - Andaluciense 1.

- Grupo Andalucía, de edad Andaluciense 2 - Plioceno 1.

- Grupo Marismas, de edad Plioceno 2 - Cuaternario.

Más tarde, en el informe del ITGE (1990), a partir de la información de subsuelo, y entre las unidades neógenas, se distinguen cuatro volúmenes de material o unidades tectosedimentarias (UTS-1, UTS-2, UTS-3 y UTS-4) equivalentes a las anteriores, separadas entre sí por discontinuidades sedimentarias visibles en sísmica de reflexión, de permanencia y constancia a lo largo y ancho de la cuenca. Posteriormente, Riaza y Martínez del Olmo (1996) identifican siete secuencias de depósito que pueden relacionarse con los principales eventos olistostrómicos y erosivos y que se agrupan en las anteriores unidades (fig. 2.6): 1-3, Secuencias Preolistostrómicas (grupo Atlántida); 4, Secuencia Sinolistostrómica (Secuencia Bética); 5, Secuencia Andalucía; 6-7, Secuencias posterosivas (Marismas y Odiel).

En la figura 2.6 se muestra el actual modelo litosecuencial propuesto por Riaza y Martínez del Olmo, (1996). A continuación se detallan estas secuencias, relacionadas con 
diferentes cortejos sedimentarios depositados durante sucesivos ciclos eustáticos (Riaza y Martínez del Olmo, 1996; Martínez del Olmo et al., 1996).

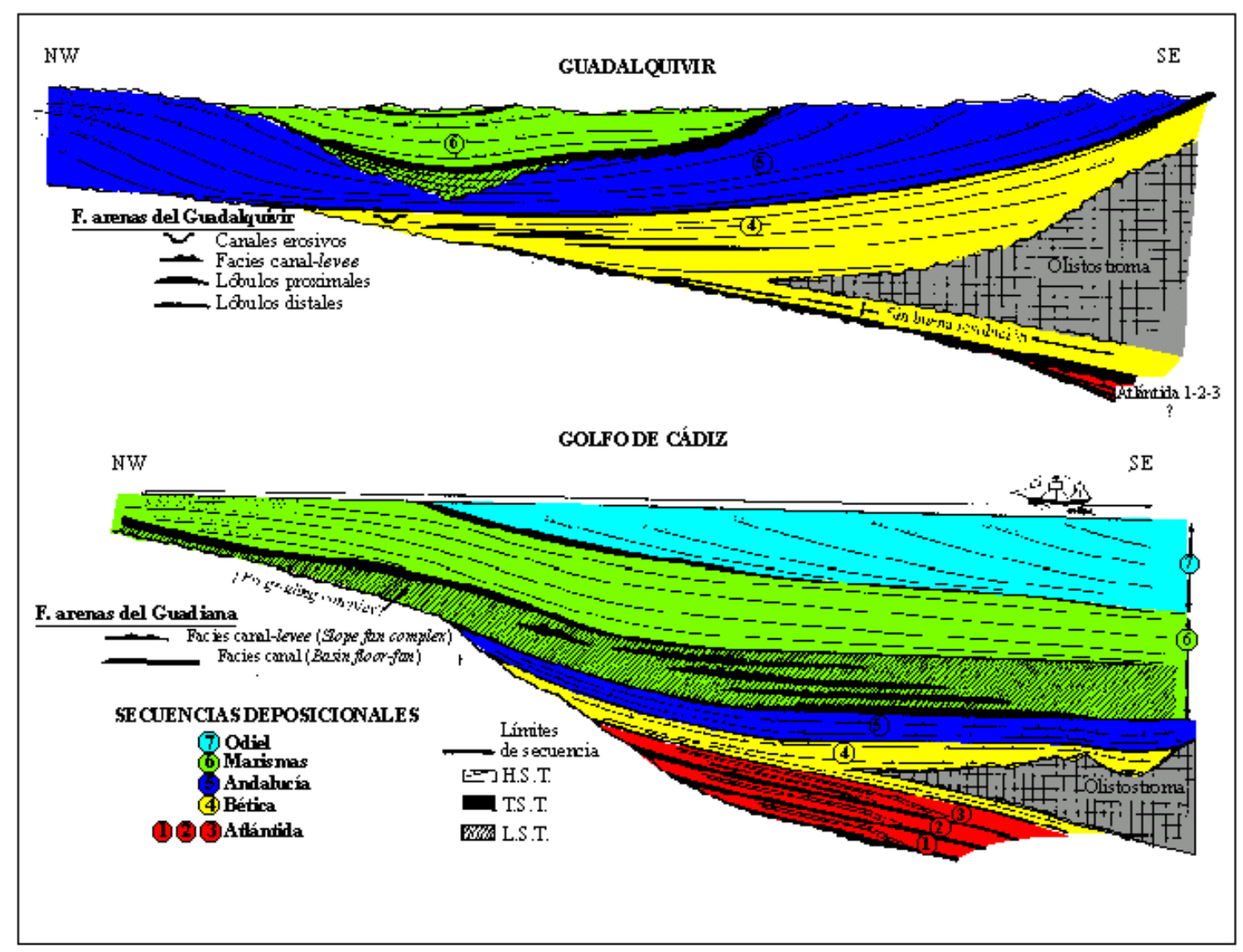

Figura. 2.6. Modelo litosecuencial del Neógeno propuesto por Riaza y Martínez del Olmo, (1996) para el Guadalquivir y golfo de Cádiz.

En este modelo litosecuencial, los autores anteriores distinguen las siguientes unidades:

- Los sedimentos pre-olistostrómicos (1-3 en la fig. 2.6) (Riaza y Martínez del Olmo, 1996) o grupo Atlántida (Martínez del Olmo et al., 1984; Suárez et al., 1989), corresponderían a la denominada UTS-1 de edad Serravalliense 2-Tortoniense 1 (ITGE, 1990). Riaza y Martínez del Olmo (1996) consideran que el emplazamiento olistostrómico se produjo en el Tortoniense superior de acuerdo con la sísmica de reflexión, por lo que el "grupo Atlántida" tendría una edad Langhiense a Tortoniense inferior. Esta unidad presenta en su base una discordancia erosiva y angular sobre un substrato de materiales que van desde el Paleozoico al Paleógeno. A techo presenta 
una discontinuidad sedimentaria de tipo paraconformidad. Inicialmente se consideraba que esta unidad incluía a techo la formación "detrítico basal" caracterizada por presentar areniscas con cemento carbonatado (Martínez del Olmo et al., 1984; Suárez et al., 1989; ITGE, 1990), muy glauconíticas, que evolucionaban a calizas margosas y margas hacia la zona del golfo de Cádiz. En el actual modelo de secuencias de depósito (Riaza y Martínez del Olmo, 1996) se considera sin embargo que el "detrítico basal" supone la facies de calcarenita transgresiva correspondiente al cortejo transgresivo (TST, Transgresive System Tract) de la secuencia Bética posterior (tal y como aparece en la figura 2.6).

Se han identificado en este grupo facies deltaicas al NE de la cuenca (Marín Señán, 1988), de sedimentos marinos proximales (Sierro et al., 1992) y abanicos turbidíticos que representan las facies profundas al pie del complejo prodeltaico, relacionado con un cortejo de alto nivel del mar (HST, Highstand System Tract). En concreto Riaza y Martínez del Olmo (1996), reconocen en el grupo Atlántida tres secuencias independientes que denominan A-1, A-2 y A-3 (fig. 2.6).

- La segunda secuencia, denominada secuencia Bética / sinolistostrómica (4 en la fig. 2.6) (Riaza y Martínez del Olmo, 1996), fue definida inicialmente por Martínez del Olmo et al. (1984) como "grupo Bética", e incluía sedimentos del Tortoniense superior y Messiniense inferior. Este grupo contenía así mismo las unidades turbidíticas denominadas "formación arenas del Guadalquivir" (onshore) y "formación arenas del Guadiana" (offshore). Sin embargo, investigaciones más modernas (Riaza y Martínez del Olmo, 1996) a través del estudio de perfiles sísmicos y de diagrafías propiciaron la nueva interpretación que aparece en la figura 2.6. Se considera a partir de entonces a la secuencia Bética, como una secuencia de depósito que incluye únicamente sedimentos TST (formación "detrítico basal") y HST cuya edad se remontaría exclusivamente al Tortoniense superior. Las turbiditas de la formación Guadalquivir son interpretadas como sedimentos profundos de los complejos Highstand System Tract. En esta etapa las masas olistostrómicas del margen sur se introducen en la cuenca, destruyendo parcialmente los sedimentos previos y formando un mega-elemento detrítico en la cuenca. La secuencia Bética / sinolistostrómica sería equivalente en parte a la UTS-2 que en el informe ITGE (1990), fue datada como Tortoniense 2 - Andaluciense 1. Presenta a su base paraconformidad con la UTS - 1 o discordancia erosiva y angular sobre un substrato variable. A techo presenta una discontinuidad sedimentaria manifestada por onlap, conformidad, erosión y downlap según la zona. Está unidad está compuesta por limolitas, arcillas y areniscas. Por otro lado, contiene materiales mesozoicos y miocenos correspondientes al olistostroma bético. En su configuración interna de N- 
NW a S-SE se observan morfologías de "top set", "fore set" y "bottom set" típicos de acreción deltaica, que evolucionan a las formas planares de fondo de cuenca entre las que se intercalan las reflexiones caóticas que identifican en sísmica al olistostroma (ITGE, 1990).

- La UTS-3, de edad Andaluciense 2 - Plioceno 1(ITGE, 1990), corresponde al denominado "Grupo Andalucía" (Martínez del Olmo et al., 1984; Suárez et al., 1989), siendo equivalente (solo en el área del Guadalquivir) con la denominada “secuencia de depósito Andalucía” (5 en la fig. 2.6) (Martínez del Olmo et al., 1984; Riaza y Martínez del Olmo, 1996). Estos autores consideran que el grupo Andalucía presenta una edad Messiniense y que constituye una secuencia parcialmente erosionada (5 en la figura 2.6). Presenta a su base paraconformidad, morfologías "onlap" sobre paleotaludes, "downlap", etc en función de su posición paleogeográfica. Esta unidad presenta a techo paraconformidad, "downlap", o truncación. Su litología está compuesta por margas azules, limolitas, arenas planares y calcarenitas en el borde, sobre el olistostroma. En su configuración interna, de $\mathrm{N}$ NW a S - SE se observan clinoformas con "downlap" basal muy suave y techo truncado pasando progresivamente a formas planares que generan un "onlap" profundo sobre el olistostroma. Riaza y Martínez del Olmo (1996) identifican en este grupo tanto un Transgresive System Tract (TST), como un Highstand System Tract (HST).

- A continuación se encuentra el "Grupo Marismas" (6 en la figura 2.6) que junto con la secuencia Odiel comprende los depósitos postolistostrómicos, que equivaldrían a la UTS-4 anteriormente citada. El grupo Marismas, definido por Martínez del Olmo et al., (1984) incluye sedimentos pliocenos y estaría caracterizado por una importante base erosiva, muy bien representada en los perfiles sísmicos de la zona este del valle del Guadalquivir y en el golfo de Cádiz. Esta cicatriz erosiva evidenciaría un importante descenso eustático (Riaza y Martínez del Olmo, 1996). Así el complejo turbidítico del Guadiana representa para estos autores el cortejo de bajo nivel del mar (LST, Lowstand System Tract) de la secuencia Marismas (fig. 2.6). Este grupo estaría muy bien caracterizado en el área inferior de la zona del Guadalquivir donde incluye un TST y un HST fosilizando las secuencias que fueron previamente erosionadas (Riaza y Martínez del Olmo, 1996).

- En el golfo de Cádiz, sobre la secuencia Marismas, se reconoce otra secuencia a través de los $\log s$ denominada Secuencia Odiel (7 en la figura 2.6). En ella Riaza y Martínez del Olmo (1996) reconocen solo el Transgresive System Tract y el Highstand System Tract estimando una edad Plioceno superior- Pleistoceno para esta secuencia. Los 
mismos autores observan que es difícil separarla de la secuencia Marismas dada su reducida potencia y extensión local.

Por otro lado, Sierro et al. $(1990 ; 1996)$ distinguen 5 secuencias de depósito en la cuenca del Guadalquivir (A, B, C, D y E) tipo offlapping, progresivamente más jóvenes hacia el oeste (fig. 2.7). Estas unidades sedimentarias han sido establecidas por medio de estudios micropaleontológicos y proponen una sucesión de eventos de plancton calcáreo (Sierro, 1984, 1985, 1986; Flores y Sierro, 1987). En afloramientos en superficie, estos autores observan que la erosión desgasta los techos de las sucesivas secuencias y que la superficie erosionada resultante está inclinada hacia el oeste.

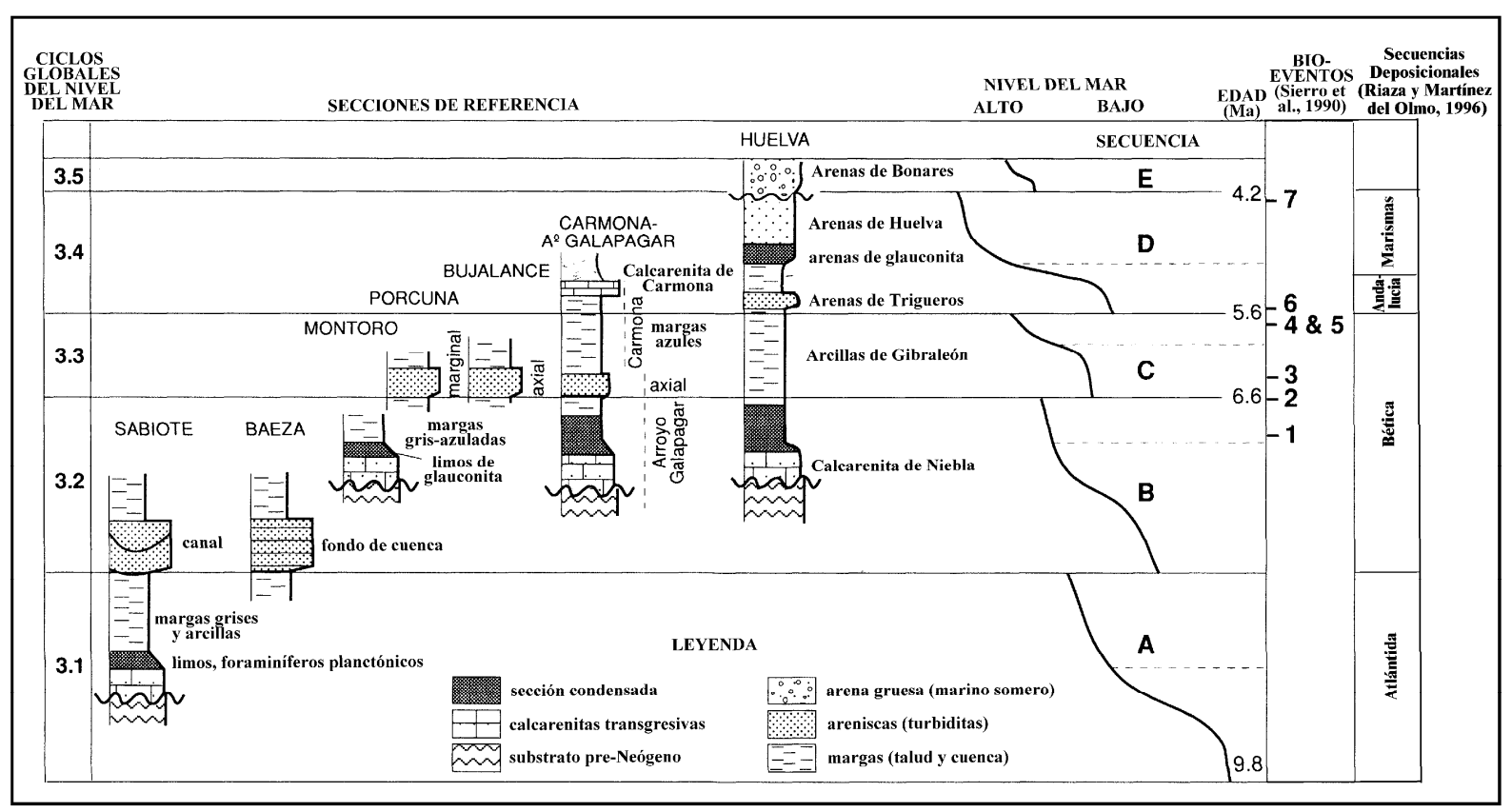

Figura 2.7. Secuencias de depósito establecidas por Sierro et al. (1996) en afloramientos de campo de la cuenca del Guadalquivir. Correlación con los ciclos globales del nivel del mar de Haq et al. (1987). A la derecha, equivalencia con las secuencias de depósito propuestas por Riaza y Martínez del Olmo (1996). Modificado de Sierro et al. (1996).

\subsubsection{Exploración de hidrocarburos}

La cuenca miocena del Guadalquivir-golfo de Cádiz ha sido objeto de una intensiva actividad en el campo de la exploración de hidrocarburos proporcionando numerosos descubrimientos de gas. La exploración de este área se remonta a los años 50, cuando las 
compañías Adaro y Valdebro realizaron los primeros sondeos en la cuenca del Guadalquivir y crearon el primer laboratorio de micropaleontología en España en colaboración con la italiana Agip. A finales de los 60 comenzó a sondear en el golfo de Cádiz la compañía Shell, introduciéndose a partir de entonces numerosas compañías en el área de estudio (Ríos, 1958; Perconig y Martínez Díaz, 1977; ITGE, 1990). En el momento de comenzar la Tesis Doctoral, la mayor parte del área estudiada se encontraba en concesiones de Repsol S.A., durante el transcurso de esta Tesis, la compañía Locs Oil Co. of Spain adquirió los derechos de explotación de varias de las concesiones existentes en el valle del Guadalquivir.

Desde hace décadas, estas compañías han venido realizando pozos de exploración y se ha realizado un levantamiento sismológico que ha permitido reconocer la arquitectura sedimentaria y las relaciones espaciales y temporales de los cortejos sedimentarios (System Tracts) y secuencias de depósito que albergan los sedimentos neógenos de la cuenca (Martínez del Olmo et al, 1984, 1986, 1996; Riaza y Martínez del Olmo, 1996). El Instituto Tecnológico GeoMinero de España realizó un interesante informe en el año 1990 (ITGE, 1990) sobre la cuenca del Guadalquivir-golfo de Cádiz, en el que se incluye un plano (1:500.000) con la situación de los sondeos llevados a cabo en la zona hasta dicha fecha, así como varias líneas sísmicas, registros composite logs, y paneles de correlación generales.

En toda la cuenca $\left(12000 \mathrm{Km}^{2}\right)$, han sido perforados hasta la fecha 101 sondeos exploratorios, 45 de los cuales fueron completados sin éxito antes de 1980. Desde entonces, utilizando nuevas técnicas, se han perforado 56 nuevos sondeos de los cuales 22 de ellos hallaron hidrocarburos, siendo desarrollados hasta el momento únicamente 17 de ellos (15 onshore y 2 offshore) con producciones de 2 a 50 BCF (Martínez del Olmo et al., 1998).

En el área del Guadalquivir, los "niveles objetivo" de los sondeos exploratorios están localizados principalmente en cuatro horizontes arenosos: en la formación denominada "calcarenita transgresiva basal" o comúnmente "arenas basales" (1); en las "arenas del Guadalquivir" del Mioceno medio ${ }^{(2)}$ y el Mioceno superior ${ }^{(3)}$, y en los niveles arenosos del Plioceno $^{(4)}$ que se disponen disconformes sobre los sedimentos miocenos (Meléndez y Álvarez, 1996). Los niveles más productivos se encuentran en la formación "arenas del Guadalquivir", donde una serie de unidades arenosas de ambiente marino somero (formadas en playas, bajíos, canales de marea y barras mareales) pasan a turbiditas de aguas profundas. Todos los descubrimientos son de gas seco, de origen biogénico, donde la fuente del gas son los restos orgánicos contenidos en las arcillas miocenas de varias decenas de metros de espesor (no muy ricas, pero que probablemente generan el gas 
desde toda la formación) (Meléndez y Álvarez, 1996). Este rápido sistema turbidítico progradante caracteriza una amplia zona de sedimentación con frecuentes capas finas a medias (2 a 15 m) de arenas reservorio. Desde 1982 se han sido descubiertos quince pequeños campos de gas comercial. Esta cuenca no ha sido deformada por fuertes mecanismos tectónicos y la trampa es fundamentalmente estratigráfica basada en pequeños cierres verticales generados por las morfologías sedimentarias a techo de los levees y por la geometría de los lóbulos proximales. La limitada extensión de estos cuerpos determina que estén sellados tanto lateral como verticalmente, resultando en pequeñas acumulaciones y en consecuencia pequeños campos de gas (Martínez del Olmo et al., 1998). No hay evidencias de posibles fuentes de petróleo, si bien a pesar de la escasa profundidad de la cuenca, se han obtenido varios descubrimientos de campos de gas comercial onshore (fig. 2.8). Es el caso de los campos: "Marismas" (con unas reservas de 30 BCF: Billón $\left(10{ }^{9}\right.$ ) pies cúbicos (pc)), "Las Barreras" (con 4.5 BCF), "El Romeral” (con 4.5 BCF) y "El Ruedo" (con 5 BCF). Todas ellas estimaciones de Meléndez y Álvarez (1996) habiendo sufrido variaciones posteriores (Martínez del Olmo, com. per.). Podemos citar como ejemplo el sondeo Santa Clara-1, analizado en esta Tesis, que produjo 140.000 metros cúbicos de gas diarios en las pruebas de producción realizadas en 1999. En estos descubrimientos, la alta calidad de los trabajos sísmicos ha sido muy importante en el trazado de la geometría de los reservorios, y en particular la utilización de la técnica de detección directa denominada AVO (Amplitude Variation with Offset) que ha incrementado el porcentaje de éxitos (García et al., 1998; 1999).

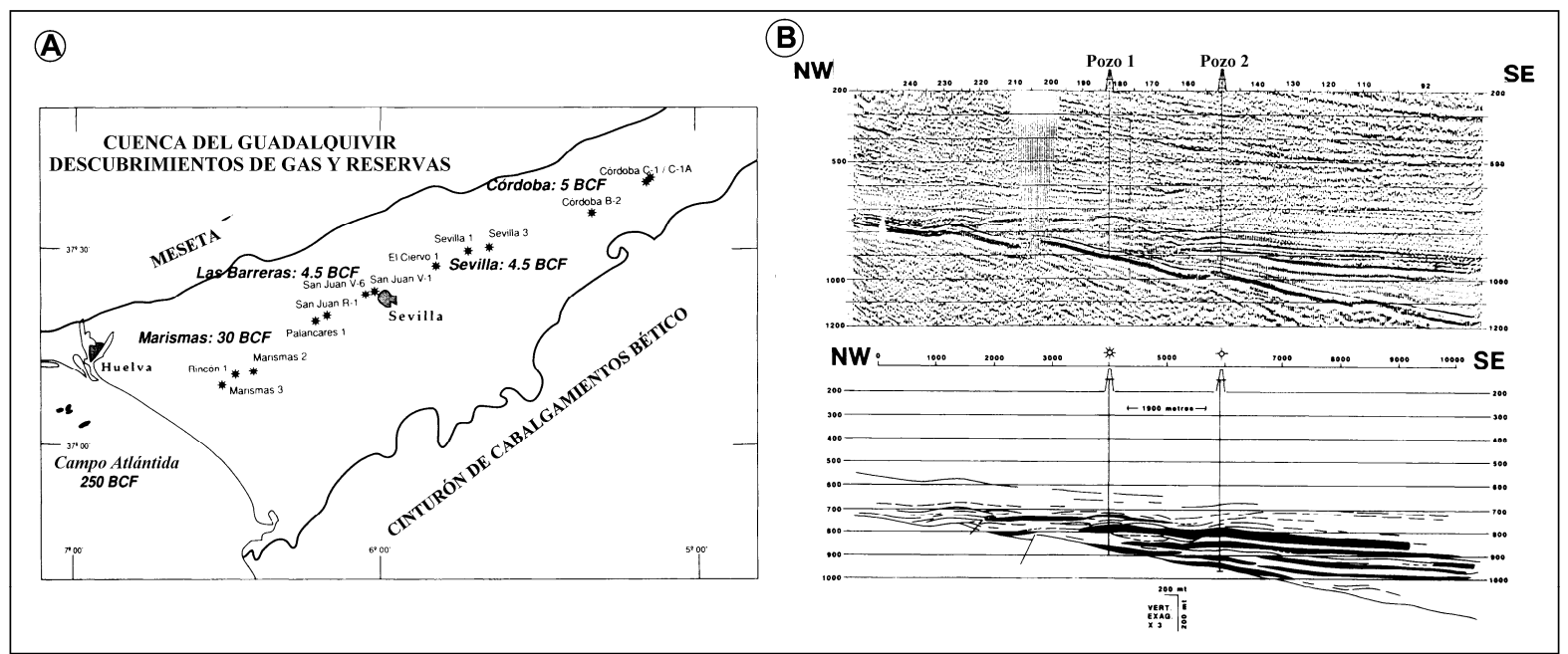

Figura 2.8.A. Localización de los principales descubrimientos y reservas de gas en la cuenca del Guadalquivir. B. Perfil sísmico interpretado en el área "Marismas", mostrando la localización de los reservorios y su interpretación de facies. Modificado de Meléndez y Álvarez (1996). 
Así mismo se han producido hasta la fecha diversos descubrimientos en el área offshore, en el golfo de Cádiz. El primero de ellos, descubierto en los años 70, se ha denominado "campo Atlántida" (fig. 2.8), estimándose unas reservas combinadas de alrededor de 250 BCF para este campo (Meléndez y Álvarez, 1996). Sin embargo, su carácter disperso retrasó inicialmente su explotación comercial. Los sondeos B1, C1 y C2 (Huelva), propiedad de Repsol (50\%), Locs Oil Co. of Spain (25\%) y Teredo Oils Ltd. (25\%), empezaron a producir en 1990, siendo Repsol la operadora. Este sistema turbidítico localizado offshore corresponde a complejos de talud y abanicos de fondo de cuenca desarrollados durante el LST del Messiniense superior-Plioceno inferior (Marismas) y corresponden a turbiditas de alta densidad canalizadas y no canalizadas. Este sistema fue alimentado por un largo y estrecho valle inciso a lo largo de la región onshore. Desde 1980 han sido descubiertos siete campos de gas de los cuales solo el mayor de ellos tiene una trampa de control estructural.

No obstante, el agotamiento de los yacimientos de gas natural en todo el país es manifiesto a la vista del cuadro siguiente, que recoge la evolución de la extracción por provincias y campos durante el quinquenio 92-96 (fig. 2.9).

\begin{tabular}{|c|c|c|c|c|c|}
\hline Provincias (campos) & 1992 & 1993 & 1994 & 1995 & 1996 \\
\hline Vizcaya (Albatros) & - & - & - & 317374908 & sd \\
\hline Huelva (Marismas) & 145381195 & 123540000 & 75441813 & 68164109 & sd \\
\hline Burgos (Ayoluengo) & 9385000 & 8234000 & 8557000 & 5584499 & $\mathrm{sd}$ \\
\hline Vizcaya (Gaviota) & 1074750991 & 509648000 & 120853569 & 25141596 & sd \\
\hline $\begin{array}{l}\text { Tarragona } \\
\text { (Casablanca) }\end{array}$ & 3143000 & 2388000 & 2242000 & - & - \\
\hline TOTAL $\left(\mathrm{m}^{3} \mathrm{~N}\right)$ & & & & & 458729000 \\
\hline
\end{tabular}

Figura 2.9. Evolución de la extracción de gas natural en España, por provincias y campos durante el quinquenio 92-96, en $\mathrm{m}^{3}$ N. Fuentes: Enciclopedia Nacional del Petróleo, Petroquímica y Gas 1996 y Estadística de Prospección y Producción de Hidrocarburos, MINER. 


\subsection{PALEOCEANOGRAFÍA}

Hasta hace 14,5 Ma la comunicación del Mediterráneo con el océano Indico se realizaba a través del Paratethis, Turquía, Irán, Irak y Siria (Rögl et al., 1978). Probablemente entre el Burdigaliense y el Langhiense se cerro dicha comunicación (Rögl et al., 1978; Adams et al., 1983). Con toda seguridad ocurrió antes del Mioceno superior. A partir de entonces, el Mediterráneo comenzó a ser un mar con déficit hídrico. Las aguas del Mediterráneo oriental quedaron con poca o nula ventilación propiciando la creación de fondos anóxicos ricos en materia orgánica en el Mediterráneo oriental y favoreciendo el comienzo de la formación de los sapropeles.

Durante el Mioceno, el intercambio de las aguas oceánicas atlánticas y mediterráneas se realizaba fundamentalmente a través de dos estrechos denominados estrecho Bético y estrecho Rifeño, activos al menos durante el Mioceno medio (SánchezAlmazo, 1999). Tanto la conexión del estrecho Norbético como el Rifeño, se restringen como consecuencia de la formación de la cordillera Bético-Rifeña y del mar de Alborán. Debido al aislamiento del Mediterráneo, la circulación marina en este mar fue principalmente termohalina. El plegamiento de la zona Prebética precede al cierre definitivo del estrecho Norbético durante el Tortoniense superior (Weijermars, 1988) y a la individualización de la cuenca del Guadalquivir. Por otro lado Benson et al. (1991) aseguran que el estrecho meridional rifeño estuvo abierto al menos en el Messiniense inferior, detectando entrada de aguas profundas atlánticas hacia el Mediterráneo mediante la presencia de ostrácodos "psicrosféricos" (fenómeno que da nombre al "evento sifón", siphon event). Krijgsman et al. (1999c) consideran que fue entre 6.7 y $6.0 \mathrm{Ma}$ (edad astronómica) cuando se cerró definitivamente el corredor rifeño.

A finales del Messiniense, el cierre de las conexiones con otros océanos debido a la actividad tectónica de la región y al descenso global del nivel del mar durante el Mioceno (Benson, 1995; Benson et al., 1991; Weijermars, 1988) provocó la formación de los depósitos evaporíticos en el Mediterráneo, en un suceso conocido como la "Crisis de Salinidad Messiniense" (Messinian Salinity Crisis, MSC) (Hsü et al., 1972; Hsü et al., 1973; Hsü et al., 1977).

La apertura del estrecho de Gibraltar durante el límite Mio-Plioceno supuso el regreso de las condiciones de mar abierto (Cita et al., 1978). Desde el Plioceno a la actualidad, el mar Mediterráneo constituye una cuenca semicerrada con déficit hídrico, en la que el volumen de agua evaporada supera al volumen de agua dulce entrante. Este déficit se compensa con la entrada de agua atlántica. El intercambio de aguas entre el Mediterráneo y el Atlántico se realiza a través del estrecho de Gibraltar, de forma que el 
agua superficial atlántica (poco salada) entra en la cuenca y el agua mediterránea más densa y profunda (más salada), fluye hacia fuera (circulación antiestuarina). El transporte de agua atlántica (aproximadamente de $0,9 \times 10^{6} \mathrm{~m} / \mathrm{seg}$ en el estrecho de Gibraltar) es el principal motor de la circulación superficial del Mediterráneo occidental y de la circulación ciclónica a gran escala de todo el Mediterráneo. La circulación termohalina, condicionada por los cambios de temperatura y salinidad de las aguas, es particularmente activa en la región, con formación de masas de agua y convección a profundidad.

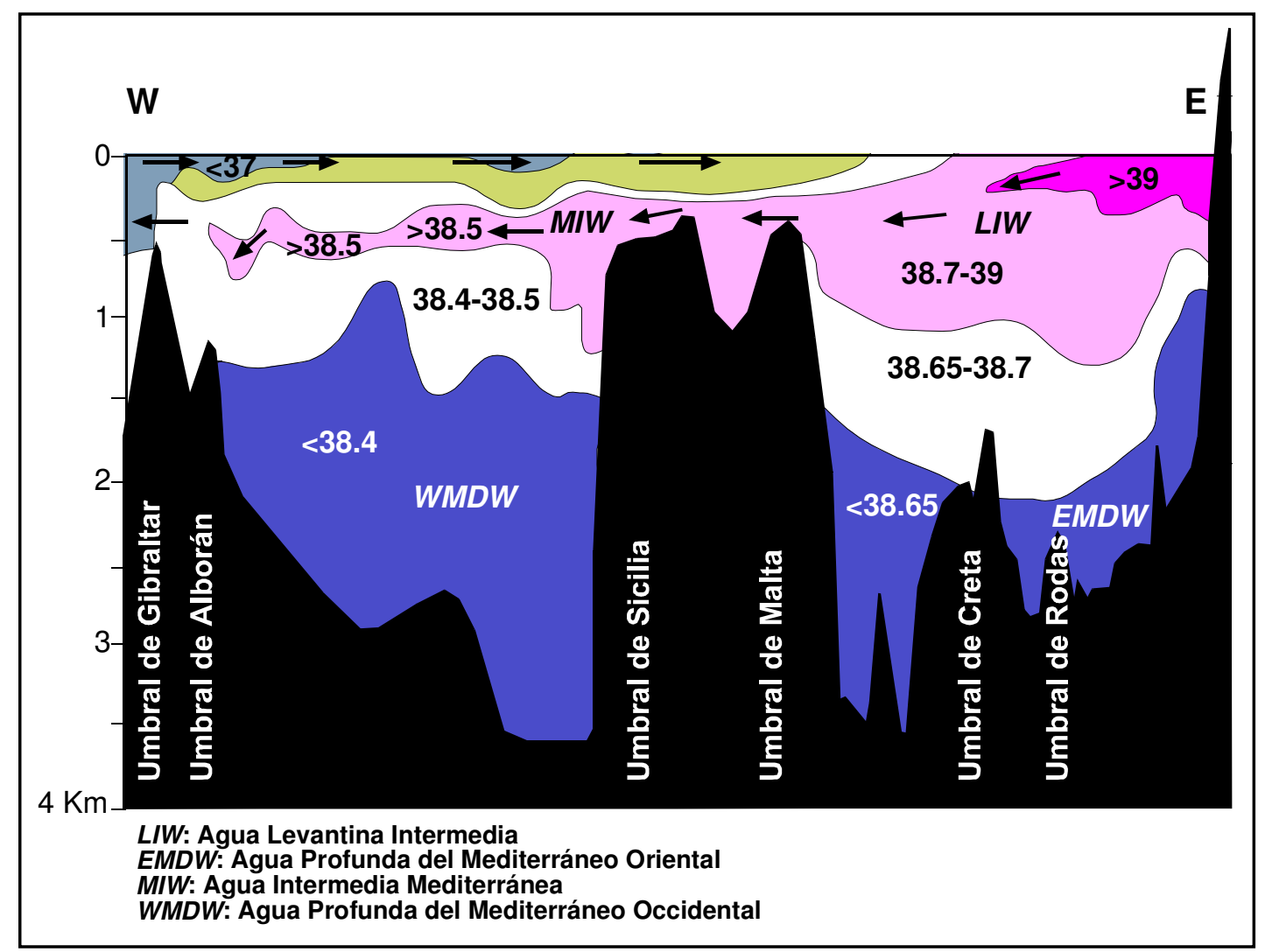

Figura 2.10. Distribución de las principales masas de agua mediterráneas (los valores indican la salinidad en $\%$ ) y sentido de la circulación termohalina.

La zona este del Mediterráneo es particularmente importante para el estudio de los procesos oceánicos globales. La masa de agua salino / cálida del Mediterráneo y que sale por Gibraltar está formada en el Mediterráneo oriental a lo largo de la ruta del agua que conecta las cuencas Oeste y Este por encima de los 300 metros. La masa de agua Atlántica fría y ligera se introduce por Gibraltar (fig. 2.10). Esta masa de agua se propaga hacia el este mientras sufre modificaciones progresivas, comienza a calentarse y a salarse y alcanza la zona oriental del Mediterráneo como una masa de agua Atlántica modificada. Aquí, la intensa evaporación en el periodo invernal, asociada a la pérdida de calor bajo los vientos 
frontales, cambia la masa de agua modificada en una masa de agua diferente, la masa de agua Intermedia Levantina $(L I W)$ que es salada, densa y se sumerge a profundidades de 300 a 500 metros (fig. 2.10). La masa de agua Intermedia Levantina se mueve desde el noreste, cruza entero el Mediterráneo (transformándose en la masa de agua Intermedia Mediterránea, $M I W$ ), y sale por Gibraltar. Las masas de agua formadas en el Mediterráneo noroccidental (golfo de León) contribuyen muy poco a esta marcha a través de Gibraltar, permaneciendo confinadas en la cuenca occidental a profundidades inferiores a los 2000 metros formando la masa de agua Profunda del Mediterráneo Occidental, WMDW (Manolette-Rizzoli, 1996).

\subsubsection{Contexto oceanográfico actual del golfo de Cádiz}

La costa española del golfo de Cádiz presenta una orientación general NW-SE, con una batimetría accidentada y con las curvas batimétricas orientadas paralelamente a la línea de costa. Los perfiles sísmicos muestran una morfología de surcos y crestas transversales a esta dirección debida a la tectónica compresiva del Terciario y a la influencia de los procesos sedimentarios (Maldonado, 1992). La plataforma continental está inclinada hacia el SE, presenta una anchura de entre 30 a $50 \mathrm{~km}$ y alcanza una profundidad máxima de alrededor de 140 m (Dañobeitia et al., 1999). La ruptura con el talud es gradual frente a las costas de Portugal y Marruecos, mientras que hacia el estrecho de Gibraltar puede llegar a tener hasta 3 y $4^{\circ}$ (Rodero et al., 1999). El talud superior es estrecho $(10 \mathrm{Km})$ y presenta una inclinación media de $1,5^{\circ}$ entre los 130 y $400 \mathrm{~m}$ de profundidad, mientras que el talud medio (entre los 400 y $800 \mathrm{~m}$ de profundidad) consiste en una plataforma de unos $40 \mathrm{Km}$ de ancho que presenta menor pendiente $\left(0,5\right.$ y $\left.1^{\circ}\right)$ (Baraza y Nelson, 1992). Este talud medio presenta una parte central deprimida y crestas morfológicas de 3 a $10 \mathrm{Km}$ de anchura con laderas fuertemente inclinadas (3 y 30) (Maldonado et al., 1999) que condicionan la dispersión de los sedimentos en las zonas más profundas (Baraza y Nelson, 1992). Tortella et al. (1996) identifican estructuras compresivas (cabalgamientos de dirección E-W buzando hacia el sur y pliegues), horsts y grabens y estructuras halocinéticas generalizadas. Toda esta morfología en la zona de conexión AtlánticoMediterráneo actúa controlando las masas de agua y los procesos sedimentarios, amplificando la señal climática en los sedimentos (Maldonado, 1992).

Actualmente, la dinámica oceánica es el principal mecanismo que controla el depósito de los materiales que llegan a la cuenca y la erosión del fondo oceánico (Maldonado, 1992). La mayor parte de los sedimentos llegan transportados por la corriente de salida del Mediterráneo $(M O W)$, junto con los procedentes del dominio continental, fundamentalmente aportados por el río Guadalquivir (en menor medida por el Guadiana, 
Guadalete, Tinto y Odiel) (Maldonado y Nelson, 1988). La alta energía del flujo en los valles submarinos hace que en éstos la sedimentación sea inexistente o de carga gruesa. Al mismo tiempo, existe una tendencia general a la disminución del tamaño de grano hacia el NW, donde la deceleración gradual de la corriente resulta en un paso de morfologías erosivas a morfologías de depósito en el talud superior (Baraza y Nelson, 1992).

En la figura 2.11, se muestra el modelo de circulación oceánica actual en el golfo de Cádiz. La figura muestra la corriente superficial atlántica en la plataforma fluyendo hacia el SE para introducirse en el Mediterráneo a través del estrecho de Gibraltar (flechas blancas). Por el contrario, la corriente submarina del Mediterráneo fluye hacia el NW paralela al contorno del talud, y hacia el SW siguiendo los valles submarinos (flechas negras). En gris se indica el área donde la corriente submarina del Mediterráneo afecta a los sedimentos del fondo (Nelson et al., 1999). El modelo de sedimentación contourítica del Plio-Quaternario del talud este del golfo de Cádiz, resulta de una interacción entre las cadenas lineares diapíricas (perpendiculares al contorno del talud) y la corriente mediterránea. Coincidiendo con el descenso de la velocidad de la corriente hacia el NW se produce una gradación de la asociación de facies en este sentido (Nelson et al., 1993).

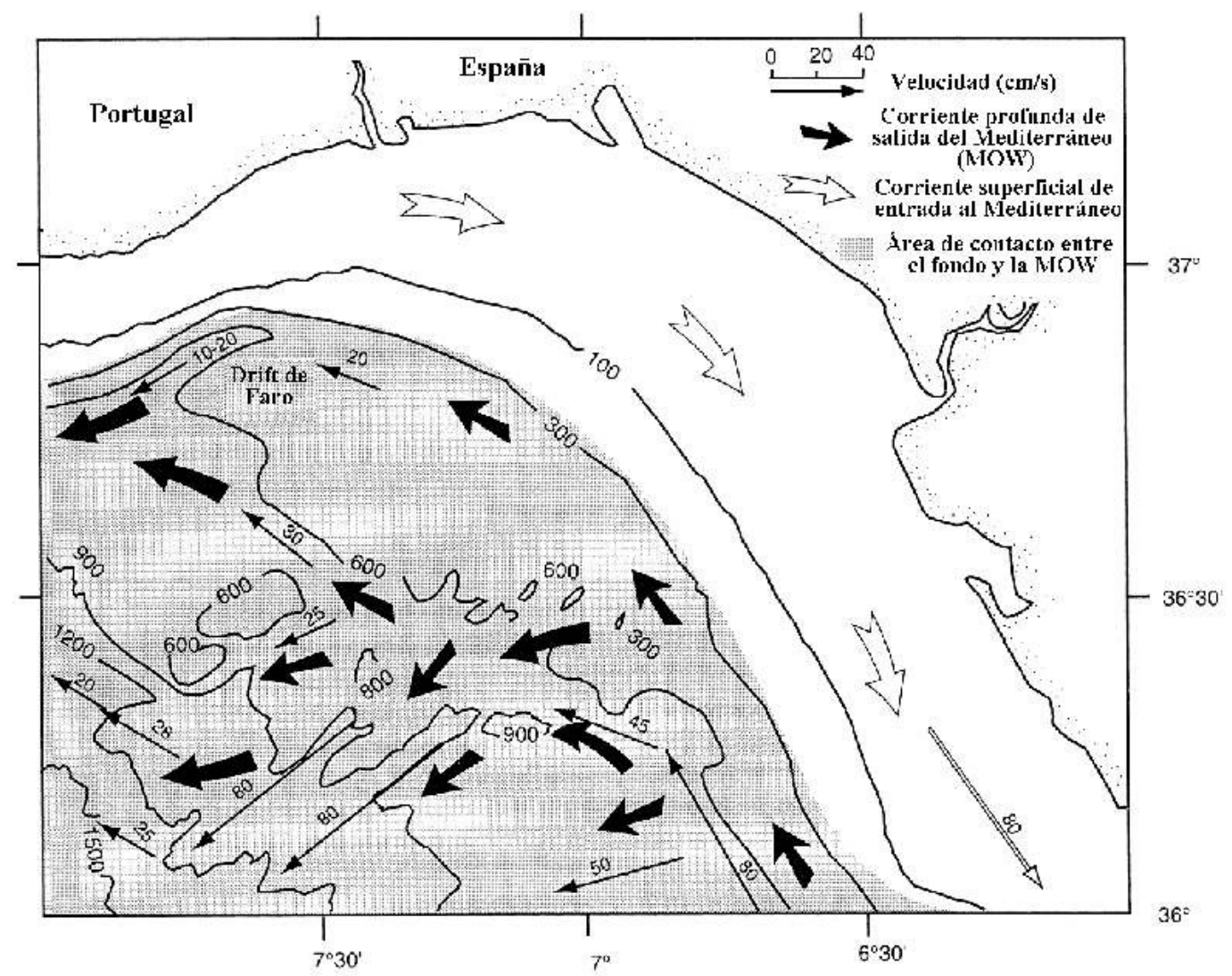

Figura 2.11. Dinámica oceanográfica en el golfo de Cádiz. Las velocidades de la corriente submarina del Mediterráneo se muestran en cm/s. Tomado de Nelson et al., 1999. 


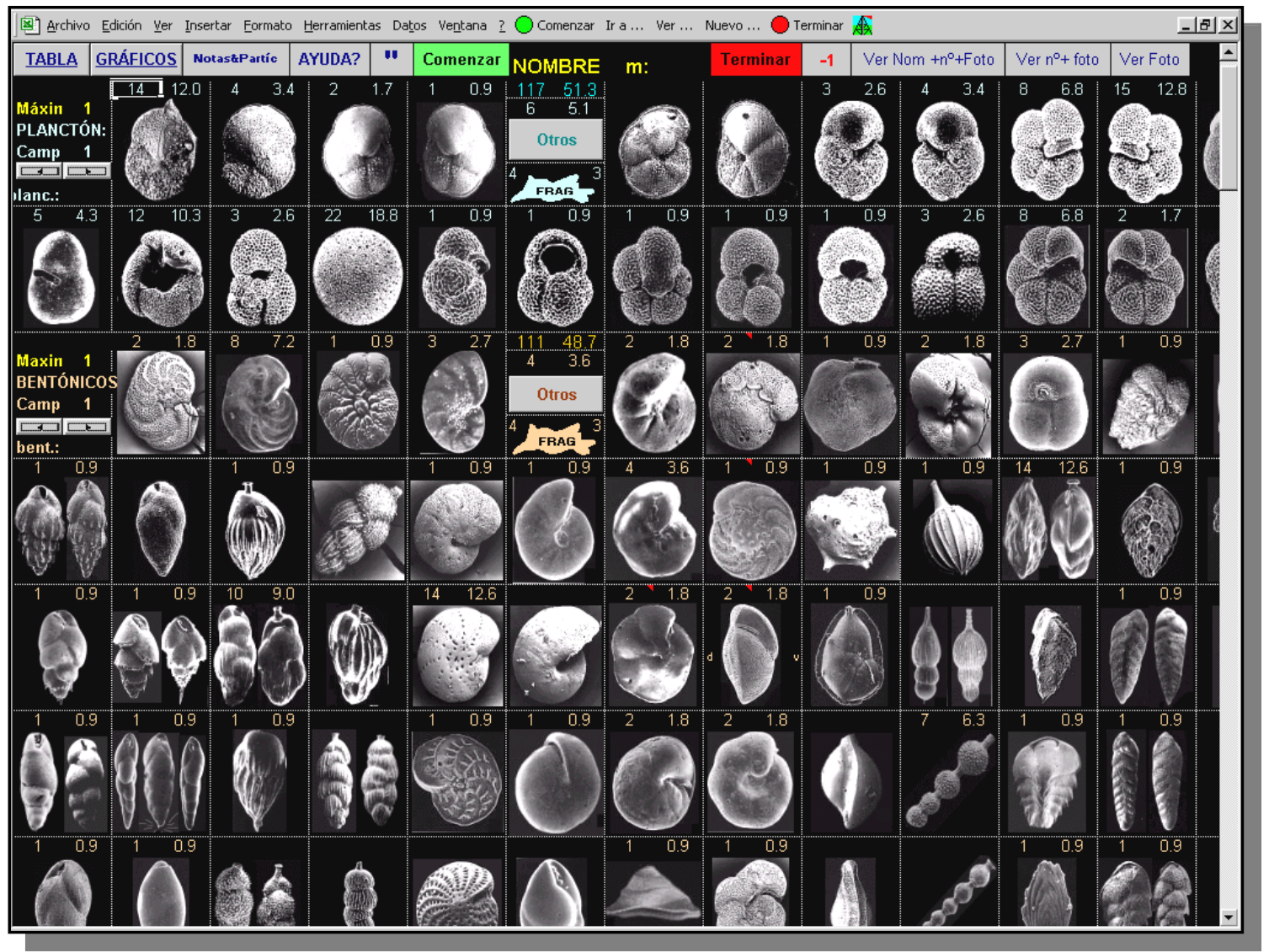


Página anterior: Entorno de trabajo del programa MICROPALEO-2000 (ver Apéndice). 


\subsection{SONDEOS Y MUESTRAS}

La estrecha colaboración mantenida con Susana Torrescusa y Wenceslao Martínez del Olmo (Repsol Exploración) nos ha permitido trabajar con muestras de sedimento de numerosos sondeos de exploración de hidrocarburos que diversas compañías petroleras han llevado a cabo en el área de estudio a lo largo de las últimas décadas. Algunos de estos sondeos, como veremos, presentan más de 2000 metros de profundidad. En la selección de los sondeos de mayor interés, se ha contado con el asesoramiento del equipo de Repsol Exploración, teniendo en cuenta sus intereses.

El análisis bioestratigráfico ha consistido en el estudio de 32 sondeos profundos de la cuenca del Guadalquivir-golfo de Cádiz. Todos los sondeos muestreados para su análisis bioestratigráfico aparecen en la figura 3.1. El muestreo se ha realizado cada 5, 10 ó $20 \mathrm{~m}$, en función de la disponibilidad de muestras en cada uno de los sondeos. En la medida de lo posible se han utilizado muestras procedentes de testigo continuo o de testigos laterales, si bien se ha trabajado fundamentalmente con muestras procedentes de ripios. El muestreo se llevó a cabo en las instalaciones que Repsol dispone en DaganzoMadrid $\left({ }^{1}\right)$, donde se encuentran depositadas la mayor parte de las muestras obtenidas en los sondeos petrolíferos llevados a cabo hasta la fecha en la cuenca del Guadalquivirgolfo de Cádiz. Por otro lado, gracias a la mediación de D. Luis Granados, algunos de los levigados estudiados fueron proporcionados por la Empresa Nacional Adaro y actualmente se encuentran depositados en el Departamento de Geología de la Universidad de Salamanca $\left(^{2}\right.$ ). Excepcionalmente, el sondeo Santa Clara-1, fue muestreado in situ, al coincidir su realización con el desarrollo de esta Tesis.

Correspondiendo al área del Guadalquivir, se muestrearon parcial o totalmente los siguientes sondeos:

$\begin{array}{ll}\text { ASPERILLO-1 } & \left({ }^{2}\right) \\ \text { CARMONA-1 } & \left({ }^{1}\right)\left({ }^{2}\right) \\ \text { CARMONA-2 } & \left({ }^{2}\right) \\ \text { CARMONA-4 } & \left({ }^{2}\right) \\ \text { CASA NIEVES-1 } & \left({ }^{1}\right)\left({ }^{2}\right) \\ \text { CASTILLEJA-1 } & \left({ }^{2}\right) \\ \text { EL CIERVO-1 } & \left({ }^{1}\right) \\ \text { ISLA MAYOR-1 } & \left({ }^{2}\right) \\ \text { MARISMAS A-1 } & \left({ }^{2}\right) \\ \text { MARISMAS-2 } & \left({ }^{1}\right) \\ \text { MARISMAS-4 } & \left({ }^{1}\right) \\ \text { MELO-1 } & \left({ }^{1}\right)\end{array}$




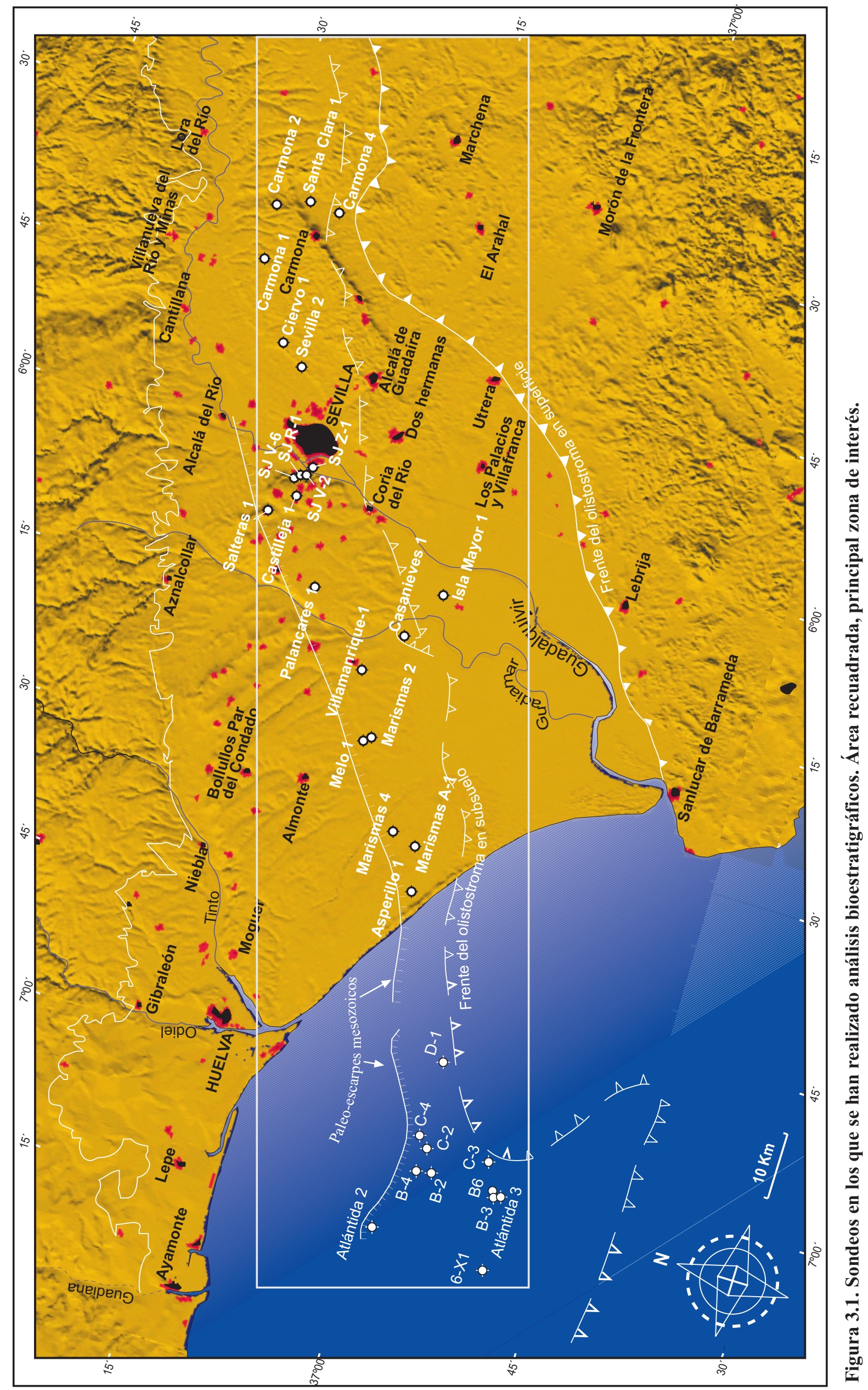




$\begin{array}{lc}\text { PALANCARES-1 } & \left(^{1}\right) \\ \text { SALTERAS-1 } & \left(^{2}\right) \\ \text { SAN JUAN R-1 } & \left(^{1}\right) \\ \text { SAN JUAN V-2 } & \left(^{1}\right) \\ \text { SAN JUAN V-6 } & \left(^{1}\right) \\ \text { SAN JUAN Z-1 } & \left(^{1}\right) \\ \text { SANTA CLARA-1 } & \\ \text { SEVILLA-2 } & \left(^{1}\right) \\ \text { VILLAMANRIQUE-1 } & \left.{ }^{1}\right)\end{array}$

Correspondiendo al área del golfo de Cádiz, se muestrearon total o parcialmente los siguientes sondeos:

Golfo de Cádiz-B2 $\left(^{2}\right)$

Golfo de Cádiz-B3 $\left(^{2}\right)$

Golfo de Cádiz-B4 $\left({ }^{1}\right)$

Golfo de Cádiz-B6 $\left(^{1}\right)$

Golfo de Cádiz-C2 $\left(^{2}\right)$

Golfo de Cádiz-C3 $\left(^{2}\right)$

Golfo de Cádiz-C4 $\left({ }^{1}\right)$

Golfo de Cádiz-D1 $\left({ }^{1}\right)$

Golfo de Cádiz-6x $1\left(^{1}\right)$

Atlántida-2 $\left({ }^{1}\right)$

Atlántida-3 $\left({ }^{1}\right)$

Por otro lado, se utilizará implícitamente diferente información procedente de otros sondeos, basada en datos publicados (ITGE, 1990) así como en información interna de Repsol Exploración. Estos datos, en general referidos a la localización de las profundidades a las que se encuentran las diferentes formaciones, o sobre el zócalo preMioceno, se han tenido en cuenta por ejemplo en el análisis del relleno sedimentario.

\subsubsection{Sondeos de exploración de hidrocarburos}

Antes de decidir la ubicación de cualquier sondeo exploratorio, se realiza un intenso estudio para evaluar la mejor localización del pozo de cara a la posible productividad efectiva del mismo. Una vez determinada la ubicación exacta se formalizan 
los permisos necesarios, incluida una evaluación de impacto ambiental según la normativa vigente, y se prepara el acceso al lugar, construyendo pistas, etc...

Un sondeo de rotación similar a los estudiados en esta Tesis aparece ilustrado en la figura 3.2 .

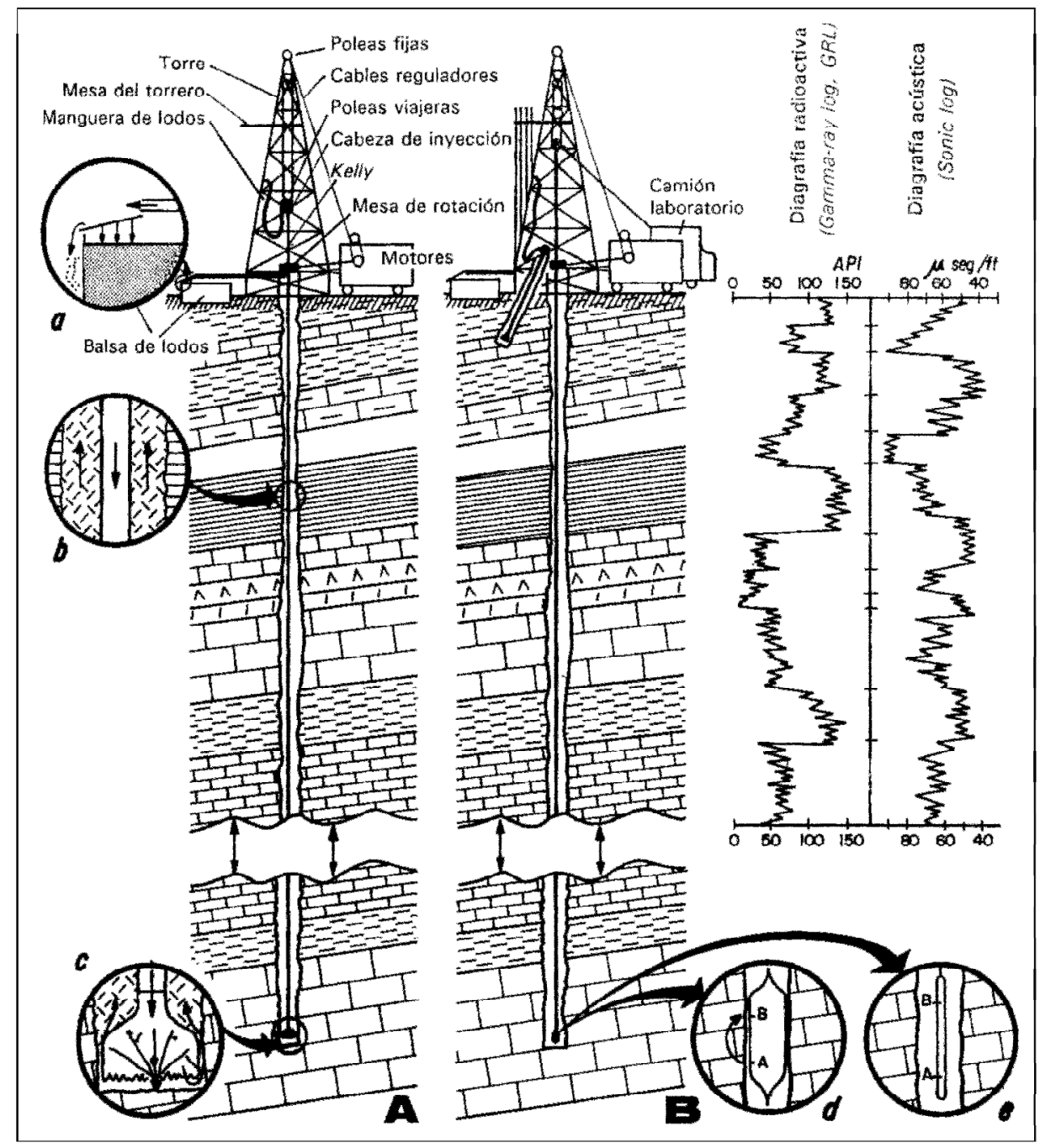

Figura 3.2. (A) Esquema de funcionamiento de un sondeo mecánico de exploración de hidrocarburos y (B) de la obtención del registro de diagrafías (Vera, 1994). Explicación en el texto.

En las siguientes fotografías (fig. 3.3), que muestran la perforación del sondeo Santa Clara-1 en las inmediaciones de Carmona (Sevilla), podemos apreciar diferentes aspectos de una perforación. Un sondeo de rotación consta de una torre (fig. 3.3A) con un juego de poleas (poleas fijas, fig. 3.2A) unido con cables a otro juego de poleas, swivel (poleas viajeras), del que cuelga el equipo de perforación (sarta) compuesto por la cabeza 

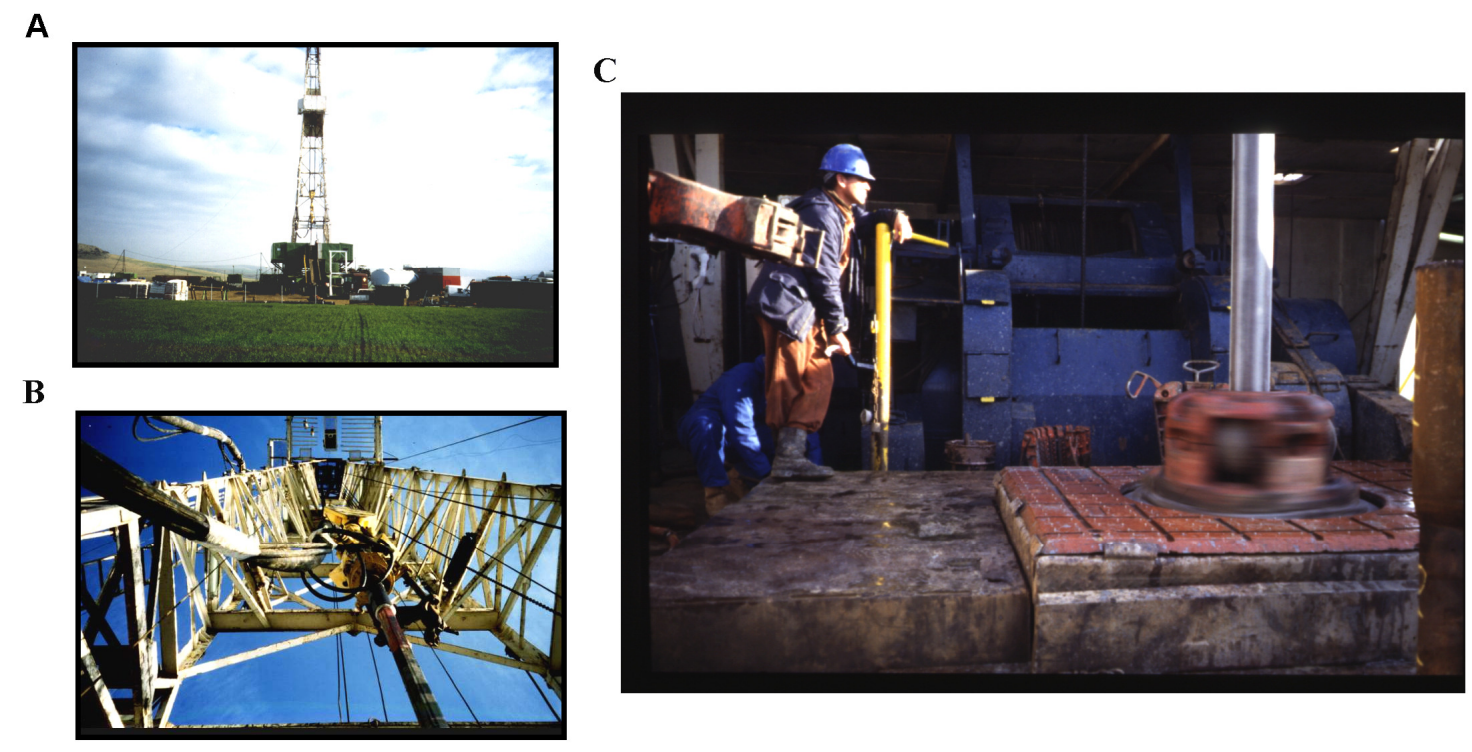

$\mathbf{E}$

\section{D}
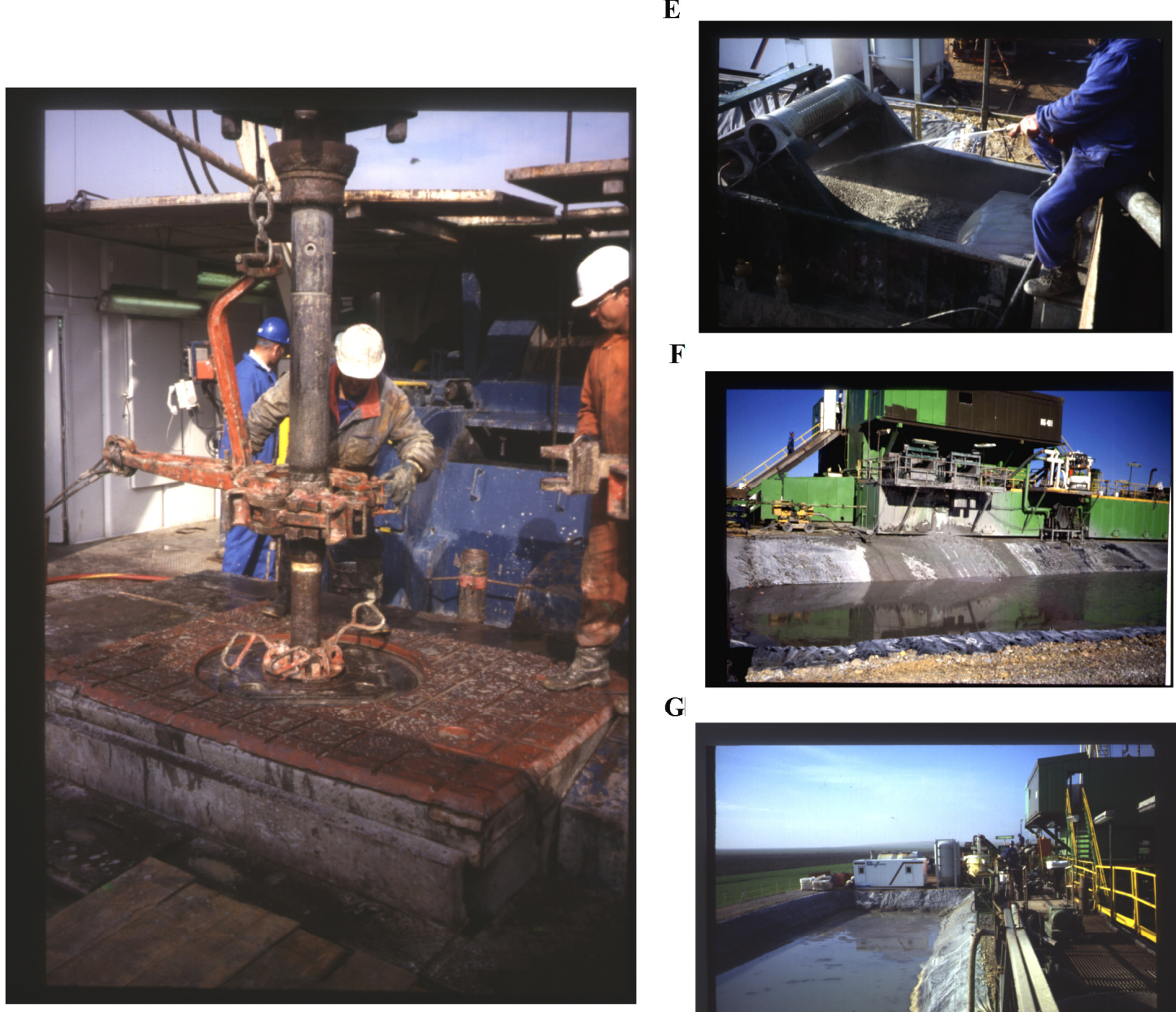

$\mathbf{F}$

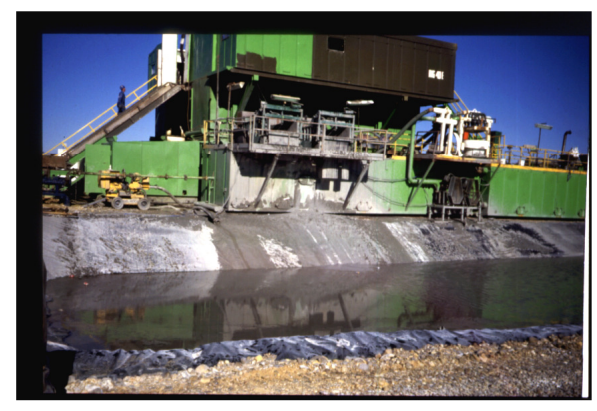

G

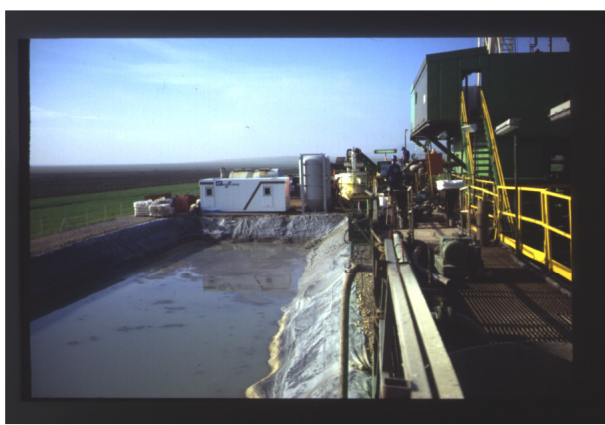

Figura 3.3. Distintos aspectos de un sondeo de exploración de hidrocarburos. Sondeo Santa Clara-1. Explicación en el texto. 
H

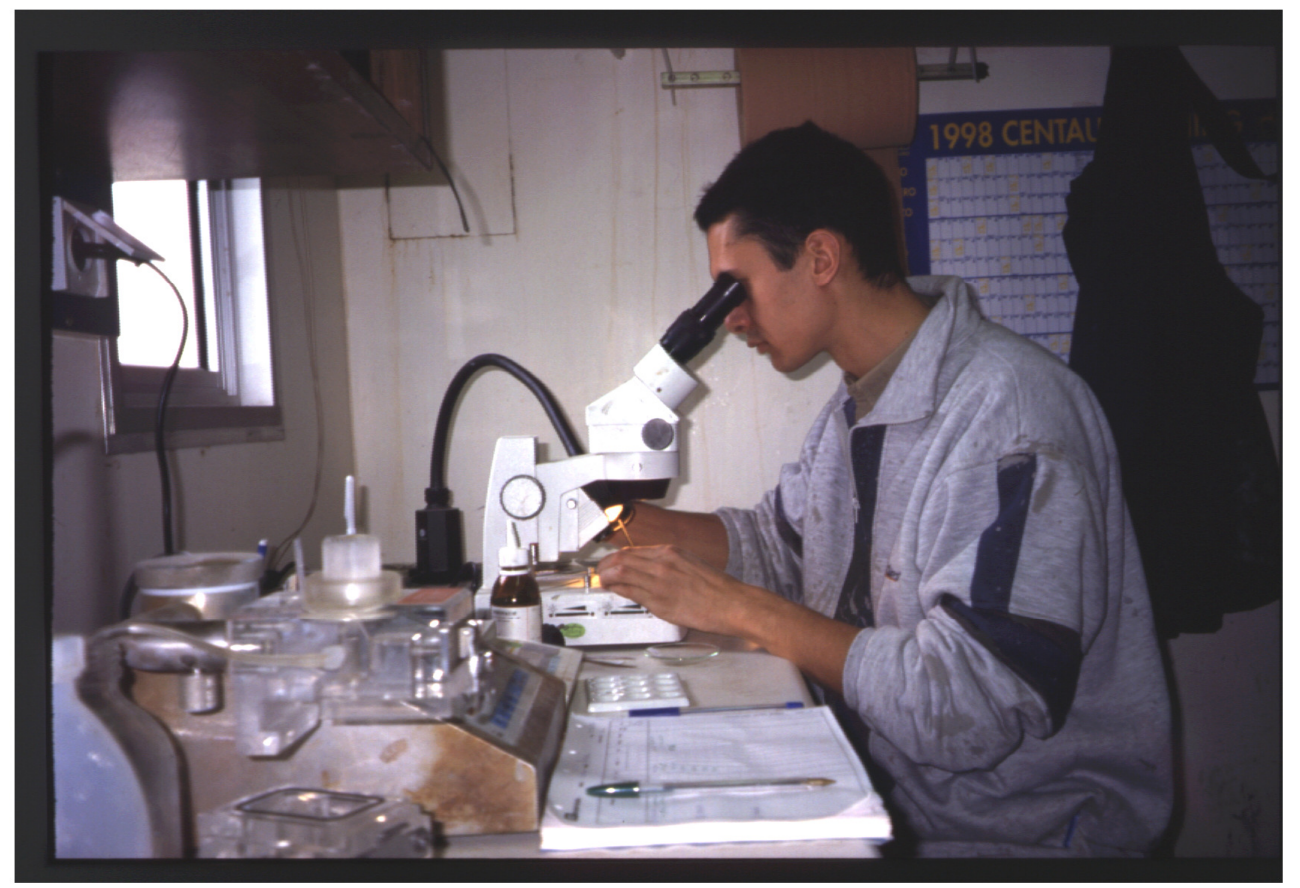

I

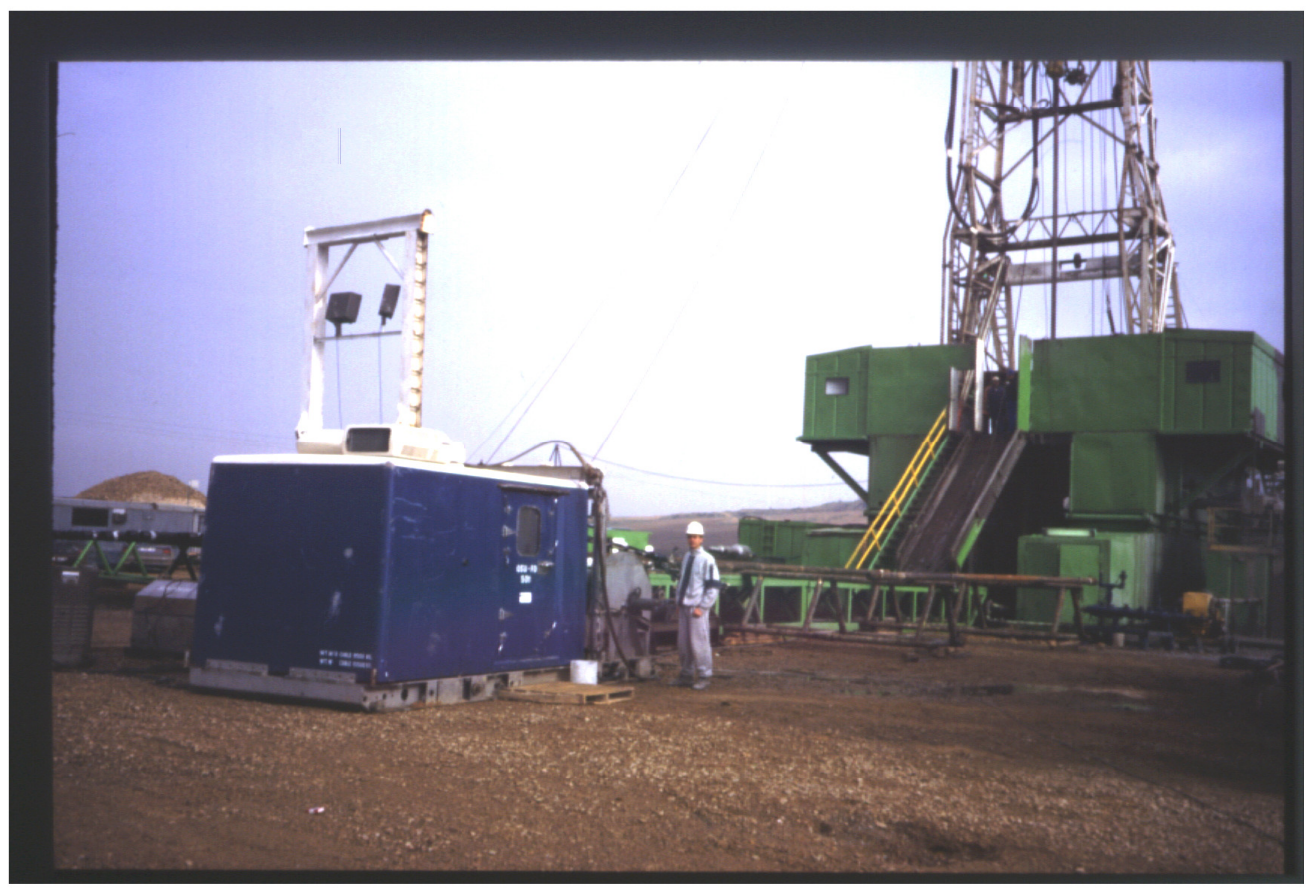

Figura 3.3 (Continuación). Distintos aspectos de un sondeo de exploración de hidrocarburos. Sondeo Santa Clara-1 Explicación en el texto. 
de inyección, kelly (primer tubo cuya sección es cuadrada para que permita transmitir la rotación (fig. 3.3B)), el conjunto de tubos (varillas) y el trépano (fig. 3.2A.c). El trépano es la herramienta que produce la perforación de las rocas, mediante la combinación de un movimiento de rotación transmitido desde el equipo motor a través de la mesa de rotación (rotary table, fig. 3.3C y fig. 3.3D) y la kelly a toda la sarta y de la presión parcial de la sarta en el fondo, controlada por la distancia entre los dos juegos de poleas y la tensión de los cables que los unen (Vera, 1994).

En la mayoría de los sondeos realizados por la industria petrolífera se utiliza como trépano un tricono (fig. 3.2A.c), constituido por tres piñas dentadas cónicas que pueden girar sobre sus propios ejes y que actúan triturando la roca. En este proceso de perforación juega un papel esencial el lodo de perforación, formado por un líquido viscoso pero poco denso (por ejemplo agua con bentonita) que circula permanentemente durante la perforación. El lodo es inyectado a presión a través de la cabeza de inyección para que circule en sentido descendente por el interior de la tubería de perforación (fig. 3.2A.b) hasta llegar al tricono, el cual tiene unos orificios por los que sale a fuerte presión, con lo que lubrica y refrigera la perforación (fig. 3.2A.c). El lodo continúa su circulación y asciende entre las paredes del sondeo y la tubería arrastrando las partículas trituradas de la roca o ripios (cuttings) (fig. 3.2A.a). Los ripios se separan del lodo con un tamiz (fig. 3.3E), de manera que el lodo pasa a través del mismo y cae en la balsa de lodos (fig. 3.3F y fig. 3.3G) para seguir en el circuito, mientras que las partículas sólidas (ripios) quedan sobre el tamiz.

Sistemáticamente, de las muestras recuperadas se describe la litología, se analiza su contenido en carbonatos mediante calcimetrías y se realiza una primera aproximación a la edad de las formaciones mediante análisis micropaleontológicos (fig. 3.3H). Con la información obtenida en la perforación se elabora una "ficha de sondeo" que contiene además de la columna litológica, las profundidades de los cambios litológicos, deducidas con los cuttings o con los parámetros de perforación, la descripción visual de los materiales (cuttings o testigo), test de producción de hidrocarburos, etc. Una vez finalizada la perforación y previamente a la entubación del sondeo, se obtienen los registros de diagrafías (fig. 3.2B) de los que hablaremos más adelante (capítulo 5). Esta última operación se lleva a cabo en un camión o laboratorio portátil como el que aparece en la figura 3.3I.

En casos especiales, durante la extracción de un testigo continuo, se utiliza un tipo de trépano con la corona de diamantes que permite la obtención de un cilindro de unos 10 $\mathrm{cm}$ de diámetro de la roca atravesada. Para la toma de un testigo de estas características se saca toda la sarta y se cambia el tricono por un tubo sacatestigos de doble pared, que 
termina en la corona de diamantes. El lodo circula en sentido descendente a través de la doble pared del tubo y sale inyectado por pequeños orificios en la corona, ascendiendo entre las paredes del pozo y las tuberías. Esta técnica de perforación es mucho más lenta y costosa que la del tricono por lo que en sondeos petrolíferos de exploración se aplica exclusivamente en los tramos de posible interés petrolífero, mientras que en sondeos de explotación normalmente no se usa nunca debido a que su coste es diez veces mayor que si el sondeo se efectúa mediante tricono. En la cuenca del Guadalquivir, durante las primeras perforaciones, de los años 50 y 60, se extrajeron varios testigos continuos (como es el caso de los sondeos Carmona-1 y Carmona-2), lo que proporcionaba, y proporciona aún hoy en día abundante información. Como solución intermedia, en casi todas las perforaciones profundas se obtienen a determinadas profundidades pequeños testigos laterales.

\subsubsection{Tipos de muestra recuperada}

En función del método de perforación utilizado se obtienen ripios, testigos laterales o bien testigo continuo. A continuación se exponen las principales características de cada tipo de muestra:

Ripios: Cuando se perfora con tricono, las muestras obtenidas son de roca triturada denominada ripio (cuttings) de las que se puede deducir la litología y en especial la composición de la formación atravesada. Cuando el tricono atraviesa la formación, la desgaja en pequeñas porciones que ascienden a superficie sustentadas en el lodo de perforación. El retardo que se produce desde que estas porciones son arrancadas de la formación hasta que alcanzan la superficie sirve para determinar en cada momento la profundidad original del ripio que aparece en superficie. La principal ventaja que aporta este tipo de muestra es la económica, ya que resulta altamente rentable respecto al coste que supone obtener un testigo continuo. A la muestra procedente de ripios se la denomina "muestra sin lavar" cuando se recoge tal y como llega a superficie, mientras que cuando se tamiza con una malla gruesa y es secada en un horno, el ripio se denomina "muestra lavada". La muestra "sin lavar" suele contener más de $100 \mathrm{~g}$ de sedimento, mientras que como muestra "lavada" apenas se conservan $10 \mathrm{~g}$ de sedimento seco.

La contaminación de los ripios supone en ocasiones un problema que limita el estudio micropaleontológico de la serie. En teoría el ascenso de los ripios sustentados por el lodo de perforación, es constante y a medida que se perfora se obtienen los ripios correspondientes. En la práctica, se han detectado numerosas contaminaciones. Una merma de la capacidad de sustentación del lodo conlleva una caída de las partículas que 
mantiene en suspensión (incluidos lógicamente los microfósiles). Esta circunstancia se ha observado especialmente al atravesar niveles ricos en arena, de tal forma que puede observarse la presencia de arena varias decenas de metros por debajo de la posición real de las formaciones de arenisca.

Lo mismo ocurre con los microfósiles. En la figura 3.4 observamos tres etapas en la perforación de un sondeo, en función de la posición de un intervalo de distribución de una especie A, utilizada como biomarcador. Antes de alcanzar dicho intervalo los ripios no contienen dicha especie (fig. 3.4A). Al perforar el techo del intervalo comienza a registrarse en los ripios la presencia de la especie A (fig. 3.4B). Sin embargo, una vez atravesado el intervalo de distribución de la especie A, seguimos registrando individuos de esa especie en los ripios (fig. 3.4C). Por este motivo los análisis bioestratigráficos deberán tener muy en cuenta este factor, siendo determinante a la hora de planificar el estudio de las muestras.

Debido a esta contaminación, la estimación del horizonte de primera aparición ( $F O$, first occurrence) y en menor medida el horizonte de primera aparición común (FCO, first common ocurrence), deben considerarse con suma precaución. Los horizontes de aparición deben estar por lo tanto calibrados con otros indicadores, como pueden ser niveles de desaparición de otras especies. En el caso de los horizontes de aparición abundante, el impacto de la contaminación suele ser menor debido a que la $F C O$ se basa en un incremento significativo del número de individuos y no en la presencia aislada de un solo ejemplar. Ya que debido a esta contaminación, el análisis cuantitativo de las especies y asociaciones puede verse seriamente afectado, el estudio bioestratigráfico realizado en esta Tesis se ha enfocado de forma cualitativa. El análisis cualitativo de los sondeos se apoya, no obstante, en análisis cuantitativos parciales que clarifican la relación de los diferentes taxones.

Testigos laterales: La certeza de la ubicación exacta de estos fragmentos de roca proporciona una información directa y precisa de la formación atravesada. Los testigos laterales proporcionan una información intermedia entre la que aportan los testigos continuos y la de los ripios. La mayor desventaja estriba en que solo ofrecen una información puntual, pues se obtienen a intervalos separados, impidiendo un estudio regular de la formación. 


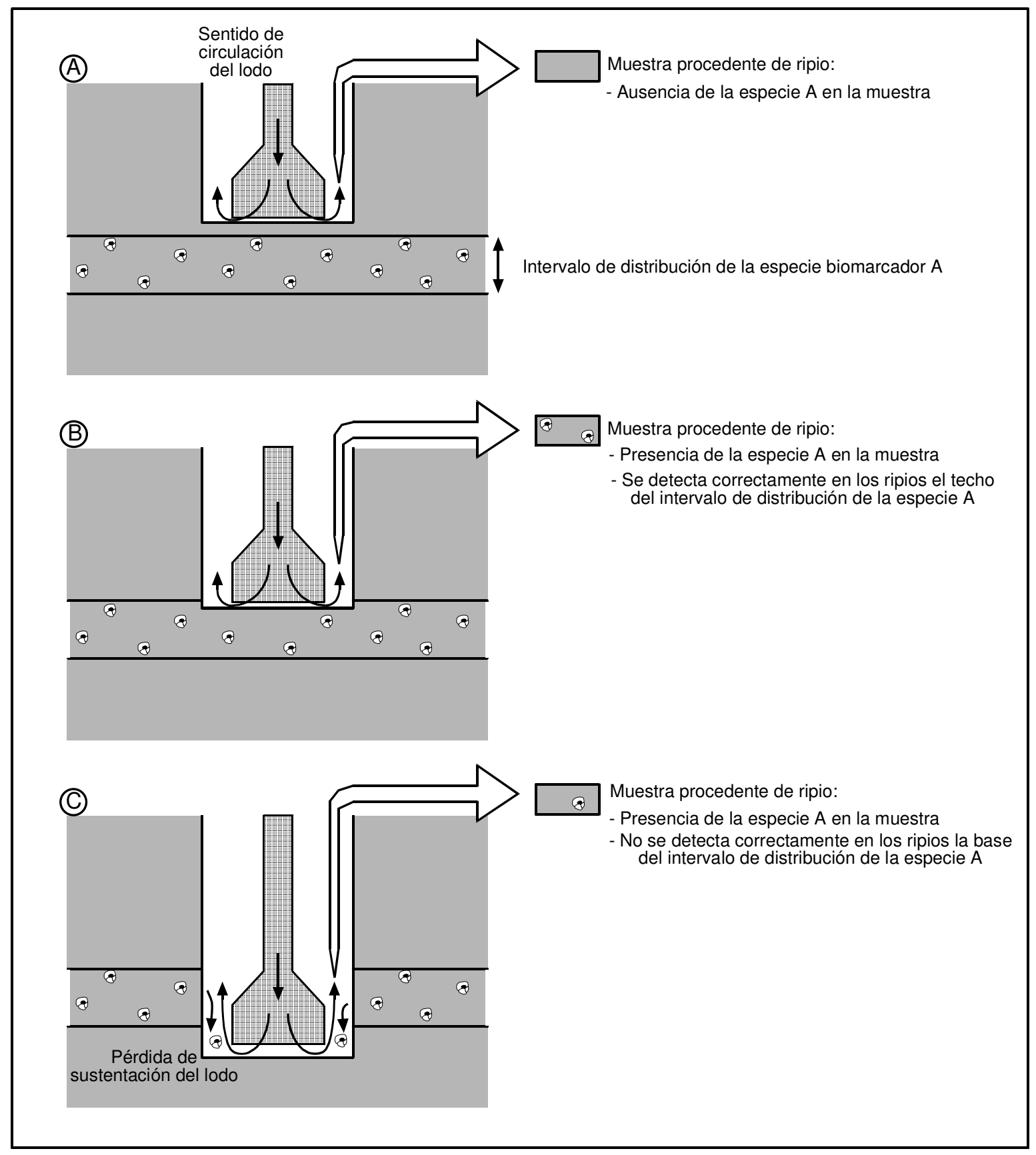

Figura 3.4. Contaminación vertical de partículas en muestras tipo "ripio" (cutting).

Testigos continuos: A partir de los testigos podemos conocer con todo detalle la litología, la textura de las rocas, algunas estructuras sedimentarias o el valor del buzamiento de los estratos (aunque no la dirección). A demás de la seguridad de la ubicación, la ausencia de contaminación y la continuidad de la muestra, los convierten en el material idóneo para un estudio micropaleontológico. 


\subsection{METODOLOGÍA DEL ANÁLISIS BIOESTRATIGRÁFICO}

\subsubsection{Preparación de las muestras}

Una vez muestreado el sondeo, el siguiente paso consiste en la preparación de las muestras para el posterior análisis micropaleontológico. A continuación se expone el procedimiento utilizado según el tipo de muestra:

Testigos y testigos laterales: Se ha pesado la muestra inicial y la resultante del tamizado para utilizar esta información posteriormente en caso necesario. En algunas ocasiones se ha aplicado $\mathrm{H}_{2} \mathrm{O}_{2}$ con el fin de eliminar la materia orgánica. Además se ha disgregado la muestra mediante una solución caliente de agua y pirofosfato sódico. Posteriormente, al cabo de unas $24 \mathrm{~h}$, se ha tamizado a $0,125 \mathrm{~mm}$, utilizando agua destilada en la solución final. A continuación se ha secado la fracción resultante, introduciéndola en un horno a unos $70^{\circ} \mathrm{C}$.

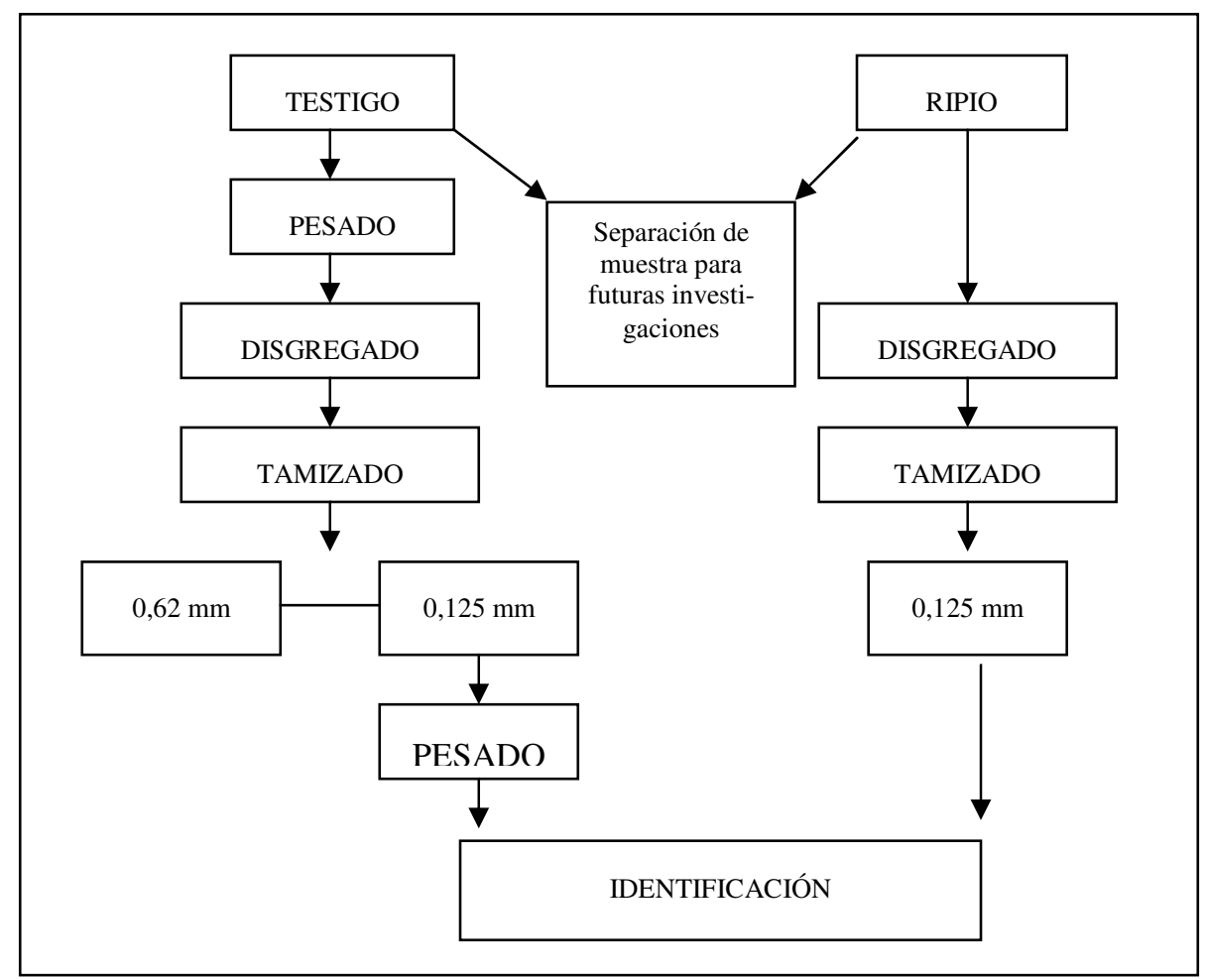

Figura 3.5. Esquema de preparación de las muestras procedentes de ripios y testigos previo a su análisis bioestratigráfico.

Ripios: En las muestras en las que ha sido preciso, después de unas horas de reacción con $\mathrm{H}_{2} \mathrm{O}_{2}$, se ha aplicado pirofosfato sódico permitiendo la reacción durante 12 h.. Sin embargo, normalmente no ha sido necesario la utilización de $\mathrm{H}_{2} \mathrm{O}_{2}$. Se ha 
observado además, la conveniencia de no utilizar agentes disgregantes o dispersantes (pirofosfato) debido a que en general, no es necesario y a que suelen quedar restos de pirofosfato que enmascaran los fósiles, dando lugar a pátinas si no se lava bien la muestra. Finalmente, se ha tamizado a $0,125 \mathrm{~mm}$. Una vez tamizada y lavada la muestra, se ha recogido el levigado superior a $0,125 \mathrm{~mm}$ (fig. 3.5). Para evitar la contaminación de los tamices, se introdujeron en un baño de ultrasonidos durante 1 minuto.

Habitualmente en ambos casos, es suficiente el reposo de la muestra en agua durante 12 a 24 h para liberar los microfósiles. El tamizado elimina las arcillas y restos del lodo de perforación en los ripios. Tanto en los testigos laterales como en los ripios, el residuo obtenido está formado en orden de abundancia por foraminíferos planctónicos y bentónicos, ostrácodos, espículas de erizos, briozoos, restos de peces...

\subsubsection{Análisis micropaleontológico}

Una vez preparadas las muestras se ha procedido al estudio cualitativo y cuantitativo de los foraminíferos. Hemos encontrado un problema inicial de escasez de muestra en determinados sondeos localizados en la cuenca del Guadalquivir donde la cantidad de foraminíferos planctónicos presentes en algunas de las muestras era escasa (sondeos Marismas-2, Sevilla-2, San Juan R1, San Juan Z1, San Juan V-2, Ciervo-1, Melo-1). En el muestreo de los ripios se ha utilizado frecuentemente "muestra lavada". Dividiendo la muestra inicial, se ha mantenido una parte para futuras investigaciones. Sin embargo, teniendo en cuenta la escasa muestra de partida, se han obtenido en general menos de $5 \mathrm{~g}$ de sedimento por muestra. A pesar de este problema se han extraído microfósiles suficientes para identificar las unidades bioestratigráficas establecidas mediante globorotálidos, así como otros bioeventos. No obstante, frente a la práctica habitual de utilizar "muestra lavada" para el estudio micropaleontológico, se ha observado la ventaja de realizar el muestreo sobre "muestra sin lavar", por vavios motivos:

- La muestra de partida (el ripio) es la misma en ambos casos.

- Es preferible que la limpieza y el tamizado de la muestra se realice en el laboratorio micropaleontológico. Durante la perforación, la recogida de muestras es solo una más de las tareas que deben atender los técnicos, que deben solucionar problemas más inmediatos.

- La cantidad de muestra sin lavar es siempre mucho mayor y puede ser, a la postre, determinante si en el levigado resultante escasean los microfósiles. Se ha observado que no son necesarios más de $150 \mathrm{cc}$ de muestra sin lavar para 
obtener un residuo rico en foraminíferos (este valor es lógicamente orientativo, siendo función de la riqueza de la muestra).

Una vez obtenido el levigado, se han identificado los foraminíferos planctónicos a nivel específico, genérico o de grupo. Así mismo, cuando se ha considerado de interés, se ha realizado un análisis cuantitativo de los foraminíferos planctónicos de la fracción $>0,125 \mathrm{~mm}$ calculándose los porcentajes relativos.

\subsubsection{Técnicas informáticas de apoyo}

Como ayuda en la realización del análisis bioestratigráfico, se ha desarrollado una aplicación informática (MICROPALEO-2000, ver anexo) en respuesta a una de las tareas mas arduas dentro de las investigaciones micropaleontológicas: el reconocimiento y recuento de microfósiles. El necesario recuento micropaleontológico, es hoy en día la labor mas tediosa y menos actualizada de las que ha de llevar a cabo el micropaleontólogo. Tradicionalmente se vienen realizado los recuentos micropaleontológicos de la siguiente forma: el micropaleontólogo sentado frente a su lupa (o microscopio) anota mediante lápiz y papel las diferentes especies que aparecen en la muestra e incrementa mediante una " $x$ " cada nuevo individuo que identifica. Existen contadores mecánicos que mediante pulsadores facilitan esta tarea. Sin embargo tienen una limitación importante, el numero de pulsadores es reducido y fijo, además, solo proporcionan el valor de la suma de individuos de cada especie considerada. En todos los casos, una vez completados los recuentos sobre el papel, se calculan los porcentajes relativos. Después de la identificación y el recuento de individuos, se trasladan los datos absolutos obtenidos a una hoja de calculo donde se obtienen los porcentajes relativos de cada especie y se realizan el resto de operaciones previas a la obtención de los gráficos donde se reflejan los resultados. Cuando esta operación se debe repetir un centenar de ocasiones, el proceso resulta largo y tedioso.

Con el objetivo de actualizar este procedimiento, he diseñado una aplicación informática desarrollada en función de las necesidades observadas para este tipo de estudio. Las principales ventajas en la utilización de esta aplicación informática son las siguientes:

\section{1- Introduce agilidad en los recuentos}

2- Elimina los pasos intermedios realizados sobre el papel, tales como el recuento y la suma de individuos, realiza de forma instantánea los porcentajes relativos y el resto de cálculos matemáticos habituales. 
3- Ayuda al investigador en el reconocimiento de los foraminíferos que componen la muestra que está analizando.

4- Estandariza las bases de datos obtenidas por el micropaleontólogo.

Finalmente la utilización de este método de recuento consigue algo no menos importante, que el recuento micropaleontológico sea ameno, resultando así mismo interesante como instrumento docente. Por otro lado, la presencia constante de las fotografías en la pantalla acompañadas de pequeñas descripciones, permite acceder de forma inmediata a la información necesaria para superar las dificultades en la identificación de los foraminíferos.

En el anexo de la Tesis, se adjunta una explicación detallada de las características, requisitos y configuración de esta aplicación. 


\subsection{RESULTADOS}

El conjunto de resultados pormenorizados obtenidos tanto del análisis micropaleontológico (capítulo 3), de los perfiles sismobioestratigráficos (capítulo 4) y del análisis cicloestratigráfico de cada sondeo (capítulo 5), se muestran en el capítulo 6, donde una serie de figuras sintéticas resumen la información más destacada obtenida en cada uno de ellos.

Existen algunos informes micropaleontológicos previos sobre varios de los sondeos empleados. Generalmente se trata de informes internos realizados a petición de las compañías prospectoras, como los elaborados por la desaparecida Empresa Nacional Adaro. También existen algunas publicaciones al respecto entre las que destacan los trabajos de Perconig $(1960,1964)$.

La bioestratigrafía de esta Tesis está basada fundamentalmente en cambios cualitativos (ocasionalmente cuantitativos) de las asociaciones de foraminíferos planctónicos. El estudio bioestratigráfico de las muestras procedentes de 32 sondeos profundos a lo largo de toda la zona de estudio, ha posibilitado la localización de diversos bieventos basados en sucesos de aparición, desaparición o reemplazamiento de diferentes foraminíferos planctónicos entre los que destacan los referidos a los globorotálidos. Se ha utilizado así mismo el cambio de enrollamiento en los neogloboquadrínidos y excepcionalmentese han utilizado eventos basados en nanofósiles calcáreos (concretamente en los sondeos Santa Clara-1, Marismas A1 y Atlántida-2). Por otro lado, la bioestratigrafía se ha completado con la consideración del resto de partículas presentes en las muestras, lo que ha proporcionado interesante información, que en algunos casos ha reforzado la correlación estrictamente bioestratigráfica. En este sentido, se han localizado por ejemplo, niveles de concentración de glauconita, pirita, mica o restos carbonosos... así como concentraciones de foraminíferos.

La abundancia relativa de los diferentes grupos de foraminíferos ha sido ampliamente utilizada para realizar estudios paleoambientales y bioestratigráficos dentro y fuera del área de estudio (Perconig, 1964; 1966; Sierro, 1985; Civis et al., 1987, 1994; Sierro et al., 1993; 1996). Sierro et al. (1996) consideran que los bioeventos de foraminíferos planctónicos son isócronos en el área estudiada, y su reconocimiento en distintas partes de la cuenca permite la identificación de sucesivas superficies definiendo cuerpos de roca isócronos.

En esta Tesis se han reconocido una serie de bioeventos utilizados en el contexto Atlántico-Mediterráneo, algunos de ellos previamente definidos en el Guadalquivir para 
el Tortoniense-Messiniense por Sierro (1985; 1986) y Sierro et al. (1993). Las abreviaturas utilizadas en el capítulo bioestratigráfico se detallan a continuación (existe igualmente un capítulo de abreviaturas general al final de la Tesis).

Abreviaturas empleadas en este capítulo:

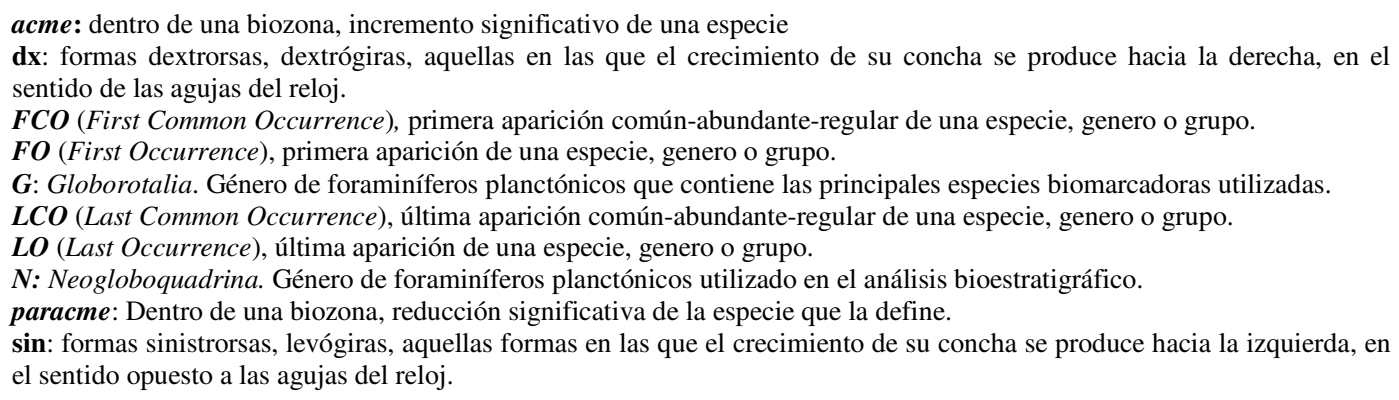

Ordenados de más antiguo a más moderno, los bioeventos reconocidos en el análisis bioestratigráfico de los sondeos analizados, han sido los siguientes:

- Última aparición común ( $L C O)$ del grupo de Globorotalia menardii sin (sensu Sierro et al., 1993) (Evento E1).

- Incremento de reticulofenéstridos $<3 \mu \mathrm{m}$ (nanoplancton calcáreo).

- Primera aparición común (FCO) del grupo de G. menardii dx (sensu Sierro et al., 1993) (Evento E2).

- Cambio de enrollamiento grupo de G. scitula (sensu Sierro et al., 1993) (Evento EA).

- Reemplazamiento del grupo de G. menardii dx por el grupo de G. miotumida $\sin$ (sensu Sierro et al., 1985, 1993) (Evento E3).

- Techo del paracme de Reticulofenestra pseudoumbilicus (nanoplancton calcáreo).

- Cambio de enrollamiento de Neogloboquadrina acostaensis (Evento E4).

- Última aparición (LO) Discoaster quinqueramus (nanoplancton calcáreo).

- Última aparición ( $L O)$ del grupo de G. miotumida sin.

- Primera aparición (FO) del grupo de G. margaritae (Evento E6).

- Primera aparición común (FCO) del grupo de G. margaritae.

- Última aparición común ( $L C O)$ del grupo de G. scitula dx.

- Base del acme de Sphaeroidinellopsis.

- Techo del acme de Sphaeroidinellopsis. 
- Última aparición común ( $L C O)$ del grupo de G. margaritae.

- Última aparición ( $L O)$ del grupo de G. margaritae.

- Última aparición (LO) de Sphaeroidinellopsis.

- Última aparición (LO) de Globoquadrina altispira.

- Última aparición $(L O)$ de G. puncticulata.

- Primera aparición $(F O)$ de G. inflata.

En cuanto a la primera aparición común $(F C O)$ del grupo de G. margaritae, se ha considerado equivalente a la base del acme de G. margaritae localizada inmediatamente después de la primera a parición de este grupo de globorotálidos.

En la figura 3.6 se muestra una relación de los sondeos estudiados y los bioeventos localizados en los mismos.

La presencia de contaminación debida a las labores de perforación y la evidencia de retrabajado en los foraminíferos (significativa en algunos casos), así como el propio muestreo realizado (con un intervalo de 5 a $10 \mathrm{~m}$ ), no permiten localizar el metro exacto en el que suceden algunos de los eventos reconocidos. El primero de estos factores, derivado de la contaminación propia de la perforación del sondeo, introduce elementos más modernos en niveles más profundos, restando fiabilidad a los eventos basados en primeras apariciones (fig. 3.4). Por otro lado, la contaminación propia del sistema sedimentario, introduce materiales retrabajados que son más antiguos, colocándolos en posiciones más elevadas dentro de la columna. En este último caso debe prestarse especial atención al establecer la extinción de un biomarcador ya que la resedimentación puede entorpecer su localización. Por lo tanto existen dos contaminaciones opuestas que afectan a los marcadores bioestratigráficos. Es preciso tener en cuenta este factor a la hora de establecer la posición de los eventos. En general se ha observado una mayor fiabilidad de los eventos de desaparición respecto a los basados en primeras apariciones.

En los sondeos estudiados, la asociación de foraminíferos planctónicos está dominada por el grupo de Globigerina bulloides y el grupo de Globigerinoides obliquusextremus. Así mismo, también es abundante el grupo de Neogloboquadrina acostaensis con formas tanto dextrorsas como sinistrorsas y es común la presencia de Orbulina universa y del grupo Globigerina apertura. Por otra parte y en menor representación aparecen Globigerina druryi, el grupo Gs. sacculifer-trilobus, Dentoglobigerina altispira y Sphaeroidinellopsis seminulina. 


\begin{tabular}{|c|c|c|c|c|c|c|c|c|c|c|c|c|c|c|c|c|c|c|c|c|}
\hline 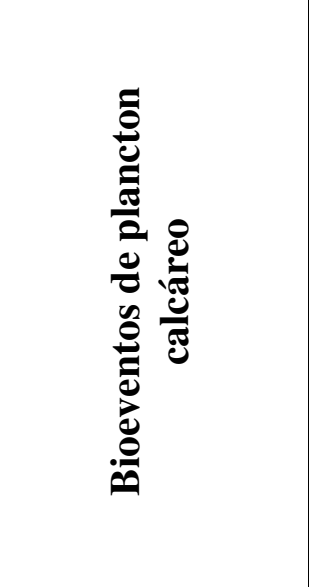 & 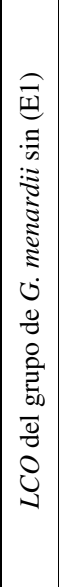 & 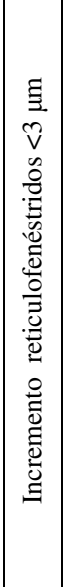 & 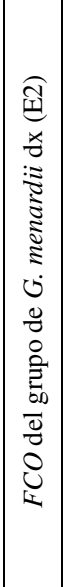 & 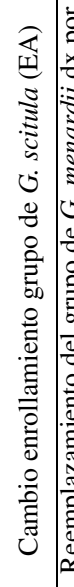 & 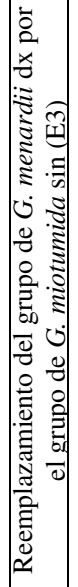 & 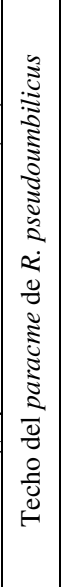 & 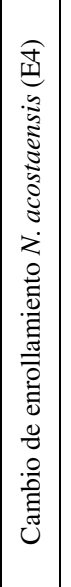 & 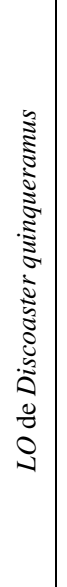 & 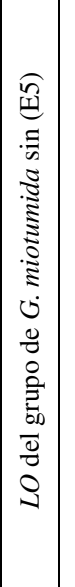 & 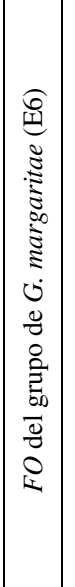 & 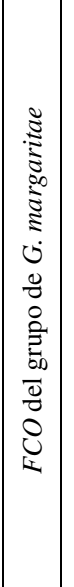 & 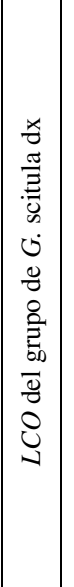 & 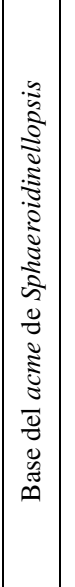 & 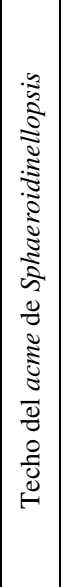 & 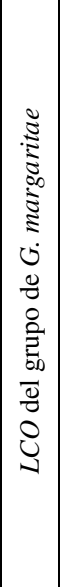 & 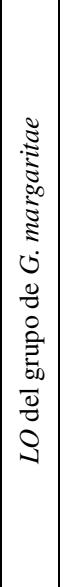 & 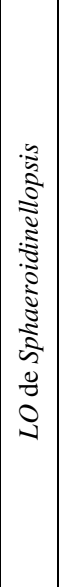 & 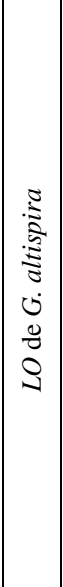 & 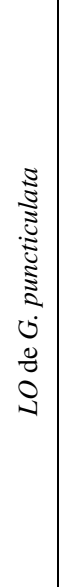 & 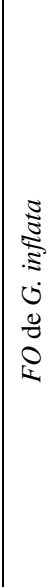 \\
\hline Asperillo-1 & & & & & & & $\mathrm{X}$ & & $X$ & $\mathrm{X}$ & & & & & & & & & & \\
\hline Carmona-1 & $X$ & & & & & & $\mathrm{X}$ & & $\mathrm{X}$ & $\mathrm{X}$ & $\mathrm{X}$ & & & & & & & & & \\
\hline Carmona-2 & $\mathrm{x}$ & & & & $\mathrm{X}$ & & $\mathrm{X}$ & & $\mathrm{x}$ & $\mathrm{x}$ & $\mathrm{X}$ & & & & & & & & & \\
\hline Carmona-4 & $X$ & & $\mathrm{X}$ & $\mathrm{X}$ & & & & & & & & & & & & & & & & \\
\hline Casanieves-1 & $\mathrm{X}$ & & $\mathrm{X}$ & $\mathrm{X}$ & $X$ & & $\mathrm{X}$ & & $\mathrm{X}$ & $\mathrm{X}$ & $\mathrm{X}$ & $\mathrm{X}$ & $\mathrm{x}$ & & & & & & & \\
\hline Castilleja-1 & & & & & & & $\mathrm{X}$ & & $\mathrm{X}$ & $\mathrm{X}$ & & & & & & & & & & \\
\hline Ciervo-1 & & & & & & & $\mathrm{X}$ & & & & $\mathrm{X}$ & & & & & & & & & \\
\hline Isla Mayor-1 & & & & & $\mathrm{X}$ & & $\mathrm{X}$ & & $\mathrm{X}$ & $X$ & & & & & & & & & & \\
\hline Palancares-1 & & & & & & & $\mathrm{X}$ & & & & $\mathrm{X}$ & & & & & & & & & \\
\hline San Juan R-1 & $\mathrm{x}$ & & $\mathrm{X}$ & $\mathrm{x}$ & $\mathrm{X}$ & & $\mathrm{X}$ & & $\mathrm{X}$ & $\mathrm{X}$ & $\mathrm{X}$ & $X$ & & & & & & & & \\
\hline San Juan V-2 & & & & & $\mathrm{X}$ & & $\mathrm{X}$ & & $X$ & & $X$ & $\mathrm{X}$ & & & & & & & & \\
\hline San Juan V-6 & & & & & & & $X$ & & $X$ & & $X$ & & & & & & & & & \\
\hline San Juan Z-1 & $\mathrm{x}$ & & & & $\mathrm{X}$ & & $X$ & & $\mathrm{X}$ & $\mathrm{X}$ & $\mathrm{X}$ & & & & & & & & & \\
\hline Santa Clara-1 & $X$ & $\mathrm{X}$ & $\mathrm{X}$ & $\mathrm{X}$ & $\mathrm{X}$ & $\mathrm{X}$ & $\mathrm{X}$ & $\mathrm{x}$ & & & & & & & & & & & & \\
\hline Salte & & & & & $\mathrm{X}$ & & $X$ & & $\mathrm{X}$ & $\mathrm{X}$ & $\mathrm{X}$ & & & & & & & & & \\
\hline Sevilla-2 & & & & & $\mathrm{X}$ & & $\mathrm{X}$ & & $\mathrm{X}$ & $\mathrm{X}$ & $\mathrm{X}$ & & & & & & & & & \\
\hline Villamanrique-1 & $X$ & & $\mathrm{X}$ & $\mathrm{X}$ & $\mathrm{X}$ & & $X$ & & $\mathrm{X}$ & $\mathrm{X}$ & $\mathrm{X}$ & $X$ & $\mathrm{X}$ & & & & & & & \\
\hline Marismas A-1 & $X$ & & $\mathrm{X}$ & $\mathrm{X}$ & $\mathrm{X}$ & & $X$ & $\mathrm{x}$ & $\mathrm{X}$ & $\mathrm{X}$ & $\mathrm{X}$ & & & & & & & & & \\
\hline Marismas-2 & $X$ & & $\mathrm{X}$ & $X$ & $X$ & & $\mathrm{X}$ & & $\mathrm{X}$ & $\mathrm{X}$ & $\mathrm{X}$ & $\mathrm{X}$ & & & & & & & & \\
\hline Marismas-4 & $X$ & & & & $\mathrm{X}$ & & & & & & $\mathrm{X}$ & & & & & & & & & \\
\hline Melo-1 & & & & & & & & & & $\mathrm{X}$ & $\mathrm{X}$ & & & & & & & & & \\
\hline Atlántida-2 & $X$ & & $\mathrm{X}$ & $X$ & $X$ & & $X$ & $\mathrm{X}$ & $\mathrm{X}$ & $\mathrm{X}$ & $\mathrm{X}$ & $X$ & & & & & & & & \\
\hline Atlántida-3 & & & & & & & $\mathrm{X}$ & & $\mathrm{X}$ & $\mathrm{X}$ & & & $\mathrm{X}$ & $\mathrm{x}$ & $\mathrm{X}$ & $\mathrm{X}$ & $\mathrm{X}$ & $\mathrm{X}$ & & \\
\hline GC -B2 & $X$ & & $\mathrm{X}$ & & $\mathrm{X}$ & & $\mathrm{X}$ & & $\mathrm{X}$ & $\mathrm{X}$ & $\mathrm{X}$ & & $\mathrm{X}$ & $\mathrm{X}$ & $\mathrm{X}$ & $\mathrm{X}$ & & & $X$ & $\mathrm{x}$ \\
\hline GC -B3 & $X$ & & $\mathrm{X}$ & & $X$ & & $X$ & & $\mathrm{X}$ & $\mathrm{X}$ & $\mathrm{X}$ & & & & $X$ & $\mathrm{X}$ & $\mathrm{X}$ & & $\mathrm{X}$ & \\
\hline GC -B4 & & & & & $X$ & & $X$ & & $\mathrm{X}$ & $\mathrm{X}$ & & & & & & & & & & \\
\hline GC -B6 & & & $\mathrm{X}$ & $X$ & $X$ & & $\mathrm{X}$ & & $\mathrm{X}$ & $\mathrm{X}$ & $\mathrm{X}$ & $X$ & $X$ & & $\mathrm{X}$ & \begin{tabular}{|l|}
$\mathrm{x}$ \\
\end{tabular} & $X$ & & & \\
\hline GC -C2 & $X$ & & $\mathrm{X}$ & & $X$ & & $\mathrm{X}$ & & $\mathrm{X}$ & $\mathrm{X}$ & $\mathrm{X}$ & & $X$ & $X$ & $\mathrm{X}$ & $X$ & & $\mathrm{x}$ & & \\
\hline GC -C3 & $X$ & & $\mathrm{X}$ & $X$ & $X$ & & $X$ & & $X$ & $\mathrm{X}$ & $X$ & $X$ & & & $X$ & $X$ & $X$ & & $X$ & \\
\hline $\mathrm{GC}-\mathrm{C4}$ & & & & & & & $X$ & & $X$ & & $X$ & & & & & & & & & \\
\hline GC-D1 & $X$ & & $\mathrm{X}$ & & $X$ & & $X$ & & $\mathrm{X}$ & $\mathrm{X}$ & $\mathrm{X}$ & $\mathrm{X}$ & & & $\mathrm{X}$ & $X$ & & & $\mathrm{X}$ & \\
\hline $6 \times 1$ & & & & & & & & & $\mathrm{X}$ & $\mathrm{X}$ & $\mathrm{X}$ & & & & $X$ & $\mathrm{X}$ & $\mathrm{X}$ & $\mathrm{X}$ & & \\
\hline
\end{tabular}

Figura 3.6. Sondeos estudiados en el análisis bioestratigráficos y principales bioeventos localizados. "X"= localización precisa." $\mathrm{X} "=$ localización dudosa 0 imprecisa. 
En la figura 3.7, se muestran los principales foraminíferos planctónicos que aparecen en las muestras examinadas, ordenados según su género (sistemática basada en Kennett, J. P. y Srinivasan, M. S., 1983):

\begin{tabular}{|c|c|c|}
\hline $\begin{array}{l}\text { Gg.: Globigerina } \\
\text { (Gg.) quinqueloba } \\
\text { (Gg.) bulloides } \\
\text { (Gg.) falconensis } \\
\text { (Zeaglobigerina) apertura } \\
\text { (Zg.) druryi } \\
\text { (Zg.) nepenthes }\end{array}$ & $\begin{array}{c}\text { Gs.: Globigerinoides } \\
\text { obliquus } \\
\text { extremus } \\
\text { bulloideus } \\
\text { triloba } \\
\text { immaturus } \\
\text { quadrilobatus } \\
\text { sacculifer } \\
\text { ruber } \\
\text { seigliei }\end{array}$ & $\begin{array}{l}\text { G.: Globorotalia } \\
\text { (G.) miotumida (grupo de G. miotumida) } \\
\text { (G.) conoidea (grupo de G. miotumida) } \\
\text { (G.) conomiozea (grupo de G. miotumida) } \\
\text { (G.) puncticulata } \\
\text { (G.) inflata } \\
\text { (Menardella) menardii (grupo de G. menardii) } \\
(\text { Globorotalia) merotumida (grupo de G. menardii) } \\
\text { (G.) plesiotumida (grupo de G. menardii) } \\
\text { (Hirsutella) scitula } \\
\text { (H.) margaritae } \\
\text { (Truncorotalia) crassaformis } \\
\text { (Jenkinsella) mayeri }\end{array}$ \\
\hline $\begin{array}{r}\text { O.: Orbulina } \\
\text { bilobata } \\
\text { suturalis } \\
\text { universa }\end{array}$ & $\begin{array}{l}\text { Gq.: Globoquadrina } \\
\text { altispira altispira }\end{array}$ & $\begin{array}{r}\text { N.: Neogloboquadrina } \\
\text { acostaensis } \\
\text { humerosa }\end{array}$ \\
\hline $\begin{array}{l}\text { Ss.: Sphaeroidinellopsis } \\
\text { seminulina seminulina }\end{array}$ & $\begin{array}{r}\text { Ga.: Globigerinita } \\
\text { glutinata }\end{array}$ & $\begin{array}{l}\text { Ge.: Globigerinella } \\
\text { obesa } \\
\text { pseudobesa }\end{array}$ \\
\hline
\end{tabular}

Figura 3.7. Relación de los principales foraminíferos planctónicos que aparecen en los sedimentos mio-pliocenos de la cuenca del Guadalquivir-golfo de Cádiz.

\subsubsection{Bioeventos de globorotálidos carenados}

Los globorotálidos carenados constituyen la principal herramienta bioestratigráfica utilizada. En la figura 3.8 se muestran los grupos de globorotálidos carenados utilizados en el análisis bioestratigráfico.

El grupo de Globorotalia miotumida (sensu Sierro et al., 1993), es el que adquiere mayor representación, superando en algún momento el $20 \%$ de la asociación de foraminíferos planctónicos, el resto aparecen generalmente con valores entre un $2 \%$ y un $15 \%$, salvo en niveles puntuales con concentraciones significativas del grupo de $G$. margaritae.

Los diferentes grupos de globorotálidos carenados se diferencian desde el punto de vista morfológico por el grado de curvatura de los lados dorsal y ventral y por la forma de la abertura (fig. 3.8). 


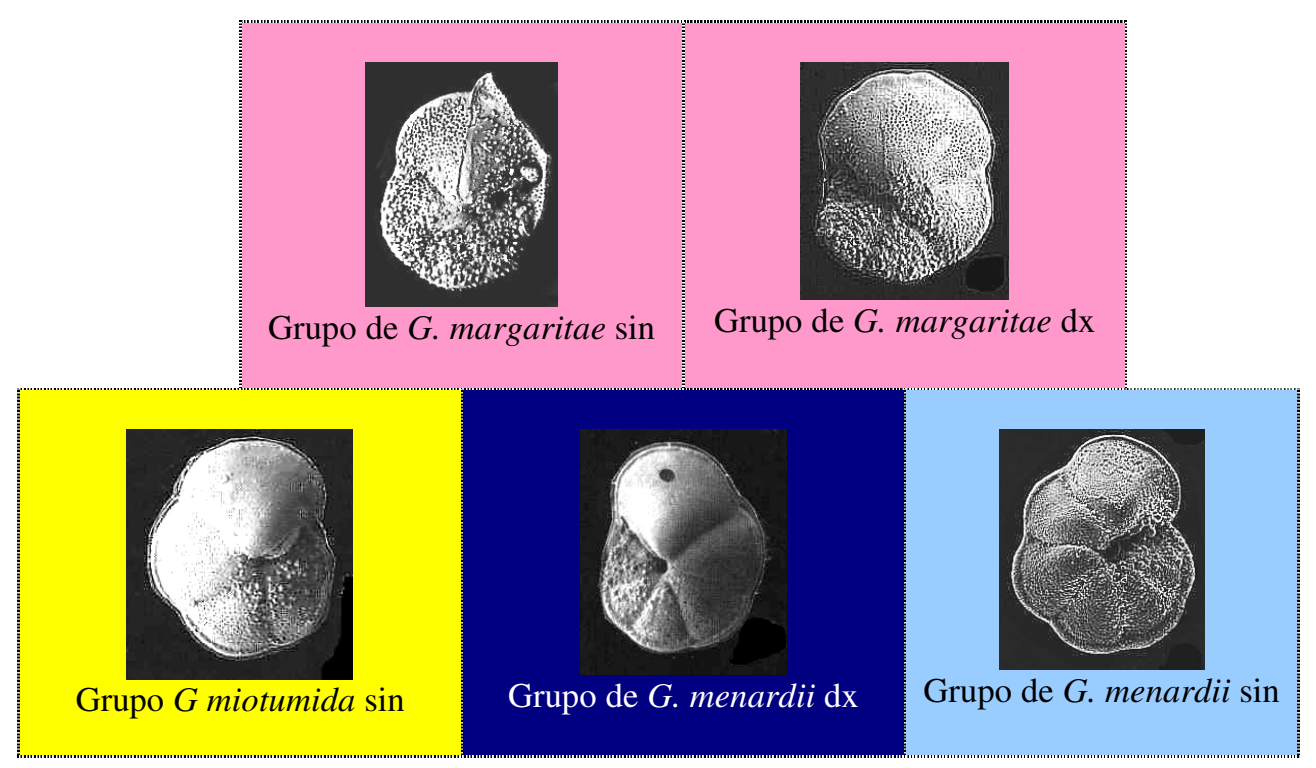

Figura 3.8. Globorotálidos carenados, biomarcadores utilizados en la datación de los sondeos estudiados. El color de fondo permite identificar la respectiva biozona y es el empleado en los mapas sismobioestratigráficos (capítulo 4) y en las figuras sintéticas de los sondeos (capítulo 6). Fotografías de Kennet $y$ Srinivasan, 1983.

\subsubsection{Bioeventos de globorotálidos no carenados}

Se ha comprobado que la distribución y las pautas de enrollamiento de los globorotálidos no carenados a lo largo del Messiniense son de gran utilidad para las correlaciones bioestratigráficas dentro y fuera del Mediterráneo (Sierro et al., 1993; Krijgsman 1996; Krijgsman et al., 1995; 1997). El grupo de Globorotalia scitula (que incluye a G. scitula s.s., G. suterae, G. nicolae, G. ventriosa) (sensu Sierro et al., 1993) (fig. 3.9), es relativamente abundante durante la parte inferior del Messiniense y padece frecuentes cambios de dirección de enrollamiento que los autores anteriores utilizan como herramienta en las correlaciones a lo largo de todo el Mediterráneo. En este trabajo se han detectado dos cambios en el sentido de enrollamiento de este grupo. El primero de ellos equivalente al evento A (EA) de Sierro et al. (1993) en el que se produce una reducción de las formas levógiras del grupo de Globorotalia scitula en favor de las formas dextrógiras. Otro de los eventos relacionados con este grupo es la reducción significativa de las formas dextrógiras inmediatamente por encima del acme del grupo de $G$. margaritae.

Posteriormente se han registrado los eventos correspondientes a la primera aparición y a la desaparición del grupo de G. puncticulata (fig. 3.9). La primera aparición $(F O)$ del grupo de $G$. puncticulata se reconoce tras la primera aparición común $(F C O)$ del 
grupo de G. margaritae, mientras que la desaparición ( $L O)$ del grupo de G. puncticulata sucede después de la $L O$ del grupo de G. margaritae. Existe por lo tanto un periodo de coexistencia entre estos dos grupos, así como posteriormente otra etapa con representación exclusiva del grupo de G. puncticulata.

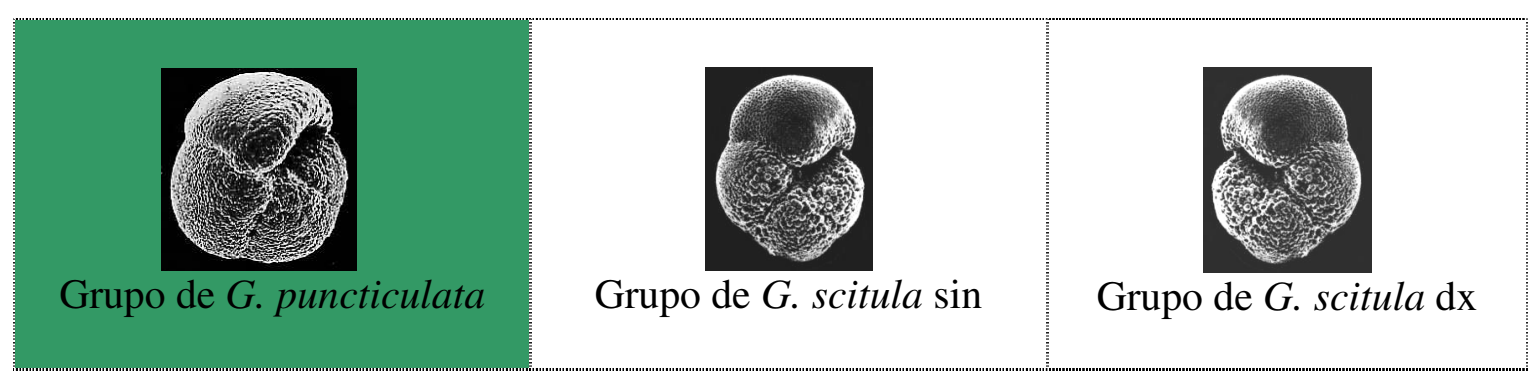

Figura 3.9. Globorotálidos no carenados, biomarcadores utilizados en la datación de los sondeos estudiados. El color de fondo permite identificar la respectiva biozona y es el mismo que se ha utilizado en los mapas sismobioestratigráficos (capítulo 4) y en las figuras sintéticas de los sondeos (capítulo 6). Fotografías de Kennet $y$ Srinivasan, 1983.

\subsubsection{Bioeventos de neogloboquadrínidos.}

Los neogloboquadrínidos son abundantes en la mayoría de los sondeos. La relación entre las formas levógiras y dextrógiras de este grupo (fig. 3.10), permite reconocer un significativo evento bioestratigráfico basado en la dirección de enrollamiento de las formas de neogloboquadrínidos que pasa de ser preferentemente levógiro a ser dextrógiro.

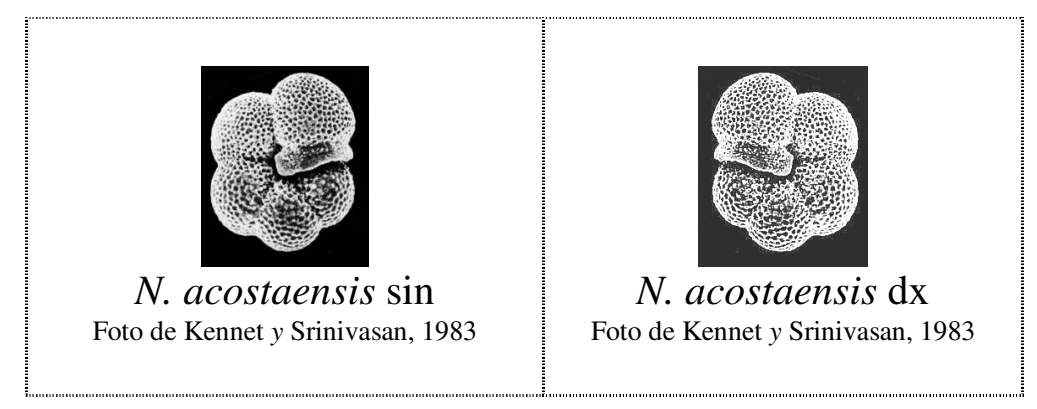

Figura 3.10. Neogloboquadrínidos, biomarcadores utilizados en la datación de los sondeos estudiados. Fotografías de Kennet y Srinivasan, 1983. 


\subsubsection{Bioeventos de nanoplancton calcáreo}

Por otra parte, se ha realizado un análisis bioestratigráfico de los nanofósiles calcáreos en los sondeos Santa Clara-1, Marismas A-1 y Atlántida-2 que han sido llevados a cabo por el Dr. J.A. Flores y que han corroborado los resultados obtenidos mediante foraminíferos planctónicos.

Se ha observado un claro dominio de los reticulofenéstridos $<3 \mu \mathrm{m}$ prácticamente coincidiendo con el evento E1 de foraminíferos planctónicos (Flores, 1985; Flores y Sierro, 1989).

También se ha detectado el incremento de Reticulofenestra pseudoumbilicus (>7 $\mu \mathrm{m})$, que supone el techo del paracme de R. pseudoumbilicus y que ha sido ampliamente utilizado como un evento sincrónico en el océano Índico, Pacífico y Atlántico (Río et al., 1990; Raffi y Flores, 1995; Backmand y Raffi, 1997).

Y por último, se ha localizado el último registro $(L O)$ de Discoaster quinqueramus en el Messiniense, situándose entre los eventos E4 y E6 de foraminíferos planctónicos (Flores, 1985; Flores y Sierro, 1989). No obstante este evento podría ser diacrónico, por lo que no se descarta que la reducción en abundancia de D. quinqueramus en los sondeos más próximos al continente (sondeo Santa Clara-1), pueda estar controlada por la somerización observada hacia el techo de la serie, y que afectaría a estos organismos planctónicos.

\subsubsection{Sucesión bioestratigráfica}

En este apartado se expone un resumen de la sucesión de bioeventos y acontecimientos sedimentológicos más destacados, ordenados cronológicamente. En la figura 3.11 se muestra la sucesión bioestratigráfica así como la datación astronómica de cada evento (apartado 3.3.6). Por otro lado, la información pormenorizada de los resultados obtenidos en cada uno de los sondeos estudiados aparece en el capítulo 6.

El zócalo sobre el que se asienta la secuencia mio-pliocena de la cuenca del Guadalquivir-golfo de Cádiz, es bien Paleozoico (sondeos Carmona-3, Carmona-4, Palancares-1, San Juan V-2), Mesozoico (sondeos Asperillo-1, Villamanrique, Marismas A1, Marismas-4), Paleoceno (GC-6x1) o Mioceno (Atlántida-2, GC-B6). 


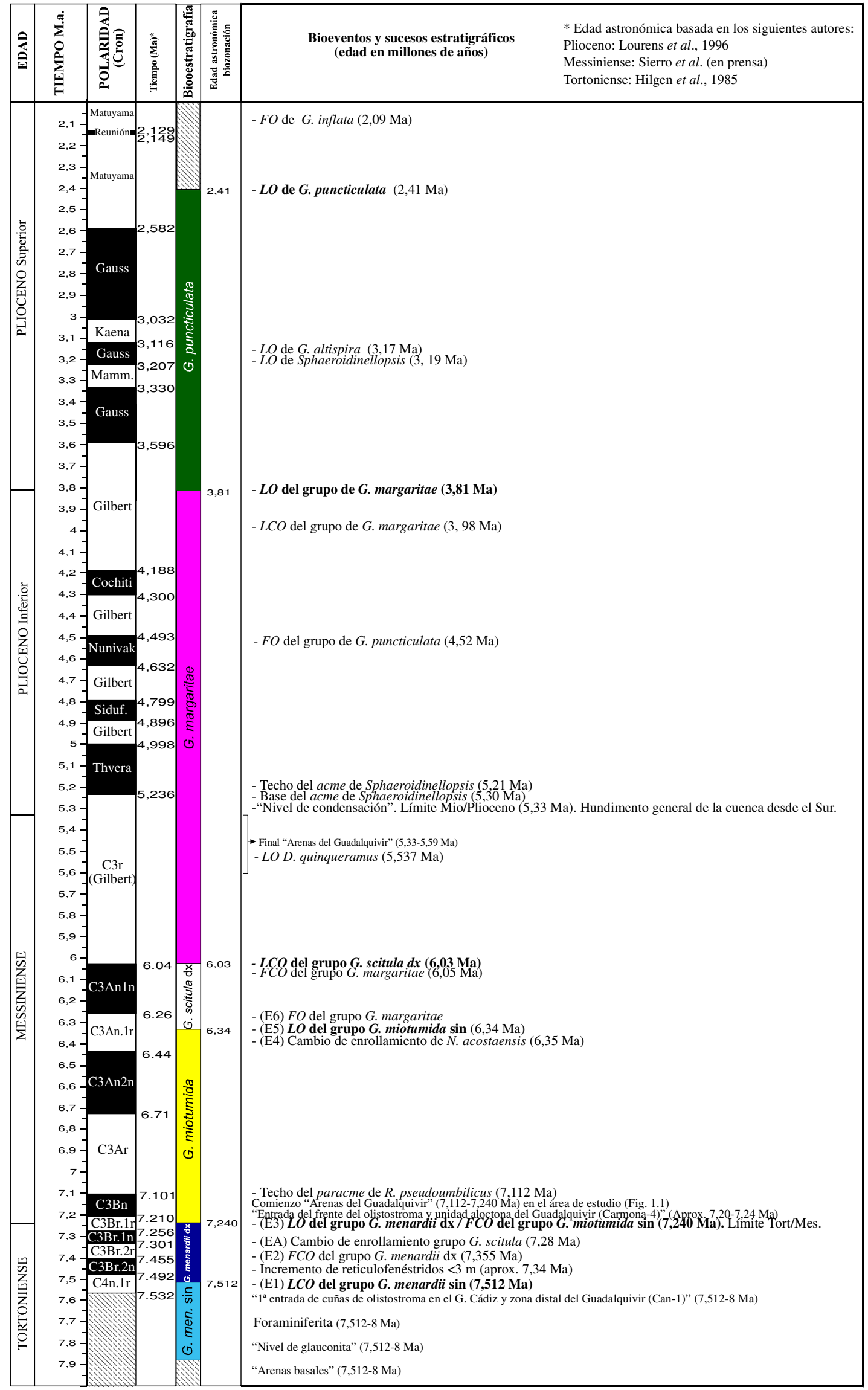

Fig. 3.11. Resumen de los bioeventos y sucesos estratigráficos más relevantes observados en el análisis bioestratigráfico. Edad astronómica en millones de años, magnetoestratigrafía deducida en función de los eventos calibrados astronómicamente en series Atláticas y Mediterráneas (*). Biozonación propuesta en el apartado 3.3.7. 
En la cuenca del Guadalquivir, el contacto entre la secuencia de depósito miopliocena y el zócalo Paleozoico-Mesozoico, se realiza mediante un contacto neto, discordante, sobre el que se asienta comúnmente una unidad de arena media a gruesa, heterogénea, angulosa y microconglomerática con cemento carbonatado. Esta unidad arenosa, denominada "calcarenita transgresiva basal” por Meléndez y Álvarez (1996), es conocida comúnmente con el sobrenombre de "arena basal" o "detrítico basal" por su posición en la columna estratigráfica (fig. 3.11). Esta unidad incorpora fauna bentónica somera, como Ammonia beccarii (en el sondeo Ciervo-1 por ejemplo), Nonion boeanum y Elphidium crispum, comúnmente fracturados y ocasionalmente algunos foraminíferos planctónicos como Gs. quadrilobatus o Sphaeroidinellopsis (sondeo Castilleja-1), así como restos de moluscos y glauconita. La potencia de esta unidad oscila entre 10 y $30 \mathrm{~m}$. A medida que nos desplazamos del Guadalquivir hacia el golfo de Cádiz, esta unidad basal va perdiendo potencia hasta desaparecer bajo los sondeos Marismas 4 y Marismas A-1.

Inmediatamente sobre las arenas basales aparece un nivel de glauconita, que puede suponer hasta un $15 \%$ de partículas de la muestra superiores a $0,125 \mathrm{~mm}$ (sondeo San Juan Z-1). Este nivel glauconítico puede marcar el comienzo de la secuencia miopliocena en ausencia de las arenas basales (sondeos Marismas-4 y Santa Clara-1) y ha sido tradicionalmente interpretado como un indicador transgresivo (Galán et al., 1987). La glauconita se deposita en la plataforma externa, interpretándose como indicador de la posición de una superficie de máxima inundación ( $m f s$, maximun flooding surface), constituyendo el límite superior de un cortejo transgresivo (TST, Transgresive System Tract) e inferior de un cortejo de alto nivel del mar (HST, Highstand System Tract).

En algunos sondeos, a unos $10 \mathrm{~m}$ por encima de las arenas basales se ha detectado un nivel de concentración de foraminíferos planctónicos que hemos denominado "foraminiferita" ya que estos fósiles constituyen el componente principal de las partículas superiores a 0,125 mm (fig. 3.11). En el sondeo Santa Clara-1 esta misma foraminiferita aparece inmediatamente por encima del nivel de glauconita que se asienta directamente sobre el zócalo. La ausencia de las arenas basales en este sondeo es debida a un sistema de fallas normales detectadas en los perfiles sísmicos y que ponen en contacto el zócalo Paleozoico con las arcillas de la secuencia Bética (S. Torrescusa, com. per.). Estas "arenas" de foraminíferos presentan gran cantidad de foraminíferos planctónicos de tamaño medio-grande, fundamentalmente Orbulina universa. El dominio de formas de tamaño medio-grande indicaría que los sedimentos han sido lavados durante su depósito; el hecho de que sean primordialmente planctónicos, junto con la ausencia de foraminíferos bentónicos someros, refleja un medio de cierta profundidad. Estas arenas 
podrían reflejar un depósito de tipo contourítico que estaría situado al pie del talud, o en un alto fondo.

En el intervalo que va desde el nivel de glauconita al primer nivel de arenas turbidíticas, se localizan varios eventos de foraminíferos planctónicos. Este intervalo arcilloso es muy rico en foraminíferos y tradicionalmente ha sido conocido con el nombre de "arcillas basales", correspondiendo a la base de la formación Bética (apartado 2.1.3.1). Los primeros metros de estas arcillas se caracterizan por la presencia destacada de globorotálidos menardiformes con enrollamiento levógiro (que pueden suponer hasta el 30\% del total de globorotálidos), junto con el grupo de G. scitula sin, acompañados en menor medida del grupo de G. scitula dx. Aunque comúnmente en los ripios aparecen individuos de G. menardii dx, se ha demostrado posteriormente que corresponden a individuos "caídos" durante la perforación y que originalmente se encontraban localizados en posiciones topográficamente más elevadas (Santa Clara-1 en capítulo 6).

La secuencia Bética (fig. 2.6) está formada por facies de talud y por lóbulos turbidíticos que proporcionan gran cantidad de arena. Por otro lado, se está produciendo en estos momentos una retroalimentación de la propia cuenca, puesto que aparecen foraminíferos de edad Paleógena y del Mioceno que están siendo incorporados a los flujos. Incluso en algunos sondeos se introducen megaelementos olistostrómicos (sondeos Casanieves-1, Carmona-4). Durante este periodo parece existir una plataforma inestable en el sur con sedimentos hemipelágicos que están siendo removilizados.

Tras unas decenas de metros de arcilla, se registra la desaparición $(\boldsymbol{L C O})$ del grupo de $\boldsymbol{G}$. menardii sin, en lo que supone el techo de la biozona definida por este grupo (apartado 3.3.7). La potencia del intervalo arcilloso que se depositó entre el nivel de glauconita y este primer bioevento oscila entre los más de $80 \mathrm{~m}$ de depósito en los sondeos al sur de la cuenca del Guadalquivir (sondeos Santa Clara-1 y Casanieves-1) a unos $50 \mathrm{~m}$ en el golfo de Cádiz (sondeos GC-B2, GC-C2, GC-D1) y a menos de $10 \mathrm{~m}$ (o ausencia total) en los sondeos al NW de la cuenca del Guadalquivir (Salteras-1, Palancares-1, Asperillo-1). Las partículas mayores de 0,125 $\mathrm{mm}$ se reparten entre arena y foraminíferos y en menor medida algo de pirita, espinas de equinodermo y algún ostrácodo.

Se ha observado un incremento significativo de reticulofenéstridos menores de 3 $\mu \mathbf{m}$ en los nanofósiles calcáreos a partir de los primeros metros de la secuencia miopliocena (José Abel Flores com. per.), siendo este evento prácticamente coincidente con la última aparición común $(L C O)$ del grupo de $G$. menardii sin de foraminíferos planctónicos (sondeo Santa Clara-1) (fig. 3.11). 
Algunos metros por encima del evento anterior se detecta un aumento sustancial de globorotálidos del grupo de $G$. menardii $\mathrm{dx}$, que representa la primera aparición común (FCO) del grupo de $\boldsymbol{G}$. menardii dx (fig. 3.11). Este grupo puede alcanzar el $20 \%$ de los foraminíferos planctónicos y suponer el $70 \%$ del total de globorotálidos (sondeo Santa Clara-1). En el intervalo que va desde la $L C O$ del grupo de G. menardii sin hasta la FCO del grupo de G. menardii dx se produce una reducción significativa de los globorotálidos carenados, estando representados los globorotálidos en más del 50\% por globorotálidos no carenados del grupo de G. scitula con enrollamiento principalmente levógiro.

El cambio de enrollamiento de los globorotálidos del grupo de G. scitula constituye el siguiente bioevento después de la aparición abundante $(F C O)$ del grupo de G. menardii dx. En este momento, el grupo de G. scitula sin (enrollamiento levógiro) es sustituido por formas del grupo de G. scitula dx (con enrollamiento dextrógiro). Este evento es difícil de localizar a menos que exista una serie suficientemente potente entre la primera aparición común ( $F C O$ ) del grupo de G. menardii dx y su reemplazamiento por el grupo de G. miotumida.

A continuación se produce un reemplazamiento de las formas del grupo de $G$. menardii por las del grupo de G. miotumida sin. Este evento supone el techo de la biozona del grupo de $\boldsymbol{G}$. menardii dx (apartado 3.3.7). No es posible separar el evento de desaparición de G. menardii dx de la primera aparición de G. miotumida debido a que ambos eventos se producen en un corto intervalo de tiempo por lo que se considera un reemplazamiento de unas formas por otras. G. miotumida se convierte a partir de ese momento en el grupo de globorotálidos más importante, alcanzando en ocasiones el $14 \%$ del total de foraminíferos (sondeo Casanieves-1) y entre el 60 y $70 \%$ de los globorotálidos.

Inmediatamente después de la aparición del grupo de G. miotumida sin, se registra un importante fenómeno tectosedimentario; si bien se producen emplazamientos olistostrómicos anteriores (Casanieves-1), el principal emplazamiento del olistostroma en la zona de estudio se registra en este momento (sondeos Carmona-5, Carmona-4, Isla Mayor-1). Es precisamente el emplazamiento del olistostroma conocido como "manto de Carmona" (Martínez del Olmo, 1984), el que determina la forma de la cuenca a partir de este momento, condicionando todo el relleno sedimentario posterior y en especial el depósito de la formación turbidítica "arenas del Guadalquivir". El olistostroma constituye una unidad alóctona formada por materiales que van desde el Triásico al Mioceno. La fuerte tectónica del borde sur origina el emplazamiento de estos sedimentos alóctonos que constituyen un conjunto plástico que se introduce en la cuenca durante el Neógeno 
desde posiciones subbéticas. En los sectores más meridionales es difícil delimitar el tránsito Subbético - cuenca del Guadalquivir, por la tectonización y mezcla caótica de sedimentos, sin embargo la presencia de amplios afloramientos de la serie considerada "paraautóctona" sobre el olistostroma hace pensar que estos sectores pertenecieron más a la cuenca del Guadalquivir como unidad estructural y estratigráfica que a la zona Subbética (ITGE, 1990).

Inmediatamente después de la primera aparición del grupo de G. miotumida, comienzan a depositarse los primeros cuerpos turbidíticos en el área de estudio (sondeos Santa Clara-1, Sevilla-2, San Juan Z-1, Marismas-2, etc) constituyendo la "formación arenas del Guadalquivir" (Martínez del Olmo, 1984).

La "formación arenas del Guadalquivir" está formada por una serie de cuerpos arenosos de origen turbidítico (con arenas formadas originalmente en playas, bajíos, canales de marea y barras mareales). La formación está normalmente compuesta de diferentes niveles de arena separados por tramos arcillosos y está constituida por arena fina, de color blanco o pardo, subredondeada, en ocasiones con cemento carbonatado que forma agregados. Pobres en fauna, solo presentan algunos foraminíferos bentónicos someros, principalmente Ammonia beccarii, así como restos de moluscos. Las "arenas del Guadalquivir" se depositan en el Messiniense a lo largo de toda la cuenca.

La interpretación de las líneas sísmicas en el alto Guadalquivir, muestra que los reflectores asociados a las arenas turbidíticas entran en afloramiento al este de Bujalance (Córdoba). Suárez et al. (1989), basándose en diversos afloramientos de campo en la cabecera de la cuenca, realizan una completa descripción de la estructura del sistema turbidítico de la formación "arenas del Guadalquivir". Su descripción coincide con la de los niveles atravesados en los sondeos estudiados. Así, las arenas que se observan en los afloramientos varían desde muy finas a medias, moderadamente a bien seleccionadas y los granos de subredondeados a subangulosos, siendo el cuarzo el componente mayoritario de los granos. Además están presentes granos de cuarcita, micas, fragmentos de rocas metamórficas y granos calcáreos, bioclastos y en menor medida restos carbonosos y glauconita. La ordenación de los espesores de los bancos de arena no presenta una tendencia claramente definida. En conjunto parece mostrar, grosso modo, una secuencia inferior estratocreciente $(0,2-1,5 \mathrm{~m})$ interpretada como la secuencia de progradación, coronada por otra secuencia estratodecreciente $(0,5-0,2 \mathrm{~m})$ que constituiría la etapa abandono (Suárez et al., 1989). La coexistencia de bancos masivos, o sin estructura interna, junto a términos de tipo $T a$ y $T a-b$ (de la secuencia de Bouma), la escasa potencia del intervalo pelítico, la escasez de estructuras (reducidas prácticamente a estructuras de escape de fluidos y huellas de corriente), la disposición en extensos sets 
tabulares, y la existencia de amalgamaciones, llevan a pensar a estos autores que se tratan de turbiditas asociadas a sistemas de baja eficacia, dominios de alta velocidad, con sistemas de transporte que varían desde el flujo de granos (grain-flow) hasta corrientes turbidíticas densas de alta velocidad (Suárez et al., 1989).

Debemos adelantar sin embargo que también en los sondeos al sur del área de golfo de Cádiz (Atlántida-3, B2, B3, B6, C3, D1) se registran aparatos turbidíticos contemporáneos a las "arenas del Guadalquivir". Este descubrimiento permite replantear el actual modelo sedimentario, como veremos en próximos capítulos. La carencia de perfiles sísmicos en la franja costera entre el Guadalquivir y el golfo de Cádiz, unido a la ausencia de sondeos en el área de conexión, ha condicionado la interpretación actual que considera a la "formación arenas del Guadalquivir" exclusiva de la zona continental, mientras que la formación "arenas del Guadiana" (Martínez del Olmo, 1984) sería posterior y agruparía en exclusiva las formaciones turbidíticas del golfo de Cádiz. Así en el modelo de secuencias de depósito de la figura 2.6, las "arenas del Guadalquivir" están ubicadas en la secuencia de depósito Grupo Bética, localizadas exclusivamente en el área continental, mientras que por otro lado, todas las arenas productoras en el golfo de Cádiz están incluidas en la siguiente secuencia de depósito Grupo Marismas (fig. 2.6) (Riaza y Martínez del Olmo, 1996; Martínez del Olmo et al., 1996; Meléndez y Álvarez, 1996). En esta Tesis, sin embargo se muestra que el desarrollo de los principales abanicos submarinos del golfo de Cádiz se produjo contemporáneamente a los últimos aparatos turbidíticos del bajo Guadalquivir. Dadas las característica fisiográficas de la cuenca del Guadalquivir, las segundas suponen la continuación natural de las "arenas del Guadalquivir". Estos resultados han desembocado por lo tanto en una reinterpretación de las líneas sísmicas y por consiguiente de las unidades atravesadas por los sondeos en el golfo de Cádiz (Ver figura 4.4, perfiles sismobioestratigráficos $\mathrm{n}^{\circ} 8,9$ y 10).

Prosiguiendo con el análisis bioestratigráfico, se observa que tras el primero de los aparatos turbidíticos que constituyen la formación "arenas del Guadalquivir" en el área de estudio (sondeo Santa Clara-1), se ha detectado un incremento de Reticulofenestra pseudoumbilicus (nanoplancton calcáreo) $(>7 \mu \mathrm{m}$ ) (J. A. Flores com. per.). Este evento supone el techo del paracme de Reticulofenestra pseudoumbilicus que desde el comienzo de la secuencia hasta este punto es escaso en las muestras.

El siguiente evento micropaleontológico, está determinado por el cambio de enrollamiento de Neogloboquadrina acostaensis (fig. 3.11) que separa dos etapas. La primera, en la que dominan las formas de Neogloboquadrina acostaensis sin (con enrollamiento levógiro) desde la base de la secuencia hasta el evento. La segunda etapa, desde el cambio de enrollamiento hasta el final de la secuencia mio-pliocena en el 
Guadalquivir, donde dominan las formas de Neogloboquadrina acostaensis dx (enrollada en sentido dextrógiro).

El cambio de enrollamiento de $N$. acostaensis se ha localizado en dos posiciones respecto a las "arenas del Guadalquivir": Bien por encima de la formación turbidítica tanto en el Guadalquivir (sondeos Marismas A1, Marismas-2, Casanieves-1, Villamanrique-1, Santa Clara-1, etc) como en el golfo de Cádiz (sondeos B3, B6, Atlántida-3). O bien entre los niveles arenosos (sondeos Sevilla-2, Carmona-1, Ciervo-1, Palancares-1....) en el Guadalquivir, y en el golfo de Cádiz (sondeos C2, D1).

Entre el evento de reemplazamiento de las formas del grupo de G. menardii dx por las del grupo de G. miotumida sin y el cambio de enrollamiento de Neogloboquadrina acostaensis, se deposita una gran cantidad de sedimentos (entorno a 250-300 m) en la zona sureste del Guadalquivir (sondeos Santa Clara-1, Carmona-4, Casanieves-1, Villamanrique-1) y en la zona axial en el golfo de Cádiz (sondeos D1, C3, B3, B6). Por otro lado, la serie equivalente en el eje de la cuenca del Guadalquivir se reduce a unos 50 m o menos (sondeos Carmona-1, San Juan Z-1, San Juan V-2, San Juan V-6, San Juan R1, Palancares-1, Melo-1, Asperillo-1) al igual que en noroeste de la cuenca del Guadalquivir (Salteras-1) y del golfo de Cádiz (sondeos C2, B2, Atlántida-2).

El siguiente bioevento corresponde a la desaparición del nanoplancton calcáreo (LO) Discoaster quinqueramus que se produce unos $30 \mathrm{~m}$ por encima del cambio de enrollamiento de N. acostaensis (sondeo Santa Clara-1) (J.A. Flores com per.).

La desaparición ( $\boldsymbol{L} \boldsymbol{O}$ ) del grupo de $\boldsymbol{G}$. miotumida sin se produce una decena de metros por encima del cambio de enrollamiento de Neogloboquadrina en los sondeos orientales de la zona del Guadalquivir, donde la velocidad de sedimentación es muy alta en este periodo (Santa Clara-1, Sevilla-2, San Juan Z1) o junto al evento anterior en lo que constituye en ese momento el talud sur de la cuenca (Casanieves-1, Villamanrique1), o incluso a pocos metros del comienzo de la secuencia mio-pliocena en los sondeos del eje de la cuenca del Guadalquivir (Asperillo-1, Melo-1, Marismas-4, Palancares-1). En el golfo de Cádiz la mayor velocidad de sedimentación se registra en los sondeos de la zona sur con algo más de $30 \mathrm{~m}$ de potencia máxima entre estos dos eventos en los sondeos B3 y B6. En los sondeos de la zona norte del golfo de Cádiz, sin embargo, los dos eventos aparecen en el mismo intervalo, siendo por lo tanto inferior a $10 \mathrm{~m}$ (distancia de muestreo) la distancia de separación entre ambos (sondeos B2, C2, D1, Atlántida-2).

La desaparición del grupo de G. miotumida, supone el techo de la biozona de este grupo (apartado 3.3.7). Coincidiendo con este evento se colmata la cuenca al sur y sureste de Carmona (sondeos Santa Clara-1, Carmona 3 y Carmona-4). 
El siguiente evento micropaleontológico corresponde a la primera aparición $(\boldsymbol{F O})$ del grupo de $\boldsymbol{G}$. margaritae, que ha presentado algunos problemas de reconocimiento debido a que la contaminación que registran algunos sondeos impide localizar su posición precisa en la columna estratigráfica.

Unos 50 m por encima del evento anterior se encuentra la $\boldsymbol{F C O}$ de $\boldsymbol{G}$. margaritae con una localización más fiable que el evento anterior pues refleja un incremento notable de individuos de este grupo, difícilmente explicable en términos de contaminación. La distancia entre la $F O$ y $F C O$ de este grupo es aproximadamente la misma en la zona sur y en el oeste del Guadalquivir y también en el golfo de Cádiz. En la primera etapa con presencia de G. margaritae, este taxón es especialmente abundante, siendo conocido este periodo como acme de $\boldsymbol{G}$. margaritae. En este periodo este grupo de globorotálidos supone entorno al $5 \%$ del total de foraminíferos planctónicos por lo que es fácilmente reconocible en las muestras de sedimento.

Inmediatamente después del acme de $G$. margaritae, se ha detectado una reducción significativa en la abundancia de las formas dextrógiras del grupo de G. scitula (LCO del grupo de G. scitula dx) (sondeos Casanieves-1, Villamanrique-1).

Poco después de la $F C O$ del grupo de G. margaritae, el eje de la cuenca partía desde el este de Carmona, pasaba por el norte de dicha localidad y discurría ligeramente al norte de la ciudad de Sevilla (a unos $800 \mathrm{~m}$ bajo la topografía actual), para dirigirse prácticamente en línea recta hasta el sondeo Asperillo-1. En el golfo de Cádiz el eje de la cuenca se encontraba desplazado hacia la posición de los sondeos del área norte, dejando los sondeos D1 y D2 en el talud sur de la cuenca. A partir de este momento la velocidad de sedimentación en el Guadalquivir oriental aumenta sensiblemente complicando el reconocimiento de los siguientes bioeventos. El incremento de partículas terrígenas supone la disminución de foraminíferos planctónicos en las muestras.

Distalmente, en el golfo de Cádiz, pueden reconocerse varios bioeventos por encima del acme de G. margaritae. El primero de ellos supone un incremento significativo de Sphaeroidinellopsis que tiene lugar unos 150-200 m por encima del acme de G. margaritae, seguido de una rápida reducción de este taxón que delimita el acme de Sphaeroidinellopsis (sondeos B2, C2).

A continuación, unos $250 \mathrm{~m}$ por encima del acme de Sphaeroidinellopsis, se produce la reducción significativa $(\boldsymbol{L C O})$ del grupo de $\boldsymbol{G}$. margaritae para desaparecer definitivamente una decena de metros por encima (sondeos Atlántida-3, B-2, C3, D1...). La desaparición $(\boldsymbol{L O})$ del grupo de $\boldsymbol{G}$. margaritae se produciría aproximadamente hacia el techo de los sondeos suroccidentales (sondeo Marismas), sin alcanzar las posiciones 
que ocupan los sondeos Villamanrique-1 y Casanieves-1, donde no se ha detectado la desaparición de este taxón. En la zona centro (entorno a Sevilla) y oriental del Guadalquivir (hacia Carmona), los últimos depósitos pliocenos contienen G. margaritae, sin que se tampoco se observe su desaparición. El evento de desaparición de las formas de G. margaritae sin, supone el techo de la biozona del este grupo (apartado 3.3.7).

Durante el millón de años que va desde la primera aparición común $(F C O)$ del grupo de G. margaritae hasta la última aparición común $(L C O)$ del mismo grupo, se depositan en el sondeo Carmona-1 más de 600 m de sedimentos (60 cm / 1000 años). En el sondeo San Juan R1 (junto a Sevilla) se registran en este intervalo $800 \mathrm{~m}$ de sedimentos del Plioceno inferior (80 cm / 1000 años) dejando colmatada la cuenca desde Carmona hasta más allá de Sevilla. Entorno al acme del grupo de G. margaritae se produce un aumento significativo de foraminíferos bentónicos someros, especialmente Nonion boeanum y Ammonia beccarii (sondeos San Juan R-1, San Juan Z-1, Sevilla-2, Carmona-2, Carmona-1, Marismas-2, Isla Mayor-1). Incluso se ha localizado unas decenas de metros por encima del acme del grupo de $G$. margaritae un nivel rico en conchas de moluscos en Carmona-1 (506 m) y en Carmona-2 (483 m) probablemente equivalente. Se alcanza en este momento el mínimo nivel del mar desde la transgresión tortoniense. Por encima, se produce una desaceleración en el relleno de la cuenca marcada por una ligera concentración de glauconita (sondeos San Juan V-2, Carmona-1) y una concentración de foraminíferos planctónicos que podrían indicar una superficie de máxima inundación (sondeos Villamanrique-1, B3, C3). En los perfiles sísmicos (capítulo 4) puede observarse como hacia el este, sobre este nivel se unen asintóticamente varios reflectores sísmicos posteriores, reflejando una importante condensación de tiempo. Seguidamente, el sistema avanza espectacularmente rellenado de sedimento el alto Guadalquivir.

Con posterioridad al nivel de condensación se ha detectado un segundo acme de G. margaritae, donde este taxón es especialmente abundante, representando desde el 40 $\%$ de los foraminíferos planctónicos en los sondeos Salteras-1 y Carmona-1, e incluso el $69 \%$ en San Juan Z-1.

Por otro lado y ya exclusivamente en el golfo de Cádiz, la sedimentación prosigue de forma más o menos continua registrándose a continuación la desaparición $(\boldsymbol{L O})$ de Sphaeroidinellopsis seminulina (sondeos B6, 6x1, Atlántida-3) e inmediatamente después la desaparición (LO) de Globoquadrina altispira (sondeos 6x1, Atlántida-3).

El último evento registrado en cuanto a extinciones se refiere, ha sido la desaparición ( $\boldsymbol{L O}$ ) de $\boldsymbol{G}$. puncticulata (sondeo C3) unos 150 m por encima del evento 
anterior, en lo que constituye el techo de la biozona formada por dicho taxón (apartado 3.3.7).

Posteriormente, en el sondeo $\mathrm{C} 3$ se ha detectado la primera aparición $(F O)$ de $G$. inflata y unos metros por encima, la aparición $(F O)$ de $G$. truncatulinoides. Finalmente la primera aparición común $(F C O)$ de Neogloboquadrina pachyderma levógiro ha supuesto el último evento identificado.

\subsubsection{Astrobiocronología de los eventos del plancton calcáreo: Correlación con otras áreas}

La mayoría de los eventos de foraminíferos planctónicos utilizados en el análisis bioestratigráfico han sido registrados con anterioridad por otros autores en secciones atlánticas (Sierro, 1985; Sierro et al., 1993) y mediterráneas, donde han sido datados astronómicamente (Hilgen, 1991b; Hilgen et al., 1995; Krijgsman et al., 1997; 1999b). La datación de los bioeventos, se ha realizado teniendo en cuenta la escala de edad absoluta de Berggren et al. (1995a), Berggren et al. (1995b) y fundamentalmente han sido correlacionados con la escala astronómica de tiempo de Lourens et al. (1996 b) y Krijgsman et al. (1999b) para el Messiniense y de Hilgen (1991 b), Hilgen et al. (1995) para el resto del Mioceno y Plioceno.

Los eventos bioestratigráficos correspondientes al Messiniense han sido datados con gran precisión gracias a los recientes trabajos conjuntos en cuencas miocenas del Mediterráneo entre nuestro departamento y el de Estratigrafía y Paleomagnetismo de la Universidad de Utrecht. Los eventos bioestratigráficos definidos por Sierro (1985) y Sierro et al. (1993) en el Mediterráneo y Atlántico adyacente se han localizado de forma precisa en secuencias cicloestratigráficas del Mediterráneo calibradas con la escala astronómica de tiempo (APTS).

En la figura 3.11, puede observarse la sucesión bioestratigráfica de los eventos de plancton calcáreo, junto con los principales eventos estratigráficos acaecidos, así como la escala magnetoestratigráfica. Se muestra así mismo la edad astronómica de los bioeventos, de los límites de las biozonas propuestas en el apartado 3.3.7. y la edad astronómica de las inversiones magnéticas.

El primero de los eventos de foraminíferos planctónicos registrado en los sondeos estudiados ha sido la última aparición común del grupo de G. menardii con enrollamiento levógiro (LCO del grupo de Globorotalia menardii sin). Este evento es equivalente al evento E1 de Sierro (1985) y Sierro et al. (1993) y a la $L O$ del grupo de G. menardii 
forma 4 de Tjalsma (1971). Tiene lugar en el Chron C3 Br. 3r y presenta una edad de 7,512 Ma de acuerdo con la escala astronómica de tiempo de Hilgen et al. (1995).

El incremento significativo de reticulofenéstridos menores de $3 \mu \mathrm{m}$ observado a partir de los primeros metros de la secuencia mio-pliocena, prácticamente coincide con el evento E1 de foraminíferos planctónicos (Flores y Sierro, 1989).

Volviendo a los foraminíferos planctónicos, el siguiente evento registrado es la primera aparición común del grupo de G. menardii con enrollamiento dextrógiro (FCO del grupo de G. menardii dx). Este evento es equivalente al evento E2 de Sierro (1985) y Sierro et al. (1993) y a la $F O$ del grupo de G. menardii forma 5 de Tjalsma (1971), tiene lugar en el Chron C3Br.2r (Krijgsman et al., 1995) y presenta una edad aproximada de 7,355 Ma de acuerdo con la escala astronómica de tiempo de Hilgen et al., 1995.

El cambio de enrollamiento en el grupo de $\boldsymbol{G}$. scitula de formas sinistrorsas a dextrorsas es equivalente al evento A de Sierro et al. (1993). De acuerdo con la escala astronómica de tiempo (Hilgen com. per.) este evento tiene una edad 7,290 Ma. Recientemente (Hilgen, com. per.) puntualiza que en la sección de Monte del Casino (Italia), el cambio de enrollamiento está localizado justo debajo del influjo de $G$. menardii forma 4 en la zona de G. menardii forma 5. El mismo pulso (m4) está registrado también en Faneromeni, en la capa gris del ciclo F14, registrándose el cambio de enrollamiento entorno a este pulso. El pulso m4 está datado en 7.28 Ma en Faneromeni (edad de la capa gris del ciclo F14) y por tanto, podemos asignar esta edad al cambio de enrollamiento del grupo de G. scitula (Hilgen y Sierro, com. per.)

Sierro et al. (en prensa) en la cuenca neógena de Sorbas (Almería) localizan la última aparición ( $\boldsymbol{L O}$ ) del grupo de $\boldsymbol{G}$. menardii $\mathbf{d x}$ (forma 5 de Tjalsma, 1971) en los primeros centímetros de la serie compuesta Abad, en el intervalo que se encuentra debajo del ciclo A1 en el miembro Abad inferior. Los mismos autores proporcionan una edad astronómica de 7.260 Ma para este evento.

La primera aparición regular (FCO) del grupo de $\boldsymbol{G}$. miotumida que es equivalente a la $F C O$ del grupo de $G$. conomiozea en el Mediterráneo oriental y al evento E3 de Sierro (1985) y Sierro et al. (1993) para la cuenca del Guadalquivir, coincide con el límite Tortoniense-Messiniense, por lo que se ha utilizado para establecer dicho límite en los diferentes sondeos. Tiene lugar en el Chron C3Br.1r (Krijgsman et al., 1995), con una edad aproximada de 7,240 Ma de acuerdo con la escala astronómica de tiempo de Hilgen et al. (1995). En Sorbas (Almería) este evento se localiza también en el intervalo anterior al primer ciclo (A1) reconocido por Sierro et al. (en prensa) en la serie de Sorbas, si bien no coexiste con el grupo de G. menardii dx, por lo que estiman una 
edad de 7, 242 Ma para dicho evento. La primera aparición regular, $(\mathrm{FrO})$ del grupo de G. miotumida es un evento bien conocido en el Mediterráneo, comúnmente citado como la FrO del grupo de G. conomiozea (Zachariasse, 1975, 1979; D’Onofrio et al., 1975; Iaccarino et al., 1975; Bossio et al., 1976; González Donoso y Serrano, 1977; Cita y Ryan, 1978; Sierro et al. 1993; Krijgsman et al., 1994, 1995, 1997). La FrO del grupo de G. conomiozea, con una edad astronómica de 7.24 Ma (Hilgen, et al., 1995), ha sido ampliamente utilizada como un indicador bioestratigráfico para el límite Tortoniense / Messiniense. El evento ha sido también reconocido en el Atlántico nororiental (Feinberg y Lorenz, 1970; Bossio et al., 1976; Cita y Ryan, 1978; Sierro, 1985; Sierro et al., 1993; Hodell et al., 1989; Benson et al., 1991). A diferencia del Mediterráneo, donde estos nunca han sido encontrados coexistiendo (con excepción de la sección "Potamida" en Creta; Zachariasse, 1979b), el grupo de G. menardii es claramente reemplazado por el grupo de G. miotumida después de un breve periodo de coexistencia (Sierro 1985; Sierro et al., 1993). En nuestro caso, dada la peculiar naturaleza de los ripios no podemos establecer con exactitud la coexistencia o no de ambos grupos. El reconocimiento de este evento en la mayor parte de los sondeos estudiados, ha permitido establecer el límite Tortoniense-Messiniense modificando la posición en la que se situaba hasta ahora dicho límite en la cuenca del Guadalquivir-golfo de Cádiz.

El techo del paracme de Reticulofenestra pseudoumbilicus (> $\mu \mathrm{m})$, recientemente calibrado en 7.1 Ma (Backmand y Raffi, 1997) ha sido ampliamente utilizado como un evento sincrónico en el océano Índico, Pacífico y Atlántico (Río et al., 1990; Raffi y Flores, 1995; Backmand y Raffi, 1997). En las secciones de la serie Abad (cuenca de Sorbas, Almería) este bioevento ha sido localizado en el ciclo A3 con una edad astronómica de $7.112 \mathrm{Ma}$ (Sierro et al., en prensa). El ciclo A3 se sitúa muy próximo a la inversión paleomagnética $\mathrm{C} 3 \mathrm{Bn}(\mathrm{y})$ en las secciones del Mediterráneo oriental (Krijgsman et al., 1995). Raffi y Flores (1995) registraron el techo de este paracme cerca del comienzo del cron C3Ar en el Pacífico Ecuatorial oriental. El mismo evento fue datado por Backmand y Raffi (1997) en 7.1 Ma en el Site 926 de ODP (Ceara Rise) utilizando la escala astronómica de tiempo de Shackleton y Crowhurst (1997). Aunque no se recogieron datos paleomagnéticos de este Hole, la asignación es coherente con la edad de la inversión C3Bn / C3Ar de acuerdo con la escala astronómica de tiempo de Hilgen et al. 1995.

El cambio en el sentido de enrollamiento del grupo Neogloboquadrina acostaensis, es equivalente al evento E4 de Sierro (1985) y Sierro et al. (1993), y tiene lugar en el Chron C3An.1r (Krijgsman et al., 1999b), presentando una edad aproximada de 6,35 Ma (Hilgen y Krijgsman, 1999b; Sierro et al. en prensa). El cambio en el sentido de enrollamiento de los neogloboquadrínidos (de levógiro a dextrógiro), sucede en Sorbas 
(Almería) en el ciclo A38 y presenta una edad astronómica de 6.36 Ma (Sierro et al., en prensa). Este evento ha sido frecuentemente reconocido en el Mediterráneo (Zachariasse, 1975; Montenat et al., 1976; Civis et al., 1979; Colalongo et al, 1979; Iaccarino, 1985; Van de Poel, 1991; Sierro et al., 1993; Gautier et al., 1994; Sprovieri et al., 1996 a, b) así como en el Atlántico (Feinberg y Lorenz, 1970; Bossio et al., 1976; Cita y Ryan, 1978; Salvatorini y Cita, 1979; Sierro, 1984, 1985, Iaccarino (1985), Sierro et al. 1993; Hodell et al., 1989; Benson et al., 1991; Zhang y Scott, 1996). Tanto en la serie de Sorbas como en similares calibraciones magnetoestratigráficas en el Atlántico Norte (Hooper y Weaver 1987; Hodell et al., 1989), este evento se dispone en medio del cron C3An.1r. Este evento ha sido reconocido también en Metochia y Gibliscemi / Falconara (Krijgsman et al., 1999b; Hilgen y Krijgsman, 1999). En nuestro caso, se trata de uno de los eventos mejor preservados, localizándose en la mayor parte de los sondeos de la cuenca del Guadalquivir-golfo de Cádiz. El evento E-4, se registra durante el desarrollo de la formación "arenas del Guadalquivir”.

Flores y Sierro (1989) encuentran que el último registro (LO) de Discoaster quinqueramus, tiene lugar entre los eventos E4 y E6 de foraminíferos planctónicos (Sierro, 1985 y Sierro et al., 1993). No obstante, este evento puede ser diacrónico en el área de estudio. En este sentido, no se descarta que la reducción en abundancia de $D$. quinqueramus esté controlada por la somerización observada en la zona de estudio entre los eventos E4 y E6, y que afectaría a estos organismos. Así mismo el retrabajado de formas de nanofósiles calcáreos es muy significativo por lo que su análisis debe estar refrendado por alguna otra información adicional. La edad astronómica de este evento es de 5.537 Ma, con un error de 0.005 Ma (Backman y Raffi, 1997).

La desaparición del grupo de G. miotumida ( $L O$ del grupo de G. conomiozea), se correlaciona con el evento E5 de Sierro (1985) y Sierro et al. (1993). Es isócrono con el mismo evento en el Atlántico Norte, donde ha sido registrado inmediatamente después del cambio de enrollamiento de los Neogloboquadrínidos. Sierro (1985), Sierro et al. (1993), Hodell et al. (1994), y Zhang y Scott (1996) lo sitúan en el cron C3An.1r. Estando pendiente de datación definitiva, en esta Tesis se propone una edad astronómica de 6.3 Ma para la desaparición de G. miotumida, pues sucede inmediatamente después del cambio de enrollamiento de $N$. acostaensis (6.35 Ma), concretamente al final del ciclo Q17 en los sondeos Casanieves-1 y Villamanrique-1 (capítulo 5). Sin embargo, este evento no es isócrono con el Mediterráneo, donde la desaparición ( $L O)$ del grupo de $G$. miotumida está registrada en Sorbas en el ciclo A31 con una edad de 6.504 Ma (Sierro et $a l$., en prensa) correlacionándose hasta el Mediterráneo central (secciones de FalconaraGibliscemi) y oriental (sección de Metochia) (Krijgsman et al., 1999b; Hilgen y Krijgsman, 1999b). En este caso, el evento sucede en la parte superior del cron C3An.2n 
y es utilizado para las correlaciones a lo largo de todo el Mediterráneo. Este diacronismo entre Mediterráneo y Atlántico es debida a la progresiva restricción de la comunicación entre el Atlántico y el Mediterráneo durante el Messiniense, lo que condicionó su pronta desaparición en el Mediterráneo.

La primera aparición del grupo de G. margaritae (FO del grupo de $\boldsymbol{G}$. margaritae) es equivalente al evento E6 de Sierro (1985) y Sierro et al. (1993) que consideran una edad astronómica de 6.1 Ma para este evento (Sierro, en prep.). En los sondeos estudiados, este evento aparece comúnmente por encima de la $L O$ del grupo de G. miotumida, sin embargo en muchas ocasiones la primera aparición de individuos del grupo de G. margaritae es un evento difícil de reconocer ya que aparecen formas de transición difíciles de clasificar. Se trata por lo tanto de un evento delicado, en el que hay que tener presente su verdadera ubicación inmediatamente por encima del la $L O$ del grupo de G. miotumida como ha podido observarse en diversas series de la cuenca del Guadalquivir (Sierro, 1985; Sierro et al., 1993). Por ello, se ha considerado preferentemente la aparición abundante $(\boldsymbol{F C O})$ del grupo de $\boldsymbol{G}$. margaritae como evento de mayor fiabilidad. La primera aparición del grupo de G. margaritae puede estar definida por la aparición de un solo individuo y podría verse afectada por la contaminación que presentan los ripios (fig. 3.4) La primera aparición común $(F C O)$ se muestra como un evento más fiable puesto que refleja un sensible aumento del valor relativo de esta especie. Este segundo bioevento coincide en el sondeo "Huelva" con el límite del cron C3 An.1n y el cron Gilbert (Civis et al., remitido) y presenta una edad astronómica de 6.05 Ma (Krijgsman et al., 1999b). Este biohorizonte se ha revelado como uno de los eventos más interesantes en el área estudiada.

Inmediatamente por encima de la $F C O$ del grupo de $G$. margaritae se produce un descenso en la abundancia de las formas dextrógiras del grupo de G. scitula dx (LCO del grupo de $\boldsymbol{G}$. scitula $\mathbf{d x}$ ). La datación de este evento se ha realizado en función de los resultados obtenidos en los sondeos Villamanrique-1 y Casanieves-1. Al igual que la desaparición de G. miotumida, es la primera vez que se puede correlacionar este evento con la curva astronómica, lo que ha permitido adelantar en esta Tesis una edad astronómica provisional de 6.03 Ma, que deberá ser contrastada en otras series Atlánticas.

La base del acme de Sphaeroidinellopsis ha sido localizada por Lourens et al. (1996) en el ciclo de insolación 507, con una edad astronómica de 5.30 Ma. Sin embargo en los sondeos estudiados su localización es imprecisa, detectándose en algunos de ellos por encima del límite Mioceno-Plioceno (a techo del cron C3r (Gilbert)) un incremento significativo de Sphaeroidinellopsis que podría suponer efectivamente la base del acme de Sphaeroidinellopsis. 
El techo del acme de Sphaeroidinellopsis, ha sido datado en $5.21 \mathrm{Ma}$, y se encuentra en el ciclo de insolación 497 para el Mediterráneo (Lourens et al., 1996b).

Aunque se ha observado en varios sondeos la primera aparición del grupo de $G$. puncticulata ( $\boldsymbol{F O}$ G. puncticulata), se ha desestimado utilizar dicho evento como biomarcador cronoestratigráfico debido a que se encuentra comúnmente desplazado de su posición original debido a la contaminación de los ripios (fig. 3.4). Este evento ha sido localizado en el Mediterráneo en el ciclo de insolación 435 y presenta una edad de 4.52 Ma (Lourens et al., 1996b)

La reducción significativa del grupo de $G$. margaritae, coincide sin lugar a dudas con la $\boldsymbol{L C O}$ del grupo de $\boldsymbol{G}$. margaritae localizada en el Mediterráneo en el ciclo de insolación 382 con una edad de 3.98 Ma (Lourens et al., 1996b).

Ligeramente por encima del evento anterior se localiza la desaparición definitiva del grupo de G. margaritae ( $\boldsymbol{O} \boldsymbol{O}$ del grupo de $\boldsymbol{G}$. margaritae), situada sobre el ciclo de insolación 367, con una edad de 3.81 Ma (Lourens et al., 1996b).

La desaparición ( $L O$ ) de Sphaeroidinellopsis, se ha registrado en el ciclo de insolación 303 y presenta una edad astronómica de 3.19 Ma (Lourens et al., 1996b).

En el siguiente ciclo de insolación (302) se produce la desaparición (LO) de Globoquadrina altispira, que presenta una edad de 3.17 Ma (Lourens et al., 1996b).

Uno de los últimos eventos utilizados ha sido la desaparición $(\boldsymbol{L O})$ del grupo de G. puncticulata en el ciclo de insolación 230, con una edad de 2.41 Ma (Lourens et al., 1996b).

Finalmente, la $\boldsymbol{F O}$ de Globorotalia inflata se ha localizado en el sondeo GC-B2, siendo el último de los eventos de plancton calcáreo utilizados. Este evento tiene lugar en el ciclo de insolación 203 y presenta una edad de 2.09 Ma (Lourens et al., 1996b), aunque en nuestro caso se encuentra comúnmente desplazado al tratarse de una primera aparición. 


\subsubsection{Unidades bioestratigráficas}

En función de los eventos micropaleontológicos identificados y para mostrar gráficamente el relleno sedimentario de la cuenca, se han definido varias unidades bioestratigráficas (biozonas), que son también cronoestratigráficas y que se han identificado con diferentes colores (figuras 3.11, 3.12 y 3.13). Estas biozonas caracterizan micropaleontológicamente las diferentes facies sísmicas. Las unidades bioestratigráficas coloreadas, aparecen tanto en los perfiles sismobioestratigráficos (capítulo 4), como en las figuras sintéticas de cada sondeo (capítulo 6). Las biozonas se han establecido en función de la presencia mayoritaria de cada uno de los globorotálidos, utilizando la desaparición o reducción significativa de cada uno de estos grupos como límite superior de la respectiva unidad bioestratigráfica.

En la figura 3.11 se adelantaba la distribución temporal de estas biozonas, mientras que en la figura 3.12 se muestra la distribución de las biozonas en cada uno de los sondeos analizados. Por otro lado, en la figura 3.13 se ha realizado un panel de correlación tridimensional entre varios de los sondeos obteniéndose una visión espacial del relleno de la cuenca.

- Biozona del grupo de G. menardii sin: La primera aparición del grupo de G. menardii sin se produce con anterioridad al comienzo de la secuencia del relleno sedimentario Mio-Plioceno en el Guadalquivir, por lo que en ningún caso se ha localizado. En los sondeos estudiados del Guadalquivir, los primeros ejemplares de G. menardii sin se detectan inmediatamente por encima del detrítico basal. Exclusivamente a efectos de diseño gráfico, se ha colocado en este punto el comienzo de la biozona. La presencia de G. menardii sin en el detrítico basal ha sido detectada en afloramientos de campo por F.J. Sierro (com. per.), por lo que hubiera sido igualmente válido incluir el detrítico basal dentro de la biozona de este grupo. El techo de la biozona si está bien definido, y viene marcado por la desaparición de dicho taxón ( $L C O$ del grupo de G. menardii sin) presentando por lo tanto una edad de 7.51 Ma. En todas las figuras se ha utilizado el color azul claro para identificar esta biozona.

- Biozona del grupo de $G$. menardii dx: La base de la biozona del grupo de G. menardii dx está definida por la desaparición del grupo de G. menardii $\sin (7.51 \mathrm{Ma})$. Ligeramente por encima de la base se registraría la $F C O$ del grupo de G. menardii dx, mientras que el techo de esta biozona viene definido por la desaparición $(L O)$ del grupo de G. menardii $\mathrm{dx}$ (7.24 Ma). Se ha utilizado el color azul oscuro para identificar esta biozona en todas las figuras de este trabajo. 

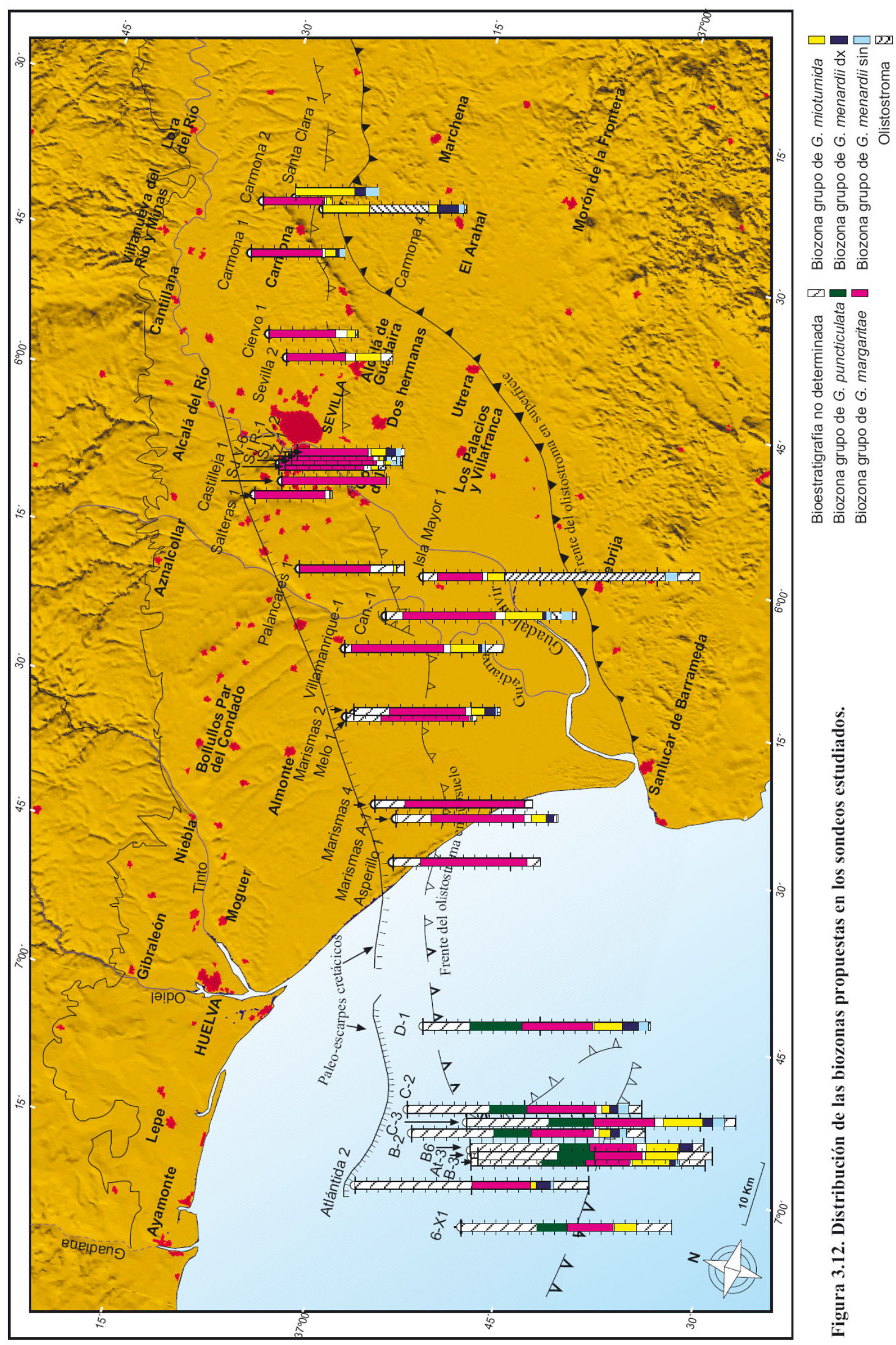

苞 
- Biozona del grupo de G. miotumida: El reemplazamiento del grupo de G. menardii dx por el grupo de G. miotumida supone la base de la biozona de G. miotumida (7.24 Ma) que termina con la desaparición de esta última ( $L O$ G. miotumida) en torno a 6.3 Ma. Se ha utilizado como base de esta biozona la desaparición de G. menardii dx, con el fin de evitar errores producidos por la contaminación de las muestras. Esta biozona está representada mediante el color amarillo en todas las figuras. En los sondeos estudiados, la zona del grupo de G. miotumida es sensiblemente distinta según nos encontremos en el margen sur o al norte de la cuenca. Al sur, tanto en el Guadalquivir como en el golfo de Cádiz, la biozona del grupo de G. miotumida representa una potencia de varios cientos de metros (sondeos Santa Clara-1, Golfo de Cádiz-C3), mientras que en el norte esta biozona apenas queda registrada (sondeos Ciervo-1, Atlántida-2) (fig. 3.13).

- Biozona del grupo de $\boldsymbol{G}$. scitula dx: La base de esta biozona viene determinada por la desaparición del grupo de G. miotumida (6.3 Ma), momento en el que desaparece este grupo de globorotálidos (el más abundante hasta ese momento). Hasta la aparición abundante del grupo de G. margaritae, G. scitula incrementa significativamente su porcentaje relativo dentro de los globorotálidos. Conforme G. margaritae aumenta su presencia, ocupa progresivamente el primer lugar en cuanto a la abundancia relativa de globorotálidos. Se produce entonces una reducción significativa $(L C O)$ del grupo de $G$. scitula (6.03 Ma), lo que supondrá el final de esta biozona. La escasa duración de esta biozona (no alcanza los $300 \mathrm{Ka}$ ) dificulta su reconocimiento. No se ha utilizado ningún color particular para diferenciar esta biozona, por lo que aparece como una zona blanca entre las biozonas con las que limita. Esta biozona ha sido establecida principalmente en función de los resultados obtenidos en los sondeos Casanieves-1 y Villamanrique-1 sobre los que se han conseguido una precisa calibración astronómica (capítulo 5).

- Biozona del grupo de $G$. margaritae: La base de la biozona del grupo de $G$. margaritae está definida por la reducción significativa ( $L C O)$ del grupo de G. scitula dx (6.03 Ma) (este evento, no siempre es fácil de localizar). La aparición abundante (FCO) del grupo de G. margaritae se produce prácticamente al tiempo que desaparece G. scitula $\mathrm{dx}$, por lo que a efectos prácticos, se han utilizado ambos eventos para localizar la base de esta biozona. El techo está definido por la desaparición $(L O)$ del grupo G. margaritae hace 3.81 Ma. Se ha utilizado el color rosa para identificar esta biozona en todas las figuras de este trabajo. 

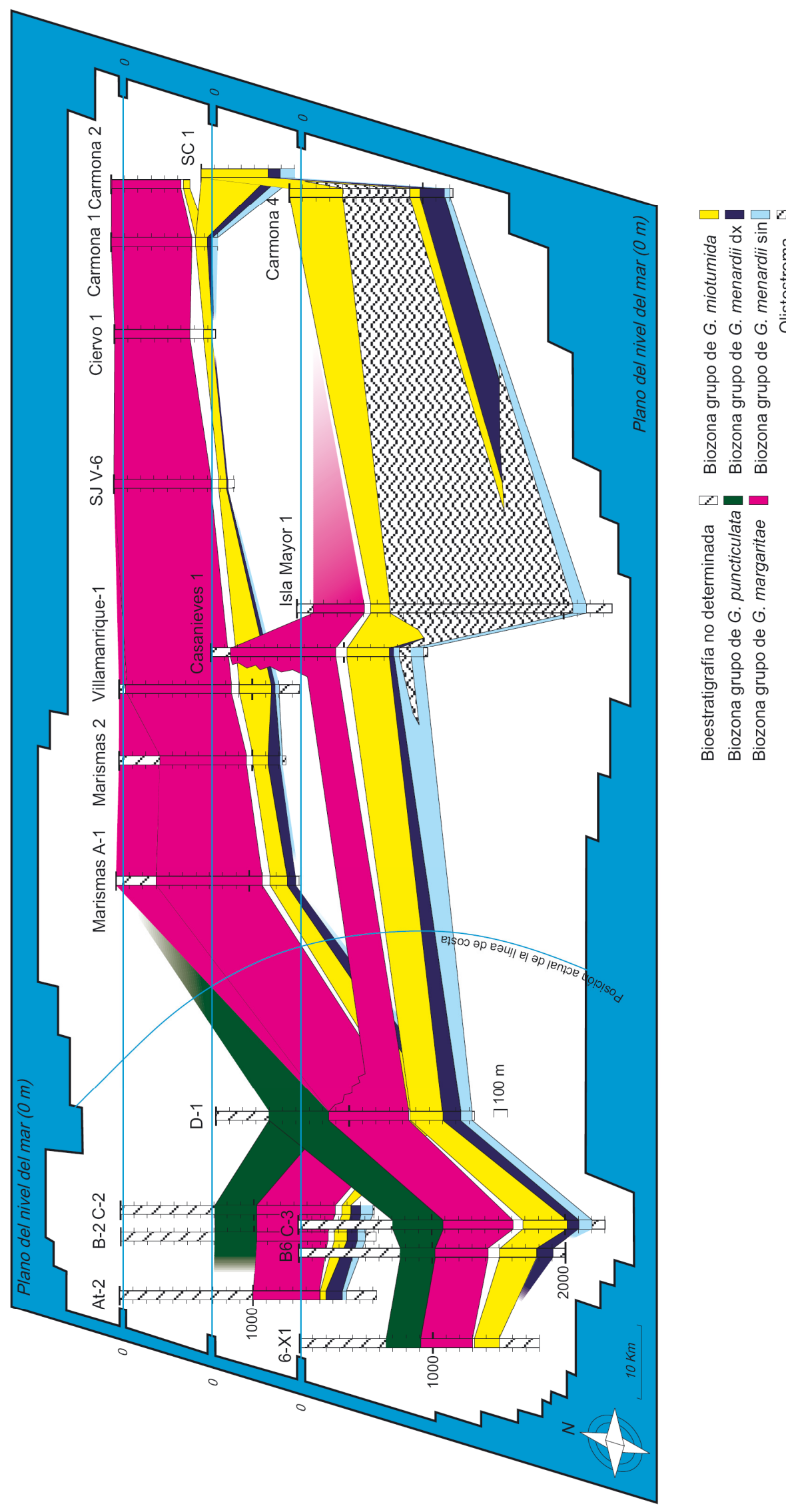

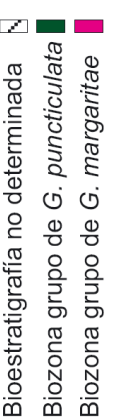

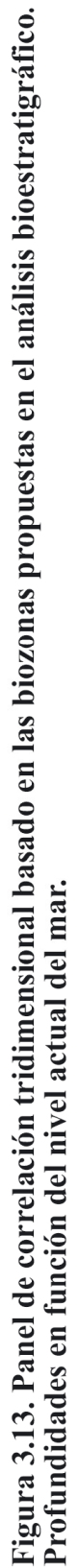


- Biozona del grupo de G. puncticulata: La base de esta biozona está definida por el techo de la biozona anterior (3.81 Ma). Globorotalia puncticulata aparece antes de que desaparezca $G$. margaritae por lo que existe un periodo de coexistencia de ambas especies. Tras la desaparición de G. margaritae, G. puncticulata pasa a ser el globorotálido con mayor representación relativa, comenzando en ese momento la biozona del grupo de $G$. puncticulata. El techo de la biozona está definido por la desaparición ( $L O)$ del grupo de G. puncticulata (2.41 Ma). Se ha utilizado el color verde oscuro para identificar esta biozona en todas las figuras. 


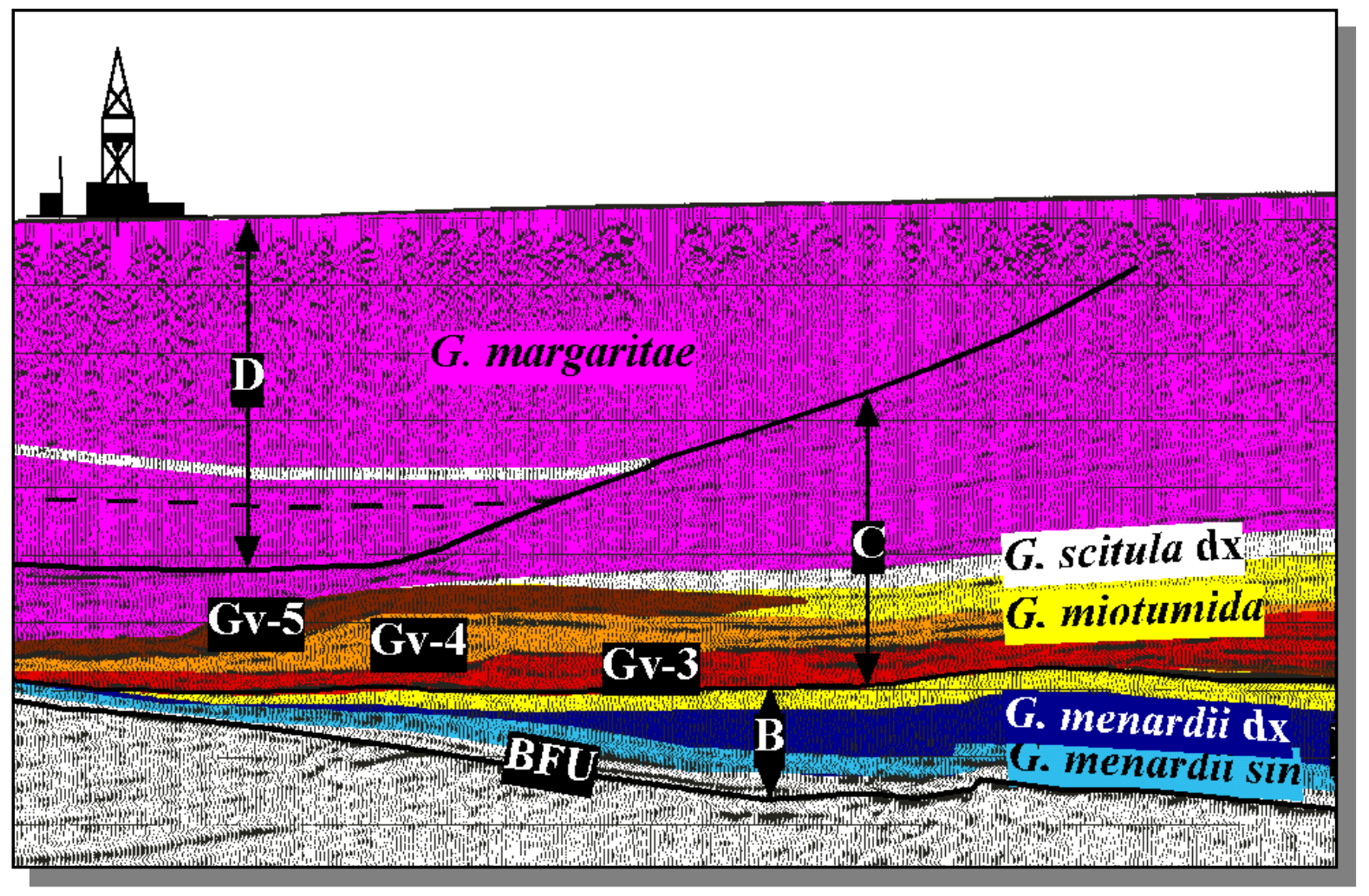

\section{PERFILES \\ SISMOBIOESTRATIGRÁFICOS Y UNIDADES LITOSÍSMICAS}


Página anterior: Detalle del perfil sismobioestratigráfico $\mathbf{n}^{0} 1$. 


\subsection{PERFILES SÍSMICOS}

Se ha llevado a cabo un análisis de las secuencias sísmicas utilizando varios perfiles distribuidos a lo largo de la zona de interés de la Tesis Doctoral. Concretamente nos hemos centrado en 11 perfiles de sísmica de reflexión multicanal, algunos de ellos facilitados por Repsol y el resto procedentes de diferentes publicaciones científicas (ITGE, 1990; Riaza y Martínez del Olmo, 1996; Maldonado et al., 1999). La localización de los perfiles utilizados en este trabajo aparece en la figura 4.1.

La sísmica de reflexión multicanal (MCS, multichannel seismic profiles) consiste en un sistema de emisión y recepción de ondas acústicas en varios canales. Esta técnica consigue buenas calidades para profundidades de penetración del orden de varios kilómetros y en general ha sido el tipo de sísmica más utilizado en la exploración de hidrocarburos. La elevada penetración que ofrece esta técnica repercute en un detrimento de la resolución (inferior a $50 \mathrm{~m}$ ), si bien es compensada con la detección de las estructuras susceptibles de contener hidrocarburos.

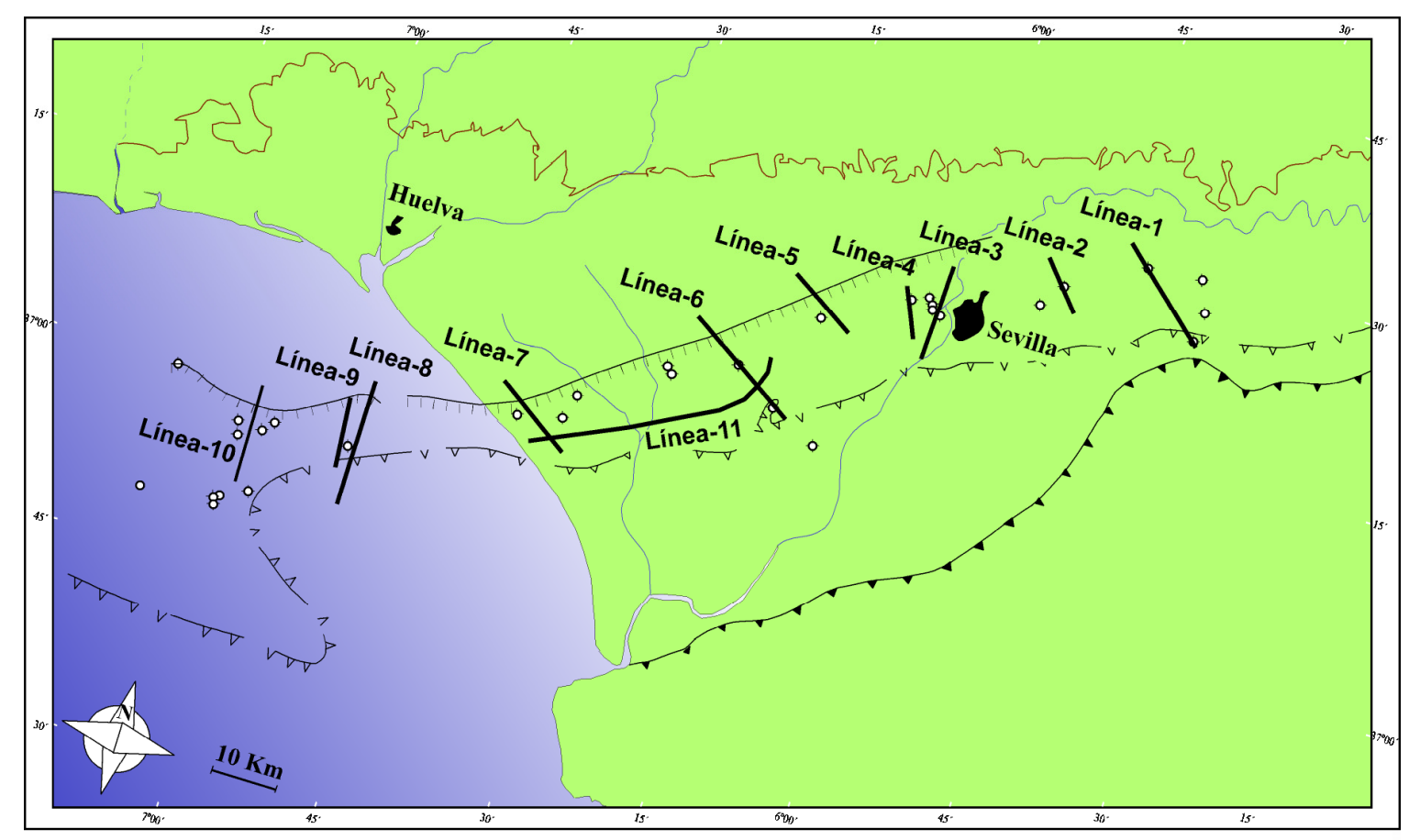

Figura 4.1. Posición de las líneas sísmicas utilizadas en el análisis sismobioestratigráfico. 
El margen continental español del golfo de Cádiz ha sido intensamente explorado debido a su interés científico y comercial especialmente por las compañías petroleras, de forma que existe una densa red de perfiles sísmicos multicanal publicados por diferentes autores (Sartori et al., 1994; Tortella et al., 1996; Martínez del Olmo et al., 1984; Riaza y Martínez del Olmo, 1996; Maldonado et al., 1999). Sin embargo, debido a la vigencia de permisos de exploración en la zona y al carácter confidencial de la información referente al golfo de Cádiz, no hemos podido acceder a gran parte de la documentación sísmica existente.

Se presentan no obstante, 11 perfiles de sísmica de reflexión, 10 de ellos transversales al eje de la cuenca, repartidos a lo largo de la misma y 1 longitudinal, que proporcionan, entre todos, una buena cobertura de la zona (fig. 4.1). Ocho de los perfiles corresponden al área del Guadalquivir y 3 a la del golfo de Cádiz.

Todos los perfiles guardan proporción en su escala vertical. La escala horizontal, sin embargo, es variable en cada uno de ellos aunque se ha tratado de mantener cierta proporción para que resulten comparables.

Los perfiles 1, 2, 3, 4, 5, 7 y 10 han sido cedidos por Repsol Exploración, los perfiles 6, 9 y 11 se han obtenido del informe ITGE (1990), y el perfil 8 de Riaza y Martínez del Olmo (1996). La interpretación de la naturaleza del zócalo y la posición de las fallas que lo fracturan está basada en datos obtenidos de estos y otros autores (ITGE, 1990; Maldonado et al., 1999; Riaza y Martínez del Olmo, 1996). Las diagrafías de velocidad sónica de diversos sondeos petrolíferos han permitido calcular los distintos rangos de velocidad para los perfiles sísmicos. García Castellanos (1998) establece para esta zona los rangos de velocidad siguientes: sedimentos pliocuaternarios: $1.8-2.2 \mathrm{~km} / \mathrm{s}$; sedimentos neógenos: 2.4-3.0 km / s; sales triásicas: 3.8-5.5 km / s. No obstante, la escala vertical de los perfiles no se expresa como unidades de longitud (salvo en el perfil $\mathrm{n}^{\mathrm{o}} 10$ ), sino como milisegundos en tiempo doble (TD), por lo que la escala vertical no es real. Para transformar en distancia los tiempos registrados es imprescindible conocer debidamente las velocidades de propagación de las ondas primarias (ondas $\mathrm{P}$ ) en los distintos materiales atravesados. Como medida orientativa podemos estimar grosso modo que los tiempos dobles que muestran los perfiles presentados en esta Tesis corresponden aproximadamente al valor en metros. En nuestro caso, como la velocidad de propagación de las ondas $\mathrm{P}$ para la serie mio-pliocena $(\mathrm{Vp})$ es de, aproximadamente y en términos muy generales $2 \mathrm{~km} / \mathrm{s}$ (tiempos dobles), un segundo (1000 ms) en la escala vertical equivale a $1 \mathrm{Km}$ (esto es: $2 \mathrm{~km} \cdot \mathrm{s}^{-1} / 2 \mathrm{~s}=1 \mathrm{~km}$ ). Así mismo, la escala vertical está exagerada varias veces con respecto a la horizontal debiendo ser previamente corregida por lo tanto para realizar cualquier tipo de calculo relacionado con la profundidad. Dicha 
exageración vertical ocasiona una distorsión, más o menos grande de las formas reales de los reflectores, magnificándose sus relaciones angulares. Las geometrías reales deberán ser por tanto, restituidas a partir del conocimiento de las velocidades de propagación en los niveles de subsuelo.

Las siguientes páginas corresponden a la figura. 4.2. En ella se muestran los 11 perfiles de sísmica de reflexión utilizados. Se han dispuesto los 10 perfiles transversales ordenados según su posición geográfica de este a oeste y en última posición el perfil longitudinal que corresponde al $\mathrm{n}^{\mathrm{o}} 11$. 
NW

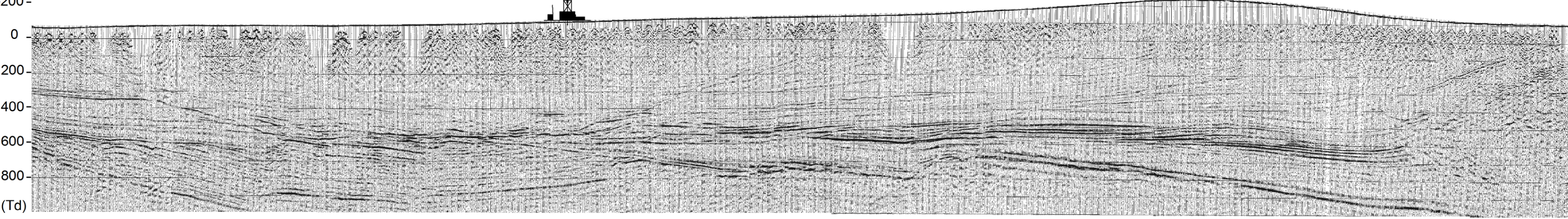

(Td)
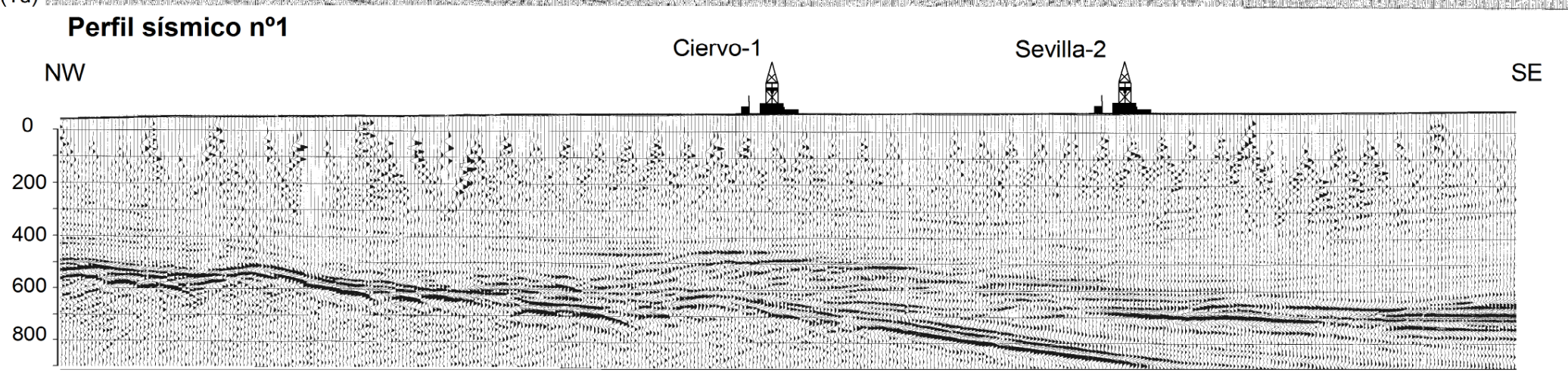

800 Perfil sísmico n²

San Juan R-1

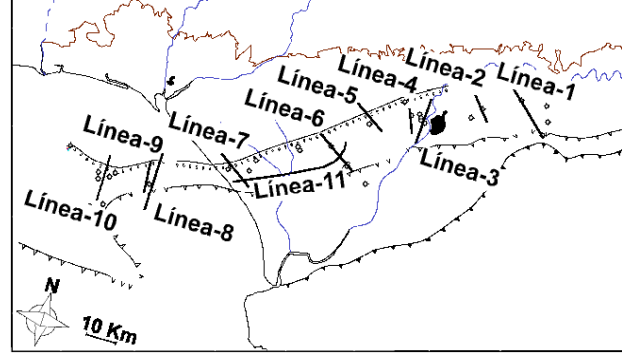

NW

Posición de las líneas sísmicas (Figura 4.1.)

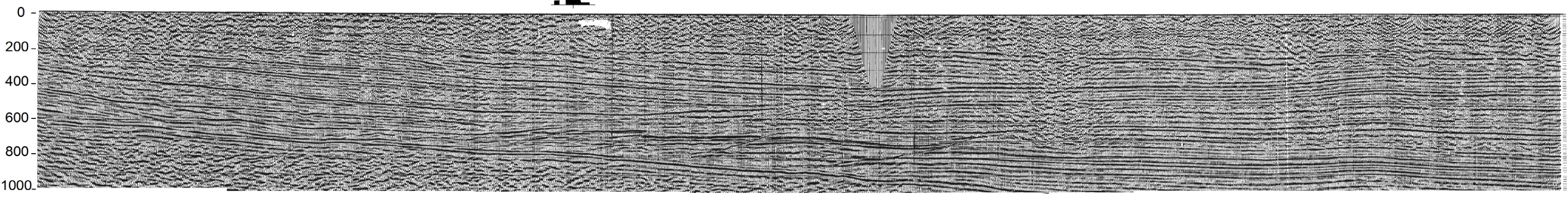

1000_(ms) Perfil sísmico n ${ }^{\circ} 3$

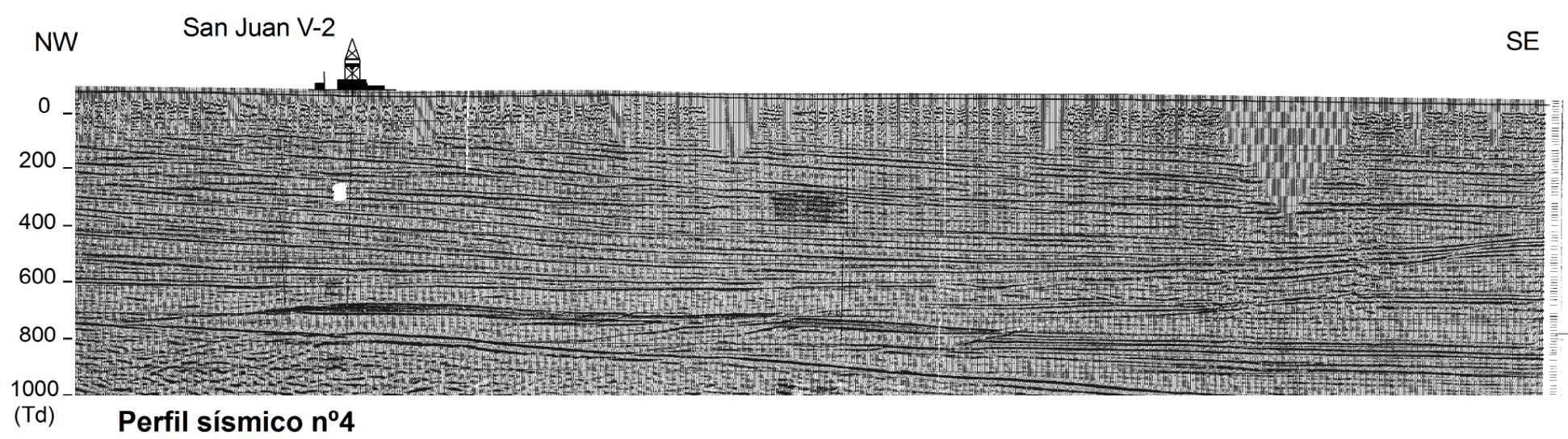

Figura 4.2. Perfiles sísmicos utilizados. 1 a 10, transversales a la cuenca; 11, longitudinal. Posición relativa de algunos de los sondeos más característicos. TD = Tiempo Doble en milisegundos. Perfiles 1, 2, 3, 4, 5, 7 y 10: Repsol Exploración. Perfiles 6, 9 y 11: informe ITGE (1990). Perfil 8: Riaza y Martínez del Olmo (1996). Posicion de las lineas sísmicas en la figura 4.1. 

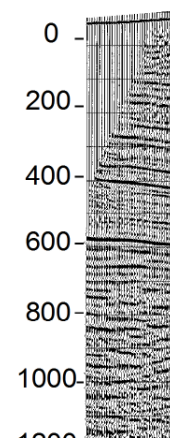
1200-

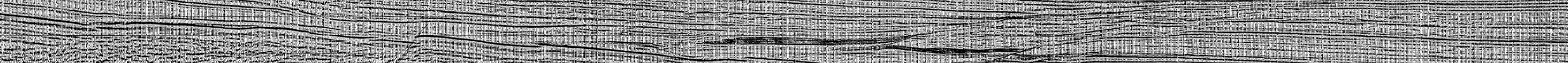
(ms) Perfil sísmico n5

NW

Casanieves-1 $\otimes_{\mathrm{SE}}$

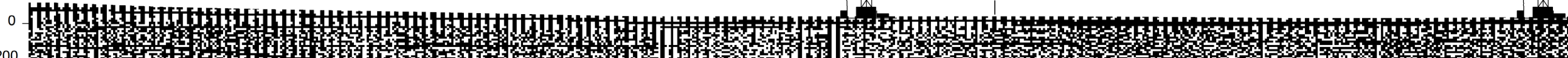

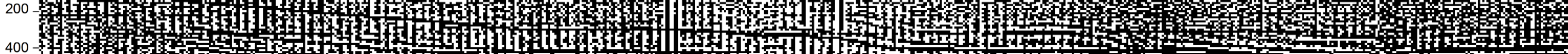

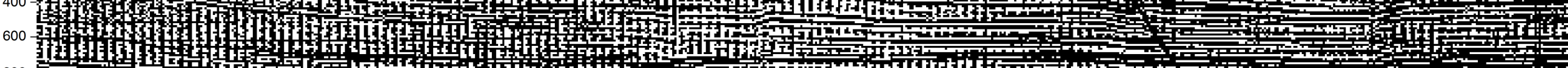

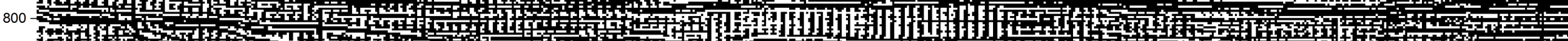

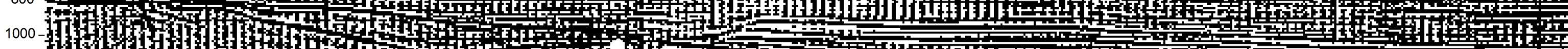

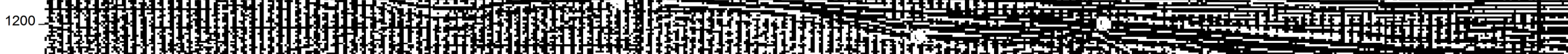
1400

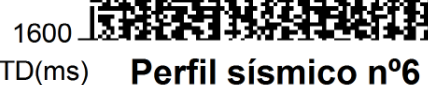

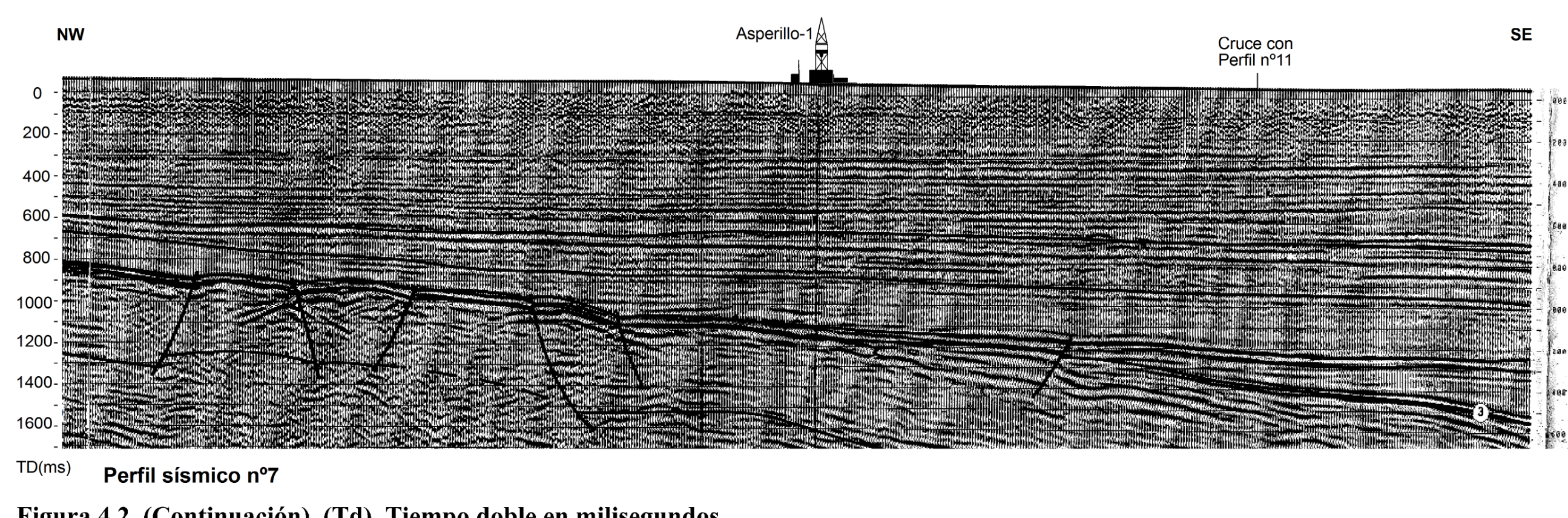

Figura 4.2. (Continuación). (Td). Tiemno doble en milisegundos. 
(1)0

(Td) Perfil sísmico $n^{\circ} 8$

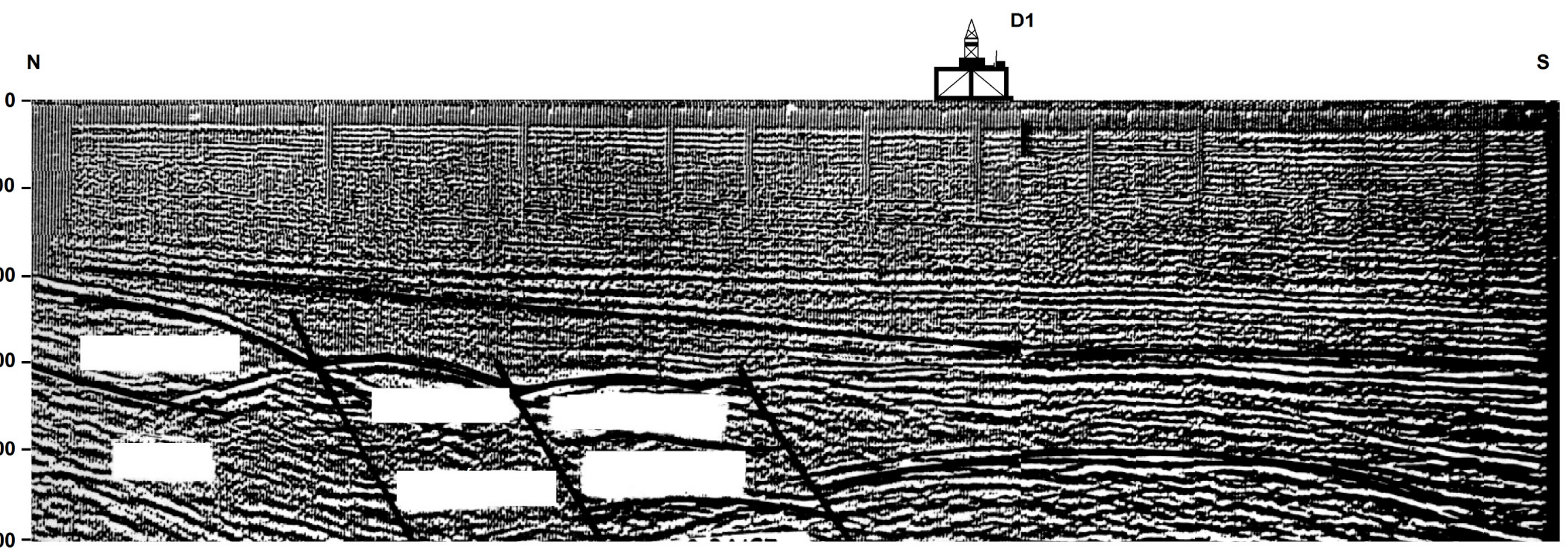

(Td) Perfil sísmico $n^{\circ} 9$

Figura 4.2. (Continuación). (Td), Tiempo doble en milisegundos. 

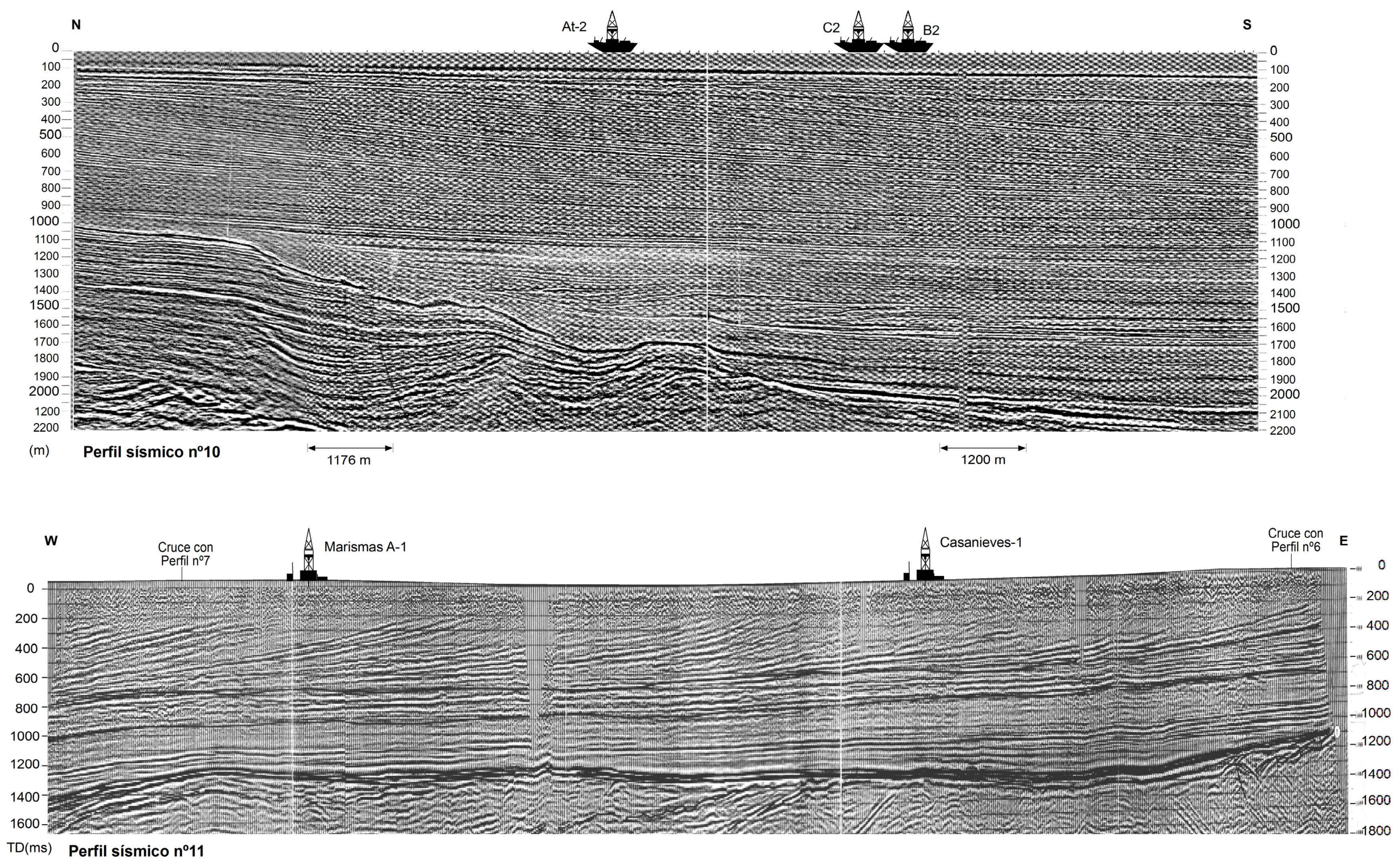

Figura 4.2. $($ Continuación) $\mathrm{TD}=$ Tiempo Doble en milisegundos . 


\subsection{METODOLOGÍA Y PERFILES SISMOBIOESTRATIGRÁFICOS}

A las líneas sísmicas originales se les han sobreimpuesto las biozonas propuestas en el capítulo 3, identificadas mediante distintos colores (azul claro, azul oscuro, amarillo, blanco, rosa y verde oscuro). El resultado de todo ello ha supuesto una serie de paneles de correlación litosísmica y bioestratigráfica basados en los perfiles sísmicos, que proporcionan una nítida visión de la configuración interna y acomodación de los materiales mio-pliocenos que rellenan la cuenca. Se han denominado a estos paneles "perfiles sismobioestratigráficos" debido a la naturaleza de la información que recogen.

Los perfiles sismobioestratigráficos reflejan la extensión de las biozonas convencionales obtenidas en los sondeos de exploración a lo largo de un perfil sísmico. En la figura 4.3, se muestra gráficamente el procedimiento utilizado en la elaboración de los perfiles sismobioestratigráficos. Se parte inicialmente del perfil sísmico original (fig. 4.3A) (en este caso corresponde al perfil $n^{\circ} 6$ de la figura 4.2) y de la bioestratigrafía de dos sondeos localizados sobre dicho perfil (sondeos Villamanrique-1 y Casanieves-1) (fig. 4.3B). El resultado del análisis bioestratigráfico (capítulo 3) se traslada al registro geofísico de cada sondeo (fig. 4.3C). De este modo se establece la ubicación de los eventos bioestratigráficos (fig. 4.3B) en relación a los reflectores sísmicos (fig. 4.3D). Finalmente se extiende la biozonación a todo el perfil sísmico en función de los reflectores utilizados (fig. 4.3E).

Una vez tratados los perfiles, se han obtenido los 11 perfiles sismobioestratigráficos (fig. 4.4) correspondientes a los perfiles sísmicos originales que aparecían en la figura 4.2. Aunque se incluye un pequeño mapa, la posición de las líneas sísmicas puede consultarse en la figura 4.1. A continuación se realiza una breve descripción de cada uno de los perfiles sismobioestratigráficos:

El perfil-1 (fig. 4.4) se extiende entre los sondeos Carmona 1 y Carmona-4. Este perfil, dispuesto transversalmente al eje de la cuenca, es uno de los más característicos. A la derecha, dentro de la biozona del grupo de G. miotumida, puede observarse la entrada del olistostroma bético con su característica imagen sísmica caótica, siendo atravesado

\footnotetext{
Figura 4.3. (Página siguiente). Método de elaboración de los perfiles sismobioestratigráficos: A.Perfil sísmico original con uno o varios sondeos localizados en su proximidad. B Bioestratigrafía de los sondeos localizados sobre la línea sísmica. C.- Datación de los reflectores mediante bioestratigrafía. D.- Biozonación del registro geofísico. E.- Extensión de la biozonación al resto del perfil sísmico y establecimiento de las unidades litosísmicas. El resultado final es un perfil sismobioestratigráfico.
} 

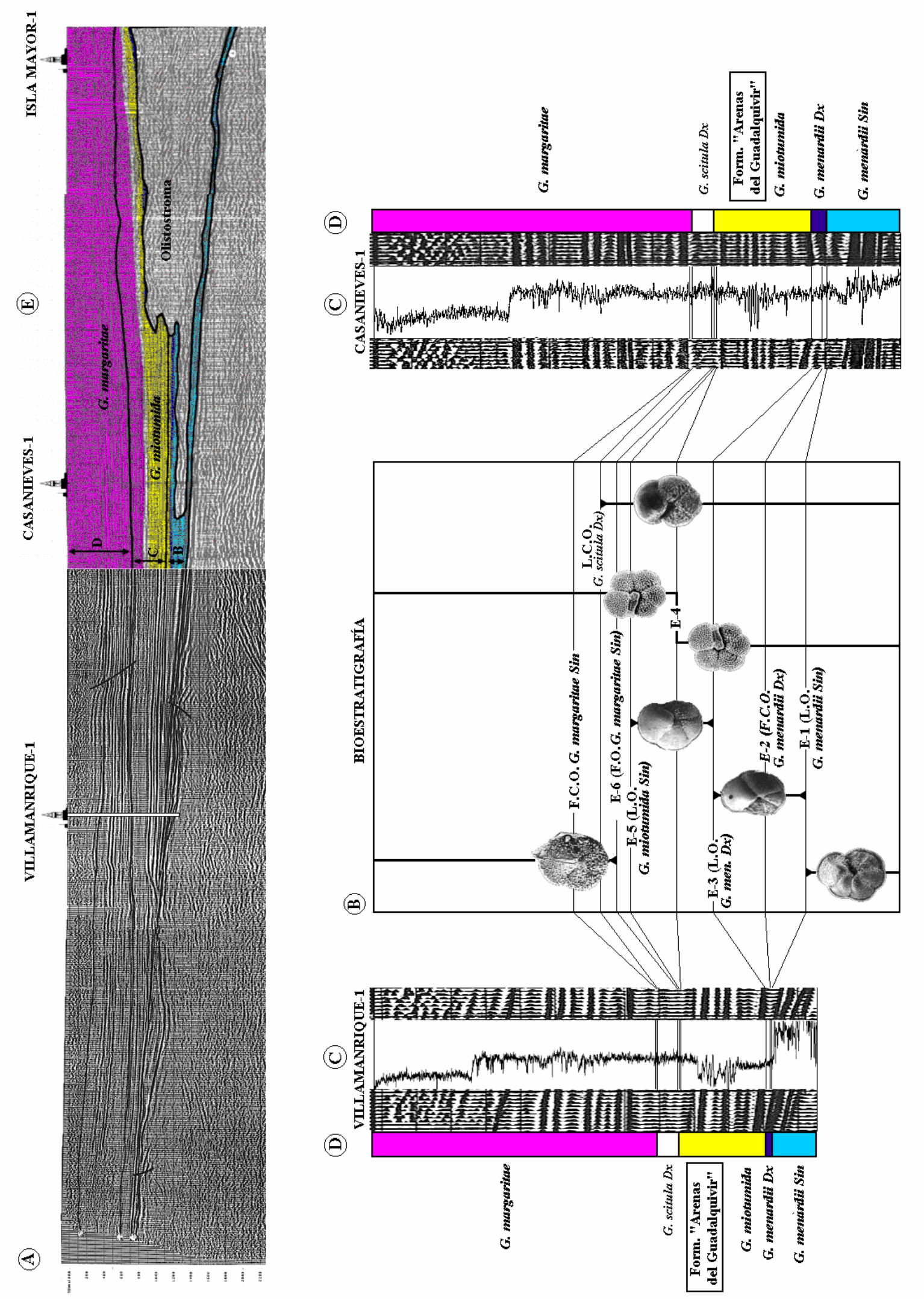
por el sondeo Carmona-4. El olistostroma bético alcanza una posición intermedia entre los sondeos Carmona 4 y Santa Clara-1. Frente al olistostroma se desarrollan diferentes cuerpos turbidíticos de los que observamos su sección transversal. Destaca la progradación lateral de estos cuerpos, cuya disposición muestra el desplazamiento de SE a NW del depocentro de la cuenca (cuerpos Gv-2 a Gv-5) (en el capítulo 7 se desarrolla ampliamente la evolución del relleno sedimentario messiniense). Desde el depósito del primero de los cuerpos arenosos, el depocentro de la cuenca se desplaza hacia el NW probablemente como consecuencia del empuje del sistema bético y del intenso aporte de materiales que recibe la cuenca desde el SE (obsérvese la acumulación de sedimentos que refleja la biozona del grupo de G. miotumida al frente del olistostroma bético). A la izquierda del perfil, en el talud NW, destaca el contacto neto (erosivo?) entre las biozonas del grupo de G. miotumida (amarillo) y la biozona del grupo de G. margaritae (rosa). Seguidamente el talud NW desarrolla una cuña de sedimentos adosada al talud, mientras que el talud SE aumenta su pendiente y desarrolla así mismo una cuña progradante que incluye en superficie facies someras como la calcarenita de Carmona. Poco tiempo después, se produce una ruptura sedimentaria significativa de modo que cambia radicalmente la dirección de los aportes. A partir de este momento, el principal área madre de los sedimentos será el talud NW junto con la incorporación de materiales a través del eje de la cuenca. Este cambio en la dirección de los aportes puede observarse en el desplazamiento del depocentro de la cuenca hacia el SE si observamos la disposición de los reflectores blancos que se unen en la base a modo de downlap (perfiles sismobioestratigráficos $\mathrm{n}^{\circ} 1 \mathrm{a} \mathrm{n}^{\circ}$ 5). La ausencia de aportes sobre el talud sur determina la formación de una serie condensada sobre el horizonte de ruptura sedimentaria y supone así mismo la fosilización de todo el talud sur de la cuenca.

El perfil-2 (fig. 4.4) es prácticamente una sección reducida del anterior, observándose la zona axial de la cuenca. Puede observarse así mismo la progradación de los lóbulos arenosos, el contacto (erosivo?) entre las biozonas del grupo de G. miotumida y $G$. margaritae, y la disposición en downlap de los reflectores blancos resaltados en la zona de G. margaritae.

En el perfil-3 (fig. 4.4) observamos la apertura de la cuenca. Los taludes laterales de la cuenca quedan más alejados y el acomodamiento de los materiales es menos acusado. A pesar de ello, se sigue observando como durante la biozona de G. margaritae, el depocentro de la cuenca se desplaza hacia el SE.

El perfil-4 (fig. 4.4) está situado muy próximo al anterior y refleja una situación similar. 
En el perfil-5 (fig. 4.4) destacan una serie de pequeñas fallas sinsedimentarias al depósito de los lóbulos arenosos. A techo del último de estos lóbulos comienza la biozona del grupo de G. margaritae. Se mantiene la disposición en downlap de los reflectores blancos en la biozona del grupo de G. margaritae.

En el perfil-6 (fig. 4.4) el sondeo Casa Nieves-1 atraviesa también el olistostroma. Aunque el principal cuerpo olistostrómico se emplaza en su posición definitiva algo más tarde entorno a Carmona (hacia el límite Tortoniense-Messiniense, 7.24 Ma) en este momento se produce la entrada de cuñas del frente olistostrómico que aparecen interestratificadas con la sedimentación autóctona (incluso antes de 7.512 Ma). El ingreso de la unidad alóctona del Guadalquivir modifica la morfología de la cuenca. Tanto el perfil-1 como el perfil-6 son muy significativos debido a que atraviesan las formaciones más características de la zona, cruzando de NW a SE la cuenca desde el talud norte al talud sur y el olistostroma. Se aprecia la presencia del substrato Mesozoico en la zona del sondeo Almonte-1 a la izquierda del perfil (Jurásico y Triásico) y en el sondeo Villamanrique-1 (Triásico).

En el perfil-7 (fig. 4.4) destaca el zócalo Mesozoico muy fracturado y el solapamiento de la biozona del grupo de G. miotumida por la del grupo de G. margaritae. No aparece nítidamente el límite entre las biozonas de $G$. margaritae y de $G$. puncticulata debido a que no se ha podido detectar la desaparición del grupo de $G$. margaritae en el sondeo Asperillo-1. Se sospecha sin embargo, que la desaparición de G. margaritae se produce a techo del perfil.

El perfil-8 (fig. 4.4) corresponde a un perfil característico del golfo de Cádiz, que abarca desde el talud norte al área ocupada por el olistostroma en el sur, atravesando el eje de la cuenca. En este perfil se observa un Plioceno-Cuaternario muy desarrollado, con una cuña de sedimentos pliocenos con G. margaritae cubriendo el resto de la serie miocena (menos potente que en las series terrestres).

En el perfil-9 (Shell-1971, fig. 4.4) se distingue el escalonamiento del Mesozoico bajo el Terciario. Así mismo se observa un Plioceno-Cuaternario muy desarrollado en cuanto a potencia y comparativamente con el resto de la serie terciaria. Destaca la cuña de sedimentos de la biozona de G. margaritae que desde el NW solapa el resto de los sedimentos miocenos.

El perfil-10 (fig. 4.4) es un perfil de "sísmica 3D” muy próximo a los sondeos B2 y C2 y que por su calidad servirá más adelante para demostrar el potencial de la cicloestratigrafía. Es el único perfil que muestra su profundidad en metros. Destaca la profundidad de la cuenca en el sur con las turbiditas más antiguas, así como el 
paleoescarpe mesozoico al norte sobre el que se disponen los últimos cuerpos turbidíticos. Al suroeste de este perfil quedaría la zona diapírica que ocupa la posición de los sondeos 6x1 y Orión 2-1. Esta estructura puede observarse en las reconstrucciones tridimensionales del capítulo 7.

El perfil-11 (fig. 4.4) es el único perfil longitudinal a la cuenca. No obstante, su longitud $(40 \mathrm{Km})$, resulta en una interesante sección del bajo Guadalquivir. Un marcado reflector sísmico separa el basamento Mesozoico de los sedimentos terciarios. Este reflector supone la base del detrítico basal tras el cual se depositan unas arcillas ricas en foraminíferos profundos y en globorotálidos del grupo de G. menardii sin, primero, y $G$. menardii dx, más tarde. La entrada de una cuña de olistostroma, equivalente a la que afecta al sondeo Casanieves, se puede observar en la zona inferior derecha de la imagen. Seguidamente se desarrolla la biozona del grupo de G. miotumida, que incluye a la formación "arenas del Guadalquivir". En la mitad superior de la biozona del grupo $G$. margaritae se observa la rápida progradación del sistema hacia el $\mathrm{SW}$, hacia el fondo de cuenca (reflectores blancos). En el extremo superior izquierda comienza la biozona del grupo G. puncticulata. 


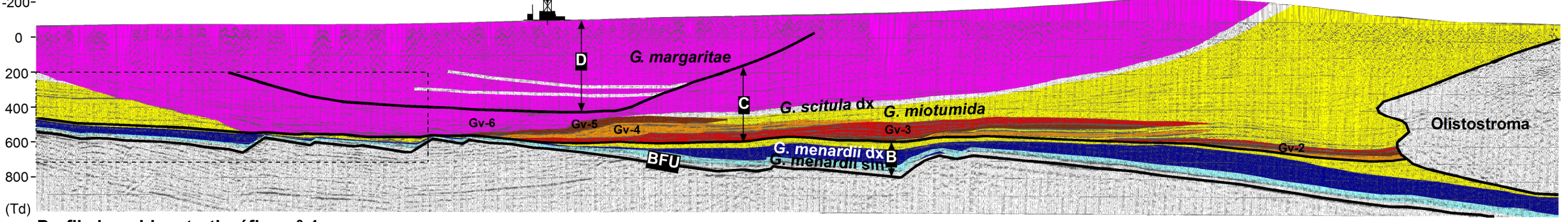

(Td) Perfil sismobioestratigráfico $\mathrm{n}^{0}-1$ NW

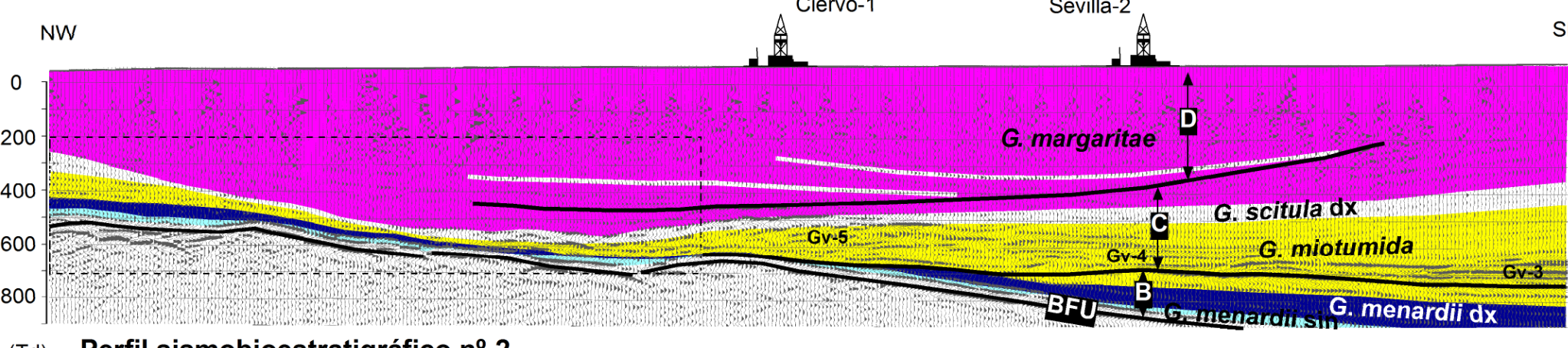

(Td) Perfil sismobioestratigráfico $\mathrm{n}^{0}-2$

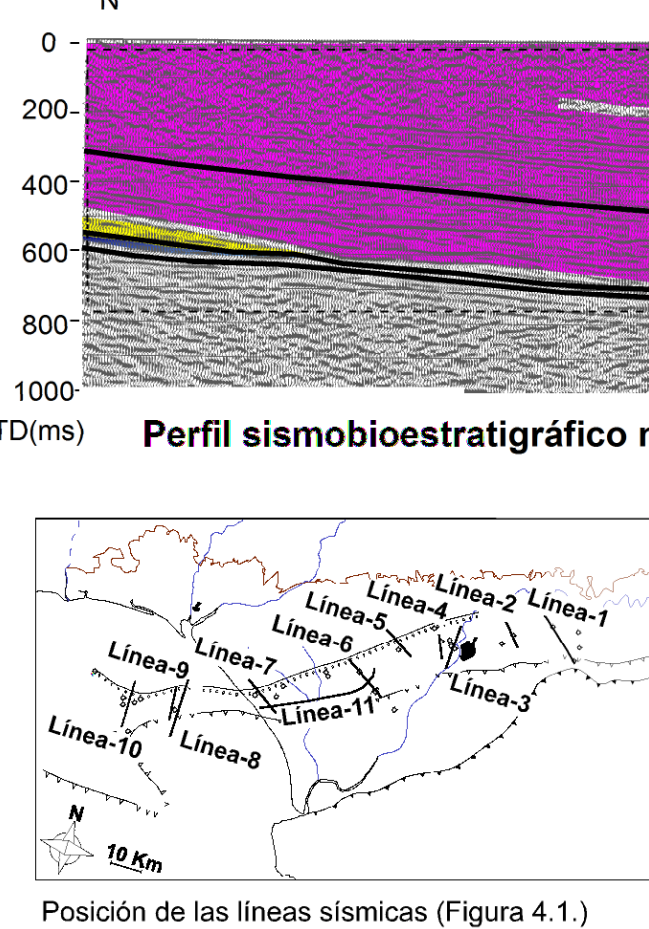

San Juan R-1

促
Zona no cubierta por los sondeos estu-
diados. Micropaleontológia deducida por interretación de las líneas sismicas

Superficies de discontinuidad. $0 \mathrm{~m}$ : Nivel del mar

A-F: Unidades litosismicas

Gv-1 a Gv-6: Principales cuerpos turbidíticos BFU: Discontinuidad de fondo de cuenca
(Basal Foredeep Unconformity)

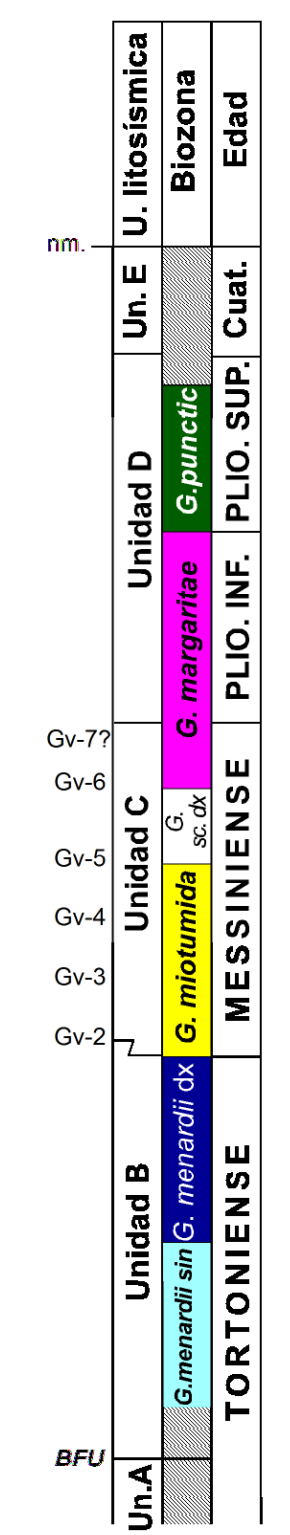

Figura 4.4. Perfiles sismobioestratigráficos: Unidades bioestatigráficas, unidades litosismicas y dataciones propuestas en la Tesis. $($ Td $)=$ Tiempo doble en milisegundos. Perfiles $1,2,3,4,5,7$ y 10 basados en sísmica original facilitada por Repsol Exploración Perfiles 6,9 y 11 basados en perfiles sísmicos del informe ITGE (1990). Perfil sismobioestratigráfico basado en perfil sísmico original de Riaza y Martínez del Olmo (1996). 


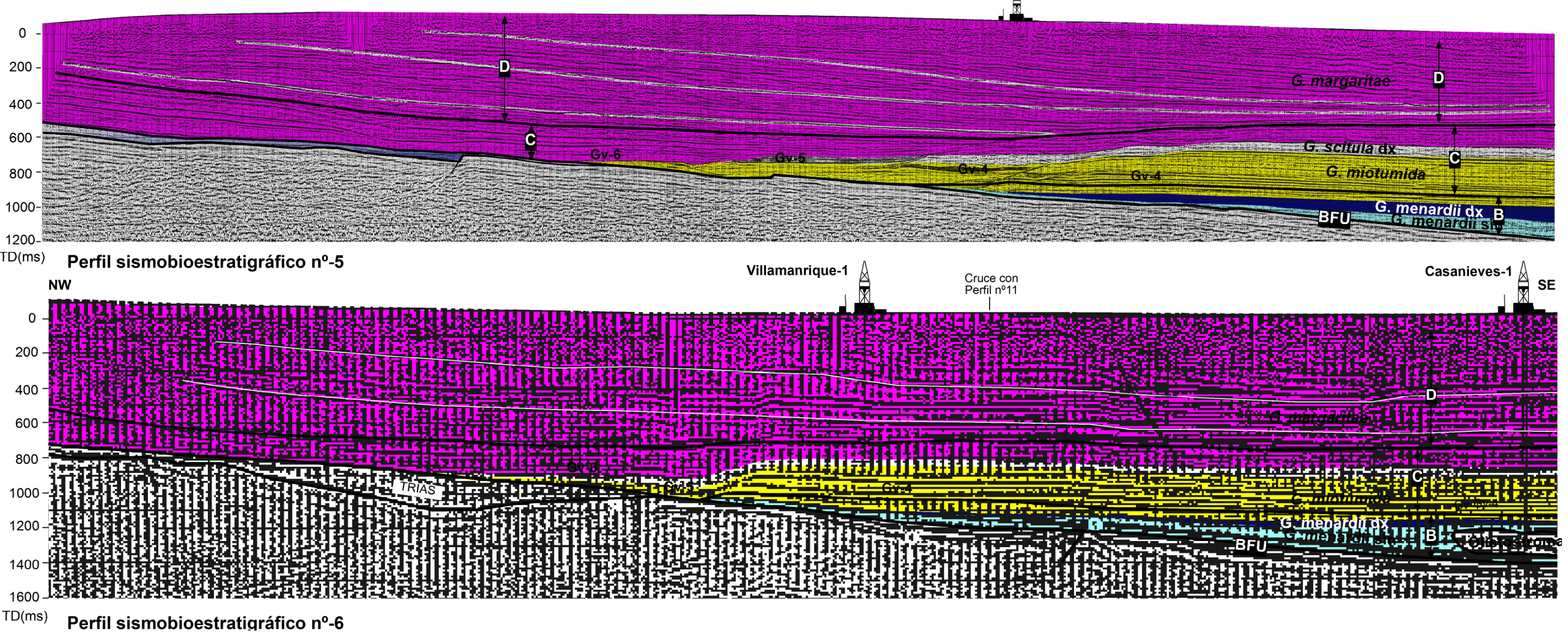

$T D(m s)$ Perfil sismobioestratiaráfico $n^{0}-6$

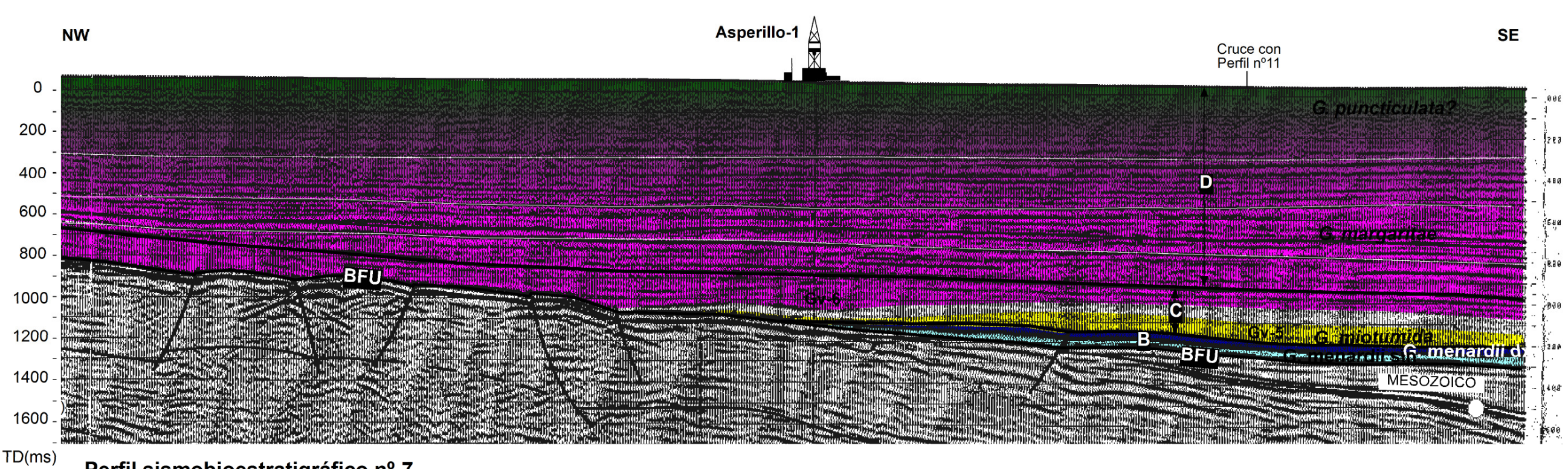

$T D(m s)$ Perfil sismobioestratigráfico $n^{0}-7$

Figura 4.4. (Continuación). (Td), Tiempo doble en milisegundos. 


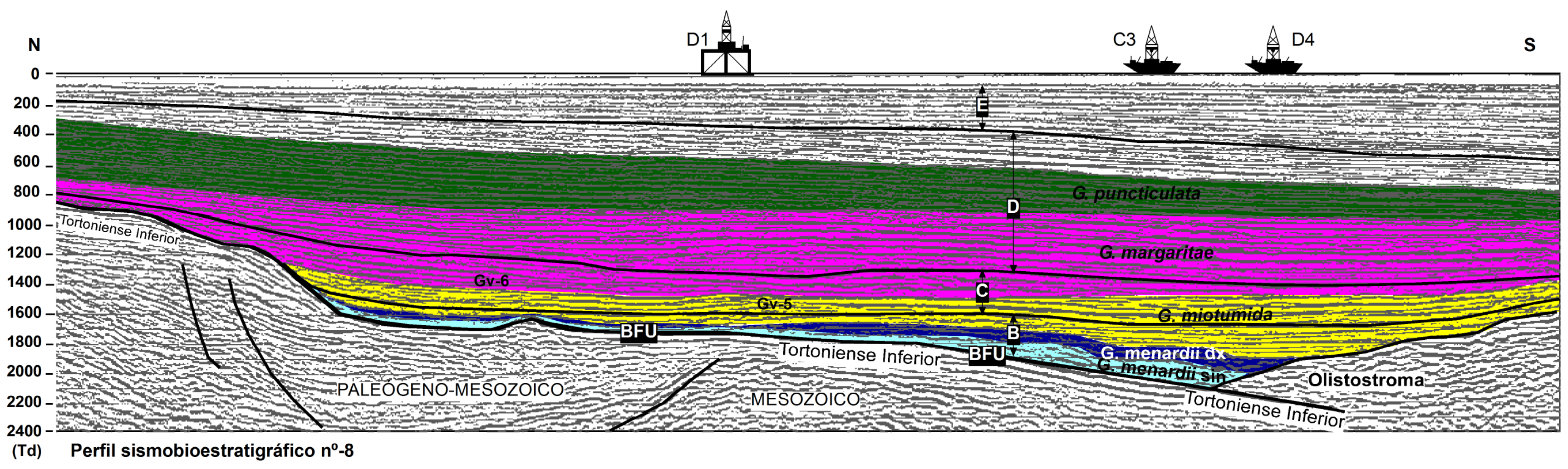

\section{NW}

D1

SE

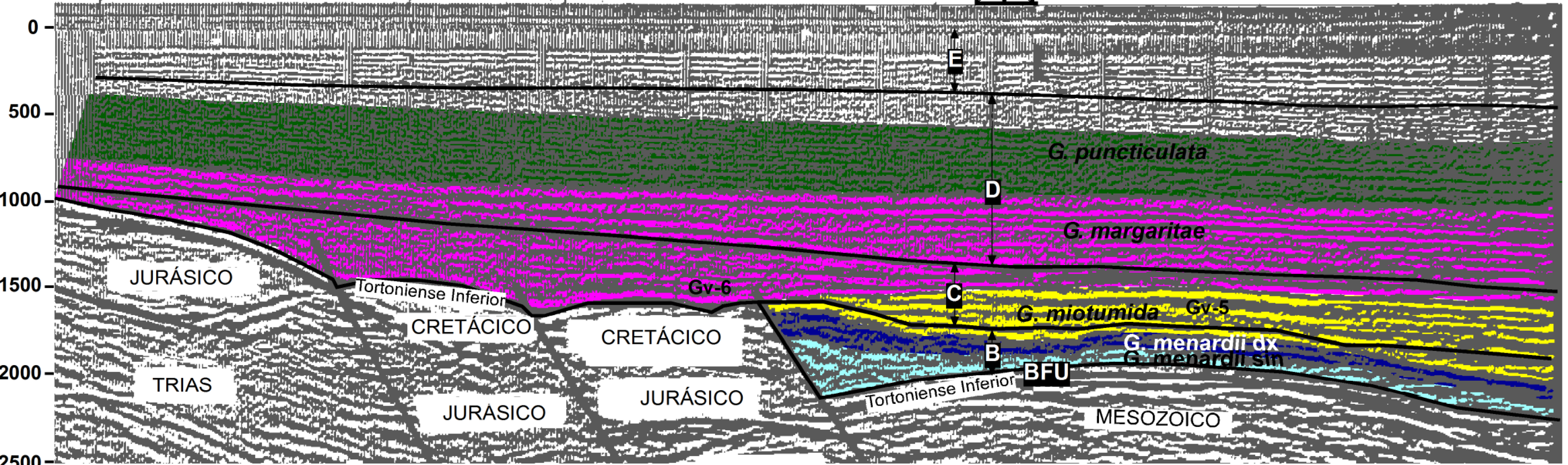

(Td) Perfil sismobioestratigráfico $\mathrm{n}^{\circ}-\mathrm{9}$

Figura 4.4. (Continuación). (Td), Tiempo doble en milisegundos. 

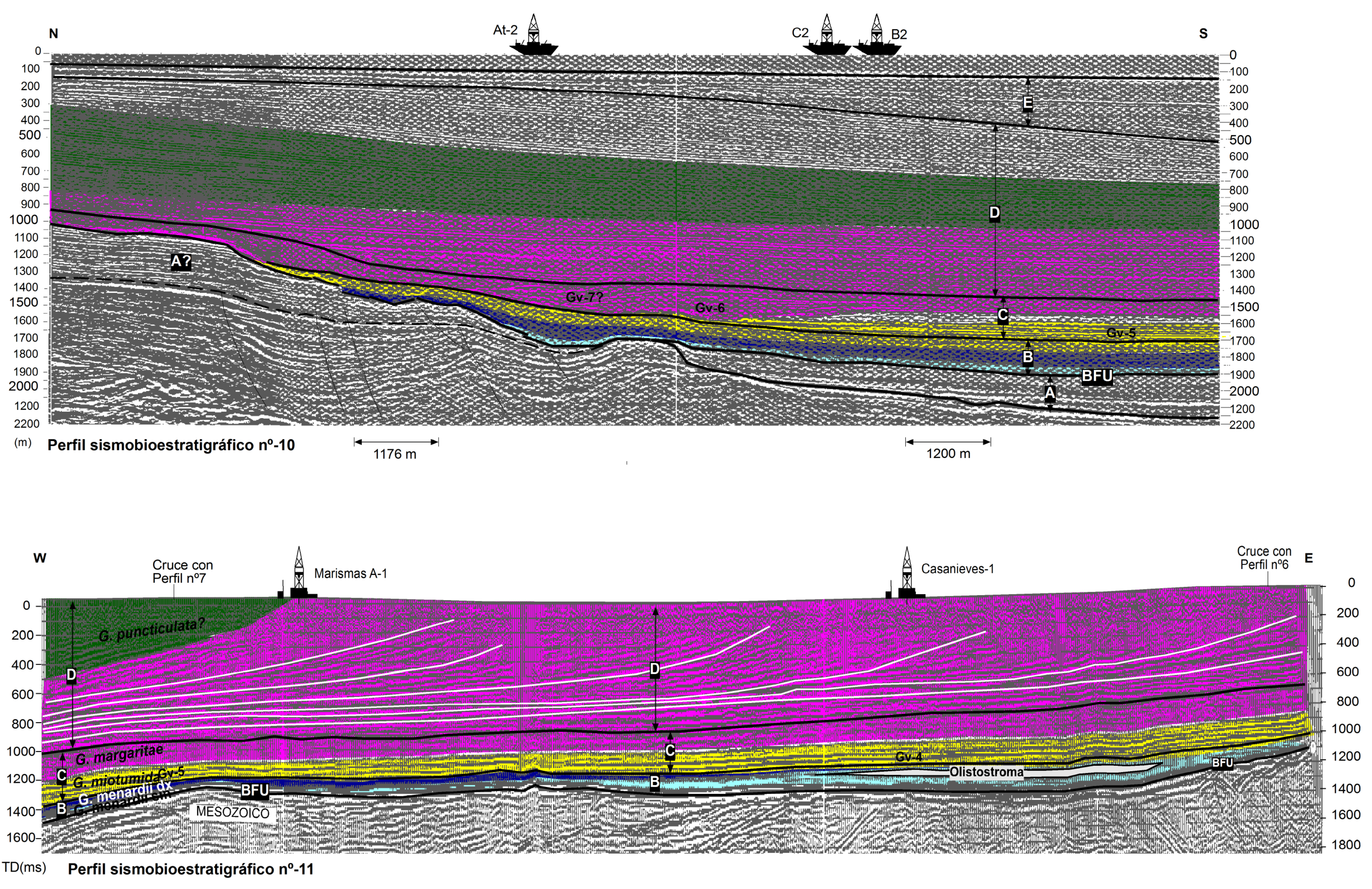

Figura 4.4. (Continuación). $($ Td $)=$ Tiempo doble en milisegundos. 


\subsection{UNIDADES LITOSÍSMICAS}

Por otro lado, sobre la señal geofísica de los perfiles anteriores se han destacado superficies de discontinuidad reconocibles a lo largo de toda la cuenca del Guadalquivirgolfo de Cádiz. Estas superficies han servido para proponer las respectivas unidades litosísmicas. Basadas en los perfiles sismobioestratigráficos se han diferenciado 6 unidades litosísmicas principales en el relleno sedimentario de la cuenca del Guadalquivir-golfo de Cádiz (fig. 4.4): Unidades litosísmicas A, B, C, D y E, además de la unidad alóctona del olistostroma.

\section{Unidad A}

Se trata de una unidad anterior a la entrada del olistostroma. De edad LanghienseSerravalliense al Tortoniense inferior, solo se ha detectado en el golfo de Cádiz, donde aparece bajo el olistostroma al sur y más desarrollada en el margen NW (perfil no 8 y 10 en figura 4.4). El techo es un reflector con una gran amplitud, que marca la base de la principal masa olistostrómica en el golfo de Cádiz (perfiles $\mathrm{n}^{\mathrm{o}} 8$ y 10). Este reflector también representa la discordancia basal de fondo de cuenca (denominada BFU, basal foredeep unconformity por Maldonado et al., 1999 en el golfo de Cádiz) y equivale a la base de las denominadas "arenas basales" en el Guadalquivir. El frente del olistostroma, bien cartografiado por la industria petrolera, alcanza el sector oriental de la cuenca del Guadalquivir-golfo de Cádiz, enmascara y parcialmente erosiona las unidades infrayacentes en todo el área sureste. Esta unidad coincide con la unidad litosísmica M1, propuesta por Maldonado et al., (1999) para el mismo área (fig. 4.5). Según los mismos autores, esta unidad alcanza la máxima potencia hacia el sur, aunque el deslizamiento del olistostroma la deforma a modo de cuña frente al olistostroma. Con el techo frecuentemente delaminado o erosionado, profundiza hacia el SE bajo el olistostroma. Incluso, esta unidad podría estar incluida en el cabalgamiento basal. La unidad litosísmica A es equivalente así mismo al grupo Atlántida descrito previamente en el área (Martínez del Olmo et al., 1984; Riaza y Martínez del Olmo, 1996) (fig. 4.5).

\section{Unidad B}

Esta unidad sinolistostrómica, está bien representada junto al frente del olistostroma, donde alcanza unos $200 \mathrm{~m}$ de potencia en el Guadalquivir (sondeo Santa Clara-1) y algo más de $300 \mathrm{~m}$ en el golfo de Cádiz (sondeo B3). En ambos casos su espesor decrece uniformemente desde el frente del olistostroma hacia el norte (fig. 4.4). 
En el golfo de Cádiz, esta unidad está interdigitada con el olistostroma, la mayoría de estos depósitos fueron desarrollados durante su emplazamiento y fueron también afectados por movimientos residuales posteriores. El límite inferior de estos depósitos lo constituye el reflector $B F U$. El límite superior, está determinado por un cambio litológico y de facies en el fondo de cuenca definido por la base de los aparatos turbidíticos desarrollados en la cuenca del Guadalquivir-golfo de Cádiz durante el Messiniense Por lo tanto el paso entre las unidades $\mathrm{B}$ y $\mathrm{C}$ no es sincrónico en toda la cuenca, estando supeditado al momento en el que se produce el cambio litológico.

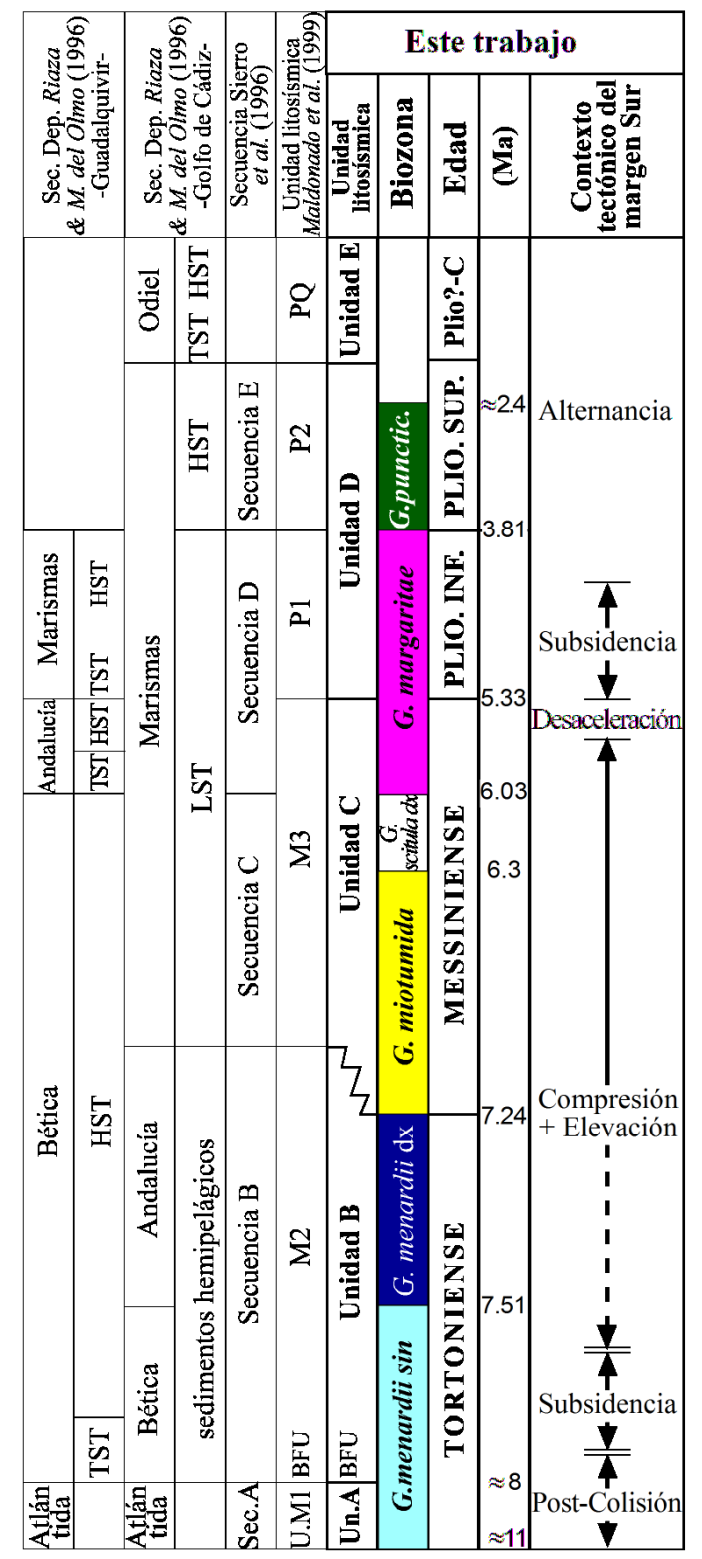

Fig. 4.5. Relación entre las unidades litosísmicas y las unidades bioestratigráficas. Equivalencia con modelos de otros autores. 
En el área de estudio, en el interior de la unidad litosísmica B se detecta el techo de la unidad bioestratigráfica del grupo de G. menardii sin, se desarrolla enteramente la unidad del grupo de $G$. menardii dx e incluso puede comenzar la biozona del grupo de $G$. miotumida antes de comenzar la unidad litosísmica superior. La unidad litosísmica B se correlaciona en parte con la secuencia B de Sierro et al. (1996) (fig. 4.5).

\section{Unidad del olistostroma.}

La unidad del olistostroma (fig. 4.4) está identificada sísmicamente por reflectores caóticos, de alta amplitud con difracciones y reflexiones hiperbólicas (Maldonado et al., 1999). El límite inferior es un fuerte reflector de alta amplitud que profundiza hacia el sur desde el frente del olistostroma y comienza a oscurecerse bajo el cuerpo del mismo. Las masas de olistostroma que alcanzan el golfo de Cádiz erosionaron los depósitos infrayacentes y formaron una unidad detrítica basal. El cabalgamiento tuvo lugar a través de planos de bajo ángulo observados como reflectores de alta amplitud en el cuerpo caótico olistostrómico. El frente está configurado en varias cuñas envolviendo los depósitos sinsedimentarios de la unidad B. Las facies de talud fueron depositadas en el frente del cabalgamiento. El primer ingreso del olistostroma se realiza en el golfo de Cádiz y en el bajo Guadalquivir en forma de cuñas de acreción en el frente olistostrómico. El principal emplazamiento del olistostroma hasta posiciones próximas a la actual, tuvo lugar justo antes y durante el depósito de la unidad B en el golfo de Cádiz y en el bajo Guadalquivir (Tortoniense superior). La gran cuña de avance fue desviada por la morfología y distribución de los depósitos previos. Posteriormente (límite Tortoniense-Messiniense), a techo de la unidad litosísmica B, se produce la entrada de la unidad alóctona del Guadalquivir en la cabecera de la cuenca, lo que coincidirá con el comienzo de una nueva unidad litosísmica en el alto Guadalquivir (zona de Carmona).

\section{Unidad C}

La base de la unidad $\mathrm{C}$ constituye un marcado cambio litológico y de facies (localmente discordante) que puede observarse en la mayor parte de los perfiles sismobioestratigráficos (fig. 4.4). Sin embargo, esta superficie no es isócrona y está definida por la base de los sucesivos aparatos turbidíticos desarrollados en la cuenca durante el Messiniense. Por lo tanto, la edad de la base de esta unidad en el este de la cuenca es anterior a la que presenta en el golfo de Cádiz debido a la progradación de los cuerpos en este sentido. En la zona axial, el reflector que separa los sedimentos arcillosos 
de fondo de cuenca, de los primeros aparatos turbidíticos, delimita la base de la unidad. La base de la unidad C coincide además con el ingreso del olistostroma (límite Tortoniense-Messiniense) al sur de la ciudad de Carmona. Esta incorporación alóctona va a producir un rápido relleno del fondo de cuenca y el cierre adelantado de la cabecera (ver perfil sismobioestratigráfico $\mathrm{n}^{\mathrm{o}}$ 1). A partir de ese momento la cuenca se estrecha y cierra por el NE dibujando una "v" que se abre hacia el golfo de Cádiz. El contexto compresivo sigue manteniéndose durante todo el Messiniense de forma que se produce una rápida progradación de todo el sistema (depósitos de base de talud con turbiditas, talud y plataforma).

En el Guadalquivir la unidad litosísmica $\mathrm{C}$ consiste en facies de talud junto a ambos márgenes (NW y SE) que progradan frontalmente y desarrollan en el fondo de cuenca al menos 7 aparatos turbidíticos. Estos cuerpos avanzan a su vez por el eje de la cuenca desde la cabecera hasta el golfo de Cádiz con una fuerte deriva lateral asociada al talud sur progradante. Los cuerpos comienzan desarrollándose en el NE de la cuenca a finales del Tortoniense, y finalizan en el golfo de Cádiz a finales del Messiniense. La bioestratigrafía permite reconocer que las "arenas del Guadalquivir" pasan progresivamente a las "arenas del Guadiana" coforme avanza la cabecera de la cuenca. Al mismo tiempo, los lóbulos más antiguos se encuentran frente al olistostroma, para ser progresivamente más modernos hacia el talud norte. Una descripción detallada de la sucesión estratigráfica de esta unidad se desarrolla ampliamente en el capítulo 7.

En el perfil sismobioestratigráfico $\mathrm{n}^{\mathrm{o}} 11$ (fig. 4.4) observamos como la unidad litosísmica $\mathrm{C}$ termina con un tramo limoso con intercalaciones de arena, rico en globorotálidos del grupo de G. margaritae. Hasta ese momento, el aporte principal de los materiales se producía desde el talud sur canalizándose en sentido este-oeste a lo largo del eje de la cuenca. En el perfil longitudinal $n^{\circ} 11$ se aprecia la continuidad y el paralelismo de los reflectores del talud sur durante el depósito de la unidad C, lo que muestra el rápido avance de forma conjunta de todo el borde sur durante este periodo. Esta organización cambió drásticamente a partir del límite Mio-Plioceno (límite entre las unidades $\mathrm{C}$ y D).

El techo de la unidad litosísmica $\mathrm{C}$ es una disconformidad sobre la que se apoya mediante una superficie de biselamiento basal (downlap) la unidad litosísmica superior. Esta discontinuidad sedimentaria ha sido sellada por el Plioceno y consiste en una superficie de inundación sobre la que se apoyan a modo de downlap los reflectores de la unidad litosísmica D (fig. 4.4).

La unidad litosísmica $\mathrm{C}$, con la base prácticamente en el límite TortonienseMessiniense y techo en el límite Mio-Plioceno, supone de hecho el cuerpo sedimentario 
depositado durante el Messiniense (fig. 4.5). La unidad C rellena la mayoría de las irregularidades y depresiones de los depósitos infrayacentes y solapa el techo del olistostroma tanto en el Guadalquivir (sondeo Carmona-4) como en el golfo de Cádiz (sondeo D-4). Los mayores depósitos se observan en las depresiones del frente del olistostroma, fundamentalmente en áreas proximales donde puede alcanzar $500 \mathrm{~m}$ de potencia (sondeo Santa Clara-1) pero los espesores decrecen rápidamente hacia el NW conforme nos alejamos del frente del olistostroma hasta los 200-300 m en el eje de la cuenca (sondeos Carmona-1, San Juan V6). Sobre el cuerpo del olistostroma presenta desde unos $200 \mathrm{~m}$ de potencia (en los sondeos D4 e Isla Mayor-1) hasta que desaparece totalmente (al sur del sondeo Carmona-4). En el golfo de Cádiz la distribución es más homogénea oscilando entorno a los $300 \mathrm{~m}$ de potencia media en los sondeos C3, B2 y C2.

La unidad litosísmica C incluye la secuencia C y parte de la secuencia D propuestas por Sierro et al. (1996) en una misma unidad ya que no se encuentran criterios estratigráficos ni paleontológicos significativos para establecer un límite de secuencia entre ambas (fig. 4.5). La unidad litosísmica $\mathrm{C}$ es equivalente en general al conjunto de las secuencias Bética y Andalucía definidas por Riaza y Martínez del Olmo (1996) para el Guadalquivir y a la unidad litosísmica M3 de Maldonado et al. (1999) para el golfo de Cádiz (fig. 4.5).

\section{Unidad D (Plioceno)}

La base de esta unidad es una discontinuidad reconocida a lo largo de toda la cuenca del Guadalquivir (Martínez del Olmo et al., 1996) y en los perfiles de sísmica multicanal en el golfo de Cádiz (Malod y Mougenot, 1979; Nelson et al., 1993, Maldonado et al., 1999), mientras que su techo está definido por una discordancia erosiva. La unidad D comprende la sección pliocena de la unidad bioestratigráfica del grupo de G. margaritae, la biozona del grupo G. puncticulata y el resto del Plioceno superior (fig. 4.4). Su base consiste en un reflector que supone el límite Mio-Plioceno y su techo coincidiría con la base erosiva de la secuencia Odiel identificada en el golfo de Cádiz (Riaza y Martínez del Olmo, 1996). La unidad D sería equivalente en parte a la secuencia de depósito D de Sierro et al. (1996), aunque no comparten su base (fig. 4.5). Así mismo, sería equivalente a la parte superior (TST y HST) de la secuencia de depósito Marismas definida por Riaza y Martínez del Olmo (1996) en el golfo de Cádiz, siendo así mismo equivalente a la suma de las unidades litosísmicas P1 y P2 definidas por Maldonado et al. (1999) (fig. 4.5). 
En la cuenca del Guadalquivir el límite entre las unidades $\mathrm{C}$ y D viene marcado por un cambio importante en la geometría del depósito. En la unidad C hay una progradación dominante desde el talud sur hacia el norte (además de la progradación axial este-oeste). Esta progradación cambia radicalmente de polaridad en la unidad suprayacente (ver fig. 4.4, perfil sismobioestratigráfico $\mathrm{n}^{\circ} 11$ ). En la unidad D se observa una rápida progradación del sistema desde el talud $\mathrm{N}$ hacia el sur y de la cabecera de la cuenca en sentido este-oeste (perfil sismobioestratigráfico $\mathrm{n}^{\circ} 11$ ). La falta de aportes desde el talud sur durante el depósito de la unidad D parece indicar un hundimiento o subsidencia de esta zona en torno al límite Mio-Plioceno quedando el talud sur fosilizado por el sistema progradante procedente del norte y noreste. Este sistema progradante define una superficie de downlap sobre la unidad anterior representado por un marcado reflector sísmico reconocido a lo largo de toda la cuenca. Martínez del Olmo et al. (1996) presentan la cartografía de este reflector, que vinculan a una discordancia intramessiniense relacionada con un cañón submarino. Efectivamente, estos autores muestran una superficie de erosión sobre el talud sur en la zona oriental de la cuenca (Carmona). La erosión de la unidad litosísmica C puede observarse en el perfil sismobioestratigráfico $\mathrm{n}^{\circ} 1$ (fig. 4.4). Así mismo afirman que la erosión producida por este cañón en el Guadalquivir, daría lugar al depósito de las "arenas del Guadiana” en el golfo de Cádiz. En cuanto a este último punto, nuestros análisis micropaleontológicos muestran que los principales cuerpos turbidíticos del golfo de Cádiz son anteriores a la edad de este reflector. De acuerdo con nuestros datos el cañón submarino descrito por Martínez del Olmo et al. (1996) es de edad Messiniense superior y podría haber erosionado el talud sur en la cabecera de la cuenca. No obstante, dicho cañón parece estar ligado a los últimos depósitos turbidíticos del bajo Guadalquivir y golfo de Cádiz en el mismo contexto regresivo de la unidad C, por lo que esta erosión podría suponer el último pulso de elevación tectónica messiniense antes de la inundación pliocena. Culminada la erosión cesa la compresión tectónica, y finalmente en el límite Messiniense-Plioceno se produce una subsidencia generalizada del margen sur que fosilizará la discontinuidad intramessiniense y el propio límite Mio-Plioceno. En el capítulo referido al relleno sedimentario se abordará ampliamente este delicado momento geológico.

La datación de alta resolución de la superficie de discontinuidad entre las unidades C y D en el golfo de Cádiz, apunta a que la base de la unidad D constituye el límite Mio-Plioceno (capítulo 5). Igualmente, en el Guadalquivir, donde se ha realizado un preciso análisis cicloestratigráfico sobre los sondeos Casanieves-1 y Villamanrique-1 (capítulo 5), los resultados indican una edad de 5.3 Ma para dicho reflector sísmico. 
La unidad D, presenta los mayores espesores a lo largo de la zona axial de la cuenca al pie del paleoescarpe y talud NW, tanto en el Guadalquivir como en el golfo de Cádiz. Los espesores disminuyen progresivamente hacia los taludes norte y sur. El aporte de sedimento se realizó fundamentalmente en dirección axial NE-SW, y con un desplazamiento lateral de los depocentros hacia el SE como puede apreciarse en los perfiles sismobioestratigráficos (fig. 4.4). Los mayores espesores se encuentran en el bajo Guadalquivir donde alcanza unos $800 \mathrm{~m}$ de potencia en los sondeos Asperillo-1, Marismas A-1, Marismas-4, etc y en el golfo de Cádiz, donde alcanza los $1000 \mathrm{~m}$ de potencia en los sondeos de la zona centro y sur del área de estudio.

Podemos observar en el perfil sismobioestratigráfico $\mathrm{n}^{\circ} 11$ como la desaparición del grupo G. margaritae se localiza hacia la línea de costa actual con lo que se deduce que durante el Plioceno inferior se produjo una rápida progradación de la cabecera de la cuenca (perfil 11 de la fig. 4.4) y del talud norte (perfiles 1 a 5 de la fig. 4.4) que supuso prácticamente el relleno definitivo de la cuenca del Guadalquivir antes del Plioceno superior.

\section{Unidad E (Plio-Cuaternario)}

El reflector basal que delimita esta unidad es una discontinuidad que se observa en la mayor parte de los perfiles del golfo de Cádiz (ver perfil sismobioestratigráfico $\mathrm{n}^{\circ}$ 10 de la fig. 4.4). Estos depósitos están compuestos de varias unidades que muestran significativos cambios de facies y de potencia. La distribución de facies en el talud está controlada por la estructura del margen, las fuentes de sedimento y las fluctuaciones del nivel del mar (Rodero et al., 1999) e influenciado por la corriente profunda mediterránea, que desarrolla grandes cuerpos sedimentarios y superficies erosivas (Nelson et al., 1993, 1999). Esta unidad aparece exclusivamente en el área del golfo de Cádiz (fig. 4.4) y es equivalente a la secuencia Odiel, descrita por Riaza y Martínez del Olmo (1996) coincidiendo así mismo con la unidad cuaternaria identificada por Malod y Mougenot (1979) en el sector central del golfo de Cádiz y por la unidad litosísmica P/Q descrita por Maldonado et al. (1999) (fig. 4.5). La unidad litosísmica E contiene sedimentos fundamentalmente cuaternarios, siendo en cualquier caso posterior a la biozona de $G$. puncticulata. No se ha desarrollado en ella el análisis bioestratigráfico. 



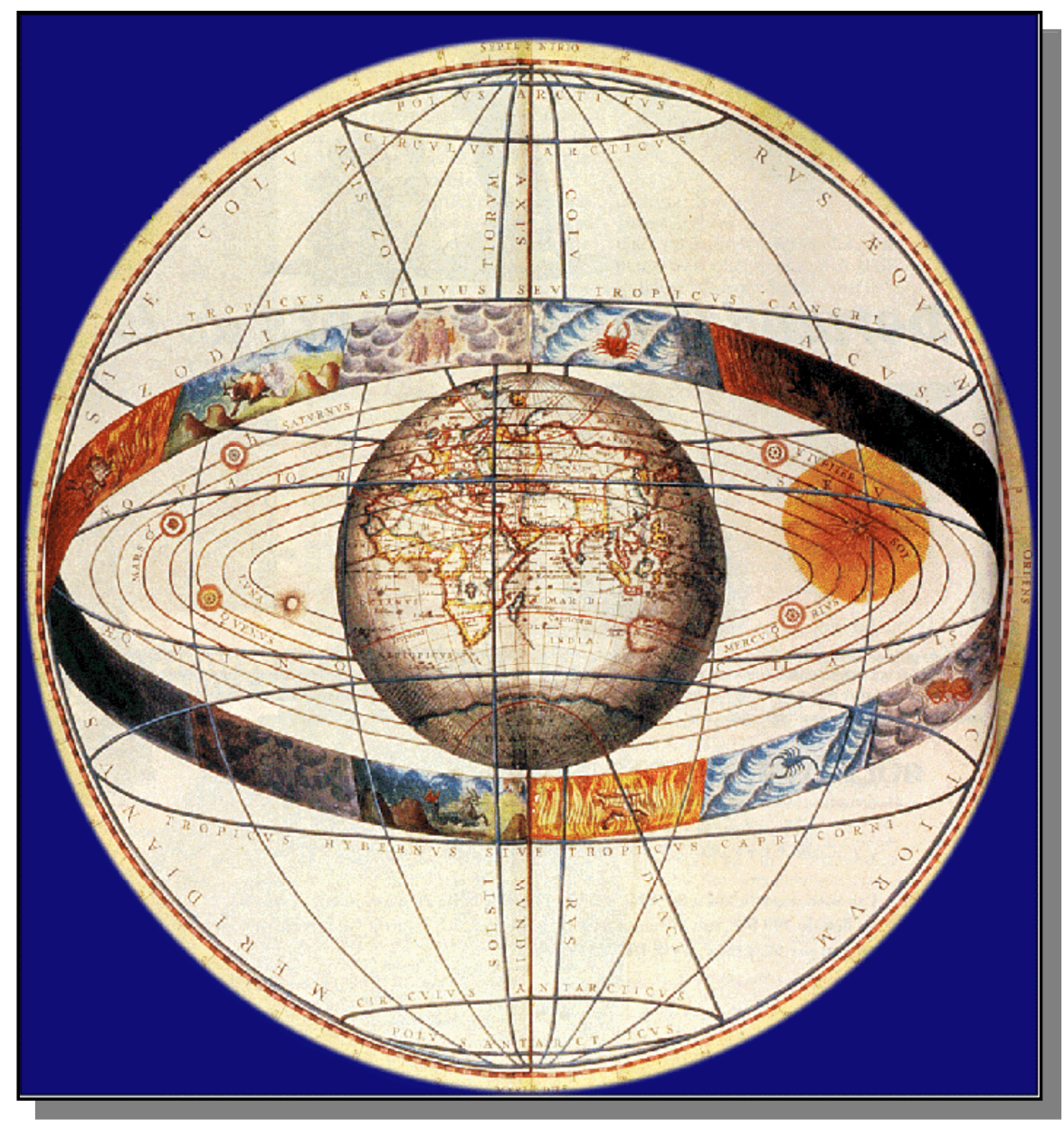

\section{CICLOESTRATIGRAFÍA Y CORRELACIÓN REGIONAL}


Página anterior: Interpretación cosmológica de Tolomeo con la Tierra inmóvil en el centro del universo. 
El término "cicloestratigrafía" fue probablemente utilizado por primera vez en un congreso organizado por A.G. Fischer e I. Premoli-Silva en Perugia (Italia) en 1988. El nombre expresa la intención de esta rama de la geología, de utilizar los ciclos sedimentarios en la construcción o perfeccionamiento de los trabajos estratigráficos. Esta Tesis, se centrará en los denominados ciclos de Milankovitch, un término que se utiliza habitualmente para referirse a cualquier ciclo relacionado con los cambios orbitales que afectan a nuestro planeta. Comenzaremos no obstante por la ciclicidad en el registro geológico, para centrarnos posteriormente en la causa de los ciclos climáticos y su relación con los cambios orbitales. Finalmente se planteará la relación de los ciclos astronómicos con los ciclos sedimentarios observados en los sondeos estudiados.

\subsection{INTRODUCCIÓN A LA CICLICIDAD EN EL REGISTRO GEOLÓGICO}

Tres factores fundamentales controlan el depósito en una cuenca sedimentaria:

- El volumen de aportes.

- La subsidencia de la cuenca y los levantamientos tectónicos que afectan a la cuenca y a áreas adyacentes.

-Los cambios de nivel del mar (eustatismo).

Estos factores están regulados por dos elementos principales: el clima y la tectónica. Como la tectónica y el clima cambian con el tiempo, se reflejan en la estratigrafía mediante sucesivos cambios verticales de facies, con gran frecuencia repetitivos (cíclicos). Estos cambios quedan reflejados en una sección estratigráfica por medio de ciclos sedimentarios de diferente naturaleza y rango (Vera, 1994).

En la figura 5.1 se recopilan los posibles ciclos reconocibles en el registro geológico ordenados de acuerdo con su rango. Los ciclos de rango mayor (1, 2 y 3 de la figura 5.1) corresponden a los denominados ciclos eustáticos (Vail et al., 1977; Haq et al., 1987), en gran parte inducidos por causas tectónicas, con duraciones de 90-100, 30-40 y 9$10 \mathrm{Ma}$, respectivamente. Los de cuarto rango (4 de la figura 5.1) tienen una duración de 1$3 \mathrm{Ma}$ y en su origen pueden combinarse tanto cambios climáticos como eustáticos o tectónicos. Los tres siguientes (5, 6 y 7 de la figura 5.1) corresponderían a los ciclos climáticos de Milankovitch. Finalmente se incluyen las varvas (ciclos anuales) con el fin de indicar las escalas relativas. 


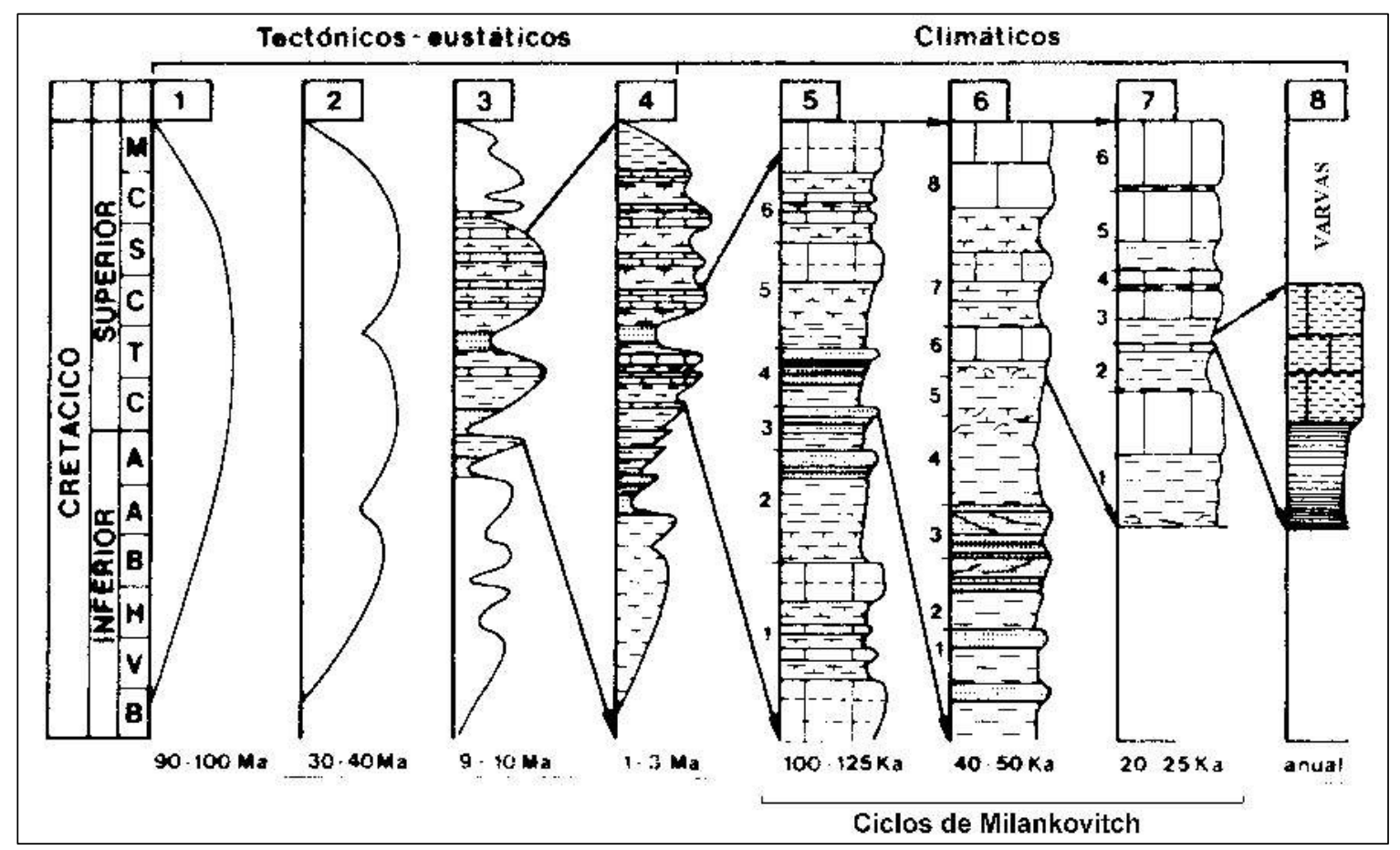

Figura 5.1. Tipos y rangos de ciclos detectados en los materiales pelágicos, modificado de Kauffman (1986). 1, 2 y 3: ciclos de primer, segundo y tercer orden de la clasificación de Vail et al. (1977), 4: ciclos eustáticos y/o climáticos, 5, 6 y 7: ciclos climáticos de Milankovitch en sus tres rangos, 8: ciclos anuales (varvas).

\subsubsection{Ciclos climáticos}

A lo largo del último millón de años se han desarrollado aproximadamente una decena de glaciaciones. Aunque se han propuesto numerosas teorías para explicar los períodos glaciales, las pruebas convergen mayoritariamente en favor de una de ellas, las causaron pequeñas variaciones en la inclinación del eje de la Tierra y en la geometría de su órbita alrededor del Sol. A esta hipótesis se la conoce por "teoría de Milankovitch", en honor de Milutin Milankovitch, astrónomo yugoslavo que la defendió en la primera mitad del siglo XX. Esta teoría afirma que las variaciones orbitales modifican el clima alterando la cantidad de energía solar que recibe la Tierra a distinta latitud y en diferentes estaciones, y demuestra la periodicidad de las variaciones orbitales.

Estos cambios climáticos cíclicos se reflejan en la sedimentación marina mediante cambios rítmicos (fig. 5.2A). En las zonas próximas al continente estos cambios rítmicos pueden basarse en materiales terrígenos de diferente tamaño, mientras que en medios pelágicos los ritmos son de calizas y margas. En la figura 5.2B, se incluye el modelo que propone Kauffman (1986) en el que considera una ciclicidad de 100.000-125.000 años 
marcándose los cambios en el carbono orgánico, los isótopos estables de oxígeno, diversidad orgánica y abundancia de organismos. Estos ritmos en materiales pelágicos antiguos presentan un espesor decimétrico o métrico.

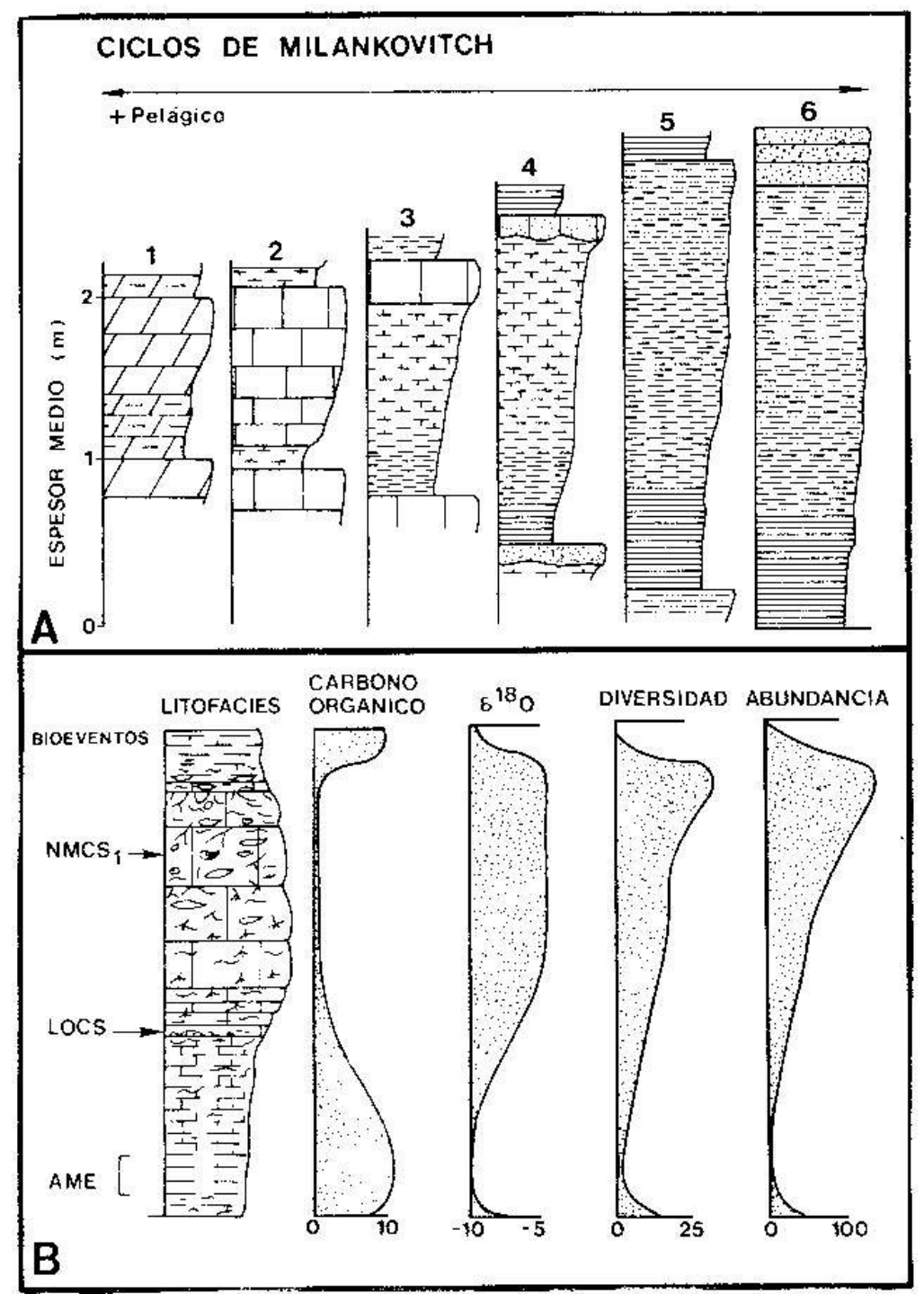

Figura 5.2. Ciclos climáticos de Milankovitch según Kauffman (1986). A.-Tipos de ciclos desde las partes más externas del margen hasta los dominios pelágicos, con indicación del orden de magnitud. B.-Ciclos de 100.000-125.000 años en los que se marcan los cambios en el carbono orgánico, los isótopos estables de oxígeno, diversidad orgánica y abundancia de organismos. $A M E$ evento anóxico de mortandad de masa, LOCS evento de colonización que marca el final de las condiciones anóxicas y NMCS-1 evento de máxima colonización del fondo marino.

Emiliani en 1955, estudiando las medidas de los isótopos de oxígeno obtenidos en materiales pelágicos del Pleistoceno de sondeos del DSDP, reconoció por primera vez estos ciclos. Trabajos posteriores, también aplicados al Cuaternario (Emiliani, 1972, 1978; Emiliani y Shackleton, 1974; Ruddiman et al., 1986 entre otros) constatan estos ciclos en 
materiales de cualquier latitud estableciendo escalas de correlación de alta precisión con los mismos. En sondeos efectuados en los hielos de la Antártida, se han reconocido así mismo ciclos climáticos de igual magnitud. Los cálculos numéricos de la duración de estos ciclos y el estudio de sus frecuencias han permitido observar un ajuste coherente con los ciclos de Milankovitch (Hays et al., 1976; Imbrie, 1985). Más tarde se han aplicado estos conceptos a materiales antiguos reconociéndose los ciclos en sedimentos pelágicos de diferentes edades y contextos (Schwarzacher y Fisher, 1982; Boer, 1982; Einsele, 1982; Cotillon y Río, 1983; Barron et al., 1985; Arthur et al., 1986; entre otros).

También han sido reconocidos ciclos de orden mayor de 100.000 años. Los ciclos debidos a la excentricidad son además de los de 100.000 años, los correspondiente a 400.000 años, mientras que las ciclicidades de orden mayor podrían tener un origen tectónico (Imbrie, 1985). El origen de estos ciclos de mayor escala se atribuyen también a factores climáticos inducidos por causas astronómicas, si bien no se descarta una relación con factores eustáticos y/o tectónicos; en cualquier caso los ciclos de la escala del millón de años pueden tener un doble origen, sin que se pueda concretar con claridad cual es el dominante (fig. 5.1).

\subsubsection{Causas de la ciclicidad. Factor orbital en los cambios climáticos}

Al margen de la tectónica global, que influye como factor alocíclico en la creación de ciclos de orden mayor o tectono-eustático $\left(1^{\mathrm{o}}, 2^{\mathrm{o}}\right.$ y $3^{\mathrm{er}}$ orden de la figura 5.1), el clima es el factor que regula la formación de los ciclos de rango menor $\left(4^{\circ}, 5^{\circ}\right.$ y $6^{\circ}$ orden de la fig. 5.1). Los cambios climáticos globales que se producen como consecuencia de modificaciones orbitales producen ciclos en la banda de frecuencias de Milankovitch (correspondientes a los ciclos de $4^{\circ}$ y $5^{\circ}$ orden de la fig. 5.1) mientras que los de menor entidad corresponderían a los ciclos anuales, varvas $\left(6^{\circ}\right.$ orden en la fig. 5.1). Nos centraremos en la variabilidad climática determinada por los cambios en la órbita de la Tierra con respecto al Sol, en los denominados ciclos de Milankovitch.

A mediados del siglo pasado, el matemático francés Joseph A. Adhémar sugirió que las variaciones de intensidad de las estaciones provocadas por factores astronómicos podrían desencadenar glaciaciones periódicamente. El astrónomo Milutin Milankovitch refinó y formalizó la hipótesis en los decenios de 1920 y 1930. Milankovitch sugirió que las fluctuaciones de los tres factores orbitales condicionaban el clima terrestre (fig. 5.3). El mecanismo astronómico que él proponía constaba de tres componentes: dos alteran la intensidad de las estaciones y el tercero afecta a la interacción entre aquellas. 
A

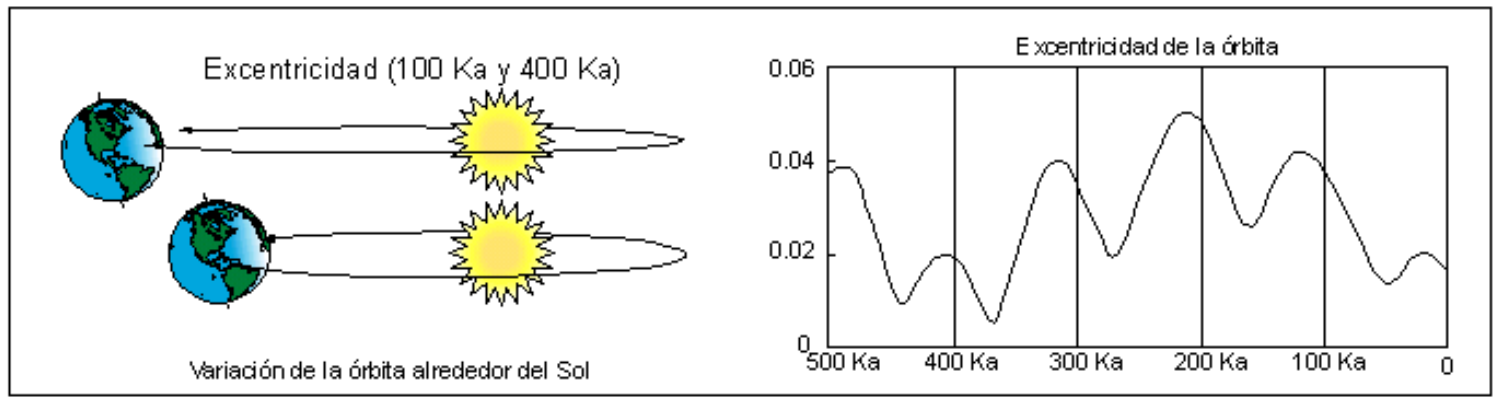

B

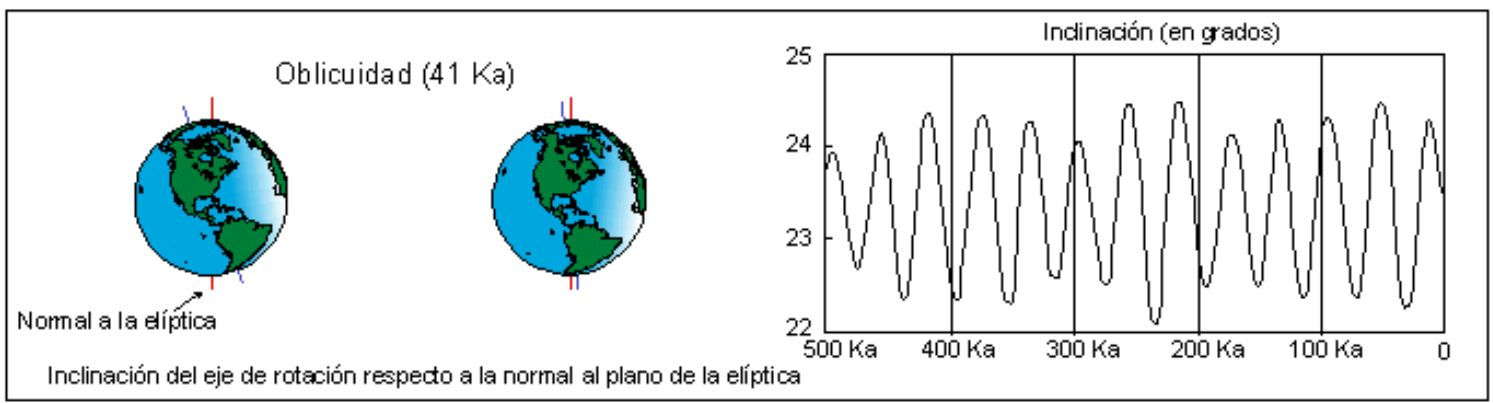

C

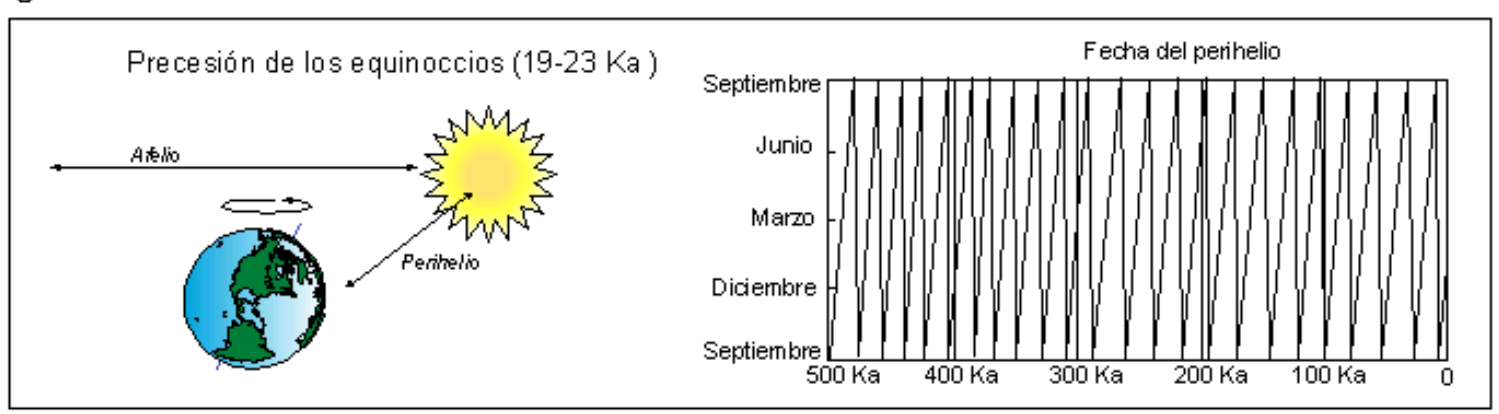

D

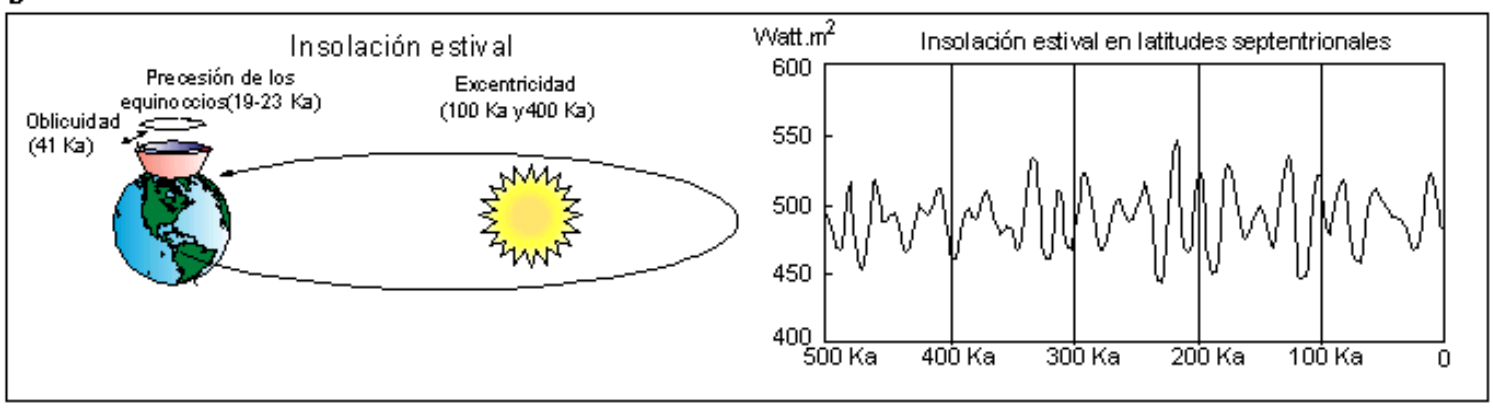

Figura 5.3. Teoria de Milankovitch: en los apartados A, B y C se presentan los tres parámetros orbitales que influyen en la energía solar que llega a la Tierra. En el apartado D, la interacción de todos ellos resulta en la radiación solar que alcanza el planeta. A la izquierda configuración astronómica, a la derecha registro de los últimos $500 \mathrm{Ka}$. Se incluye entre paréntesis la periodicidad general con que oscila cada uno de ellos. Las variaciones de excentricidad, oblicuidad y precesión se calcularon por el método desarrollado por André Berger. A) Excentricidad de la orbita terrestre. Las etapas de máxima excentricidad están separadas entre sí por unos 100.000 y 400.000 años.

B) Oblicuidad (inclinación) del eje respecto a la normal a la eliptica. Los ciclos de inclinación-oblicuidad tienen periodos de unos 41.000 .

C) Precesión de los equinoccios (fecha del perihelio). La precesión determina si el verano en un hemisferio dado cae en un punto de la órbita cercano o lejano al Sol. La precesión consta de dos ciclos. 19.000 y 23.000 años. D) Insolación estival en latitudes septentrionales en los últimos $500 \mathrm{Ka}$ (Watt.m2). 
La interferencia gravitatoria entre la Tierra y los distintos planetas del sistema solar provocan cambios periódicos en la configuración de la geometría Tierra-Sol que a su vez modifican la insolación recibida por la Tierra. Estos cambios periódicos en la configuración Tierra-Sol afectan fundamentalmente a tres parámetros.

- En primer lugar la excentricidad orbital mide la desviación de la órbita terrestre respecto a una circunferencia perfecta (fig. 5.3A). En el momento actual, la excentricidad de la órbita terrestre es de 0,017. Este parámetro varia a lo largo del tiempo entre 0,005 y 0,06 con dos periodicidades medias, una de 100.000 y otra de 400.000 años. La distancia de la Tierra al Sol varía con la época del año. Actualmente en enero, la Tierra está en la posición más próxima al Sol (perihelio) y, en julio, en la más lejana (afelio). De acuerdo con ello, la radiación solar global debida al factor distancia es ligeramente mayor en enero que en julio. Este efecto proporciona al hemisferio norte inviernos más templados y veranos más frescos que los que tendría si la órbita fuese circular.

- La segunda magnitud es la oblicuidad o ángulo de inclinación del eje de la Tierra con respecto al plano de su órbita (fig. 5.3B); la oblicuidad es hoy de 23,5 grados. La inclinación de este eje varia con una periodicidad media de 41.000 años entre 22,1 y 24,5 grados lo que determina una menor o mayor estacionalidad respectivamente.

- En tercer lugar, al girar la Tierra sobre sí misma, la dirección a la cual apunta su eje sufre una lenta precesión (cabeceo del eje de la tierra), cuyo polo norte va girando a lo largo del tiempo describiendo un circulo en el firmamento respecto a la referencia fija de las estrellas lejanas (fig. 5.3C). El eje terrestre apunta hoy en día a la Estrella Polar. Las variaciones de precesión originan una rotación de los puntos cardinales en la órbita terrestre con una periodicidad entre 19 y $23 \mathrm{Ka}$ determinando el momento del año en el que se alcanza el perihelio y el afelio (fig. $5.3 \mathrm{C})$.

Las variaciones de excentricidad modulan los cambios de precesión induciendo unas veces oscilaciones de gran amplitud en los ciclos de precesión (cuando la excentricidad es alta) y otras veces oscilaciones de baja amplitud (cuando la excentricidad es baja). La interacción de todas las frecuencias resulta en la radiación solar recibida (insolación). Esto es, la variación de los parámetros orbitales de la Tierra produce 
las correspondientes variaciones en la cantidad de radiación solar recibida a una latitud dada y en determinada época del año (fig. 5.3D).

Estas perturbaciones en la órbita de la Tierra y en el eje de rotación son climáticamente relevantes ya que afectan a la distribución estacional y latitudinal de la insolación solar que llega a la Tierra y son responsables por ejemplo de las glaciaciones del Pleistoceno. Pero además, afectan a los sistemas climáticos de bajas latitudes, como por ejemplo a los monzones (Hilgen et al., 1997).

La influencia de estos ciclos orbitales en la radiación solar incidente (insolation, INcident SOLar radiATION) recibida a diferentes latitudes y tiempo geológico, fue calculada por Berger y Loutre (1991) y por Laskar (1993) (fig. 5.4).

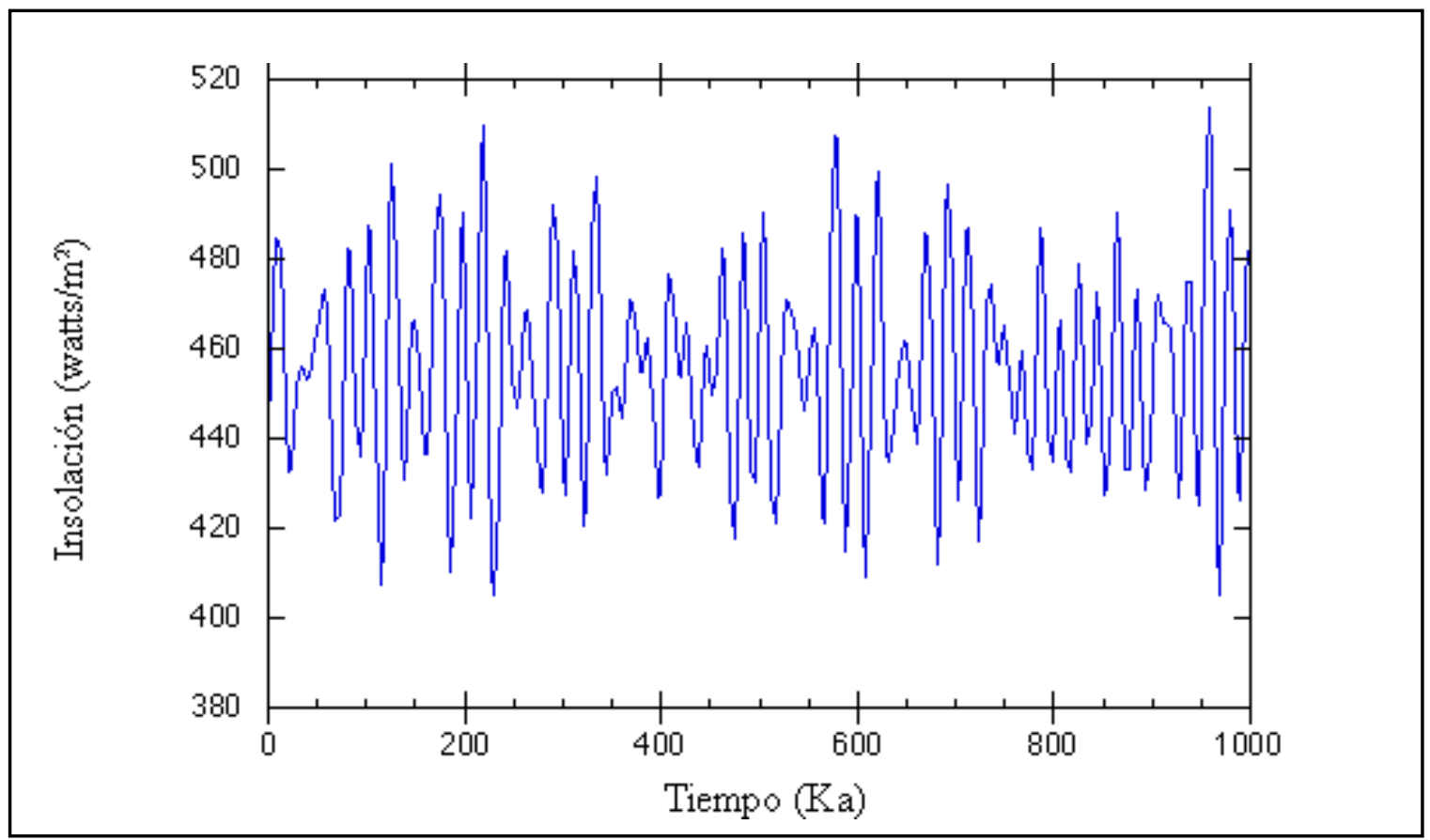

Figura 5.4. Solución astronómica de Berger para una latitud de $65^{\circ} \mathrm{N}$ (imagen de la Scott Rutherford University of Rhode Island).

Las variaciones de los parámetros orbitales de la Tierra producen fundamentalmente variaciones en la intensidad del ciclo estacional. El aumento de la inclinación del eje terrestre (oblicuidad) refuerza los rigores del ciclo: los inviernos se hacen más fríos y los veranos más cálidos en ambos hemisferios. El efecto de la precesión sobre la insolación es menos directo; ahora bien, junto con la rotación de la eclíptica alrededor del Sol, determina la fecha del perihelio. En general, una variación en la fecha del perihelio aumenta la intensidad de las estaciones en un hemisferio y las disminuye en 
el otro. El perihelio sucede hoy en día el 3 de enero; así pues, el invierno del hemisferio norte es ligeramente más templado de lo que podría ser, y el verano del hemisferio sur es algo más fresco. Dentro de unos 12.000 años, cuando el eje de la Tierra deje de apuntar hacia la estrella Polar para mirar hacia Vega, la situación se invertirá.

La precesión rige la interacción entre los efectos de la inclinación y la excentricidad, determinando si el verano en un hemisferio dado cae en un punto cercano o lejano de la órbita. Dicho de otra forma, si la inclinación y la distancia se oponen mutuamente o colaboran entre si para reforzar las estaciones. Cuando estos dos factores que influyen en la estacionalidad se complementan entre si en un hemisferio, se contraponen en el hemisferio opuesto.

La excentricidad de la órbita terrestre ejerce dos efectos bien definidos sobre la insolación. Cuanto mayor es la excentricidad de la órbita, tanto mayor es la diferencia entre la máxima y la mínima distancia de la Tierra al Sol y, con ello, tanto mayor es la amplitud del efecto de precesión. La variación anual de la insolación debida exclusivamente a la excentricidad es un efecto pequeño; debido a esta variación la insolación global ha cambiado un 0,3\% a lo largo del último millón de años. Y según la mayoría de los cálculos, una variación del 0,3\% en la insolación global modificaría en solo unas décimas de grado la temperatura media.

En resumen, la excentricidad origina pequeños cambios en la insolación global anual, mientras que la inclinación y precesión alteran la distribución de la insolación con la estación del año y la latitud, pero no la insolación total. Milankovitch mantenía que la fuerza que impulsó las épocas glaciares no era la insolación total, sino la insolación en las altas latitudes del hemisferio norte durante el verano, que varía hasta en un $20 \%$ (mucho mayor que la oscilación de la insolación total).

Weltje y de Boer (1993) estudiando depósitos turbidíticos influenciados por aportes continentales, llegaron a la conclusión de que la precesión induce variaciones en la sedimentación a bajas latitudes. Broecker (1984), Manabe y Broccoli (1984) presentan algunos ejemplos en los que se trata ampliamente la relación de la ciclicidad de Milankovitch con los cambios climáticos. Por otro lado Beaufort y Aubry (1990) muestran un ejemplo sobre el control orbital de la ciclicidad mediante el estudio de nanofósiles calcáreos. Como contrapunto, debemos recordar que existen limitaciones en la extrapolación de la teoría orbital más allá de los primeros 10 Ma (Cachäo, 1992, 1993) al existir factores condicionantes como el rigor de las constantes utilizadas, las condiciones iniciales del sistema, o el alejamiento gradual de la Luna en relación a nuestro planeta (que tiene implicaciones directas en el cálculo de la precesión, Berger 1984). Los análisis espectrales del registro isotópico de oxígeno para el primer período de la figura 5.5 (hasta 
$0.65 \mathrm{Ma}$ ) revelan el dominio de periodicidades de aproximadamente 40.000 y 23.000 años, mientras que en los realizados para el último período (de $0.65 \mathrm{Ma}$ a la actualidad) domina una periodicidad de 100.000 años coincidiendo con las glaciaciones del hemisferio norte.

No obstante, la prueba decisiva a favor de la teoría orbital procede del examen de las relaciones isotópicas de los sedimentos oceánicos. En los registros de la figura 5.5, durante el período de tiempo que va desde los 2,5 Ma a los 0,65 $\mathrm{Ma}$, el $\delta^{18} \mathrm{O}$ para foraminíferos bentónicos fluctúa con una amplitud, que es la mitad de la que presentan los ciclos de los últimos 650.000 años (Broecker, 1992).

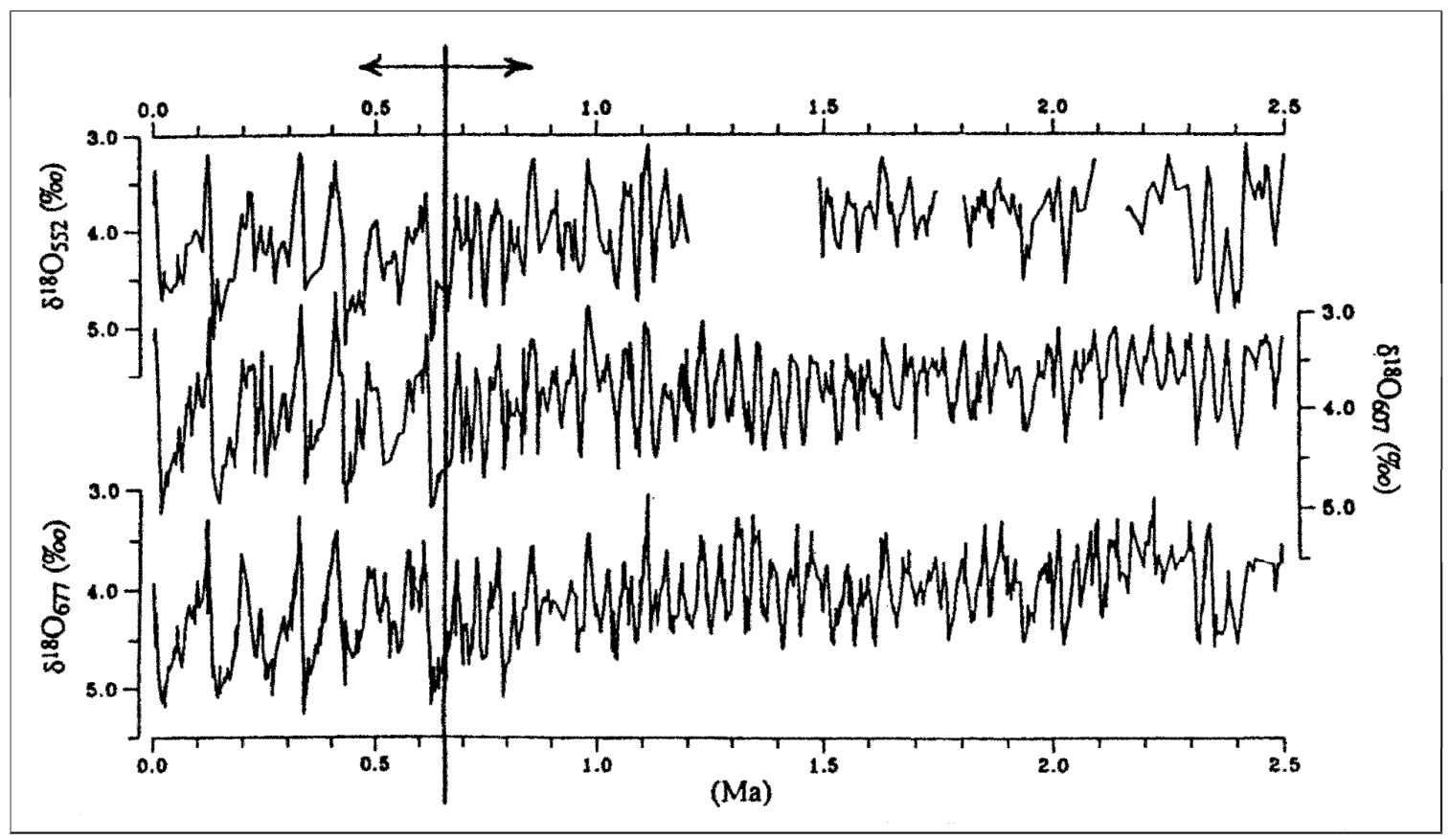

Figura 5.5. Registros isotópicos de oxígeno para foraminíferos bentónicos de tres sondeos profundos. La línea vertical a 650.000 años marca la transición desde los ciclos de alta frecuencia-baja amplitud a los de baja frecuencia-gran amplitud (Broecker, 1992).

En la figura 5.6 puede observarse la varianza espectral para el isótopo de oxígeno de los últimos 0.8 Ma (Imbrie, 1985). Destaca la ciclicidad con rangos de frecuencias de la banda de Milankovitch. 


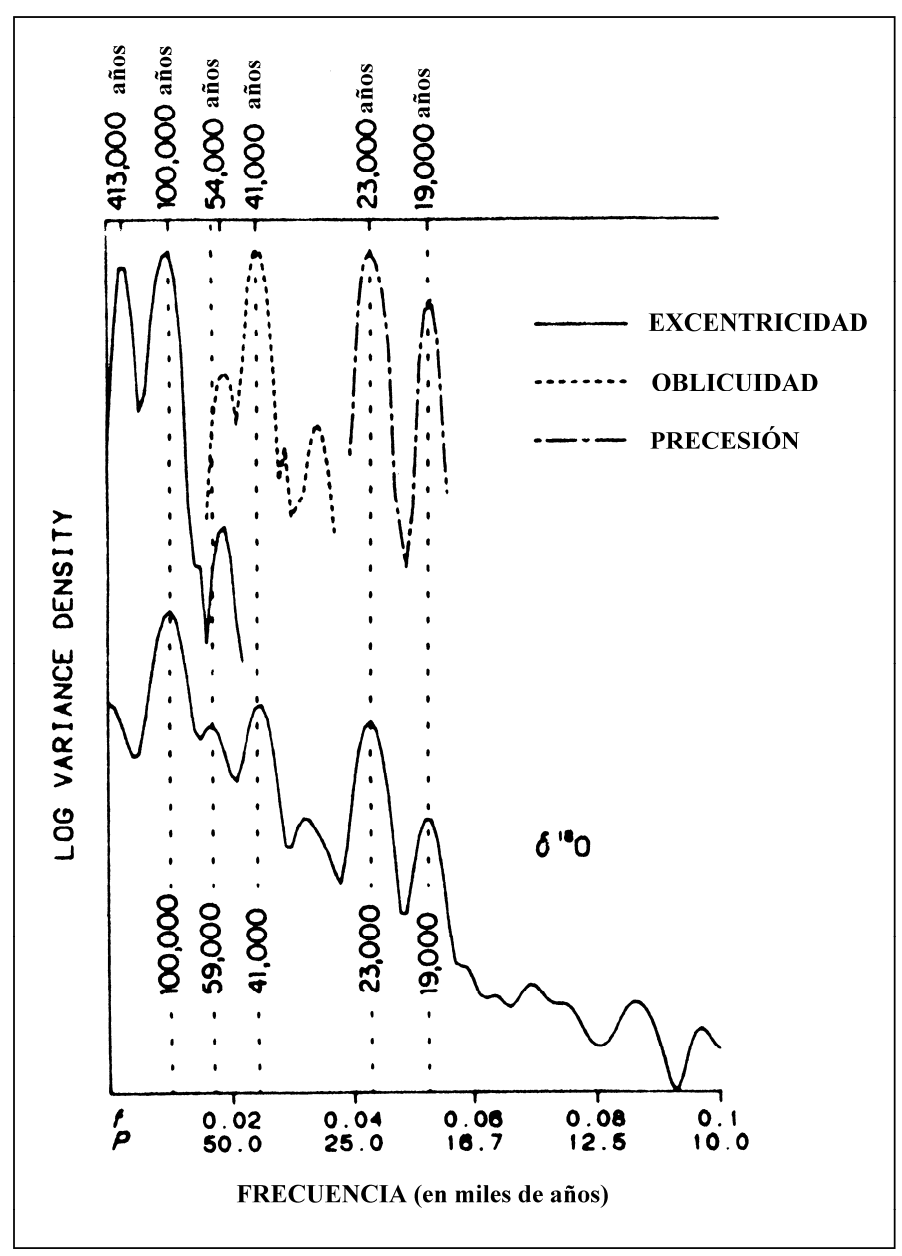

Figura 5.6. Varianza espectral para el isótopo de oxígeno marino de los últimos 800.000 años (curva de abajo) comparada con el espectro de los parámetros orbitales, excentricidad, oblicuidad y precesión (Imbrie, 1985).

\subsubsection{Registro geológico de los ciclos climáticos orbitales. El ejemplo de los sapropeles del Mediterráneo.}

Los sedimentos marinos dan a conocer gran cantidad de información sobre los cambios climáticos, por tanto recuperar secuencias de sedimento de áreas sensibles a estos cambios es una línea de investigación de primer orden en los estudios paleoclimáticos actuales.

Como el Mediterráneo es un mar semicerrado, su agua no se mezcla demasiado con el agua del océano abierto. La composición de los sedimentos del Mediterráneo es muy sensible a los cambios climáticos y las señales ambientales se preservan en ellos con gran detalle. Uno de los resultados más importantes ha sido el descubrimiento de capas oscuras, laminadas y extraordinariamente ricas en materia orgánica (más del 30\% de su 
composición) y entre un 0,8 y 2,5 \% de carbono orgánico; estas capas características se conocen con el nombre de sapropeles (fig. 5.7).

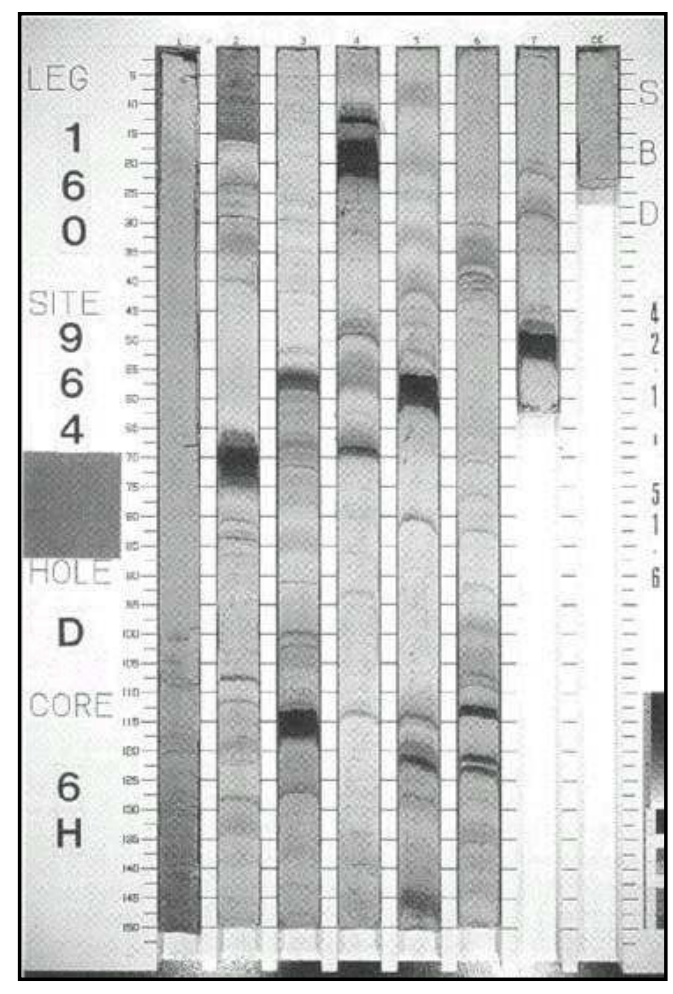

Figura 5.7. Sapropeles recuperados en un testigo del Mediterráneo oriental. Earth in Space (1996, American Geophysical Union) Vol. 8, No. 9, May 1996, pp. 10-11. En la primavera de 1995, se recuperaron más de $\mathbf{7 0 0 0}$ metros de sedimento en el Mediterráneo por el Ocean Drilling Program $(O D P)$ y se atravesaron importantes series de sapropeles alcanzandose los $5 \mathrm{Ma}$.

Los sapropeles son sedimentos no consolidados compuestos de restos algales, fango y esporas. Inicialmente se localizaron en el Mediterráneo oriental, en el sur de Italia, Sicilia, y Creta, y más recientemente en el lado occidental del Mediterráneo. Los sapropeles se han depositado periódicamente desde hace más de 10 Ma y se piensa que reflejan los cambios climáticos y de producción biológica del Mediterráneo. Diferentes autores correlacionan la formación de los sapropeles con los periodos de mayor insolación estival en el hemisferio norte (Rossignol-Strick, et al., 1983; Hilgen 1991). Una elevada insolación provocaba mayor intensidad de los monzones estivales a lo largo de todo Asia y África, incrementando el transporte de humedad sobre las cuencas hidrográficas que vierten al Mediterráneo. Cuando desciende la relación de evaporación / precipitación en el Mediterráneo oriental, la estructura de la columna de agua se estabiliza, y deja de formarse agua profunda (fig. 2.10). Los nutrientes disueltos, que normalmente se acumulan en las aguas profundas, permanecen en la zona eufótica 
estimulando la productividad en aguas superficiales. La paralización de la formación de agua profunda frena el aporte de oxigeno al fondo lo que favorece la acumulación de materia orgánica en el sedimento y por tanto la formación de los sapropeles.

Las etapas con fuerte insolación de verano en el hemisferio norte ocasionan monzones Africanos fuertes, que se correlacionan con un alto volumen de avenidas del río Nilo (Brumsack y Wehausen, 1997; Wehausen y Brumsack, 1998; 1999). El sapropel más reciente se formó hace 8500 años $B P$ con la insolación próxima a un máximo fuerte, en un momento bien documentado, con alto volumen de descargas en el Nilo (RossignolStrick, 1983).

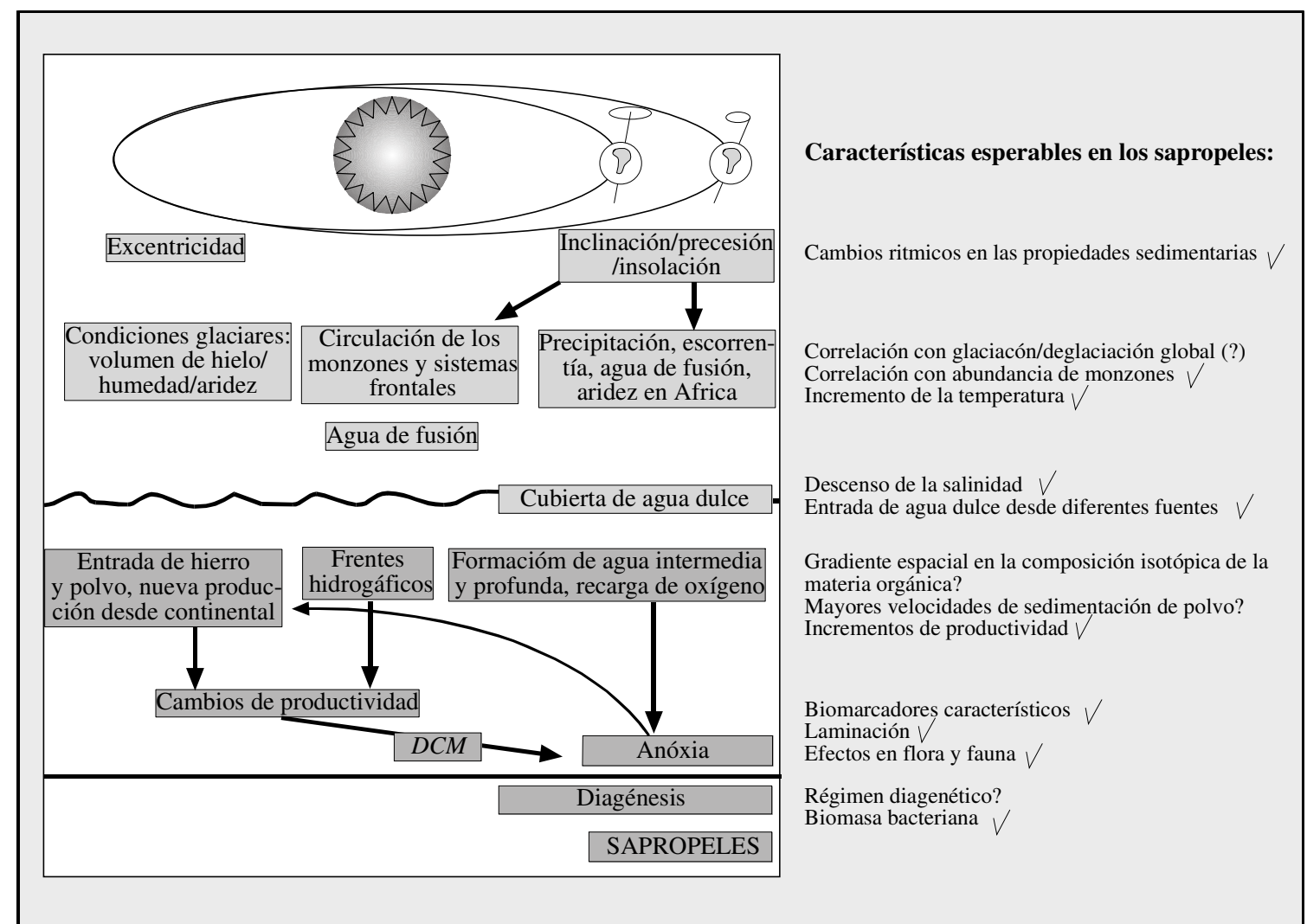

Figura 5.8. Diagrama de flujo esquemático de algunos de los posibles procesos que conducen a la formación de sapropeles y señales que deberían registrarse en los sedimentos para que pueda ser corroborada la hipótesis. Las marcas detrás de las señales esperadas indican aquellas que ya han sido verificadas. DCM (Deep clorophyll Maxima) Máximo profundo de clorofila. Modificado de Emeis y Sakamoto, 1988.

La figura 5.8 representa un esquema con los posibles procesos que conducen a la formación de los sapropeles, relacionando los cambios de insolación y la evolución 
climática global con los sapropeles. Es de esperar que el desarrollo de las diferentes disciplinas aporte luz a las cuestiones más controvertidas como el papel del factor productividad / preservación en la anóxia como un agente en la formación de sapropeles así como el origen del agua dulce durante la formación de los mismos (Emeis y Sakamoto, 1988; Nijenhuis et al. 1996; Castradori, 1998; Howell et al., 1998; Schenau, et al., 1999).

\section{Otros ejemplos}

Existen en la bibliografía numerosos ejemplos de series donde se han registrado ciclos sedimentarios calibrados de forma coherente con los ciclos astronómicos.

Schwarzacher (1993) presenta numerosos ejemplos de ciclicidad astronómica en series carbonatadas desde el Carbonífero al Cretácico. Eicher y Diner (1991) ó Arthur y Dean (1991) exponen algunos ejemplos de ciclicidad orbital reconocida en series mesozoicas. Por otro lado Benson et al. (1995) se centran en la sección messiniense de Bou Regreg en Ain el Beida cerca de Rabat (Marruecos). Krijgsman et al. (1999a), muestran la ciclicidad astronómica que refleja una unidad evaporítica de los Apeninos italianos. Sierro et al. (1999b) observan por su parte fluctuaciones cíclicas (relacionadas con la precesión) en las asociaciones de foraminíferos de los depósitos pre-evaporíticos messinienses en la cuenca de Sorbas. Los análisis espectrales realizados por Kroon et al. (1998) en el Site 967 (Mediterráneo oriental) muestran que las fluctuaciones en el registro de $\delta^{18} \mathrm{O}$ estaban influenciadas predominantemente por la oblicuidad y la precesión orbital desde 3.2 a 1 Ma. Por su parte Aziz et al. (en prensa) presentan una serie continental en la cuenca de Calatayud (NE, de España) compuesta por ciclos de $23 \mathrm{Ka}$, agrupados en torno a ciclos de menor frecuencia de $400 \mathrm{Ka}$ registrados entre 10.7 y $12.8 \mathrm{Ma}$, relacionados con periodos de expansión y contracción de un lago.

\subsubsection{Sapropeles del Mediterráneo y la escala astronómica de tiempo}

La calibración de las secuencias sapropelíticas cíclicas del Mediterráneo con las soluciones astronómicas, ha sido utilizada para construir la escala astronómica de tiempo del Mioceno y el Plioceno. Esta nueva astrocronología está basada en estudios cicloestratigráficos, magnetoestratigráficos y bioestratigráficos de varias secciones del Mediterráneo oriental y occidental que muestran alternancias cíclicas de margas blancas homogéneas y capas laminadas ricas en materia orgánica (sapropeles) o en su defecto capas de margas grises. La escala astronómica de tiempo está basada en la correlación de 
patrones característicos en los ciclos sedimentarios con las curvas de precesión e insolación derivadas de la solución astronómica de Laskar (1990).

Los análisis detallados de la polaridad magnética en las secuencias cíclicas calibradas con las curvas astronómicas, han permitido construir la escala astronómica de tiempo de polaridad magnética (APTS, Astronomical Polarity Time Scale).

Los ciclos sedimentarios reflejan las oscilaciones climáticas, que como hemos visto están en último término controladas por los ciclos orbitales terrestres. Por esta razón, los ciclos sedimentarios pueden ser utilizados para reconstruir escalas de tiempo astronómicas. Utilizando este método, se han establecido las escalas astronómicas de tiempo para los últimos 12 millones de años. Hace una década, el calibrado de secuencias cicloestratigráficas pliocenas del Mediterráneo con la curva de radiación solar de verano del hemisferio norte, permitió construir por primera vez una escala astronómica de tiempo que facilita las correlaciones geológicas a nivel global (Hilgen, 1991a; Hilgen, 1991b).

La escala de tiempo astronómica es más precisa, fiable y tiene mayor resolución que las escalas de tiempo geológico convencionales. Las investigaciones actuales están encaminadas a extender la escala de tiempo astronómica a periodos de tiempo más antiguos y a establecer escalas de tiempo similares para el registro continental (Hilgen et al., 1997, 1999).

Las oscilaciones climáticas de carácter orbital son reconocidas en los registros sedimentarios a través de los cambios en las propiedades sedimentarias, comunidades fósiles, y características químicas. Los astrónomos han formulado soluciones matemáticas que incluyen los sistemas solar-planetario y el Tierra-Luna, mediante las que calculan las variaciones en la precesión, en la oblicuidad y en la excentricidad de la Tierra. El calibrado astronómico del registro sedimentario, va a resultar en escalas de tiempo que son independientes de la datación de isótopos radiactivos y muestran una equivalencia directa con las curvas astronómicas (Hilgen et al., 1997). En las últimas décadas se ha conseguido una resolución sin precedentes para los últimos 15 Ma.

Durante la última década, la bioestratigrafía de alta resolución, la magnetoestratigrafía y los estudios cicloestratigráficos de secciones marinas en el Mediterráneo central u oriental han proporcionado un excelente marco cronoestratigráfico para el Neógeno superior (Hilgen 1987; Langereis y Hilgen, 1991; Krijgsman et al. 1995, 1997). El resultado más destacado de estos estudios ha sido la creación de escalas de tiempo astronómicas para el Plio-Pleistoceno (Hilgen 1991 a, b; Lourens et al. 1996) y el Mioceno superior (Hilgen et al. 1995). 
La APTS ha probado ser más precisa y tener mayor resolución que las escalas de tiempo convencionales y ha sido consiguientemente incorporada en la escala de tiempo estándar de polaridad geomagnética de Cande y Kent (1995). Fundamentalmente se han utilizado las conocidas series de Capo Rossello, Eraclea Minoa, Singa, y Vrica para la construcción de las escalas de tiempo del Plioceno. Estas secciones muestran claramente una sucesión cíclica que está principalmente controlada por la precesión y la excentricidad. Las secciones están constituidas por ciclos en los que alternan capas ricas en $\mathrm{CO}_{3} \mathrm{Ca}$ con sapropeles (Hilgen et al., 1997)(fig. 5.9).

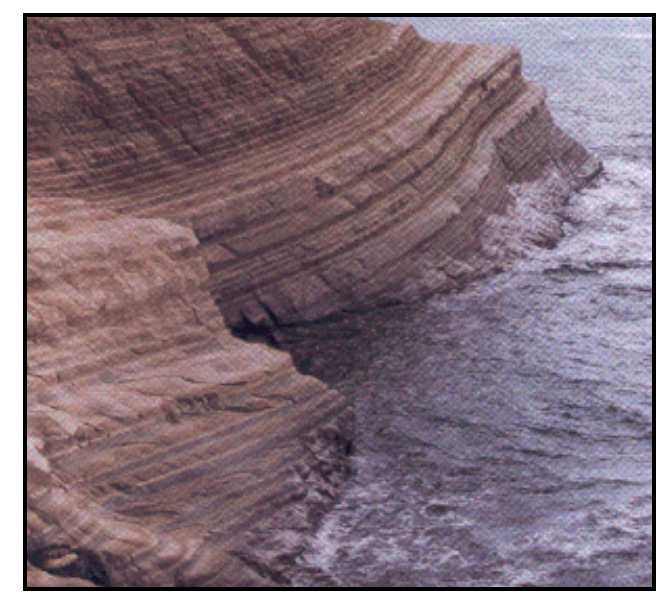

Figura 5.9. Sección clásica de Punta di Maiata al sur de Sicilia, Italia. Los ciclos de color cuatripartitos de pequeña escala (gris-blanco, beige-blanco) reflejan la precesión, los grandes capas endurecidas que destacan en la imagen (blanco) reflejan los ciclos de excentricidad de 100 y $400 \mathrm{Ka}$. (Hilgen et al., 1997).

La eficacia de la escala de tiempo astronómica fue corroborada cuando se dataron los cambios magnéticos independientemente de las técnicas radioisotópicas. Desde 1982 en adelante, la escala de tiempo de polaridad astronómica (APTS) comenzó a desviarse de las escalas de tiempo de polaridad basadas en dataciones de $\mathrm{K}$ / Ar. Las nuevas escalas de tiempo revelaron discrepancias entre un 5 y un 10\%, siendo las edades astronómicas consistentemente más viejas que las edades basadas en K / Ar. Desde entonces, la validación de la APTS ha sido confirmada por la datación radioisotópica utilizando la nueva técnica de fusión láser de ${ }^{40} \mathrm{Ar} /{ }^{39} \mathrm{Ar}$ (un único cristal). Las discrepancias iniciales son explicadas por la dificultad de desgasear completamente la sanidina feldespato alcalina utilizando el método convencional K / Ar (Hilgen et al., 1997, 1999)

Wilson (1993) proporciona un soporte independiente para la APTS mediante un estudio que muestra como la astrocronología es la técnica de datación que proporciona 
una reconstrucción más consistente y fiable de las velocidades de expansión del fondo oceánico.

Además, la aplicación de la APTS proporciona edades precisas en la datación de las pequeñas inversiones magnéticas, pulsos tectónicos y rotaciones, biocronología, productividad, variaciones de largo plazo en litología tales como las secuencias de tercer orden, etc... (Hilgen et al., 1997, 1999).

\subsubsection{Desarrollo de la $A P T S$}

Inicialmente, las investigaciones se centraron en la influencia orbital en las edades de hielo del Pleistoceno. Siguiendo el calibrado del Pleistoceno superior, la escala de tiempo astronómica se estableció firmemente para los últimos 5.3 millones de años (todo el Plioceno-Pleistoceno) utilizando en este caso los registros paleoclimáticos de los Sites del Ocean Drilling Project en el Pacífico ecuatorial oriental y en el Atlántico Norte así como los modelos de sedimentación cíclica en diversos afloramientos de la cuenca Mediterránea (Hilgen, 1991 a, b).

Recientemente, Lourens et al. (1996 b) modificó ligeramente la escala astronómica de Hilgen (1991 b) utilizando diferentes soluciones astronómicas y una curva de insolación más realista. Hilgen et al. (1997, 1999) observan que determinados detalles en la sedimentación cíclica, en particular aquellos causados por la interferencia entre la precesión y la oblicuidad, están mejor reflejados en la solución astronómica formulada por Laskar (1990) siendo esta escala más precisa desde el punto de vista geológico. Esta solución presenta valores cercanos a los actuales para la elipticidad dinámica de la Tierra y la disipación de las mareas por la Luna (ambos parámetros son importantes pues afectan al sistema Tierra-Luna y cambia cuando nos encontramos en un periodo glacial) (Hilgen et al., 1997, 1999).

Para extender la APTS al Mioceno, se estudiaron las secciones cíclicas de Creta, Gavdos y Sicilia calibrándose con las curvas astronómicas (Hilgen et al., 1995, 1999). Actualmente, la APTS del Mediterráneo abarca desde el Messiniense inferior (6.8 Ma) al Serravalliense superior (12.2 Ma) (Hilgen et al., 1995; Hilgen y Krijgsman, 1999b). Comprobada una edad de 7.24 Ma para el límite Tortoniense-Messiniense, esto significó que el Messiniense perduró 1.91 Ma puesto que el límite Mioceno-Plioceno tiene una edad astronómica de 5.33 Ma.

Puesto que la APTS del Plio-Pleistoceno cubrió los últimos 5.3 Ma, esto resultó en una laguna messiniense (Messinian Gap) desde 5.3 Ma a $6.8 \mathrm{Ma}$, comprendiendo las 
inversiones magnéticas del cron C3 An. Esta laguna está justificada por los sedimentos poco favorables (diatomitas y evaporitas) depositadas durante la denominada Crisis de Salinidad Messiniense y la compleja historia sedimentaria del Mediterráneo durante este intervalo. Los sedimentos del Messiniense también reflejan sin embargo la ciclicidad astronómica. Las edades astronómicas del cron C3 An son de especial interés ya que una importante fase de reorganización de las placas y de cambios asociados en las velocidades de expansión están atribuidas al Mioceno superior (Hilgen et al., 1997).

Recientemente, Sierro et al. (en prensa) construyen una sección compuesta para la cuenca de Sorbas y Nijar (Almería) en el miembro Abad, que servirá como referencia para el Messiniense superior preevaporítico del Mediterráneo occidental en la escala de tiempo de polaridad astronómica. Las margas del miembro Abad son la única unidad cíclica en el Mediterráneo que proporciona una magnetoestratigrafía de confianza para este intervalo. Por otro lado Krijgsman et al. (en prensa) completan el calibrado astronómico de la serie messiniense de la cuenca de Sorbas (miembros Yesares, Sorbas y Zorreras) tratando de cerrar el mencionado gap messiniense.

Actualmente se está trabajando para extender la calibración de series continentales con la APTS. Esto ayudará a determinar la evolución del clima continental y su intercalibración con el dominio marino. De hecho, el registro sedimentario terrestre parece ser el lugar ideal para buscar ciclos de Milankovitch ya que la ausencia de procesos oceanográficos con sus complicados mecanismos de retroalimentación no lineal, se traduce en un registro más directo de los cambios inducidos orbitalmente en el clima. Un buen ejemplo es el citado anteriormente en series lacustres del NE de España (Aziz, et $a l$., en prensa). Sin embargo normalmente existen serios inconvenientes en la utilización de sucesiones continentales, como son la habitual ausencia de un control temporal preciso y la presencia de hiatos como resultado de la actividad tectónica, cambios del nivel del mar, procesos autocíclicos, y erosión intermitente. No obstante, puede registrarse una subsidencia regular equilibrada con una sedimentación continua tal y como sucede en los estudios cicloestratigráficos en sucesiones continentales de Olsen et al. (1996). Estos ejemplos sin embargo, datan de periodos remotos en la historia de la Tierra y carecen del necesario control temporal de primer orden (Hilgen et al., 1997).

El valor de la metodología del calibrado orbital, está claramente demostrado por la adopción de la escala de tiempo astronómica como un estándar para el Plio-Pleistoceno en la mayoría de las escalas de tiempo recientes. En el futuro inmediato las escalas de tiempo astronómicas se extenderán hacia el Mesozoico. Para estos intervalos de tiempo más antiguos, el ciclo de excentricidad de $400 \mathrm{Ka}$ es particularmente adecuado para establecer correlaciones de primer orden con el registro astronómico. Las sucesiones 
pelágicas del Cretácico al Paleógeno (p.e. Fischer et al., 1991, Eicher y Diner, 1991) y las sucesiones lacustres del Triásico de la cuenca de rift de Newark (Baker, G. S., 1994; Kent, et al., 1995; Olsen et al., 1996) podrían ser utilizadas para extender la escala de tiempo astronómica; asumiendo que sean continuos y que claramente reflejen la influencia de ciclos de excentricidad de baja frecuencia. Para estos intervalos de tiempo más antiguos, no pueden emplearse los pequeños detalles de las curvas astronómicas ya que la precisión de la solución astronómica viene limitada por el inherente movimiento caótico de nuestro sistema solar. Sin embargo, estos detalles pueden ser derivados desde el registro geológico, ayudando a perfeccionar las soluciones y los modelos astronómicos teóricos.

\subsubsection{Ciclicidad orbital en registros geofísicos}

Los cambios orbitales generan cambios climáticos globales o regionales que se reflejan en la mineralogía o la porosidad de los sedimentos. Los logs detectan los cambios de mineralogía y porosidad por lo que son susceptibles de reflejar los ciclos orbitales de Milankovitch (fig. 5.10).

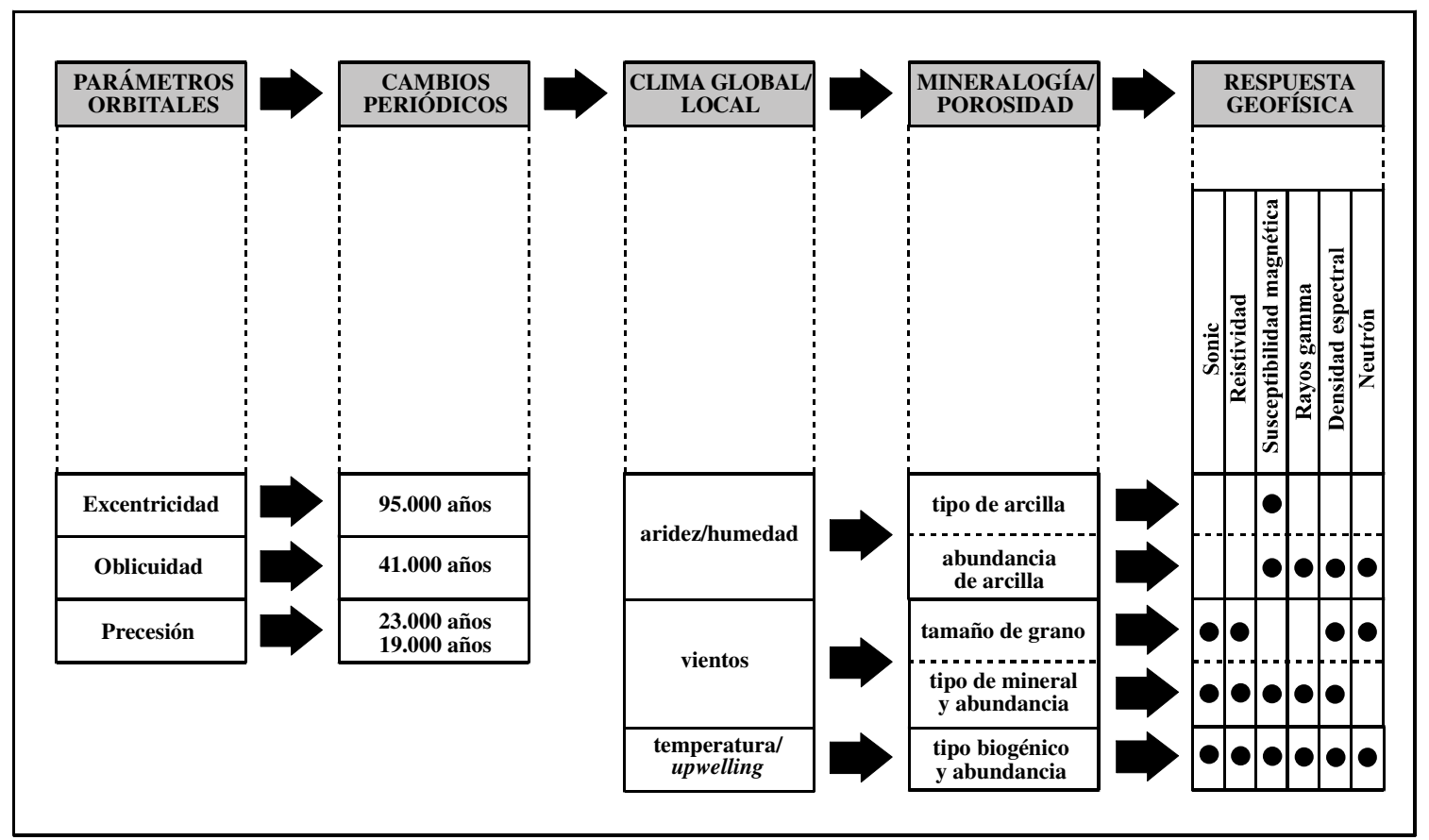

Figura 5.10. Los registros geofísicos $(\operatorname{logs})$ son ideales para la detección de ciclos ya que proporcionan un registro continuo, y porque diferentes herramientas miden distintos parámetros que son resultado de la variabilidad climática y en última instancia de las oscilaciones orbitales (modificado de Borehole Research Group, 1999). 
Las variables climáticas tales como la aridez y la humedad, parámetros del viento y nivel del mar afectan a la mineralogía y porosidad de los sedimentos. Aparte de los cambios climáticos de gran escala (causados por movimientos tectónicos de masas de tierra a través de diferentes cinturones climáticos), los cambios de menor escala están asociados como hemos visto a variaciones climáticas inducidas astronómicamente por los cambios cíclicos en la órbita de la Tierra. El registro geofísico de los sondeos puede reflejar esta ciclicidad allí donde la velocidad de sedimentación es suficientemente alta para que los eventos puedan ser detectados por las herramientas de registro. Para un registro geofísico típico, con una resolución de la herramienta de medida de 0,6 m, una resolución de $100 \mathrm{Ka}$ requiere una velocidad de sedimentación de al menos 6 m / Ma. Si contamos con un control de edad (como puede ser la astrobiocronología), los logs se convierten en herramientas ideales para la detección de ciclos orbitales ya que proporcionan un registro continuo, y porque diferentes herramientas miden distintas variables que responden a la variabilidad climática. Incluso en casos donde la velocidad de sedimentación no está bien definida, el uso conjunto de varias herramientas permite asociar apropiadamente los ciclos geofísicos a frecuencias de Milankovitch. 


\subsection{SONDEOS Y DIAGRAFÍAS UTILIZADAS}

Después de este paréntesis introductorio, nos centraremos en el análisis cicloestratigráfico del registro geofísico de los sondeos analizados en la cuenca del Guadalquivir-golfo de Cádiz.

En esta Tesis se han utilizado numerosas diagrafías (well logs o wireline well $\log s$ ) preparadas por las compañías operadoras de los sondeos con el fin de realizar un profundo análisis cicloestratigráfico. El estudio cicloestratigráfico que se presenta está basado en el análisis de $\log s$ eléctricos, sónicos y radioactivos de 15 sondeos de exploración de hidrocarburos de la cuenca del Guadalquivir-golfo de Cádiz. Algunas de las diagrafías se encontraban ya publicadas (sondeos Casanieves-1,Villamanrique-1 y golfo de Cádiz D-1) (ITGE, 1990), mientras que el resto han sido proporcionadas por Repsol Exploración para su estudio en esta Tesis.

Las diagrafías constituyen un método geofísico muy habitual en la investigación petrolífera. Este método fue puesto a punto hacia el año 1930 y progresivamente ha mejorado su tecnología y, consecuentemente, la calidad y fiabilidad de los datos obtenidos. Las propiedades físicas que se registran pueden ser: conductividad o resistividad al paso de una corriente eléctrica, radioactividad, velocidad de propagación de ondas sonoras, etc. Entre dos sondeos cercanos, las diagrafías constituyen normalmente la técnica de correlación de mayor precisión y fiabilidad.

En los métodos de resistividad utilizados en los sondeos Casanieves-1 y Villamanrique-1 por ejemplo, se mide la resistencia al paso de una corriente eléctrica entre dos puntos de la pared de un sondeo. Existen diversas modalidades según el tipo de sonda (resistividad, conductividad, inducción). En el caso de los dos sondeos analizados se ha utilizado la inducción-resistividad (barn y ohm/m respectivamente), utilizándose concretamente la curva de Normal Short N16". Las rocas con mayor resistividad (menor conductividad) son las más compactas y tienen valores de 1.000 a 10.000 ohm-m, mientras que las de menor resistividad (mayor conductividad) son las más porosas y sus valores oscilan entre 0,5 y $200 \mathrm{ohm}-\mathrm{m}$.

La digrafía de radioactividad natural (gamma-ray $\operatorname{logs}$ ) es otra de las técnicas clásicas y consiste en medir con un escintilómetro la radioactividad natural emitida por las diferentes rocas atravesadas en el sondeo. Los valores de rayos gamma se muestran usualmente en unidades API (unidad de medida estandard de rayos gamma). La radioactividad de cada nivel de roca está regulada por su contenido en isótopos radioactivos que son los que emiten de manera espontánea los rayos gamma. Los 
elementos radioactivos pertenecen a las familias de potasio $\left({ }^{40} \mathrm{~K}\right)$, del torio $\left({ }^{232} \mathrm{Th}\right)$ y del uranio $\left({ }^{238} \mathrm{U}\right.$ y $\left.{ }^{235} \mathrm{U}\right)$. En los sondeos B2, C2, B5, C3, D1, B3, B6 y Orión 2-1, se ha utilizado el registro de rayos gamma como base del análisis cicloestratigráfico.

Las diagrafías acústicas (sonic logs) consisten en la medida del tiempo que tarda una onda sonora en atravesar una distancia fija (DT, Delta Time, velocidad estimada en microsegundos por pie, $\mu \mathrm{s} / \mathrm{f}$ ). Esta distancia fija consiste en el espacio comprendido entre el emisor y el receptor, ambos situados en la sonda que se introduce en el sondeo. Esta herramienta, junto con la de rayos gamma ha sido la más utilizada en el análisis cicloestratigráfico de los sondeos estudiados en esta Tesis. Se ha trabajado sobre el registro de velocidad sónica de los sondeos C2, 6x1, C4, C5, D4 y Atlántida-3 para realizar el análisis cicloestratigráfico.

Los niveles típicamente lutíticos presentan valores máximos en radioactividad y medios en velocidad de propagación de ondas acústicas, mientras que los niveles arenosos presentan valores mínimos de radioactividad y alta velocidad de propagación de ondas. Junto con la densidad, los cambios en la porosidad tienen un fuerte impacto en el registro sónico. En los sedimentos mio-pliocenos de la cuenca del Guadalquivir-golfo de Cádiz, la mayor parte de los depósitos poseen un carácter más o menos limoso que produce oscilaciones entre valores intermedios en ambos tipos de registro.

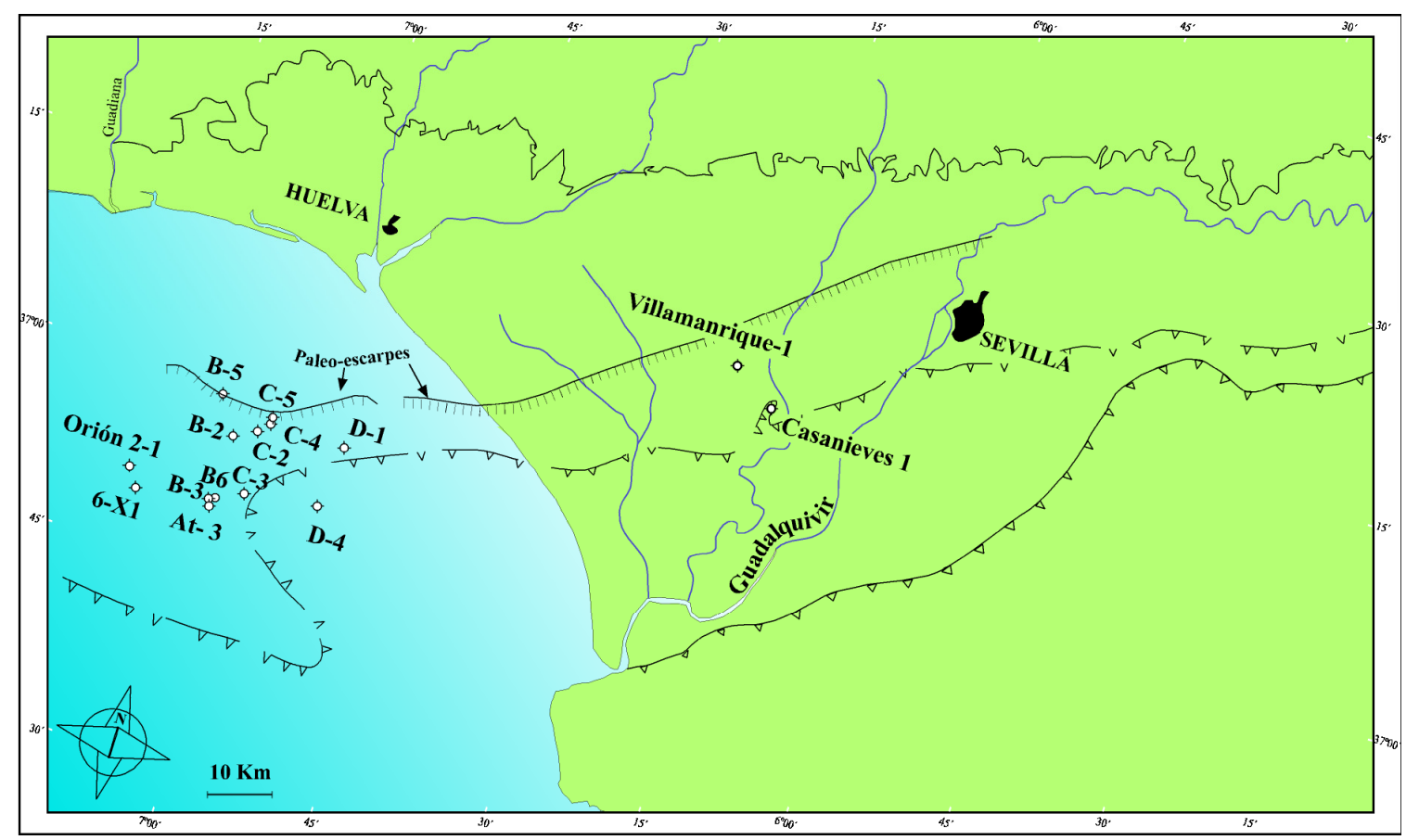

Figura 5.11. Posición de los 15 sondeos en los que se ha realizado el estudio cicloestratigráfico. 
La utilidad de las diagrafías como técnica de correlación se circunscribe habitualmente a sondeos cercanos y siempre de una misma cuenca, de manera que exista una continuidad lateral de los materiales. En esta Tesis se pretende ampliar la capacidad de correlación de las diagrafías en dos sentidos: aumentar la resolución de las correlaciones habituales y extender las correlaciones a sondeos distantes e incluso fuera de la propia cuenca. Para conseguir este propósito será imprescindible contar con una segunda herramienta de correlación como es la bioestratigrafía, que permitirá comparar series y sondeos alejados.

Para el estudio cicloestratigráfico de la cuenca del Guadalquivir-golfo de Cádiz, se han utilizado diagrafías de los siguientes sondeos: Atlántida-3, Casanieves-1, Golfo de Cádiz-B2, Golfo de Cádiz-B3, Golfo de Cádiz-B5, Golfo de Cádiz-B6, Golfo de CádizC2, Golfo de Cádiz-C3, Golfo de Cádiz-C4, Golfo de Cádiz-C5, Golfo de Cádiz-D1, Golfo de Cádiz-D4, Golfo de Cádiz-6x1, Orión 2-1 y Villamanrique-1 (estos sondeos aparecen localizados en la figura 5.11). 


\subsection{METODOLOGÍA DEL ANÁLISIS CICLOESTRATIGRÁFICO}

\subsubsection{Ciclicidad orbital en diagrafías de sondeos de la cuenca del Guadalquivir-golfo de Cádiz}

El análisis inicial de las diagrafías obtenidas en la cuenca del Guadalquivir-golfo de Cádiz reveló la existencia de una marcada ciclicidad que posteriormente ha podido ser calibrada con la escala astronómica de tiempo. Hemos publicado recientemente un estudio preliminar de los resultados obtenidos para el Plioceno de cuatro de estos sondeos en un artículo de la revista Geology del mes de Agosto de 2000 (Sierro et al., 2000).

En los siguientes apartados se realizará un exhaustivo estudio de la ciclicidad que presentan las diagrafías de rayos gamma, de velocidad sónica y de inducción-resistividad de 20 diagrafías pertenecientes a 15 sondeos profundos de la cuenca del Guadalquivirgolfo de Cádiz. Este es el primer estudio cicloestratigráfico de estas características que se realiza en esta cuenca. Se pretende destacar como la combinación de la astrobiocronología y la cicloestratigrafía multiplican la capacidad y la fiabilidad de las correlaciones basadas en las de diagrafías.

Los registros de las diagrafías utilizadas (algunas con más de $2000 \mathrm{~m}$ ) muestran valores a intervalos de $15 \mathrm{~cm}$. Tras el análisis de 20 diagrafías de rayos gamma $(G R)$ y registro sónico (Sonic) se ha observado que los tramos que atraviesan sedimentos hemipelágicos, muestran patrones cíclicos característicos que pueden ser comparados con las variaciones en la precesión y excentricidad de la órbita terrestre (Laskar, 1990; Laskar et al. 1993). La calibración del registro sónico y de rayos gamma de 13 sondeos del golfo de Cádiz y 2 sondeos del Guadalquivir con la escala astronómica de tiempo, ha permitido establecer una serie de unidades cicloestratigráficas de carácter astronómico que han servido para establecer una datación de gran precisión de todos los sondeos analizados.

La ciclicidad sedimentaria está definida por ciclos de unos $3 \mathrm{~m}$ de potencia en los que alternan sedimentos arcillosos que producen mínimos de resistividad y máximos de rayos gamma y velocidad sónica, con niveles limosos que registran valores opuestos. Los análisis de alta resolución de las pautas cíclicas observadas, han permitido realizar una correlación capa a capa con la serie de Sorbas (Almería) (Sierro et al., en prensa y Krijgsman et al., en prensa) y de Capo Rossello (Sicilia) (Hilgen, 1991b; Langereis y Hilgen, 1991; Lourens et al., 1996b), que son las secciones de referencia global para la escala astronómica de tiempo del Messiniense y del Plioceno respectivamente.

En la sección de Sorbas destaca el miembro Abad (7.24-5.96 Ma) que comprende 55 ciclos sedimentarios inducidos orbitalmente y caracterizados por alternancias de 
margas homogéneas y capas ricas en ópalo-ct en su tramo inferior (Abad inferior) y una alternancia de margas homogéneas y sapropeles en su parte superior (Abad superior) (Krijgsman et al., en prensa). La sección de Capo Rossello por su parte consiste en una alternancia de unidades "pobres en carbonato" (margas grises) y de unidades "ricas en carbonato" (capas blanco-beige-blanco). Las margas grises se intercalan entre las unidades carbonatadas, y son sustituidas por los sapropeles en la parte superior de la sección. Los sapropeles del Mediterráneo oriental (Metochia, Grecia) y sus equivalentes capas de margas grises son generalmente pobres en carbonato y fueron generadas en periodos de mayor aporte terrígeno o menor productividad orgánica durante períodos climáticos húmedos en el área mediterránea (De Visser et al., 1989; Howell et al., 1990; Thunell et al. 1991; Van Os et al. 1994). Por el contrario, las capas homogéneas blanquecinas son capas ricas en carbonato originadas en momentos de clima árido con un influjo terrígeno reducido o con mayor productividad orgánica (Sierro et al., en prensa).

En la cuenca del Guadalquivir-golfo de Cádiz, no se esperan para el intervalo de tiempo estudiado grandes procesos de compactación en el relleno terciario, ni procesos diagenéticos significativos que pudieran estar afectando a las lecturas de las herramientas geofísicas (S. Torrescusa, com. per.). Por lo tanto se considera que la respuesta geofísica y los patrones de ciclicidad que presentan los logs de los sondeos de la cuenca del Guadalquivir-golfo de Cádiz reflejan cambios sedimentológicos producidos por la variabilidad climática o evolución del sistema de depósito.

El estudio cicloestratigráfico realizado en este trabajo se compone de varias fases. Inicialmente se realiza un análisis cicloestratigráfico y bioestratigráfico, a continuación un sintonizado con la solución matemática de los parámetros astronómicos y finalmente se establece la correlación con otros sondeos o series calibradas astronómicamente. El desarrollo de este proceso puede seguirse en la figura 5.12:

A) Análisis de la ciclicidad geofísica. En primer lugar se realiza un análisis de la información apoyándose en dos apartados (fig. 5.12A).

- Investigación de pautas y patrones de repetición en el registro geofísico. Se ha prestado especial atención a los patrones característicos que se producen como resultado de la interferencia entre precesión y oblicuidad, así como a la modulación de la precesión producida por las variaciones de excentricidad. 
(A)

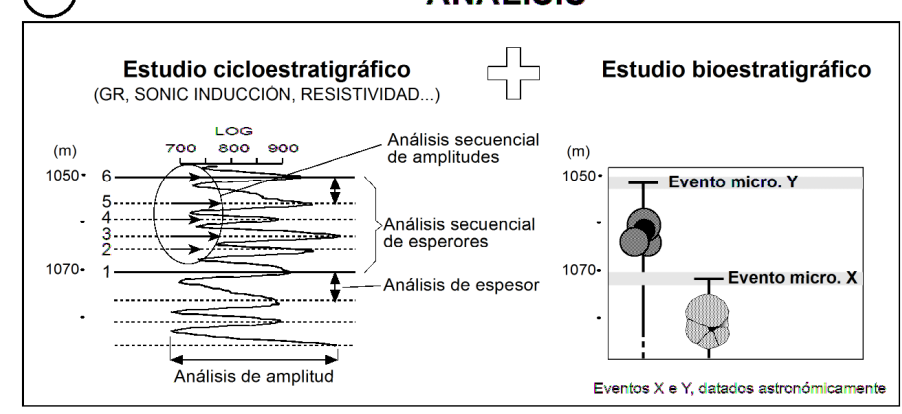

INTEGRACIÓN

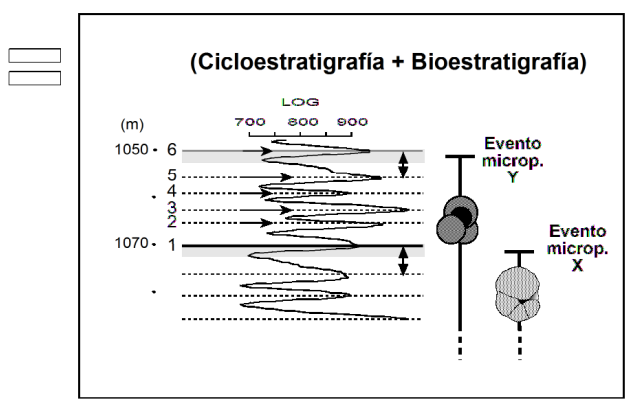

(B)

SINTONIZADO

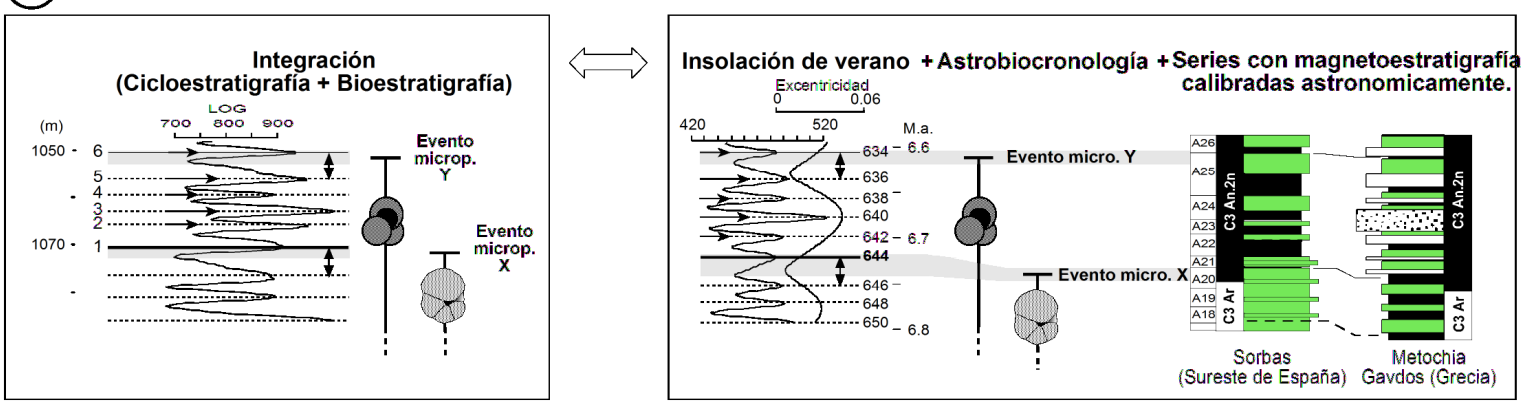

(C) CORRELACION

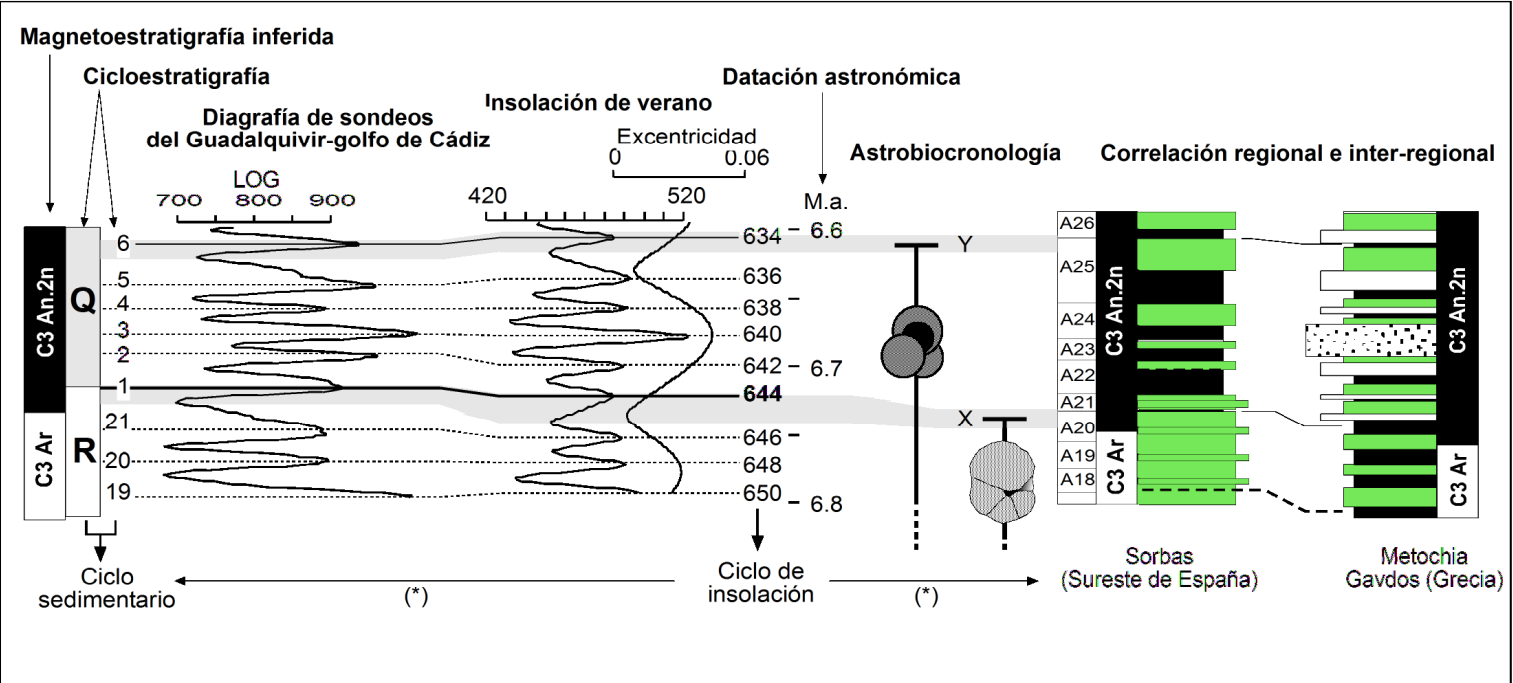

Figura 5.12. Metodología del análisis cicloestratigráfico realizado en 20 diagrafías de 15 sondeos de la cuenca del Guadalquivir-golfo de Cádiz. (A) En una fase inicial, el estudio se centra en el análisis bioestratigráfico y en las pautas ritmicas del registro geofísico. (B) Mediante la sintonización con la curva de insolación, el registro geofísico puede ser correlacionado con otras series del ámbito regional o mundial. (C) La correlación con la curva de insolación permite obtener una datación de ultra alta-resolución (con un error inferior a $\mathbf{2 0 . 0 0 0}$ años y un registro de edad continuo para la diagrafía). Con esta resolución, puede inferirse por ejemplo la escala magnetoestratigráfica. (*): Se asume la existencia de un retardo de 3.000 años entre el factor desencadenante (variaciones en la insolación estival) y la respuesta sedimentaria (Retardo establecido para la formación de sapropeles en el Mediterráneo). 
- Un análisis bioestratigráfico de alta resolución basado en eventos de plancton calcáreo que permite evaluar las velocidades de sedimentación y acotar intervalos. Si asignamos a los eventos obtenidos en el análisis bioestratigráfico (apartado 3.3.5.) la edad de los eventos calibrados astronómicamente en otras series (apartado 3.3.6), podemos calcular la velocidad de sedimentación y evaluar si la ciclicidad que presenta el registro geofísico corresponde a frecuencias de Milankovitch.

B) Sintonizado. Tras la integración de la bioestratigrafía y del análisis de ciclicidad, se realiza el sintonizado de la diagrafía con la curva de insolación de verano mediante la solución astronómica de Laskar (1990) (fig. 5.12B). Gracias a la astrobiocronología (bioeventos datados astronómicamente) se consigue correlacionar las diagrafías con series previamente calibradas o series de referencia (Sorbas y Metochia en la figura 5.12) y de esta forma concretar la correlación entre la diagrafía y la escala de tiempo astronómica. Obsérvese como en el intervalo entre cada dos bioeventos, se encuentra el mismo número de ciclos geofísicos que en la curva de insolación; de esta forma se adjudica a cada pico del registro geofísico su correspondiente pico en la curva de insolación (fig. 5.12C).

C) Datación y correlación. Conseguida la correlación con la curva de insolación, el sondeo puede correlacionarse con cualquier otra serie de ámbito regional o mundial previamente calibrada con la curva de insolación. Se establece la datación astronómica del registro geofísico y se deduce la magnetoestratigrafía en función de los resultados obtenidos en las series de referencia (fig. 5.12C). La datación astronómica que proporciona este método otorga una resolución en la datación semejante a la que permiten las propias diagrafías (en nuestro caso 15 $\mathrm{cm})$. Considerando una velocidad de sedimentación constante entre dos puntos conocidos, podemos obtener la edad del punto medio con una simple interpolación, consiguiendo datar astronómicamente cada punto de la diagrafía con un error siempre inferior a 20.000 años (que es la duración de un ciclo de precesión) y en términos generales con un error menor.

Las aplicaciones de este tipo de datación y calibración con la curva astronómica son inmediatas y significativas:

- Además de conseguir una datación de ultra-alta resolución, la correlación con otras series calibradas astronómicamente permite por ejemplo estimar la escala magnetoestratigráfica, realizar correlaciones de alta precisión entre sondeos de la misma cuenca o de cualquier otra zona del planeta. 
- En cuanto a la exploración y explotación de hidrocarburos, una datación de estas características permite asignar edades fiables a niveles productivos, relacionarlos con procesos locales o regionales, datar eventos tectónicos (fallas...), estratigráficos (slumps, niveles de interés productivo...), climáticos, o de cualquier otra naturaleza.

- Este análisis cicloestratigráfico sirve como base para establecer una interpretación detallada del relleno de la cuenca. Además, la datación ofrece un marco de referencia para futuras investigaciones que podrán asignar una edad concreta a cualquier evento geológico localizado en los sondeos analizados.

Por otra parte, los pequeños desajustes que pudieran presentarse respecto a la solución astronómica utilizada (todavía en proceso de construcción) pueden reflejar pequeñas diferencias entre el registro geológico y el astronómico. La investigación científica futura con una solución astronómica más precisa puede resultar en pequeñas modificaciones de los resultados en el futuro pero el calibrado no será seriamente afectado ni por lo tanto la astrocronología. Más aún, son estos pequeños desajustes los que pueden proporcionar a las investigaciones futuras las pistas a una solución astronómica más acertada (Sierro et al., en prensa). 


\subsection{CALIBRACIÓN DE LOS LOGS CON LA SOLUCIÓN ASTRONÓMICA. CORRELACIONES}

En la figura 5.13 se observa el procedimiento utilizado en la calibración astronómica del registro geofísico mediante un ejemplo real de correlación entre dos de los sondeos estudiados en el golfo de Cádiz (sondeos 6-x1 y Atlántida-3). Este procedimiento basado en la metodología que acabamos de adelantar ha sido el utilizado en todos los sondeos. Sirva por lo tanto este ejemplo pormenorizado como ilustración de la metodología empleada en todos los casos.

\section{ANÁLISIS}

- Investigación de pautas y patrones de repetición en el registro geofísico (fig. 5.13). En las diagrafías se observan directamente 3 frecuencias de repetición diferentes que hemos denominado de $1^{\text {er }}, 2^{\circ}$ y $3^{\text {er }}$ orden.

Destacan fundamentalmente los ciclos de alta frecuencia ( $3{ }^{\text {er }}$ orden) que presenta la curva de velocidad sónica, repitiéndose estos ciclos a intervalos de 3 a $5 \mathrm{~m}$. Los ciclos de alta frecuencia se han individualizado delimitándolos en función de los máximos de rayos gamma y velocidad sónica (mínimos de resistividad). Los "ciclos de baja amplitud" (de onda) presentan valores máximos "débiles" y valores mínimos "débiles". Por otro lado, los "ciclos de gran amplitud" presentan máximos "fuertes" y mínimos "fuertes".

Analizando en detalle las diagrafías se observa así mismo que cada 17 o 18 ciclos de $3^{\text {er }}$ orden se registra un intervalo con 1 o más ciclos de muy baja amplitud, o incluso sin ciclicidad aparente. Estos intervalos con mínimos de amplitud han servido para identificar los ciclos de baja frecuencia ( $1^{\mathrm{er}}$ orden). En el interior de los ciclos de baja frecuencia ( $1^{\mathrm{er}}$ orden), los ciclos de alta frecuencia $\left(3^{\mathrm{er}}\right.$ orden) se encuentran bien desarrollados, con grandes amplitudes de onda, mientras que hacia los extremos, los ciclos de alta frecuencia reducen su amplitud o incluso desaparecen. A cada uno de los ciclos mayores $\left(1^{\mathrm{er}}\right.$ orden) se le ha asignado una letra. Por otro lado, a cada ciclo de alta frecuencia ( $3^{\text {er }}$ orden) se le ha asignado un número que junto con la letra del ciclo mayor en el que esta incluido, constituye un código único que permite identificar individualmente cada ciclo de alta frecuencia ( $3^{\text {er }}$ orden). 


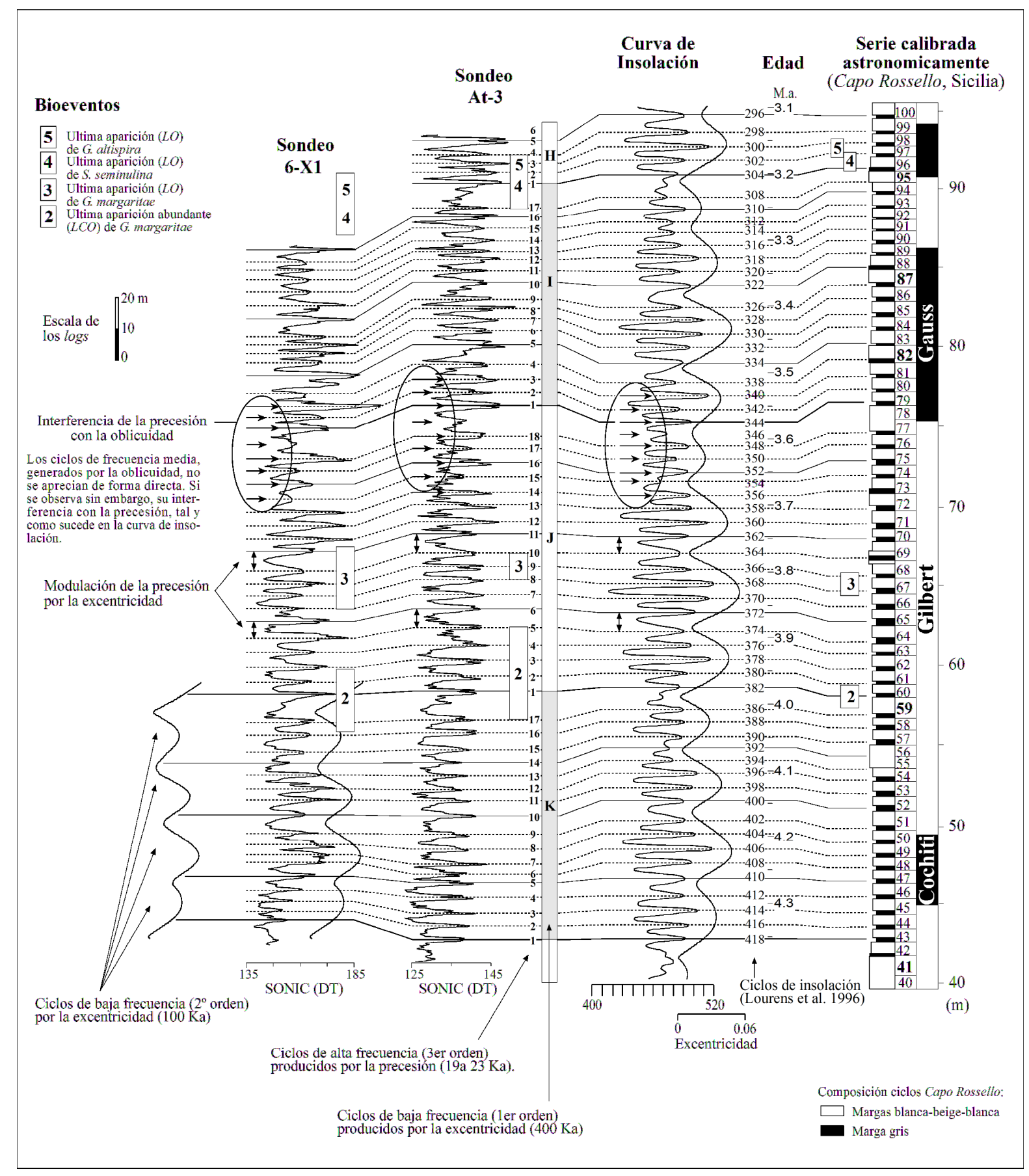

Figura 5.13. Ejemplo de correlación y datación astronómica de dos sondeos del golfo de Cádiz. Correlación, sintonizado con la curva de insolación para una latitud de $65^{\circ} \mathrm{N}$ (Laskar, 1990), asignación de unidades cicloestratigráficas, edad astronómica y correlación con la serie de Rossello (Hilgen, 1991b; Langereis y Hilgen, 1991; Lourens et al. 1996), que constituye la sección de referencia global para la escala astronómica de tiempo del Plioceno. Explicación en el texto. 
Cada 4 o 5 ciclos de alta frecuencia ( $3^{\text {er }}$ orden) se registra periódicamente un ciclo más potente que sirve para identificar una ciclicidad de baja frecuencia ( $2^{\circ}$ orden). A su vez, cada 4 de estos ciclos más potentes se produce uno especialmente significativo de modo que es posible reconocer nuevamente la periodicidad de baja frecuencia ( $1^{\mathrm{er}}$ orden). Recíprocamente, la configuración interna de los ciclos de $1^{\mathrm{er}}$ orden permite identificar 4 ciclos de $2^{\circ}$ orden dentro de cada ciclo de $1^{\mathrm{er}}$ orden. A su vez cada ciclo de $2^{\mathrm{o}}$ orden engloba entre 3 y 5 ciclos de $3^{\text {er }}$ orden (fig. 5.13 abajo izquierda)

En los registros de rayos gamma, velocidad sónica y resistividad analizados se han detectado por lo tanto 3 frecuencias de observación directa $\left(1^{\mathrm{er}}, 2^{\mathrm{o}}\right.$ y $3^{\mathrm{er}}$ orden $)$. Gracias al análisis de Fourier ha sido posible detectar la existencia de una $4^{\mathrm{a}}$ frecuencia indirecta (fig. 5.14). A pesar de no observarse directamente, la presencia de esta frecuencia intermedia se deja sentir como interferencia sobre los ciclos de alta frecuencia $\left(3^{\text {er }}\right.$ orden) de modo que se producen interferencias que resultan patentes en algunos tramos (en la figura 5.13 intervalos señalados mediante un círculo). Esta interferencia sobre los ciclos de alta frecuencia se refleja como alternancias entre ciclos de gran amplitud y ciclos de baja amplitud.

\section{- Análisis bioestratigráfico}

A pesar de lo característico de los patrones anteriores, estas pautas se repiten a lo largo de la curva geofísica sin que podamos precisar su ubicación temporal. Para acometer dicho objetivo es necesario un análisis bioestratigráfico de alta resolución que permita ubicar temporalmente las pautas cicloestratigráficas. La bioestratigrafía por lo tanto constituye la obligada referencia temporal que permite fijar en el tiempo las curvas geofísicas para su posterior sintonizado con la curva astronómica de tiempo (APTS).

El siguiente paso por lo tanto supone establecer la bioestratigrafía del sondeo correspondiente. La diagrafía del sondeo se complementa con la información bioestratigráfica mediante eventos calibrados astronómicamente en otras series con el fin de que sirvan de referencia los bioeventos comunes (serie de Capo Rossello, Sicilia en el ejemplo de la figura 5.13). En la figura 5.13 se han utilizado los bioeventos de desaparición 2 a 5 que son comunes tanto en las series mediterráneas como en los sondeos del golfo de Cádiz. El apartado bioestratigráfico se ha desarrollado ampliamente en los capítulos 3 y 6 de la Tesis. 


\section{SINTONIZADO}

Tras la integración del análisis de ciclicidad y de la bioestratigrafía, se realiza el sintonizado de la ciclicidad del registro geofísico con la curva de insolación de verano mediante la solución astronómica de Laskar (1990) (fig. 5.12B). Mediante la astrobiocronología se consigue correlacionar las diagrafías con las series de referencia y de esta forma ubicar la posición de la curva geofísica en la escala de tiempo astronómica.

La primera conclusión obtenida es que en el intervalo de la diagrafía entre cada bioevento se registran el mismo número de ciclos geofísicos que ciclos de insolación contiene la curva astronómica para el mismo periodo, por lo que se adjudica cada pico del registro geofísico con su correspondiente pico en la curva de insolación. A partir de ese momento podemos concluir que los ciclos de alta frecuencia ( $3^{\text {er }}$ orden) se correlacionan y están producidos por la precesión $(21 \mathrm{Ka})$.

En la curva de insolación los ciclos de precesión se encuentran modulados por la excentricidad (fig. 5.13). Esta característica se traduce en la presencia de ciclos de precesión más potentes de lo normal cada 4 o 5 ciclos. Así mismo en la diagrafía se puede observar la modulación de los ciclos de alta frecuencia ( $3^{\text {er }}$ orden) por los grandes ciclos de baja frecuencia ( $1^{\mathrm{er}}$ orden). En este caso la modulación se traduce en la presencia de ciclos sedimentarios con mayor potencia que el resto cada 4 o 5 ciclos de alta frecuencia (ver figura 5.13 abajo izquierda). Esta característica permite correlacionar los ciclos de excentricidad de $100 \mathrm{Ka}$ en la curva de insolación con los ciclos de baja frecuencia $\left(2^{\circ}\right.$ orden) de las curvas geofísicas. Lo mismo sucede con los ciclos de excentricidad de $400 \mathrm{Ka}$ y los grandes ciclos de baja frecuencia $\left(1^{\mathrm{er}}\right.$ orden $)$ en el registro geofísico. Por lo tanto los ciclos de baja frecuencia ( $1^{\mathrm{er}}$ y $2^{\mathrm{o}}$ orden) responden a ciclos de excentricidad de la órbita terrestre, registrándose tanto los ciclos de $400 \mathrm{Ka}$ (baja frecuencia, $3^{\text {er }}$ orden) como los de $100 \mathrm{Ka}$ (baja frecuencia, $2^{\circ}$ orden) (fig. 5.13).

La relación 1 / 5 / 20 en la curva de insolación, muestra la relación entre los ciclos de excentricidad de $400 \mathrm{Ka} /$ excentricidad de $100 \mathrm{Ka} /$ precesión respectivamente; esta característica también ha sido observada en los ciclos de la velocidad sónica y de rayos gamma correspondiendo a los ciclos de $1^{\mathrm{er}} / 2^{\circ} / 3^{\mathrm{er}}$ orden respectivamente.

\section{Modulación de la precesión por la excentricidad:}

En la curva de insolación, la excentricidad modula a la onda de precesión dando lugar a ciclos de insolación distintivos durante los mínimos de excentricidad. En realidad estos ciclos distintivos van a corresponder a uno o dos ciclos de insolación de baja amplitud localizados al final de los ciclos de excentricidad (de 100.000 y 400.000 años). 
De la misma forma, en las diagrafías la modulación de los grandes ciclos de baja frecuencia ( $1^{\mathrm{er}}$ orden) sobre los ciclos de alta frecuencia $\left(3^{\mathrm{er}}\right.$ orden) se traduce en la presencia de ciclos con mayor potencia que el resto cada 4 o 5 ciclos de alta frecuencia (ver fig. 5.13). Como hemos visto, cada 4 o 5 ciclos de alta frecuencia se registra un ciclo más potente que sirve para identificar la ciclicidad de baja frecuencia de $2^{\circ}$ orden. A su vez, cada 4 de estos ciclos más potentes se produce uno de mayor espesor de modo que es posible distinguir la periodicidad de baja frecuencia de $1^{\mathrm{er}}$ orden. Se trata de ciclos geofísicos distintivos, de baja amplitud de onda y de potencia mayor a la media (fig. 5.13).

Esta característica permite individualizar los grandes ciclos de excentricidad de 400.000 años en la curva geofísica (F, G, H, I, J, K...) e incluso los de 100.000 años (fig. 5.13). Este último caso puede observarse en la configuración interna de los ciclos $\mathrm{K}$ y J, donde se aprecian los ciclos de 100.000 años ( $2^{\circ}$ orden $)$.

\section{Interferencia precesión-oblicuidad:}

La alternancia de ciclos geofísicos de $3^{\text {er }}$ orden con gran amplitud de onda y ciclos de $3^{\text {er }}$ orden con escasa amplitud de onda, refleja la interferencia entre precesión y oblicuidad que puede observarse así mismo en la curva de insolación. En el registro geofísico obtenemos esta interferencia en los mismos intervalos en los que se producen en la curva de insolación. Así por ejemplo sucede en el intervalo J14-I3 que corresponde a un intervalo de interferencia entre precesión y oblicuidad en la curva de de insolación (ic356-ic340) (fig. 5.13). Lo mismo sucede en los intervalos R15-R18, Q10-Q14, P6P9,H15-G5 que veremos más adelante.

La interferencia entre precesión y oblicuidad también produce alternancias entre ciclos con mínimos fuertes y ciclos con mínimos débiles como sucede en el intervalo L13-L18 (fig. 5.21 por ejemplo).

\section{Ciclos dobles:}

Algunos de los ciclos de insolación presentan escasa amplitud de onda, de modo que no desarrollan expresión sedimentaria en las series cíclicas mediterráneas. Son los denominados "ciclos dobles" (Hilgen, 1991b; Hilgen et al., 1995; Krijgsman et al., 1999b; Sierro et al., en prensa) que constituyen ciclos de mayor espesor de lo habitual y que en realidad engloban dos ciclos de precesión.

Algunos de los ciclos que no presentan expresión sedimentaria en las secciones de Capo Rossello o Sorbas, si aparecen reflejados sin embargo en los registros geofísicos de los sondeos del golfo de Cádiz y Guadalquivir, muy probablemente debido a que en 
nuestro caso (al ser la diagrafía un registro prácticamente contínuo) es reflejada cualquier variación litológica por pequeña que sea.

Más aún, cuando en las diagrafías no se registra un determinado ciclo de precesión, es debido comúnmente a la interferencia de las distintas componentes de la curva de insolación. Sirva como ejemplo el caso del ciclo de insolación ic324, que no encuentra reflejo en la curva de insolación (al anularse con el resto de frecuencias que componen la curva de insolación). Obsérvese como tampoco se refleja este ciclo en el registro geofísico, quedando un intervalo más potente de lo normal (fig. 5.13).

Otro ejemplo de ciclo doble que aparece en la misma figura sería el pequeño ciclo de insolación ic384 que no obtiene representación sedimentaria en la serie de Capo Rossello (por lo que genera el ciclo doble CR59). Este ciclo de insolación apenas deja constancia en los sondeos del golfo de Cádiz (en este caso se intuye la presencia de un ciclo al duplicarse la potencia del ciclo K17).

\section{DATACIÓN Y CORRELACIÓN}

Conseguida la correlación con la curva de insolación, los sondeo 6-x1 y Atlántida3 (en el ejemplo de la figura 5.13) quedan datados de forma precisa y pueden correlacionarse con cualquier otro sondeo o sección de ámbito regional o mundial previamente calibrada con la curva de insolación.

Como resultado del calibrado astronómico se ha obtenido la datación del registro geofísico y se ha deducido la magnetoestratigrafía en función de los resultados obtenidos en las series de referencia, en el ejemplo de la figura 5.13 basada en la sección de referencia de Capo Rossello. En las correlaciones cicloestratigráficas que aparecen en este capítulo se ha utilizado la magnetoestratigrafía obtenida por Krijgsman et al. (1995) para el Messiniense inferior (hasta $6.7 \mathrm{Ma}$ ) y posteriormente con la reciente magnetoestratigrafía obtenida por Krijgsman et al. (1999b) y Sierro et al. (en prensa) para el Messiniense superior (hasta $6 \mathrm{Ma}$ ) en la cuenca de Sorbas, y de Shackleton et al. (1995b) (en Krijgsman et al., 1999b) para el leg 138, así como la desarrollada por Langereis y Hilgen (1991). Como series de referencia para la escala astronómica de tiempo hemos utilizado la serie de Sorbas (Sierro et al., en prensa y Krijgsman et al., en prensa) para el Messiniense y la serie compuesta de Rossello (Sicilia) (Hilgen, 1991b; Langereis y Hilgen, 1991) para el Plioceno. 
Además de la correlación regional de los sondeos del Guadalquivir-golfo de Cádiz (cuenca atlántica), se presenta por lo tanto la correlación de los sondeos estudiados con distintas series de ámbito mediterráneo.

\section{EVALUACIÓN DEL SINTONIZADO}

La utilización del análisis de Fourier demuestra hasta que punto la curva geofísica se adapta a la curva astronómica (fig. 5.14). El análisis de Fourier refleja la existencia de las tres frecuencias de observación directa y revela la presencia de una cuarta frecuencia intermedia con un periodo de 41.000 años, que también pertenece a la ciclicidad de

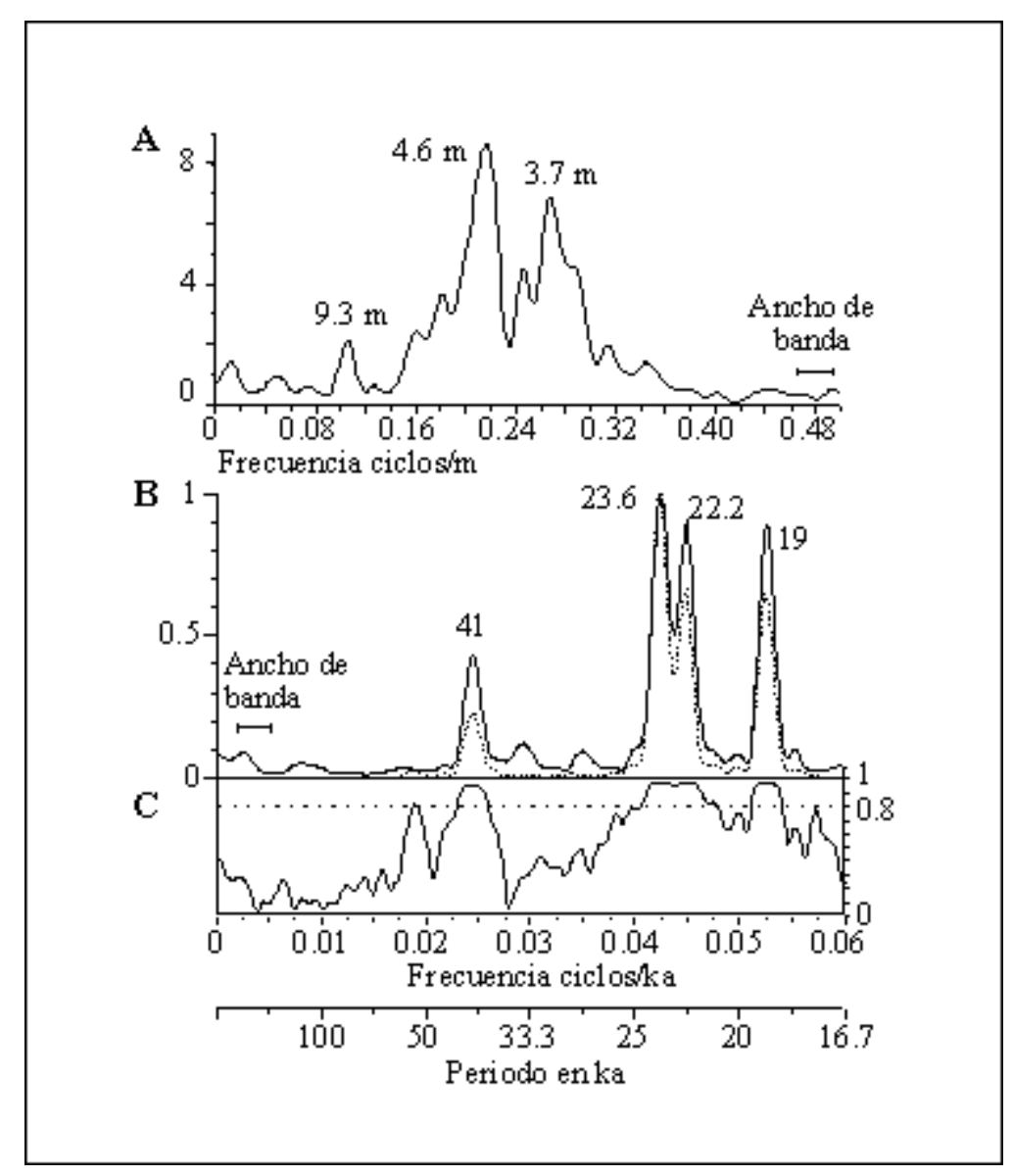

Figura 5.14. A- Análisis espectral del registro de velocidad sónica del sondeo Atlántida-3. B y CEspectro cruzado (cross spectra) y coherencia entre la curva de insolación de verano para $65^{\circ} \mathrm{N}$ de latitud norte, mediante la solución de Laskar, 1990 (línea de puntos) y la diagrafía de velocidad sónica calibrada (línea continua). Las densidades espectrales han sido estimadas empleando el programa Analyseries (Macintosh Program Performs Time-Series Analysis, www.agu.org/eos_elec_) utilizando el método Blackman-Tuckey con $1 / 3$ de retardo (lag) y una ventana tipo Barlett (fig. 5.14. B) y tipo Parzen (fig. 5.14. A). Para construir el modelo de edad del sondeo Atlántida-3, las edades de los máximos de insolación estival se asignaron a sus máximos correlativos de velocidad sónica (fig. 5.13). El muestreo consistió en un registro sónico cada 700 años de media. 
Milankovitch y que corresponde a la oblicuidad. Las cuatro frecuencias detectadas en el análisis de Fourier pertenecen a la ciclicidad de Milankovitch y explican la mayor parte de la curva real, lo que convierte este análisis cicloestratigráfico en uno de los de mejor calibrado con la curva astronómica en todo el mundo.

El análisis espectral es el instrumento más utilizado para identificar periodicidad en los logs. Existen numerosos programas válidos en diferentes plataformas que permiten realizar el análisis espectral. Actualmente se utiliza en todo el mundo el programa para Macintosh Analyseries (ver Glosario). Por otro lado para desarrollar la demodulación compleja se utiliza comúnmente el programa STARPAC (ver Glosario). Para obtener más información sobre el análisis espectral y la demodulación compleja puede consultarse a Schwarzacher (1993), Weedon (1991) y Shackleton et al., (1995).

\subsubsection{Messiniense inferior}

Las secciones estudiadas de los sondeos Casanieves-1 y Villamanrique-1 se han calibrado con la curva de insolación de Laskar (1990), para una latitud de $65^{\circ} \mathrm{N}$ (fig. 5.15). Siguiendo la metodología detallada anteriormente, se realizó previamente un estudio bioestratigráfico de los sondeos utilizando preferentemente bioeventos de extinción (para prevenir posibles contaminaciones). En los capítulos 3 y 6 se muestra detallada información sobre la bioestratigrafía de los sondeos estudiados.

En las series Tortoniense y Messiniense de los sondeos Casanieves-1 y Villamanrique-1 se han utilizado 7 bioeventos previamente calibrados con la escala astronómica de tiempo (APTS):

1- El primero de los eventos de foraminíferos planctónicos utilizados ha sido la última aparición común del grupo Globorotalia menardii sinistrorso que se localiza en el tramo inferior del ciclo $S$ de baja frecuencia en los sondeos Villamanrique-1 y Casanieves-1 (fig. 5.15). La desaparición del grupo de G. menardii sin se produce unos metros por encima del ciclo de insolación 718, en el Chron C4n.1r y presenta una edad de 7,512 Ma (Hilgen et al. 1995).

2- Por encima, en el tramo medio del ciclo $S$ de baja frecuencia (fig. 5.15), se encuentra la primera aparición común $(F C O)$ del grupo de G. menardii dx (evento E2). Hilgen et al. (1995) estiman que la aparición abundante de G. menardii dx tiene lugar encima del ciclo de insolación 704 en el Chron C3Br.2r, con una edad de 7,355 Ma 
3- La desaparición del grupo anterior ( $L O$ del grupo de G. menardii dx) se localiza en el tramo final del ciclo $S$ de baja frecuencia de los sondeos Villamanrique-1 y Casanieves- 1. (fig. 5.15) El reemplazamiento de G. menardii dx por el grupo de G. miotumida se produce en torno al ciclo de insolación 692 con una edad astronómica de $7.260 \mathrm{Ma}$ (Sierro et al., en prensa). Esta desaparición coincide prácticamente con la primera aparición regular $(F C O)$ del grupo de G. miotumida que tiene lugar en el Chron C3Br.1r, con una edad aproximada de 7,240 Ma (Hilgen et al., 1995). Este reemplazamiento (Evento E3; capítulo 3) coincide con el límite Tortoniense-Messiniense.

4- El cambio en el sentido de enrollamiento de $N$. acostaensis (Evento E4; capítulo 3) se registra en el tercio final del ciclo $Q$ de baja frecuencia (fig. 5.15). Este mismo evento aparece hacia el ciclo de insolación 606, teniendo lugar en el Chron C3An.1r (Krijgsman et al., 1999b), con una edad aproximada de 6,35 Ma (Sierro et al. en prensa) de acuerdo con la escala astronómica de tiempo de Hilgen et al. 1995.

5- La desaparición del grupo de G. miotumida (Evento E5) se halla en el cron C3An.1r, si bien actualmente se encuentra pendiente de datación definitiva. En esta Tesis se plantea una edad astronómica de 6.3 Ma para la desaparición de G. miotumida, en función del registro de desaparición de este taxón en los sondeos Villamanrique-1 y Casanieves-1 (al final del ciclo Q17) inmediatamente después del cambio de enrollamiento de $N$. acostaensis (6.35 Ma) (fig. 5.15). Por otro lado, este evento no es isócrono con el Mediterráneo, donde la $L O$ del grupo de G. miotumida está registrada hacia los $6.504 \mathrm{Ma}$ (Krijgsman et al., 1999b; Hilgen y Krijgsman, 1999b, Sierro et al., en prensa). Este diacronismo entre las series mediterráneas y atlánticas se produce debido a la progresiva restricción de la comunicación entre el Atlántico y el Mediterráneo durante el Messiniense, que afecta directamente a la distribución de los globorotálidos en el Mediterráneo.

6- La aparición del grupo de G. margaritae se produce entorno al ciclo P15 en el sondeo Villamanrique y en un intervalo más amplio bajo este ciclo en el sondeo Casanieves-1 (fig. 5.15). La primera aparición abundante (FCO) del grupo de G. margaritae, está localizada en el ciclo de insolación 578 y presenta una edad de 6,05 Ma de acuerdo con la escala astronómica de tiempo (Hilgen com. per.).

7- Finalmente, e inmediatamente por encima de la FCO del grupo de G. margaritae, en el ciclo de insolación 576, se produce una reducción significativa de la abundancia de formas dextrógiras del grupo de G. scitula dx. Es conocida su posición relativa (inmediatamente por encima de la $F C O$ del grupo de G. margaritae) en la escala de tiempo astronómica (Sierro com. per.), pero al igual que la desaparición de G. miotumida, 


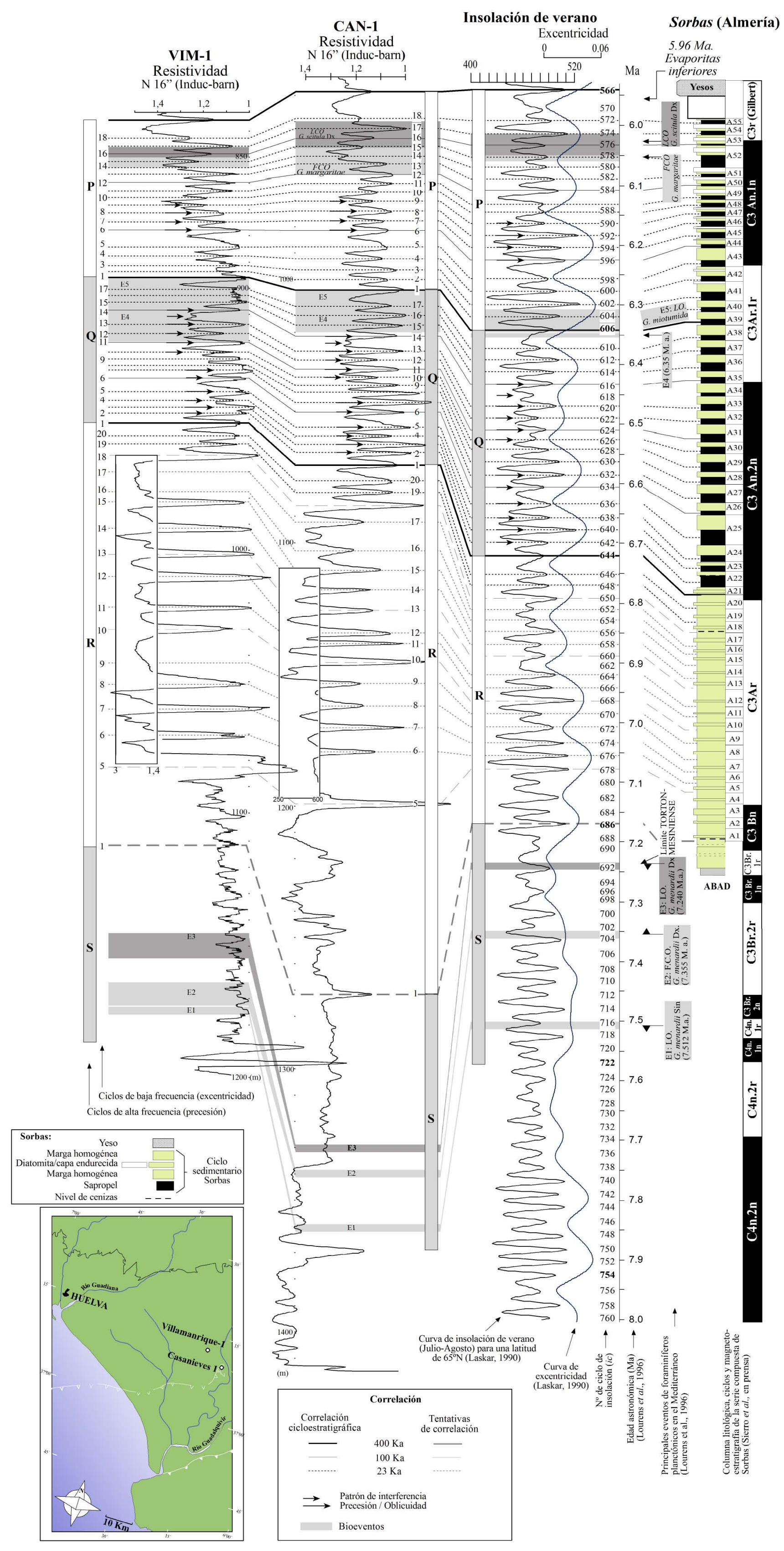

Figura 5.15. Correlación cicloestratigráfica y astrobiocronológica de los sondeos Villamanrique-1 y Casanieves-1. La denominación propuesta para cada ciclo sedimentario es del tipo $\mathrm{Xn}^{\circ}$, donde $\mathrm{X}$ corresponde al ciclo de excentricidad de $\mathbf{4 0 0 . 0 0 0}$ años (ciclos de baja frecuencia, 1er orden) y $\mathbf{n}^{\circ}$ el número de ciclo de precesión (alta frecuencia, 3er orden) dentro del ciclo de excentricidad. La correlación se encuentra calibrada con la curva de insolación (Laskar, 1990) y con la serie de la cuenca de Sorbas ( basada en Sierro et al., en prensa y Krijgsman et al., en prensa). Junto a la curva de insolación aparece la curva de excentricidad que refleja los ciclos de excentricidad de $\mathbf{1 0 0 . 0 0 0}$ años (ciclos de baja frecuencia, $2^{\circ}$ orden), el número de ciclo de insolación (insolation cycle, ic.) extablecido por Lourens et al. (1996) y la edad en millones de años según la escala astronómica de tiempo. 

es la primera vez que se puede correlacionar este evento con la curva astronómica. Proponemos por lo tanto una datación de 6.03 Ma para este evento en función de su localización entre los ciclos P16 y P17 de los sondeos Villamanrique-1 y Casanieves-1 (fig. 5.15).

Es muy probable que incluso los intervalos arcillosos intercalados entre los aparatos turbidíticos, respondan a los parámetro orbitales (tal y como se sugiere en la figura 5.15). Sin embargo, no es hasta el ciclo R18 cuando comienzan a definirse nítidamente los patrones orbitales en los sondeos Casanieves-1 y Villamanrique-1. A partir del ciclo R-18 se abandona la sedimentación turbidítica en ambos sondeos, siendo este ciclo el primero depositado en facies de talud. A partir de ese momento (6.8 Ma) y hasta el límite Mio-Plioceno (5.35 Ma) ambos sondeos registrarán una sedimentación de limo y arcilla, probablemente ligada al talud sur de la cuenca del Guadalquivir. En la cuenca de Nijar (en las secciones de Almendral y Gafares) el primer sapropel sucede curiosamente en el ciclo A18 (Sierro et al., en prensa) equivalente al ciclo R18 en el Guadalquivir. Cabe la posibilidad de que ambos eventos estén relacionados mediante un fenómeno global como puede ser un cambio climático o un evento tectónico regional.

Entre los ciclos Q13 y Q14 (fig. 5.15) se distingue un pequeño ciclo no contabilizado por sus pequeñas dimensiones, pero que si tiene su correspondiente homólogo en la curva de insolación (ic618), siendo un ciclo de amplitud considerablemente pequeña. Sierro et al. (en prensa) destacan en la serie de Sorbas la presencia de un sapropel extremadamente pequeño (A34) que se corresponde con el ciclo de insolación ic618.

Por otra parte el ciclo Q17 es un ciclo potente y el último de la serie Q en un momento de excentricidad mínima. Este ciclo equivale en realidad a dos ciclos de insolación (ic608, ic610) el primero de los cuales no tuvo respuesta sedimentaria suficiente para individualizar un ciclo de precesión debido a la ínfima amplitud que presenta la curva de insolación (fig. 5.15). De la misma forma, en Sorbas el ciclo equivalente (A38) está ampliamente desarrollado y destaca respecto a los ciclos inmediatamente inferiores. El ciclo A38 engloba así mismo los ciclos de insolación ic608 e ic610.

Todos los ciclos de 400.000 años terminan con un ciclo comparativamente más grueso que el resto (con baja amplitud de onda y de potencia superior a la media). Esta característica es debida, como hemos visto, a la modulación de la precesión por la 
excentricidad. Este hecho característico, de existencia de ciclos de insolación sin expresión sedimentaria durante los mínimos de insolación ayuda a identificar los ciclos de excentricidad de 400.000 y 100.000 años. En función de las características de la cuenca sedimentaria y de los parámetros utilizados en el análisis cicloestratigráfico, estos ciclos podrán ser reconocidos en el registro geológico. Así por ejemplo, en la parte superior de la serie de Sorbas, el ciclo A52 es muy buen marcador ya que es muy grueso y está poco laminado (Sierro et al., en prensa). Este mismo ciclo en Casanieves-1 y Villamanrique-1 comprende dos pequeños ciclos (P14 y P15) que se correlacionan con sendos ciclos de insolación (ic578 y ic580). La ventaja de trabajar con parámetros físicos como las diagrafías, estriba en que las pequeñas variaciones también pueden quedar registradas como demuestra este último ejemplo.

Tanto en la curva de insolación como en las diagrafías de los sondeos Casanieves1 y Villamanrique-1, la interferencia entre precesión y oblicuidad se refleja en alternancias del tipo: máximo fuerte - máximo débil - máximo fuerte -... (fig. 5.15). Podemos observar esta interferencia en los valores máximos de los ciclos Q2 a Q7 (débilfuerte-débil-fuerte-débil-fuerte), de los ciclos Q10 a Q14 (débil-fuerte-débil-fuerte-débilfuerte) y de los ciclos P6 a P9 (fuerte-débil-fuerte-débil). En la Serie de Sorbas, son modelos del tipo: ciclo delgado - ciclo grueso, los que reflejan la interferencia entre precesión y oblicuidad; correspondiendo los sapropeles más gruesos a los máximos de insolación fuertes (Hilgen et al., 1995; Lourens et al., 1996b). Así por ejemplo, Sierro et al.(en prensa) identifican la interferencia entre oblicuidad y precesión equivalente a la de los ciclos del Guadalquivir Q10-Q14, en el intervalo de ciclos A30-A35 (delgado-gruesodelgado-grueso-delgado-grueso) en la serie de Sorbas.

\subsubsection{Messiniense superior}

En la figura 5.16 se muestra como el análisis cicloestratigráfico permite correlacionar de forma inequívoca los registros de diagrafías de los sondeos de la cuenca del Guadalquivir-golfo de Cádiz con las secciones datadas astronómicamente de Sorbas (Sierro et al., en prensa), Falconara (Sicilia, Italia) y Metochia (Gavdos) (Hilgen et al., 1995, 1999; Krijgsman et al., 1997; Sprovieri et al., 1999). La bioestratigrafía de las series mediterráneas calibradas astronómicamente está basada fundamentalmente en 9 bioeventos de foraminíferos planctónicos (Hilgen et al., 1995, 1999; Krijgsman et al., 1997). Tres de estos bioeventos han sido igualmente registrados en los sondeos del Guadalquivir: 
- El reemplazamiento del grupo G. menardii dx por el grupo G. miotumida sin (Evento E3) en el Guadalquivir, equivalente a la FRO (primera aparición regular) de $G$. conomiozea.

- El cambio de enrollamiento levógiro a enrollamiento dextrógiro de $N$. acostaensis (Evento 4) en el Guadalquivir y Mediterráneo.

- La desaparición $(L O)$ del grupo $G$. miotumida sin, equivalente a la $L O$ de $G$. conomiozea.

Si bien este último bioevento se registra con anterioridad en el Mediterráneo (debido a las condiciones de aislamiento que experimenta el Messiniense), los otros dos bioeventos son isócronos en ambas áreas y permiten correlacionar los ciclos sedimentarios de ambas regiones y calibrar todos ellos con la escala astronómica de tiempo (fig. 5.16).

Krijgsman et al. (1999b) calibraron los ciclos pre-evaporíticos con el registro astronómico utilizando lascurvasde precesión y de insolación de verano para una latitud de $65^{\circ} \mathrm{N}$ pertenecientes a la solución de Laskar90(1,1). Comenzando desde el calibrado astronómico previamente establecido de los ciclos más antiguos del Tortoniense y del Messiniense (Hilgen et al., 1995), los ciclos más jóvenes fueron calibrados en primer lugar con sucesivos máximos de insolación (mínimos de precesión). El calibrado final fue conseguido después de tener en cuenta todos los detalles de los patrones cíclicos sedimentarios relacionados con la modulación de la precesión mediante la excentricidad y de la interferencia entre precesión y oblicuidad con una metodología equivalente a la explicada en el apartado 5.3. Estos patrones cíclicos son claros en Metochia y Falconara (Hilgen y Krijgsman, 1999 y en datos no publicados). De la misma forma, detalles en los modelos de ciclicidad sedimentaria han permitido el calibrado astronómico de la serie compuesta Abad (Almería) (Sierro et al., en prensa). Por otro lado, y como se ha demostrado en el capítulo 5, los patrones de ciclicidad astronómica son perfectamente nítidos en los sondeos Casanieves-1, Villamanrique-1 (fig. 5.15).

Los modelos cíclicos del Guadalquivir-golfo de Cádiz son correlacionables por lo tanto con las secciones orientales del Mediterráneo (fig. 5.16). Así por ejemplo, los ciclos R16 y R17 que son ciclos de escasa amplitud de onda en el Guadalquivir, son muy delgados en Sorbas (A16 y 17) (Sierro et al., en prensa) y se corresponden con sapropeles muy finos en Metochia (M89-90) y Faneromeni (F32-33) (Hilgen et al., 1995). Todo ello en un contexto de excentricidad mínima que determina una curva de insolación con ciclos de baja amplitud (fig. 7.5). Sobre el sondeo Casanieves-1, después de la etapa de sedimentación turbidítica, se registra un ciclo sedimentario fuertemente marcado (R18) 
que se corresponde en Sorbas con el primer sapropel grisáceo bien definido (A18) y que tienen lugar durante un incremento de la amplitud de la precesión y de la insolación relacionadas con la modulación que ejerce la excentricidad sobre la precesión (fig. 5.16). De igual forma, el ciclo Q5 en el Guadalquivir-golfo de Cádiz se correlaciona con el nivel de margas homogéneas del ciclo A25 en Sorbas que presenta una elevada potencia y que se correlaciona con un ciclo de precesión que posee un prolongado periodo de 29 Ka (fig. 5.16). Otro ciclo característico en el Guadalquivir-golfo de Cádiz es el ciclo Q17, con una potencia mayor a la media. Este ciclo es equivalente en Sorbas al ciclo A38 que representa así mismo, una potente serie de margas homogéneas. En ambos casos el ciclo supone un ciclo doble en la curva de insolación (ic608-ic610), en la que el ciclo ic608 no ha tenido representación sedimentaria en ninguna de las dos cuencas. Este ciclo perdido se correlaciona con un ciclo de baja amplitud en precesión / insolación producido por la modulación que la excentricidad ejerce sobre la precesión. Por otro lado, mientras que en Sorbas el ciclo A52 es interpretado como un ciclo doble (Sierro et al., en prensa), en Casanieves-1 si se observan los dos ciclos originales, al igual que en la curva de insolación (fig. 5.16).

Como en los sondeos del Guadalquivir, el ciclo de insolación ic618 corresponde a un ciclo prácticamente sin representación sedimentaria (solo reflejado por un pequeño máximo entre los ciclos Q13-Q14), en todas las secciones de Sorbas y Nijar, el sapropel del ciclo de insolación ic618 es extremadamente delgado y está desprovisto de la fauna oligotrófica típica de los sapropeles (fig. 5.16). Por otro lado, en los sondeos del Guadalquivir, los ciclos ic622 (Q12) y ic626 (Q10) destacan principalmente por ser ciclos de baja amplitud, al igual que la curva de insolación. Mientras que en Sorbas, los sapropeles correspondientes a los ciclos ic622 (Q12) y ic626 (Q10) son más delgados que los sapropeles adyacentes en la mayoría de las secciones (Sierro et al., en prensa) (fig. 5.16).

\footnotetext{
Figura 5.16 (página siguiente). Cicloestratigrafía del sondeo Casanieves-1 y su correlación con las series preevaporíticas messinienses de Sorbas (Sierro et al., en prensa y Krijgsman et al., en prensa), Metochia y Falconara/Gibliscemi (Hilgen et al., 1995, 1999; Krijgsman et al., 1997) . Calibración astronómica con la curva de insolación de Laskar et al. (1990). APTS basada en datos de Sorbas complementados con recientes resultados procedentes de Creta (Krijgsman et al., 1999b).

En el sondeo Casanieves-1, la ciclicidad sedimentaria está definida por una alternancia entre capas de arcilla y niveles de limo o arena. La ciclicidad en la cuenca de Sorbas está caracterizada por una alternancia de margas homogéneas y capas ricas en ópalo-ct en la parte baja de Abad y una alternancia de sapropeles y margas homogéneas (con diatomitas intercaladas irregularmente) en la parte superior. La ciclicidad en Gavdos y Sicilia es bipartita (sapropel / marga) en la parte inferior y principalmente tripartita (sapropel / diatomita / marga) en la parte superior.

Las capas de arcilla en el Guadalquivir, y las laminitas (sapropeles y diatomitas) en el Mediterráneo, corresponden a los máximos de insolación. Por el contrario, las capas de limo en el Guadalquivir y las margas y margas homogéneas en el Mediterráneo, corresponden a los mínimos de insolación. Las alternancias de capas gruesas y finas se correlacionan en ambos casos con variaciones de amplitud (grande-pequeña) en la curva de insolación. Los patrones de interferencia entre la precesión y la oblicuidad y la astrobiocronología permiten comprobar que no se han perdido ciclos sedimentarios y que las correlaciones alternativas pueden ser desestimadas.
} 


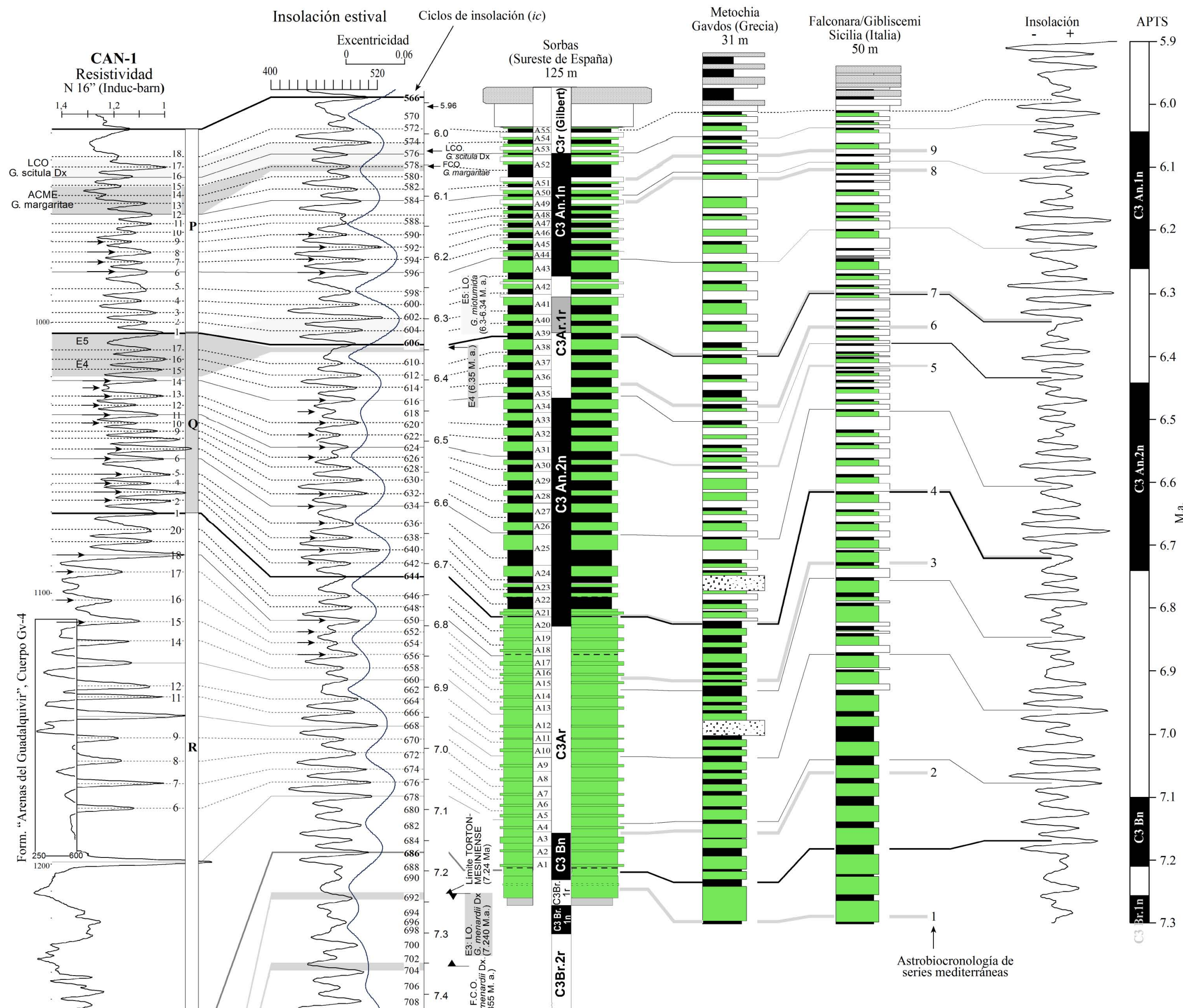

Astrobiocronología sondeos Guadalquivir-golfo de Cádiz:

$\begin{array}{ll}\text { (E1) }=L C O \text { del grupo G. menardii } \sin (7,512 \mathrm{Ma}) \\ \text { 兽: } & \text { (E2) }=F C O \text { del grupo G. menardii } \mathrm{dx}(7,355 \mathrm{Ma})\end{array}$

(E3) = LO del grupo G. menardii $\mathrm{dx} / F C O$ del grupo G. miotumida $\sin (7,240 \mathrm{Ma})$

$($ E4) $=$ Cambio de enrollamiento de $N$. acostaensis (6,35 Ma)

$(\mathrm{E} 5)=L O$ del grupo G. miotumida $\sin (6,3 \mathrm{Ma})$

$\begin{array}{ll}\text { ஸุ } & \text { (E5) }=\text { LO del grupo G. miotumir } \\ \text { F⿻ } & \text { FCO G. margaritae, } 6,05 \mathrm{Ma}\end{array}$

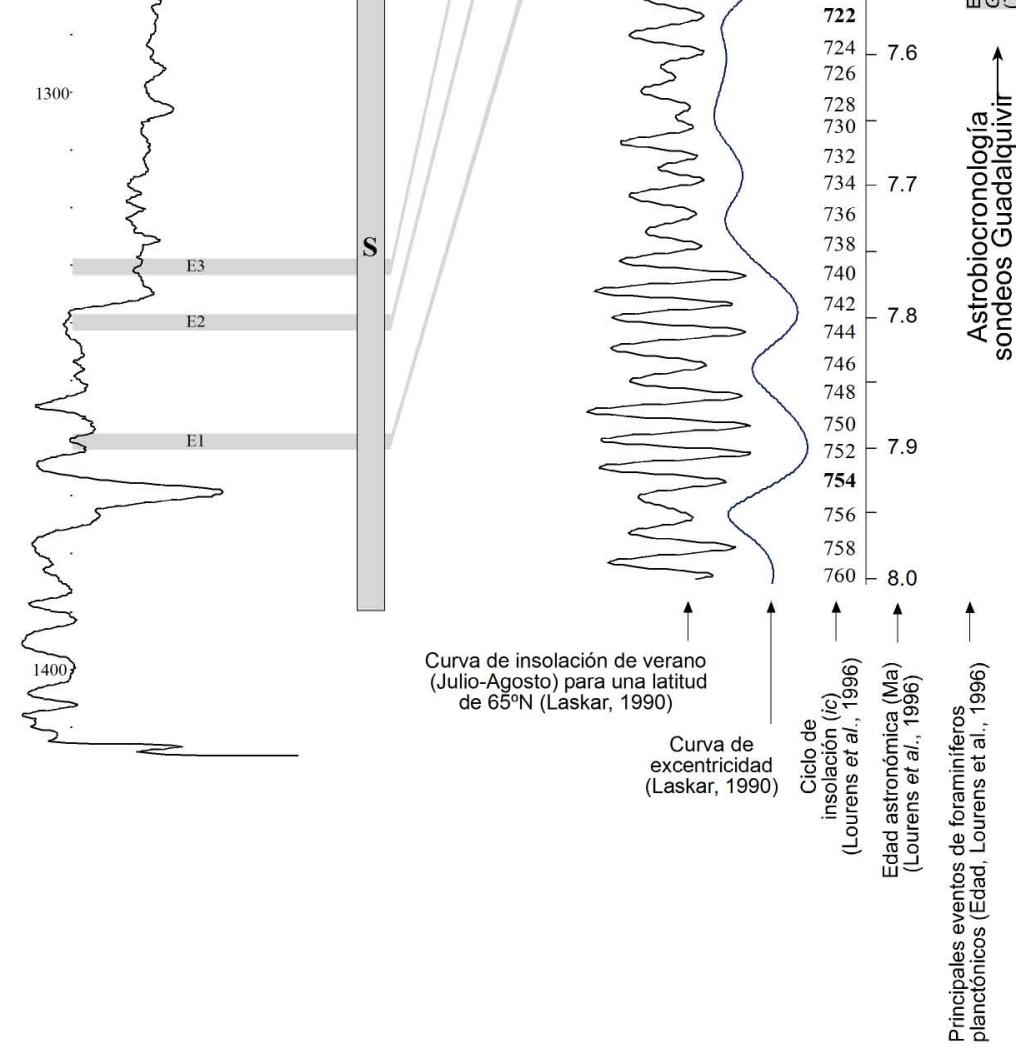

LCO G. scitula 6,28 Ma

Astrobiocronología series del Mediterráneo:

1, aparición regular (FRO) del grupo de Globorotalia conomiozea equivalente al evento E3 en el Guadalquivir

2, última aparición (LO) de Globorotalia scitula sinistrorsa

3, primera aparición (FO) de Globorotalia nicolae

4, última aparición (LO) de G. nicolae

5, última aparición (LO) del grupo G. conomiozea. Equivalente al evento E5 en el

Guadalquivir-golfo de Cádiz. Las condiciones de aislamiento del Mediterráneo al

final del Mesiniense explican su diacronismo.

6, primera aparición común (FCO) de Turborotalita multiloba

7 , cambio de enrollamiento sinestrorso a dextrorso de Neogloboquadrina acostaensis equivalente al evento E4 en el Guadalquivir

8 , primer pulso (influx) de neogloboquadínidos sinestrorsos $(90 \%)$

9 , segundo pulso de neogloboquadrínidos sinistorsos $(40 \%)$

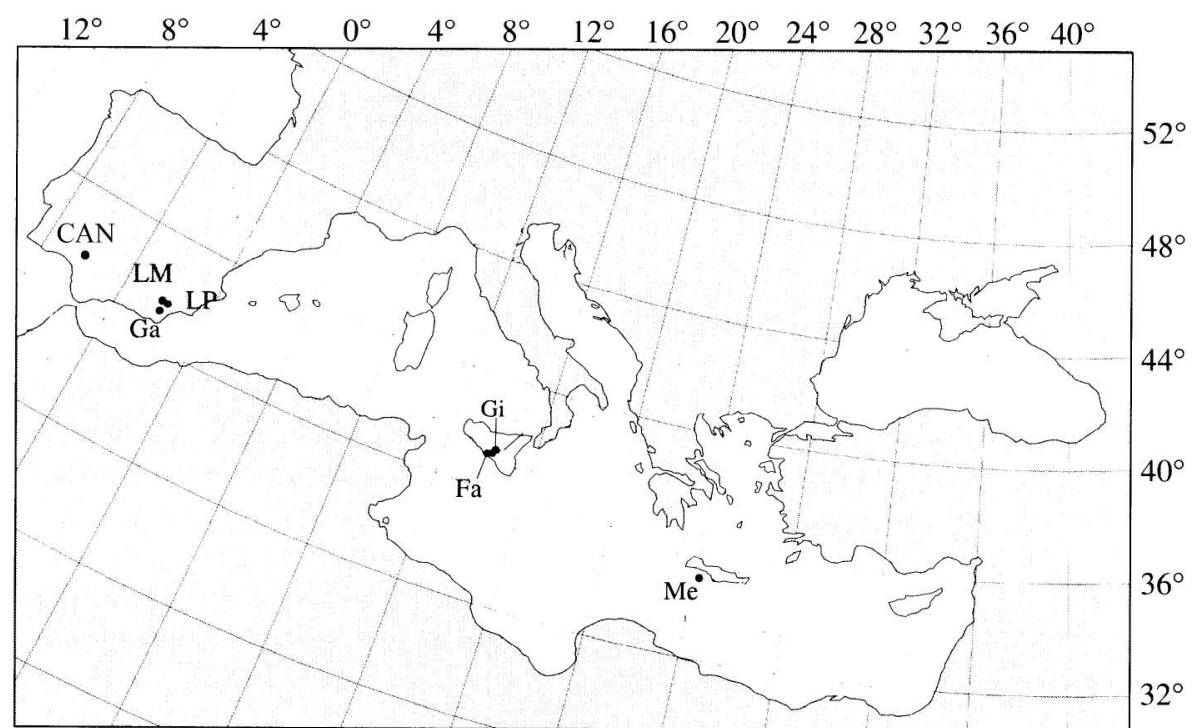



Además del registro de resistividad de los sondeos Casanieves-1 y Villamanrique1, en la figura 5.17 se incluye el registro de rayos gamma del sondeo GC-C2, localizado en el golfo de Cádiz. En esta figura se ha prestado especial atención al intervalo de tiempo que va desde el comienzo de las evaporitas inferiores en el Mediterráneo (5.96 Ma) al límite Mio-Plioceno (5.33 Ma), calibrándose astronómicamente los ciclos de resistividad de los sondeos Villamanrique-1 y Casanieves-1 del último periodo del Messiniense (5.96 a $5.33 \mathrm{Ma}$ ). El análisis cicloestratigráfico que se presenta en la figura 5.17, supone junto con la calibración de las unidades Yesares y Sorbas (cuenca de Sorbas) propuesta por Krijgsman et al. (en prensa), las únicas secciones europeas calibradas con la curva de insolación para este intervalo de tiempo. El intervalo que existe entre el comienzo de las evaporitas inferiores y el límite Mio-Plioceno constituye actualmente una laguna en la reconstrucción de la escala de tiempo de polaridad astronómica (APTS), comúnmente conocida como "gap Messiniense". Por tanto, la correlación que se presenta en la figura 5.17 entre los sondeos Villamanrique-1 y Casanieves-1, puede ayudar a completar este vacio debido a la ausencia de series messinienses completas en el Mediterráneo.

Como contrapunto cabe subrayar que la ausencia de biomarcadores en este intervalo dificulta el seguimiento de los ciclos de alta frecuencia, más aún teniendo en cuenta que han sido inferidos dos posibles slumps en el sondeo Casanieves-1 que entorpecen la correlación. Por otro lado, el registro de resistividad del sondeo Villamanrique-1 y la curva de insolación presentan un alto grado de semejanza en este intervalo, apoyando la correlación que se presenta en la figura 5.17.

Ligeramente después del límite Tortoniense-Messiniense, en los sondeos Casanieves-1 y Villamanrique-1 se desarrolla una etapa de sedimentación turbidítica que va a desplazarse más tarde al golfo de Cádiz (sondeo GC-C2 en la misma figura 5.17). Tras el depósito turbidítico, los sondeos Casanieves-1 y Villamanrique-1 ocupan una posición privilegiada en el talud sur de la cuenca, lo que va a permitir el registro de la ciclicidad orbital durante unos 800.000 años (ciclos P y Q). A partir de este momento, la identificación de la ciclicidad astronómica en el Guadalquivir también se complica debido a la probable intrusión de slumps sobre el sondeo Casanieves-1, que entorpecen el seguimiento de los ciclos (fig. 5.17). Después del límite Mio-Plioceno (5.33 Ma), el retorno de los sondeos a posiciones de fondo de cuenca ocasiona una elevada velocidad de sedimentación que impide la identificación de la ciclicidad astronómica. 


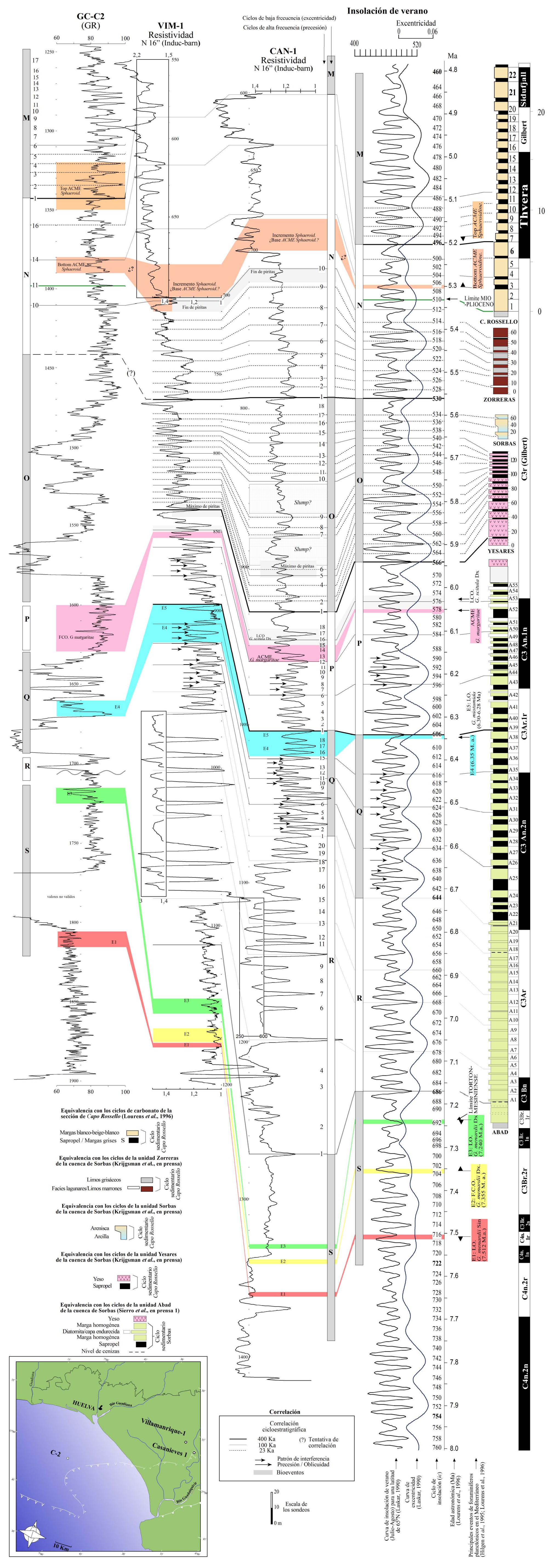

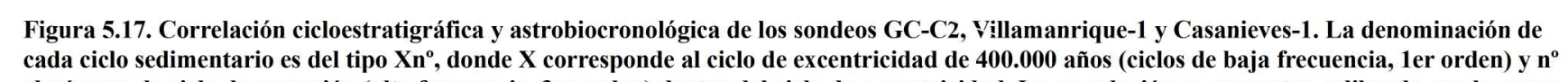

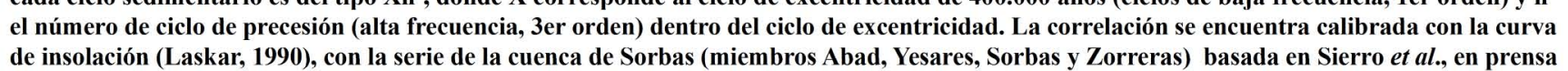

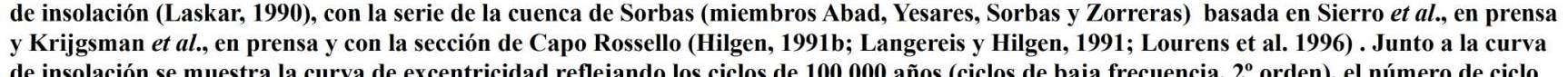

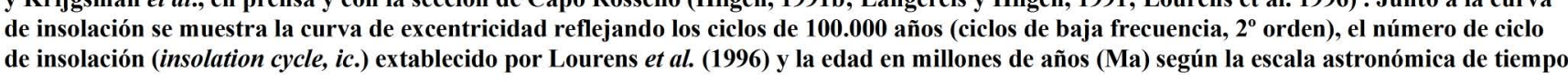



Durante el Tortoniense, el golfo de Cádiz se caracterizó por su reducida velocidad de sedimentación. Esta característica dificulta el reconocimiento de la ciclicidad astronómica en las diagrafías. En el Messiniense el ingreso de los cuerpos turbidíticos impide nuevamente aplicar la cicloestratigrafía astronómica. Para superar esta dificultad en el intervalo Tortoniense-Messiniense del golfo de Cádiz se ha utilizado una correlación bioestratigrafía (capítulo 3) para relacionar los sondeos en las figuras.

\subsubsection{Límite Mio-Plioceno}

En la figura 5.18 podemos observar la correlación de los sondeos C3, C2 y C4 basada en la bioestratigrafía para el intervalo Tortoniense y Messiniense y apoyada en la correlación cicloestratigráfica del intervalo correspondiente al Plioceno (ciclo $\mathrm{M}$ ). Destaca en esta figura la diferencia del registro geofísico Mioceno respecto al que se produce en el Plioceno. La sedimentación turbidítica messiniense impide el reconocimiento de la ciclicidad astronómica. A partir del límite Mio-Plioceno la ausencia de turbiditas y el continuo suministro de material desde el Guadalquivir, permiten la individualización de los ciclos en el golfo de Cádiz.

La curva de insolación (ciclo ic510) y la posición del límite Mio-plioceno (5.33 Ma) en la base de la sección de Capo Rossello, permiten estimar la posición de este límite en los logs de velocidad sónica y gamma ray de los sondeos del golfo de Cádiz. 



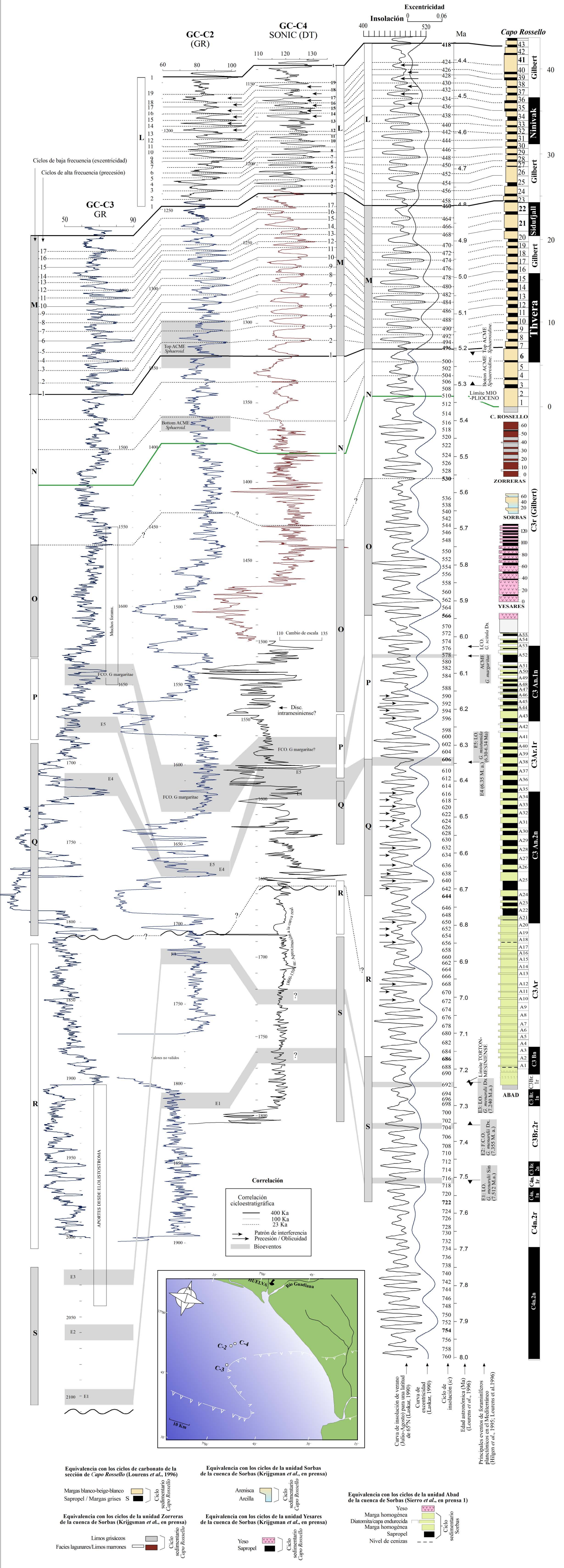

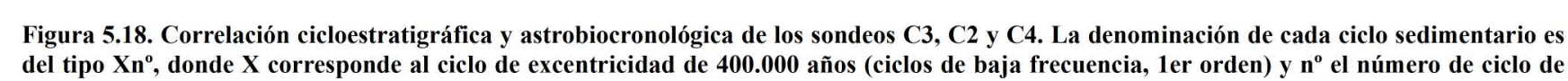
precesión (alta frecuencia, 3er orden) dentro del ciclo de excentricidad. La correlación se encuentra calibrada con la curva de insolación et al., en prensa y con la sección de Capo Rossello (Hilgen, 1991b; Langereis y Hilgen, 1991; Lourens et al. 1996). Junto a la curva de insolación se muestra la curva de excentricidad reflejando los ciclos de 100.000 años (ciclos de baja frecuencia, $2^{\circ}$ orden), el número de ciclo 



\subsubsection{Plioceno}

En el caso del golfo de Cádiz, se ha utilizado la serie de Capo Rossello en Sicilia (Hilgen, 1991b; Langereis y Hilgen, 1991; Lourens et al., 1996b) como referencia para correlacionar las variaciones cíclicas del registro geofísico Plioceno y calibrarlas con la escala astronómica. Como en el caso de los sondeos Casanieves-1 y Villamanrique-1 en el Guadalquivir, se realizó previamente un estudio bioestratigráfico en el que se ha determinado la posición de seis bioeventos calibrados con la escala astronómica de tiempo. La localización de estos eventos ha permitido correlacionar ciclo a ciclo los registros geofísicos de estos sondeos con la escala astronómica de tiempo (APTS).

Se han utilizado los siguientes eventos en la cicloestratigrafía de los sondeos del golfo de Cádiz :

1- En los sondeos B2 y C2 fue identificado un intervalo con Sphaeroidinellopsis muy abundante. Este género aumenta su presencia en las muestras entorno al ciclo N12-N14. Este bioevento se ha relacionado con el comienzo del acme de Sphaeroidinellopsis observado en Capo Rossello (CR) en el ciclo CR1 (Hilgen, 1991b) (fig. 5.18).

2- La disminución de Sphaeroidinellopsis unos metros por encima del evento anterior alrededor del ciclo $\mathrm{M} 1$ en los sondeos B2 y C2 (fig. 5.18), se ha comparado con el final del acme de este género, que ha sido observado en Capo Rossello $(C R)$ en el ciclo $C R 7$ (Hilgen, 1991b).

3- La última aparición común ( $L C O$ ) de Globorotalia margaritae situada en la base del ciclo CR60 en Capo Rossello (Hilgen, 1991b), con una edad astronómica de 3,98 Ma (Lourens et al., 1996b), está situada entre los ciclos K15 y J5 en el sondeo C2 (fig. 5.19), entre los ciclos K16 y J3 en el sondeo 6x1 (fig. 5.20), entre los ciclos K17-J5 en el sondeo Atlántida-3 (fig. 5.20), y en la mitad superior del ciclo K de los sondeos B6, B3 y C3 (Póster).

4- La última aparición ( $L O)$ de Globorotalia margaritae ha sido localizado entre los ciclos J7-J9 en el sondeo C2 (fig. 5.19), entre J7 y J11 en 6X1 (fig. 5.20), y entre J8-J10 en Atlántida-3 (fig. 5.20), así como en la zona media del ciclo J en los sondeos B3 y C3 (Póster). Este bioevento sucede en el ciclo CR67 en Capo Rossello, con una edad astronómica de 3,81 Ma (Lourens et al., 1996b)

5- La última aparición de Sphaeroidinellopsis seminulina sucede inmediatamente por encima del ciclo 117 en el sondeo 6x1 (fig. 5.20), entre los ciclos (I17-H4) en Atlántida-3 (fig. 5.20)y en la base del ciclo $\mathrm{H}$ en el sondeo B6 (Póster), correlacionándose con el 
mismo acontecimiento en el ciclo CR96 en Capo Rossello. La edad astronómica de este bioevento es de 3,19 Ma (Lourens et al., 1996b).

6- La última aparición de G. altispira sucede entre el ciclo I y el H en el sondeo 6x1 y en el intervalo I17-H4 en Atlántida-3 (fig. 5.20), que se correlaciona con el ciclo de insolación ic302 y presenta una edad de 3.17 Ma (Lourens et al., 1996b).

\section{Ciclos de baja frecuencia - Ciclos de excentricidad}

Utilizando los bioeventos datados astronómicamente, puede ser establecida una correlación directa entre los ciclos de baja frecuencia de rayos gamma o velocidad sónica y los mínimos de excentricidad de $400 \mathrm{Ka}$. Como vimos en el apartado metodológico, la presencia de periodos de baja amplitud de onda en los $\log s$ caracterizan el final de los ciclos de baja frecuencia ( $1^{\mathrm{er}}$ orden). Los ciclos de excentricidad L y M en las diagrafías de los sondeos B2 y C2 (fig. 5.19) son fácilmente reconocibles por el patrón observado en las variaciones de amplitud, con altas fluctuaciones en la zona central de los ciclos correspondiendo con los máximos de excentricidad (400 Ka) y fluctuaciones de baja amplitud hacia el muro y techo del ciclo que se corresponden con periodos de baja amplitud de insolación durante los mínimos de excentricidad (400 Ka). Obsérvese que los ciclos de excentricidad L y M son también característicos en la curva astronómica. Sin embargo, en la parte superior de estos sondeos y en los sondeos 6x1 y At-3 (fig. 5.20), los intervalos con baja amplitud de onda no son tan fácilmente reconocibles. En este caso, los ciclos de $1^{\text {er }}$ orden pueden identificarse por la regular aparición de intervalos extraordinariamente gruesos, cada 17 o 19 pequeños ciclos de alta frecuencia ( $3{ }^{\text {er }}$ orden). De acuerdo con este criterio, se han identificado otros 5 ciclos de baja frecuencia- ${ }^{\text {er }}$ orden (K, J, I, H, G) en los logs de rayos gamma y velocidad sónica de sondeos del golfo de Cádiz (fig. 5.21).

\section{Ciclos de alta frecuencia - Ciclos de precesión}

Una vez realizada la calibración de los grandes ciclos de excentricidad, los ciclos sónicos y de rayos gamma de pequeña escala, pueden ser correlacionados con la precesión. Para continuar con la correlación se comparan las pautas que aparecen en los logs atlánticos con las que aparecen en la serie compuesta de Capo Rossello (Hilgen, 1991b; Langereis y Hilgen, 1991; Lourens et al., 1996b) y con las soluciones astronómicas (Laskar, 1990). El análisis cicloestratigráfico se centra en el espesor y amplitud de los pequeños ciclos de precesión. 

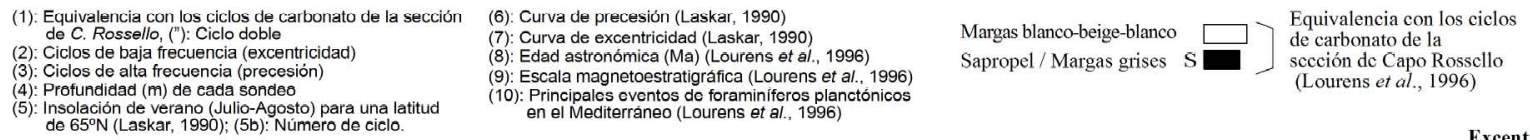

Escala de
los sondeos $\prod_{0 \mathrm{~m}}^{20}$

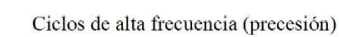

Ciclos de baja frecuencia (excentricidad)

GC-B2

GC-C2

Capo Rossello

GR

GR

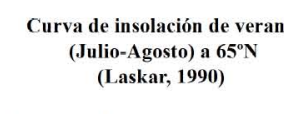

Excentricidad 0.06

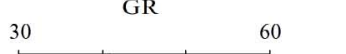

60

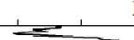

100

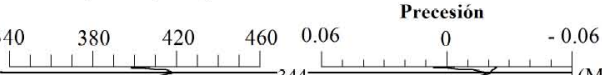

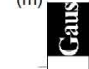

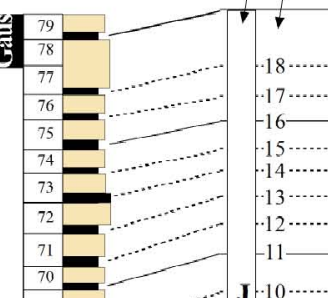

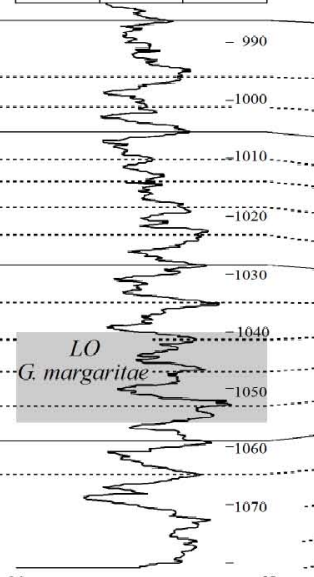
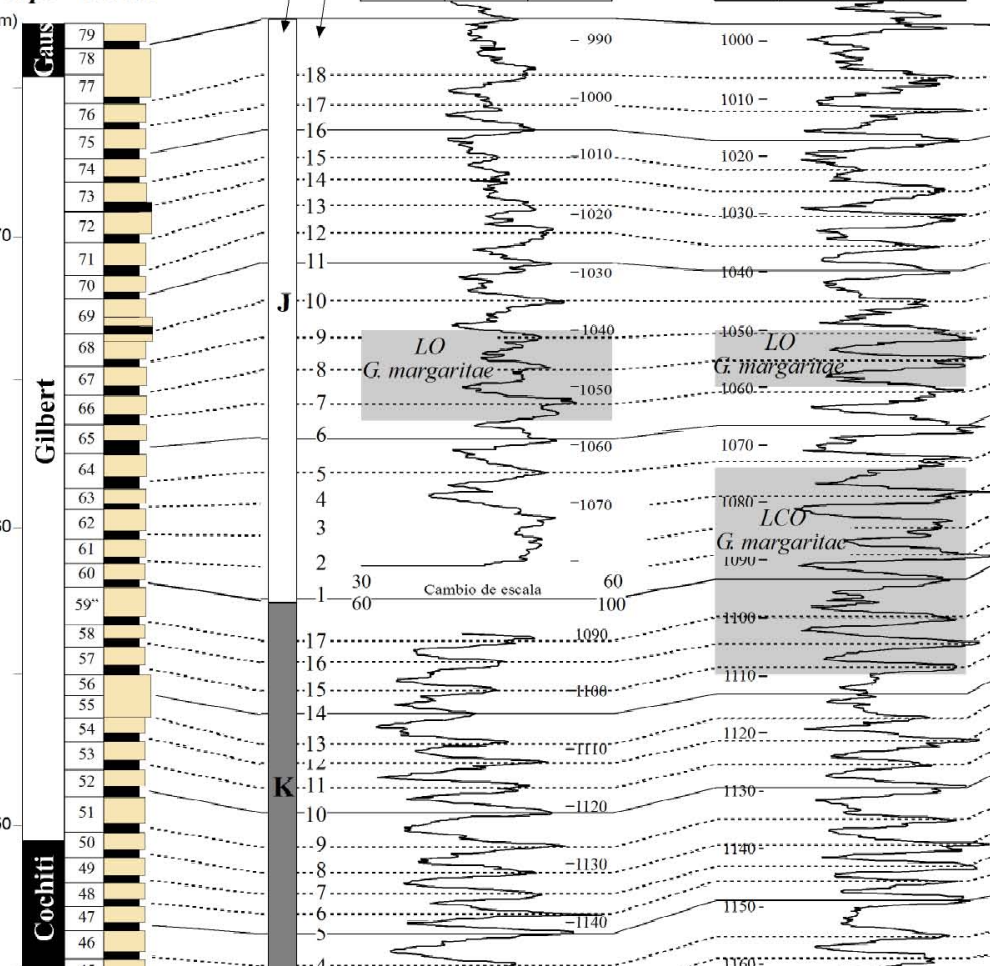

40 产
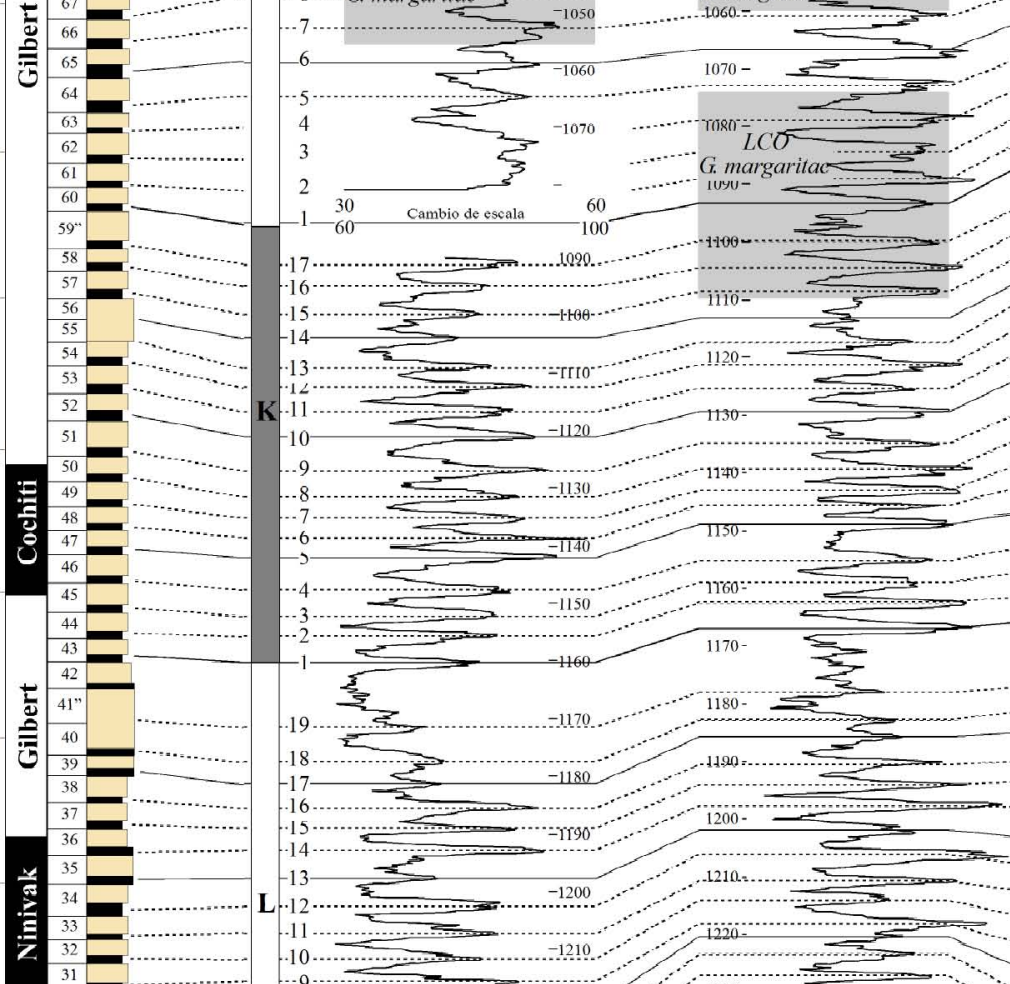

30
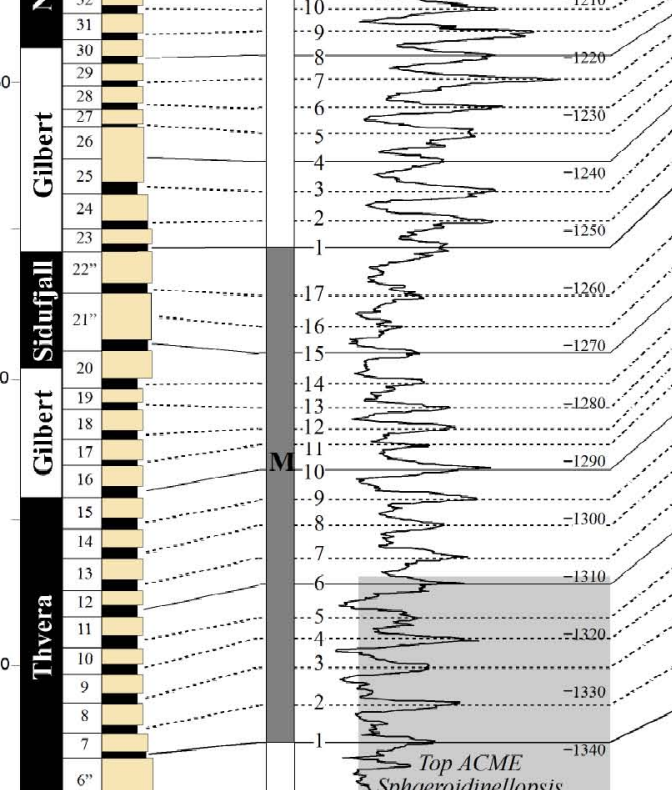

in

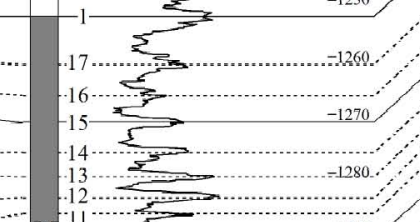

$\mathbf{M}_{10}^{11}$

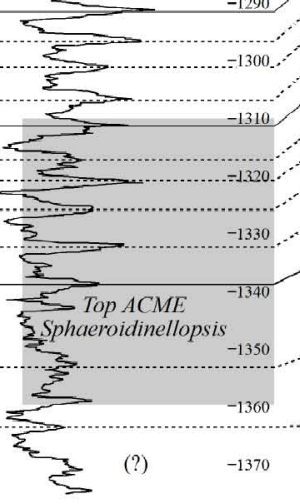

(2) (3)

(4)
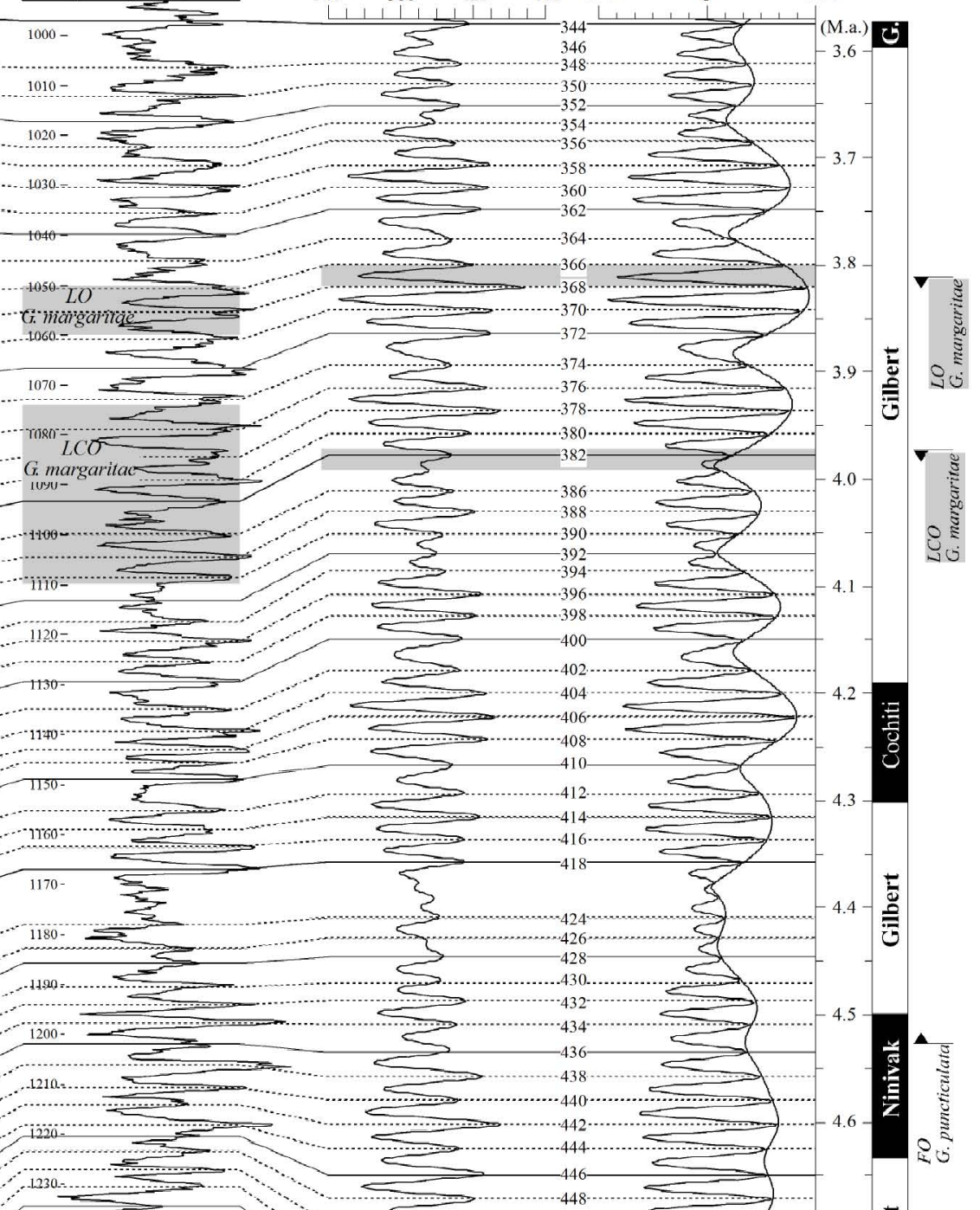

(1)
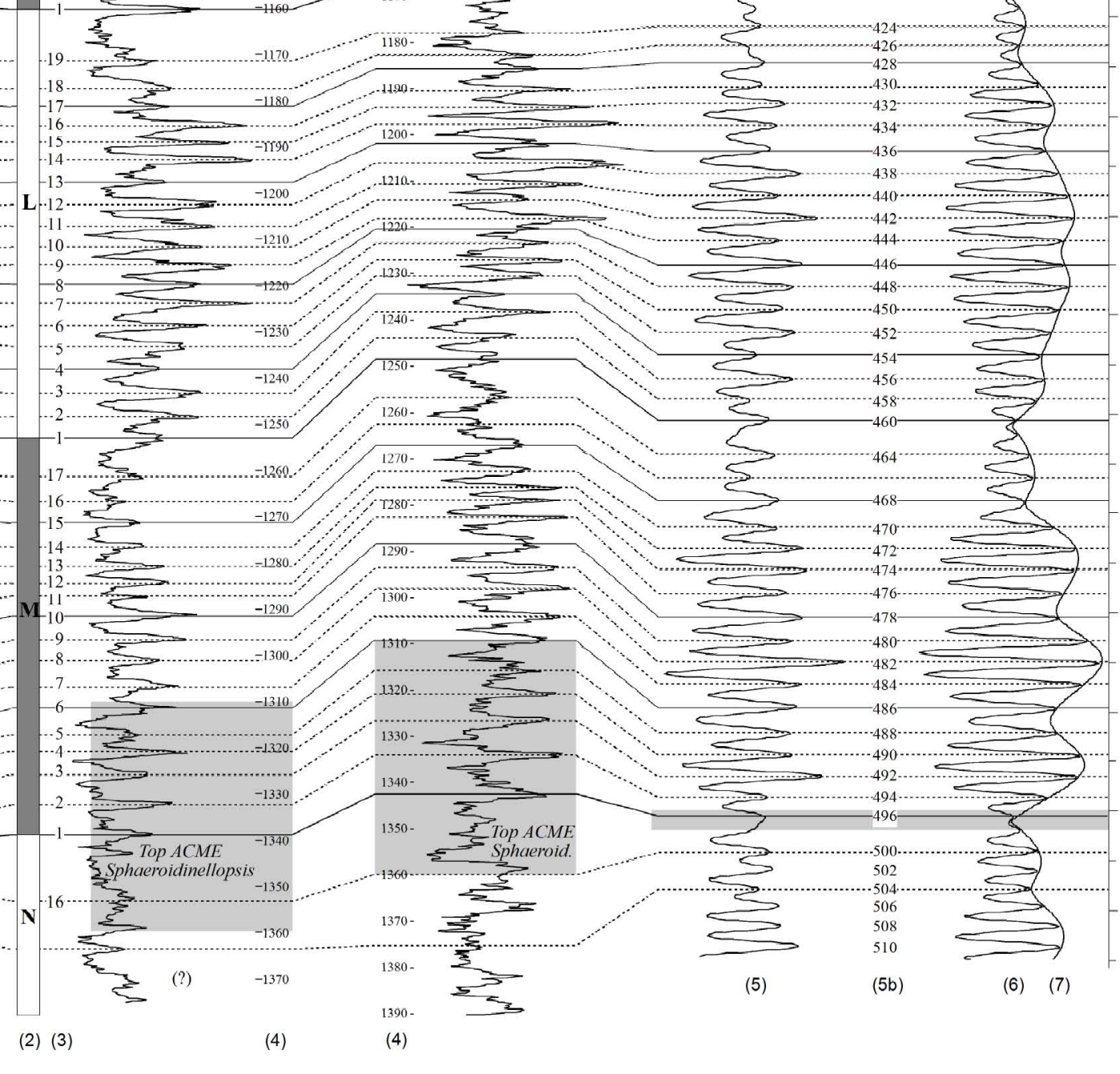

Figura 5.19. Correlación cicloestratigráfica y astrobiocronológica de los sondeos GC-B2 y GC-C2. La correlación se encuentra calibrada con la curva de insolación (Laskar, 1990) y con la sección de referencia de Capo Rossello (Hilgen, 1991b; Langereis y Hilgen, 1991; Lourens et al. 1996). 
En particular, es significativa la baja amplitud y la mayor potencia del ciclo sedimentario ligado a los mínimos de excentricidad, cada $100 \mathrm{Ka}$ y cada $400 \mathrm{Ka}$ (fig. 5.21). En el apartado metodológico se muestra una amplia información sobre las pautas y características distintivas de los ciclos sedimentarios en relación a la curva astronómica.

\section{Ciclos característicos. Modulación de los ciclos de precesión por la excentricidad}

En la figura 5.19, se muestra la correlación cicloestratigráfica y astrobiocronológica de los registros de rayos gamma de los sondeos B2 y C2 comparándolos a su vez con la serie de Capo Rossello (Sicilia), que es la sección de referencia global para la escala astronómica de tiempo en el Plioceno (Hilgen, 1991b; Langereis y Hilgen, 1991; Lourens et al., 1996b). En Capo Rossello los ciclos CR6, 21, $22,41,59,82,87,95,110$ y 111 son ciclos característicos, mucho más gruesos que el resto, de hecho, son ciclos dobles que se correlacionan con dos ciclos consecutivos de precesión de baja amplitud (Hilgen, 1991b; Lourens et al., 1996b). Contienen por lo tanto un ciclo extra que no tuvo expresión sedimentaria. Estos ciclos característicos, que no se registran en el Mediterráneo, si están reflejados en las diagrafías de los sondeos del golfo de Cádiz aunque débilmente (figura 5.19). El intervalo característico localizado inmediatamente debajo de M1 con valores de pequeña amplitud en gamma ray (sondeos B2 y C2), se correlaciona con el ciclo CR6 de Capo Rossello y corresponde a la pareja de ciclos de insolación ic498-ic500. El ciclo M17, que es mucho más grueso que los ciclos colindantes, se correlaciona indudablemente con el ciclo doble $C R 22$, que contiene un ciclo extra sin expresión sedimentaria (ic462) en la curva de insolación. Sin embargo, M16, caracterizado por una baja amplitud en $G R$, constituye el ciclo extra ic446 no registrado en el ciclo doble $C R 21$. Se debe notar sin embargo, que este ciclo extra (ic446) también está presente en Capo Spartivento (Hilgen, 1991b). El intervalo entre L17-K1, como el intervalo CR39-CR42 en Capo Rossello, marca el mínimo de excentricidad de $400 \mathrm{Ka}$ y es el más problemático para subdividir en ciclos individuales de pequeña escala, registrándose picos muy débiles en las diagrafías de rayos gamma. El ciclo K17 es nuevamente un ciclo doble que se correlaciona con en ciclo CR59 en Capo Rossello, equivalente a la pareja de ciclos de insolación ic384-ic386, que marcan el mínimo de excentricidad de $400 \mathrm{Ka}$. 


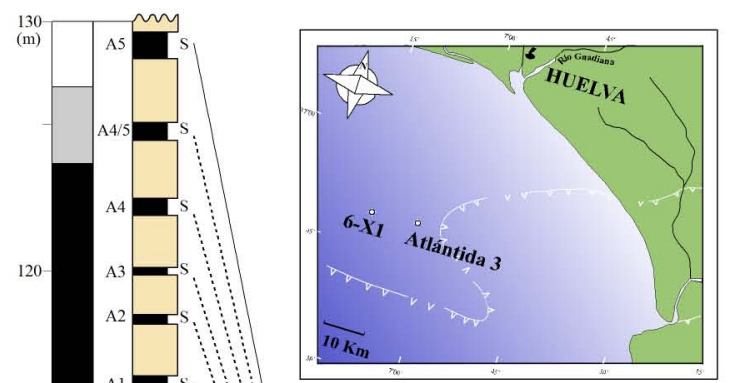

1 :Escala

magnetoestratigráfica

2:Principales eventos d

foraminiferos planctóni-

cos en el Mediterráneo
(Lourens et al., 1996)

Excentricidad

Ciclo sedimentario Capo Rossello

$\square$ Margas blanco-beige-blanco

S Sapropel / Margas grises

ATLANTIDA - 3

SONIC (DT)

\section{0}

Insolación estival

(W/m2)

$0.06-0+0.06$

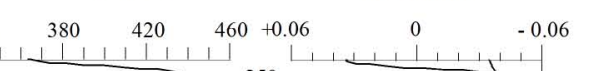

(1) (2)

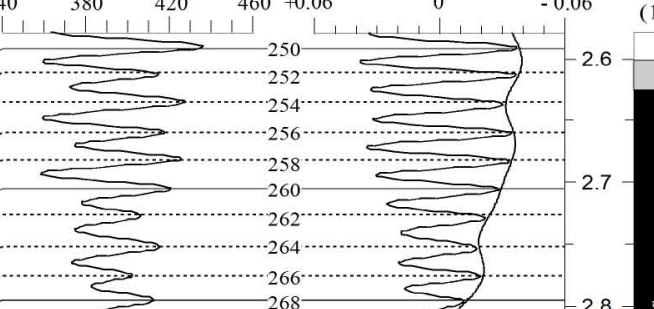

10
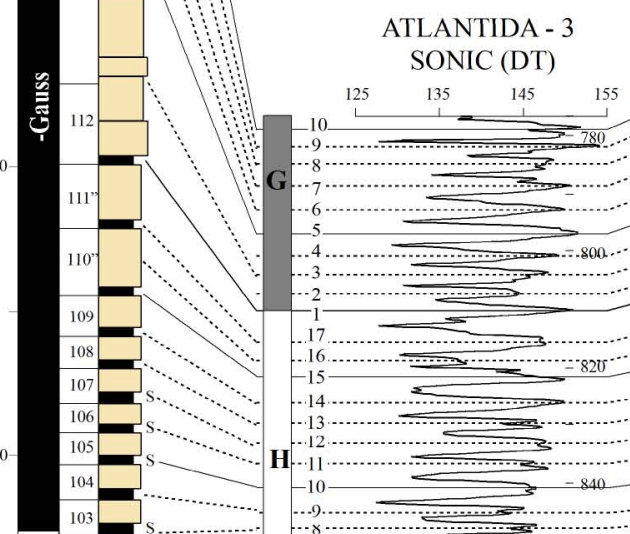
En la figura 5.20 además de las anteriores características, los ciclos I4, I9, I17 y H17 son también ciclos dobles que se correlacionan con CR82, CR87, CR95 y CR111 respectivamente. El ciclo extra ausente en $C R 110$ sin embargo, se expresa mediante un pequeño pico de baja amplitud en el registro sónico del sondeo At-3. El ciclo extra ausente (ic336) en el ciclo doble I4 en Atlántida-3 (equivalente al ciclo doble CR87 en Capo Rossello), se registra sin embargo por un pico de baja amplitud en el registro sónico del sondeo 6-X1.

En la figura 5.21 se presenta la correlación cicloestratigráfica y astrobiocronológica de los sondeos B2, C2, 6x1 y Atlántida-3 con la curva de insolación de verano para una latitud de $65^{\circ} \mathrm{N}$ (Laskar, 1990) y con la serie de Capo Rossello calibrada astronómicamente (Hilgen, 1991b; Langereis y Hilgen, 1991; Lourens et al., 1996b). El resultado es una correlación de ultra-alta resolución entre los cuatro sondeos con una precisión siempre inferior a 20.000 años (duración de un ciclo de precesión). En esta figura podemos observar nuevamente uno de los patrones cicloestratigráficos característicos registrado en las diagrafías: la presencia regular de ciclos sedimentarios más potentes que la media, que se correlacionan con ciclos de insolación más duraderos que la media, marcando la excentricidad mínima cada $100 \mathrm{Ka}$. Esto sucede en los ciclos más potentes que la media M5, M14, K4, K9, J5, J10, H4, H9 y H14 equivalentes a los respectivos ciclos $C R 11, C R 20, C R 46, C R 51, C R 64, C R 69, C R 99, C R 104$ y $C R 109$ en Capo Rossello y que corresponden a los ciclos de insolación de mayor longitud de onda (duración): ic488, ic470, ic412, ic402, ic374, ic364, ic298, ic288 y ic278 respectivamente (fig. 5.21).

Los ciclos de baja amplitud y/o máximos débiles en nuestros $\log s$, como por ejemplo M16, L4, L17, L18, L19, K14, J15, H16 (fig. 5.21) se corresponden con ciclos sin capas grises o sapropeles en los ciclos $C R 21$ (sin capa gris), $C R 26$ (sin capa gris), $C R 39, C R 40, C R 41$ (sin capa gris), $C R 56$ (sin capa gris), $C R 74$, y $C R 110$ (sin capa gris) de Capo Rossello. Estos máximos de baja amplitud en los $\log s$ pueden correlacionarse directamente con los máximos de baja amplitud en la curva de insolación acaecidos durante los mínimos de excentricidad cada $100 \mathrm{Ka}$ (fig. 5.21).

Los patrones cíclicos descritos arriba son coherentes entre los diferentes logs tanto sónicos como de rayos gamma y sostienen con fuerza las correlaciones de sondeos en el golfo de Cádiz y las correlaciones entre ellos y Capo Rossello así como su calibración astronómica. 

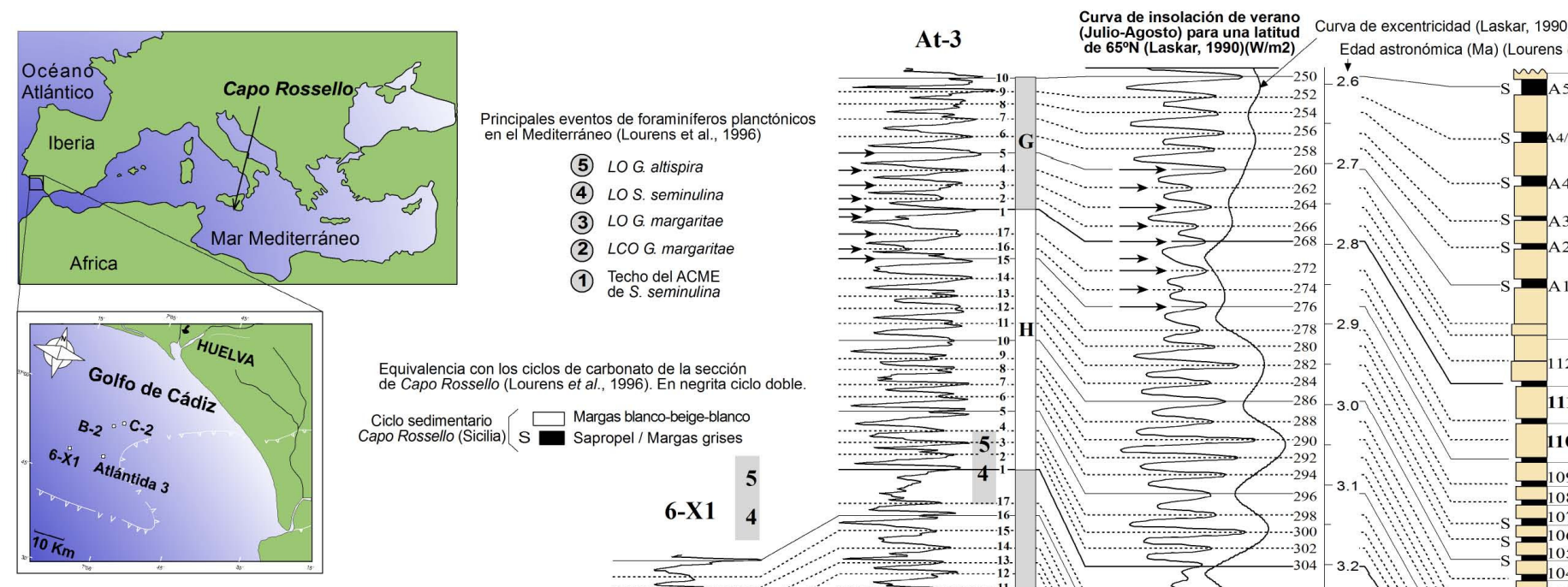

Curva de insolación de verano Curva de excentricidad (Laskar, 1990)

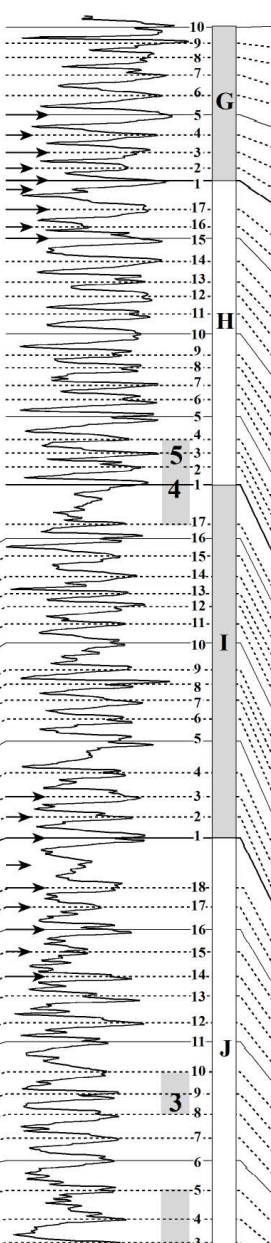

Equivalencia con los ciclos de carbonato de la sección
de Capo Rossello (Lourens et al., 1996). En negrita ciclo doble Ciclo sedimentario $\square$ Margas blanco-beige-blanco Capo Rossello (Sicilia) S Sapropel / Margas grises
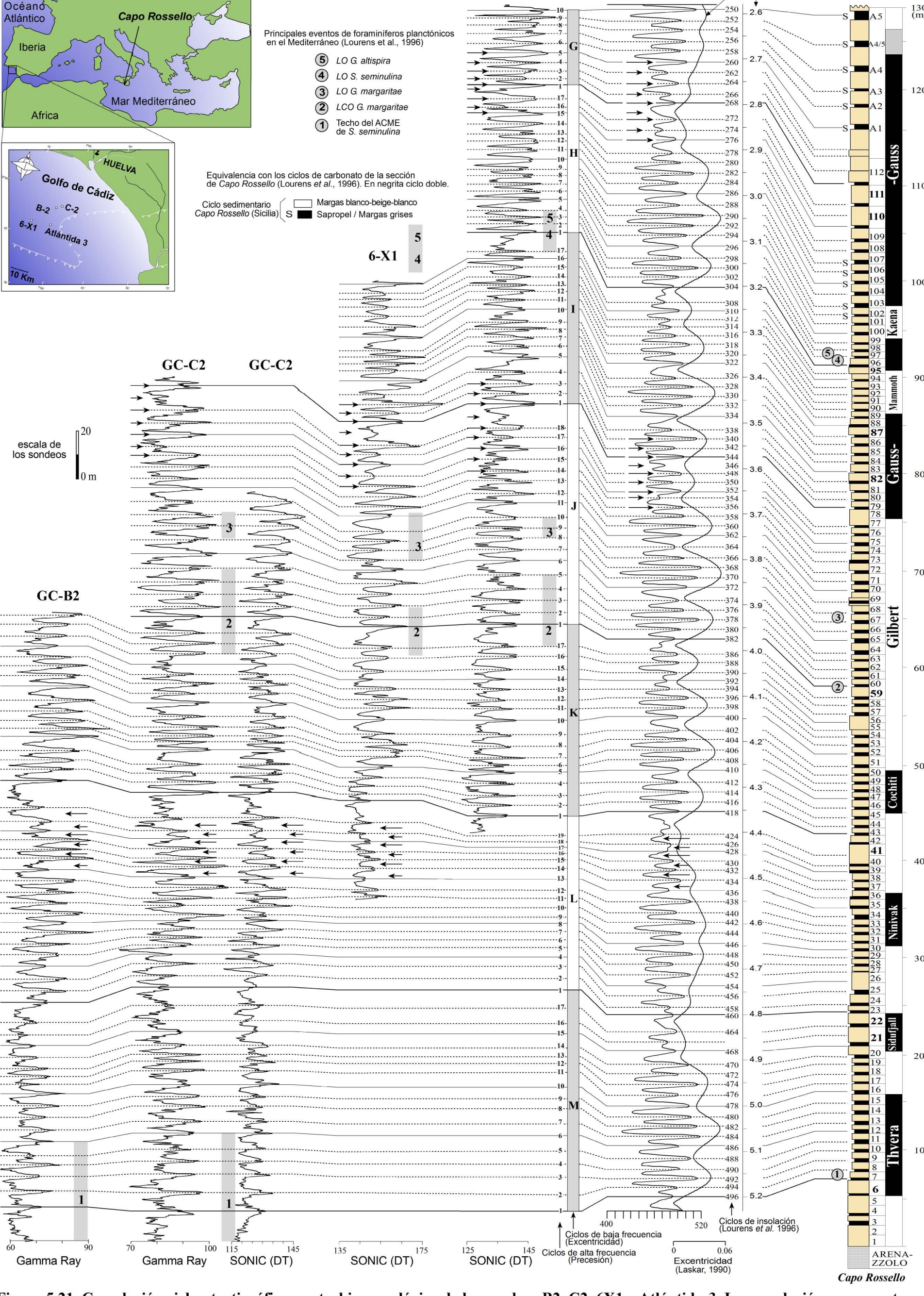


\section{Interferencia entre precesión y oblicuidad}

Los ciclos de rayos gamma y velocidad sónica son controlados principalmente por la precesion, aunque la influencia de la oblicuidad puede ser también observada en algunos intervalos comúnmente relacionados con los mínimos de excentricidad de 400 Ka. Observamos un claro modelo de interferencia entre precesión y oblicuidad en el intervalo entre L14 y L19 (fig. 5.21) definido por una alternancia entre ciclos con mínimos débiles (baja amplitud de la onda de rayos gamma) y/o de menor potencia con ciclos con mínimos fuertes (gran amplitud de onda) y/o mayor potencia. Los mínimos fuertes ocurren en L14, L16, L18 y en la parte superior de L19 y se suceden alternativamente con mínimos débiles en los ciclos L15, L17 y la parte inferior de L19 respectivamente. Se ha observado el mismo modelo de interferencia en Capo Rossello entre los ciclos $C R 36-C R 42$ y es también evidente en todas las curvas de insolación (ver Lourens et al 1996b).

No obstante, el modelo de interferencia entre precesión y oblicuidad más característico puede verse en el intervalo entre los ciclos J14 e I3 (fig. 5.21). Los ciclos J14, J16, J18, I1 y I3, están caracterizados por máximos fuertes (gran amplitud de la onda de insolación) y/o potentes (mayor duración de tiempo) tanto en el registro sónico como de rayos gamma, alternando con los ciclos J15, J17, la parte superior de J18 así como I2 que se caracterizan por ser máximos de insolación débiles y/o de menor duración. Esta interferencia es también muy evidente en la curva de insolation de Laskar, 1990 y se observó también en Capo Rossello entre los ciclos CR73-CR81, donde alternan capas grises bien desarrolladas con estratos grises débilmente desarrollados (Hilgen, 1991b; Langereis y Hilgen, 1991; Lourens et al 1996b).

Nuevamente, entre los ciclos H15 y G5 (fig. 5.21) aparece un claro modelo de interferencia entre oblicuidad y precisión. Los máximos fuertes en el registro sónico en los ciclos H15, H17, G1, G3, G5, alternan con máximos débiles H16, parte superior del ciclo doble H17, G2 y G4. Este modelo de interferencia está así mismo reflejado en las curvas de insolación y ha sido observado en Capo Rossello (Hilgen, 1991b; Langereis y Hilgen, 1991; Lourens et al 1996b).

\section{Repercusiones del análisis cicloestratigráfico}

La resolución que ofrece el método cicloestratigráfico ha permitido por ejemplo establecer el límite Tortoniense-Messiniense, calcular la posición del límite Mio-Plioceno o identificar posibles slumps tanto en sondeos del Guadalquivir (fig. 5.17) como en sondeos del golfo de Cádiz (fig. 5.22). 
(1): Equivalencia con los ciclos de carbonato de la sección de C. Rossello, (): Ciclo doble

(2): Ciclos de baja frecuencia (excentricidad)

Ciclo sedimentario Capo Rossello:

(3): Ciclos de alta frecuencia (precesión)

Margas blanco-beige-blanco Sapropel / Margas grises
(4): Profundidad ( $\mathrm{m}$ ) de cada sondeo

(5): Insolación de verano (Ju
(6): Curva de precesión (Laskar, 1990)

$\begin{aligned} & \text { (7): Curva de excentricidad (Laskar, 1990) } \\ & \text { (8): Edad astronómica (Ma) (Lourens et al., 1996) }\end{aligned} \|_{10}^{20} \quad$ Escala de

(9): Escala magnetoestratigráfica (Lourens et al., 1996) : Principales eventos de foraminiferos planctónicos
en el Mediterríneo (Lourens et al , 1996)

Ciclos de alta frecuencia (precesión)

GC-C3

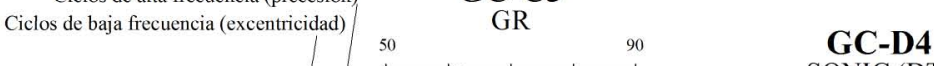

SONIC (DT)

Curva de insolación de verano
(Julio-Agosto) para una latitud de $65^{\circ} \mathrm{N}(\mathrm{W} / \mathrm{m} 2)$ (Laskar, 1990)

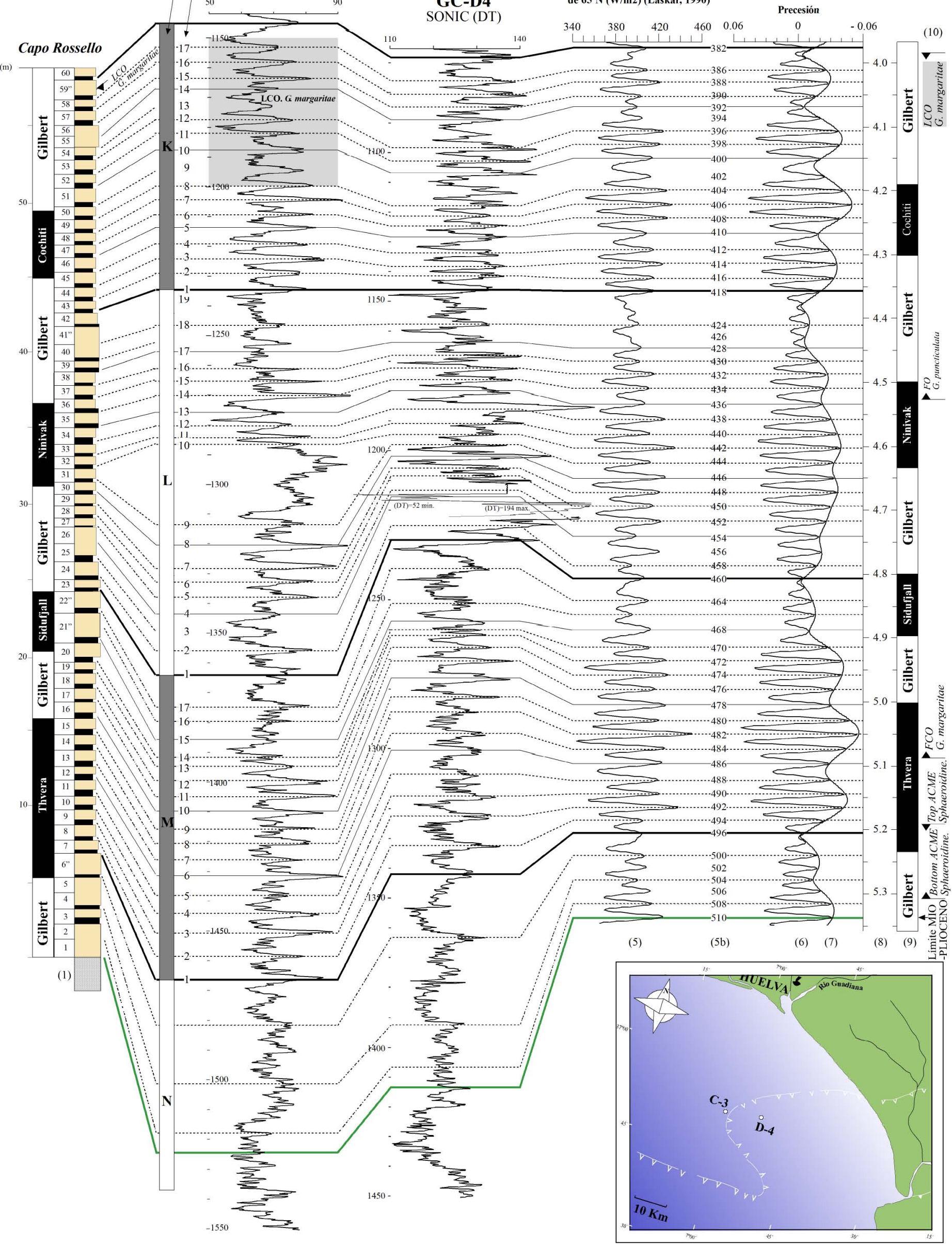

Figura 5.22. Correlación cicloestratigráfica y astrobiocronológica de los sondeos C3 y D4. La correlación se encuentra calibrada con la curva de insolación (Laskar, 1990) y con la sección de referencia de Capo Rossello (Hilgen, 1991b; Langereis y Hilgen, 1991; Lourens et al. 1996). 
Inicialmente es imprescindible poseer una bioestratigrafía de alta resolución para sintonizar el registro de las diagrafías con la curva de insolación. Sin embargo, la proximidad de los sondeos del golfo de Cádiz ayuda a que el análisis de las pautas y patrones característicos de la curva de insolación sean suficientes para realizar la correlación cicloestratigráfica capa a capa con alto grado de fiabilidad. En la figura 5.23 se presenta la correlación capa a capa entre tres sondeos del golfo de Cádiz (B5, C5 y At3), donde únicamente Atlántida-3 presenta un análisis bioestratigráfico. Con la información obtenida de las pautas de la ciclicidad de las diagrafías (capítulo 5.3) y los resultados bioestratigráficos obtenidos en sondeos cercanos (capítulo 3), pueden realizarse correlaciones altamente fiables. En estos casos, solo el muestreo de estos sondeos y el análisis bioestratigráfico de las muestras permitirá asegurar la exactitud de la correlación.

En la figura 5.24 se presenta otro ejemplo de correlación bioestratigráfica en la sección correspondiente al Messiniense y Tortoniense por un lado y una correlación cicloestratigráfica capa a capa con posterioridad al límite Mio-Plioceno. Nuevamente observamos que existe un aparato turbidítico desarrollado tanto en el sector sur como en el norte del golfo de Cádiz (sondeos C4, D1 y D4), mientras que un posterior aparato turbidítico se restringe al sector norte (sondeo $\mathrm{C} 4$ ). Destaca la potente serie arenosa del sondeo D1. Localizado en el eje de la cuenca durante el Messiniense, este sondeo fue paso obligado al golfo de Cádiz registrando la superposición de varios pulsos turbidíticos. Según la cicloestratigrafía, hacia 2.6 Ma los ciclos de precesión se diluyen en favor de ciclos de menor frecuencia, probablemente relacionados con la ciclicidad de 100.000 años. A partir de ese momento, la cicloestratigrafía capa a capa se complica y muestra la importancia del control bioestratigráfico para superar posibles complicaciones en un análisis púramente cicloestratigráfico. 


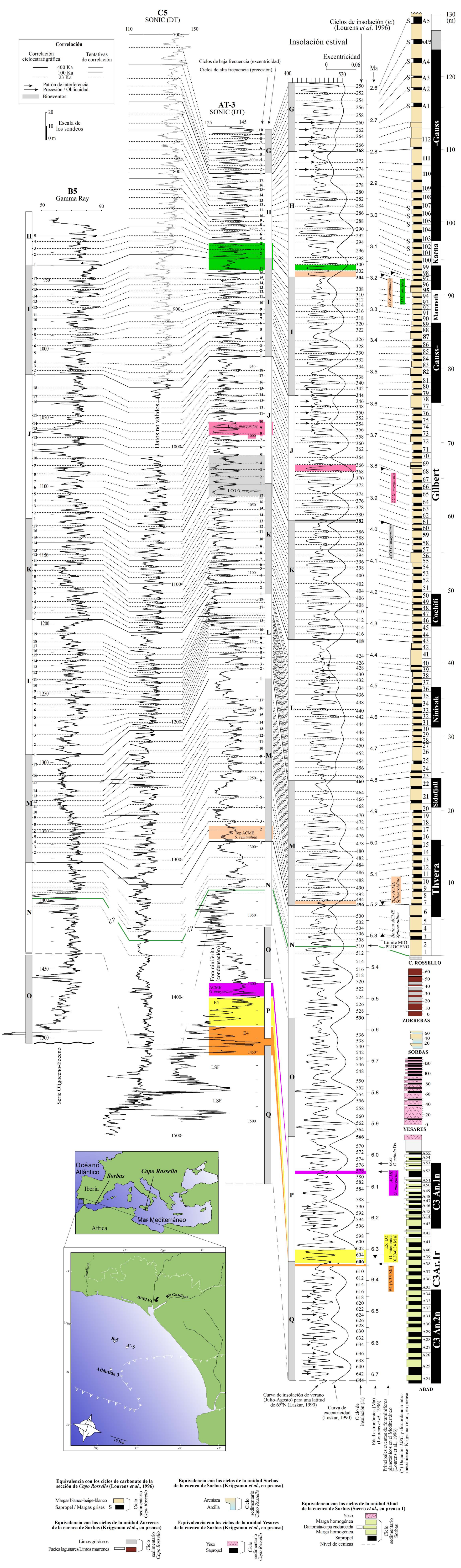




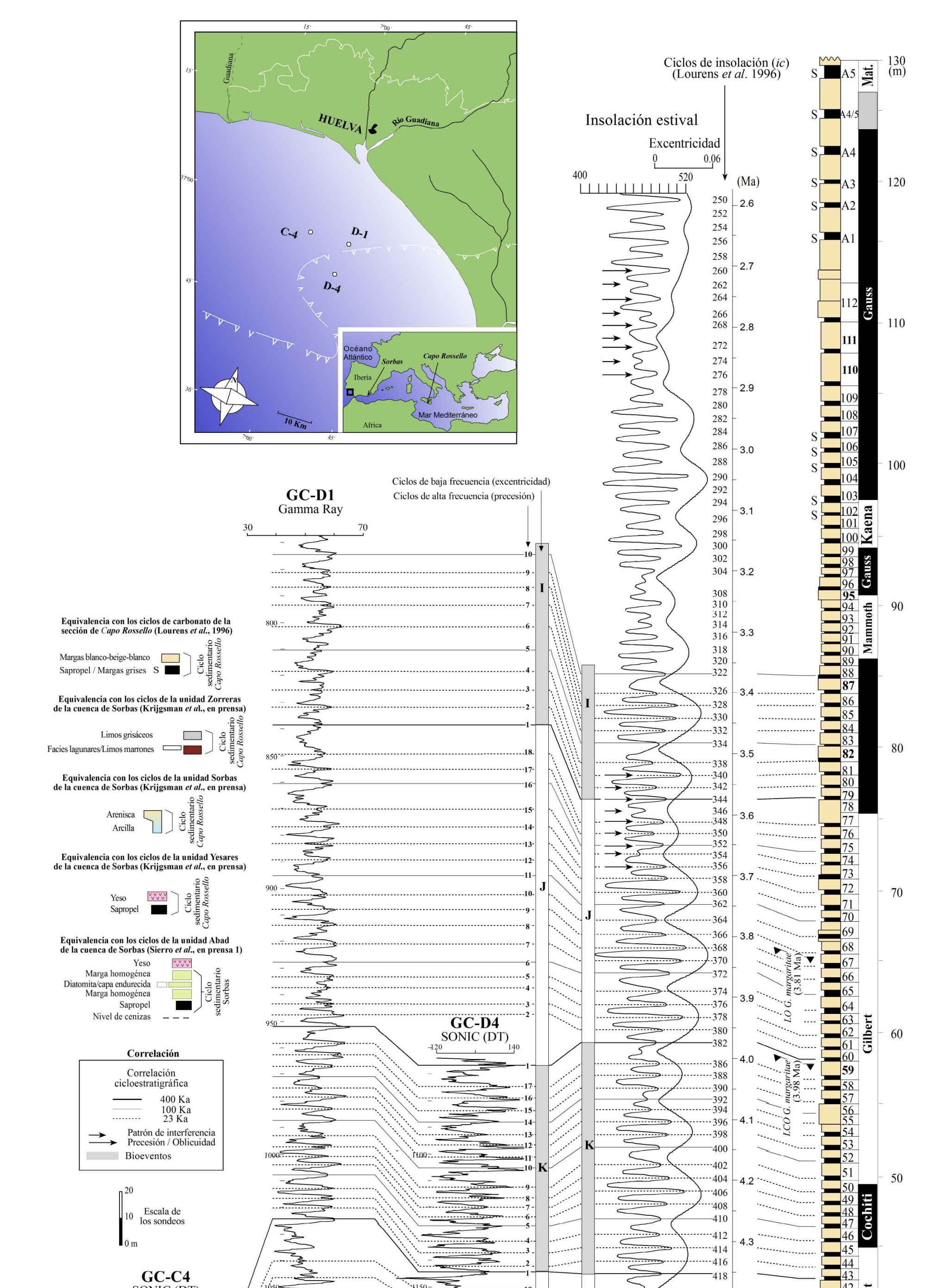

il

I

.

些:

:

I

है
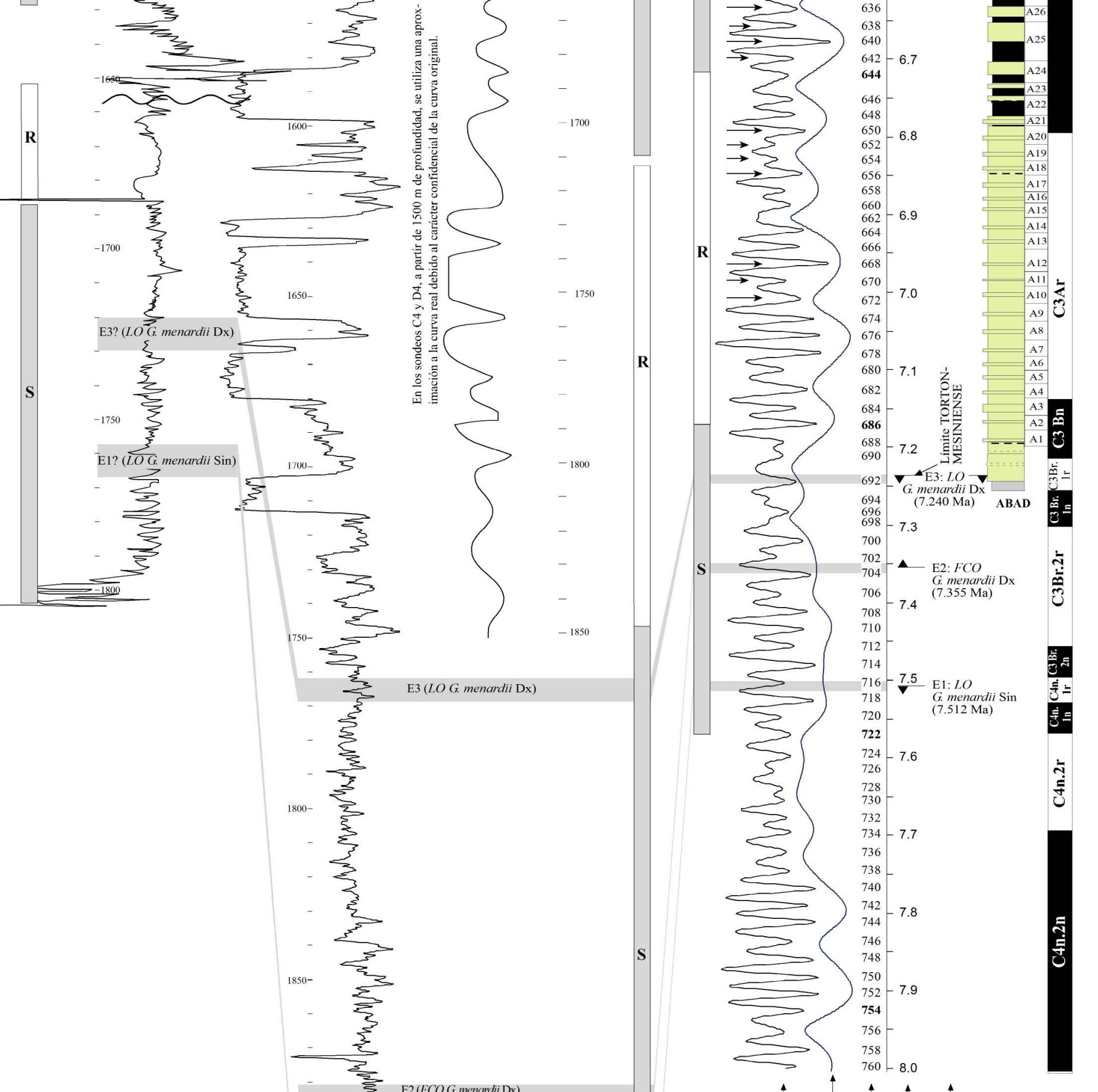

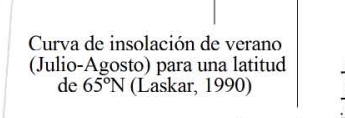

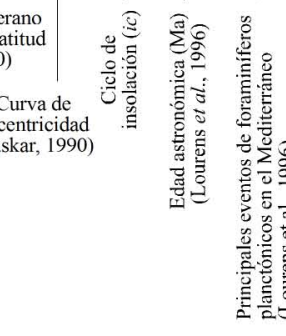

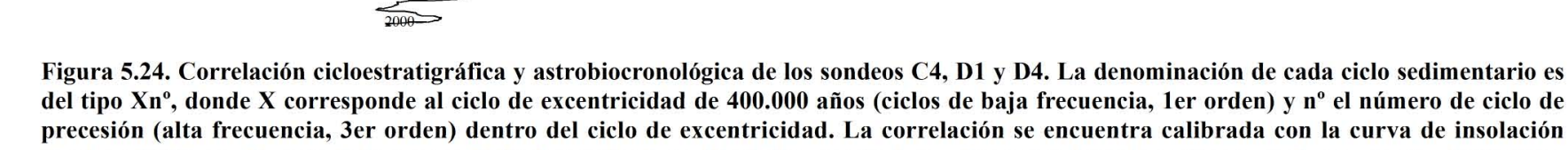





\subsection{IMPLICACIONES PALEOCLIMÁTICAS Y PALEOCEANO- GRÁFICAS}

Puesto que los ciclos sedimentarios presentan una importante periodicidad de precesión, no podemos explicar los cambios mineralógicos (limo-arcilla) en términos de fluctuaciones glacioeustáticas ya que estas están controladas principalmente por la oblicuidad (Tiedemann et al. 1994; Shackleton et al. 1995). Como se refleja en las figuras anteriores, la correlación capa a capa entre los registros sónicos y de rayos gamma del Plioceno inferior del golfo de Cádiz y los ciclos del Mediterráneo oriental parecen indicar que el mismo mecanismo climático pudo ser responsable de la ciclicidad sedimentaria en ambos casos.

A lo largo del Plioceno y el Pleistoceno, los sedimentos terrígenos del margen continental atlántico del golfo de Cádiz han sido suministrados por los ríos Guadalquivir y Guadiana, que drenan la mayor parte del sur de España (ver figura 2.4). Los flujos de sedimentación arcillosa están por tanto controlados principalmente por las descargas de los ríos, reflejando la media anual de pluviosidad. El clima del sur de España y del Mediterráneo está controlado hoy en día principalmente por la posición de la Zona de Convergencia Intertropical (ITCZ) y sus oscilaciones estacionales (Cramp, et al., 1999). Durante el verano, el sistema de altas presiones es muy estable en el Mediterráneo, dando lugar a condiciones cálidas y secas, mientras que durante el invierno la ITCZ se desplaza al sur y el paso de las depresiones procedentes del oeste provoca un enfriamiento y mayor humedad (Weather in the Mediterranean, Meteorological Office, 1962). Según nuestros datos, puede inferirse que el clima del sur de España ha fluctuado entre periodos muy secos y periodos más húmedos. Los periodos secos, similares al que existe hoy en día estarían ligados a momentos de insolación mínima. Por el contrario los periodos más húmedos, serían debidos al paso de depresiones atlánticas con mayor frecuencia durante los periodos de insolación máxima.

El aumento de la escorrentía debido a la intensificación de los monzones y al incremento de la pluviosidad de las zonas periféricas ha sido considerada como la primera causa de la formación de los sapropeles en el Mediterráneo oriental y mar Rojo durante el Plio-Pleistoceno (Rossignol-Strick et al., 1982; Rossignol-Strick, 1983; Hilgen, 1987, 1991a; Thunell et al., 1988; Thunell y Williams, 1989; Rohling y Hilgen, 1991; Rohling, 1994) así como durante el Mioceno superior (Nijenhuis et al., 1996). Estos cambios climáticos regionales se producían en momentos de precesión mínima (fig. 5.25) cuando se 

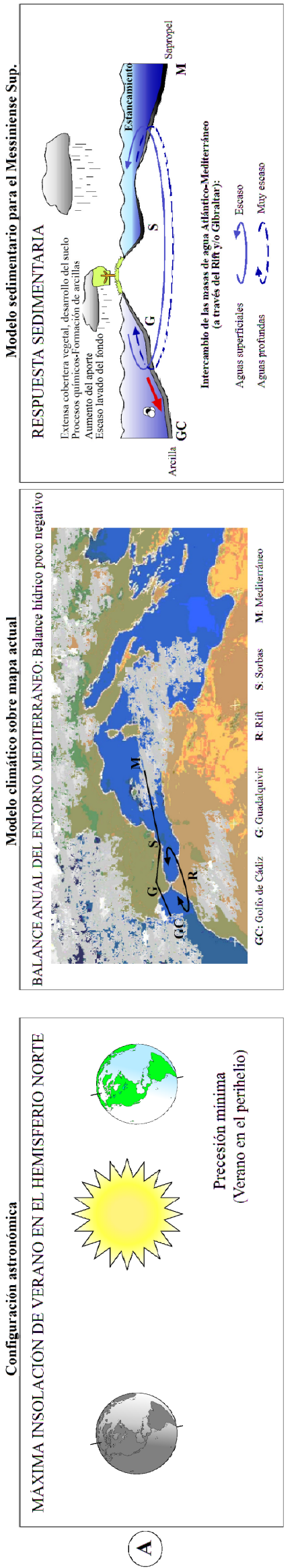
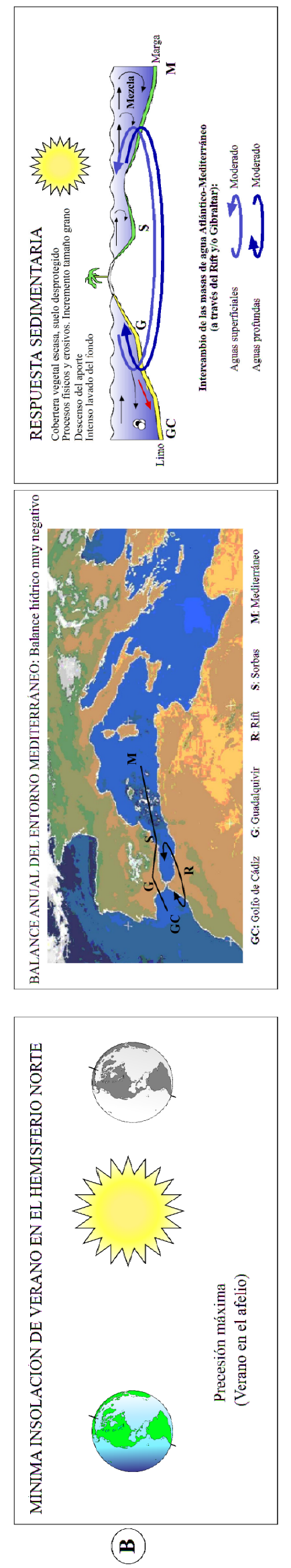

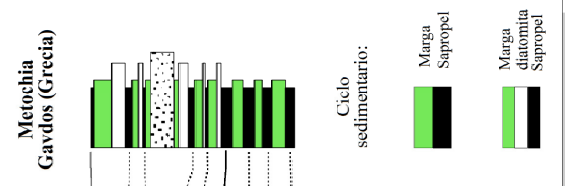

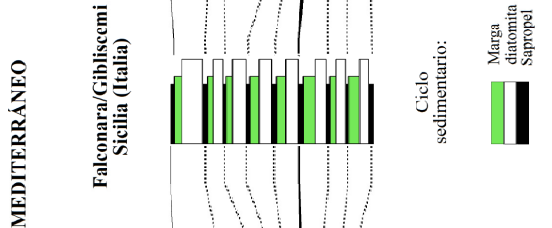

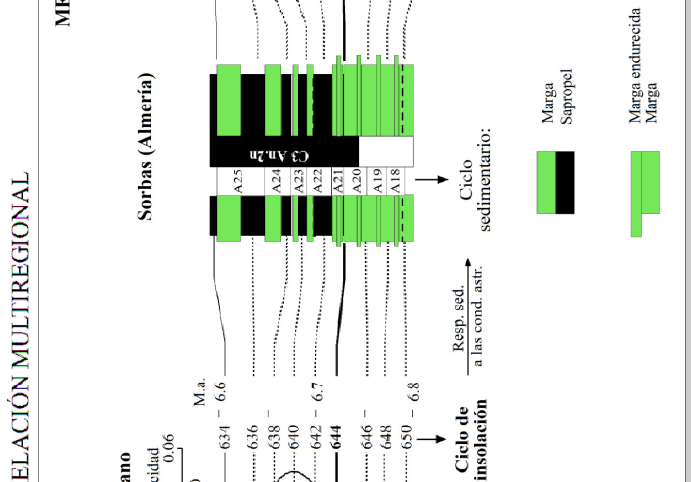

妾

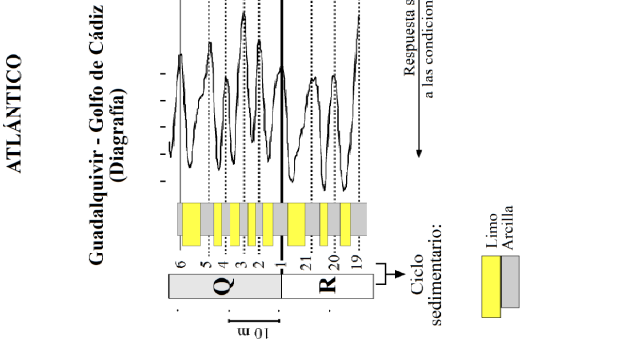

(0) 
alcanzaba el perihelio durante el verano del hemisferio norte (Rossignol-Strick et al., 1982, Rossignol-Strick, 1985; Hilgen, 1991a,b). Recientes modelos climáticos estiman que en el hemisferio norte las mayores precipitaciones se registran en momentos de precesión mínima (Kutzbach y Webb, 1993).

En la figura 5.25 podemos observar dos configuraciones astronómicas extremas para la insolación recibida durante el verano del hemisferio norte (controlada fundamentalmente por la precesión astronómica). Las dos situaciones se suceden en el tiempo con una ciclicidad media de $21.7 \mathrm{Ka}$ (ciclicidad media de la precesión en el Neógeno) repercutiendo directamente en la situación climática y en la consiguiente respuesta sedimentaria.

En el Mediterráneo, los $\log s$ de rayos gamma registran frecuentemente variaciones en el contenido de carbono orgánico (Veen y Postma G. 1996). En el Atlántico (con una buena ventilación del fondo durante el Plioceno), estas capas ricas en materia orgánica no están presentes. Por lo tanto, los ciclos de rayos gamma y sónicos se deben interpretar en términos de cambios litológicos rítmicos que reflejan variaciones en la entrada de aportes terrígenos de grano fino a la cuenca y que diluyen la fracción biogénica, más gruesa y rica en carbonato (foraminíferos planctónicos).

El incremento de lluvia ocasiona un aumento de los contenidos en arcilla en el aporte de los ríos (debido al dominio de los procesos de alteración química en terrenos con una vegetación más densa) y una reducción de la fracción biogénica-carbonatada (De Visser et al., 1989; Howell et al., 1990; Schenau et al., 1999; Vázquez et al., en prensa). Así, los valores máximos en los logs de rayos gamma o velocidad sónica se han correlacionado con los sapropeles o las capas grises y por lo tanto con los máximos de insolación de verano (Rossignol-Strick 1983, Hilgen 1991b). Por el contrario, los mínimos de rayos gamma han sido correlacionados con las capas ricas en carbonato formadas durante los momentos de mínima insolación estival en el hemisferio norte. La dilución de terrígenos desciende en los momentos de clima más seco (con una reducción de las lluvias y de la escorrentía), permitiendo un incremento de la fracción biogénica más gruesa (fracción de foraminíferos) (Scheneau, 1999). La reducción de terrígenos se reflejará posteriormente en valores mínimos de rayos gamma.

Por otro lado, los registros sónicos están ligados generalmente a cambios en la porosidad. Los máximos de velocidad sónica normalmente se correlacionan con los máximos en rayos gamma, y por tanto están en fase con los ciclos astronómicos. Las capas margosas con mayor contenido en foraminíferos planctónicos normalmente presentan mayor porosidad debido a la presencia de grandes cámaras vacías en las conchas de foraminíferos. Por el contrario, el aumento del suministro de partículas 
terrígenas de grano fino (durante los máximos de insolación) da lugar a una baja porosidad en el sedimento y a una dilución de los foraminíferos planctónicos.

Cabe la posibilidad de que la reapertura de la comunicación AtlánticoMediterráneo haya repercutido significativamente en la construcción de los ciclos de alta frecuencia ( $3^{\text {er }}$ orden, inducidos por la precesión) del Plioceno del golfo de Cádiz. En este sentido se barajan dos posibilidades:

- $1^{\text {a }}$. Que el reflejo de la ciclicidad astronómica en los ciclos sedimentarios es posible debido a la oscilación periódica del clima mediterráneo (y sur peninsular) de forma que la oscilación del clima incremente o disminuya el aporte de material al fondo de cuenca. En este contexto, una circulación oceánica constante lavaría por igual el sedimento. Si existe una baja velocidad de sedimentación asociada a periodos con escasas precipitaciones (durante los periodos de precesión máxima-insolación mínima) el lavado del material fino permitiría la acumulación de partículas con un mayor tamaño de grano. Por el contrario ante una mayor velocidad de sedimentación (durante los periodos de precesión mínimainsolación máxima), la corriente oceánica sería incapaz de lavar el sedimento preservándose entonces la fracción fina. Sierro (com. per.) estima que este proceso de lavado constante con variaciones en la velocidad de sedimentación pudo haberse producido en los ciclos observados por este autor en un afloramiento de campo de Montoro (Córdoba).

- 2 ${ }^{\text {a }}$. La segunda posibilidad consiste en que la ciclicidad observada esté relacionada con el lavado diferencial de las corrientes de comunicación Atlántico-Mediterráneo. En este caso, cambios en la intensidad de la corriente (probablemente de la corriente de salida del Mediterráneo, $M O W$ ) producirían una alternancia entre capas con alto contenido arcilloso (cuando la corriente fuera poco intensa) y capas de bajo contenido en arcilla (cuando la corriente fuera lo suficientemente intensa para lavar esta fracción). Variaciones en la intensidad de la $M O W$ pudieron originar los ciclos sedimentarios pliocenos en el golfo de Cádiz (fig. 2.11).

Sin embargo también en este último caso, es la variabilidad climática del área mediterránea la que condiciona la intensidad de la corriente de salida del Mediterráneo, por lo que en ambas hipótesis la ciclicidad astronómica se traduce en variabilidad climática y finalmente en ciclos sedimentarios (fig. 5.25C). Incluso es muy probable que ambos mecanismos hayan funcionado complementariamente (fig. 5.25). Así, en periodos de precesión mínima (máxima insolación), el incremento de precipitaciones atmosféricas provoca un aumento de la sedimentación terrígena en las áreas próximas al continente permitiendo la acumulación de arcilla. Al mismo tiempo, el incremento de agua dulce en 
el Mediterráneo disminuiría la intensidad de la $M O W$, lo que reduciría a su vez el lavado de los sedimentos del margen continental (fig. 5.25A).

Por el contrario, en periodos de precesión máxima (mínima insolación), la reducción de las precipitaciones en el área mediterránea se traduciría en una disminución de la cantidad de aportes a la cuenca, permitiendo un lavado más eficaz por parte de las corrientes oceánicas. El aumento de la salinidad del Mediterráneo intensificaría el gradiente de densidad entre las aguas atlánticas y mediterráneas, lo que acentuaría la acción de la $M O W$ sobre los sedimentos del margen continental del golfo de Cádiz, lavando con eficacia los sedimentos del talud continental tal y como sucede en la actualidad (Baraza et al., 1989)(fig. 5.25B).

Simplificando este razonamiento, se ha asumido que los valores elevados en rayos gamma y los máximos de velocidad sónica están relacionados con el incremento de aportes de material terrígeno en momentos de máxima insolación de verano en el hemisferio norte (precesión mínima). La ciclicidad que registran las curvas de rayos gamma y de velocidad sónica se ha interpretado en términos de oscilaciones climáticas de aridez / humedad inducidas por las variaciones precesionales en la orbita terrestre. Las etapas de mayor pluviosidad inducirían un mayor aporte de terrígenos en el golfo de Cádiz y al mismo tiempo serían responsables de un mayor aporte de agua dulce en el Mediterráneo (propiciando la formación de los sapropeles, Brumsack y Wehausen, 1997).

Se ha observado en distintos ambientes cambios cíclicos similares a los descritos en este trabajo. Tiedemann et al. (1994) describen cambios climáticos inducidos por la precesión en los flujos de polvo africano hacia el Atlántico ecuatorial (ODP Site 659,). En este caso, los mínimos en los flujos de polvo están ligados a climas húmedos en el norte de África y fueron registrados en periodos de máxima insolación en el hemisferio norte debido a una intensificación de los monzones africanos. Además, el incremento en la descarga del Nilo en momentos de mayor intensidad monzónica es uno de los mecanismos principales que se han propuesto para explicar el aporte de agua dulce necesaria para provocar la estratificación de la columna de agua del Mediterráneo oriental en periodos de formación de los sapropeles (Rossignol-Strick, 1983).

Si bien, el incremento de las lluvias monzónicas estivales no puede explicar las variaciones climáticas en el sur de España, diferentes autores han determinado que otros ríos distintos al Nilo han contribuido también a la entrada de agua dulce al Mediterráneo (Rossignol-Strick 1987, Rholing y De Rijk, 1999). Esta Tesis apoya también esta hipótesis, demostrando que en la parte atlántica del sur de España, lejos de la influencia de los monzones, el aumento de la lluvia y de la escorrentía sucede en los momentos de formación de los sapropeles. Las relaciones de fase entre el incremento de la lluvia en 
España y en el África tropical implica que ambos mecanismos podrían haber estado actuando conjuntamente para incrementar el suministro de agua dulce hacia el Mediterráneo.

Los registros de susceptibilidad magnética han sido utilizados por Shackleton y Crowhurst (1997) y por Tiedemann y Franz (1997) para registrar el suministro de sedimentos terrígenos de la cuenca del Amazonas hacia el Atlántico ecuatorial. Sin embargo, en este caso los máximos en la descarga de terrígenos estaban en sincronía con los mínimos de la insolación estival en el hemisferio norte, siendo explicado por la localización de la cuenca amazónica en una posición subtropical del hemisferio sur. 


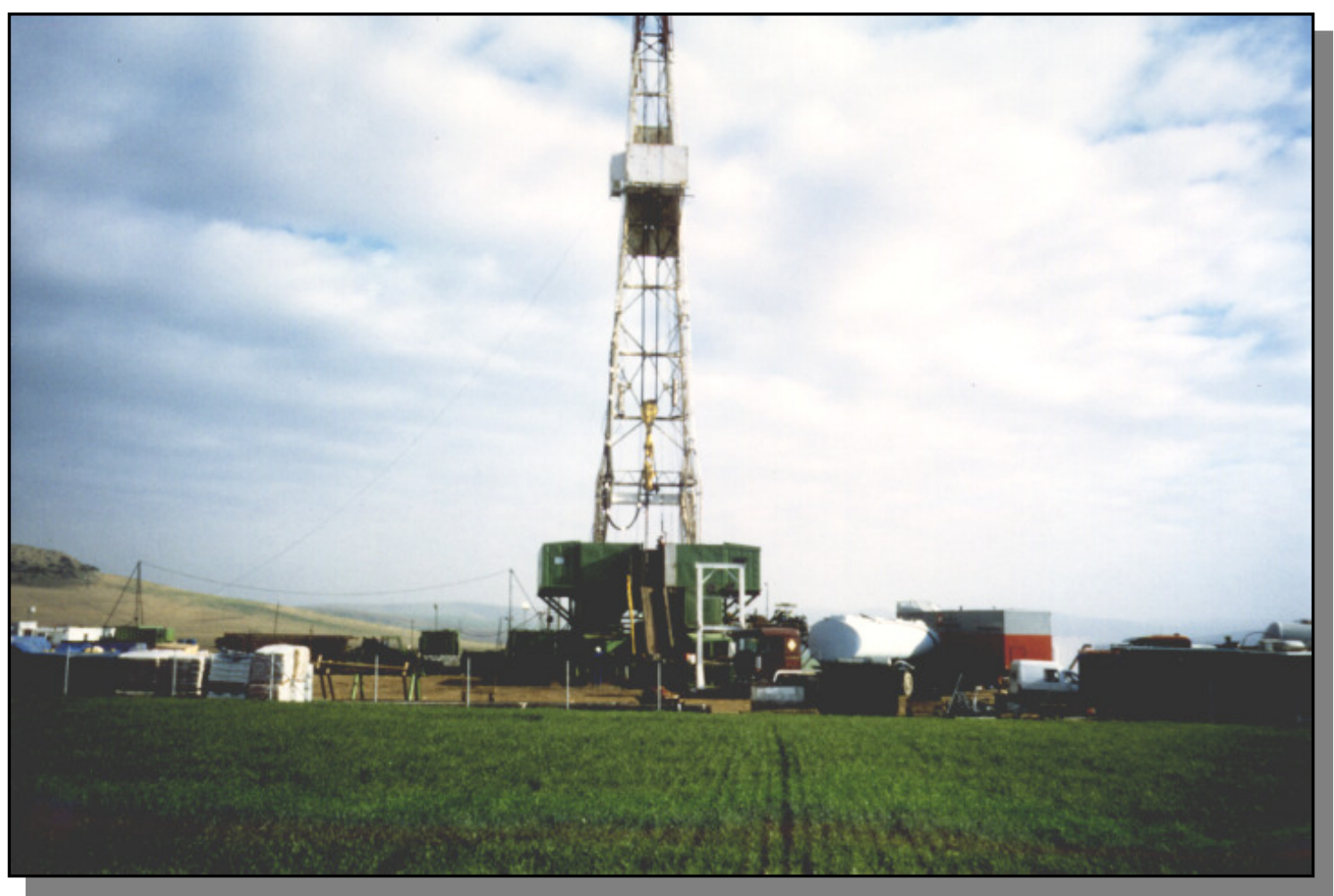

6. SONDEOS. SÍNTESIS DE RESULTADOS 
Página anterior: Torre de perforación del sondeo Santa Clara-1 en las inmediaciones de Carmona (Sevilla). 
Se presentan en este capítulo las figuras correspondientes a 30 de los 32 sondeos en los que se ha realizado el análisis bioestratigráfico. Los sondeos se encuentran ordenados de este a oeste y se tratarán en el siguiente orden:

Carmona-2, Santa Clara-1, Carmona-4, Carmona-1, Ciervo-1, Sevilla-2, San Juan V-6, San Juan V-2, San Juan R-1, Juan Z-1, Salteras-1, Castilleja-1, Palancares-1, Villamanrique-1, Casanieves-1, Isla Mayor-1, Melo-1, Marismas-2, Marismas-4, Marismas A-1, Asperillo-1, golfo de Cádiz-D1, golfo de Cádiz-C4, golfo de Cádiz-C2, golfo de Cádiz-B2, golfo de Cádiz-B4, Atlántida-2, golfo de Cádiz-C3, golfo de CádizB6, golfo de Cádiz-B3, Atlántida-3, y 6x1

La figura 6.1 muestra la leyenda sobre la información contenida en las figuras sintéticas de cada sondeo que aparecen en este capítulo. El análisis bioestratigráfico de las muestras de ripios y testigos ha permitido localizar la posición de una serie de bioeventos en la columna estratigráfica. Estos bioeventos determinan la biozonación, edad y datación astronómica de los sedimentos y se han utilizado para deducir la posición de las inversiones magnéticas. La datación de los bioeventos supone en muchos casos una reinterpretación de las edades consideradas hasta la fecha. Por ejemplo, el límite Tortoniense-Messiniense será modificado en la mayor parte de los sondeos y será reinterpretada la edad las formaciones arenosas objetivo de las perforaciones, conforme a los resultados obtenidos en este trabajo.

En las figuras se mantiene la uniformidad de las escalas, de forma que son perfectamente comparables entre los diferentes sondeos. Cada página contiene un máximo de $1000 \mathrm{~m}$ de sondeo, por lo que en función de la profundidad de cada sondeo, éste puede estar representado por 1, 2 ó 3 páginas. Se ha establecido un encabezamiento que informa del contenido incluido en cada figura (figura 6.1).

En la parte superior izquierda de las figuras se muestra la profundidad en metros y la columna litológica. Esta información viene determinada por la aparecida en las "fichas de sondeo" elaboradas por Repsol y diagrafías facilitadas por esta compañía . En algunos casos, la información litológica se ha completado con los datos obtenidos en el análisis de las muestras analizadas, siendo en ocasiones fuente exclusiva de la información litológica.

Seguidamente aparecen dos columnas con la edad y la denominación que han recibido tradicionalmente las distintas formaciones que atraviesan el sondeo.

En las siguientes columnas se muestran la edad y unidades litosísmicas propuestas en esta Tesis. Seguidamente, en la columna "Tiempo Ma", aparece la datación estimada 


\section{LEYENDA FIGURAS SINTETICAS DE SONDEO}

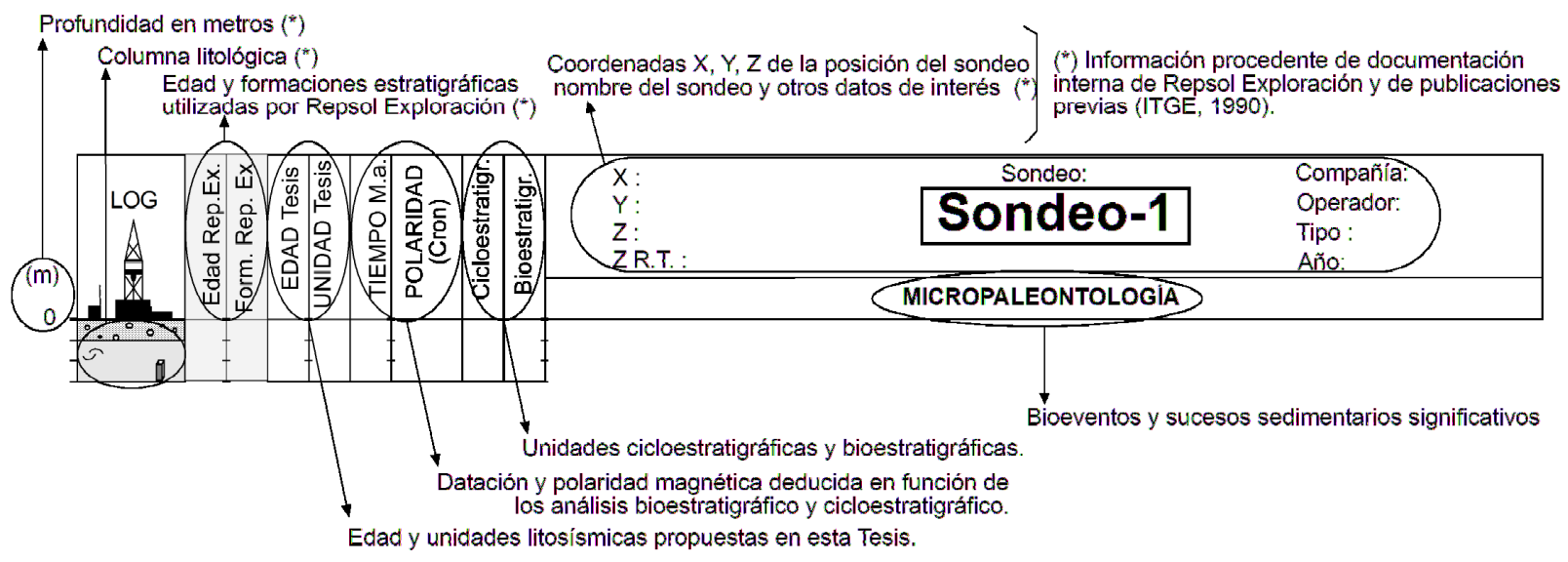

LITOLOGIA

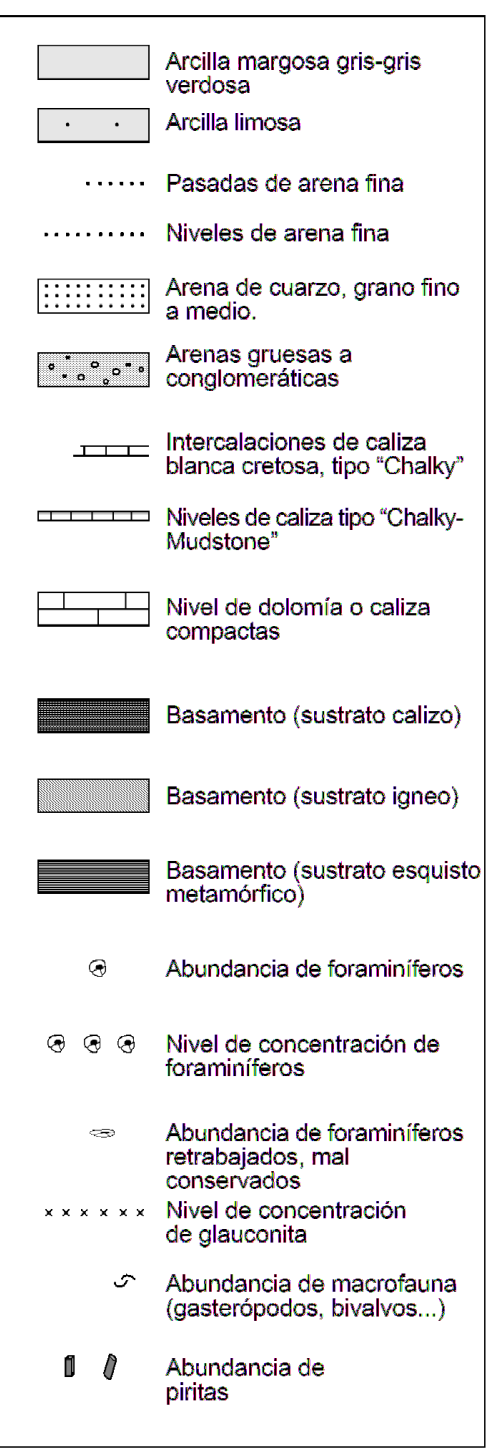

POLARIDAD MAGNETICA

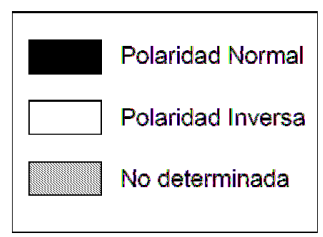

BIOESTRATIGRAFIA

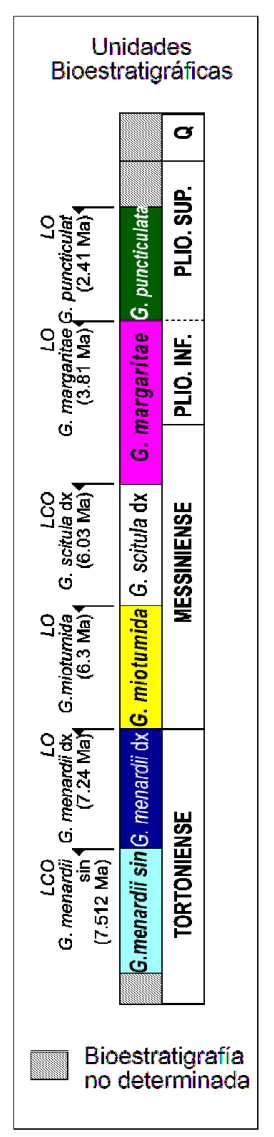

ABREVIATURAS EMPLEADAS

Acme: Incremento significativo de una especie.

BFU. Basal Foredeep Unconfomity, Discord. basal de fondo de cuenca

dx: formas dextrorsas, dextrógiras, aquellas en las que el crecimiento de su concha se produce hacia la derecha, en el sentido de las agujas del reloj.

$(E)=$ Evento bioestratigráfico:

(E6) $=$ FO del grupo G. margaritae

$(E 5)=$ LO del grupo G. miotumida $\sin (6,34 \mathrm{Ma})$

(E4) = Cambio de enrollamiento de $N$. acostaensis $(6,35 \mathrm{Ma})$

(E3) $=\angle O$ del grupo $G$. menardii $d x /$

FCO del grupo G. miotumida $\sin (7,240 \mathrm{Ma})$

$(E A)=$ Cambio de enrollamiento grupo $G$ scitula $(7,28 \mathrm{Ma})$

$(\mathrm{E} 2)=$ FCO del grupo $\mathrm{G}$ menardii $\mathrm{dx}(7,355 \mathrm{Ma})$

$(E 1)=$ LCO del grupo G. menardii $\sin (7,512 \mathrm{Ma})$

\section{FCO. First Common Occurrence, primera aparición} común-abundante-regular de una especie, genero o grupo. FO: First Occurrence, primera aparición de una especie, genero o grupo

GC: Golio de Cádiz

Gg: Globigerina

G: Globorotalia

GR: Gamma Ray (API Units), rayos gamma (unidades API)

Gs: Giobigerinoides

mfs: maximum flooding suface, superficie de máxima inundación. LCO. Last Common Occurrence última aparición común-abundante-regular de una especie, genero o grupo. LO: Last Occumence, última aparición de una especie, genero o grupo.

Ma: Millones de años

mbsf: meters below sea fioor, metros bajo el fondo marino

N.: Neogloboquadrina

n.m.: nivel del mar

paracme: Dentro de una biozona, reducción significativa de la especie que la define.

PF: Profundidad final del sondeo.

Rep. Ex.: Información procedente de Repsol Exploración

Sec: Secuencia (de secuencia deposicional)

sin: formas sinistrorsas, levógiras, aquellas formas en las que el crecimiento de su concha se produce hacia la izquierda, en el sentido opuesto a las agujas del reloj.

TI T. lateral: Testigo lateral

Z.R.T.: Altura sobre el suelo

$Z$ mar: Altura sobre el fondo del mar

Z K.b: Altura sobre el nivel del mar

Figura 6.1. Leyenda general de las figuras sintéticas de los sondeos. 


\section{LEYENDA PERFILES SISMOBIOESTRATIGRAFICOS}

MAPA ÍNDICE CON LA POSICIÓN DEL SONDEO Y PERFIL SISMICO UTILIZADO

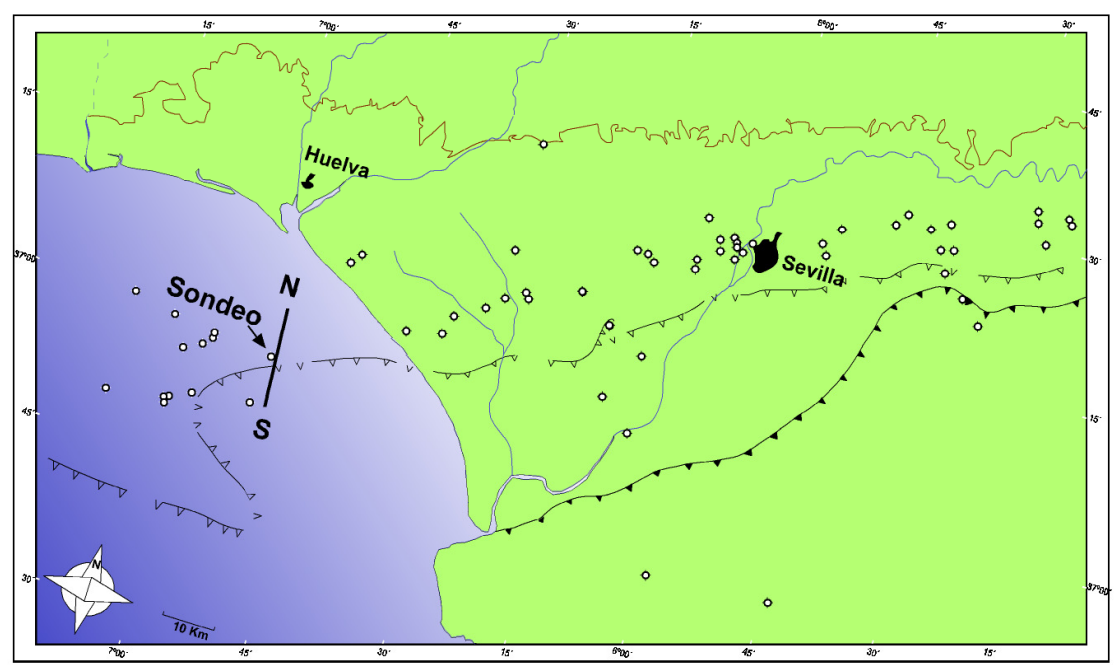

PERFIL SISMOBIOESTRATIGRÁFICO Y PROYECCIÓN DEL SONDEO

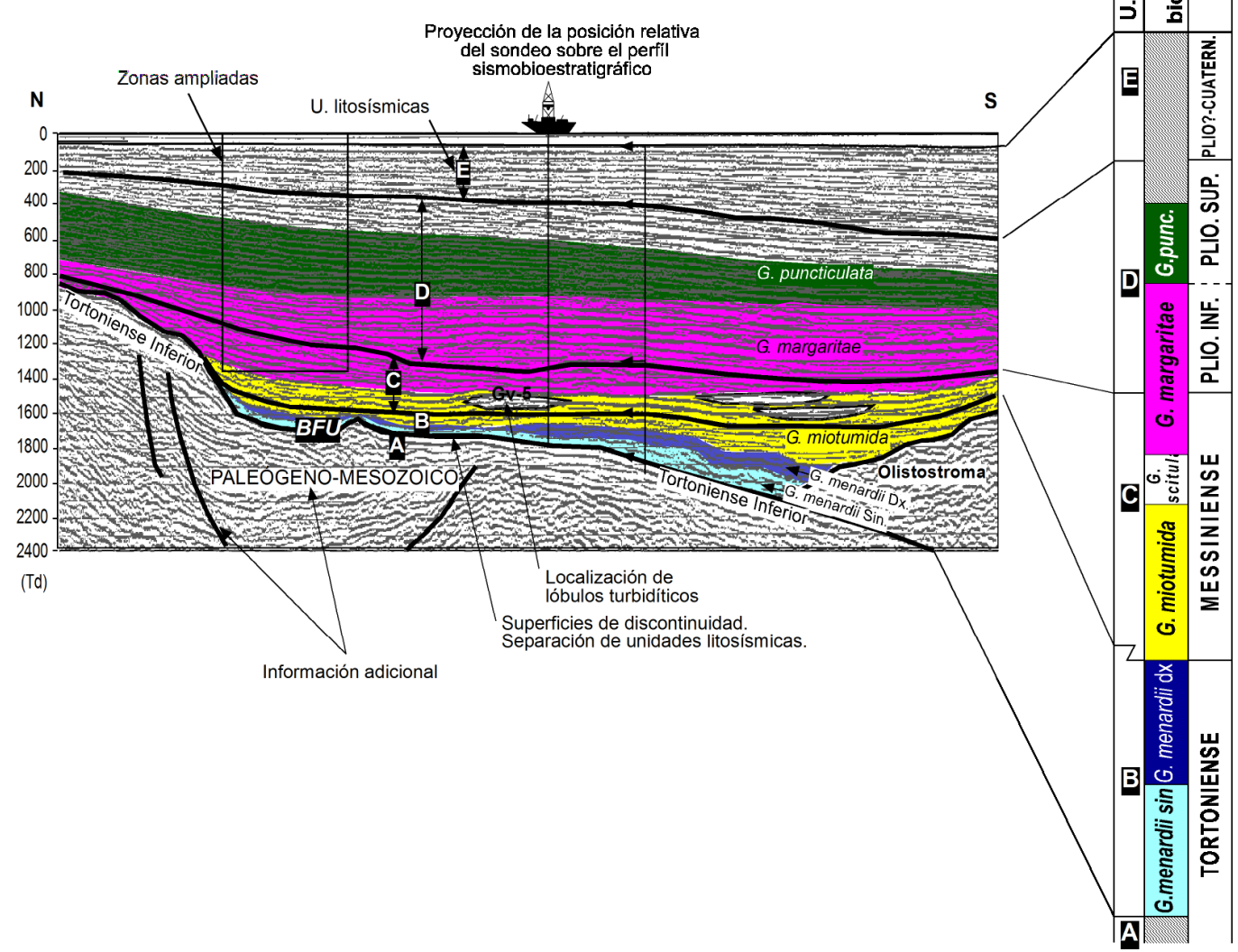

Figura 6.2. Leyenda general de los perfiles sismobioestratigráficos incluidos en las figuras sintéticas de los sondeos. 
en función del análisis bioestratigráfico y cicloestratigráfico. Teniendo en cuenta la posición de los diferentes eventos, y conocida su posición en la escala magnética de tiempo, se ha reconstruido una hipotética columna magnetoestratigráfica. La magnetoestratigrafía está basada en las edades astronómicas para las inversiones magnéticas obtenidas por Krijgsman et al. (1995) y Hilgen et al. (1995) para el Tortoniense y Messiniense (hasta 7 Ma), Krijgsman et al. (1999b) para el resto del Messiniense (de 7 a $5.33 \mathrm{Ma}$ ) y Lourens et al. (1996b) para el Plioceno.

Por otro lado, en algunas de las figuras sintéticas se ha incorporado parte de la información geofísica $(G R)$ proporcionada por Repsol. En las figuras correspondientes a los sondeos en los que se ha realizado el estudio cicloestratigráfico (capítulo 5), se incorpora además una columna en la que se distinguen los ciclos de $1^{\text {er }}$ orden detectados (ciclos de 400.000 años) e identificados mediante la letra correspondiente. Los ciclos astronómicos han servido para establecer una serie de unidades cicloestratigráficas datadas astronómicamente y que constituyen por lo tanto unidades cronoestratigráficas. En la última columna se ha establecido la biozonación basada en el análisis de los globorotálidos (capítulo 3) diferenciando las biozonas mediante distintos colores.

Finalmente y bajo los datos generales del sondeo, como son coordenadas, compañía, operador, tipo y año de la perforación, se disponen los bioeventos de plancton calcáreo (en negrita) así como diversas observaciones de carácter paleontológico o sedimentológico registradas en las muestras estudiadas. Para ubicar la posición de los bioeventos se utiliza bien un intervalo o bien se indica directamente una profundidad estimada. En el caso de la desaparición de un taxón, el intervalo está definido inferiormente por la última muestra que contiene el taxón, mientras que el valor superior es el de la primera muestra que no contiene dicho taxón. Cuando se utiliza únicamente una profundidad para determinar la posición del bioevento, debe tenerse en cuenta que por lo general el muestreo de los sondeos se ha realizado cada $10 \mathrm{~m}$, por lo tanto la posición del bioevento tiene un error de $\pm 10 \mathrm{~m}$. Si se muestra una interrogación a continuación del bioevento, indica cierto grado de incertidumbre en su posición. La presencia abundante de arenas en la muestra, resulta comúnmente en una ausencia total de globorotálidos, característica que unida a la escasez habitual de muestra, ha complicado ocasionalmente la localización de los bioeventos.

En el caso de haber sido realizados análisis cuantitativos en las muestras, se añade en la correspondiente figura un gráfico reflejando el porcentaje relativo de globorotálidos o bien otras relaciones. Los gráficos porcentuales no tienen carácter estadístico aunque si representativo. La escasez de la muestra, y la abundante presencia de arena en la fracción 
estudiada impiden obtener un número suficiente de globorotálidos que permita realizar un estudio estadístico de la asociación con márgenes de error admisibles. Esta limitación, unida a los problemas derivados del tipo de muestra (apartado 3.1.2) han condicionado los análisis cuantitativos, optándose como norma general por un estudio cualitativo de las muestras.

Las figuras sintéticas vienen acompañadas de un mapa con la posición del sondeo y la localización de un perfil sísmico próximo al mismo. Este perfil sísmico interpretado incorpora la información micropaleontológica (perfiles sismobioestratigráficos, capítulo 4) y proporcionan una nítida visión espacial de la configuración y geometría del relleno sedimentario de la cuenca. La leyenda que aparece en la figura 6.2 muestra la información que recogen dichos perfiles. La proximidad del sondeo a la línea sísmica determinará el grado de coincidencia entre las profundidades del sondeo y las del perfil sísmico

Al mismo tiempo, acompañando a cada figura se muestra una breve descripción de los resultados obtenidos en los sondeos estudiados que acompaña a la figura correspondiente. En la descripción de la sucesión estratigráfica y de los sucesos bioestratigráficos se ha utilizado, como en el resto de la Tesis, un sentido de la narración de más antiguo a más moderno.

Un resumen con la datación astronómica de los resultados obtenidos en los sondeos analizados se presenta en la figura 6.33, al final de este capítulo. En esta figura se muestra la sucesión de bioeventos identificados (capítulo 3), los principales acontecimientos estratigráficos y la disposición de las unidades litosísmicas (capítulo 4), así como la sucesión cicloestratigráfica obtenida y la secuencia magnetoestratigráfica deducida (capítulo 5).

En el caso de los sondeos C4, B-4, D-4 y Orión 2-1, no disponemos de una litología detallada por lo que hemos desestimado incluir las figuras correspondientes. No obstante se ha realizado sobre ellos un reducido chequeo bioestratigráfico y también se han tenido en cuenta en la cicloestratigrafía (capítulo 5) y en el análisis del relleno de la cuenca (capítulo 6). 


\subsection{GUADALQUIVIR}

En las siguientes figuras se muestra un resumen de los resultados obtenidos en los sondeos estudiados localizados onshore, en el área del Guadalquivir.

\subsubsection{Carmona-2}

El sondeo Carmona-2 (figura 6.3) es el más oriental de los sondeos analizados. La primera formación arenosa (más grosera) corresponde probablemente al detrítico basal, mientras que el paquete superior, que presenta individuos del grupo de G. miotumida, corresponde probablemente a la formación "arenas del Guadalquivir". En este caso, dada la proximidad a la costa messiniense del sondeo Carmona-2, los canales erosivos pudieron haber llegado al detrítico basal o incluso al zócalo. La escasez de biomarcadores en este tramo arenoso determina un amplio intervalo de posible localización para los eventos E1, E2, E3, E4, E5 y E6. No así, la FCO del grupo de G. margaritae que se detecta nítidamente sobre el paquete arenoso, hacia los $516 \mathrm{~m}$. El nivel de arenas conchíferas localizado por encima de este evento, puede ser correlacionado con el que aparece en igual posición en el sondeo Carmona-1.

El sondeo Carmona-2 se encuentra alejado de las líneas sísmicas utilizadas, por lo que no se acompaña de perfil sismobioestratigráfico. 


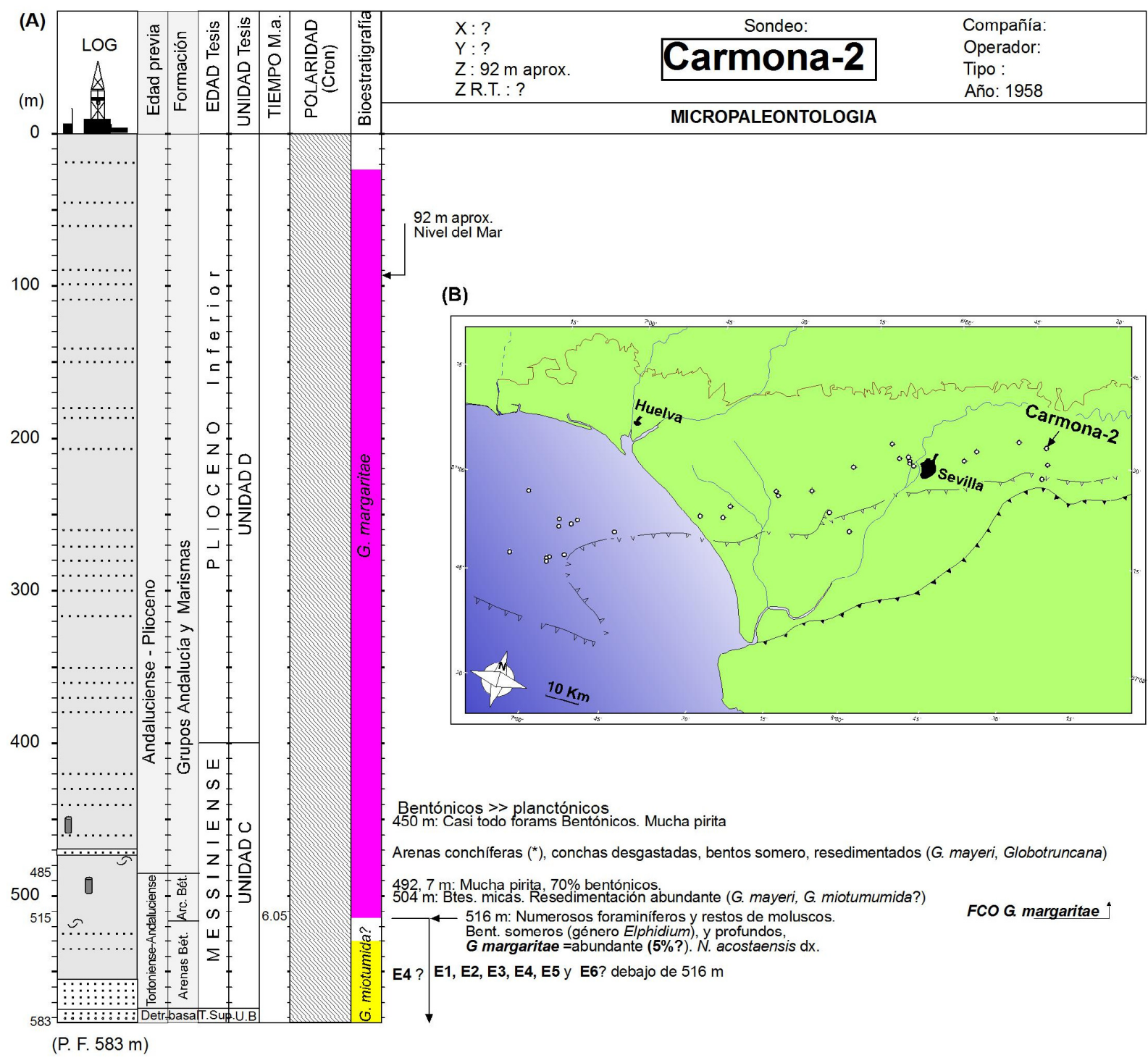

(E6) $=$ FO del grupo $G$. margaritae

$(E 5)=L O$ del grupo $G$. miotumida $\sin (6,3 \mathrm{Ma})$

$(\mathrm{E} 4)=$ Cambio de enrollamiento de $N$. acostaensis $(6,35 \mathrm{Ma})$

$(E 3)=\angle O$ del grupo G. menardii $\mathrm{dx} /$ FCO del grupo $\mathrm{G}$. miotumida $\sin (7,240 \mathrm{Ma})$

$(E 2)=F C O$ del grupo $G$. menardii $d x(7,355 \mathrm{Ma})$

$(E 1)=L C O$ del grupo $G$. menardii $\sin (7,512 \mathrm{Ma})$

$\left({ }^{\star}\right)$ Nivel similar localizado a $506 \mathrm{~m}$ en el sondeo Carmona-1 (Nivel

conchífero sobre FCO de G. margaritae).

Figura 6.3. Síntesis de los resultados obtenidos en el sondeo Carmona-2. Leyenda general en la fig. 6.1. (A) Profundidad en metros y columna litológica (ITGE, 1990). Edades y formaciones utilizadas anteriormente. Edad, unidades litosísmicas, datación, magnetoestratigrafía deducida, unidades cicloestratigráficas y biozonas propuestas en esta Tesis en función de los bioeventos de plancton calcáreo. Información micropaleontológica, sedimentológica y otros datos de interés. (B) Localización del sondeo Carmona-2. 


\subsubsection{Santa Clara-1}

El sondeo Santa Clara-1 (figura 6.4) se encuentra al este de la ciudad de Carmona. Durante el Tortoniense (desde los 673 a $500 \mathrm{~m}$ del sondeo) el sondeo se encontraba sobre el talud norte de la cuenca. El emplazamiento del olistostroma, produce un rápido desplazamiento del depocentro de la cuenca, pasando el sondeo a ocupar una posición primero en el eje de la cuenca (hacia los $500 \mathrm{~m}$ ) y después en el talud sur messiniense (los últimos $300 \mathrm{~m}$ de sedimentación) (figura 6.4D).

A $673 \mathrm{~m}$ se produce el contacto con el basamento. Entre $673 \mathrm{~m}$ y $670 \mathrm{~m}$ debe existir un nivel rico en glauconita, puesto que la presencia de este mineral es patente en la primera muestra del basamento $(673 \mathrm{~m})$. A continuación $(660-670 \mathrm{~m})$ aparecen unas "arenas" de foraminíferos que presentan gran cantidad de foraminíferos planctónicos de tamaño medio-grande y regular, fundamentalmente Orbulina universa. El dominio de formas de tamaño medio-grande sugiere que los sedimentos han sido lavados durante su depósito; el hecho de que sean primordialmente planctónicos, junto con la ausencia de foraminíferos bentónicos someros, refleja un medio de cierta profundidad. Estas arenas pueden ser debidas a un depósito de tipo contourítico que estaría situado al pie del talud, o en un alto fondo. Así mismo este intervalo (glauconita + "arenas de foraminíferos"), podría estar asociado a una sección condensada relacionada con una superficie de máxima inundación ( $m f s$, maximun flooding surface). Por todo ello resulta evidente que las arenas basales, normalmente ricas en fauna bentónica somera, no están presentes en este sondeo. Se ha observado que el sondeo Santa Clara-1 podría estar situado sobre un salto de fallas, quedando el detrítico basal a ambos lados del sondeo (S. Torrescusa com. per.).

La fauna, está dominada en toda la columna por formas tortonienses y messinienses. Al margen de los indicadores bioestratigráficos, la asociación de foraminíferos está dominada por el grupo Globigerina bulloides y el grupo Gg. apertura, por el grupo de Globigerinoides obliquus, grupo Gs. bulloideus y grupo Gs. sacculifertrilobus; es también abundante el grupo de Neogloboquadrina acostaensis con formas tanto dextrorsas como sinistrorsas. También es habitual Orbulina universa, principalmente en las arenas de la base del sondeo $(660-670 \mathrm{~m})$. En cuanto a los globorotálidos, únicamente el grupo de Globorotalia miotumida supera en algún momento el $20 \%$ de la asociación $(161 \mathrm{~m})$, el resto aparecen siempre en menor proporción. No obstante, se han podido establecer al menos 5 de los eventos bioestratigráficos definidos en el Guadalquivir para el Tortoniense - Messiniense por Sierro (1985) y Sierro et al. (1993). 
Se han localizado los eventos E1, E2, EA, E3 y E4 de foraminíferos planctónicos (capítulo 3). La desaparición del grupo G. menardii sin (E1) se produce hacia el intervalo 580-595 m. La aparición abundante del grupo de G. menardii $d x$ (E2) tiene lugar hacia los $560 \mathrm{~m}$, si bien al tratarse de una aparición su localización precisa puede estar condicionada por la contaminación de materiales suprayacentes. El cambio de enrollamiento en el grupo de G. scitula (EA) de formas sinistrorsas a dextrorsas, se produce entre los metros 525-535. El paso del Tortoniense al Messiniense (E3), determinado por la desaparición del grupo de G. menardii $d x$ y aparición del grupo de $G$. miotumida sucede al tiempo que comienza el depósito de las "arenas del Guadalquivir" $(500 \mathrm{~m})$. Si la base de estos depósitos turbidíticos es erosiva, el evento E3 podría encontrarse ligeramente desplazado. El establecimiento del evento E3 en el contacto con las "arenas del Guadalquivir" viene reforzado por la introducción de formas del grupo de G. scitula Sin (muestras 470-490 m). El evento E4, donde se pasa de un fuerte dominio de las formas levógiras del grupo $N$. acostaensis a formas dextrógiras, se produce en torno al metro 161. Por otro lado, el análisis de nanoplancton calcáreo realizado por J.A. Flores (com. per.) ha detectado el techo del paracme de $R$. pseudoumbilicus hacia los 425 m, así como la desaparición de Discoaster quinqueramus que estaría localizada entre 140 y $123 \mathrm{~m}$. La desaparición de $D$. quinqueramus sin embargo, parece ser debida a la somerización del ambiente marino que se está produciendo hacia el techo de la serie y que sería un factor limitante para el desarrollo de este taxón, por lo que se su desaparición debe considerarse de carácter local.

Como puede observarse en la figura 6.4B con el porcentaje acumulado de globorotálidos, las primeras apariciones son complicadas de identificar. En el caso del grupo de G. menardii dx, se observa como este grupo está presente en las muestras de ripio desde la base del sondeo, cuando en realidad aparece tras la reducción significativa del grupo de G. menardii sin (hacia $580 \mathrm{~m}$ ). La presencia de individuos del grupo de $G$. menardii dx, por debajo de $580 \mathrm{~m}$ refleja la contaminación que presentan los ripios y el riesgo que supone trabajar con eventos de aparición en este tipo de muestras. En cuanto al evento E5 a techo del sondeo (desaparición del grupo G. miotumida), su localización también es delicada: aunque podría encontrarse alrededor del metro 60 (que registra un incremento del grupo de G. margaritae), el grupo G. miotumida sigue apareciendo en las muestras más superficiales, por lo que se ha desestimado la localización del evento de aparición del grupo de G. margaritae. La aparición de formas dextrosas del grupo de $G$. margaritae indicarían no obstante, la inmediatez de la desaparición de G. miotumida.

Se han obtenido las siguientes velocidades de sedimentación en el sondeo Santa Clara-1, en función de los eventos de foraminíferos planctónicos: 
- Del evento E1 al evento E2: 123,4 m / Ma (12,3 cm / 1000 años). En este momento se produce la menor velocidad de sedimentación de todo este sondeo. Probablemente esta velocidad de sedimentación es similar desde la base de la unidad B.

- Del evento E2 al evento EA: 428,5 m / Ma (42,8 cm / 1000 años). Aumento de la velocidad de sedimentación que va a culminar en el evento E3.

- Del evento EA al evento E3: $750 \mathrm{~m} / \mathrm{Ma}$ (75 cm / 1000 años). "Arenas del Guadalquivir"; los episodios turbidíticos incrementan la velocidad de sedimentación.

- Del evento E3 al techo del paracme de R. pseudoumbilicus: 585,9 m / Ma (58,5 cm / 1000 años). "Arenas del Guadalquivir".

- Del techo del paracme de R. pseudoumbilicus al evento E4: $341 \mathrm{~m} / \mathrm{Ma}$ (34,1 cm / 1000 años). Con el abandono de los aparatos turbidíticos se reduce la velocidad de sedimentación. 


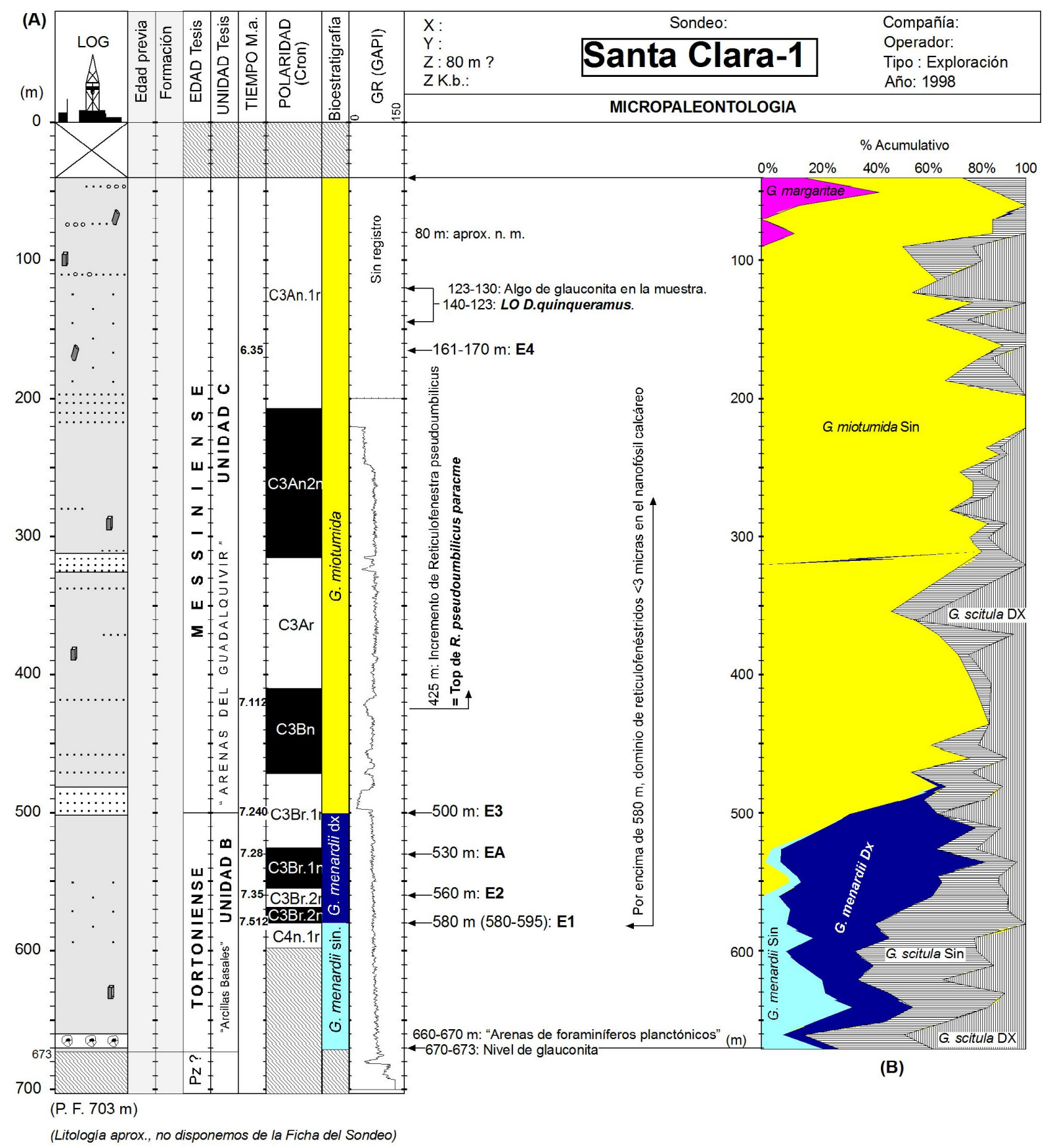

$(E 6)=F O$ del grupo $G$. margaritae

$(E 5)=L O$ del grupo G. miotumida $\sin (6,3 \mathrm{Ma})$

$(\mathrm{E} 4)=$ Cambio de enrollamiento de $N$. acostaensis $(6,35 \mathrm{Ma})$

$(E 3)=L O$ del grupo $G$. menardii dx / FCO del grupo G. miotumida sin $(7,240 \mathrm{Ma})$

$(E A)=$ Cambio de enrollamiento grupo $G$. scitula $(7,28 \mathrm{Ma})$

$(E 2)=F C O$ del grupo $G$. menardii $\mathrm{dx}(7,355 \mathrm{Ma})$

$(E 1)=L C O$ del grupo $G$. menardii $\sin (7,512 \mathrm{Ma})$

Figura 6.4. Síntesis de los resultados obtenidos en el sondeo Santa Clara-1. Leyenda general en figuras 6.1. y 6.2. (A) Profundidad en metros y columna litológica. Edad, unidades litosísmicas, datación, magnetoestratigrafía deducida, unidades cicloestratigráficas y biozonas propuestas en esta Tesis en función de los bioeventos de plancton calcáreo. Registro de rayos gamma. Información micropaleontológica, sedimentológica y otros datos de interés.

(B) Porcentaje de los diferentes globorotálidos en función del análisis cuantitativo.

(C) Localización del sondeo y del perfil sísmico.

(D) Perfil sismobioestratigráfico $\mathbf{n}^{\circ} 1$ (sísmica original facilitada por Repsol). 


\section{Santa Clara -1}

(C)

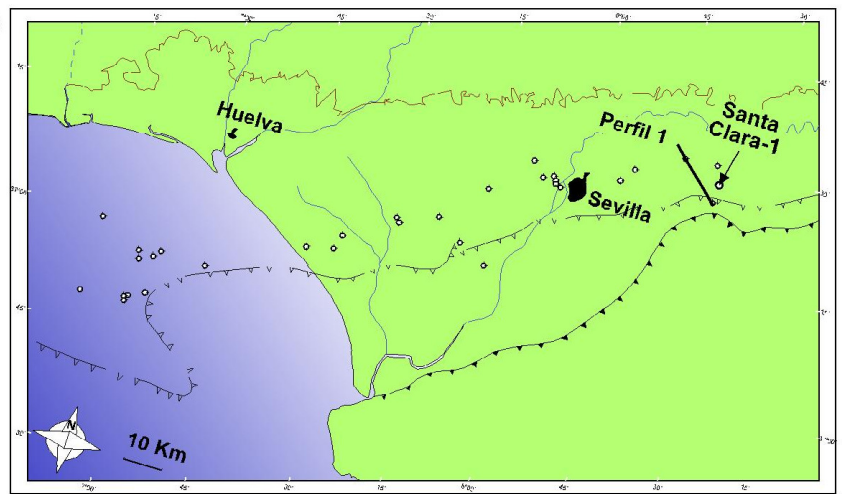

(D)

$-200-$

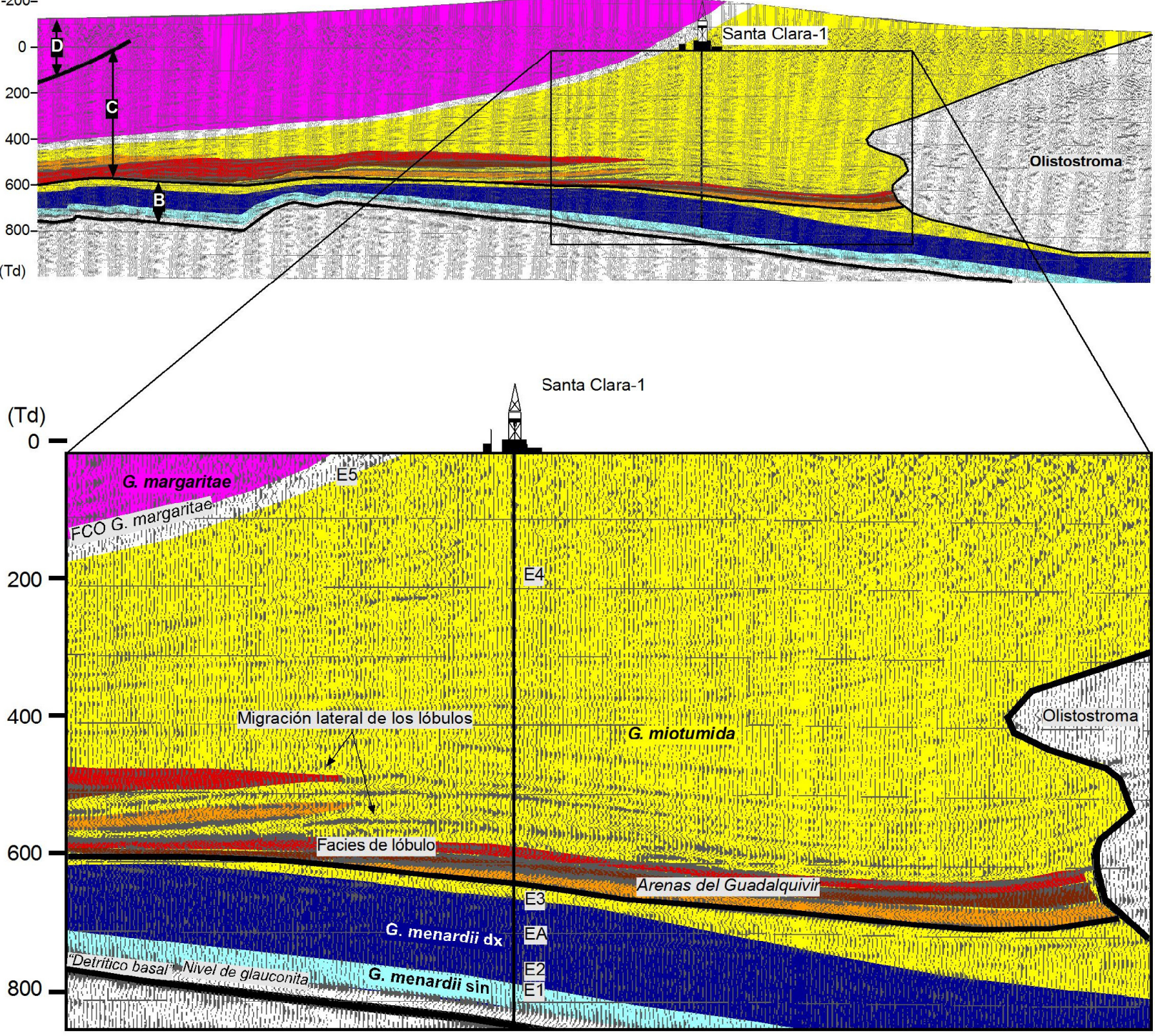

Figura 6.4. (Continuación). Síntesis de los resultados obtenidos en el sondeo Santa Clara-1. Leyenda general en fig. 6.1. y fig. 6.2. (C) Localización del sondeo Santa Clara-1 y del perfil sísmico interpretado. (D) Perfíl sísmobioestratigráfico no1 (NW-SE) y proyección de una posición equivalente a la del sondeo Santa Clara-1. (Td) = Tiempo doble en milisegundos. (Sísmica original facilitada por Repsol). 


\subsubsection{Carmona-4}

El sondeo Carmona-4 (fig. 6.5) se encuentra localizado al sur de la ciudad de Carmona, situándose sobre una cuña subsuperficial del olistostroma. Durante el Tortoniense el sondeo se localizaba en una zona profunda de la cuenca. Después de más de $500 \mathrm{~m}$ de olistostroma (fig. 6.5C), ya en el Messiniense, se situaba en el talud sur de la cuenca que presentaba una elevada pendiente.

Sobre las arenas del "detrítico basal" se desarrollan las "arcillas basales", ricas en foraminíferos bentónicos profundos ( $P$. wellerstorfi...). La secuencia de eventos tortonienses se encuentra espaciada. La naturaleza del evento E2 (primera aparición común del grupo de G. menardii dx) no permite su localización precisa, existiendo un rango muy amplio para su localización. La localización del evento E3 bajo la cuña del olistostroma indica que el frente olistostrómico avanzó sobre esta posición inmediatamente después del límite Tortoniense-Messiniense. El ingreso del frente olistostrómico en esta zona, parece haber sucedido después de que las primeras cuñas de olistostromas accedieran al golfo de Cádiz y bajo Guadalquivir (ver sondeo Casanieves1). Este ingreso olistostrómico parece producirse en un contexto tectónico compresivo desarrollándose un fuerte incremento de la pendiente en el talud sur. El acceso de los materiales someros al fondo de cuenca se incrementó notablemente tras el ingreso del frente del olistostroma en el alto Guadalquivir. El incremento de la energía potencial de las partículas del talud y cabecera de cuenca, se tradujo en el emplazamiento de un sistema turbidítico de alta energía y de gran longitud, con lóbulos muy alargados en el sentido del eje de la cuenca. Estos cuerpos, atravesados por varios de los sondeos estudiados, pueden apreciarse en la parte izquierda del perfil sismobioestratigráfico que acompaña la figura sintética del sondeo Carmona-4 (fig. 6.5C.). 

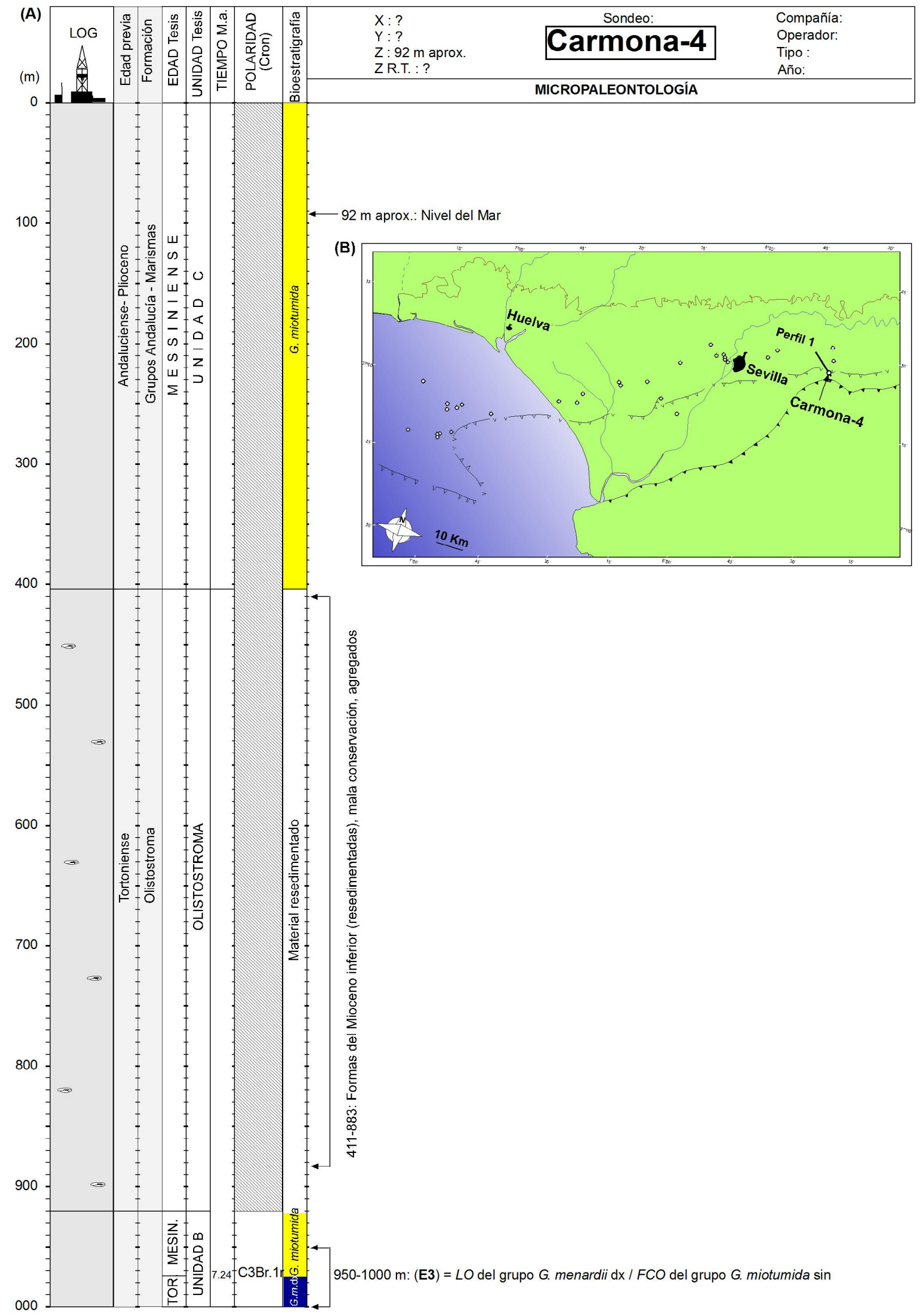

Figura 6.5. Síntesis de los resultados obtenidos en el sondeo Carmona-4. Leyenda general en figs. 6.1. y 6.2. (A) Profundidad en metros y columna litológica (ITGE, 1990). Edades y formaciones utilizadas anteriormente. Edad, unidades litosísmicas, datación, magnetoestratigrafía deducida y biozonas propuestas en esta Tesis en función de los bioeventos de plancton calcáreo. Información micropaleontológica, sedimentológica y otros datos de interés. (B) Localización del sondeo y del perfil sísmico. (C) Perfil sismobioestratigráfico no 1 (sísmica original facilitada por Repsol). 


\section{Carmona-4}

(C)

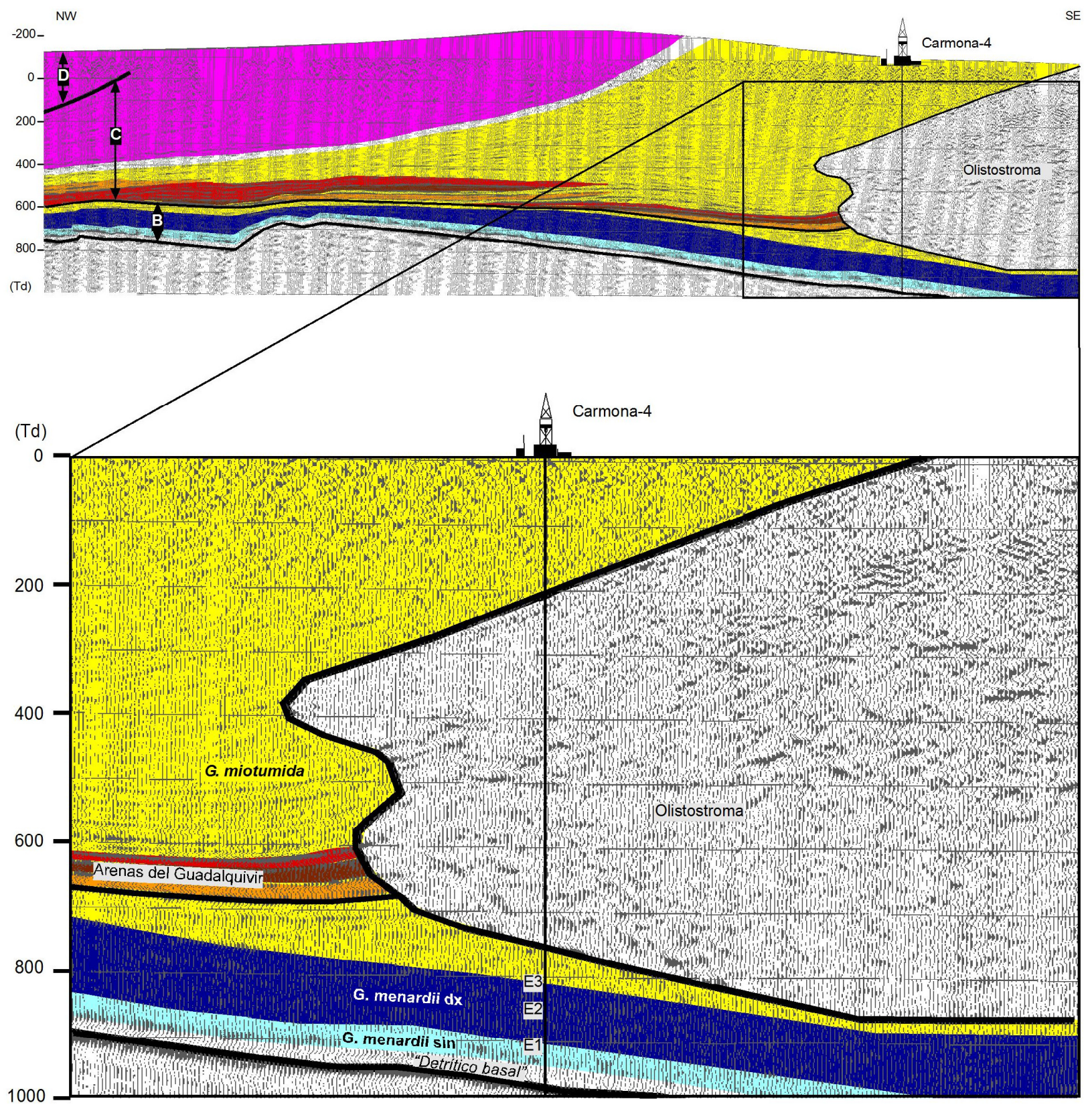

Figura 6.5 (Continuación). Síntesis de los resultados obtenidos en el sondeo Carmona-4. Leyenda general en la figuras 6.1. y 6.2. (C) Perfíl sísmobioestratigráfico $n^{0} 1$ (NW-SE) transversal a la cuenca y proyección de una posición equivalente a la del sondeo Carmona-4. (Td) = Tiempo doble en milisegundos (sísmica original facilitada por Repsol). 


\subsubsection{Carmona-1}

El sondeo Carmona-1 (figura 6.6) está localizado en la parte nororiental del área estudiada, al norte de la ciudad de Carmona. En este sondeo, se han utilizado muestras procedentes de testigo continuo para el análisis bioestratigráfico.

Tras un nivel arenoso en la base del sondeo $(792,08 \mathrm{~m})$, se detecta la presencia de glauconita $(785 \mathrm{~m})$, que refleja probablemente la posición del máximo transgresivo alcanzado en el Tortoniense superior. Seguidamente, las arcillas de este primer tramo, contienen globorotálidos del grupo de G. menardii sin, por lo que nos encontramos en la biozona homónima. La primera aparición de G. miotumida (E3) y el cambio de enrollamiento de $N$. acostaensis (E4) se localizan en la base del principal paquete arenoso (a $720 \mathrm{~m}$ ). La proximidad de este último evento (E4, 6.35 Ma) al evento de desaparición del grupo de G. menardii sin (E1, 7.355 Ma), indica la naturaleza erosiva de los canales que podrían haber erosionado hasta 1 Ma de depósitos tortonienses.

El sondeo atraviesa varios niveles arenosos en facies de canal y canal-levee, apreciándose en la sísmica de reflexión fuertes pendientes en la configuración interna de los canales (figura 6.6C). Los cuerpos canalizados poseen base erosiva y están compuestos fundamentalmente de granos de cuarzo grueso, subredondeados a subangulosos, en numerosas ocasiones agregados con cemento carbonatado. Los niveles de arena también contienen granos de cuarcita, micas, fragmentos de rocas metamórficas así como granos calcáreos y bioclastos. Estos cuerpos se encuentran en la biozona del grupo de G. miotumida, concretamente entre el cambio de enrollamiento de $N$. acostaensis (E4, 6.35 Ma) y la desaparición de G. miotumida (E5, 6.34 Ma).

Inmediatamente por encima de los principales paquetes arenosos se detecta la desaparición del grupo de G. miotumida sin (E5), por lo que termina en este punto la biozona de dicho grupo. Rápidamente, el grupo de G. margaritae, comienza a ser el globorotálido más abundante, pasando por lo tanto a la biozona de este globorotálido (capítulo 3). Tras la primera aparición común del grupo de G. margaritae, se distingue un marcado nivel de arenas conchíferas a $506 \mathrm{~m}$, que sirve de correlación con otro nivel similar localizado en el sondeo Carmona-2. Es probable que este nivel marque el máximo descenso relativo del nivel del mar de edad Messiniense superior y podría estar relacionado con el descenso relativo del nivel del mar que se produjo durante la Crisis de Salinidad en el Mediterráneo (capítulo 8). La composición biogénica de este nivel indica su conexión con la calcarenita de Carmona, que estaría desarrollándose en ese momento en las facies proximales del margen sur de la cuenca. 


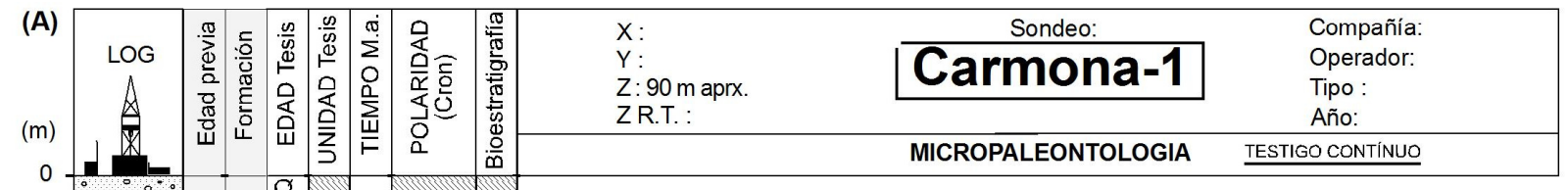

$16.10 \mathrm{~m}: 70 \%$ Bentónicos: Buliminas, globobulimínidos. G. extremus abundante

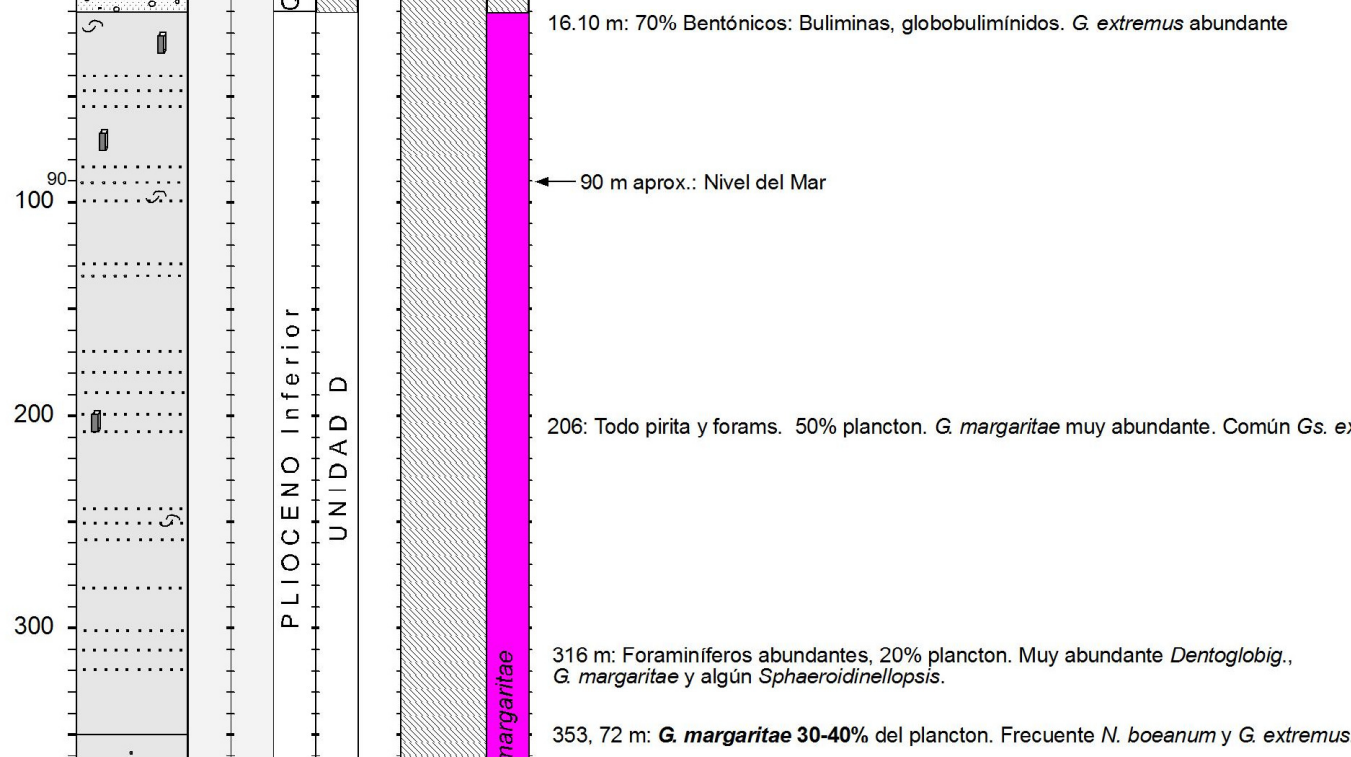

353, 72 m: G. margaritae $30-40 \%$ del plancton. Frecuente N. boeanum y G. extremus.

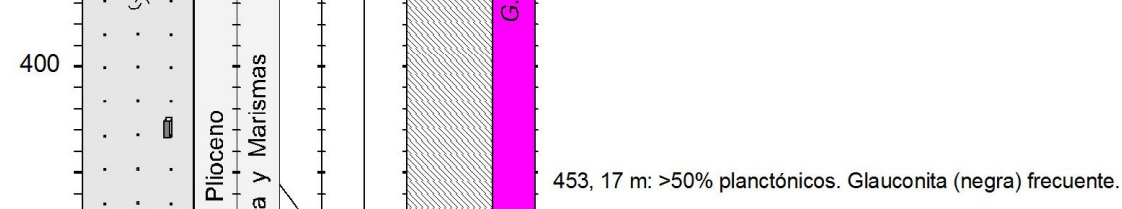

$506 \mathrm{~m}$ : Arenas conchiferas $\left.{ }^{* *}\right)$. Elphidium. Arena gruesa redondeada. Poco plancton.

$528 \mathrm{~m}$ : Dominio de bentos (70\%), abundancia de Globobulimina y Valvulineria. G. margaritae.

$556 \mathrm{~m}$ : Todo pirita y forams, 50-60\% plancton. G. margaritae abundante. N. acosta. dx,
Gs. extremus frecuente. No bentónicos someros.

$555,7 \mathrm{~m}$ : Abundante fauna bentónica

$566,8 \mathrm{~m}$ : G. margaritae frecuente

595.40 m: G. margaritae (5\%), 5 Dento. (1-2\%),

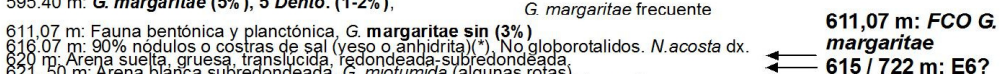

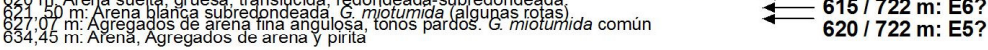

600

[i

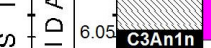

644: G. miotumida

Bentos > plancton, Anmonia y Valvulineria abundante

$90 \%$ bentónicos, Anmonia, Valvulineria.

$693 \mathrm{~m}$ : Predominio de Anmonia
$693.55 \mathrm{~m}$ : Arena parda, angulosa, en agregados, $90 \%$ Bent., abundante Anmonia, Valvulineria, Cibicidoides. Arena gruesa,
715 (1)

$\longleftarrow 720 \mathrm{~m}: \mathrm{E4}$ $722,39 \mathrm{~m}$. Arenas gruesas, translúcidas, redondeadas. Plancton $>$ bentos.

$725,20 \mathrm{~m}$ : Plancton $>>$ bentos.

$741.08 \mathrm{~m}$ : Plancton $>>$ bentos.

Arena fina, angulosa

785: Presencia de glauconita

$800-$

(P. F. $792,08 \mathrm{~m}$ )
$(E 6)=F O$ del grupo $G$. margaritae

$(\mathrm{E} 5)=L O$ del grupo $\mathrm{G}$. miotumida $\sin (6,3 \mathrm{Ma})$

(E4) = Cambio de enrollamiento de $N$. acostaensis (6,35 Ma)

$(E 1)=L C O$ del grupo $G$. menardii $\sin (7,512 \mathrm{Ma})$

${ }^{*}$ ): Presencia de yesos en los levigados. Nivel similar localizado a $700 \mathrm{~m}$ en el sondeo San Juan V-6

$\left({ }^{* *}\right)$ Nivel similar localizado a $483 \mathrm{~m}$ en el sondeo

Carmona-2 (Nivel conchífero sobre FCO de G. margaritae).

Figura 6.6. Síntesis de los resultados obtenidos en el sondeo Carmona-1. Leyenda general en figs. 6.1. y 6.2.

(A) Profundidad en metros y columna litológica (ITGE, 1990). Edades y formaciones utilizadas anteriormente. Edad, unidades litosísmicas, datación, magnetoestratigrafía deducida, unidades cicloestratigráficas y biozonas propuestas en esta Tesis en función de los bioeventos de plancton calcáreo. Información micropaleontológica, sedimentológica y otros datos de interés. (B) Localización del sondeo y del perfil sísmico. (C) Perfil sismobioestratigráfico n⿳亠丷厂 1 (sísmica original facilitada por Repsol). 


\section{Sondeo:}

(B)

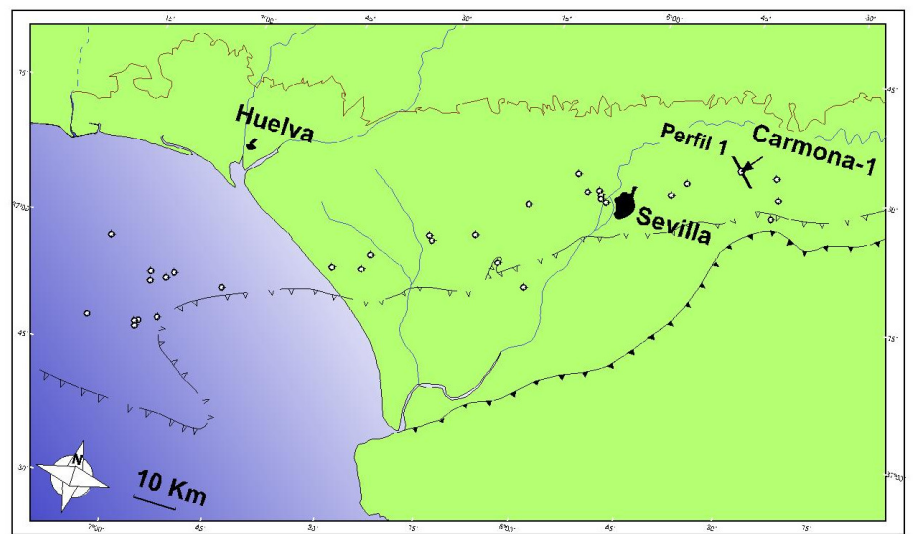

(C)

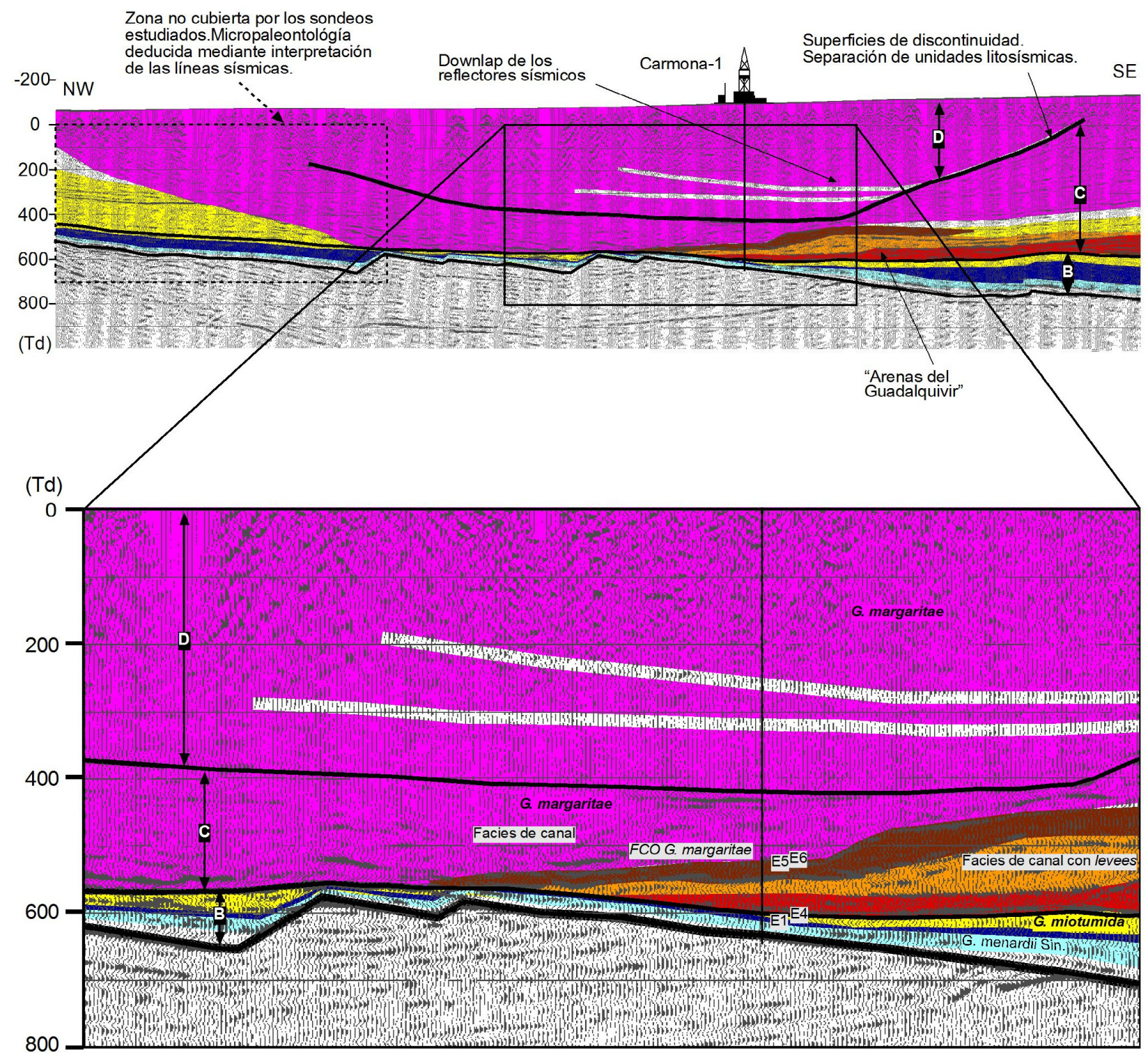

Figura 6.6 (Continuación). Síntesis de los resultados obtenidos en el sondeo Carmona-1. Leyenda general en las figuras 6.1. y 6.2. (B) Localización del sondeo Carmona-1 y del perfil sísmico interpretado. (C) Perfil sísmobioestratigráfico n 1 (NWSE) transversal a la cuenca y proyección del sondeo Carmona-1. (Td) = Tiempo doble en milisegundos (sísmica original facilitada por Repsol). 
A unos $450 \mathrm{~m}$, dentro de la misma biozona, se detecta un nivel rico en glauconita. Por encima de $450 \mathrm{~m}$ los depósitos pliocenos consisten en arcillas y limos con frecuentes intercalaciones de arena. Además de la presencia de pirita y restos de moluscos, este tramo se caracteriza por la presencia de individuos del grupo de G. margaritae. En ningún caso se registra la presencia de G. puncticulata, por lo que se mantiene la biozona del grupo de G. margaritae. La serie termina tras una decena de metros de depósito cuaternario que se apoya discordante sobre el Plioceno inferior.

La localización de los bioeventos antes descritos permite inferir la posición de tres periodos magnéticos: $\mathrm{El}$ periodo inverso $\mathrm{C} 3 \mathrm{Br}$.3r ubicado respecto a la posición del evento de desaparición de G. menardii sin (E1). El periodo inverso C3An.1r deducido por la posición de los eventos E4 y E5. Y el periodo normal C3An.1n respecto a la FCO del grupo de G. margaritae.

En el perfil sismobioestratigráfico (figura 6.6C), podemos observar diferentes cuerpos turbidíticos en el intervalo definido por la biozona del grupo de G. miotumida. Los cuerpos turbidíticos han sido coloreados para su mejor identificación. En el perfil se observa la migración lateral de SE a NW de estos aparatos, así como la configuración de canal-canal levee a la derecha de la imagen y la naturaleza erosiva de los canales más modernos a la izquierda.

\subsubsection{Ciervo-1}

Está localizado entre las localidades de Sevilla y Carmona (figura 6.7). Durante el Messiniense se encontraba dispuesto en el eje de la cuenca de forma que la presencia masiva de arena en la base del sondeo dificulta el análisis bioestratigráfico de las muestras. La presencia puntual del grupo de G. miotumida indica que al menos parte de las arenas corresponden a las "arenas del Guadalquivir". En el perfil sismobioestratigráfico que acompaña a la figura sintética del sondeo (figura 6.8C), obervamos que este sondeo está ubicado en una posición en la cual la base de la unidad litosísmica C (base de las "arenas del Guadalquivir") se une prácticamente al reflector que define la base de la unidad litosísmica B (base del detrítico basal). Por encima de los niveles de arena se detecta la primera aparición común del grupo de G. margaritae. En torno a este bioevento se ha localizado como en otros sondeos una abundante presencia de pirita. Por otro lado, por encima de la primera aparición común de G. margaritae, en el perfil sismobioestratigráfico se distingue un reflector sobre el que se disponen el resto a modo de downlap (fig. 6.8C). Se ha considerado que dicho reflector corresponde al límite Mio-Plioceno. La presencia de G. margaritae hasta el techo del sondeo determina que la mayor parte de la sedimentación de este sondeo se produjo en el Plioceno inferior. 


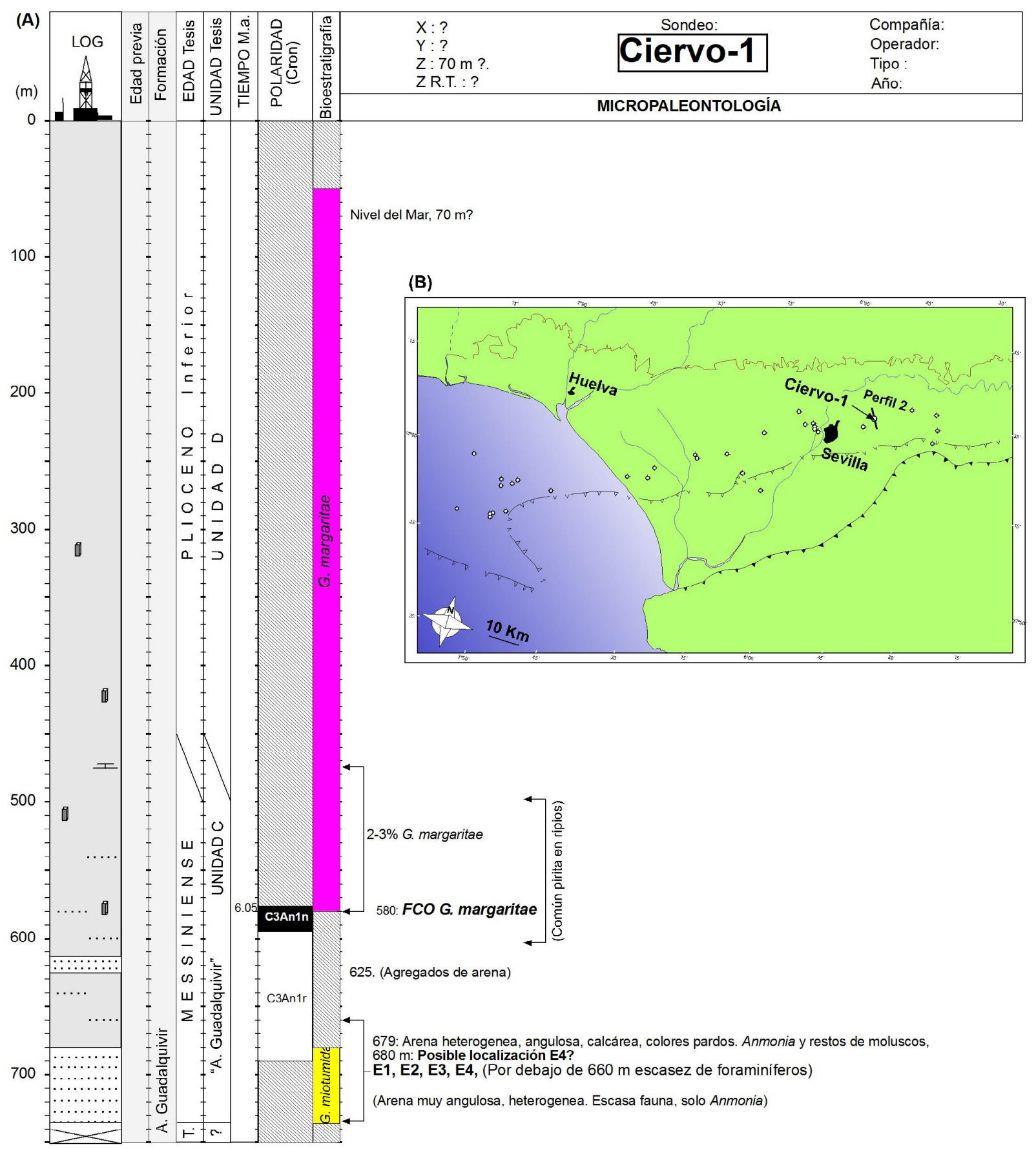

(P.F. ?)

(E4) = Cambio de enrollamiento de $N$. acostaensis $(6,35 \mathrm{Ma})$

$(E 3)=L O$ del grupo G. menardii dx / FCO del grupo G. miotumida $\sin (7,240 \mathrm{Ma})$

$(\mathrm{E} 2)=$ FCO del grupo $G$. menardii $\mathrm{dx}(7,355 \mathrm{Ma})$

$(E 1)=L C O$ del grupo $G$. menardii $\sin (7,512 \mathrm{Ma})$

Figura 6.7. Síntesis de los resultados obtenidos en el sondeo Ciervo-1. Leyenda general en figs. 6.1. y 6.2.

(A) Profundidad en metros y columna litológica. Edades y formaciones utilizadas anteriormente. Edad, unidades litosísmicas, datación, magnetoestratigrafía deducida, unidades cicloestratigráficas y biozonas propuestas en esta Tesis en función de los bioeventos de plancton calcáreo. Información micropaleontológica, sedimentológica y otros datos de interés. (B) Localización del sondeo Ciervo-1 y del perfil sísmico interpretado. Perfil sismobioestratigráfico correspondiente enla figura 6.8 (continuación), basado en perfil sísmico original proporcionado por Repsol. 


\subsubsection{Sevilla-2}

Próximo al sondeo Ciervo-1, pero más al sur, el sondeo Sevilla-2 (figura 6.8) alcanza el zócalo Paleozoico (esquistos verdes). Los primeros depósitos miocenos consisten en unas arenas limpias y areniscas con pasadas de caliza donde no ha podido establecerse la bioestratigrafía debido a la ausencia de biomarcadores. Sin embargo, la presencia de foraminíferos bentónicos, principalmente Ammonia beccarii, y la interpretación del perfil sismobioestratigráfico (fig. 6.8C), indican que se trata del detrítico basal. En el sondeo Sevilla-2 se ha observado otro nivel de concentración con un $50 \%$ de Orbulina universa a $841 \mathrm{~m}$ de profundidad, intercalado entre una formación arenosa de unos $80 \mathrm{~m}$ de potencia. Esta formación arenosa se catalogó originalmente como arena basal. La "excesiva" potencia de estas arenas basales, la presencia de un nivel de concentración de foraminíferos planctónicos intercalado entre las arenas (¿superficie de máxima inundación?), la ausencia de formas del grupo de G. menardii sin, o del grupo de G. menardii dx en las arcillas inmediatamente superiores y las características sedimentológicas de este nivel, podrían indicar que al menos en su parte superior, este paquete arenoso puede corresponder a las "arenas del Guadalquivir".

Tras un intervalo de arcillas grises calcáreas, con G. miotumida, se atraviesan dos niveles de arena. A la altura del nivel superior desaparece G. miotumida, comenzando a registrarse individuos de G. margaritae unos $30 \mathrm{~m}$ por encima del nivel arenoso. Seguidamente, en un intervalo de limos con frecuente presencia de partículas de pirita se localiza la primera aparición común $(F C O)$ del grupo de G. margaritae, que continua presente hasta el techo de la serie.

En el perfil sismobioestratigráfico correspondiente a este sondeo (figura 6.8C) se distinguen los reflectores del detrítico basal y varios cuerpos turbidíticos superpuestos que constituyen la formación "arenas del Guadalquivir". 


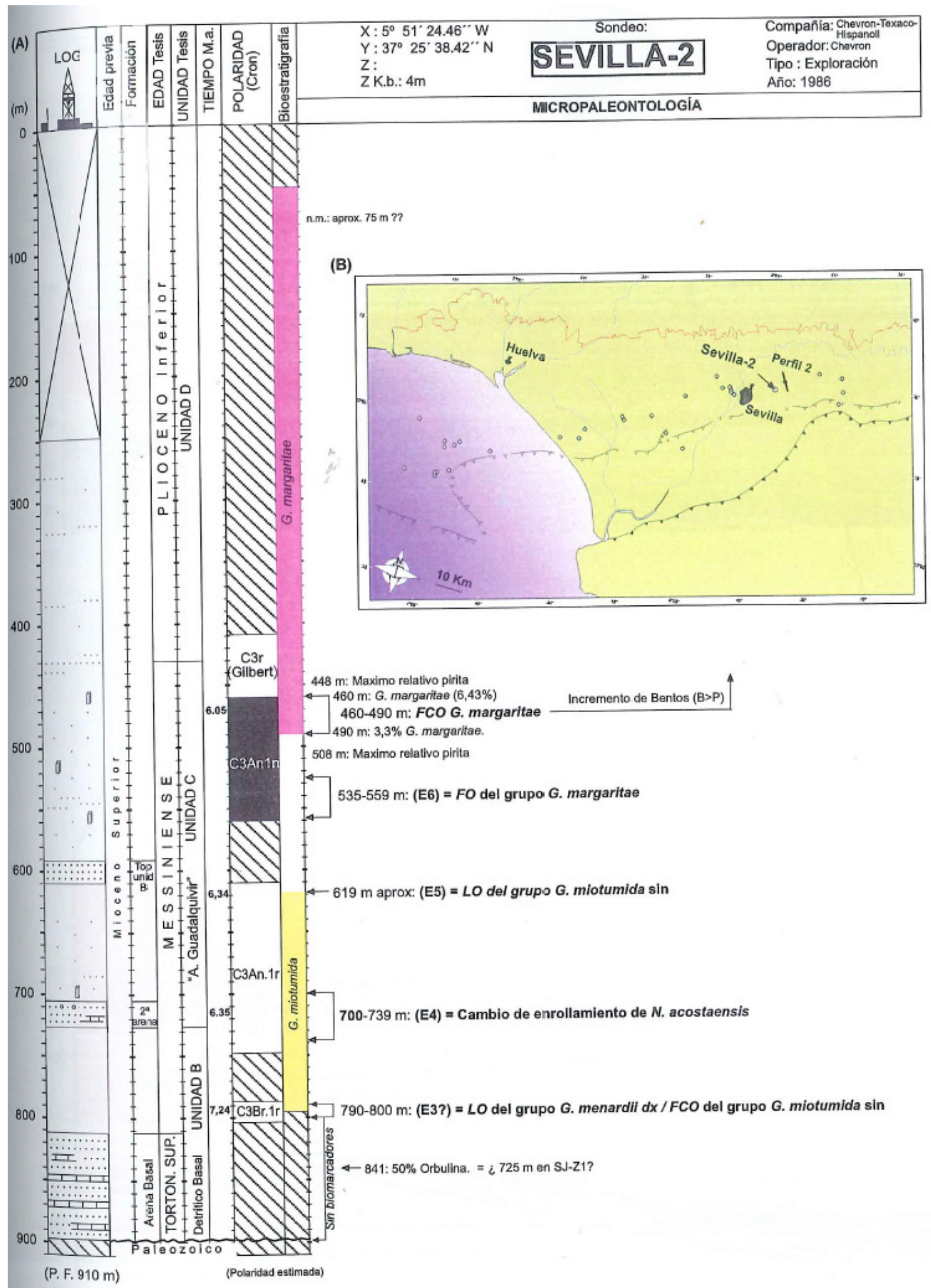

Figura 6.8. Síntesis de los resultados obtenidos en el sondeo Sevilla-2. Leyenda general en la figuras 6.1. y 6.2. (A) Profundidad en metros y columna litológica (basada en documentación facilitada por Repsol). Edades y formaciones utilizadas anteriormente. Edad, unidades litosísmicas, datación, magnetoestratigrafía deducida y biozonas propuestas en esta Tesis en función de los bioeventos de plancton calcáreo. Información micropaleontológica, sedimentol6gica y otros datos de interés. (B) Localización del sondeo Sevilla-2 y del perfil sísmico interpretado. (C) Perfil sismobioestratigráfico $\mathrm{n}^{\circ} 2$, basado en perfil sísmico original proporcionado por Repsol. 
Sondeos:

Ciervo-1

Sevilla-2

(C)

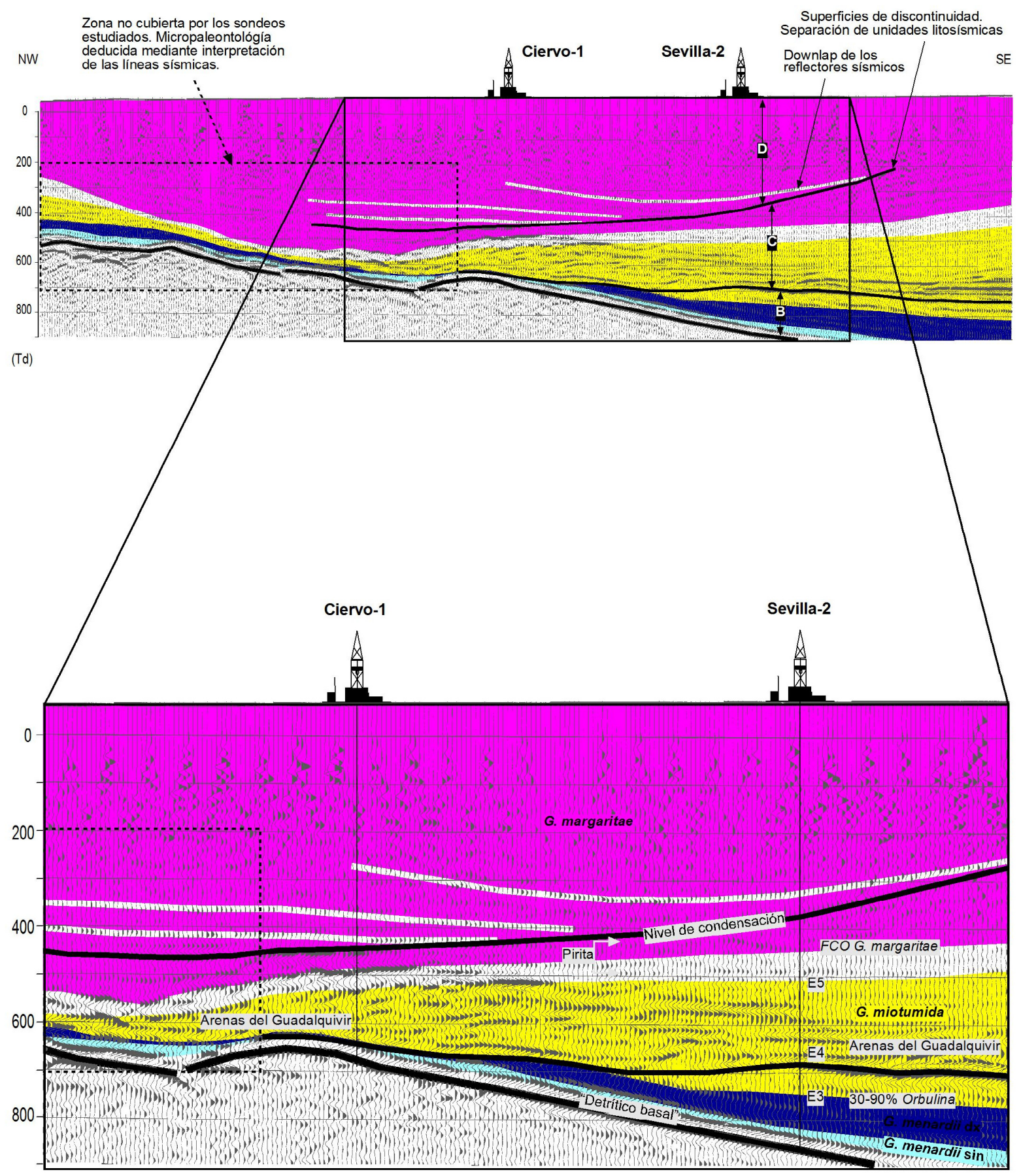

(Td)

Figura 6.8 (Continuación). (C) Perfil sísmobioestratigráfico n². Proyección sobre esta línea de posiciones equivalentes a las de los sondeos Ciervo-1 y Sevilla-2. Sísmica original facilitada por Repsol, (Td) = Tiempo doble en milisegundos. Leyenda general en figs. 6.1. y 6.2. 


\subsubsection{San Juan V-6}

En torno a la ciudad de Sevilla se localizan numerosos sondeos de exploración. Además del sondeo San Juan V-6 (figura 6.9), se han estudiado los sondeos San Juan V-2 (figura 6.10), San Juan R-1 (figura 6.11) y San Juan Z-1 (figura 6.12). En todos ellos, en menos de 200 metros de abundantes niveles arenosos se suceden la mayor parte de los bioeventos. La escasez de "muestra lavada" disponible para el análisis de las muestras, así como la contaminación de los ripios, unido a la abundante presencia de arena y al retrabajado de muchos de estos biomarcadores ha complicado la bioestratigrafía de estos sondeos.

En todos ellos se han registrado varias pasadas de niveles arenosos que corresponden a facies de canal-levee superpuestos unos a otros (figura 6.9C). Los primeros lóbulos prácticamente conectan con el detrítico basal mientras que los últimos terminan en torno al comienzo de la zona del grupo de G. margaritae (San Juan V-6). La presencia de G. menardii sin y G. menardii dx en los primeros metros de arcilla, pueden indicar la presencia de restos de detrítico basal y arcillas basales bajo las "arenas del Guadalquivir" (como refleja la figura 6.9), pero cabría la posibilidad de que su presencia fuera debida a incorporaciones a los flujos turbidíticos de material resedimentado.

En los sondeos próximos a Sevilla el aporte de materiales desde el margen norte (la Meseta) incrementa la presencia de micas (moscovita y biotita) y de restos carbonosos en los ripios. Probablemente, la presencia de micas en torno a Sevilla indica la denudación del macizo granítico que aflora al norte de Alcalá de Río y Cantillana. La presencia de un cañón submarino N-S al norte de la ciudad de Sevilla, siguiendo el curso actual del río Guadalquivir (S. Torrescusa, com. per.) puede proporcionar estos materiales al eje principal de la cuenca del Guadalquivir. Por otro lado el aporte de materia orgánica y restos vegetales a través de los ríos, pudo crear un ambiente reductor en el fondo de cuenca. Esta hipótesis justificaría la presencia en los sondeos del eje de la cuenca de elevadas proporciones de globobulimínidos en las muestras, teniendo en cuenta que estos foraminíferos bentónicos suelen reflejar fondos poco oxigenados o ricos en materia orgánica. La presencia de micas en los ripios de sondeos próximos a Sevilla es especialmente notable en Palancares-1, San Juan R1, San Juan V-6. 

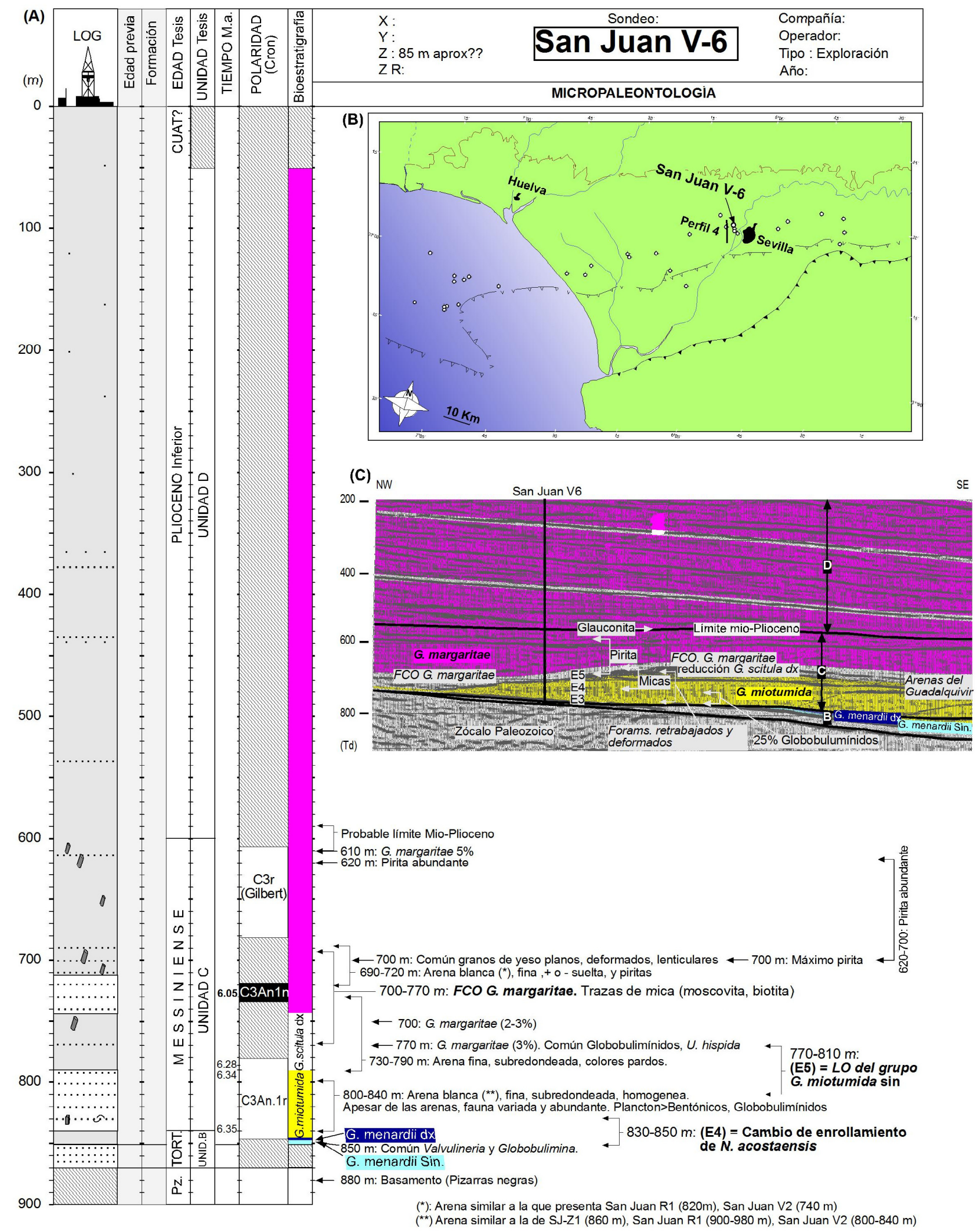

Figura 6.9. Síntesis de los resultados obtenidos en el sondeo San Juan V-6. Leyenda general en figuras 6.1. y 6.2. (A) Profundidad en metros y columna litológica. Edades y formaciones utilizadas anteriormente. Edad, unidades litosísmicas, datación, magnetoestratigrafía deducida y biozonas propuestas en esta Tesis en función de los bioeventos de plancton calcáreo. Información micropaleontológica, sedimentológica y otros datos de interés.

(B) Localización del sondeo San Juan V6 y del perfil sísmico $n^{\circ} 4$.

(C) Zona ampliada del perfil sismobioestratigráfico $\mathrm{n}^{\circ} 4$ (basado en perfil sísmico original facilitado por Repsol). 


\subsubsection{San Juan V-2}

La glauconita presente en la base del sondeo (figura 6.10), la heterogeneidad de la arena y la presencia de globorotálidos del grupo de G. menardii sin en las arcillas inmediatamente superiores, indica que el primer nivel arenoso detectado en la base del sondeo, constituye el detrítico basal. El resto de niveles de arena atravesados (hasta los $720 \mathrm{~m}$ ), se encuentran en la biozona del grupo de $G$. miotumida, por lo que corresponderían a las "arenas del Guadalquivir". El análisis de los perfiles sísmicos indica que se tratan de cuerpos de arena en facies de canal-levee, depositados en una etapa próxima al evento de desaparición de G. miotumida (6.34 Ma), o incluso durante la biozona de G. scitula (6.05-6.34 Ma).

La coincidencia del reflector sísmico base de la unidad litosísmica D (figura 6.10D), con niveles ricos en glauconita localizados por encima de la $F C O$ del grupo de $G$. margaritae (San Juan V-2), sugiere que dicho reflector puede corresponder al límite MioPlioceno. Sobre este reflector se disponen hacia el este a modo de downlap el resto de reflectores de la unidad litosísmica D. Esta característica observada en la mayor parte de los perfiles, ha servido para identificar el límite Mio-Plioceno. Se puede observar en los perfiles sismobioestratigráficos, como a partir de este horizonte el margen NW cobra mayor importancia como área fuente, desplazándose hacia el este los sucesivos depocentros.

El porcentaje de abundancia relativa en el conjunto de los globorotálidos que aparece en la figura 6.10B, muestra la presencia de G. margaritae desde la base del sondeo, al tiempo que en los niveles de arena aparecen individuos de todos los grupos de globorotálidos. La presencia de G. margaritae desde la base del sondeo se ha interpretado como consecuencia de la contaminación de las muestras inferiores por material superior (contaminación muy frecuente al atravesar niveles arenosos).

El incremento de foraminíferos bentónicos $(700-800 \mathrm{~m})$ detectado a techo de los niveles de arena parece indicar que en torno a la FCO del grupo de G. margaritae existió un descenso relativo del nivel del mar. Esta situación propiciaría el incremento de foraminíferos bentónicos en las muestras así como el de partículas terrígenas y piritas que se detectan en numerosos sondeos entorno a este evento. 


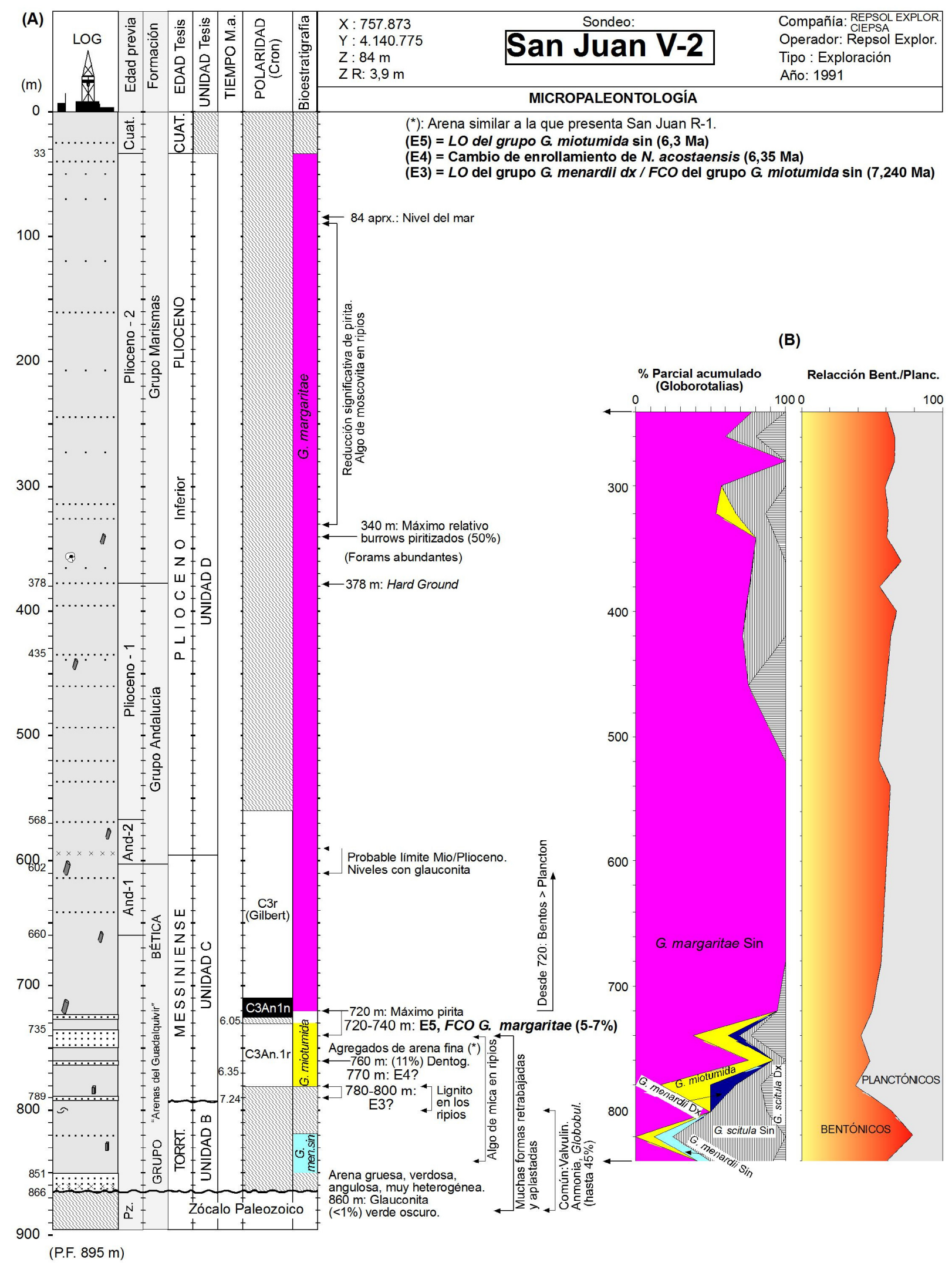

Figura 6.10. Síntesis de los resultados obtenidos en el sondeo San Juan V-2. Leyenda general en figs. 6.1. y 6.2.

(A) Profundidad en metros y columna litológica (basada en documentación facilitada por Repsol). Edades y formaciones utilizadas anteriormente. Edad, unidades litosísmicas, datación, magnetoestratigrafía deducida y biozonas propuestas en esta Tesis en función de los bioeventos de plancton calcáreo. Información micropaleontológica, sedimentológica y otros datos de interés.

(B) Porcentaje relativo de globorotálidos (análisis cuantitativo). Relación de foramíferos planctónicos/bentónicos.

(C) Localización del sondeo y del perfil sísmico.

(D) Perfil sismobioestratigráfico $\mathrm{n}^{\circ} \mathbf{4}$, basado en perfil sísmico original proporcionado por Repsol. 


\section{Sandeo:}

(C)

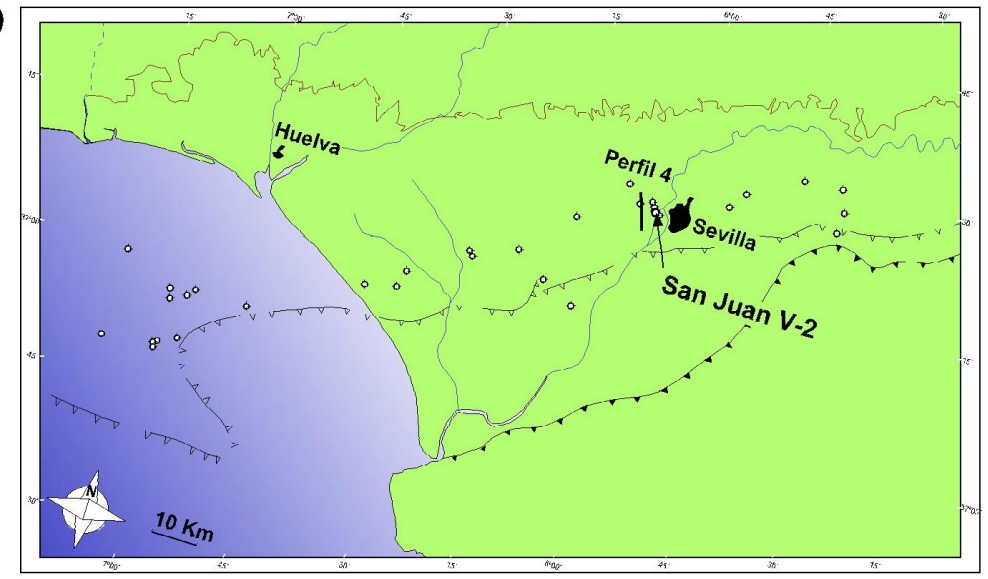

(D)

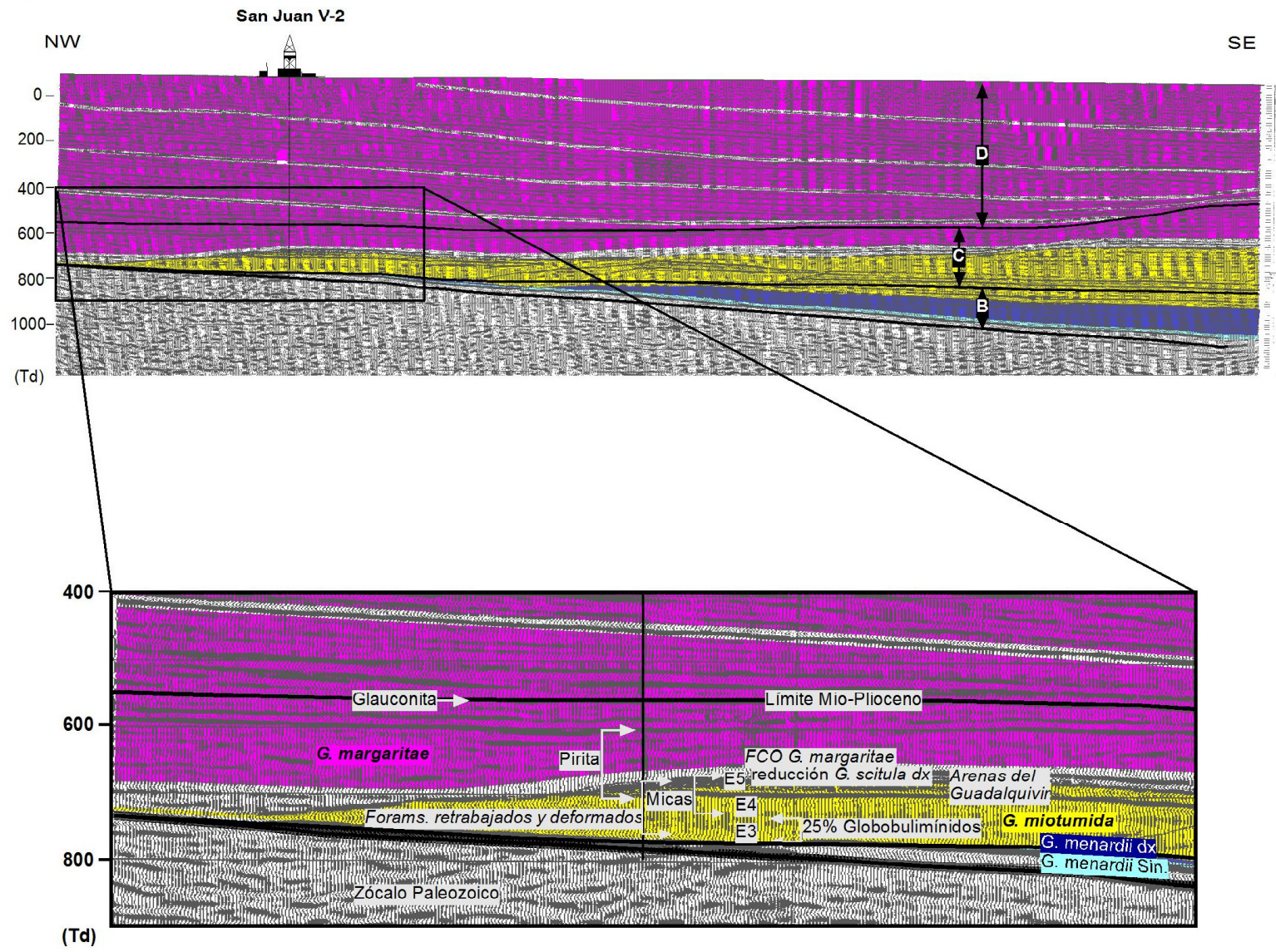

Figura 6.10 (Continuación). Síntesis de los resultados obtenidos en el sondeo San Juan V-2. Leyenda general en las figuras 6.1. y 6.2.

(A) Profundidad en metros y columna litológica (basada en documentación facilitada por Repsol). Edades y formaciones utilizadas anteriormente. Edad, unidades litosísmicas, datación, magnetoestratigrafía deducida y biozonas propuestas en esta Tesis en función de los bioeventos de plancton calcáreo. Información micropaleontológica, sedimentológica y otros datos de interés.

(B) Porcentaje relativo de globorotálidos basado en análisis cuantitativos.

(C) Localización del sondeo San Juan V2 y del perfil sísmico interpretado.

(D) Perfil sismobioestratigráfico $\mathrm{n}^{\circ}$ 4, proyección del sondeo San Juan V2. TD = Tiempo doble en milisegundos. Sísmica original facilitada por Repsol. 


\subsubsection{San Juan R-1}

La presencia de G. menardii sin en la base del sondeo (figura 6.11), muestra la posibilidad de que el primer nivel arenoso constituya el detrítico basal. A $905 \mathrm{~m}$ se detecta la desaparición de G. menardii sin. No se ha detectado la presencia de $G$. menardii $\mathrm{dx}$, por lo que esta biozona podría acuñarse hacia el talud noroeste de la cuenca. La biozona del grupo de G. miotumida es muy estrecha, acuñándose igualmente hacia el oeste (figura 6.11D). Los últimos cuerpos de arena se desarrollan en la biozona del grupo de G. scitula dx (figura 6.11C). Hacia 790-740 m se aprecia un aumento significativo de globorotálidos del grupo de G. margaritae, por lo que se considera que en ese intervalo se encuentra la base de la biozona del grupo de G. margaritae (figura 6.11B). La magnetoestratigrafía se ha deducido únicamente mediante los eventos más fiables: E1 (LCO del grupo de G. menardii sin), E4 (cambio de enrollamiento N. acostaensis) y reducción significativa del grupo de G. scitula. La presencia de G. margaritae hasta prácticamente el techo del sondeo, indica que la mayor parte del relleno sedimentario se produce durante el Plioceno inferior (últimos $600 \mathrm{~m}$ ) soportando una elevada velocidad de sedimentación durante ese periodo. 


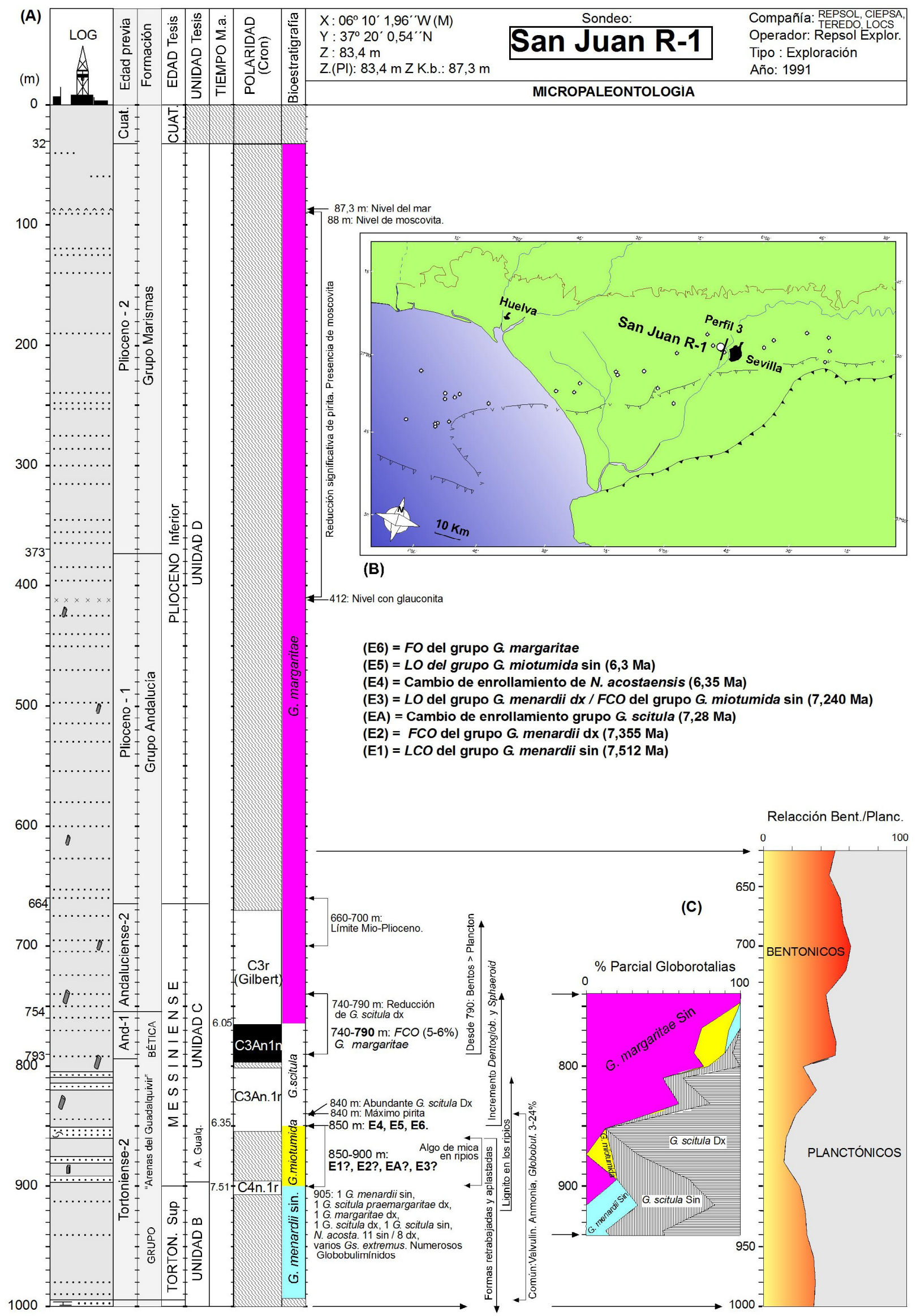

Figura 6.11. Síntesis de los resultados obtenidos en el sondeo San Juan R-1. Leyenda general en figs. 6.1. y 6.2. (A) Profundidad y columna litológica basada en documentación facilitada por Repsol. Edades y formaciones utilizadas anteriormente. Edad, unidades litosísmicas, datación, magnetoestratigrafía deducida y biozonas propuestas. Información micropaleontológica, sedimentológica y otros datos de interés. (B) Localización del sondeo San Juan R-1 y del perfil sísmico interpretado. (C) Porcentaje relativo de globorotálidos basado en análisis cuantitativos; relación de foraminíferos planctónicos respecto a bentónicos. (D) Perfil sismobioestratigráfico n 3 (original facilitado por Repsol). 


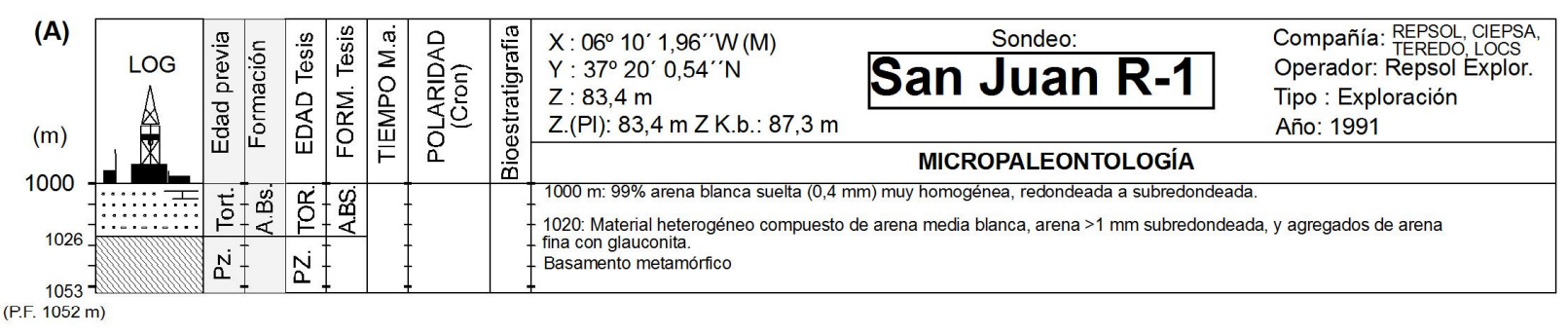

(D)
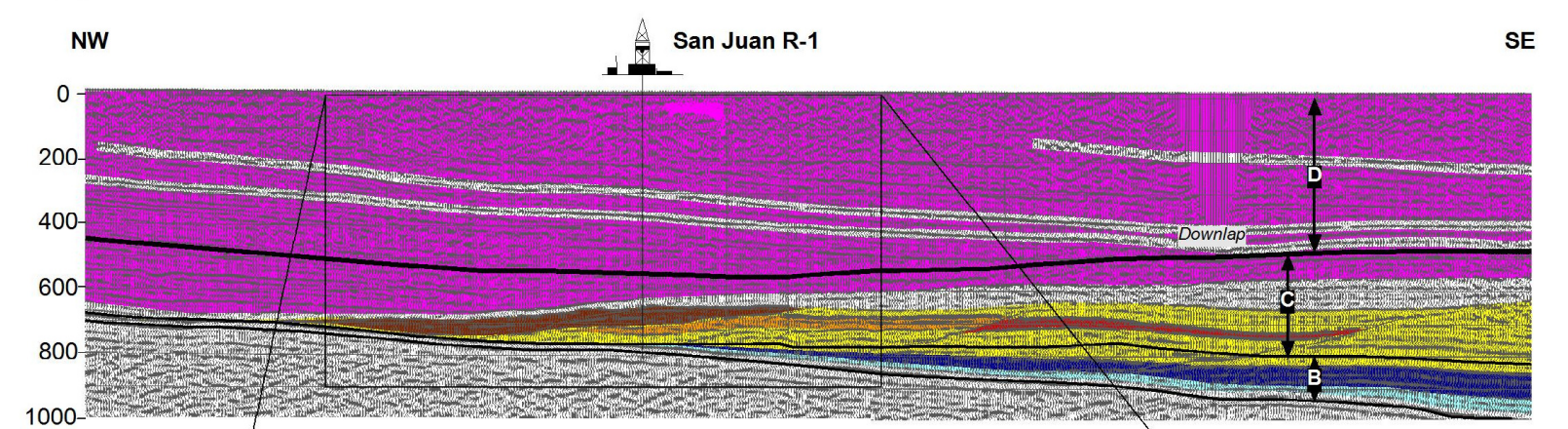

(TD)

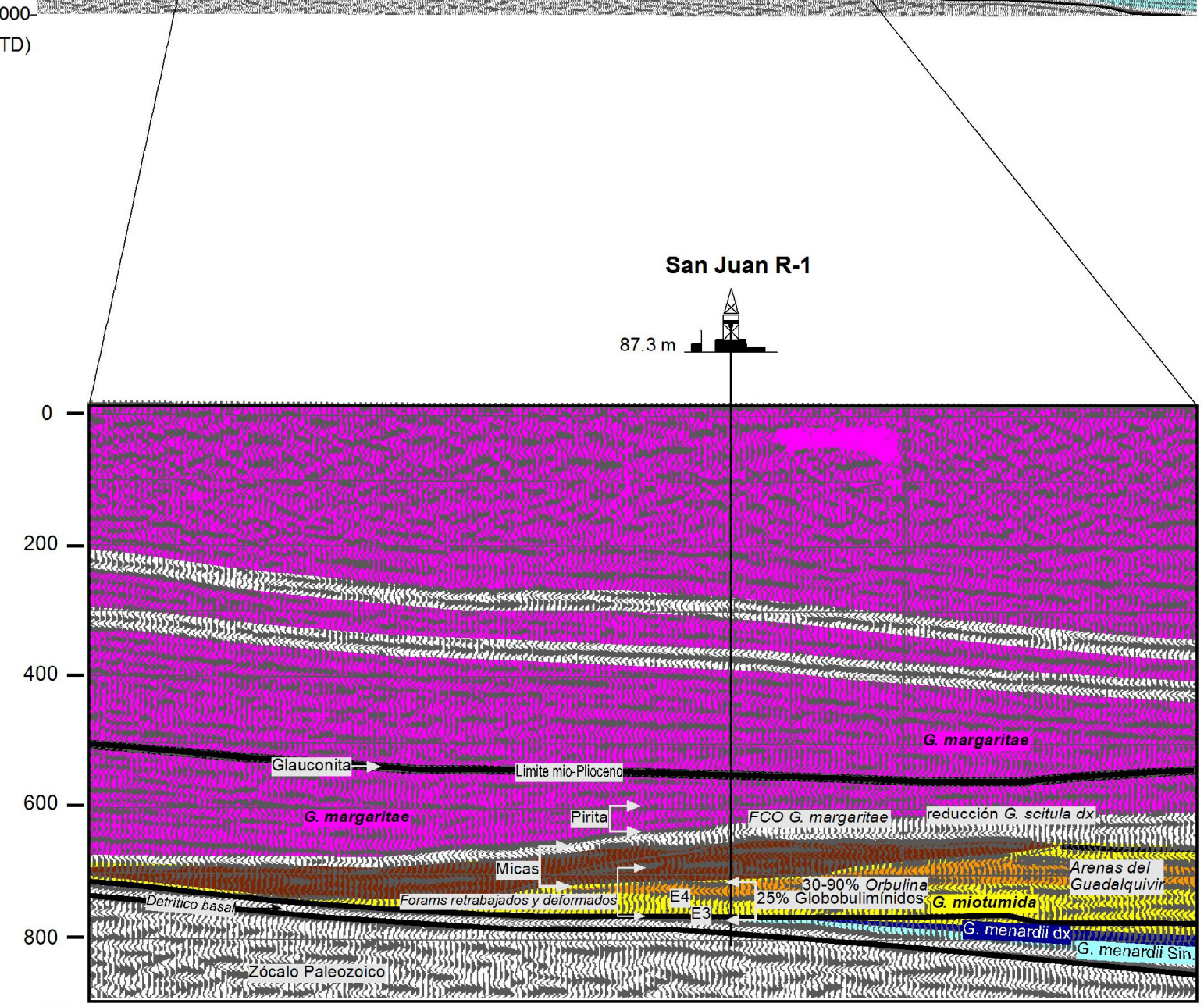

(TD)

Figura 6.11 (Continuación). Síntesis de los resultados obtenidos en el sondeo San Juan R-1. Leyenda general en las figuras 6.1. y 6.2. (A) Profundidad en metros y columna litológica (basada en documentación facilitada por Repsol). Edades y formaciones utilizadas anteriormente. Edad, unidades litosísmicas, datación, magnetoestratigrafía deducida y biozonas propuestas en esta Tesis en función de los bioeventos de plancton calcáreo. Información micropaleontológica, sedimentológica y otros datos de interés.

(B) Localización del sondeo y del perfil sísmico.

(C) Porcentaje relativo de globorotálidos basado en análisis cuantitativos.

(D) Perfil sismobioestratigráfico $\mathbf{n}^{\circ} 3$ y proyección del sondeo San Juan R-1. (Td) = Tiempo doble en milisegundos (basado en perfil sísmico original facilitado por Repsol). 


\subsubsection{San Juan Z-1}

No cabe duda en este caso, de que la formación arenosa en la base del sondeo (figura 6.12) corresponde al detrítico basal. El contenido en glauconita (15\% de las partículas), el tamaño microconglomerático de las arenas y su heterogeneidad así lo indican. El perfil sismobioestratigráfico confirma esta observación (figura 6.12C). También se observa en el perfil sismobioestratigráfico el acuñamiento de las biozonas del grupo de G. menardii sin y G. menardii dx hacia el NW (a la izquierda del sondeo San Juan Z-1). El desplazamiento del depocentro hacia el NW durante todo el Messiniense es la causa de que los canales de las "arenas del Guadalquivir", y con ellos la biozona del grupo de G. miotumida, alcance la posición del detrítico basal como sucede en los sondeos Salteras-1 y Castilleja-1. 


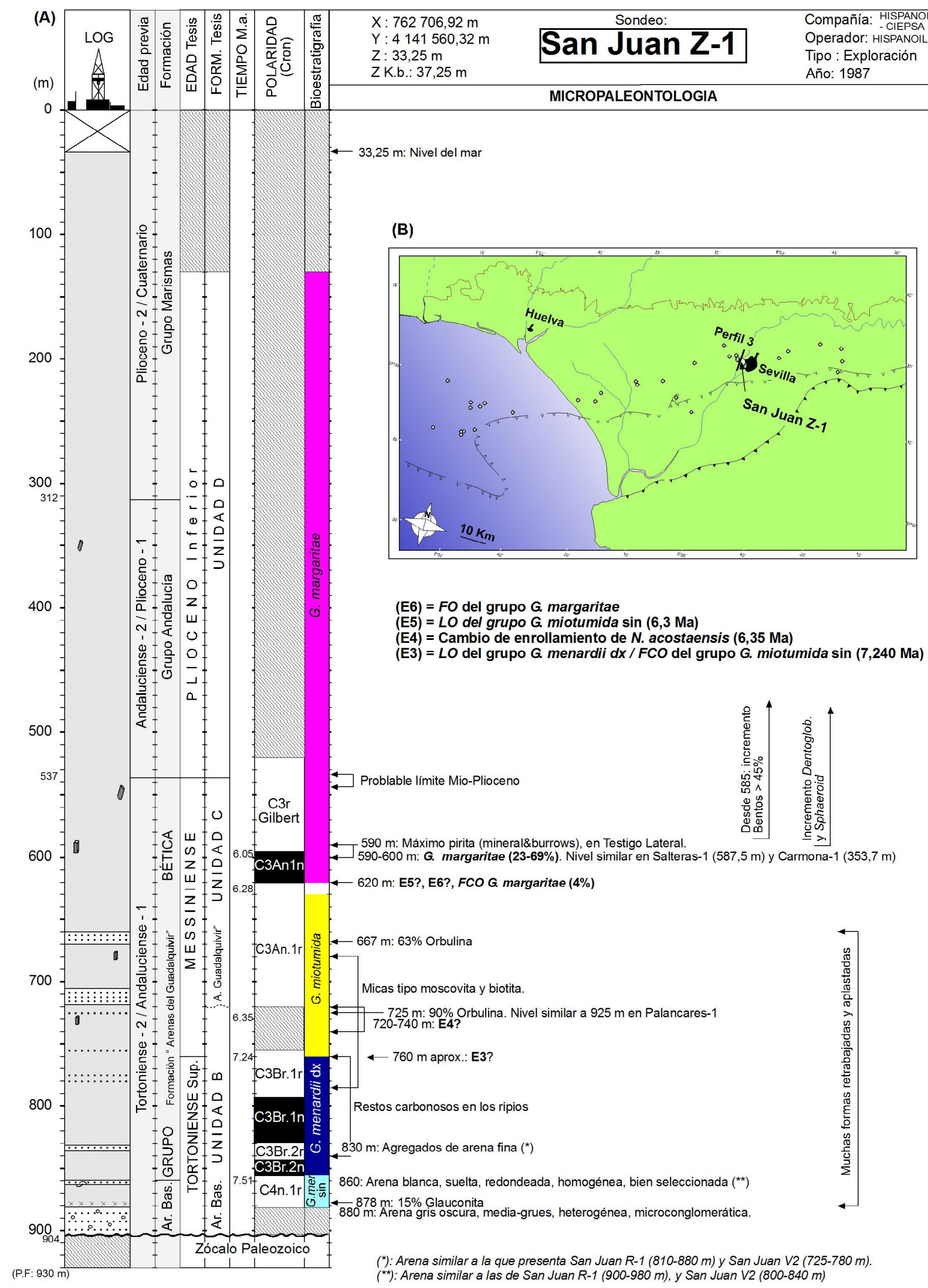

Figura 6.12. Síntesis de los resultados obtenidos en el sondeo San Juan Z-1. Leyenda general en la figuras 6.1. y 6.2. (A) Profundidad en metros y columna litológica. Edades y formaciones utilizadas anteriormente. Edad, unidades litosísmicas, datación, magnetoestratigrafía deducida y biozonas propuestas en esta Tesis en función de los bioeventos de plancton calcáreo. Información micropaleontológica, sedimentológica y otros datos de interés.

(B) Localización del sondeo San Juan Z-1 y del perfil sísmico interpretado.

(C) Perfil sismobioestratigráfico $\mathbf{n}^{\mathbf{0} 3}$, basado en perfil sísmico original facilitado por Repsol. 
Sondeo:

\section{San Juan Z-1}

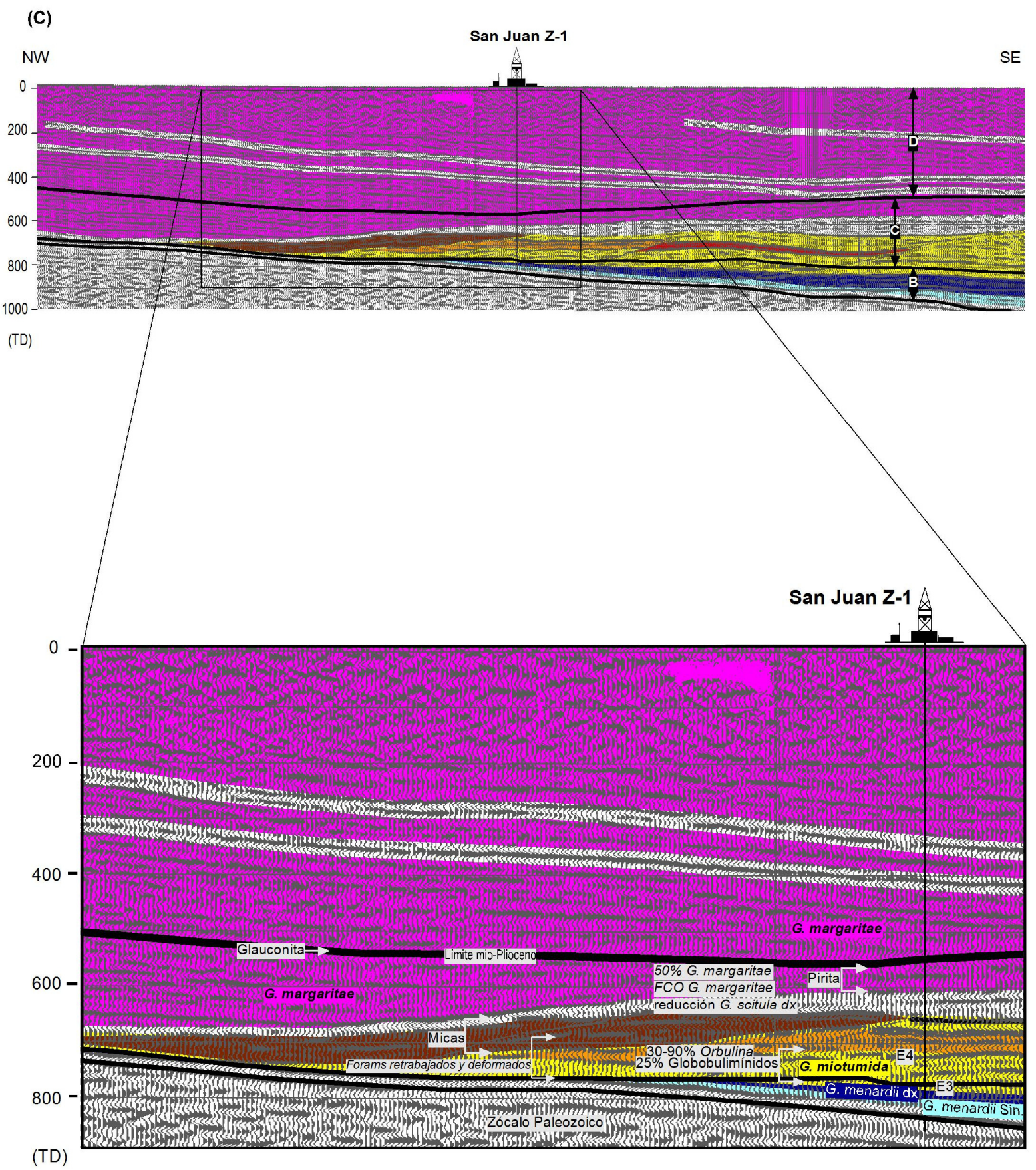

Figura 6.12 (Continuación). Síntesis de los resultados obtenidos en el sondeo San Juan Z-1. Leyenda general en las figuras 6.1. y 6.2. (C) Perfíl sismobioestratigráfico $n^{\circ} 3$ (NW-SE) transversal a la cuenca y proyección del sondeo San Juan Z-1. (Td) = Tiempo doble en milisegundos. Basado en perfil sísmico original facilitado por Repsol. 


\subsubsection{Salteras-1}

Tras 20 metros de arenas con abundante Heterostegina y otros organismos someros, se registra un nivel de glauconita sobre el que aparecen directamente individuos del grupo de G. miotumida. Así mismo solo una veintena de metros por encima se registra la primera aparición común $(F C O)$ del grupo de G. margaritae (figura 6.13). La proximidad de la FCO del grupo de G. margaritae a la base del sondeo, solo se entiende deduciendo una importante discontinuidad o bien una laguna estratigráfica significativa entre los niveles con glauconita y la $F C O$ del grupo de G. margaritae. Es probable que en lugar de un solo evento erosivo, se hayan sucedido varias superficies de erosión, o mejor aún, que el sondeo se encuentre situado en una posición de by-pass sobre la que no hubo depósito durante la primera mitad del Messiniense. A finales del Messiniense se registran depósitos someros con restos de gasterópodos que indicarían una posición baja del nivel del mar. A continuación se registra un nivel con una significativa concentración de globorotálidos del grupo de G. margaritae (30-40 \%) detectado en otros sondeos (San Juan Z-1) que probablemente puede servir de apoyo en correlaciones locales. Tras el límite Mio-Plioceno, deducido a través de los perfiles sismobioestratigráficos (figura 6.14C) en torno a $500 \mathrm{~m}$, se registra una elevada velocidad de sedimentación durante el Plioceno inferior que rápidamente colmata la posición sobre la que se encuentra el sondeo. 


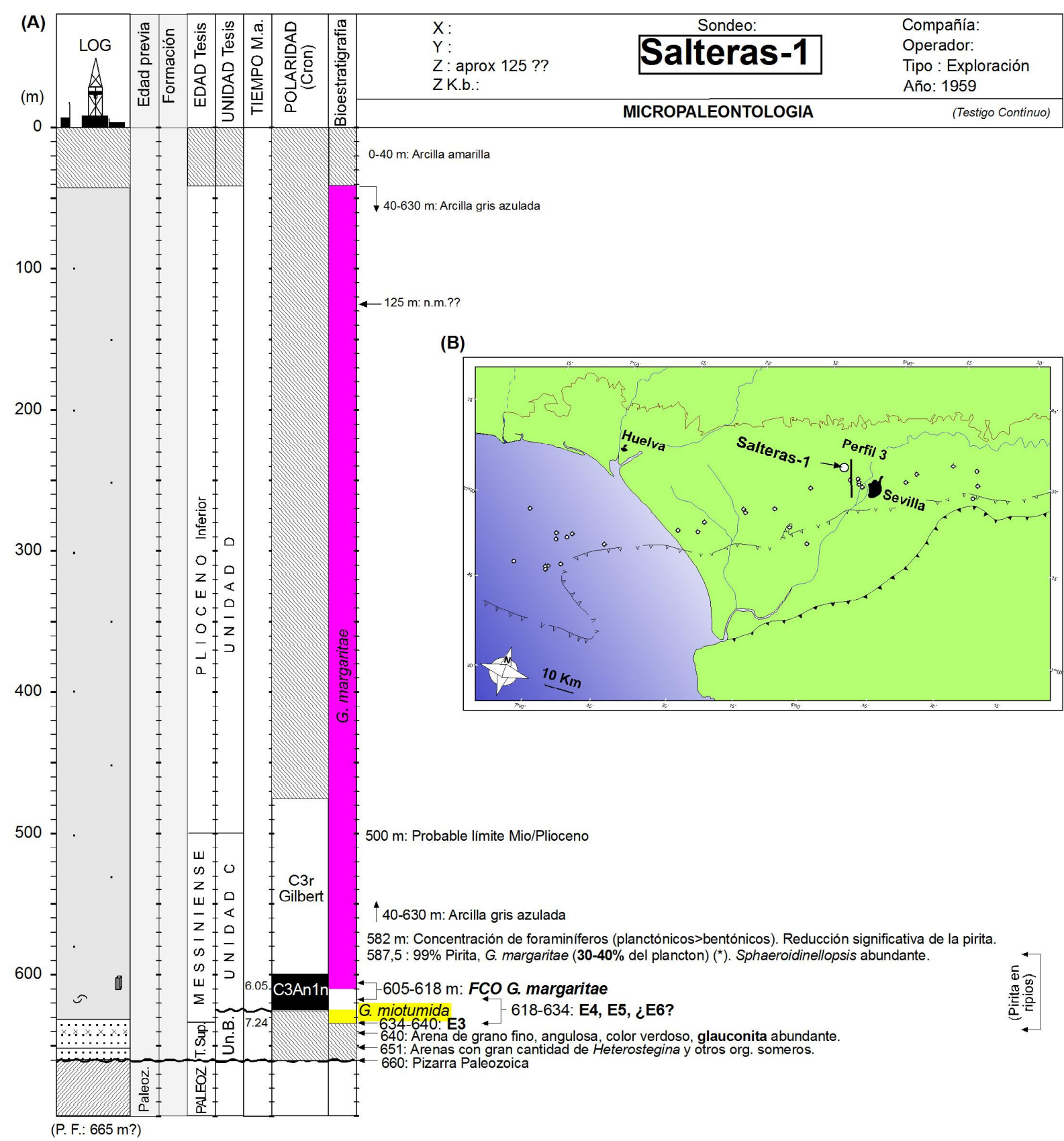

(E6) $=$ FO del grupo $G$. margaritae

(E5) $=$ LO del grupo $\mathrm{G}$. miotumida $\sin (6,3 \mathrm{Ma})$

(E4) = Cambio de enrollamiento de $N$. acostaensis $(6,35 \mathrm{Ma})$

(E3) = LO del grupo G. menardii dx / FCO del grupo G. miotumida $\sin (7,240 \mathrm{Ma})$

${ }^{\star}$ ) Existe un nivel con similares características a $590 \mathrm{~m}$ en $\mathrm{S}$. Juan Z-1 y a 353,72 m en Carmona-1.

Figura 6.13. Síntesis de los resultados obtenidos en el sondeo Salteras-1. Leyenda general en figs. 6.1. y 6.2.

(A) Profundidad en metros y columna litológica basada en análisis de las muestras. Edades y formaciones utilizadas anteriormente. Edad, unidades litosísmicas, datación, magnetoestratigrafía deducida y biozonas propuestas en esta Tesis en función de los bioeventos de plancton calcáreo. Información micropaleontológica, sedimentológica y otros datos de interés.

(B) Posición del sondeo Salteras-1 y del perfil sísmico interpretado (el perfil sismobioestratigráfico correspondiente a este sondeo aparece en la figura $6.14 \mathrm{C}$.) 


\subsubsection{Castilleja-1}

Al igual que el sondeo Salteras-1, la biozona del grupo de G. miotumida apenas aparece representada (figura 6.14). Incluso podría ser reflejo de la resedimentación de individuos aislados de G. miotumida. En el panel sismobioestratigráfico podemos observar la proyección del sondeo sobre la línea sísmica más próxima (figura 6.14C). En el perfil se puede apreciar como la biozona del grupo de G. margaritae alcanza prácticamente el detrítico basal. La base de la biozona del grupo de G. margaritae dibuja el fondo de cuenca en un momento de bajo nivel del mar relativo, en el que se pudieron producir erosiones que alcanzan el detrítico basal en el fondo de cuenca. El rápido depósito de la parte inferior de la biozona de este grupo, parece estar ligado al talud norte de la cuenca que a partir de ese momento cobra importancia significativa como área madre de los sedimentos que alcanzan el fondo de cuenca. La presencia de G. margaritae hacia el techo del sondeo indica que la mayor parte del relleno sedimentario se produjo en el Plioceno inferior. En el panel sismobioestratigráfico podemos ver primero el desplazamiento de la cuenca messiniense desde el talud sur hacia el norte, con el depósito de las "arenas del Guadalquivir" (que aparecen coloreadas dentro de la biozona del grupo de $G$. miotumida) a la derecha de la imagen. Más tarde la biozona del grupo de $G$. margaritae, parece estar dominada sin embargo por una componente lateral de norte a sur de modo que los depocentros migran en ese sentido, especialmente a partir del límite Mio-Plioceno (obsérvese la posición en downlap de los reflectores resaltados en la biozona del grupo de G. margaritae). 


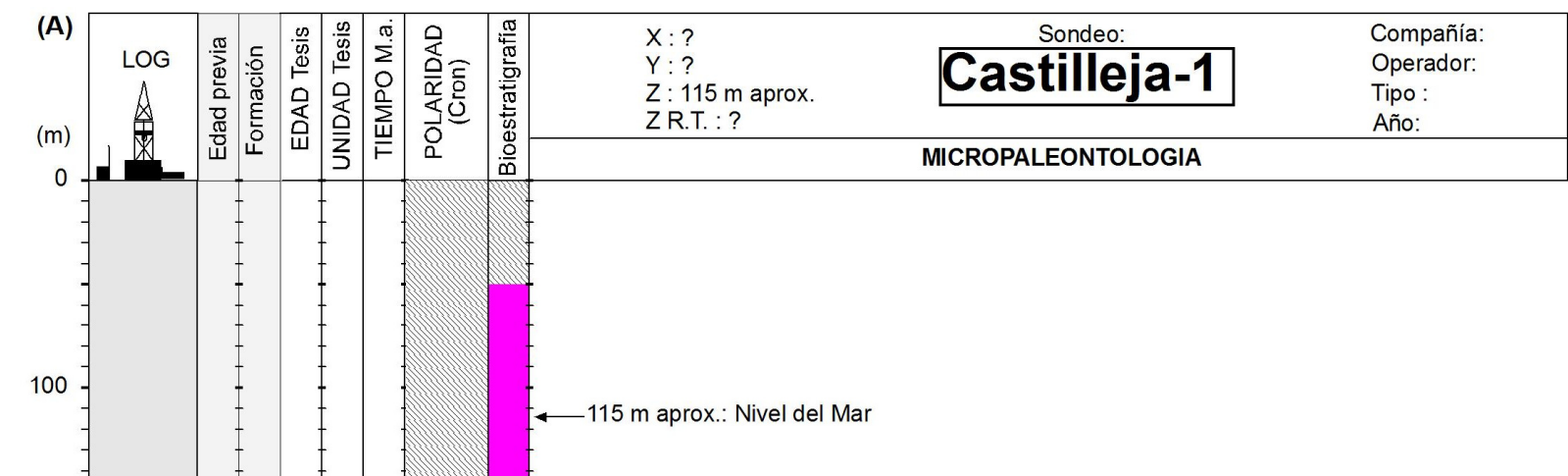

(B)

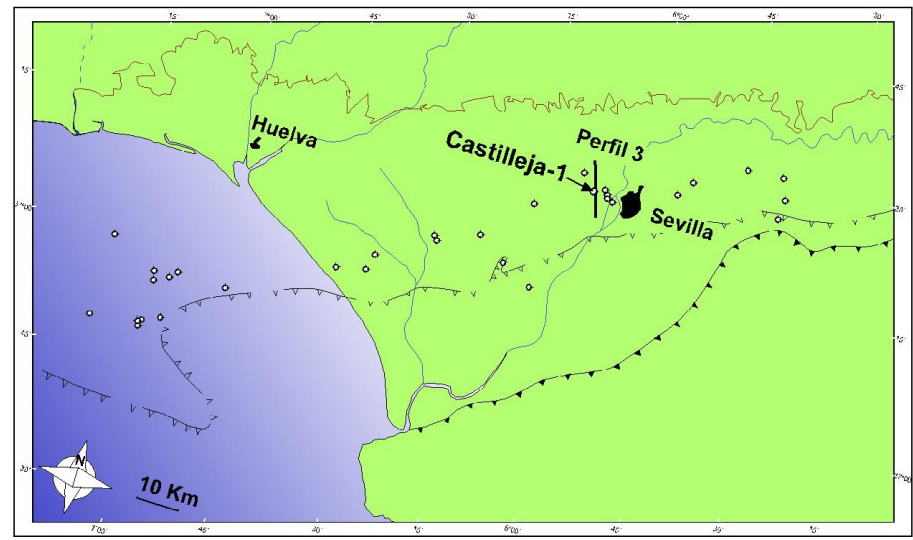

(E6) $=F O$ del grupo $G$. margaritae

$(E 5)=L O$ del grupo $G$ miotumida $\sin (6,3 \mathrm{Ma})$

(E4) = Cambio de enrollamiento de $N$. acostaensis $(6,35 \mathrm{Ma})$

E4, E5, E6 910: "Arenisca" granos subredondeados. Común Sphaeroid. G. extremus muy Morozovella). G. miotumida.

G. miotumida (?)

915: "Arena globular". Arena calcarea, muchos restos de moluscos, glauconita, poco bentos. Biocalcarenita. Muchos restos de moluscos, algo cementados,
glauconita. Anmonia, N. boeanum, Elphidium... (muchos rotos), glauconita.

(P.F.: 937)

930: Pizarra

Figura 6.14. Síntesis de los resultados obtenidos en el sondeo Castilleja-1. Leyenda general en figuras. 6.1. y 6.2. (A) Profundidad en metros y columna litológica. Edades y formaciones utilizadas anteriormente. Edad, unidades litosísmicas, datación, magnetoestratigrafía deducida y biozonas propuestas en esta Tesis en función de los bioeventos de plancton calcáreo. Información micropaleontológica, sedimentológica y otros datos de interés. (B) Posición del sondeo Castilleja-1 y del perfil sísmico interpretado.

(C) Perfil sismobioestratigráfico n⿳⺈, basado en perfil sísmico original proporcionado por Repsol. 


\section{Salteras-1}

Sondeo:

Castilleja-1

(C)

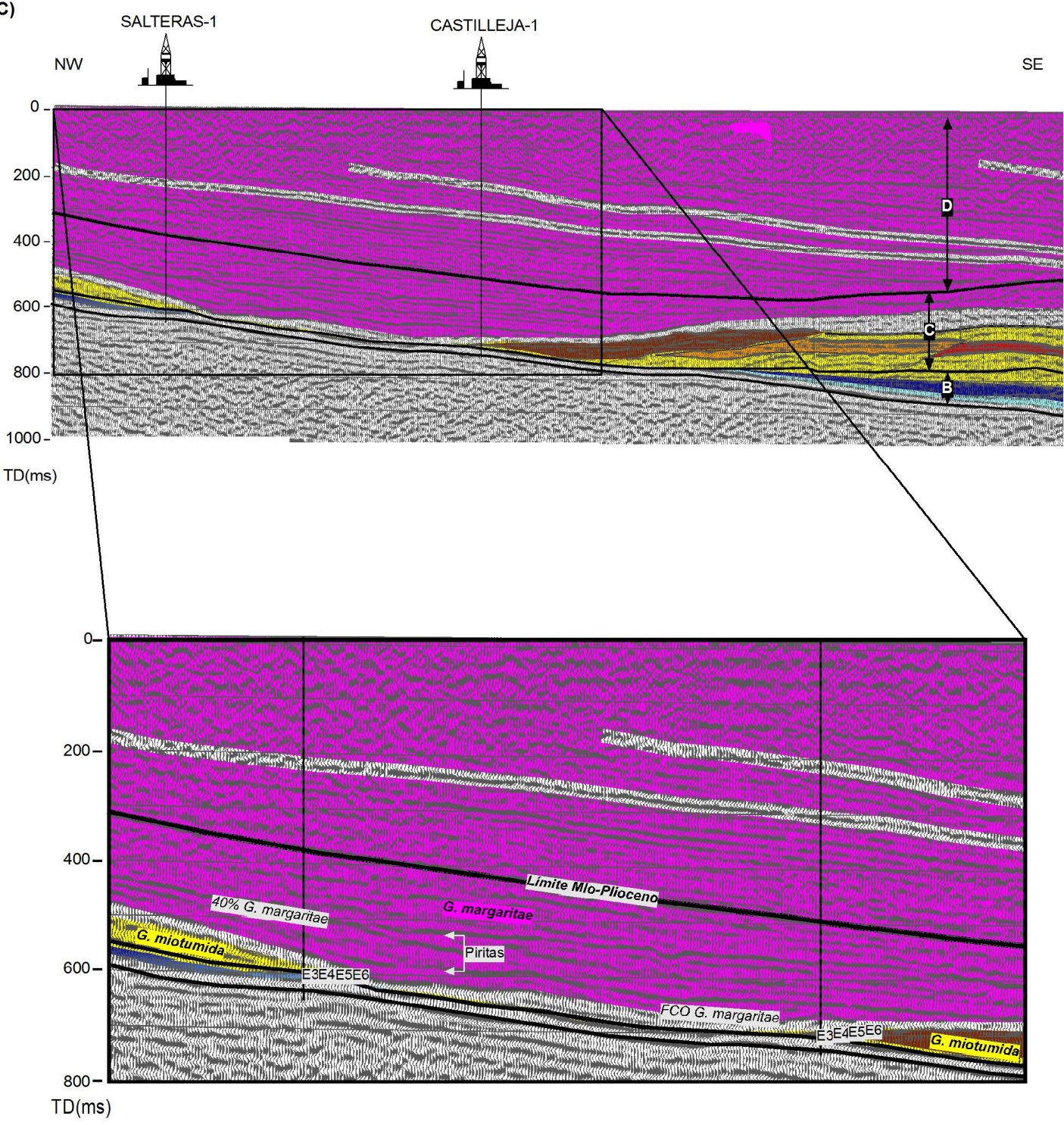

Figura 6.14 (Continuación). (C) Perfil sísmobioestratigráfico nº3 (NW-SE) transversal a la cuenca. Proyección sobre esta línea de posiciones equivalentes a las de los sondeos Salteras-1 y Castilleja-1. Sísmica original facilitada por Repsol, (Td) = Tiempo doble en milisegundos. Leyenda general en las figura 6.1. y 6.2. 


\subsubsection{Palancares-1}

La ausencia de globorotálidos en la base del sondeo, impide localizar los principales eventos utilizados (figura 6.15). Tras un potente nivel arenoso a $900 \mathrm{~m}$, se depositan arcillas grises con abundante $G$. margaritae, que indicaría la base de la biozona de este grupo de globorotálidos. La abundancia de piritas en torno a la $F C O$ del grupo de G. margaritae, se reduce al llegar al límite Mio-Plioceno identificado en el perfil sismobioestratigráfico como el reflector posterior a la $F C O$ de G. margaritae sobre el que se disponen en downlap el resto de reflectores de la unidad litosísmica D (figura 6.15C). La presencia hacia $550 \mathrm{~m}$ de una superficie tipo hardground, podría utilizarse como nivel de correlación local.

La muestra más superficial estudiada mantiene la presencia de G. margaritae, sin que desaparezca en ningún momento este taxón. No se ha detectado la presencia de $G$. puncticulata, por lo que desde los 680-700 m hasta los $300 \mathrm{~m}$ al menos, correspondería a la biozona del grupo de $G$. margaritae $\sin$. El estudio de los perfiles sismobioestratigráficos sugiere además que esta biozona podría extenderse hasta el techo del sondeo. 


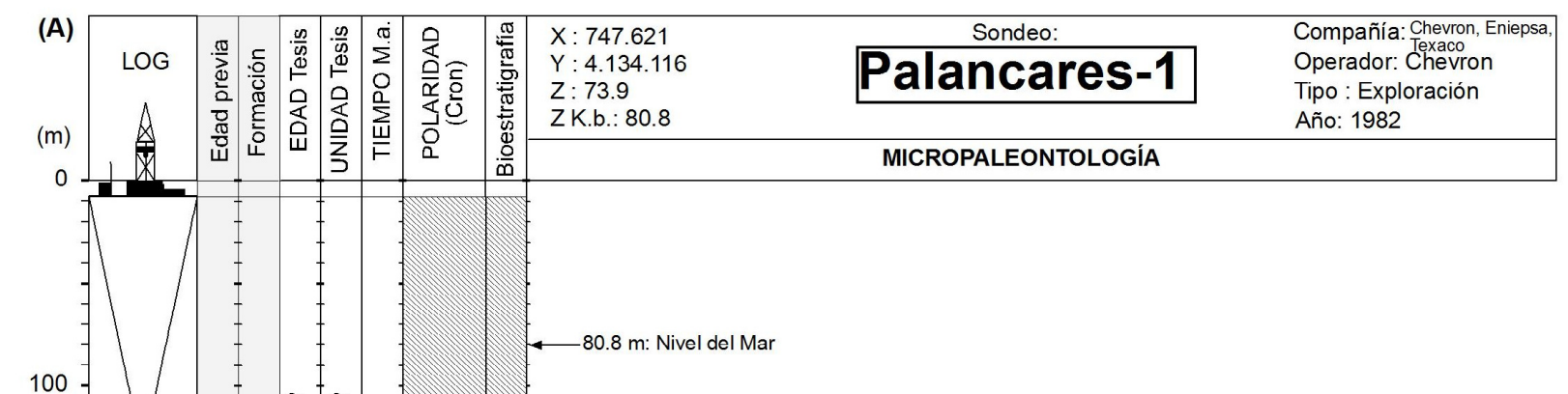

(B)

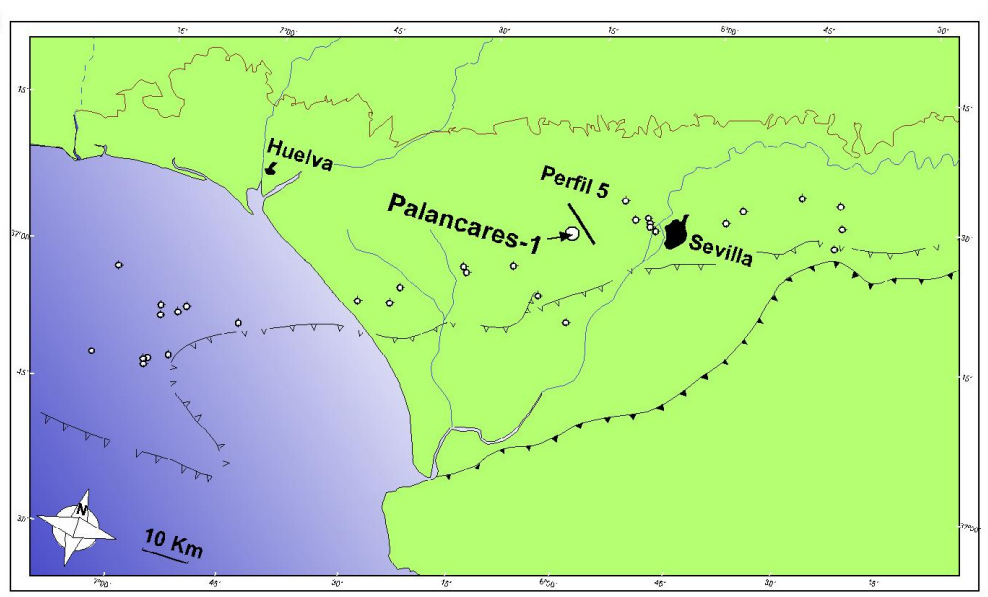

(E4) = Cambio de enrollamiento de $N$. acostaensis $(6,35 \mathrm{Ma})$

(E3) = LO del grupo G. menardii $d x / F C O$ del grupo G. miotumida $\sin (7,240 \mathrm{Ma})$

$(E 2)=F C O$ del grupo $G$. menardii $d x(7,355 \mathrm{Ma})$

$(\mathrm{E} 1)=$ LCO del grupo G. menardii $\sin (7,512 \mathrm{Ma})$

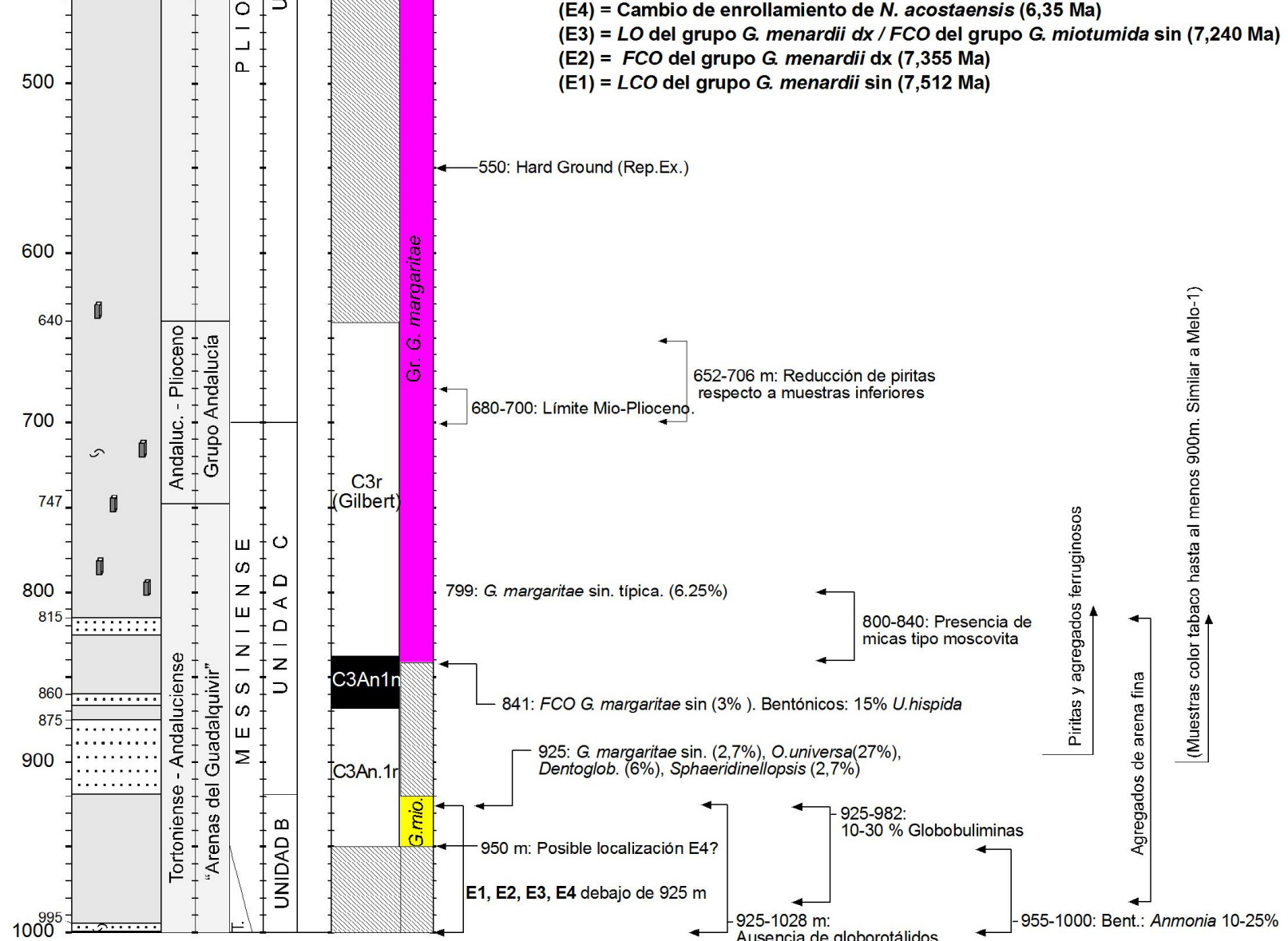

Figura 6.15. Síntesis de los resultados obtenidos en el sondeo Palancares-1. Leyenda general en las figuras 6.1. y 6.2. (A) Profundidad en metros y columna litológica (basada en documentación facilitada por Repsol). Edades y formaciones utilizadas anteriormente. Edad, unidades litosísmicas, datación, magnetoestratigrafía deducida y biozonas propuestas .

(B) Localización del sondeo Palancares-1 y del perfil sísmico interpretado.

(C) Perfil sismobioestratigráfico $\mathbf{n}^{0} 5$, basado en perfil sísmico original facilitado por Repsol. 


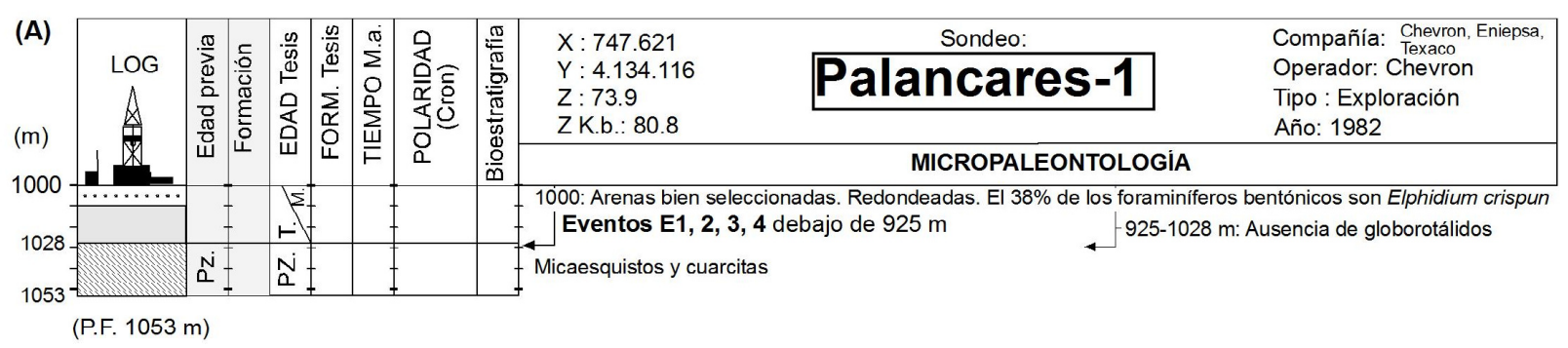

(c)

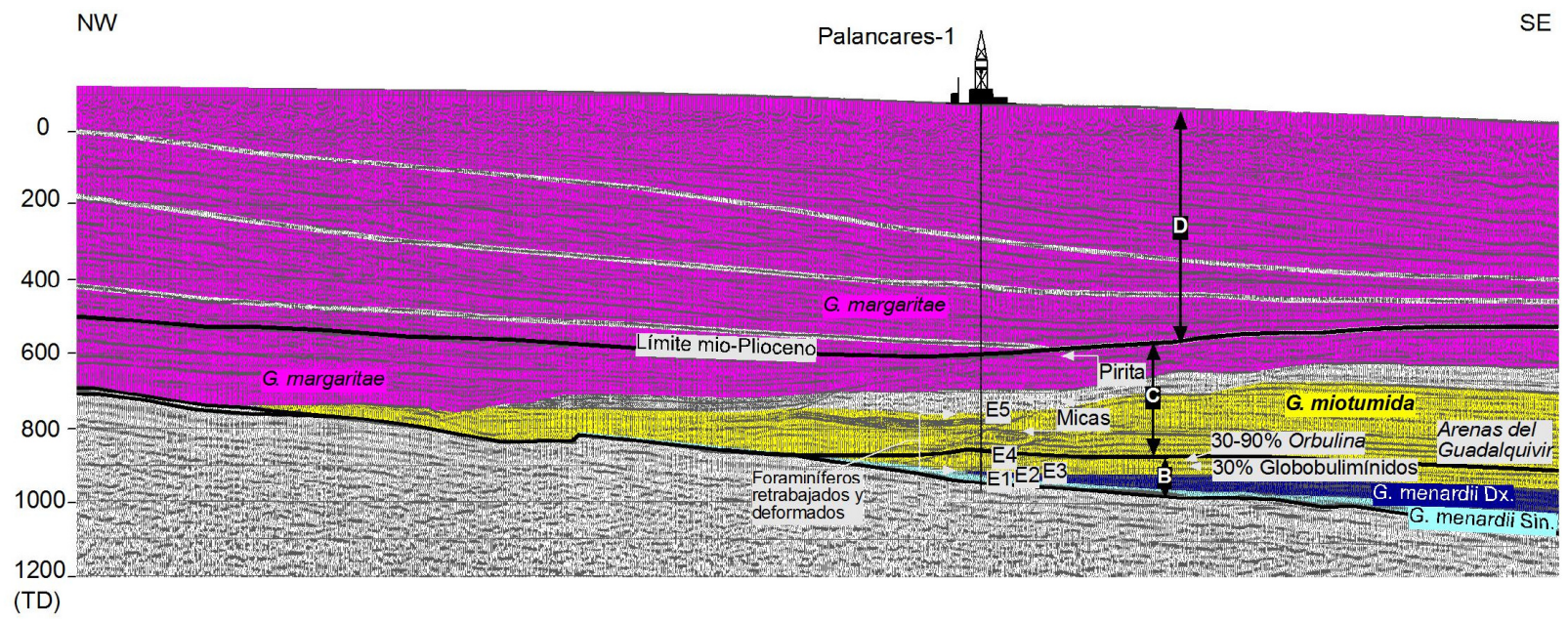

Figura 6.15 (Continuación). Síntesis de los resultados obtenidos en el sondeo Palancares-1. Leyenda general en las figuras 6.1 y 6.2 .

(A) Profundidad en metros y columna litológica (basada en documentación facilitada por Repsol). Edades y formaciones utilizadas anteriormente. Edad, unidades litosísmicas, datación, magnetoestratigrafía deducida y biozonas propuestas en esta Tesis en función de los bioeventos de plancton calcáreo. Información micropaleontológica, sedimentológica y otros datos de interés.

(B) Localización del sondeo y del perfil sísmico.

(C) Perfil sismobioestratigráfico $\mathrm{n}^{\circ} 5$, y proyección del sondeo Palancares-1. (Td) $=$ Tiempo doble en milisegundos (basado en perfil sísmico original facilitado por Repsol). 


\subsubsection{Villamanrique-1}

La existencia de testigo continuo en varios tramos de este sondeo, junto con un muestreo cada $5 \mathrm{~m}$ de la principal zona de interés, han resultado en un preciso análisis bioestratigráfico (figura 6.16). Los sondeos Villamanrique-1 y Casanieves-1 (figura 6.17) registran una serie continua a lo largo del Messiniense. El análisis cicloestratigráfico de las oscilaciones rítmicas de los registros de rayos gamma y conductividad / resistividad ha permitido identificar seis grandes ciclos de primer orden subdivididos en pequeños ciclos de $3^{\text {er }}$ orden (capítulo 5). La calibración astronómica de estos ciclos ha permitido una precisa datación del Messiniense. Este calibrado se ha obtenido gracias a la localización de bioeventos previamente contrastados con la escala astronómica de tiempo en series Mediterráneas (Sierro, et al., en prensa) y ha permitido calcular la magnetoestratigrafía del Messiniense para los sondeos Villamanrique-1 y Casanieves-1 con un alto grado de precisión.

En la base del sondeo, tras el zócalo Paleozoico de esquistos se registra un centenar de metros de depósitos de arcilla calcárea, marrón, con numerosas pasadas de arenisca fina a media. Esta serie ha sido datada previamente como triásica (ITGE, 1990). A continuación, las arenas localizadas a $1190 \mathrm{~m}$, con fauna bentónica somera y glauconita, localizadas en la base de la biozona del grupo de G. menardii sin, constituyen sin duda el detrítico basal. Sobre el detrítico basal descansan un centenar de metros de margas grises ricas en foraminíferos. En los primeros $40 \mathrm{~m}$ de sedimento tras el detrítico basal, se suceden los eventos del Tortoniense superior. Estas arcillas, que corresponden a las "arcillas basales" contienen inicialmente unos $15 \mathrm{~m}$ de sedimento con G. menardii sin, a lo que siguen unos $25 \mathrm{~m}$ de depósitos con G. menardii dx. A $1150 \mathrm{~m}$ desaparece $G$. menardii dx en favor del grupo de G. miotumida, lo que indica el límite TortonienseMessiniense.

Tras $75 \mathrm{~m}$ de arcillas con G. miotumida, aparecen los primeros niveles de arenisca fina, grisácea, con cemento margoso, en ocasiones calcáreo (ITGE, 1990), con restos de equinodermos, espículas de esponja y lamelibranquios. Después de los depósitos turbidíticos localizados en el fondo de la cuenca messiniense (figura 6.16C), el desplazamiento del depocentro de la cuenca hacia el norte sitúa la posición del sondeo Villamanrique en el talud sur, lo que se traduce en una reducción significativa de la velocidad de sedimentación y resulta en la individualización de los ciclos sedimentarios de $3^{\text {er }}$ orden.

Unos $45 \mathrm{~m}$ por encima del último nivel de arena, desaparece el grupo de $G$. miotumida. Durante los siguientes $50 \mathrm{~m}$ de arcilla gris, calcárea, el grupo de globorotáli- 


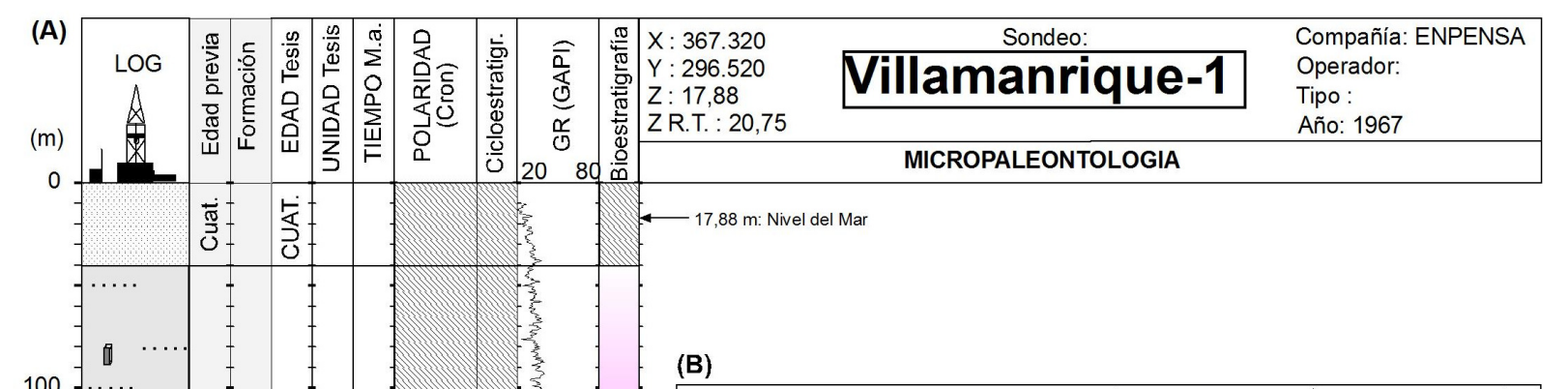

(B)

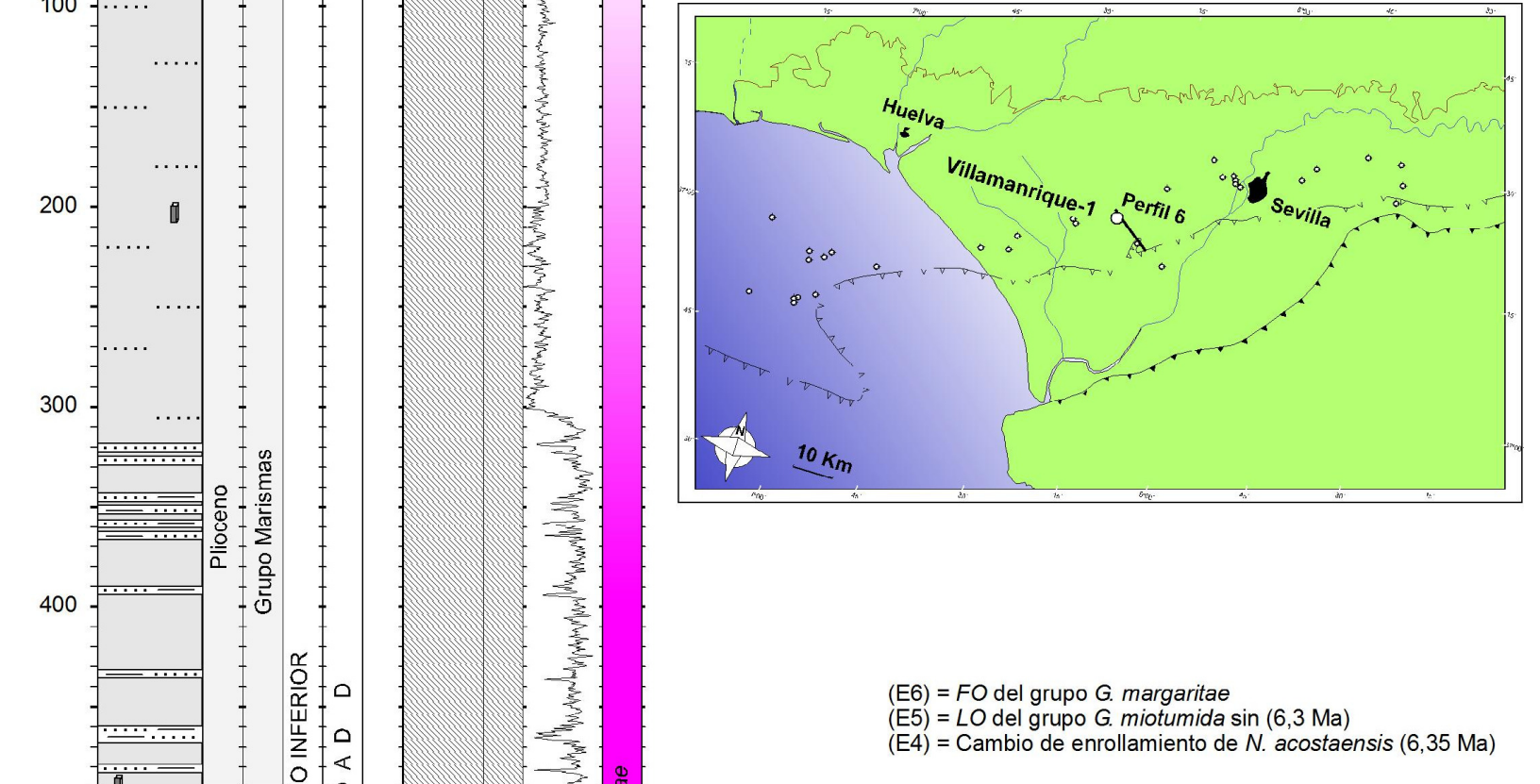

1000

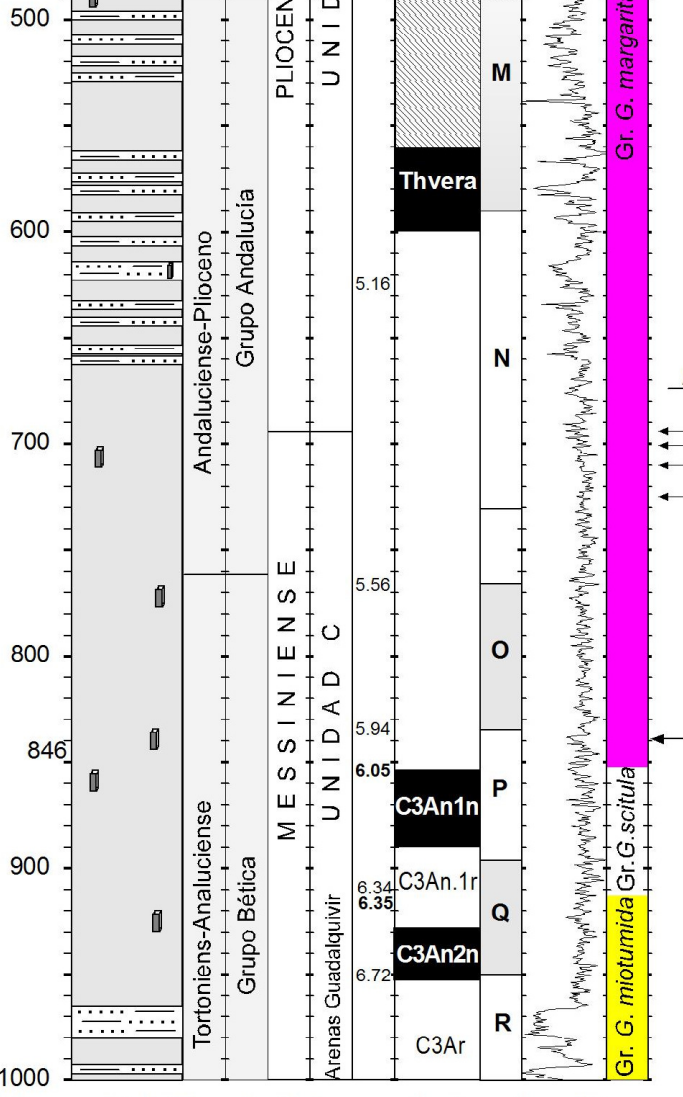

(E4) = Cambio de enrollamiento de $N$. acostaensis $(6,35 \mathrm{Ma})$

Figura 6.16. Síntesis de los resultados obtenidos en el sondeo Villamanrique-1. Leyenda general en las figuras 6.1. y 6.2.

(A) Profundidad en metros y columna litológica (ITGE, 1990). Edades y formaciones utilizadas anteriormente. Edad, unidades litosísmicas, datación, magnetoestratigrafía deducida, unidades cicloestratigráficas, registro de rayos gamma (facilitado por Repsol) y biozonas propuestas en esta Tesis en función de los bioeventos de plancton calcáreo.

(B) Localización del sondeo Villamanrique-1 y del perfil sísmico interpretado.

(C) Perfil sismobioestratigráfico ${ }^{0} 6$ (sísmica original: ITGE, 1990) 
dos más importante es G. scitula dextrógira. Esta observación ha permitido la identificación de la biozona de este grupo cuya base está definida por la desaparición de G. miotumida. Por otro lado, el techo de la biozona del grupo de G. scitula dx, se localiza en el horizonte de reducción significativa de este grupo, tras el cual, el grupo de $G$. margaritae pasa a ser el globorotálido más importante de la asociación de foraminíferos planctónicos.

La FCO del grupo de G. margaritae viene acompañada también en esta ocasión de frecuentes inclusiones de pirita en forma tabular, que se reducen significativamente hacia el límite Mio-Plioceno. Hacia el metro 695 se puede deducir el límite Mio-Plioceno en función de los análisis cicloestratigráficos (capítulo 5). En torno a este momento (680$710 \mathrm{~m}$ ) se observa un incremento de Sphaeroidinellopsis que podría corresponder a la base del acme de Sphaeroidinellopsis, corroborando de este modo la posición del límite Mio-Plioceno. Sin embargo el incremento de Sphaeroidinellopsis, no es tan significativo como para asegurarlo de forma incuestionable. A continuación, se registra un importante aumento de la velocidad de sedimentación que va a impedir la localización de cualquier otro de los eventos pliocenos. La ausencia de G. puncticulata en las muestras más superficiales, junto con la presencia de G. margaritae, indica que la mayor parte de los $700 \mathrm{~m}$ superiores del sondeo se depositaron durante el Plioceno inferior.

Los $40 \mathrm{~m}$ finales de la serie, compuestos por arenisca grosera, calcárea, de color gris verdosa, la primera mitad, y por arenas grises, heterogéneas la parte más superficial, corresponderían al Cuaternario. 

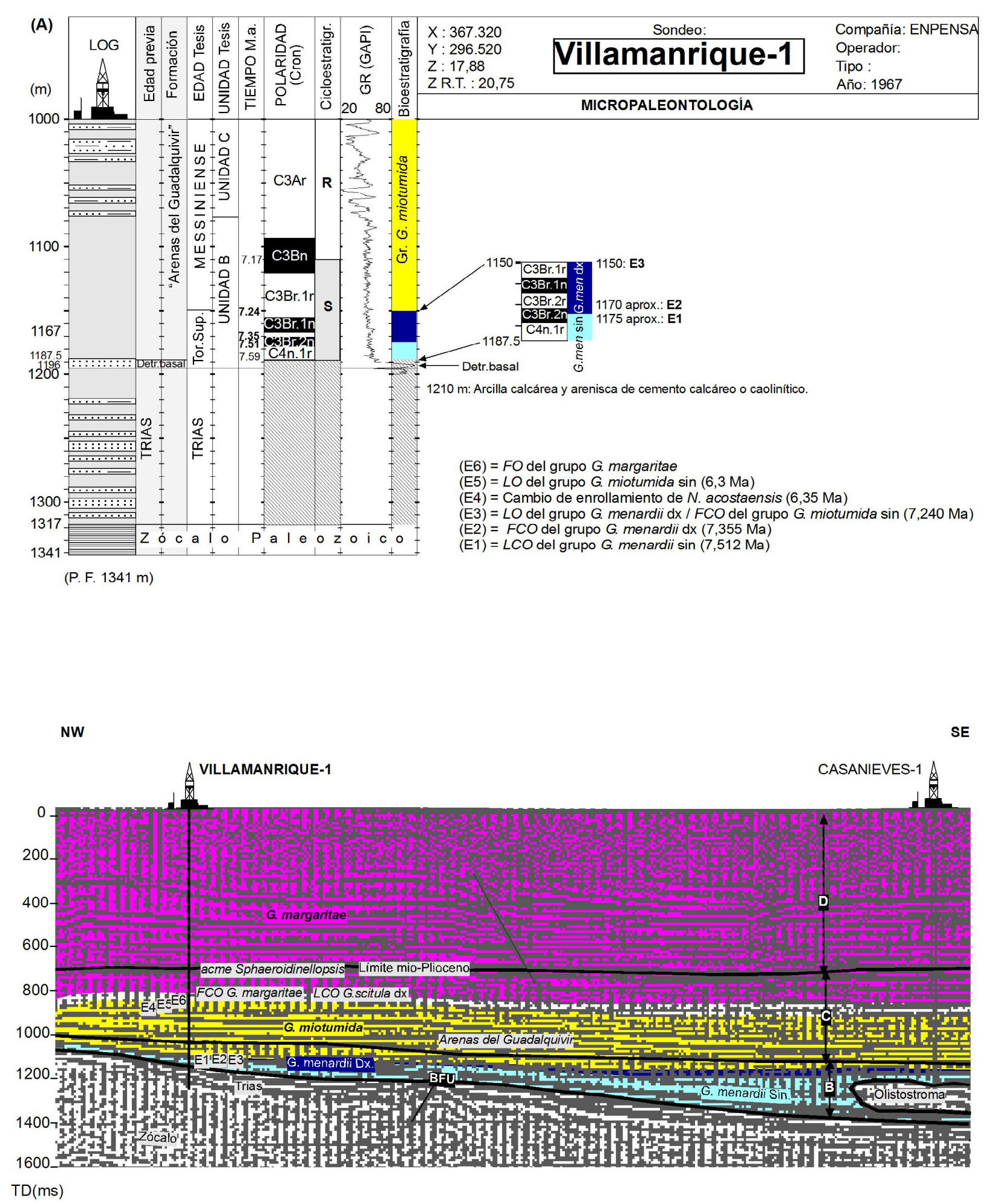

Figura 6.16 (Continuación). Síntesis de los resultados obtenidos en el sondeo Villamanrique-1. Leyenda general en las figuras 6.1. y 6.2. (A) Profundidad en metros y columna litológica (ITGE, 1990). Edades y formaciones utilizadas anteriormente. Edad, unidades litosísmicas, datación, magnetoestratigrafía deducida, unidades cicloestratigráficas y biozonas propuestas en esta Tesis en función de los bioeventos de plancton calcáreo. Información micropaleontológica, sedimentológica y otros datos de interés. (B) Localización del sondeo y del perfil sísmico. (C) Perfil sismobioestratigráfico $\mathrm{n}^{\circ} \mathrm{y}$ y proyección sobre esta línea de los sondeos Villamanrique-1 y Casanieves-1. (Td) $=$ Tiempo doble en milisegundos (sísmica original: ITGE, 1990). 


\subsubsection{Casanieves-1}

El sondeo Casanieves-1 (figura 6.17), atraviesa un zócalo Paleozoico de esquistos metamórficos a $1630 \mathrm{~m}$. Sobre este zócalo se apoya el detrítico basal, que está compuesto de arena gris, con foraminíferos bentónicos someros y glauconita a techo.

Uno de los hechos más característicos de este sondeo es que atraviesa una cuña olistostrómica con anterioridad a la desaparición del grupo de globorotálidos de $G$. menardii $\sin (7,512 \mathrm{Ma})$ (figura 6.17D). Esta cuña olistostrómica contemporánea a las detectadas en el golfo de Cádiz, es ligeramente anterior al frente olistostrómico atravesado en subsuperficie por el sondeo Isla Mayor-1 (aproximadamente hacia los 7,3 Ma) y a la entrada principal de la unidad alóctona atravesada en Carmona-4 (7,20-7,24 Ma). Parece por lo tanto, que la unidad alóctona del Guadalquivir está compuesta en realidad de varios olistostromas que conforman un frente con avances producidos en diferentes momentos del Tortoniense superior y posiblemente del Messiniense.

Tras la incursión de la cuña olistostrómica el sondeo queda ubicado sobre el fondo de cuenca, de forma que las primeras incursiones arenosas se detectan unos 100.000 años antes que en Villamanrique-1. La más que probable correlación de los niveles de arena entre los sondeos Casanieves-1 y Villamanrique-1 (capítulo 5), refleja la naturaleza distal de las facies de abanico atravesadas por estos dos sondeos, con una amplia extensión de los lóbulos.

El análisis cuantitativo de los globorotálidos (figura 6.17C) refleja la relación porcentual de los mismos en la asociación de foraminíferos planctónicos. En el gráfico de la figura $6.17 \mathrm{C}$, de muro a techo puede apreciarse la desaparición de G. menardii sin, que es sustituida por formas del grupo de G. menardii dx. Se detecta así mismo la presencia de individuos "caídos" de G. miotumida que se encuentran en algunas de las muestras junto con individuos del grupo de G. menardii levógiros y dextrógiros, hecho solo justificable por la contaminación de las muestras (fig. 3.4). Hasta un centenar de metros por encima de las "arenas del Guadalquivir", G. miotumida es el globorotálido con mayor representación. Tras la desaparición de este grupo (Evento E5), G. scitula dx ocupa este lugar durante unas decenas de metros. Después de la reducción significativa del grupo de globorotálidos de G. scitula dx (que supone el techo de dicha biozona), se detecta la FCO del grupo de G. margaritae (10\% de los foraminíferos planctónicos).

En función del análisis cicloestratigráfico (capítulo 5) se ha establecido la posición del límite Mio-Plioceno a $705 \mathrm{~m}$. La posición de dicho límite estaría refrendada si el incremento significativo de individuos de Sphaeroidinellopsis detectado hacia 680- 

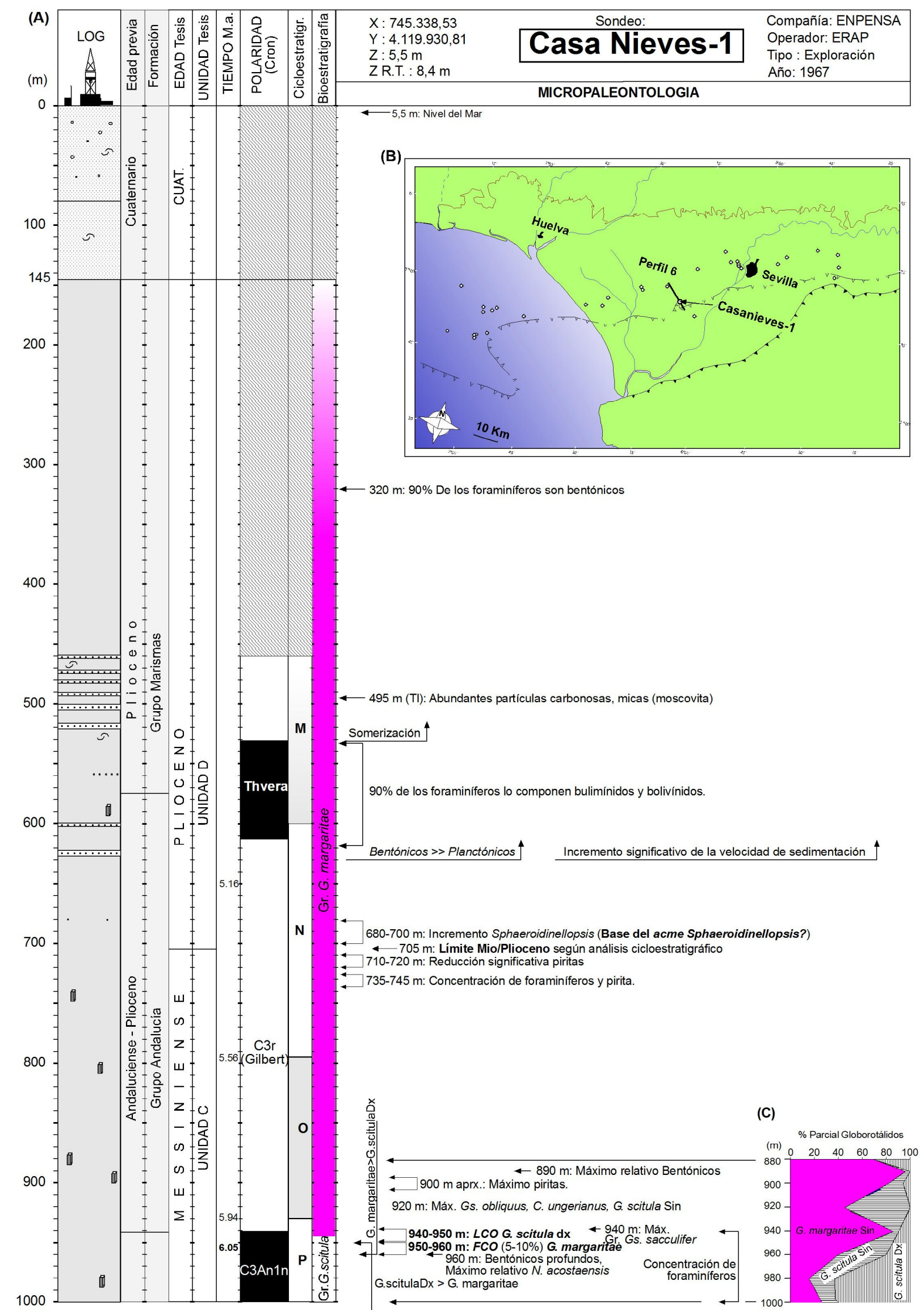

Figura 6.17. Síntesis de los resultados obtenidos en el sondeo Casanieves-1. Leyenda general en figs. 6.1.y 6.2 (A) Profundidad en metros y columna litológica (basada en documentación facilitada por Repsol). Edades y formaciones utilizadas anteriormente. Edad, unidades litosísmicas, datación, magnetoestratigrafía deducida, unidades cicloestratigráficas y biozonas propuestas en esta Tesis en función de los bioeventos de plancton calcáreo. (B) Localización del sondeo Casanieves-1 y del perfil sísmico interpretado. (C) Porcentaje de globorotálidos basado en análisis cuantitativos. (D) Perfil sismobioestratigráfico $\mathrm{n}^{\mathrm{0}} 6$ (sísmica original tomada de ITGE, 1990). 

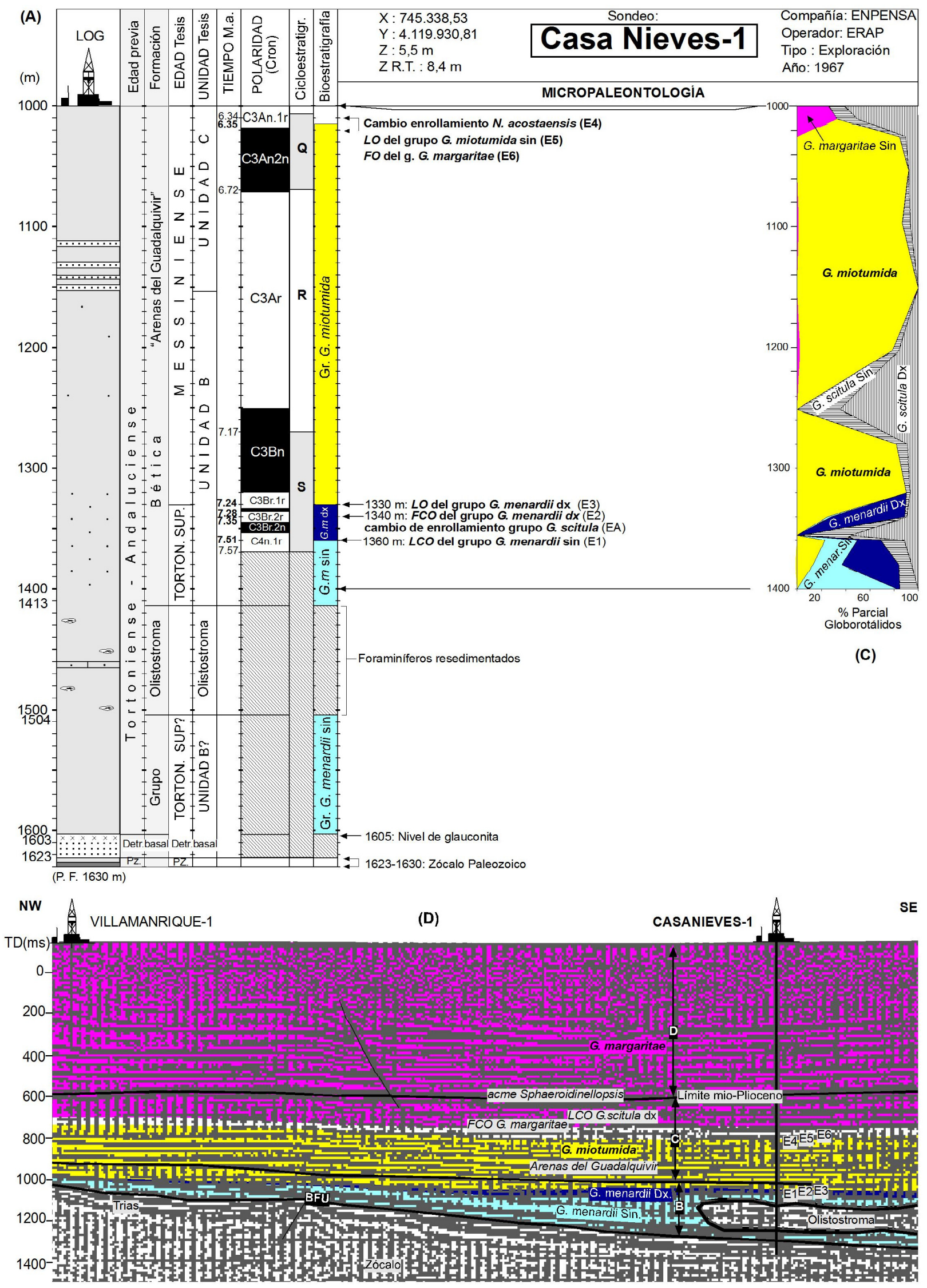

Figura 6.17 (Continuación). Síntesis de los resultados obtenidos en el sondeo Casanieves-1. Leyenda general en figuras 6.1. y 6.2. (A) Profundidad en metros y columna litológica (basado documentación facilitada por Repsol). Edades y formaciones utilizadas anteriormente. Edad, unidades litosísmicas, datación, magnetoestratigrafía deducida, unidades cicloestratigráficas y biozonas propuestas en esta Tesis en función de los bioeventos de plancton calcáreo. Otros datos de interés.

(C) Porcentaje de globorotálidos basado en análisis cuantitativos.

(D) Perfíl sismobioestratigráfico n ${ }^{\circ}$ (NW-SE) y proyección sobre esta línea de los sondeos Villamanrique-1 y Casanieves-1.

(Td) = Tiempo doble en milisegundos (sísmica original tomada de ITGE, 1990). 
$700 \mathrm{~m}$, supusiera realmente la base del acme de Sphaeroidinellopsis. No obstante el incremento de este taxón no es lo suficientemente claro para afirmar con rotundidaz la presencia de este bioevento.

Conocida la posición del límite Mio-Plioceno en los sondeos Casanieves-1 y Villamanrique-1, se ha podido identificar el reflector sísmico que representa la base del Plioceno, sirviendo de referencia para el resto de perfiles sismobioestratigráficos.

A partir del límite Mio-Plioceno la velocidad de sedimentación aumenta considerablemente, registrándose la mayor parte del relleno sedimentario durante el Plioceno inferior (dada la presencia de G. margaritae en las muestras más altas). Finalmente el Cuaternario cubre los últimos $145 \mathrm{~m}$ del sondeo.

\subsubsection{Isla Mayor-1}

Junto con el sondeo Carmona-4, Isla Mayor-1 es el sondeo localizado más al sureste de los analizados en este trabajo (figura 6.18). Sobre el basamento se depositan unos $100 \mathrm{~m}$ de margas profundas con G. menardii sin. Antes de alcanzar el techo de esta biozona, se emplaza el olistostroma (figura 6.18C), que sobre este sondeo presenta casi $1400 \mathrm{~m}$ de potencia.

A techo del olistostroma se registra la desaparición del grupo de G. menardii dx tras un breve intervalo con presencia de este grupo. Esto supone que el límite Tortoniense-Messiniense se encuentra a 674-690 m, mientras que hacia el centro de cuenca (Casanieves-1) el mismo límite se encuentra a $1330 \mathrm{~m}$. Esta importante pendiente del talud sur condicionó el depósito turbidítico en el eje de la cuenca y junto a la sucesión de empujes tectónicos, provocó el desplazamiento del depocentro de la cuenca hacia el NW durante todo el Messiniense.

La localización del limite Mio-Plioceno se produce después de la FCO del grupo de G. margaritae y se deduce gracias al análisis de los perfiles sismobioestratigráficos. La posición elevada, sobre el talud sur permite la llegada de restos de bioclastos durante todo el Plioceno inferior. El último tramo de material arenoso heterogéneo, debe corresponder al Cuaternario. 

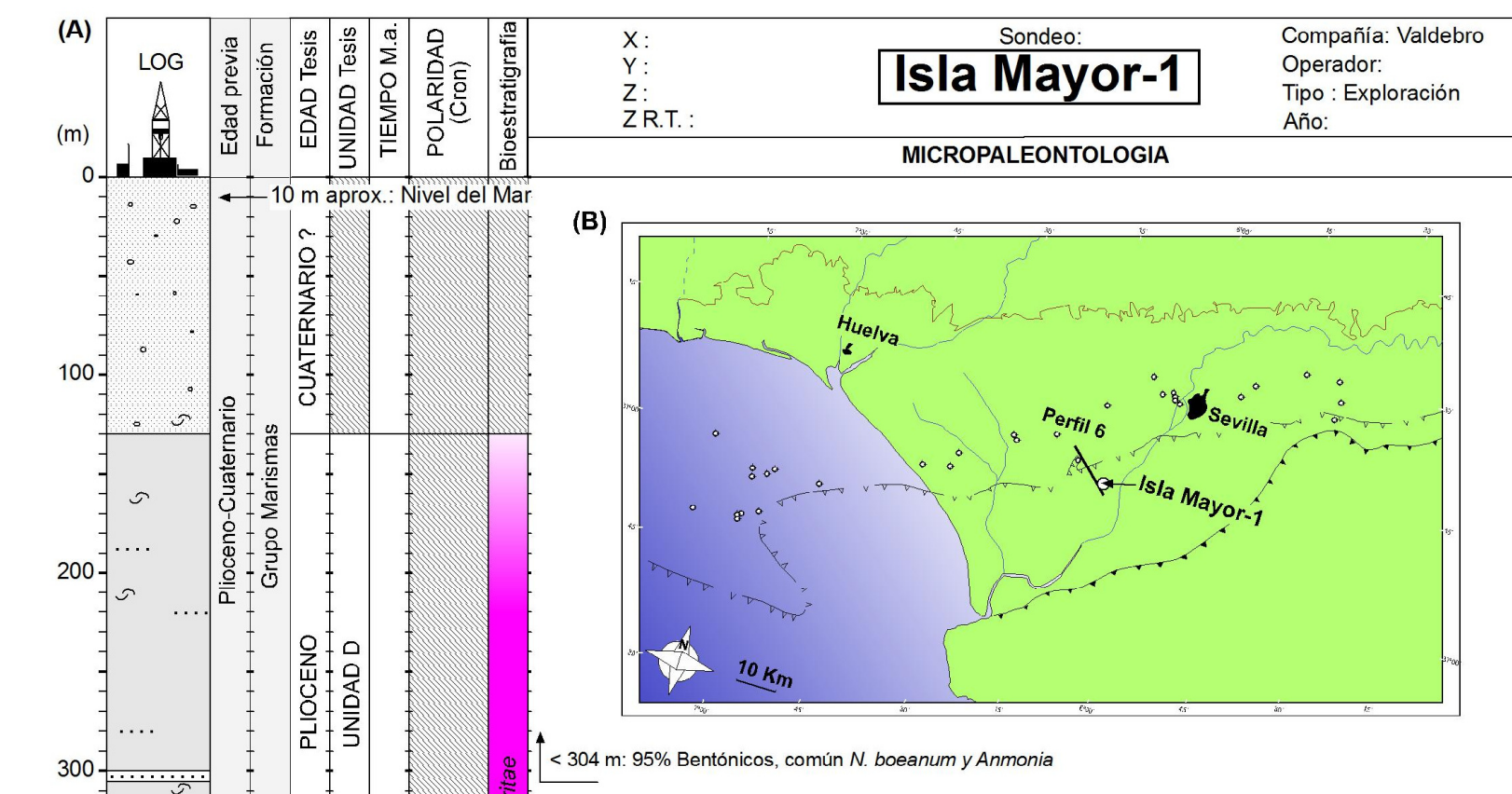

335: Restos de moluscos, abundante cuarzo y glauconita. G. margaritae, G. extremus, U. peregrina.

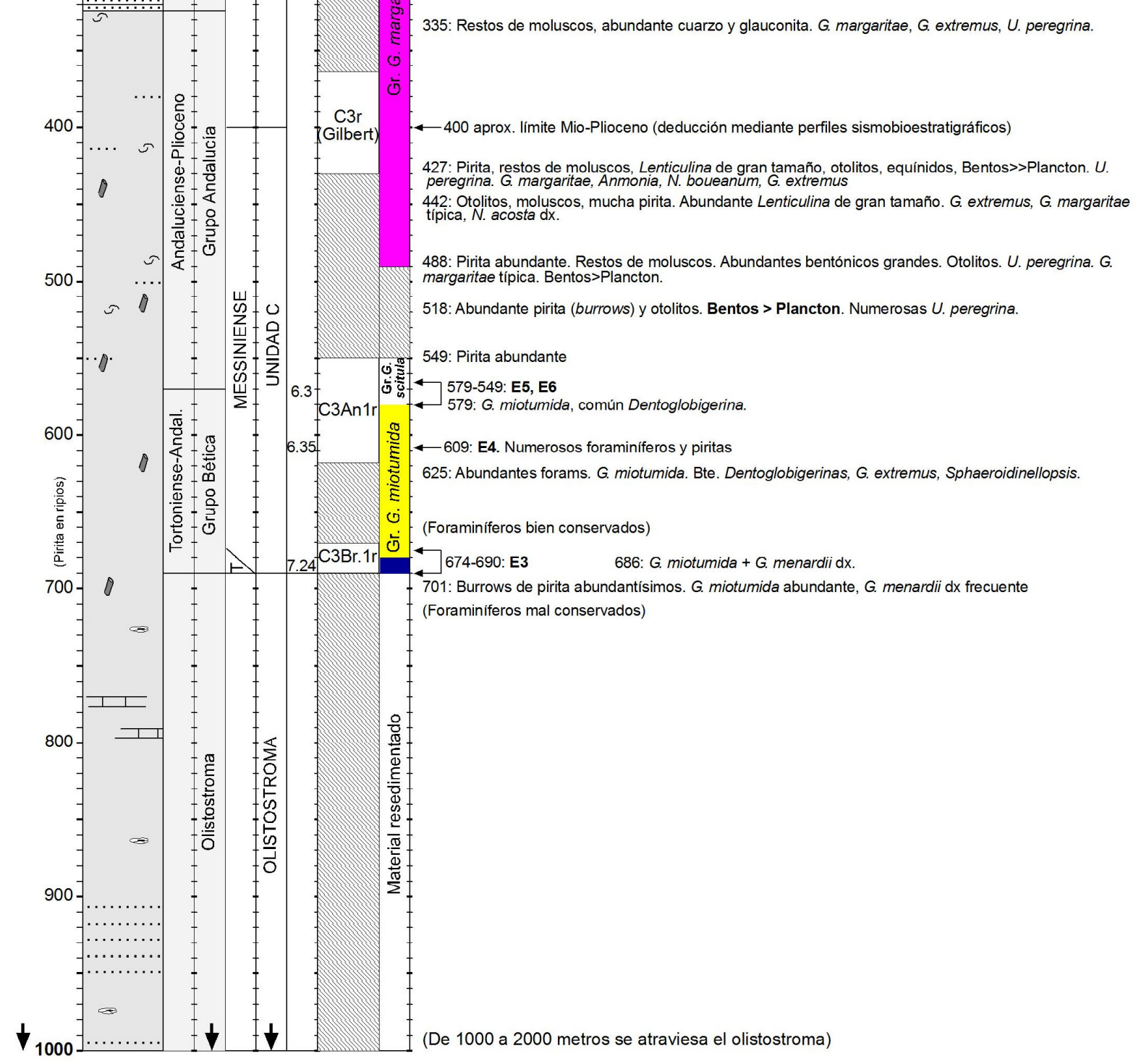

Figura 6.18. Síntesis de los resultados obtenidos en el sondeo Isla Mayor -1. Leyenda general en figuras 6.1. y 6.2. (A) Profundidad en metros y columna litológica (ITGE, 1990). Edades y formaciones utilizadas anteriormente. Edad, unidades litosísmicas, datación, magnetoestratigrafía deducida y biozonas propuestas en esta Tesis en función de los bioeventos de plancton calcáreo. Información micropaleontológica, sedimentológica y otros datos de interés. (B) Localización del sondeo Isla Mayor-1 y del perfil sísmico interpretado. (C) Perfil sismobioestratigráfico n⿳6 (sísmica original: ITGE, 1990). 


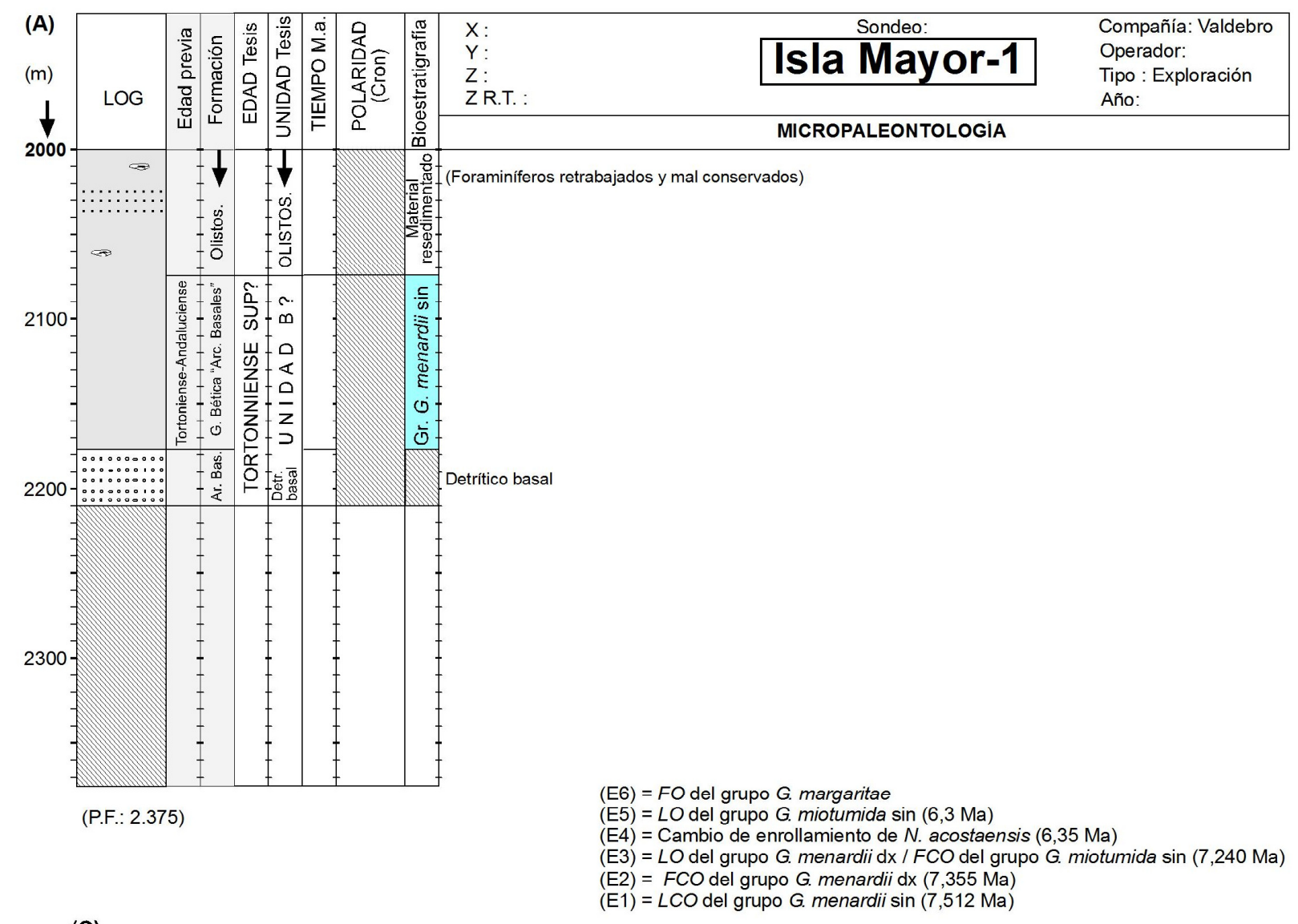

(C)

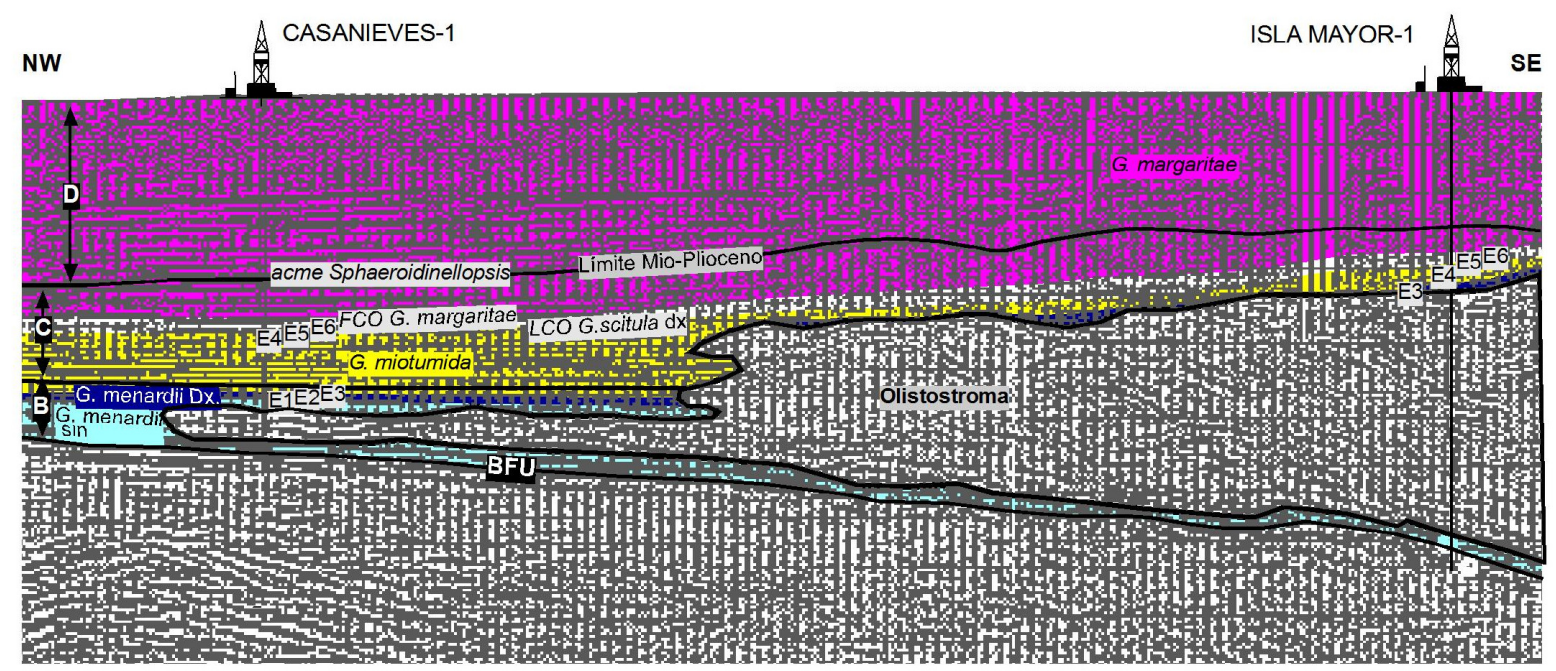

Figura 8.18 (Continuación). Síntesis de los resultados obtenidos en el sondeo Isla Mayor-1. Leyenda general en figuras 6.1. y 6.2. (A) Profundidad en metros y columna litológica (ITGE, 1990). Edades y formaciones utilizadas anteriormente. Edad, unidades litosísmicas, datación, magnetoestratigrafía deducida y biozonas propuestas en esta Tesis en función de los bioeventos de plancton calcáreo. Información micropaleontológica, sedimentológica y otros datos de interés.

(C) Perfil sismobioestratigráfico $\mathbf{n}^{\circ} \mathbf{6}$ y proyección sobre esta línea de los sondeos Casanieves-1 e Isla Mayor-1. (Td) = Tiempo doble en milisegundos (sísmica original: ITGE, 1990). 


\subsubsection{Melo-1}

Las muestras lavadas del sondeo Melo-1 (figura 6.19) contenían en general escasos foraminíferos, lo que ha complicado precisar la posición de los bioeventos. Entre 1059-1089 m no se ha registrado ningún biomarcador por lo que no ha sido posible precisar la edad de los primeros sedimentos terciarios. Por otro lado, la presencia de $G$. margaritae junto a la base del sondeo, además de la ausencia de G. miotumida indican que los últimos canales messinienses, con una edad en torno a la del $F C O$ del grupo de $G$. margaritae (6.05 Ma) pudieron alcanzar el zócalo Paleozoico. En el perfil sismobioestratigráfico de la figura 6.19C, se puede observar una marcada truncación de los niveles arenosos desarrollados en el sondeo Marismas-2 (figura 6.19). La erosión pudo haber sucedido entre el evento E5 ( $L O$ del grupo de G. miotumida) y la FCO del grupo de G. margaritae, la escasez de muestra recuperada en el sondeo Melo-1 impide concretar la edad exacta. Los niveles de arena que se localizan entre 1000-1200 m en el sondeo Marismas-4 que presentan un alto contenido en G. margaritae (figura 6.19), apoyan la idea de que incluso después de la FCO del grupo de G. margaritae (6.05 Ma) se produjeron depósitos turbidíticos en el eje de la cuenca del Guadalquivir, incluyendo canales con base erosiva.

La posición del reflector sísmico identificado en otros sondeos como límite MioPlioceno y la observación de restos de peces hacia 840 m, sitúan la posición aproximada de este límite.

La reducción significativa de ejemplares hacia $471 \mathrm{~m}$ presagia la desaparición del grupo de G. margaritae hacia techo del sondeo. Sin embargo, durante la perforación de este sondeo no se recogió muestra por encima de $250 \mathrm{~m}$, lo que ha impedido detectar el techo de la biozona del grupo de G. margaritae. 


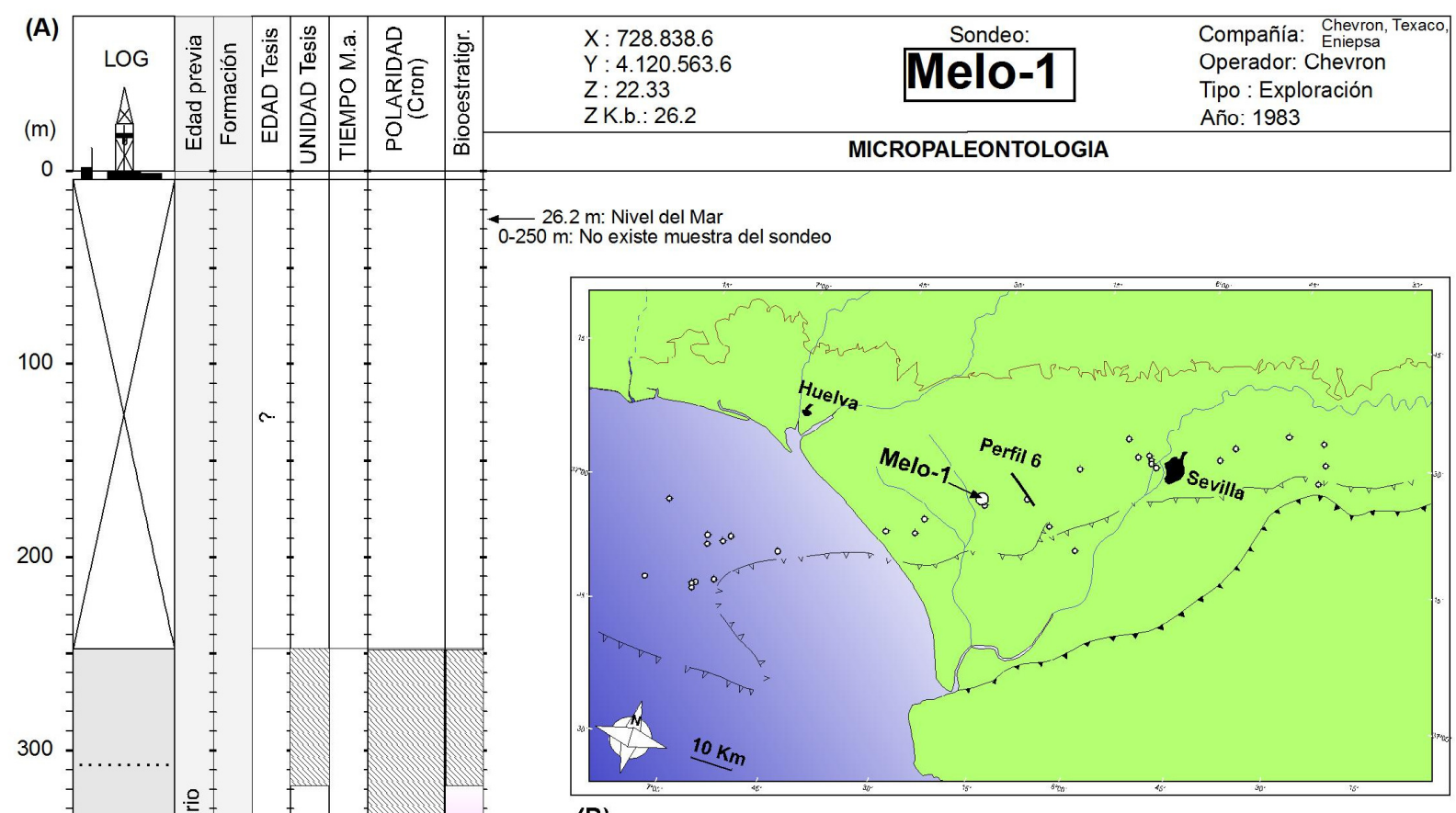

(B)

471: Reducción significativa de planctónicos. ¿ LCO G. margaritae?

$588 \mathrm{~m}$ : Aumento significativo de la velocidad de sedimentación. Bentónicos>>Planctónicos
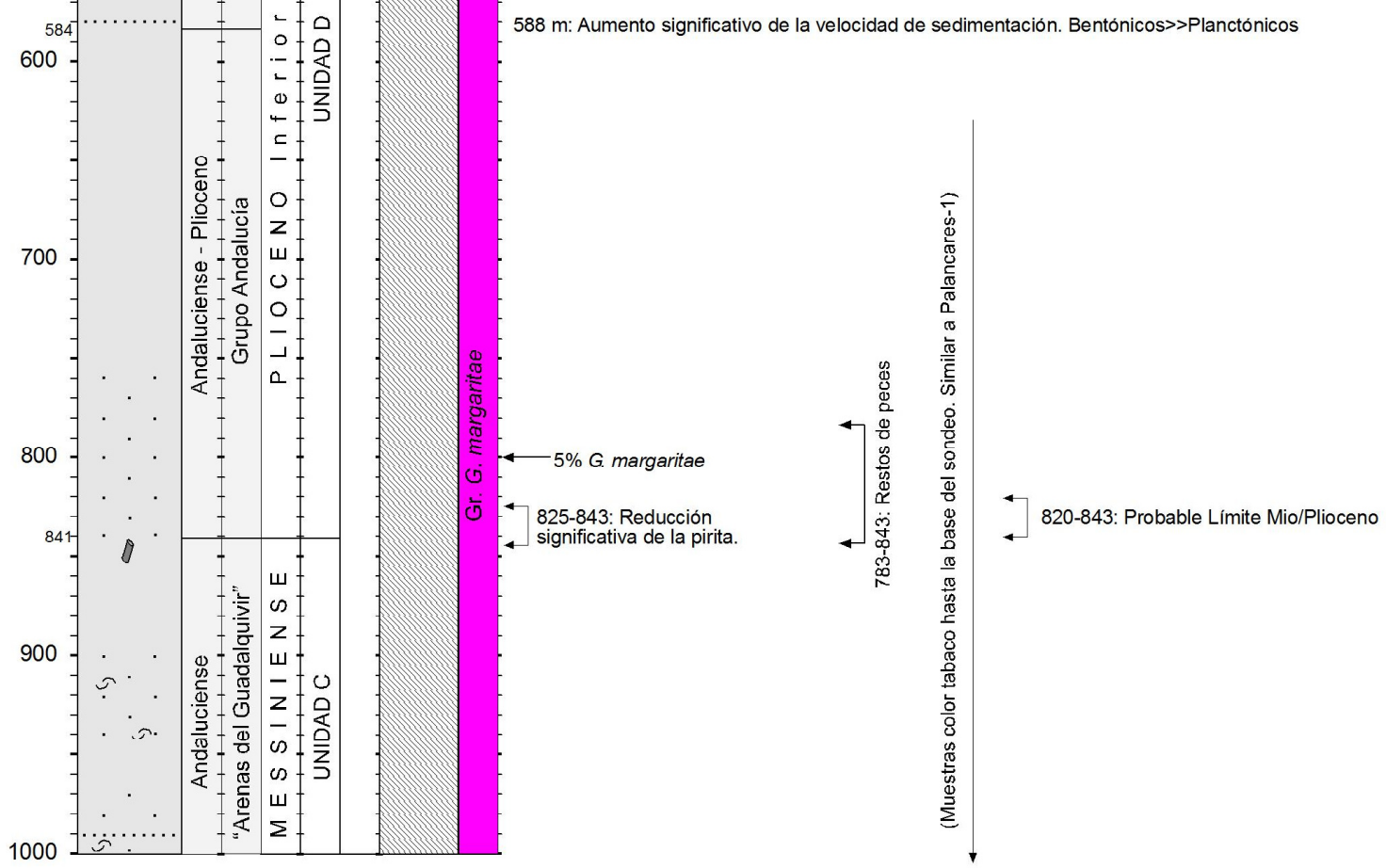

Figura 6.19. Síntesis de los resultados obtenidos en el sondeo Melo-1. Levenda general en figuras 6.1. y 6.2. (A) Profundidad en metros y columna litológica (Repsol). Edades y formaciones utilizadas anteriormente. Edad, unidades litosísmicas, datación, magnetoestratigrafía deducida y biozonas propuestas en esta Tesis en función de los bioeventos de plancton calcáreo. Información micropaleontológica, sedimentológica y otros datos de interés. (B) Localización del sondeo Melo-1 y del perfil sísmico interpretado. (C) Perfil sismobioestratigráfico n6 (sísmica original: ITGE, 1990). 


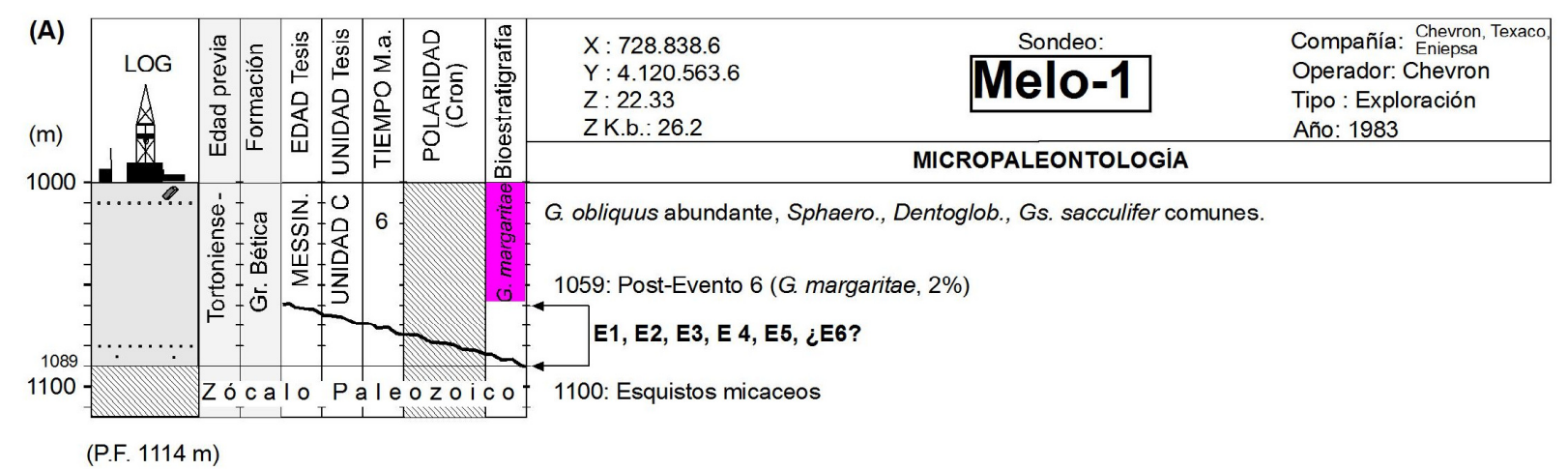

(C)

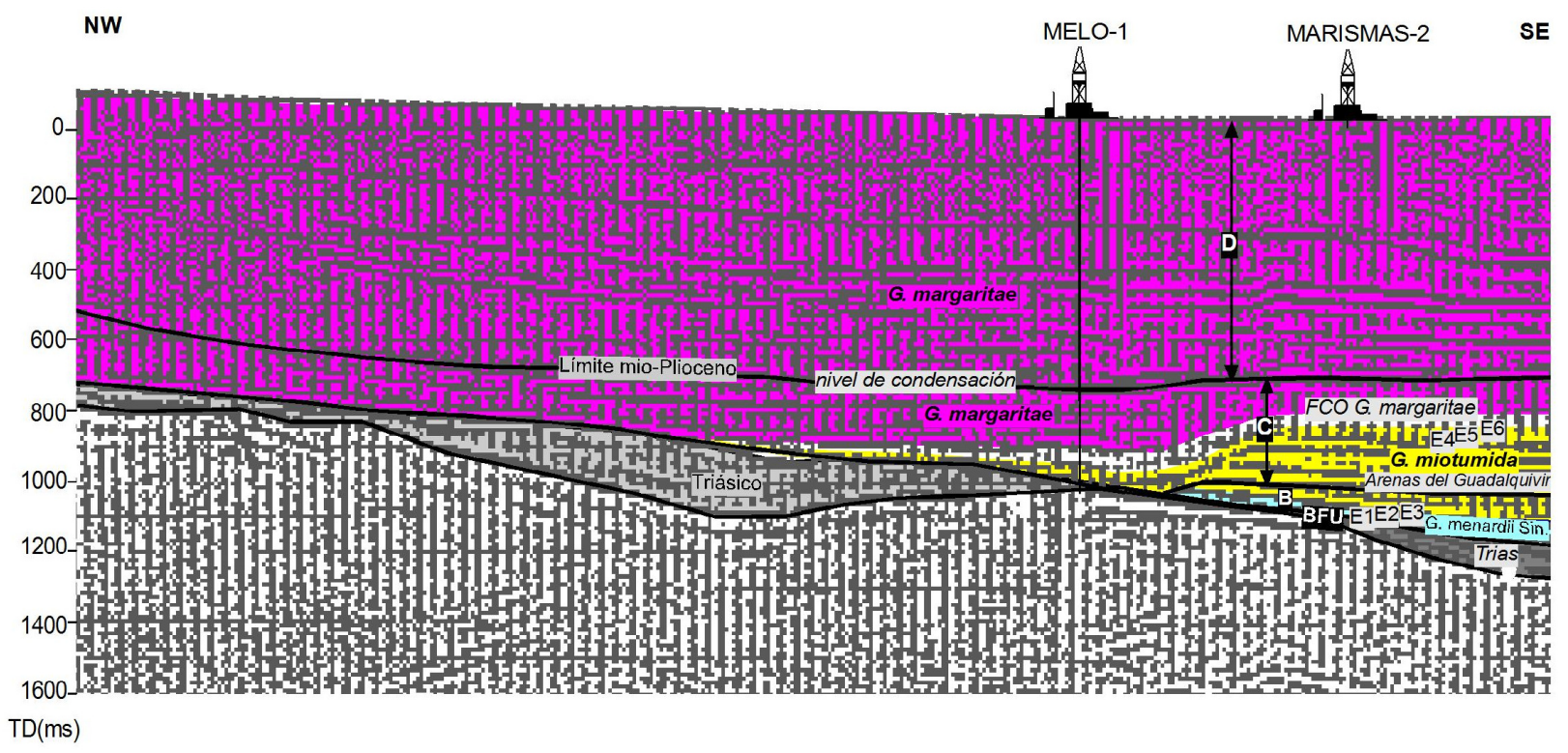

(E6) = FO del grupo $G$. margaritae

$(E 5)=L O$ del grupo $G$ miotumida $\sin (6,3 \mathrm{Ma})$

(E4) = Cambio de enrollamiento de $N$. acostaensis (6,35 Ma)

$(E 3)=\angle O$ del grupo $G$. menardii dx / FCO del grupo G. miotumida $\sin (7,240 \mathrm{Ma})$

$(E 2)=F C O$ del grupo $G$. menardii dx $(7,355 \mathrm{Ma})$

$(E 1)=L C O$ del grupo $G$. menardii $\sin (7,512 \mathrm{Ma})$

Figura 6.19 (Continuación). Síntesis de los resultados obtenidos en el sondeo Melo-1. Leyenda general en las figs. 6.1. y 6.2. (A) Profundidad en metros y columna litológica (información proporcionada por Repsol). Edades y formaciones utilizadas anteriormente. Edad, unidades litosísmicas, datación, magnetoestratigrafía deducida y biozonas propuestas en esta Tesis en función de los bioeventos de plancton calcáreo. Información micropaleontológica, sedimentológica y otros datos de interés. (B) Localización del sondeo y del perfil sísmico. (C) Perfíl sismobioestratigráfico $\mathrm{n}^{\circ} 6$ y proyección de los sondeos Melo-1 y Marismas-2. (Td) = Tiempo doble en milisegundos (sísmica original: ITGE, 1990). 


\subsubsection{Marismas-2}

Sobre el zócalo paleozoico, se deposita el detrítico basal con arenas grises, gruesas, con glauconita (figura 6.20). Las arcillas basales que aparecen encima contienen $G$. menardii sin primero y rápidamente pasan a estar dominadas por el grupo de $G$. menardii dx. La desaparición de este último grupo se registra unos metros antes del primer depósito arenoso (figura 6.20C). En el perfil sismobioestratigráfico (figura 6.20D) podemos observar una serie de paquetes arenosos en la biozona del grupo de $G$. miotumida. La proximidad del sondeo Melo-1 (figura 6.20), donde no se han registrado estos lóbulos, y donde el grupo de G. margaritae se registra prácticamente desde la base del sondeo, indicaría que entre ambos sondeos existe una cicatriz erosiva de edad Messiniense superior. Efectivamente, en el perfil sismobioestratigráfico observamos la truncación de los lóbulos al NW de la posición del sondeo Marismas-2 (figura 6.20D).

Después de los niveles de arena se registra la $F C O$ del grupo de G. margaritae (hacia $940 \mathrm{~m}$ ). Se observa una abundante presencia de pirita en la fracción superior a $0,125 \mathrm{~mm}$ hasta aproximadamente los $800 \mathrm{~m}$ donde se localiza la base del acme de Sphaeroidinellopsis y con él, el límite Mio-Plioceno. Con la llegada del Plioceno, podemos observar en la columna y en el perfil sismobioestratigráfico la rápida llegada de material terrígeno procedente del talud NW. Hacia los $620 \mathrm{~m}$ se detecta la primera aparición de individuos del grupo de G. puncticulata, si bien la abundante presencia de arenas impide determinar si se trata realmente de la posición de este evento o bien se encuentra desplazado (caído) desde posiciones más elevadas.

Las muestras existentes de este sondeo terminan a los $250 \mathrm{~m}$, por lo que no existe registro de ripios por encima de esta profundidad. Esta laguna a impedido constatar la desaparición de G. margaritae (lo que hubiera supuesto el techo de esta biozona) y la existencia de la biozona del grupo de G. puncticulata a techo del sondeo. 


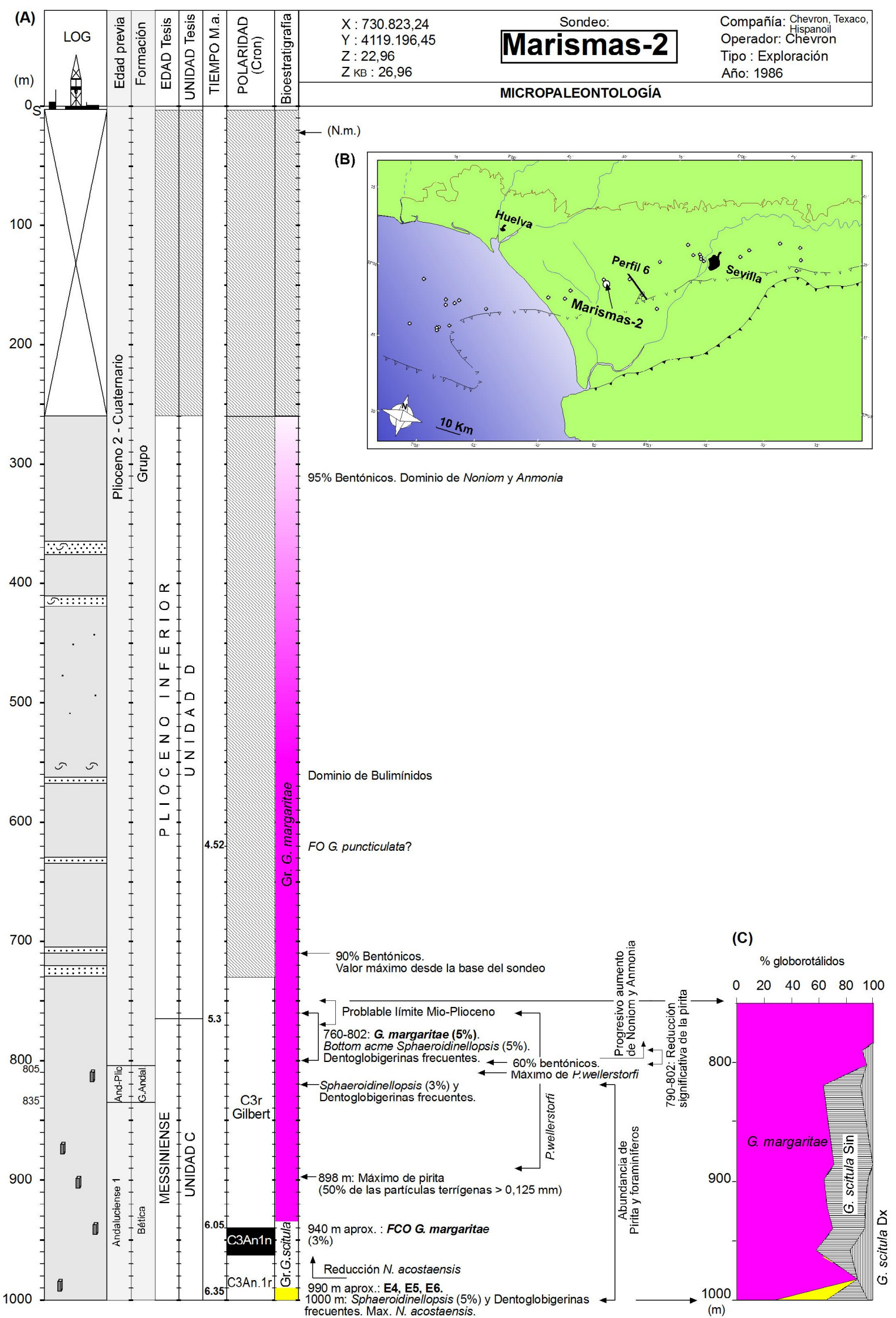

Figura 6.20. Síntesis de los resultados obtenidos en el sondeo Marismas-2. Leyenda general en figuras 6.1. y 6.2. (A) Profundidad en metros y columna litológica (Repsol). Edades y formaciones utilizadas anteriormente. Edad, unidades litosísmicas, datación, magnetoestratigrafía deducida y biozonas propuestas en esta Tesis. Otros datos de interés. (B) Localización del sondeo Marismas-2 y del perfil sísmico interpretado. (C) Porcentaje relativo de globorotálidos basado en análisis cuantitativos. (D) Perfil sismobioestratigráfico nº6 (sísmica original: ITGE, 1990). 


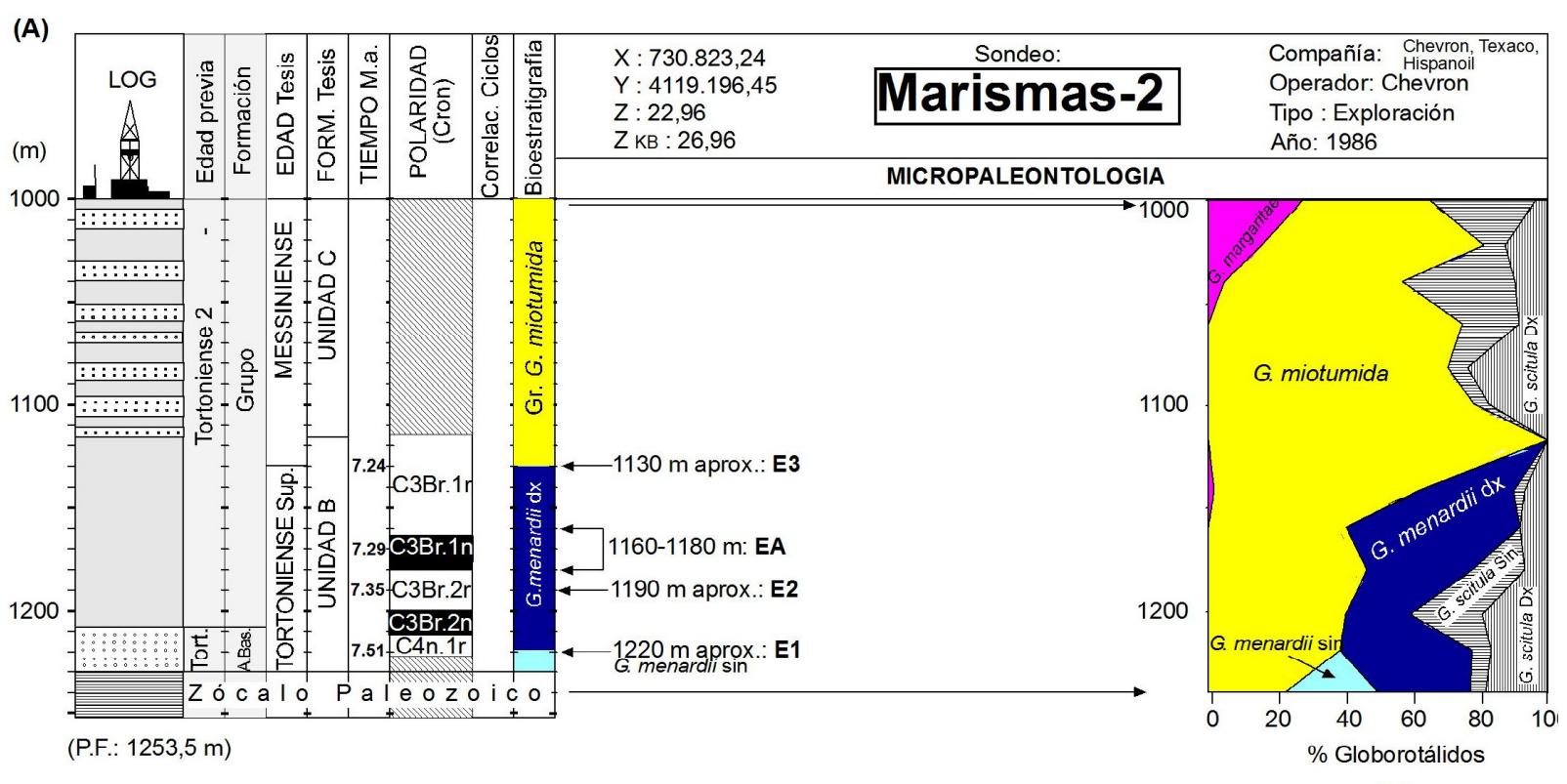

$(E 6)=F O$ del grupo $G$. margaritae

$(E 5)=L O$ del grupo G. miotumida $\sin (6,3 \mathrm{Ma})$

$(E 4)=$ Cambio de enrollamiento de $N$. acostaensis $(6,35 \mathrm{Ma})$

$(E 3)=L O$ del grupo G. menardii dx / FCO del grupo G. miotumida sin $(7,240 \mathrm{Ma})$

$(E A)=$ Cambio de enrrollamiento del grupo $G$. scitula $(7,28 \mathrm{Ma})$

$(\mathrm{E} 2)=$ FCO del grupo $\mathrm{G}$. menardii dx $(7,355 \mathrm{Ma})$

$(\mathrm{E} 1)=$ LCO del grupo $\mathrm{G}$. menardii $\sin (7,512 \mathrm{Ma})$

(D)

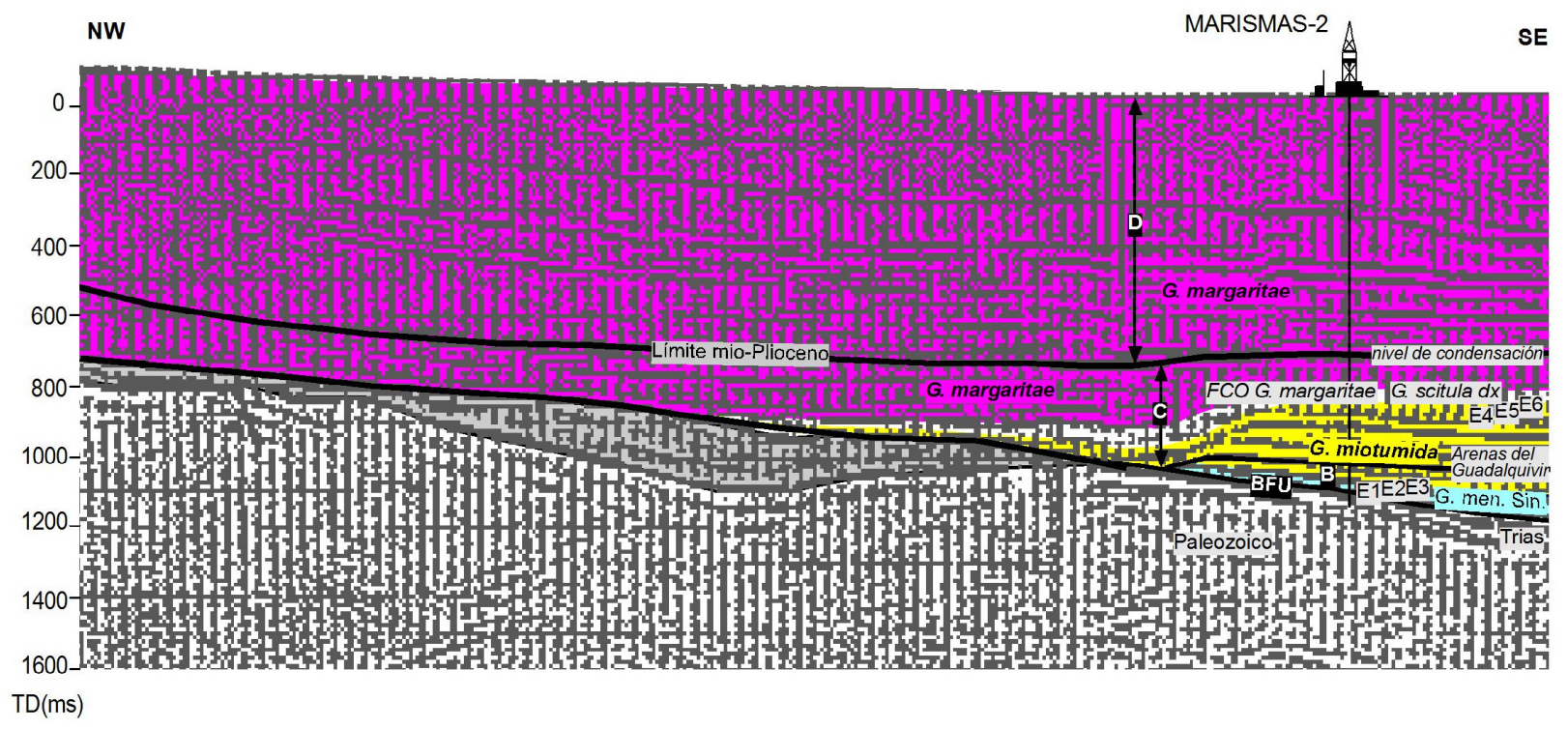

Figura 6.20 (Continuación). Síntesis de los resultados obtenidos en el sondeo Marismas-2. Leyenda general en figs. 6.1. y 6.2. (A) Profundidad en metros y columna litológica (Repsol). Edades y formaciones utilizadas anteriormente. Edad, unidades litosísmicas, datación, magnetoestratigrafía deducida y biozonas propuestas en esta Tesis en función de los bioeventos de plancton calcáreo. Información micropaleontológica, sedimentológica y otros datos de interés. (B) Localización del sondeo y del perfil sísmico.

(C) Porcentaje relativo de globorotálidos basado en análisis cuantitativos.

(D) Perfil sismobioestratigráfico $\mathbf{n}^{\mathbf{0} 6}$ y proyección del sondeo Melo-1 y Marismas-2.

(Td) = Tiempo doble en milisegundos (sísmica original: ITGE, 1990). 


\subsubsection{Marismas-4}

Este sondeo se encuentra en la zona noroccidental de la cuenca del Guadalquivir (figura 6.21). El contacto entre el zócalo mesozoico y la serie mio-pliocena se encuentra a $1326 \mathrm{~m}$. Desde esta profundidad hasta $1280 \mathrm{~m}$, se encuentran solo globorotálidos dispersos (G. menardii sin, G. menardii dx, G. margaritae), sin que se pueda establecer la biozona a la que pertenece este tramo. Sin embargo, la presencia de $N$. acostaensis levógiro, parece descartar que se trate de la biozona del grupo de G. margaritae. La proximidad de la biozona del grupo de G. margaritae a la base del sondeo, podría indicar la presencia de una discontinuidad (figura 6.21D), o probablemente una zona de bypass durante el Messiniense, en la que apenas se depositaron sedimentos. Como se aprecia en el perfil sismobioestratigráfico (figura 6.21C) las biozonas de los globorotálidos anteriores se acuñan hacia el oeste, pudiendo estar este tramo limoso incluido en cualquiera de ellas, o concentrar varias biozonas. El hecho más característico de este sondeo es la presencia abundante de individuos del grupo de G. margaritae por debajo de los niveles de arena. Esta característica, semejante a los sondeos del área norte del golfo de Cádiz, indica que se trata de cuerpos de arena más modernos que los atravesados en los sondeos estudiados en el este y sureste del Guadalquivir. G. margaritae se encuentra presente en las muestras superiores a los cuerpos arenosos, y no se observa su desaparición al menos hasta los $300 \mathrm{~m}$. A partir de esta profundidad no se dispone de muestras, por lo que no se ha podido comprobar la desaparición de este grupo que debería producirse en los últimos metros del sondeo según los perfiles sismobioestratigráficos (ver perfil sismobioestratigráfico n11). 


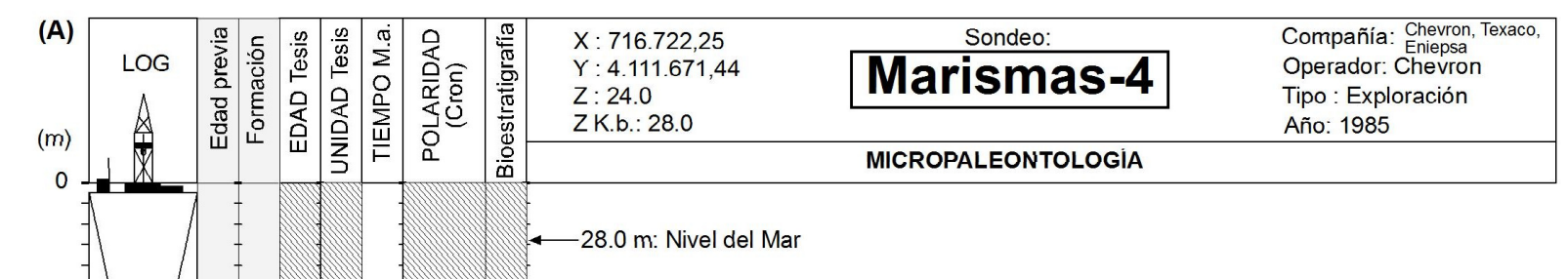

(B)
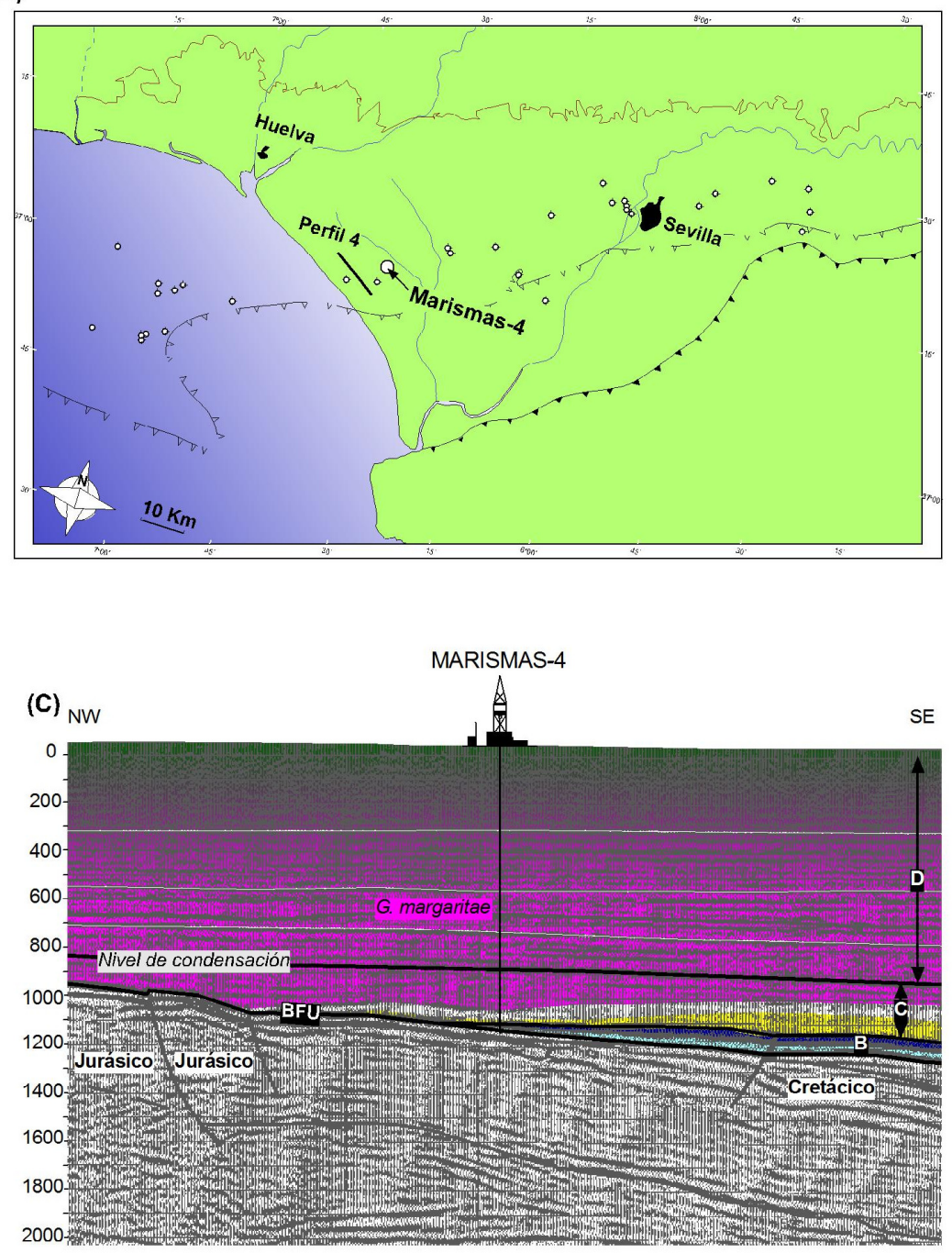

(TD)

1000

Figura 6.21. Síntesis de los resultados obtenidos en el sondeo Marismas-4. Leyenda general en figs. 6.1. y 6.2. (A) Profundidad en metros y columna litológica (basado documentación facilitada por Repsol). Edades y formaciones utilizadas anteriormente. Edad, unidades litosísmicas, datación, magnetoestratigrafía deducida y biozonas propuestas en esta Tesis en función de los bioeventos de planctoncalcáreo. Otros datos de interés. (B) Localización del sondeo y del perfil sísmico. (C) Zona ampliada del perfil sismobioestratigráfico $n^{\circ}$ 7. Proyección del sondeo Marismas-4. (Td) $=$ Tiempo doble (sísmica original: ITGE, 1990) (D) Porcentaje de globorotálidos, neogloboquadrínidos, Gs. obliquus y porcentaje de bentónicos respecto al total de forminiferos basados en análisis cuantitativos. 


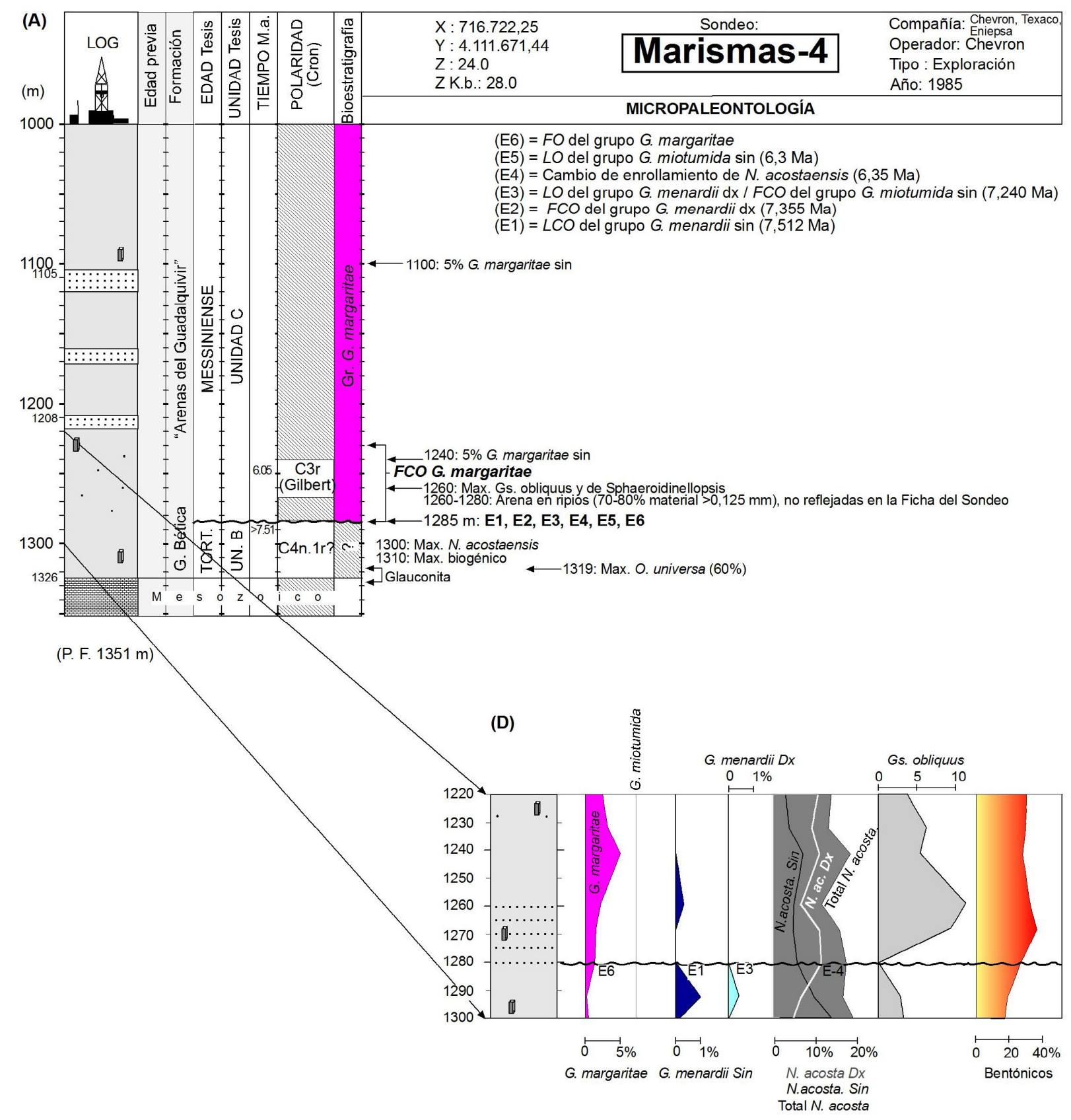

Figura 6.21 (Continuación). Síntesis de los resultados obtenidos en el sondeo Marismas-4. Leyenda general en figuras 6.1. y 6.2. (A) Profundidad en metros y columna litológica (basado documentación facilitada por Repsol). Edades y formaciones utilizadas anteriormente. Edad, unidades litosísmicas, datación, magnetoestratigrafía deducida y biozonas propuestas en esta Tesis en función de los bioeventos de plancton calcáreo. Información micropaleontológica, sedimentológica y otros datos de interés. (B) Localización del sondeo y del perfil sísmico. (C) Perfil sismobioestratigráfico $\mathrm{n}^{\circ} 7$ (sísmica original: ITGE, 1990). (D) Porcentaje de globorotálidos, neogloboquadrínidos, Gs. obliquus y porcentaje de bentónicos respecto al total de forminíferos (análisis cuantitativo). 


\subsubsection{Marismas A-1}

La base del sondeo (figura 6.22) se asienta sobre una serie Jurásica, tras la que se deposita una arcilla profunda donde en los primeros metros desaparece G. menardii sin. A partir de ese momento pasará a dominar la asociación de globorotálidos el grupo de $G$. menardii $\mathrm{dx}$ hasta el comienzo de los niveles de arena. En el contacto con las arenas desaparece G. menardii dx, siendo sustituida por G. miotumida hasta $40 \mathrm{~m}$ por encima de los paquetes de arena, momento en el que también desaparece. A continuación, tras un intervalo arcilloso con $G$. margaritae se localiza la primera aparición común de este grupo de globorotálidos. Tras la FCO del grupo de G. margaritae se observa una reducción significativa de los foraminíferos planctónicos a favor de los bentónicos.

El límite Mio-Plioceno se ha establecido en función del evento de desaparición de Discoaster quinqueramus (J.A. Flores com. per.) entre los 900-940 m (5.537 Ma) y del análisis de los perfiles sismobioestratigráficos (figura 6.22C). La magnetoestratigrafía se ha deducido únicamente en función de los eventos de desaparición por lo que no se ha tenido en cuenta la primera aparición de G. puncticulata.

No se ha podido constatar la desaparición del grupo de G. margaritae debido a la falta de muestra de los $300 \mathrm{~m}$ superiores. En el perfil sismobioestratigráfico $\mathrm{n}^{\circ} 11$, longitudinal a la cuenca podemos observar el rápido avance que experimenta la cabecera de la cuenca durante el Messiniense superior en la biozona de G. margaritae. Podemos estimar así mismo, que la desaparición del grupo de G. margaritae se va a registrar hacia la actual línea de costa, hacia el techo del sondeo Asperillo-1. Podría por lo tanto producirse este evento hacia el techo del sondeo Marismas A-1. 


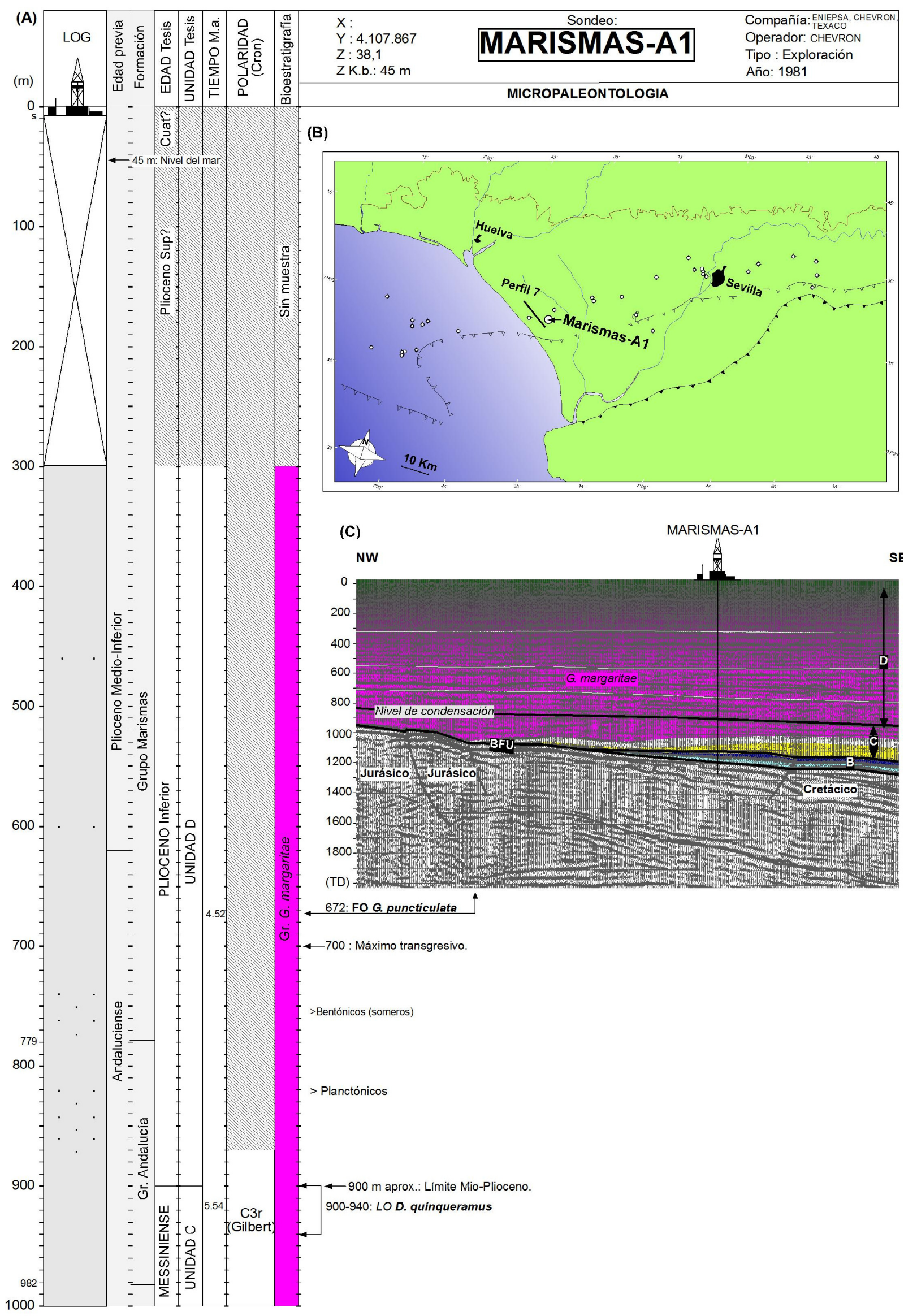

Figura 6.22. Síntesis de los resultados obtenidos en el sondeo Marismas-A1. Leyenda general en figs. 6.1. y 6.2. (A) Profundidad en metros y columna litológica (basado en documentación facilitada por Repsol). Edades y formaciones utilizadas con anterioridad. Edad, unidades litosísmicas, datación, magnetoestratigrafía deducida y biozonas propuestas en esta Tesis. Otros datos de interés. (B) Localización del sondeo Marismas-A1 y del perfil sísmico interpretado. (C) Perfil sismobioestratigráfico $n^{\circ}$ 7. Proyección del sondeo Marismas-A1. (Td) = Tiempo doble (sísmica original: ITGE, 1990). 


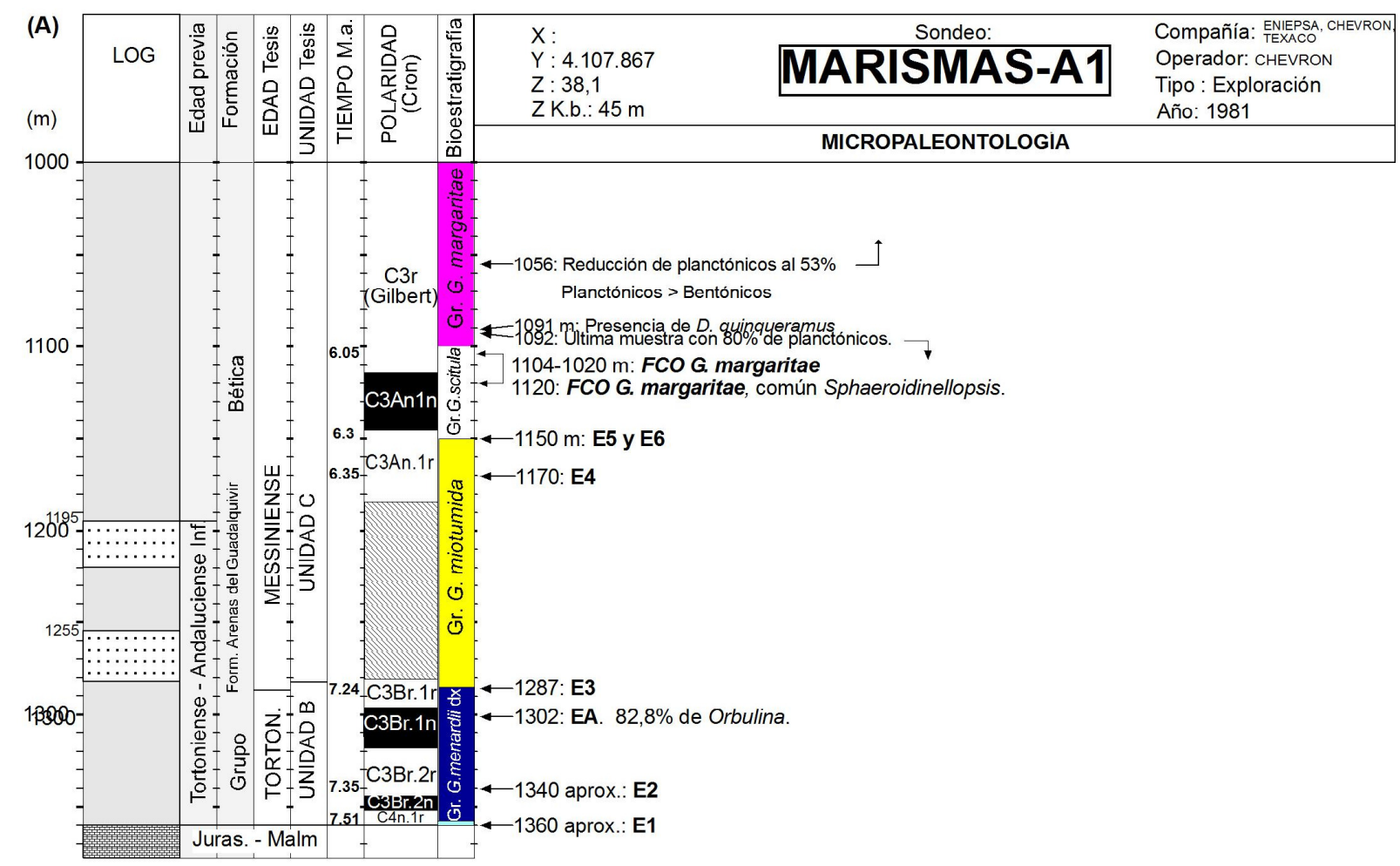

(P.F: $1378 \mathrm{~m}$ )

$(E 6)=F O$ del grupo $G$. margaritae

$(E 5)=L O$ del grupo $G$. miotumida $\sin (6,3 \mathrm{Ma})$

(E4) = Cambio de enrollamiento de $N$. acostaensis $(6,35 \mathrm{Ma})$

$(\mathrm{E} 3)=\angle O$ del grupo $G$. menardii dx / FCO del grupo G. miotumida $\sin (7,240 \mathrm{Ma})$

$(E A)=$ Cambio de enrrollamiento del grupo $G$. scitula $(7,28 \mathrm{Ma})$

$(E 2)=F C O$ del grupo $G$. menardii $\mathrm{dx}(7,355 \mathrm{Ma})$

$(E 1)=$ LCO del grupo $G$. menardii $\sin (7,512 \mathrm{Ma})$

Figura 6.22 (Continuación). Síntesis de los resultados obtenidos en el sondeo Marismas-4. Leyenda general en figs. 6.1. y 6.2. (A) Profundidad en metros y columna litológica (basado en documentación facilitada por Repsol). Edades y formaciones utilizadas con anterioridad. Edad, unidades litosísmicas, datación, magnetoestratigrafía deducida y biozonas propuestas en esta Tesis en función de los bioeventos de plancton calcáreo. Información micropaleontológica, sedimentológica y otros datos de interés. (B) Localización del sondeo y del perfil sísmico. (C) Perfil sismobioestratigráfico $\mathrm{n}^{\circ} 7$ (sísmica original: ITGE, 1990). 


\subsubsection{Asperillo-1}

La falta de biomarcadores en la base del sondeo impide precisar si las arenas que aparecen en la base del mismo corresponden al detrítico basal de la unidad litosísmica B o a la formación "arenas del Guadalquivir" (figura 6.23) de la unidad litosísmica C. Pocas decenas de metros por encima del nivel de arena se localiza la unidad bioestratigráfica del grupo de G. margaritae. El perfil sismobioestratigráfico no resuelve el problema del origen del nivel de arenas basal puesto que en el entorno del sondeo confluyen varios reflectores correspondientes a la base de la unidad litosísmica B y la base de la unidad litosísmica C.

Aunque es probable que el límite entre la biozona del grupo de G. margaritae y la biozona del grupo de G. puncticulata se localice en la parte superior del sondeo, no se dispone de muestra de los primeros $150 \mathrm{~m}$. La posición de este límite entre estas dos biozonas puede inferirse a partir de la proyección del sondeo sobre el perfil sismobioestratigráfico $\mathrm{n}^{\circ} 11$. 


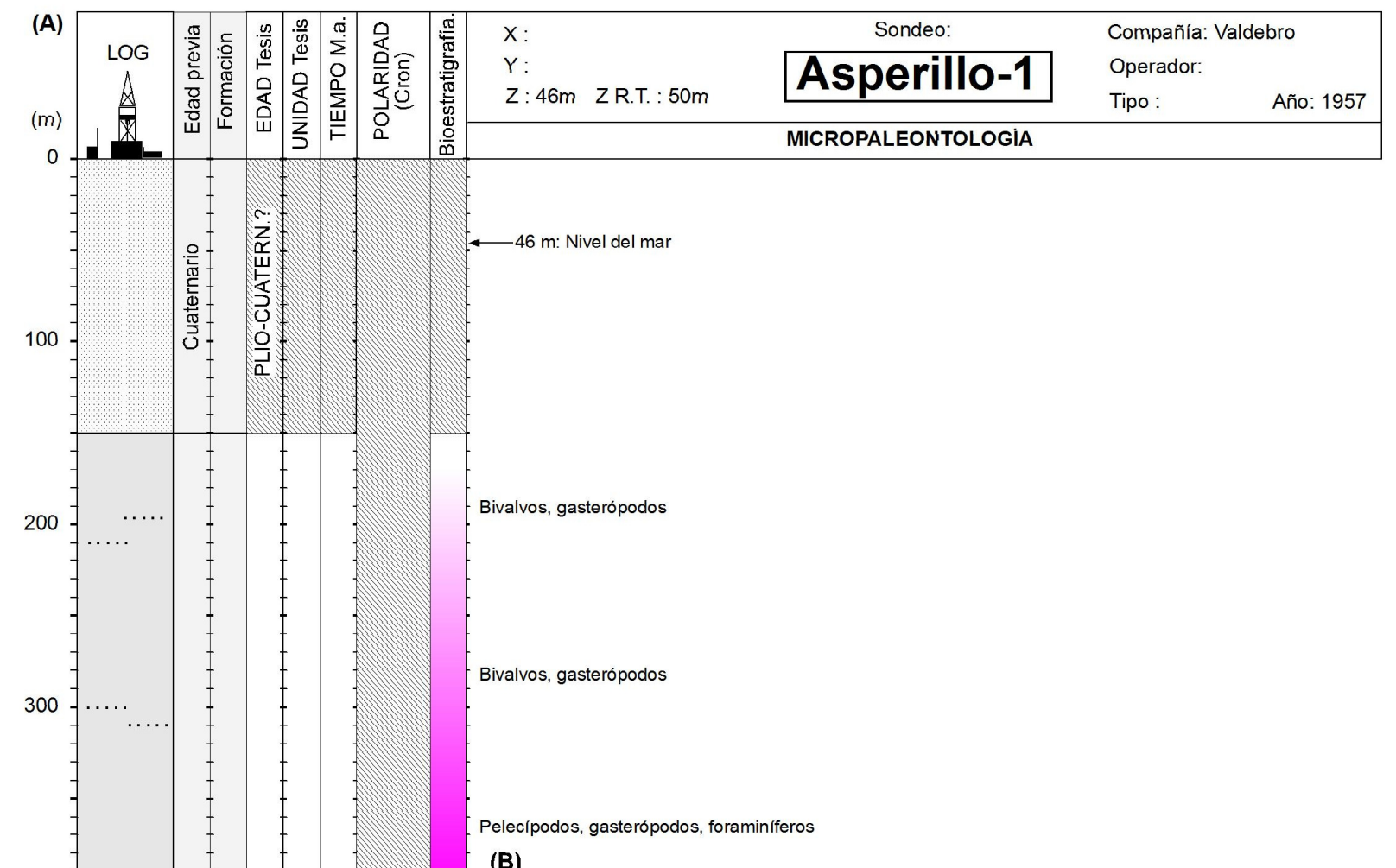

(B)

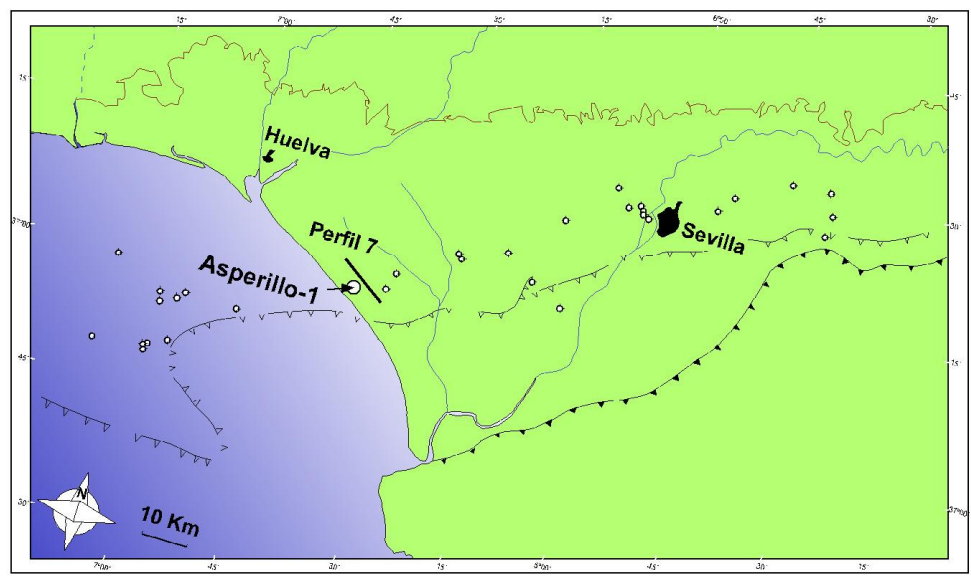

685,8-689.46 m: (T. Lateral) Bentónicos >98\%.

N. boeanum abundante. Algúnos moluscos.

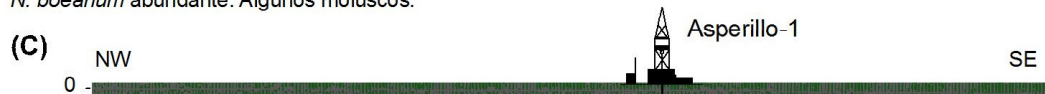

(C)

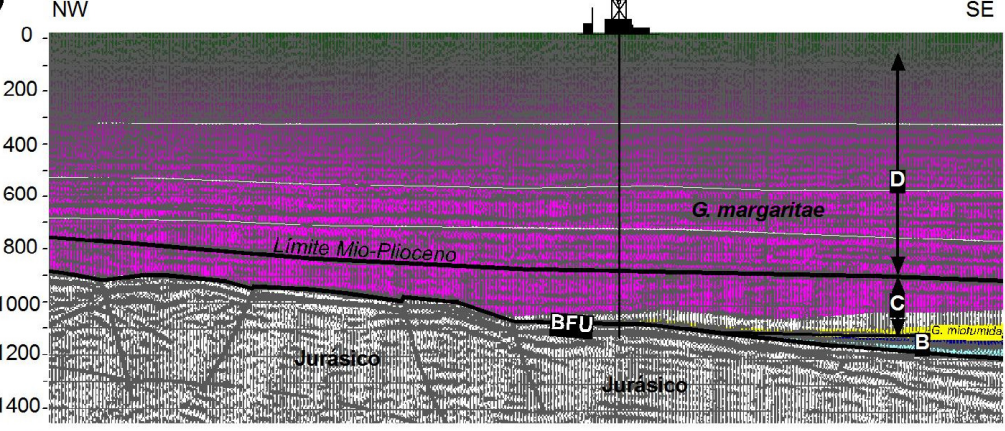

(TD)

1000

Figura 6.23. Síntesis de los resultados obtenidos en el sondeo Asperillo-1. Leyenda general en figs. 6.1. y 6.2. (A) Profundidad en metros y columna litológica basada en el registro de diagrafías depositadas en el Ministerio de Industria y Energía. Edades y formaciones utilizadas anteriormente. Edad, unidades litosísmicas, datación, magnetoestratigrafía deducida y biozonas propuestas en esta Tesis en función de los bioeventos de plancton calcáreo. Información micropaleontológica, sedimentológica y otros datos de interés. (B) Localización del sondeo Asperillo-1 y del perfil sismobioestratigráfico $\mathbf{n}^{0} 7$. (C) Perfil sismobioestratigráfico n ${ }^{0}$ 7. Proyección del sondeo Asperillo-1. (Td) = Tiempo doble (sísmica original: ITGE, 1990). 


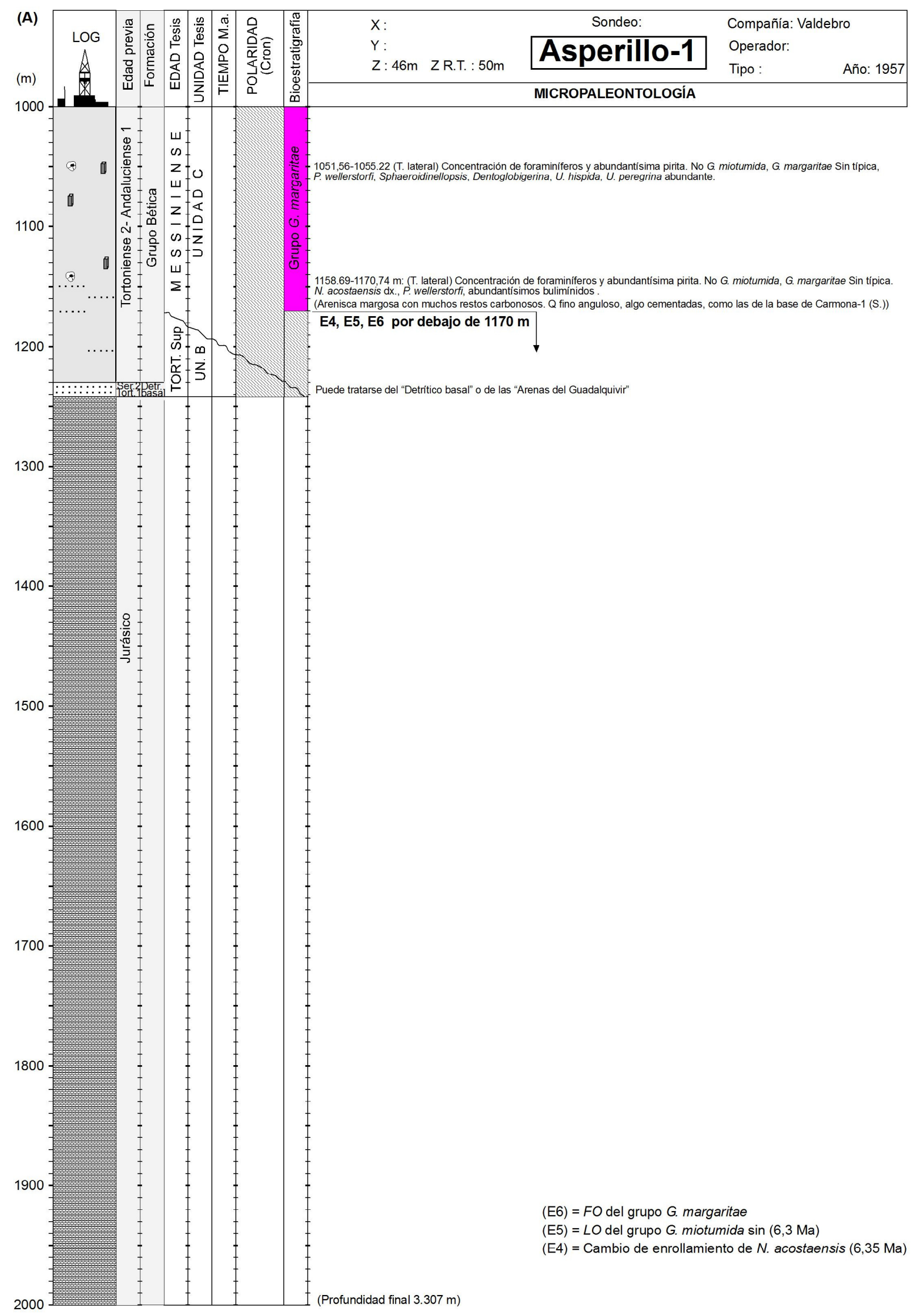

Figura 6.23 (Continuación). Síntesis de los resultados obtenidos en el sondeo Asperillo-1. Leyenda general en figs. 6.1. y 6.2. (A) Profundidad en metros y columna litológica basada en el registro de diagrafias depositadas en el Ministerio de Industria y Energía. Edades y formaciones utilizadas anteriormente. Edad, unidades litosísmicas, datación, magnetoestratigrafía deducida y biozonas propuestas en esta Tesis en función de los bioeventos de plancton calcáreo. Información micropaleontológica, sedimentológica y otros datos de interés. (B) Localización del sondeo y del perfil sísmico. (C) Perfil sismobioestratigráfico $\mathrm{n}^{0} 7$ (sísmica original: ITGE, 1990). 


\subsection{GOLFO DE CÁDIZ}

Las figuras que aparecen a continuación corresponden a los sondeos offshore, en la plataforma del golfo de Cádiz. En función de los resultados obtenidos en el análisis bioestratigráfico, se han agrupado los sondeos en dos sectores. En el sector norte se han incluido los sondeos Atlántida-2, B2, C2, C4, D1... que atraviesan los cuerpos de arenas turbidíticas más modernas. En el sector sur se presentan los sondeos Orión 2-1, 6x1, B3, B6, C3... atravesando todos ellos cuerpos turbidíticos anteriores, localizados en la biozona del grupo de G. miotumida.

\subsubsection{Golfo de Cádiz D-1 (D1)}

El sondeo D1 (figura 6.24), es el más próximo a la costa de entre todos los sondeos estudiados en el golfo de Cádiz. Es un sondeo muy profundo (4084 m) que atraviesa una potente serie Mesozoica (figura 6.24, C y D). A $1920 \mathrm{~m}$ la unidad litosísmica B se asienta discordante sobre un sustrato carbonatado. La unidad B contiene arcillas del Tortoniense superior con globorotálidos del grupo G. menardii sin. Desaparecido el grupo de G. menardii sin, comienza la biozona del grupo de G. menardii $\mathrm{dx}$ que finaliza antes del comienzo de los paquetes de arena. Una potente serie arenosa se desarrolla entre 1640 m y 1415 m dentro de la unidad litosísmica C.

En el análisis cuantitativo realizado en este sondeo puede observarse la relación porcentual de los distintos globorotálidos (figura 6.24F). Se aprecia también la presencia de contaminación por cuanto el grupo de G. miotumida aparece hasta la base de la unidad $\mathrm{B}$, cuando su presencia debería ser incompatible con la del grupo de G. menardii dx y menos aún con G. menardii sin.

La práctica totalidad de los niveles de arena se localizan en la biozona del grupo de G. miotumida, mientras que por encima de $1460 \mathrm{~m}$ los niveles de arena aparecen en la biozona del grupo de G. margaritae. No se descarta que dicho contacto represente una discontinuidad (Ver Perfil sismobioestratigráfico $n^{\circ}$ 9). Para estimar la presencia o no de esta discontinuidad se ha realizado un análisis cuantitativo entre 1430 y $1480 \mathrm{~m}$ (figura 6.24E). En este gráfico se aprecia como en el mismo intervalo se suceden varios eventos bioestratigráficos (eventos E4, E5 y E6) así como un aumento significativo de los foraminíferos bentónicos y de otros foraminíferos planctónicos. Todo ello sugiere la posibilidad de que exista una discontinuidad entre ambos grupos de arena. 


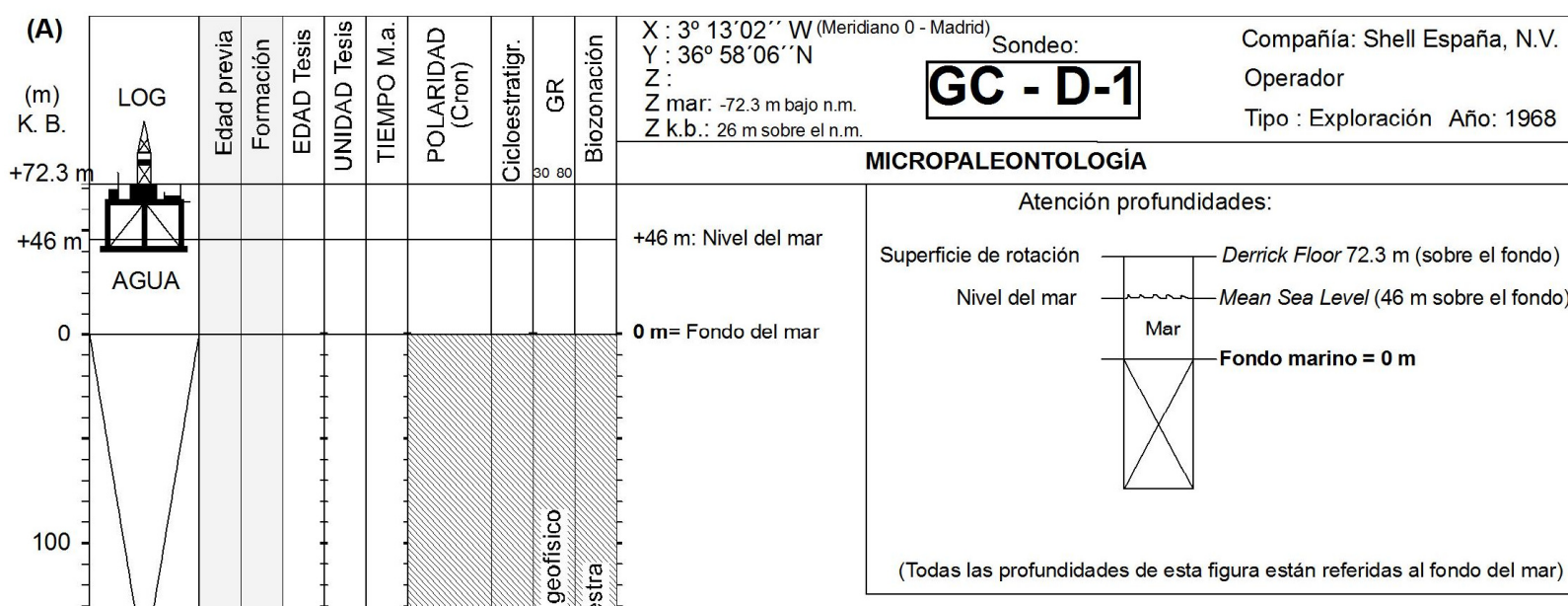

(B)

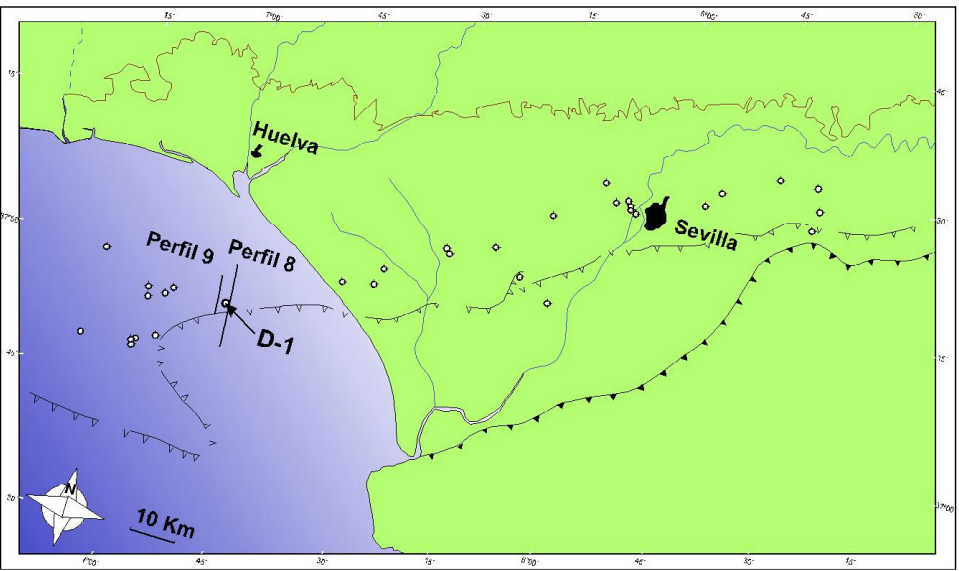

(C)

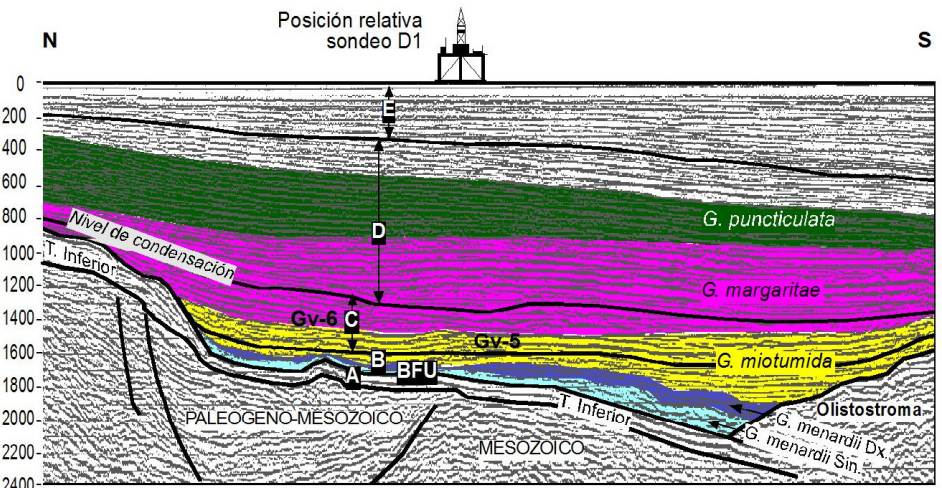

(Td) (A) Profundidad en metros y columna litológica basada en informe ITGE, 1990. Edades y formaciones utilizadas anteriormente. Edad, unidades litosísmicas, datación, magnetoestratigrafía deducida, registro de rayos gamma (Repsol), unidades cicloestratigráficas y biozonas propuestas en esta Tesis en función de los bioeventos de plancton calcáreo. Información micropaleontológica, sedimentológica y otros datos de interés. (B) Localización del sondeo y de los perfiles sísmicos utilizados. (C) Perfil sismobioestratigráfico $n^{0} 8$ (sísmica original en Riaza y Martínez del Olmo, 1996). Proyección del sondeo D1. (Td) = Tiempo doble. (D) Perfil sismobioestratigráfico $n^{\circ} 9$ (sísmica original: ITGE, 1990). (E) Porcentaje relativo de neogloboquadrínidos, Gs. sacculifer, D. altispira y porcentaje de foraminíferos bentónicos respecto al total de foraminíferos basados en análisis cuantitativos. (F) Porcentaje relativo de globorotálidos. 


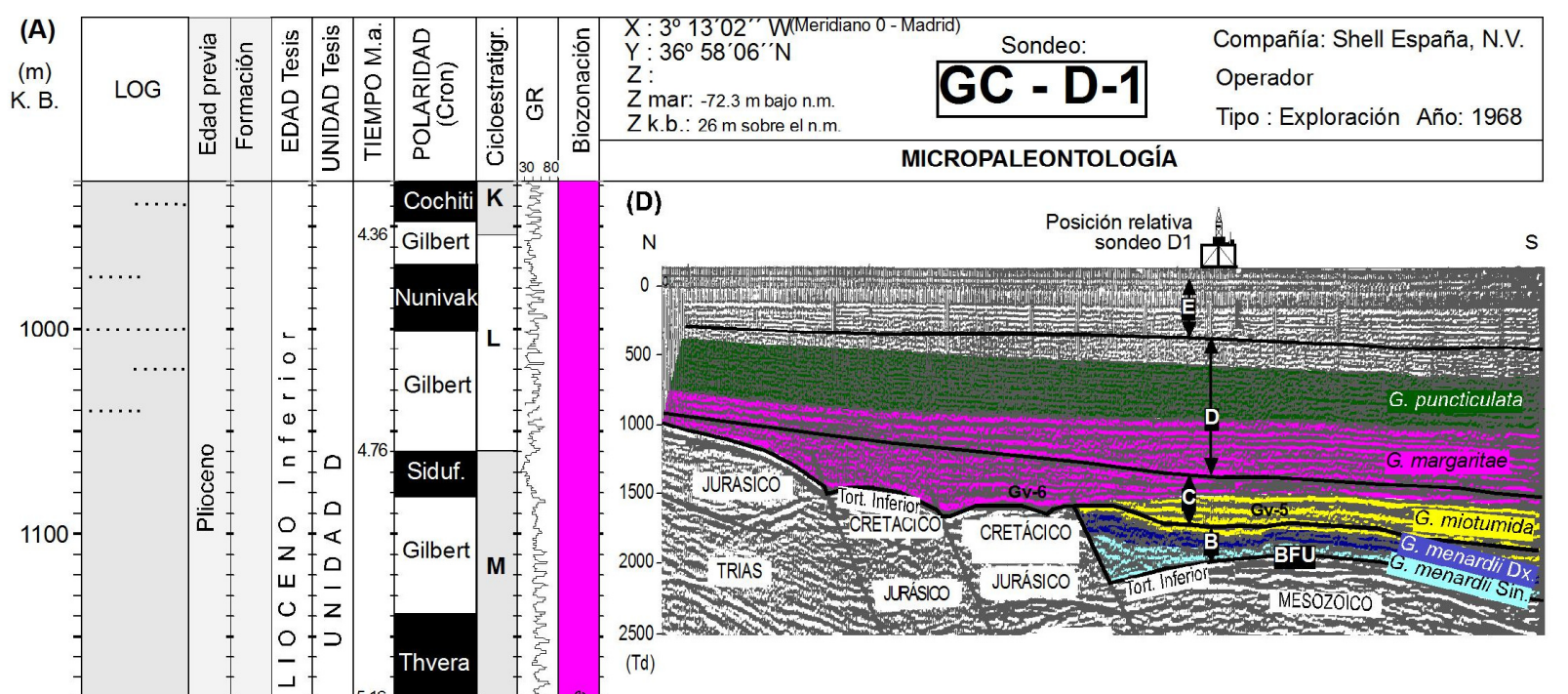

(E)

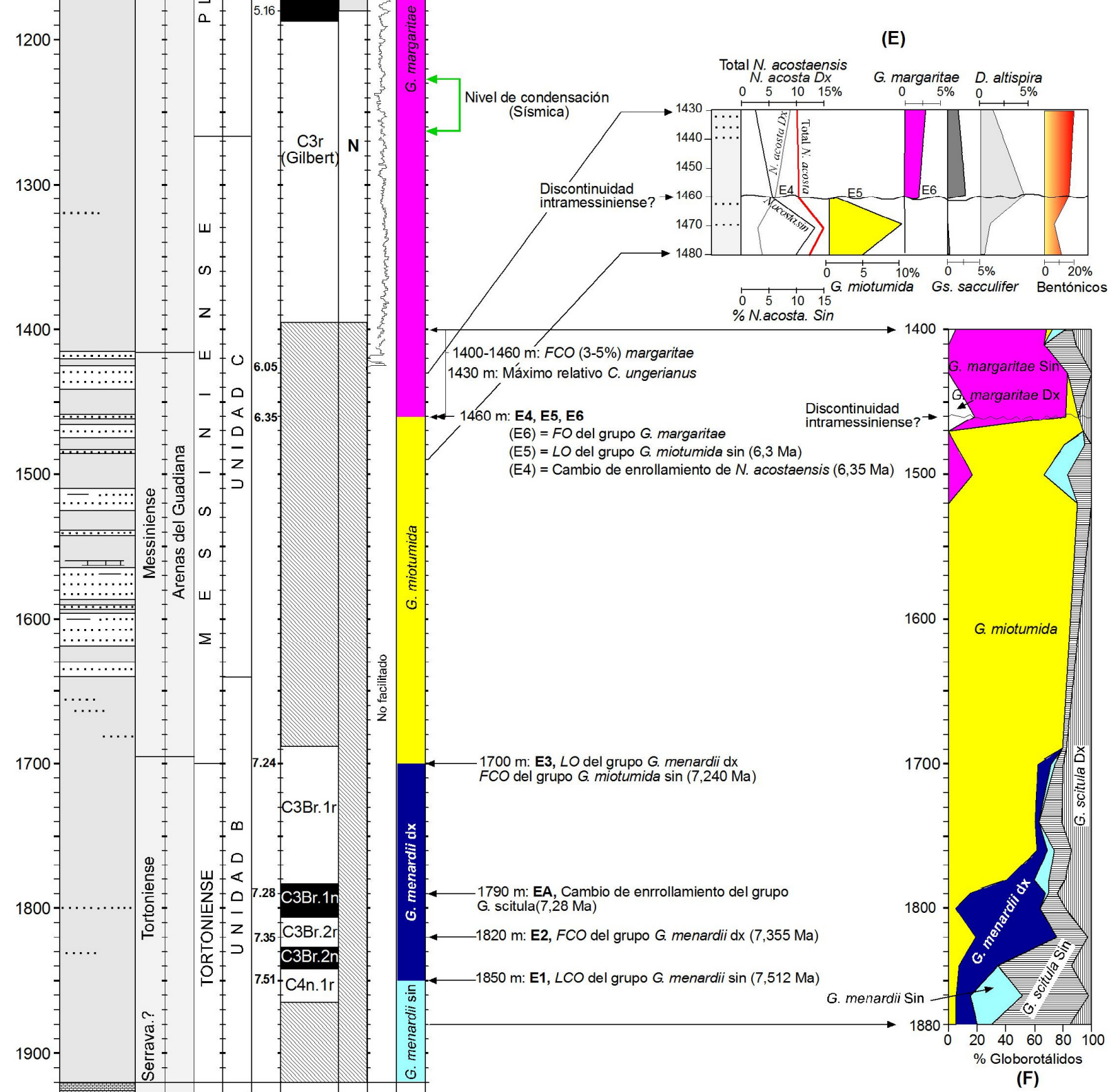

Figura 6.24 (Continuación) Síntesis de los resultados obtenidos en el sondeo D-1. Leyenda en figuras 6.1. y 6.2. (A) Profundidad en metros y columna litológica basada en informe ITGE, 1990. Edades y formaciones utilizadas anteriormente. Edad, unidades litosísmicas, datación, magnetoestratigrafía deducida, registro de rayos gamma (Repsol), unidades cicloestratigráficas y biozonas propuestas en esta Tesis en función de los bioeventos de plancton calcáreo. Información micropaleontológica, sedimentológica y otros datos de interés. (B) Localización del sondeo y de los perfiles sísmicos utilizados. (C) Perfil sismobioestratigráfico $\mathbf{n}^{0} 8$ (sísmica original en Riaza y Martínez del Olmo, 1996). Provección del sondeo D1. (Td) = Tiempo doble. (D) Perfil sismobioestratigráfico $n^{0} 9$ (sísmica original: ITGE, 1990) (Td) = Tiempo doble). (E) Porcentaje relativo de neogloboquadrínidos, Gs. sacculifer, D. altispira y porcentaje de foraminíferos bentónicos respecto al total de foraminíferos, basado en análisis cuantitativos. (F) Porcentaje relativo de globorotálidos. 
El límite Mio-Plioceno se ha determinado así mismo en función de los perfiles sismobioestratigráficos (figura 6.24, C y D) y del análisis clicloestratigráfico. La desaparición del grupo de G. margaritae se registra entorno a $850 \mathrm{~m}$, de forma que entonces comenzaría la biozona del grupo de G. puncticulata.

La localización de numerosos eventos bioestratigráficos en el sondeo D-1 ha permitido calibrar el registro sónico y de rayos gamma con la curva astronómica de tiempo (capítulo 5). Gracias a esta datación de alta resolución ha sido posible extrapolar la posición de las inversiones magnéticas en función del análisis cicloestratigráfico y de la posición de los bioeventos.

La ausencia de muestra y de registro geofísico los últimos centenares de metros de sondeo impiden concretar la litología y lógicamente la bioestratigrafía, por lo que no se ha podido establecer la desaparición del grupo de G. puncticulata. En función del perfil sismobioestratigráfico y del análisis bioestratigráfico estimamos que puede localizarse entorno a $500 \mathrm{~m}$.

\subsubsection{Golfo de Cádiz C-4 (C4)}

No se presenta ninguna figura de este sondeo debido a que solo se ha obtenido información parcial de la litología y bioestratigrafía del mismo.

A $1800 \mathrm{~m}$ de profundidad se encuentra localizada la discontinuidad basal de fondo de cuenca $(B F U)$, momento en el que comenzaría el depósito de la unidad litosísmica B. Durante casi $300 \mathrm{~m}$ se registra una serie arcillosa en la que presumiblemente se localizan los eventos de desaparición del grupo de G. menardii sin y G. menardii dx. Al menos, la parte superior de estas arcillas, entre 1720 y 1650 m, está dominada por el grupo de $G$. miotumida por lo que previamente al desarrollo de los paquetes arenosos, nos encontraríamos en la biozona del grupo de G. miotumida. Los primeros niveles de arena se han detectado en el análisis de los ripios a $1650 \mathrm{~m}$. A continuación se depositan unos niveles de arena fina subangulosa por encima de los cuales se ha detectado el cambio de enrollamiento de Neogloboquadrina acostaensis (E4), así como la desaparición del grupo de G. miotumida (E5), ambos eventos hacia $1580 \mathrm{~m}$ y seguidamente la primera aparición común del grupo de G. margaritae (FCO G. margaritae) hacia 1560 m. A continuación se desarrolla una serie de niveles de arena hasta $1460 \mathrm{~m}$ que se encuentran localizados en la biozona del grupo de G. margaritae. La localización del límite Mio-Plioceno se ha establecido a $1400 \mathrm{~m}$ gracias al análisis cicloestratigráfico. Tras el límite Mio-Plioceno se registra una potente serie arcillosa, con una llamativa alternancia entre niveles de arcilla 
con bajo contenido en limo y niveles de arcilla con alto contenido en limo. Esta alternancia cíclica ha sido estudiada a fondo en el capítulo de cicloestratigrafía (capítulo 5). No se ha establecido la bioestratigrafía en el resto de la serie pilo-cuaternaria.

\subsubsection{Golfo de Cádiz C-2 (C2)}

Este sondeo se encuentra localizado en el sector norte del golfo de Cádiz (figura 6.25). Tras la unidad litosísmica A, perforada hacia $1900 \mathrm{~m}$, se depositan unas arcillas grises calcáreas con glauconita en los metros basales. A 1690 m comienza un depósito arenoso que termina hacia $1500 \mathrm{~m}$. Este depósito, igual que en el sondeo D-1 comienza en la biozona del grupo de $G$. miotumida, mientras que los último niveles de arena se encuentran en la biozona del grupo de G. margaritae.

La presencia de lóbulos de arena con G. miotumida en los nivles de arena más antiguos, se han interpretado en un contexto similar a los registrados en el Guadalquivir. La sección transversal de los lóbulos que presentan los perfiles sismobioestratigráficos indicarían una procedencia NE (desde el eje de la cuenca), aunque no se descarta que alguno de ellos puedan tener relación con el talud NW, como proponen Riaza y Martínez del Olmo (1996). La falta de biomarcadores en la zona intermedia del tramo arenoso, ha impedido localizar de forma precisa el evento E4 y el evento E6, que han sido deducidos a partir de la comparación geofísica con el sondeo B2.

Un significativo incremento en Sphaeroidinellopsis hacia 1380-1390 m marcaría el límite Mio-Plioceno. A partir de ese momento se registra una potente serie pliocena con una marcada ciclicidad que ha quedado reflejada en las diagrafías de velocidad sónica y de gamma ray. Esta ciclicidad a permitido datar la serie pliocena con gran resolución (capítulo 5). Así mismo, se ha extrapolado la posición de las inversiones magnéticas en función del análisis cicloestratigráfico y de la posición de los bioeventos.

Hacia 1070-1090 se produce una reducción significativa del grupo de $G$. margaritae, que desaparece definitivamente hacia $1020 \mathrm{~m}$. En el intervalo entre la última aparición común $(L C O)$ y la desaparición definitiva $(L O)$ del grupo de G. margaritae, se detecta la presencia de individuos de G. margaritae enrollados en sentido dextrógiro y que son particulares de este periodo, habiendo sido registrados en el mismo intervalo en otros sondeos del área estudiada (ver sondeo golfo de Cádiz B2, fig. 6.26A). 


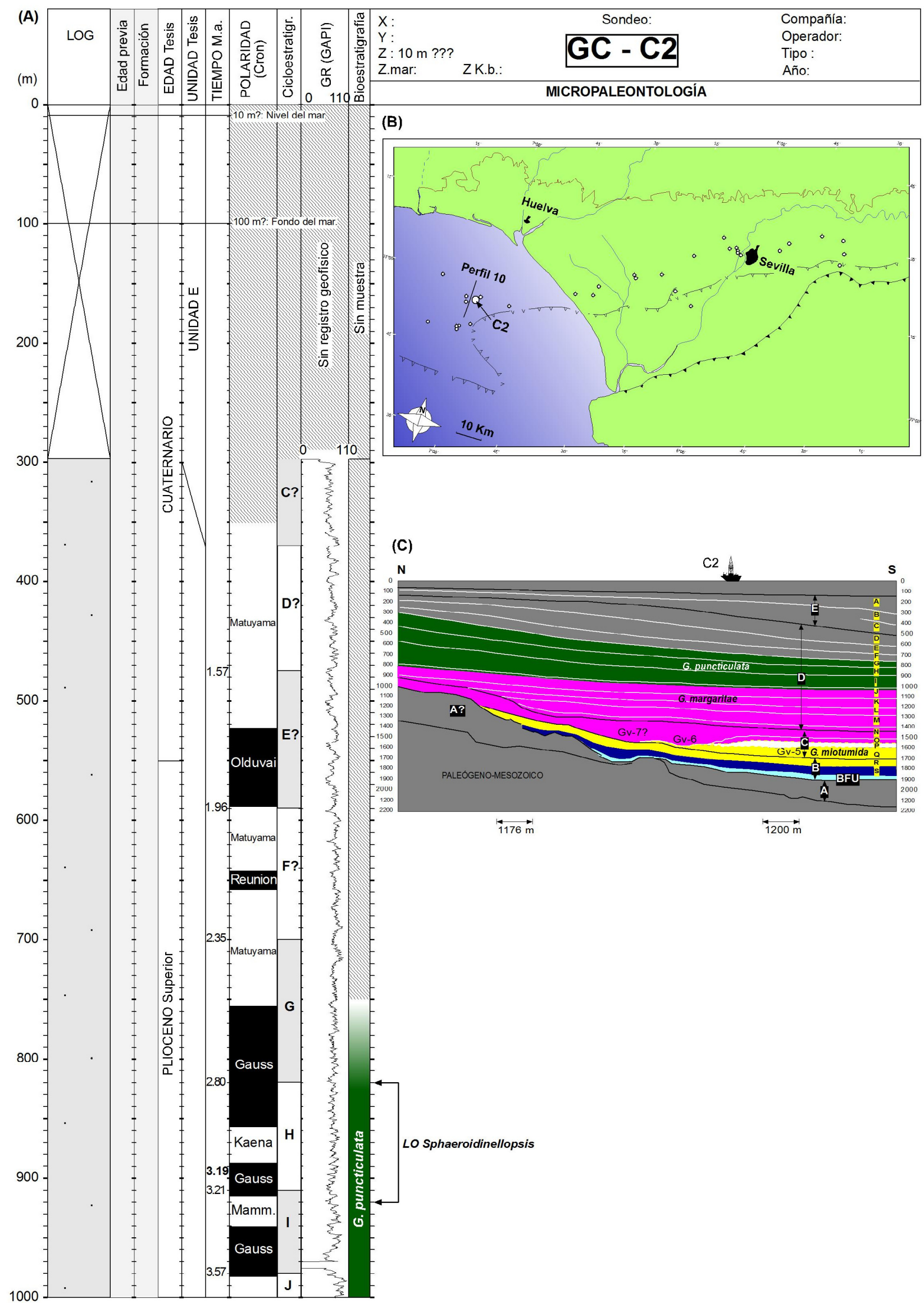

Figura 6.25. Síntesis de los resultados obtenidos en el sondeo Golfo de Cádiz-C2 (C2). Leyenda general en figuras 6.1. y 6.2. (A) Profundidad en metros y columna litológica deducida del registro geofísico y análisis de las muestras. Edades y formaciones utilizadas anteriormente. Edad, unidades litosísmicas, datación, magnetoestratigrafía deducida, unidades cicloestratigráficas, registro de rayos gamma y biozonas propuestas en esta Tesis en función de los bioeventos de plancton calcáreo. Información micropaleontológica, sedimentológica y otros datos de interés. (B) Posición del sondeo C2 y del perfíl sísmico interpretado. (C)Síntesis del perfíl sismobioestratigráfico n ${ }^{\circ} 10$. Proyección del sondeo C2. Profundidad en metros. 


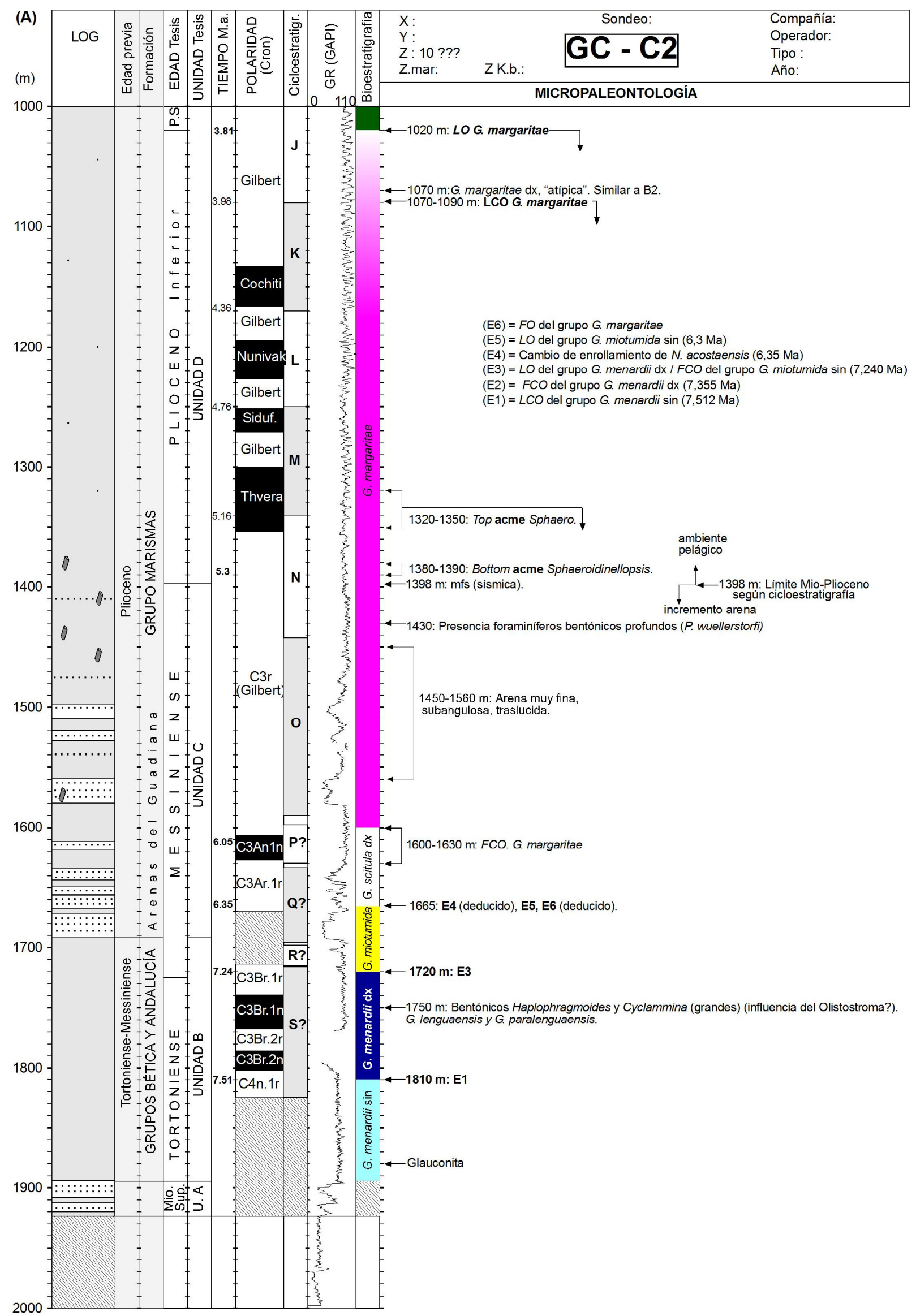

Figura 6.25. Síntesis de los resultados obtenidos en el sondeo Golfo de Cádiz-C2 (C2). Leyenda general en figuras 6.1. y 6.2. (A) Profundidad en metros y columna litológica deducida del registro geofísico y análisis de las muestras. Edades y formaciones utilizadas anteriormente. Edad, unidades litosísmicas, datación, magnetoestratigrafía deducida, unidades cicloestratigráficas, registro de rayos gamma y biozonas propuestas en esta Tesis en función de los bioeventos de plancton calcáreo. Información micropaleontológica, sedimentológica y otros datos de interés. (B) Posición del sondeo C2 y del perfíl sísmico interpretado. (C)Síntesis del perfil sismobioestratigráfico n¹0. Proyección del sondeo C2. Profundidad en metros. 
En torno a la desaparición del grupo de G. puncticulata se interrumpe la sedimentación cíclica anterior. A partir de este momento se ha determinado la presencia de una ciclicidad de orden mayor lo que ha permitido extender el análisis cicloestratigráfico hasta el techo del registro geofísico.

\subsubsection{Golfo de Cádiz B-2 (B2)}

Este sondeo (figura 6.26) se encuentra localizado en el sector norte del golfo de Cádiz y presenta unas características similares a las del sondeo C2 (figura 6.26). Tras una serie carbonatada de edad Eoceno medio a superior, se registra la unidad litosísmica A, que puede distinguirse con claridad en el perfil sismobioestratigráfico (figura 6.26C). La unidad B, comienza con unas arcillas grises, calcáreas y limolíticas que presentan en su base un nivel de glauconita (1845 m). Tras un intervalo con G. menardii sin, se localiza el evento E1 con la desaparición de este grupo. Seguidamente, después de un intervalo con G. menardii dx, se alcanza el límite Tortoniense-Messiniense hacia $1730 \mathrm{~m}$. La biozona del grupo de G. miotumida no termina hasta ser sobrepasado el primer tramo de arenas. Al igual que en los dos sondeos anteriores, el techo de los niveles arenosos está localizado en torno a la $F C O$ de $G$. margaritae y como se aprecia en la columna posee numerosos restos de conchas.

Hacia $1400 \mathrm{~m}$ se observa un incremento significativo de Sphaeroidinellopsis que corresponde a la base del acme de Sphaeroidinellopsis, por lo que se ha considerado como indicador del límite Mio-Plioceno. A partir de dicho límite se registra una serie cíclica de arcillas con mayor o menor contenido limoso, que ha servido para correlacionar toda la serie pliocena con la escala astronómica de tiempo. El análisis cicloestratigráfico basado en los bioeventos de plancton calcáreo ha permitido además deducir la escala magnetoestratigráfica con alto grado de fiabilidad. La desaparición de G. puncticulata se ha localizado hacia $820-800 \mathrm{~m}$. La primera aparición de G. inflata a $670 \mathrm{~m}$ ha sido el último bioevento localizado. La posición de la base del Cuaternario (1.806 Ma según Lourens et al., 1996a) se ha establecido en función del análisis cicloestratigráfico del registro de rayos gamma registrado a techo del sondeo. Sin embargo no ha sido determinada la bioestratigrafía del intervalo, por lo que la posición de la base del Cuaternario no está suficientemente contrastada. Como en el resto de sondeos analizados en el golfo de Cádiz, la ausencia de muestra y de registro geofísico de los últimos centenares de metros a techo del sondeo ha impedido proseguir el análisis bioestratigráfico y cicloestratigráfico. 


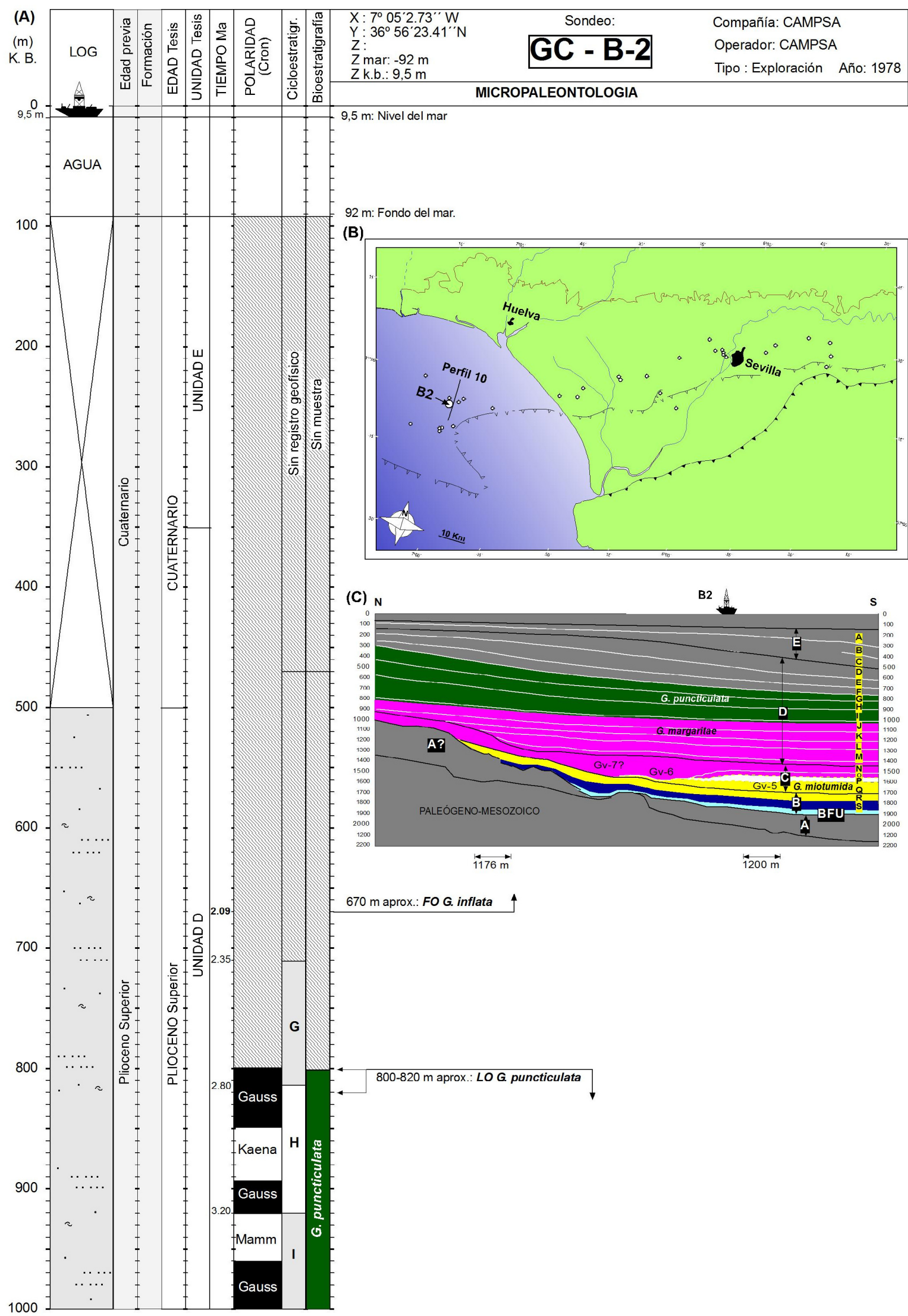

Figura 6.26. Síntesis de los resultados obtenidos en el sondeo Golfo de Cádiz-B2 (B2). Leyenda general en figuras 6.1. y 6.2. (A) Profundidad en metros y columna litológica basada en información facilitada por Repsol. Edades y formaciones utilizadas anteriormente. Edad, unidades litosísmicas, datación, magnetoestratigrafía deducida, unidades cicloestratigráficas y biozonas propuestas en esta Tesis en función de los bioeventos de plancton calcáreo. Información micropaleontológica, sedimentológica y otros datos de interés. (B) Posición del sondeo B2 y del perfíl sismobioestratigráfico $\mathbf{n}^{\circ} 10$. (C) Síntesis del perfil sismobioestratigráfico n ${ }^{\circ} 10$. Proyección del sondeo B2. Profundidad en metros. 


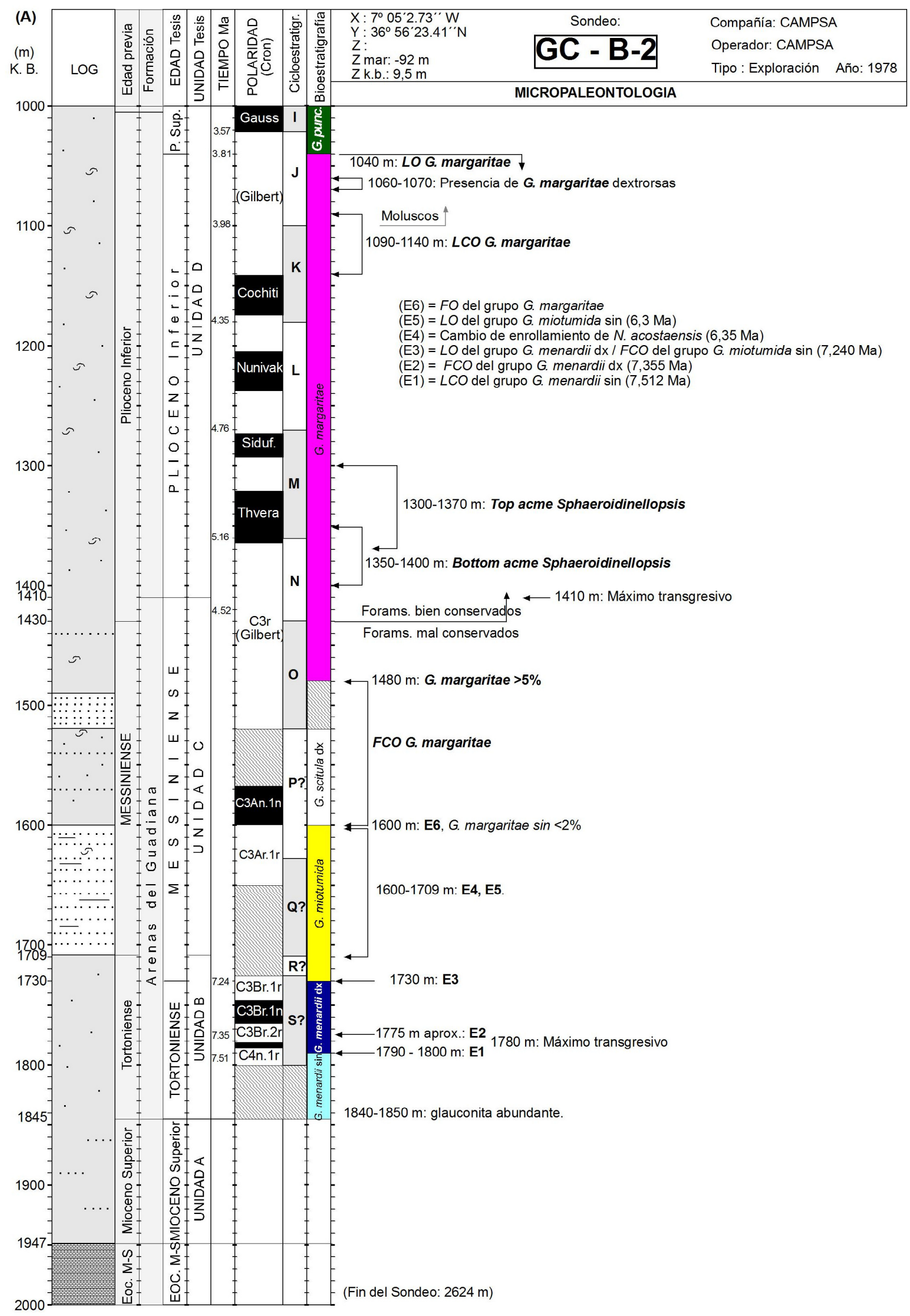

Figura 6.26. Síntesis de los resultados obtenidos en el sondeo Golfo de Cádiz-B2 (B2). Leyenda general en figuras 6.1. y 6.2. (A) Profundidad en metros y columna litológica basada en información facilitada por Repsol. Edades y formaciones utilizadas anteriormente. Edad, unidades litosísmicas, datación, magnetoestratigrafía deducida, unidades cicloestratigráficas y biozonas propuestas en esta Tesis en función de los bioeventos de plancton calcáreo. Información micropaleontológica, sedimentológica y otros datos de interés. (B) Posición del sondeo B2 y del perfíl sismobioestratigráfico $\mathrm{n}^{0}$ 10. (C) Síntesis del perfíl sismobioestratigráfico n ${ }^{0} 10$. Proyección del sondeo B2. Profundidad en metros. 


\subsubsection{Golfo de Cádiz B-4 (B4)}

No se presenta ninguna figura de este sondeo debido a que solo se ha obtenido información parcial de la litología y bioestratigrafía del mismo. Por su posición, podemos considerar la estratigrafía de este sondeo similar a la del sondeo B2. En el sondeo B4 únicamente se ha realizado un chequeo bioestratigráfico. A $1760 \mathrm{~m}$ nos encontramos en un tramo arcilloso dentro de la biozona del grupo de G. menardii dx, que desaparece antes de llegar a $1715 \mathrm{~m}$, donde G. miotumida es muy abundante, pasando por lo tanto en ese intervalo de la biozona del grupo de G. menardii dx, a la biozona del grupo de $G$. miotumida. Entre 1695 y $1675 \mathrm{~m}$ se ha detectado el cambio de enrollamiento de $N$. acostaensis (E4), y entre este intervalo y 1625 m, la desaparición de G. miotumida (E5). Hasta este momento, se han depositado niveles de arena blanca, redondeada. Mientras que desde $1600 \mathrm{~m}$ hasta $1515 \mathrm{~m}$ se aprecia una arena fina localizada en la biozona del grupo de G. margaritae. Por encima de este punto no se ha realizado ningún otro tipo de análisis.

\subsubsection{Atlántida-2 (At-2)}

Atlántida-2 es el sondeo más noroccidental del sector norte del golfo de Cádiz (figura 6.27). Entre $1910 \mathrm{~m}$ y $1685 \mathrm{~m}$ se deposita una potente serie de la unidad litosísmica A, con más de $200 \mathrm{~m}$ de potencia (figura 6.27C). Unos $25 \mathrm{~m}$ después de la discontinuidad de fondo de cuenca (reflector $B F U$, a techo de la unidad litosísmica A), se registra la desaparición de G. menardii sin, que determina el techo de su biozona. A continuación se deposita una serie de arcilla gris claro durante la biozona del grupo de $G$. menardii dx, que no desaparece hasta los $1545 \mathrm{~m}$, donde se localiza el límite TortonienseMessiniense. La localización de este sondeo junto al talud norte del golfo de Cádiz ha condicionado la ausencia de arenas en la biozona del grupo de G. miotumida. Esta biozona está muy condensada respecto a la potencia que presentan los sondeos del sector sur para el mismo intervalo de tiempo. Teniendo en cuenta la distancia al principal área fuente durante el Messiniense inferior (el valle del Guadalquivir), y su elevada posición (1473 m) en relación a los sondeos localizados en el eje de la cuenca (en torno a $1700 \mathrm{~m}$ en los sondeos B2, C2...) es comprensible la falta de depósitos turbidíticos durante el Messiniense inferior. Sin embargo hacia la $F C O$ del grupo de G. margaritae (6.05 Ma) se registra en torno a este sondeo, el último de los aparatos turbidíticos detectado en el área de estudio. Tras este depósito arenoso se localizaría el límite Mio-Plioceno, si bien la proximidad al talud norte ha impedido realizar un análisis cicloestratigráfico en profundidad equivalente al elaborado en el resto de sondeos. 


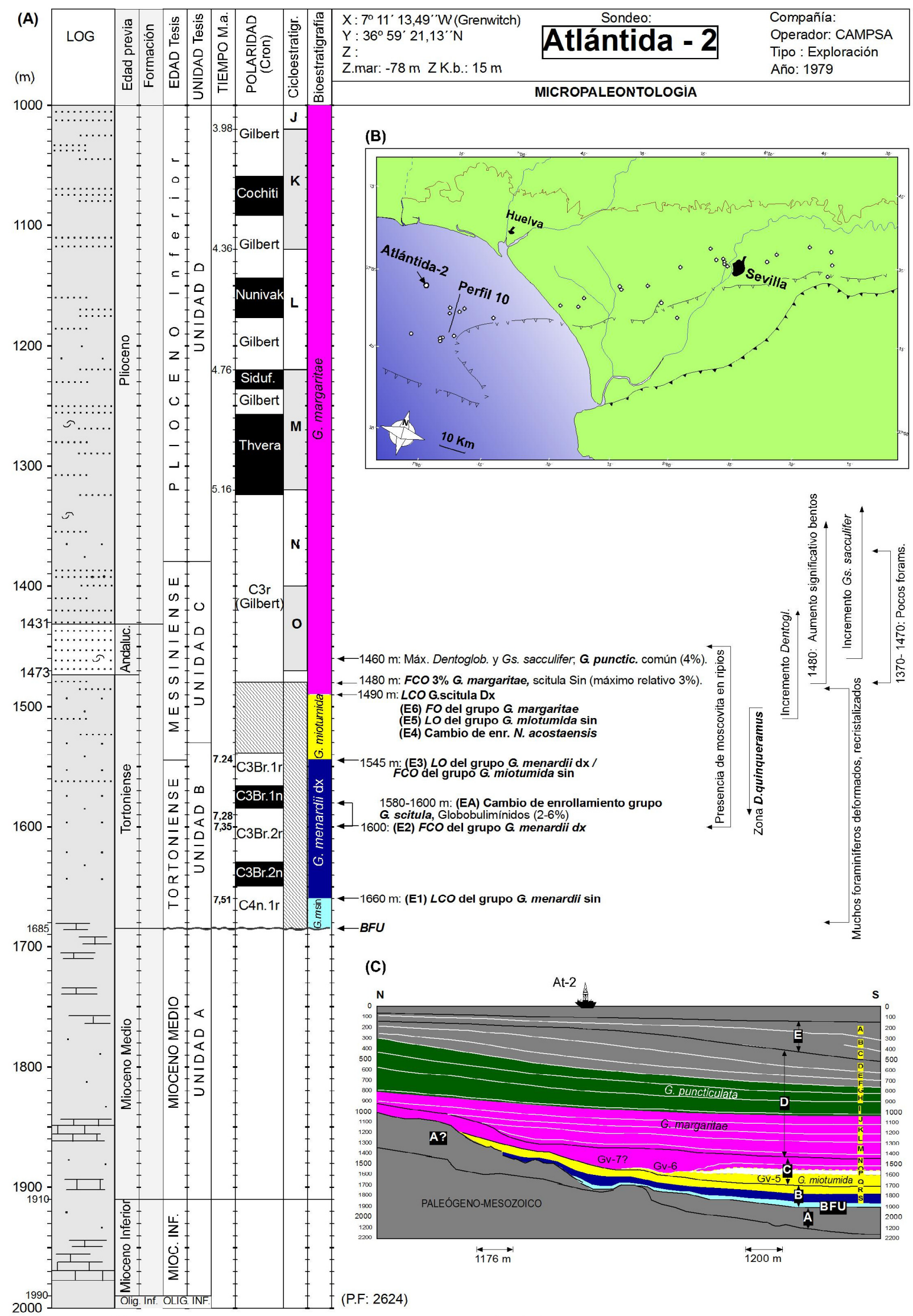

Figura 6.27. Síntesis de los resultados obtenidos en el sondeo Atlántida-2. Leyenda general en figs. 6.1. y 6.2.

(A) Profundidad en metros y columna litológica (Repsol). Edades y formaciones utilizadas anteriormente. Edad, unidades litosísmicas, datación, magnetoestratigrafía deducida, unidades cicloestratigráficas y biozonas propuestas en esta Tesis en función de los bioeventos de plancton calcáreo. Información micropaleontológica, y otros datos de interés. (B) Posición del sondeo Atlántida-2 y del perfíl sísmico interpretado. (C) Síntesis del perfíl sismobioestratigráfico ${ }^{0} 10$. Proyección del sondeo At-2. Profundidad en metros. 


\subsubsection{Golfo de Cádiz C-3 (C3)}

Este sondeo se encuentra localizado en el sector sur del área estudiada en el golfo de Cádiz (figura 6.28). Es el sondeo que presenta una serie mio-pliocena más potente de los estudiados al encontrarse localizado junto al olistostroma en un surco que fue depocentro de la cuenca durante todo el Tortoniense superior (figura 6.28C). El sondeo atraviesa desde $2533 \mathrm{~m}$ a $2218 \mathrm{~m}$ una serie carbonatada, de caliza y caliza margosa que corresponde a la unidad litosísmica A. Tras ella comienza el depósito de la unidad B, con arcillas margosas grises, con intercalaciones de arena fina. Después del evento de desaparición del grupo de G. menardii sin $(2100 \mathrm{~m})$ se registran los eventos E2, EA y E3 previamente al depósito de la secuencia arenosa. En este caso, todos los niveles de arena se depositan en la biozona del grupo de G. miotumida, por lo que son anteriores a 6.3 Ma. Tras la desaparición del grupo de G. miotumida y la FCO del grupo de G. margaritae, se ha localizado el límite Mio-Plioceno gracias al análisis cicloestratigráfico de las diagrafías. Por encima del límite Mio-Plioceno se registra una potente serie arcillosa que registra una ciclicidad de $3^{\text {er }}$ orden que ha permitido correlacionar el registro geofísico con la curva astronómica de tiempo y con el resto de sondeos del golfo de Cádiz (capítulo 5). El último bioevento registrado ha sido la desaparición de G. puncticulata hacia $800 \mathrm{~m}$. Hasta ese punto por lo tanto existe un control bioestratigráfico sobre los ciclos registrados en las diagrafías. La continuación del análisis cicloestratigráfico propuesta por encima de este evento, no está contrastada bioestratigráficamente. En el intervalo que va desde el último bioevento hasta techo del registro de gamma ray, únicamente se ha tenido en cuenta la velocidad de sedimentación media de los grandes ciclos de $1^{\text {er }}$ orden, así como la presencia de ciclos de $2^{\circ}$ orden que presentan varios centenares de metros de registro geofísico a techo del sondeo. Por tanto, la posición de la base del Cuaternario (1.806 Ma, Lourens et al., 1996a) se ha establecido únicamente en función del análisis cicloestratigráfico del registro de rayos gamma. No ha sido determinada la bioestratigrafía del intervalo por lo que la posición de la base del Cuaternario no está suficientemente contrastada. 


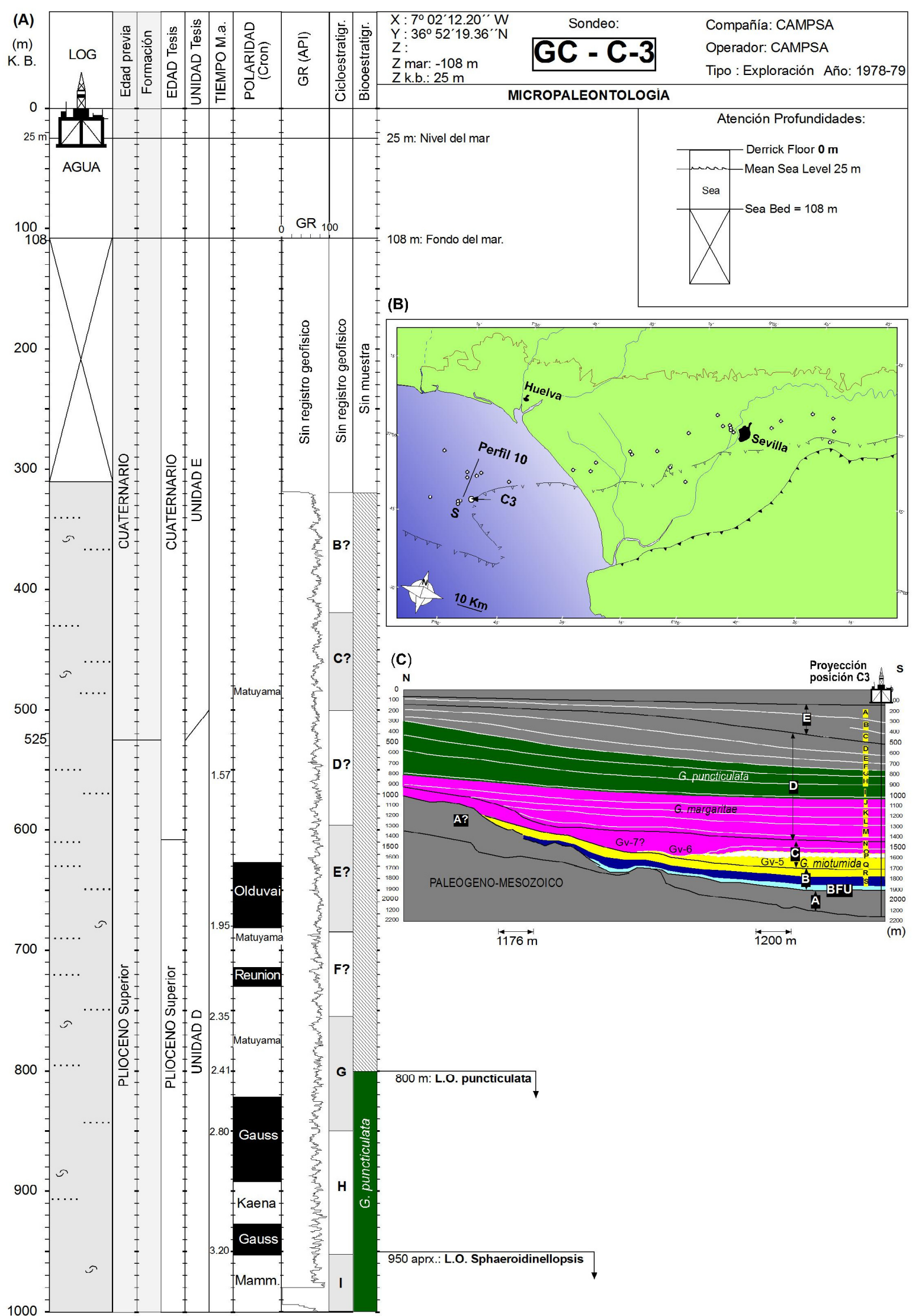

Figura 6.28. Síntesis de los resultados obtenidos en el sondeo Golfo de Cádiz-C3 (C3). Leyenda general en figuras 6.1. y 6.2. (A) Profundidad en metros y columna litológica basada en información facilitada por Repsol. Edades y formaciones utilizadas anteriormente. Edad, unidades litosísmicas, datación, magnetoestratigrafía deducida, registro de rayos gamma, unidades cicloestratigráficas y biozonas propuestas en esta Tesis en función de los bioeventos de plancton calcáreo. Información micropaleontológica, sedimentológica y otros datos de interés. (B) Posición del sondeo C3 y del perfíl sísmico. (C) Síntesis del perfíl sismobioestratigráfico n ${ }^{0} 10$. Proyección del sondeo C3. 


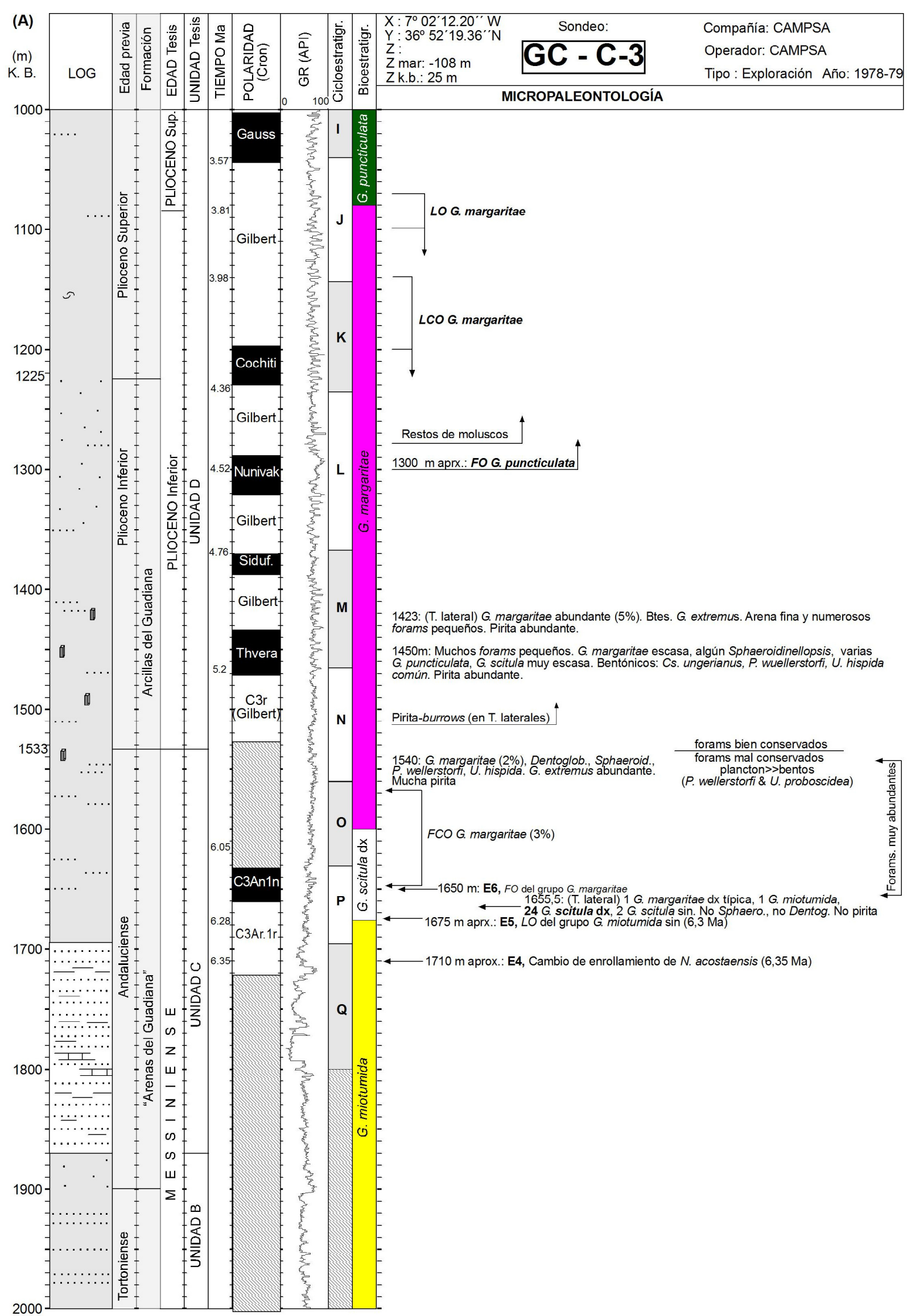

Figura 6.28 (Continuación). Síntesis de los resultados obtenidos en el sondeo Golfo de Cádiz-C3 (C3). Leyenda general en figuras 6.1. y 6.2. (A) Profundidad en metros y columna litológica basada en información facilitada por Repsol. Edades y formaciones utilizadas anteriormente. Edad, unidades litosísmicas, datación, magnetoestratigrafía deducida, registro de rayos gamma, unidades cicloestratigráficas y biozonas propuestas en esta Tesis en función de los bioeventos de plancton calcáreo. Información micropaleontológica, sedimentológica y otros datos de interés. (B) Posición del sondeo C3 y perfíl sísmico. (C) Síntesis del perfíl sismobioestratigráfico n⿳10. Proyección del sondeo. 


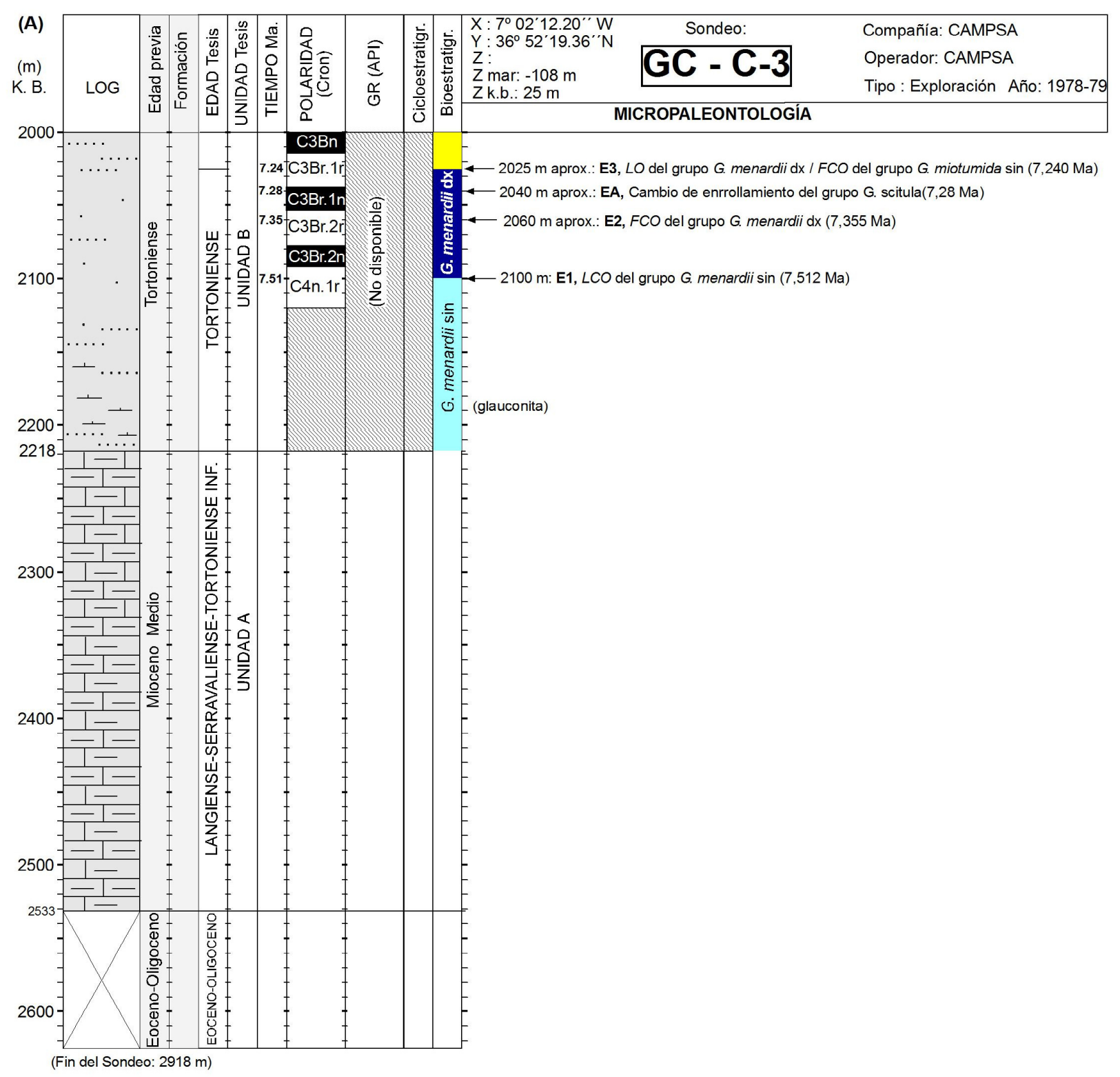

Figura 6.28 (Continuación). Síntesis de los resultados obtenidos en el sondeo Golfo de Cádiz-C3 (C3). Leyenda general en figuras 6.1. y 6.2. (A) Profundidad en metros y columna litológica basada en información facilitada por Repsol. Edades y formaciones utilizadas anteriormente. Edad, unidades litosísmicas, datación, magnetoestratigrafía deducida, registro de rayos gamma, unidades cicloestratigráficas y biozonas propuestas en esta Tesis en función de los bioeventos de plancton calcáreo. Información micropaleontológica, sedimentológica y otros datos de interés. (B) Posición del sondeo C3 y perfíl sísmico. (C) Síntesis del perfíl sismobioestratigráfico nº 10. Proyección del sondeo. 


\subsubsection{Golfo de Cádiz B-6 (B6)}

El sondeo B6 se encuentra en el sector sur de la cuenca (figura 6.29). Después de la serie del Mioceno superior atravesada desde $2040 \mathrm{~m}$ a $1910 \mathrm{~m}$, perteneciente a la unidad litosísmica A (figura 6.29C), se deposita una serie arcillosa, de color gris, calcárea, limolítica, con ligeras pasadas de arenas de cuarzo de grano fino. En este intervalo se han localizado los eventos E2 y EA, en los primeros $100 \mathrm{~m}$ de la unidad B. El límite Tortoniense-Messiniense $(1780 \mathrm{~m})$ se localiza unos 150 metros por debajo del principal nivel de arena. Teniendo en cuenta que los primeros niveles de arena en el alto Guadalquivir se registran contemporáneamente al límite Tortoniense-Messiniense, entendemos que el desarrollo de los niveles de arena messinienses en el golfo de Cádiz son ligeramente más modernos que aquellos. En concreto el nivel de arena del sondeo B6 presenta a techo el cambio de enrollamiento de Neogloboquadrina acostaensis (E4), de forma que se desarrolló antes de 6.35 Ma.

En la figura 6.29D se muestra el porcentaje relativo de globorotálidos donde podemos observar la falsa presencia de G. miotumida incluso por debajo de la biozona del grupo de G. menardii dx. Esto refleja nuevamente el peligro que supone en muestras de tipo ripio, la datación basada en eventos de aparición de microfósiles. Por otro lado después de la desaparición de G. miotumida (E5), se observa la reducción significativa del grupo de G. scitula dx, que supone el techo de la biozona del mismo nombre. Nuevamente, la primera aparición de G. puncticulata se encuentra desplazada frente a la posición real. Esta observación ha sido posible gracias al calibrado astronómico de los ciclos sedimentarios de $3^{\text {er }}$ orden que aparecen a partir del límite Mio-Plioceno (1355 m aproximadamente). Este calibrado a permitido además la deducción de la posición de las inversiones magnéticas establecidas con un alto grado de precisión gracias al análisis cicloestratigráfico. En el gráfico adjunto podemos observar la relación de foraminíferos planctónicos respecto a los bentónicos, sufriendo estos últimos un incremento significativo en torno a la $F C O$ del grupo de G. margaritae. También observamos el porcentaje de neogloboquadrínidos respecto al total de foraminíferos planctónicos, que nos permite establecer la posición del evento E4 hacia $1545 \mathrm{~m}$, momento en el que las formas dextrógiras pasan a dominar la asociación de neogloboquadrínidos.

Por encima de la desaparición de Sphaeroidinellopsis (870-890 m) con una edad de 3.19 Ma, no se ha podido establecer la desaparición del grupo de G. puncticulata por falta de muestras, aunque si se ha observado una disminución progresiva de este taxón que debería culminar hacia $750 \mathrm{~m}$. Es a partir de ese punto cuando se pierde también la ciclicidad de $3^{\text {er }}$ orden observada desde el límite Mio-Plioceno, en el registro geofísico. 


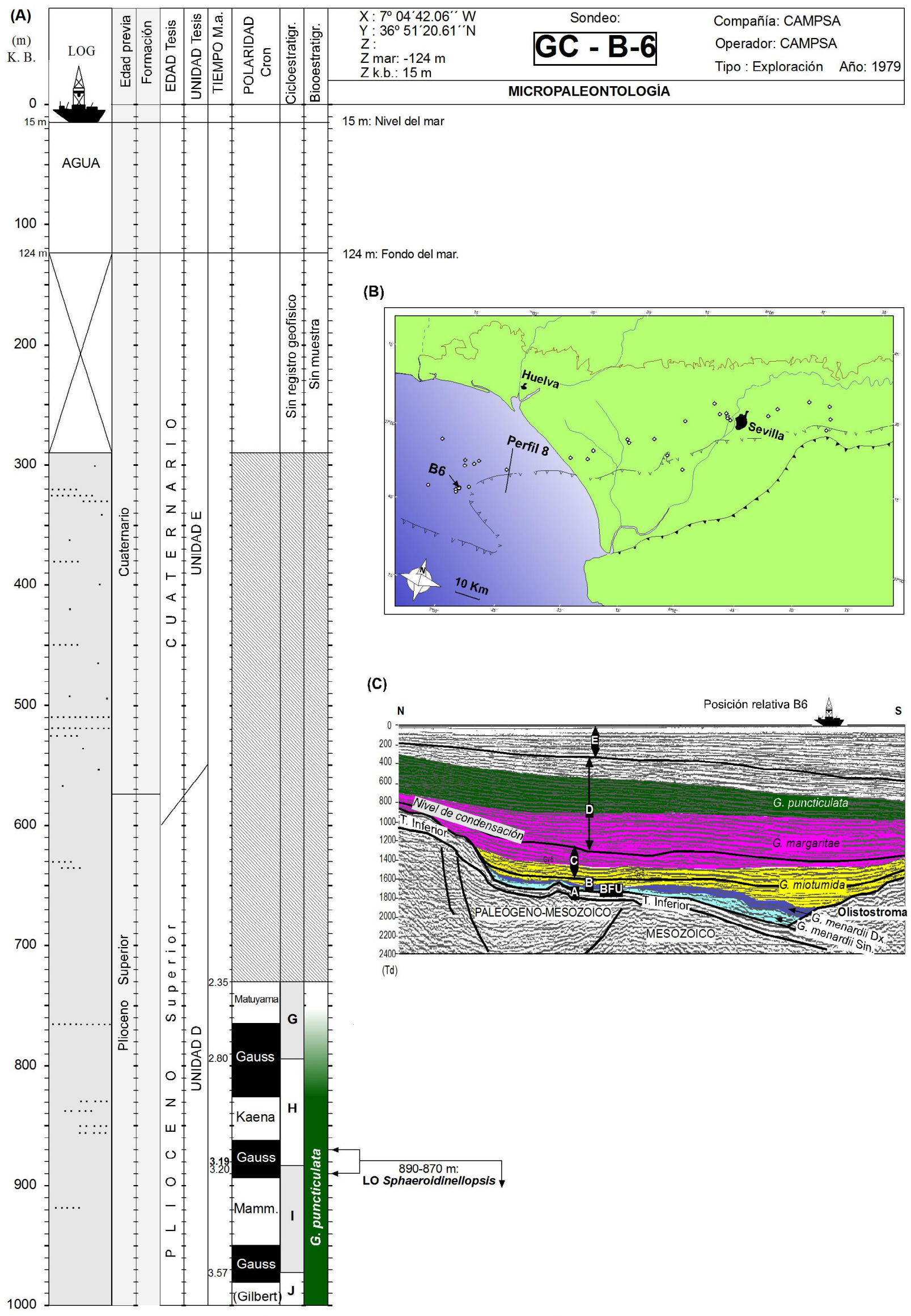

Figura 6.29. Síntesis de los resultados obtenidos en el sondeo Golfo de Cádiz-B6 (B6). Leyenda general en figs. 6.1. y 6.2. (A) Profundidad en metros y columna litológica basada en información facilitada por Repsol. Edades y formaciones utilizadas anteriormente. Edad, unidades litosísmicas, datación, magnetoestratigrafía deducida, unidades cicloestratigráficas y biozonas propuestas en esta Tesis en función de los bioeventos de plancton calcáreo. Información micropaleontológica, sedimentológica y otros datos de interés. (B) Localización del sondeo B6 y del perfil sísmico interpretado. (C) Perfil sismobioestratigrăfico $\mathrm{n}^{\circ} 8$ y proyección de una posición equivalente a la del sondeo B6. En su posición real no atraviesa el olistostroma. (Td) = Tiempo doble. Sísmica original en Riaza y Martínez del Olmo, 1996. (D) Porcentaje relativo de globorotálidos, relacción de foraminíferos planctónicos respecto a bentónicos y porcentaje de neogloboquadrínidos respecto al total de foraminíferos planctónicos. 


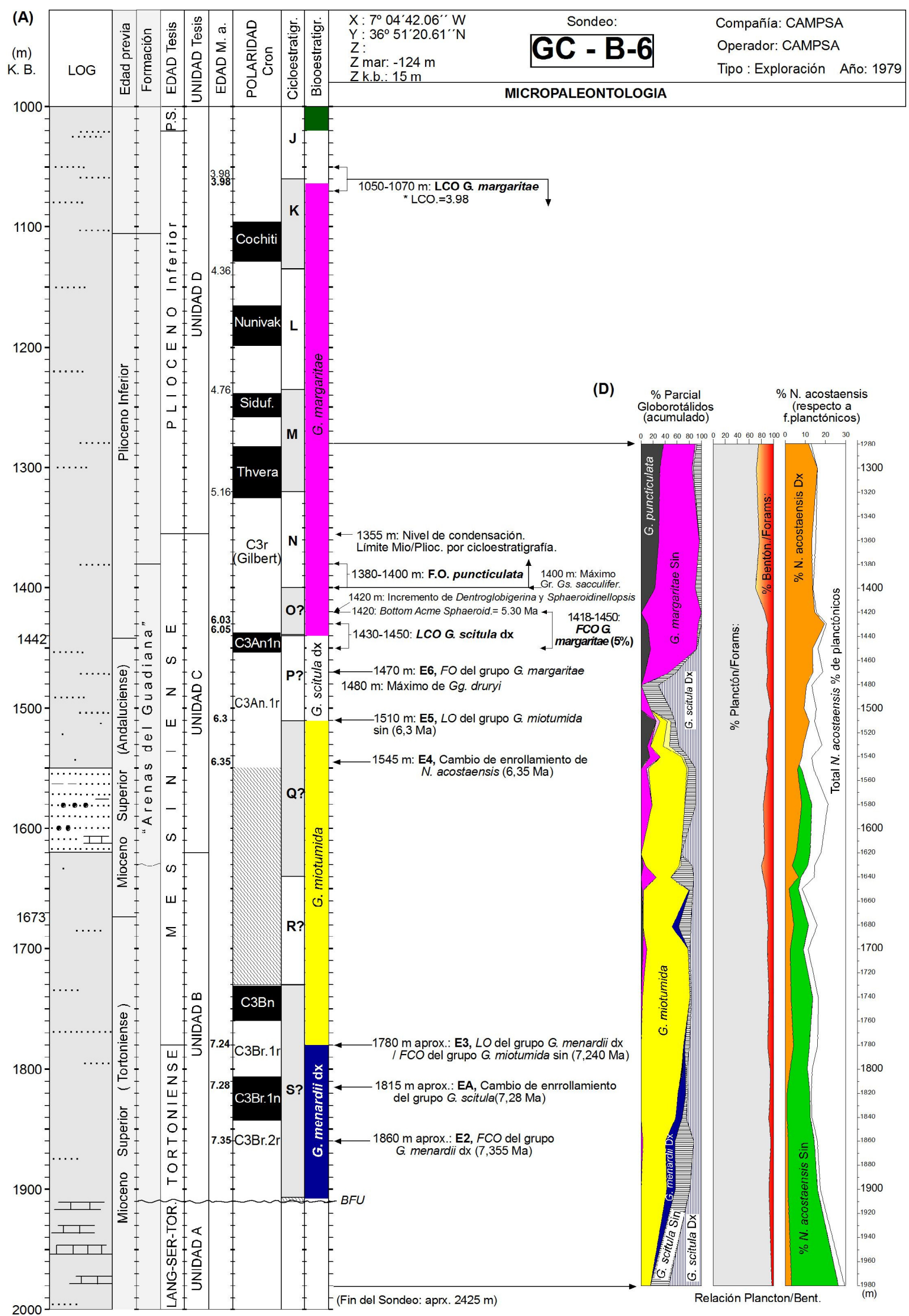

Figura 6.29 (Continuación). Síntesis de los resultados obtenidos en el sondeo B6. Leyenda general en figs. 6.1. y 6.2. (A) Profundidad en metros y columna litológica basada en información facilitada por Repsol. Edades y formaciones utilizadas anteriormente. Edad, unidades litosísmicas, datación, magnetoestratigrafía deducida, unidades cicloestratigráficas y biozonas propuestas en esta Tesis en función de los bioeventos de plancton calcáreo. Información micropaleontológica, sedimentológica y otros datos de interés. (B) Localización del sondeo B6 y del perfíl sísmico interpretado. (C) Perfil sismobioestratigráfico $\mathrm{n}^{0} 8$ y proyección de una posición equivalente a la del sondeo B6. En su posición real no atraviesa el olistostroma. (Td) = Tiempo doble. Sísmica original en Riaza y Martínez del Olmo, 1996. (D) Porcentaje relativo de globorotálidos, relacción de foraminíferos planctónicos respecto a bentónicos y porcentaje de neogloboquadrínidos respecto al total de foraminíferos planctónicos. 


\subsubsection{Golfo de Cádiz B-3 (B3)}

Se encuentra situado en el sector sur de la cuenca, junto al sondeo B6 (figura 6.30). La unidad A, se desarrolla entre 1850-1757 m con una serie de caliza blanquecina, compacta, con intercalaciones de arcilla y arena. Después, de la transgresión del Tortoniense superior, ya en la unidad litosísmica B, se deposita una serie arcillosa, gris, limolítica, con pasadas de arena fina. A la presencia de glauconita en los primeros metros de la unidad B, se suceden rápidamente la desaparición del grupo de globorotálidos $G$. menardii sin (E1), la aparición abundante del grupo de G. menardii dx (E2), y su rápida desaparición (E3) a favor del grupo de G. miotumida que hasta más de 50 metros por encima del paquete de arenas messinienses no desaparece (E5). También el cambio de enrollamiento de Neogloboquadrina acostaensis (E4) se produce unos metros por encima del techo del paquete arenoso. De esta forma, parece que el nivel de arena del sondeo B3, presenta la misma edad que el del sondeo B6 y el de Atlántida-3, e incluso a las arenas del sondeo C3. En todos estos sondeos del sector sur del golfo de Cádiz, se ha localizado fundamentalmente un paquete principal de arena Messiniense. Este aparato turbidítico común es anterior al detectado en los sondeos del área norte del golfo de Cádiz. Los sondeos del área sur se caracterizan por la ausencia de los últimos niveles de arena (desarrollaods en la biozona del grupo de G. margaritae) y por presentar un nivel de concentración de foraminíferos inmediatamente anterior al límite Mio-Plioceno.

La desaparición de $G$. puncticulata a $620 \mathrm{~m}$ supone el último bioevento identificado. A partir de dicha profundidad, y hacia techo del sondeo, se pierde la ciclicidad de alta frecuencia ( $3^{\mathrm{er}}$ orden) que desde el límite Mio-Plioceno, ha servido para correlacionar este sondeo con la curva astronómica de tiempo y con el resto de sondeos del golfo de Cádiz (capítulo 5). 


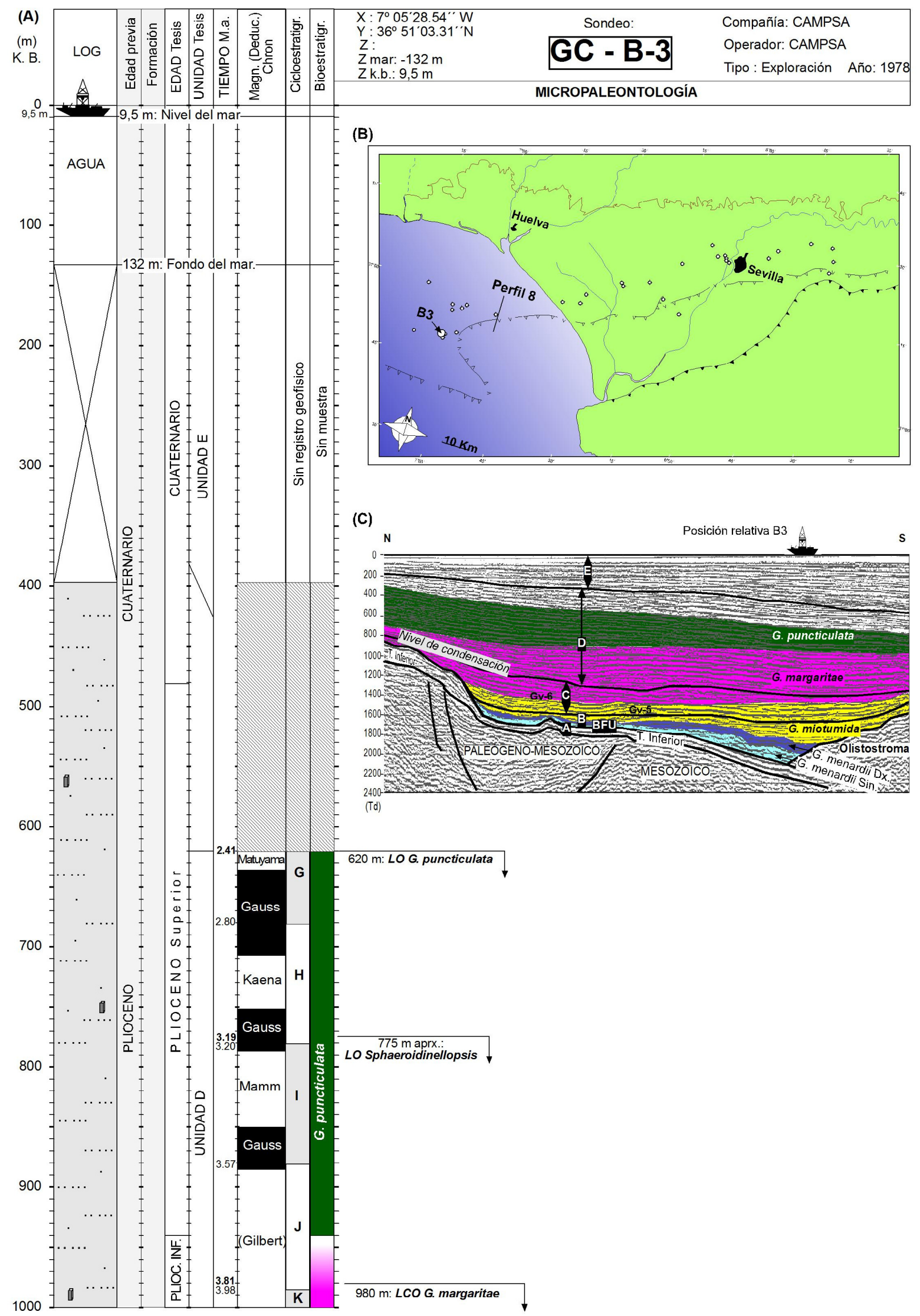

Figura 6.30. Síntesis de los resultados obtenidos en el sondeo Golfo de Cádiz-B3 (B3). Leyenda general en figs. 6.1. y 6.2. (A) Profundidad en metros y columna litológica basada en información facilitada por Repsol. Edades y formaciones utilizadas anteriormente. Edad, unidades litosísmicas, datación, magnetoestratigrafía deducida, unidades cicloestratigráficas y biozonas propuestas en esta Tesis en función de los bioeventos de plancton calcáreo. Información micropaleontológica, sedimentológica y otros datos de interés. (B) Posición del sondeo B3 y del perfíl sísmico interpretado. (C) Perfil sismobioestratigráfico $\mathbf{n}^{0} 8$. Proyección del sondeo B3 (en su posición real no atraviesa el olistostroma). (Td) $=$ Tiempo doble (Sísmica original en Riaza y Martínez del Olmo, 1996). 


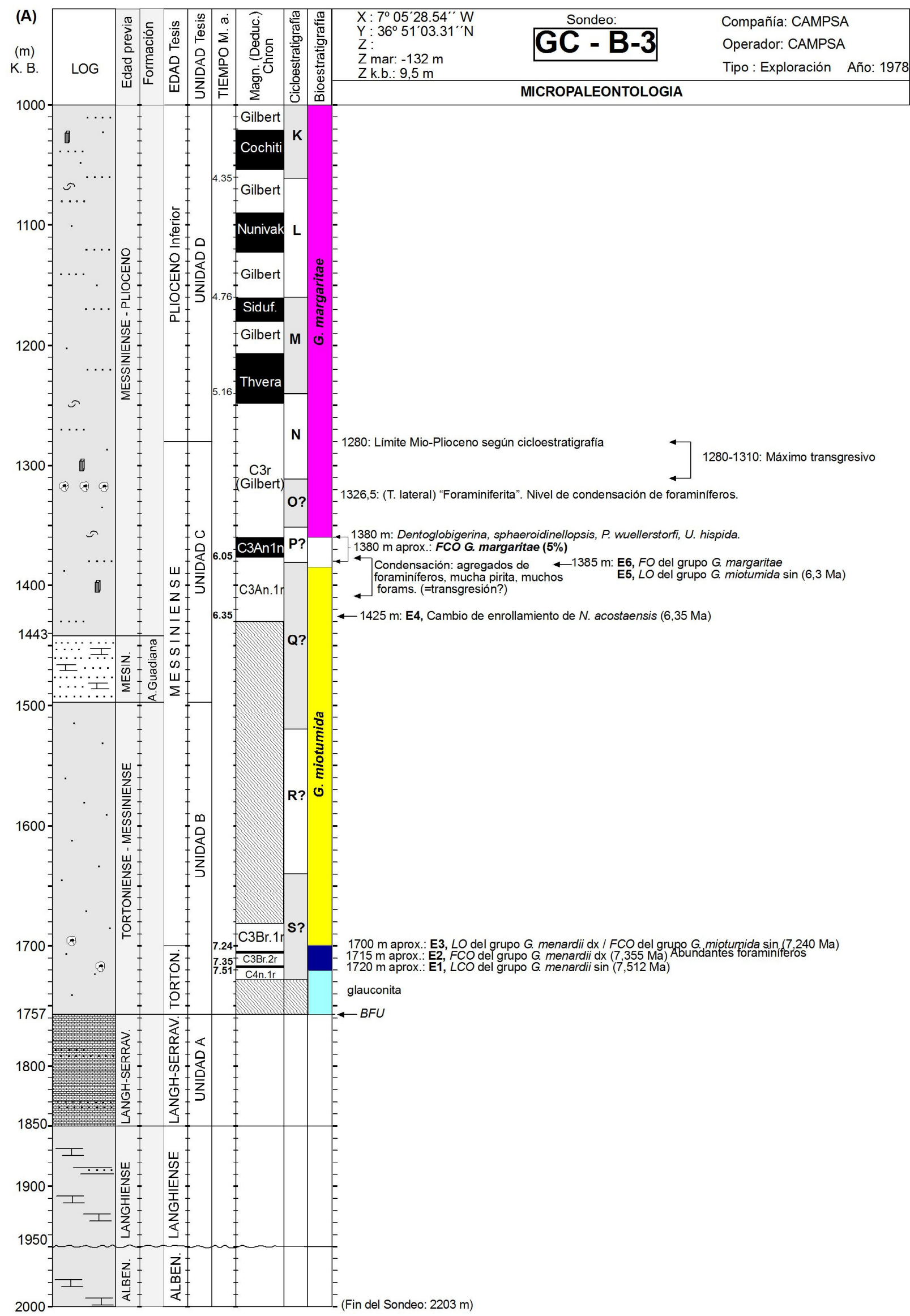

Figura 6.30 (Continuación). Síntesis de los resultados obtenidos en el sondeo B3. Leyenda general en figs. 6.1. y 6.2. (A) Profundidad y columna litológica basada en información facilitada por Repsol. Edades y formaciones utilizadas anteriormente. Edad, unidades litosísmicas, datación, magnetoestratigrafía deducida, unidades cicloestratigráficas y biozonas propuestas en esta Tesis. Información micropaleontológica, sedimentológica y otros datos de interés. (B) Posición del sondeo B3 y del perfíl sísmico interpretado. (C) Perfíl sismobioestratigráfico $\mathbf{n}^{\circ}$ 8. Proyección del sondeo B3 (en su posición real no atraviesa el olistostroma). (Td) = Tiempo doble (Sísmica original: Riaza y Martínez del Olmo, 1996). 


\subsubsection{Atlántida-3 (At-3)}

Localizado en el sector sur de la cuenca, presenta características similares a las de los sondeos B3 y B6, todos ellos muy próximos (figura 6.31). Entre $2115 \mathrm{~m} 1746 \mathrm{~m}$ se deposita la unidad litosísmica A (figura 6.31C), compuesta de caliza blanca, cretosa y arcillas compactas. Seguidamente se deposita una arcilla gris donde desaparece $G$. menardii sin. Ya en la biozona de $G$. miotumida se registran pasadas de microconglomerado hasta llegar a al principal nivel arenoso, que como en los sondeos B3 y B6, registra el cambio de enrollamiento de N. acostaensis a techo del mismo. Poco después se registra la desaparición del grupo de G. miotumida. Tras un periodo con escaso aporte, reflejado por una concentración de foraminíferos, llegamos al límite MioPlioceno, deducido mediante cicloestratigrafía (capítulo 5) y que estaría localizado hacia $1320 \mathrm{~m}$. Tras el límite Mio-Plioceno, se individualizan los ciclos sedimentarios de $3^{\text {er }}$ orden formados por arcillas más o menos ricas en limo, que perduran hasta unos 100 metros por encima de la desaparición de Sphaeroidinellopsis y de G. altispira, últimos bioeventos determinados. 


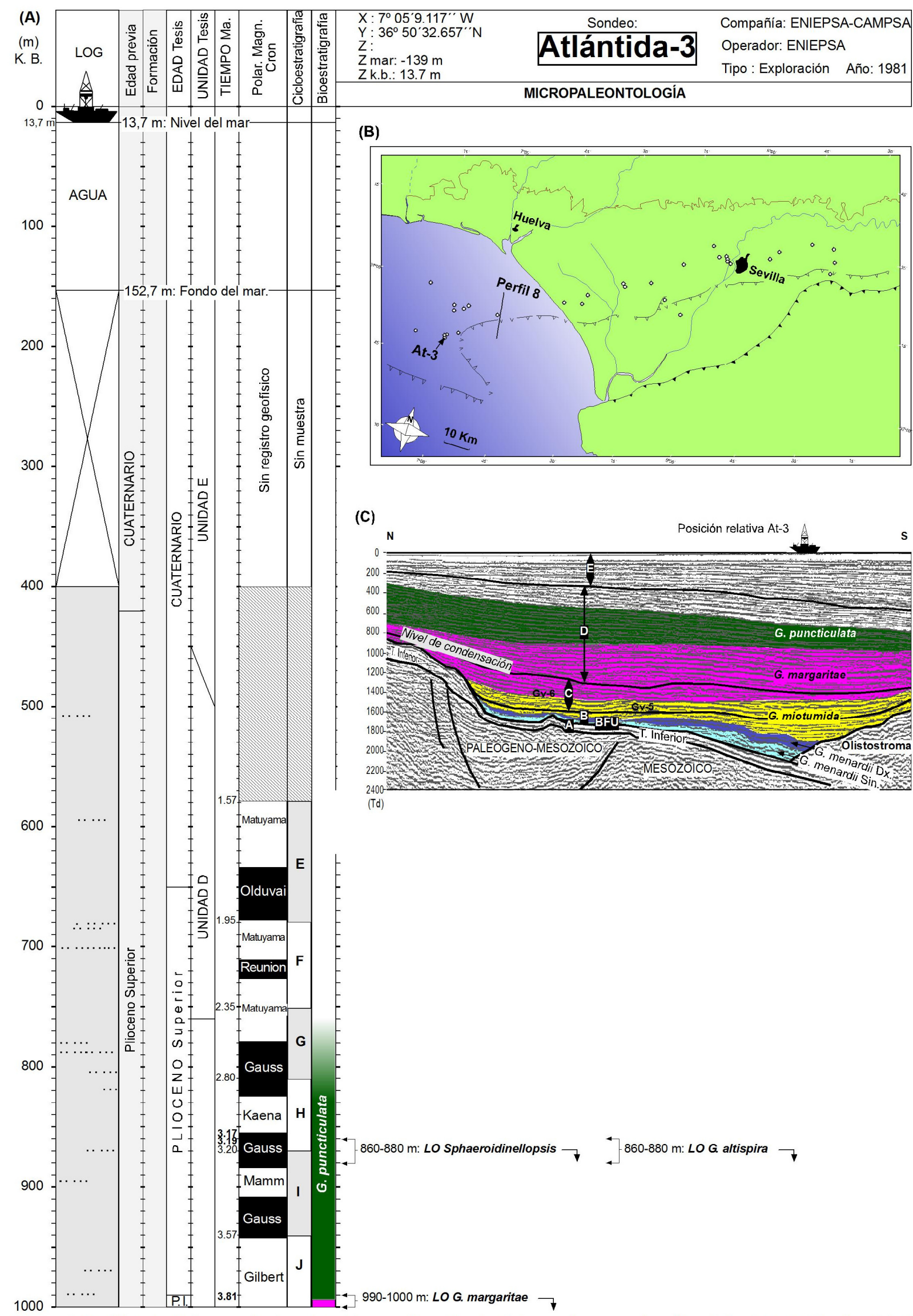

Figura 6.31. Síntesis de los resultados obtenidos en el sondeo At-3. Leyenda general en figs. 6.1. y 6.2. (A) Profundidad en metros y columna litológica (basado documentación facilitada por Repsol). Edades y formaciones utilizadas anteriormente. Edad, unidades litosísmicas, datación, magnetoestratigrafía deducida, unidades cicloestratigráficas y biozonas propuestas en esta Tesis en función de los bioeventos de plancton calcáreo. Información micropaleontológica, sedimentológica y otros datos de interés. (B) Posición del sondeo Atántida-3 y del perfíl sísmico interpretado. (C) Perfíl sismobioestratigráfico n ${ }^{\circ}$. Proyección del sondeo At-3. En su posición real no atraviesa el olistostroma. (Td) $=$ Tiempo doble. Desarrollado sobre perfil sísmico original de Maldonado et al., 1999) 


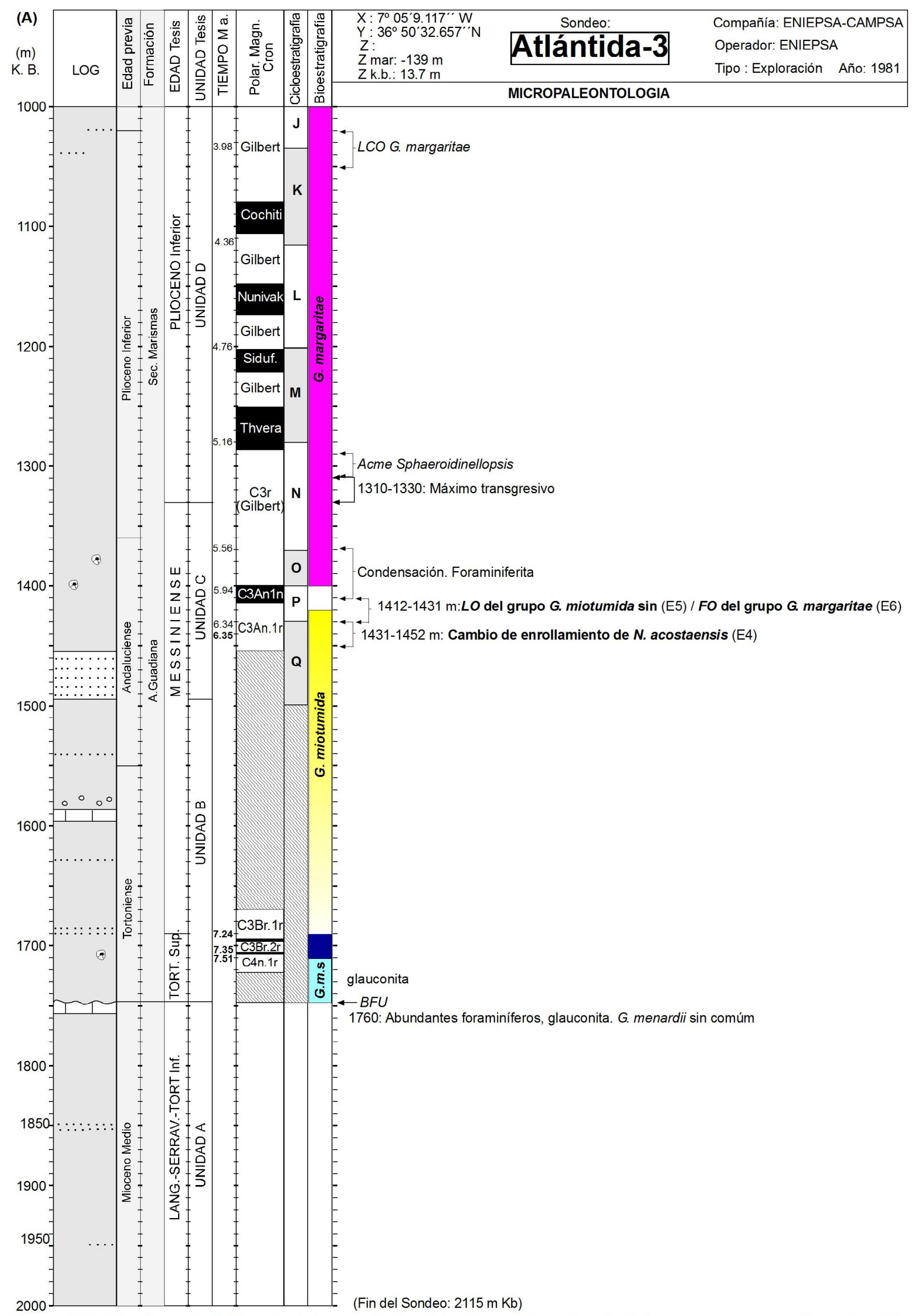

Figura 6.31 (Continuación). Síntesis de los resultados obtenidos en el sondeo At-3. Leyenda general en figs. 6.1. y 6.2. (A) Profundidad en metros y columna litológica (basado documentación facilitada por Repsol). Edades y formaciones utilizadas anteriormente. Edad, unidades litosísmicas, datación, magnetoestratigrafía deducida, unidades cicloestratigráficas y biozonas propuestas en esta Tesis en función de los bioeventos de plancton calcáreo. Información micropaleontológica, sedimentológica y otros datos de interés. (B) Posición del sondeo Atántida-3 y del perfíl sísmico interpretado. (C) Perfíl sismobioestratigráfico $\mathbf{n}^{\mathbf{0}} 8$. Proyección del sondeo At-3. En su posición real no atraviesa el olistostroma. $($ Td) $=$ Tiempo doble. Desarrollado sobre perfil sísmico original de Maldonado et al., 1999). 


\subsubsection{Golfo de Cádiz 6x1 (6x1)}

Este sondeo está localizado al SW de la zona de estudio (figura 6.32). Los primeros metros muestreados contienen abundantes arenas con escasos ejemplares del grupo de G. miotumida sin, por lo que los dos intervalos arenosos estarían desarrollados en la biozona de este grupo de globorotálidos. Tras el intervalo de arena superior, la velocidad de sedimentación se reduce rápidamente. Hacia $1320 \mathrm{~m}$, desaparece $G$. miotumida y comienza a ser abundante el grupo de G. margaritae sin, pasando rápidamente a la biozona de este grupo con una biozona del grupo de G. scitula dx que pasa desapercibida. Tras la FCO del grupo de G. margaritae, en torno al límite MioPlioceno, comienzan a definirse ciclos sedimentarios de alta frecuencia ( $3^{\text {er }}$ orden). Estos ciclos una vez calibrados con la curva astronómica han permitido datar con precisión el Plioceno inferior. Tras la desaparición del grupo de G. margaritae, pasamos a la biozona del grupo de G. puncticulata, donde se detecta la desaparición $(L O)$ G. altispira y de Sphaeroidinellopsis hacia 780-800 m. Poco después, la ciclicidad de alta frecuencia $\left(3^{\text {er }}\right.$ orden) se atenúa. No se ha localizado con precisión el techo de la biozona del grupo de $G$. puncticulata, si bien parece desaparecer progresivamente hacia techo del ciclo $\mathrm{G}$ de baja frecuencia ( 1 er orden). Los $200 \mathrm{~m}$ superiores de sondeo, no fueron muestreados al quedar fuera de los objetivos del proyecto de Tesis Doctoral, por lo que quedaría pendiente su estudio y el desarrollo de la bioestratigrafía para este intervalo. El estudio cicloestratigráfico, con la calibración astronómica de los ciclos geofísicos ha permitido deducir una amplia escala magnetoestratigráfica para este sondeo entre 5.2 y $2.8 \mathrm{Ma}$.

La peculiaridad de este sondeo reside en su localización geográfica sobre uno de los diapiros característicos de la zona central del golfo de Cádiz. En la reconstrucción en tres dimensiones de la cuenca que se presenta en el capítulo 7, se aprecia la posición de este sondeo sobre este diapiro y el efecto que provoca sobre los sondeos del sector sur del golfo de Cádiz. La ascensión de este diapiro pudo producirse inmediatamente después del depósito de las arenas messinienses en el sector sur de la cuenca. La elevación diapírica del sector suroccidental del área estudiada probablemente limitó la influencia de los últimos depósitos turbidíticos, que si aparecen en el área norte del golfo de Cádiz. 


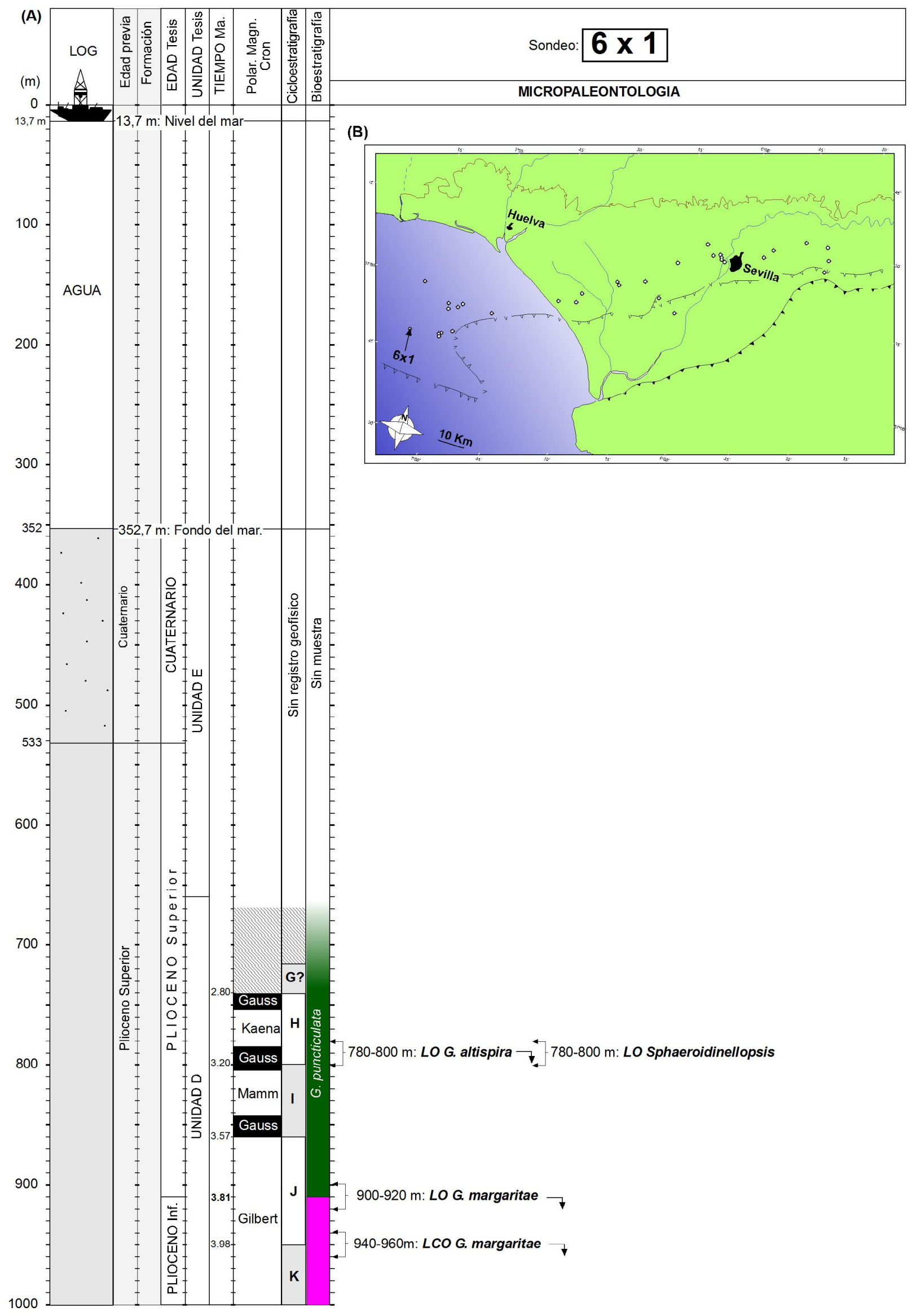

Figura 6.32. Síntesis de los resultados obtenidos en el sondeo 6x1. Leyenda general en figs. 6.1. y 6.2. (A) Profundidad en metros y columna litológica (basado en el informe del ITGE, 1990). Edades y formaciones utilizadas anteriormente. Edad, unidades litosísmicas, datación, magnetoestratigrafía deducida, unidades cicloestratigráficas y biozonas propuestas en esta Tesis en función de los bioeventos de plancton calcáreo. Información micropaleontológica, sedimentológica y otros datos de interés. (B) Posición del sondeo 6x1. 


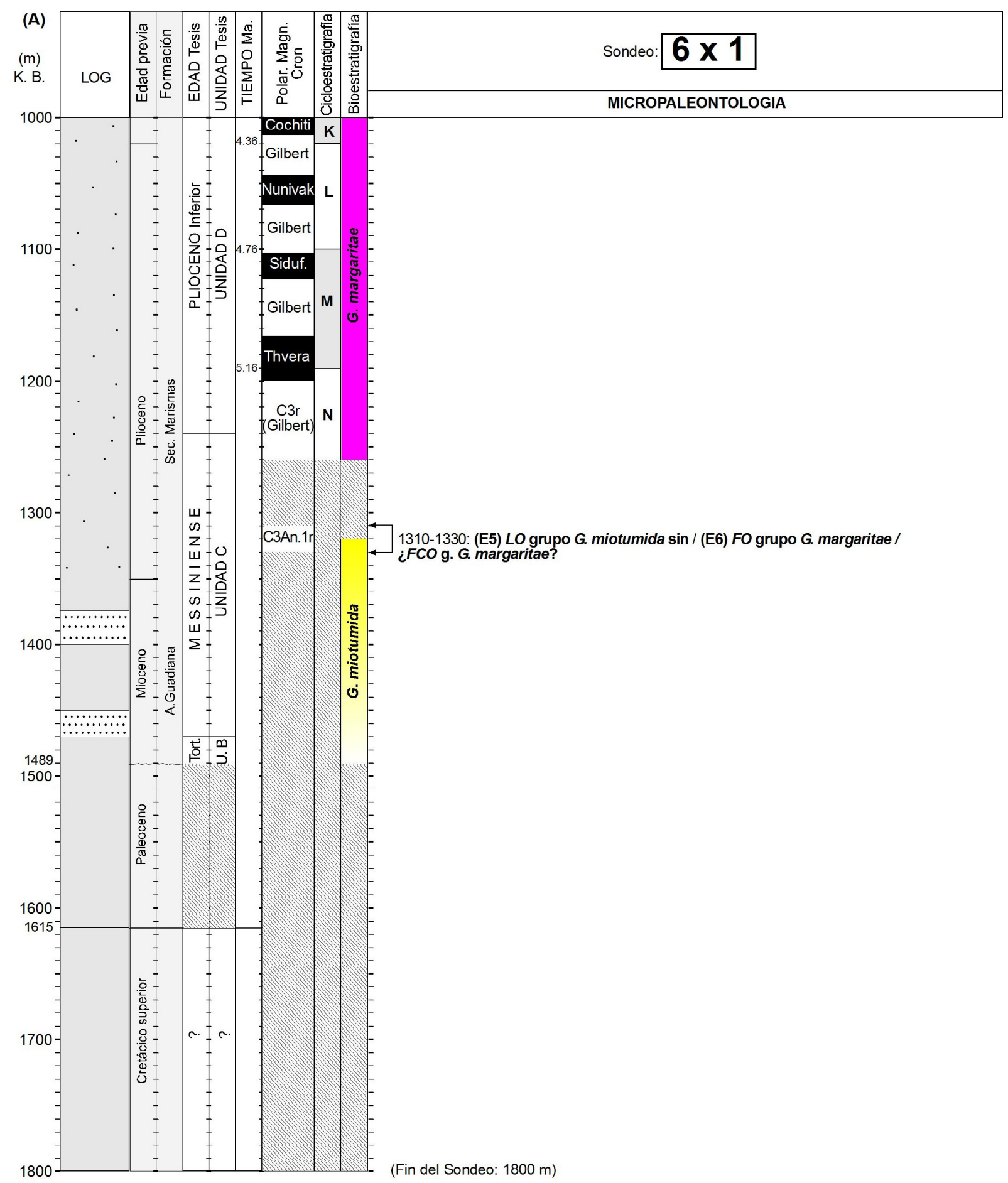

Figura 6.32 (Continuación). Síntesis de los resultados obtenidos en el sondeo 6x1. Leyenda general en figs. 6.1. y 6.2. (A). Profundidad en metros y columna litológica (basado en el informe del ITGE, 1990). Edades y formaciones utilizadas anteriormente. Edad, unidades litosísmicas, datación, magnetoestratigrafía deducida, unidades cicloestratigráficas y biozonas propuestas en esta Tesis en función de los bioeventos de plancton calcáreo. Información micropaleontológica, sedimentológica y otros datos de interés. (B) Localización del sondeo. 


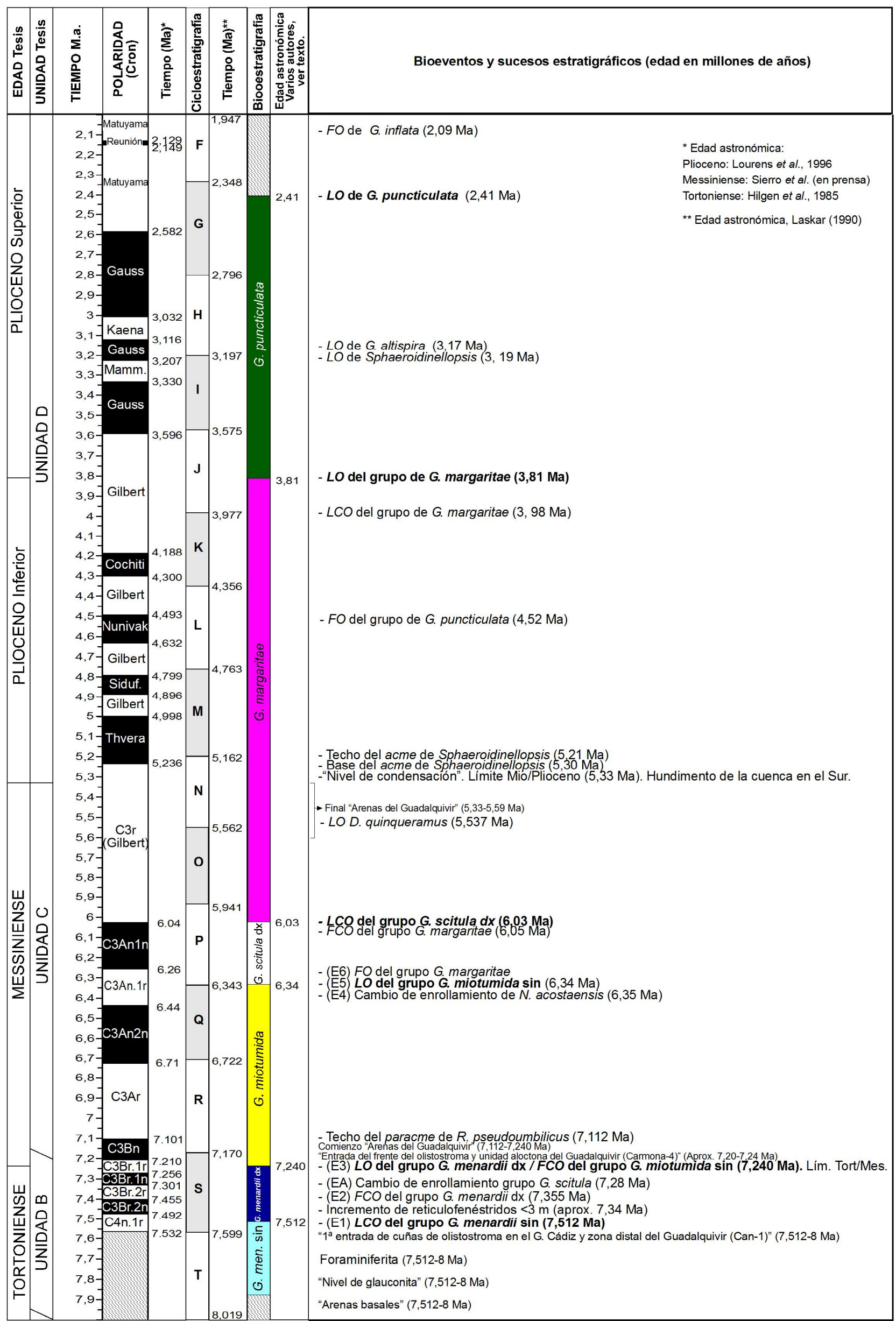

Figura 6.33. Resumen de la datación astronómica de los sondeos analizados. Edad, unidades litosísmicas, datación, magnetoestratigrafía deducida, unidades cicloestratigráficas y biozonas (datación astronómica de los límites de unidad y de los eventos). Finalmente, bioeventos y sucesos sedimenatarios significativos. 


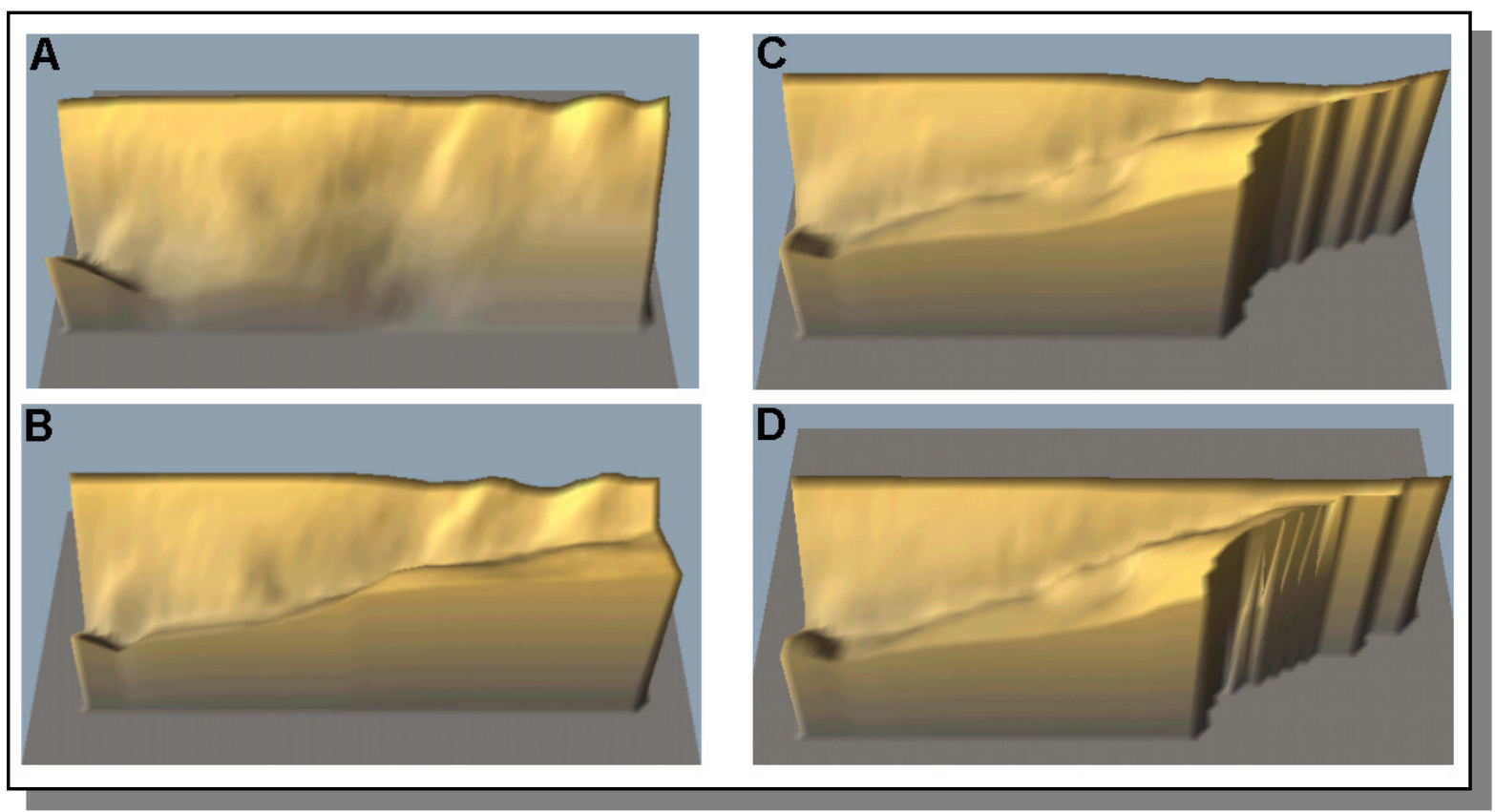

7. MODELO SEDIMENTARIO 
Página anterior: Topografía de la cuenca del Guadalquivir-golfo de Cádiz (vista desde el sur): (A) En torno a 8 Ma. (B) Evento E3 (7.24 Ma). (C) Evento E4 (6.35 Ma). (D) FCO del grupo de $G$. margaritae (6.05 Ma). 


\subsection{LA CUENCA TORTONIENSE-MESSINIENSE}

En este apartado se presenta una reconstrucción de la geometría de la cuenca del Guadalquivir basada en las superficies isócronas definidas por algunos de los principales bioeventos de la asociación de foraminíferos planctónicos (capítulo 3). Estas superficies isócronas constituyen isobatas (con profundidad referida al actual nivel del mar) que muestran el paleorelieve de la cuenca del Guadalquivir-golfo de Cádiz en distintos momentos del Tortoniense y Messiniense.

Se ha elaborado en primer lugar una matriz de datos (ver Apéndice) por cada uno de los cuatro momentos geológicos contemplados:

- Base de la unidad litosísmica B (en torno a $8 \mathrm{Ma}$ )

- Evento 3, LO del grupo G. menardii dx / FO del grupo G. miotumida $\sin (7.240 \mathrm{Ma})$

- Evento 4, cambio de enrollamiento del grupo de N. acostaensis (6.35 Ma)

- FCO del grupo G. margaritae (6.05 Ma)

Teniendo en cuenta la isocronía de los bioeventos de foraminíferos planctónicos, se han modelado en tres dimensiones los mapas de isobatas correspondientes a estos cuatro episodios significativos del relleno de la cuenca, durante el depósito de las unidades litosísmicas B y C. Además de la información obtenida del análisis micropaleontológico de las muestras de los sondeos, los mapas se apoyan en información procedente de diagrafías y líneas sísmicas. Se ha considerado así mismo la información de distintos afloramientos de campo junto al borde norte de la cuenca del Guadalquivir (Sierro com. per.), lo que ha permitido conocer la tendencia de las isobatas en este área. Se muestra asimismo la proyección de las principales ciudades localizadas en el área de estudio para facilitar la comprensión de la figura.

El primero de los planos (fig. 7.1) y su versión tridimensional (fig.7.2) muestran el mapa de isobatas de la isocrona de 8 Ma correspondiente a la base de la unidad litosísmica B. En este momento, el frente olistostrómico no ha alcanzado todavía el área de estudio y la cuenca presenta una pendiente que puede reflejar en parte el emplazamiento posterior del olistostroma. La elevación que aparece al suroeste, en el golfo de Cádiz, es debida al diapirismo localizado en esta zona. Se trata de una elevación creada con posterioridad y que ha modificado la profundidad original a la que se registraron los eventos. El sondeo Orión 2-1 se encuentra en el centro de este domo y el sondeo 6x1 en la falda SE del mismo. Ambos mapas muestran aproximadamente la topografía del reflector $B F U$, que separa las unidades litosísmicas A y B. 
Alcanzada la máxima inundación tortoniense (entre 8 y $7.5 \mathrm{Ma}$ ), se producen los primeros ingresos olistostrómicos desde el margen sur al fondo de cuenca (tanto en el golfo de Cádiz, como en el Guadalquivir) al tiempo que comienza la elevación de la cabecera de la cuenca por el NE.

Como consecuencia del contexto tectónico compresivo, comienzan a desarrollarse los primeros aparatos turbidíticos en el NE de la cuenca (fuera del ámbito de estudio). Casi en el límite Tortoniense-Messiniense se produce un nuevo avance del frente olistostrómico que alcanza el sur de Carmona. La nueva situación condiciona la canalización de los cuerpos turbidíticos al norte del frente olistostrómico. Este momento inmediatamente posterior al ingreso olistostrómico es el que reflejan las figuras 7.3 y 7.4.

En la figura 7.3 se muestra el plano de isobatas del evento 3 (límite TortonienseMessiniense, $7.24 \mathrm{Ma}$ ), donde puede observarse la enorme influencia del frente olistostrómico en la morfología de la cuenca. El mapa tridimensional correspondiente (fig. 7.4) muestra dos perspectivas diferentes del mismo momento (desde el sur fig. 7.4A y desde el suroeste fig. 7.4B). En el mapa tridimensional puede observarse como son las áreas situadas más al SE, las que sufren el ingreso del olistostroma (Regina-Los PalaciosUtrera-El Arahal-Marchena). Después de la entrada del frente olistostrómico del Guadalquivir en el sureste, queda definida la forma de la cuenca condicionando la evolución del relleno sedimentario. La figura 7.4A refleja por lo tanto el momento inmediatamente anterior al depósito de la formación "arenas del Guadalquivir" en el área de estudio. La superficie que aparece proyectada en el fondo de cuenca representa el plano sobre el que se van a disponer los sucesivos aparatos turbidíticos.

Comparando las figuras anteriores con el siguiente mapa tridimensional (fig. 7.5) correspondiente al Evento $4(6.35 \mathrm{Ma})$, podemos observar la rápida colmatación que sufre el área SE debido fundamentalmente a la progradación del talud SE y al ascenso de todo el sistema bético. El progresivo aumento de la pendiente propiciará un rápido emplazamiento de los lóbulos turbidíticos desde Carmona al golfo de Cádiz.

La sedimentación turbidítica en el fondo de la cuenca parece ser una constante durante todo el Messiniense, depositándose una serie de lóbulos turbidíticos de gran longitud a lo largo del depocentro creado por la entrada del olistostroma. Los cuerpos turbidíticos se distribuyen primero en el Guadalquivir (Santa Clara-1, Sevilla-2, Casanieves-1, Villamanrique-1) y finalmente en el golfo de Cádiz (D-1, C-3, Atlántida 3, B3, B6, 6x1). La creación y progradación de estos cuerpos turbidíticos está directamente relacionada con el levantamiento tectónico de las Béticas en general y el emplazamiento olistostrómico en particular. El aporte de sedimento se realiza principalmente desde la 
cabecera de la cuenca, mientras que el levantamiento bético se traduce en una significativa progradación lateral de los lóbulos turbidíticos hacia el norte.

En el tercero de los planos de isobatas, correspondiente al evento E4 (cambio de enrollamiento de $N$. acostaensis, 6.35 Ma), (fig. 7.5) se observa como el eje de la cuenca ha sido rápidamente rellenado y se ha desplazado hacia el norte. Obsérvese por ejemplo la posición de Carmona, que ha pasado de ser el talud norte (fig. 7.1), a centro de cuenca (fig. 7.3) y finalmente a formar parte del talud sur (fig. 7.5). En el correspondiente mapa tridimensional (fig. 7.6) se observa igualmente el resultado de la rápida colmatación que sufre el área SE. El avance del talud sur se deja sentir ya junto a la línea que forman las ciudades de Coria, Alcalá y El Viso. El aporte de sedimentos desde el talud norte parece haber sido más escaso, hasta este momento.

El último de los planos (fig. 7.7) y de los mapas tridimensionales (fig. 7.8), corresponde a la $F C O$ del grupo de $G$. margaritae (6.05 Ma), observándose el máximo avance del depocentro de la cuenca hacia el norte. En el NE del Guadalquivir, la sección transversal de la cuenca pasa de tener forma de "U" con una amplia base a dibujar una "V" cada vez más cerrada reflejando el acercamiento de la cabecera de la cuenca. La proximidad de los taludes y el estrechamiento progresivo de la cuenca configuran una cuenca alargada y profunda en el Guadalquivir que se abre hacia el golfo de Cádiz. Al tiempo que la cabecera de la cuenca se estrecha y avanza, continúan depositándose en el eje de la cuenca nuevos aparatos turbidíticos que alcanzan ya el golfo de Cádiz. 


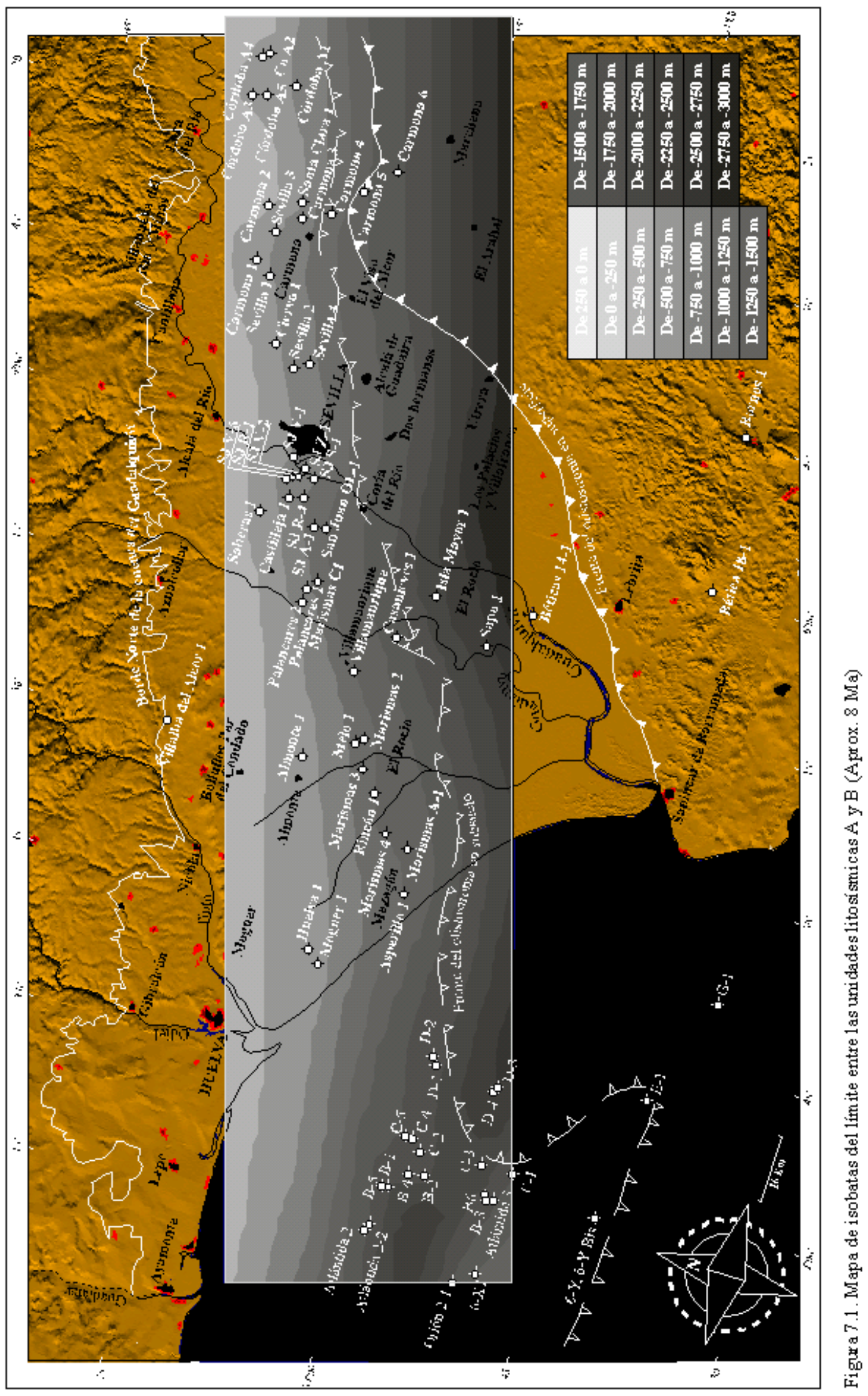


(A)

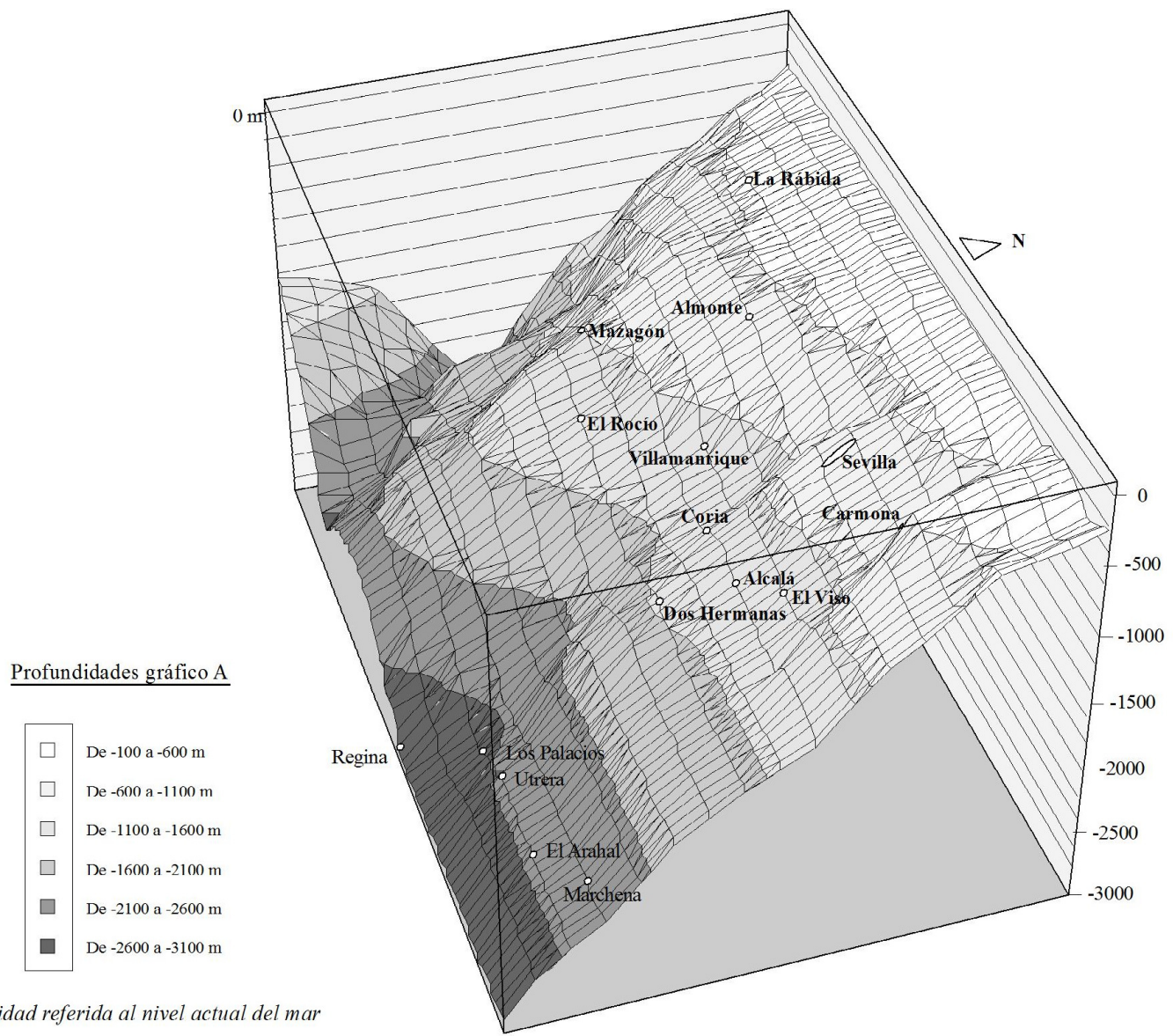

Profundidad referida al nivel actual del mar

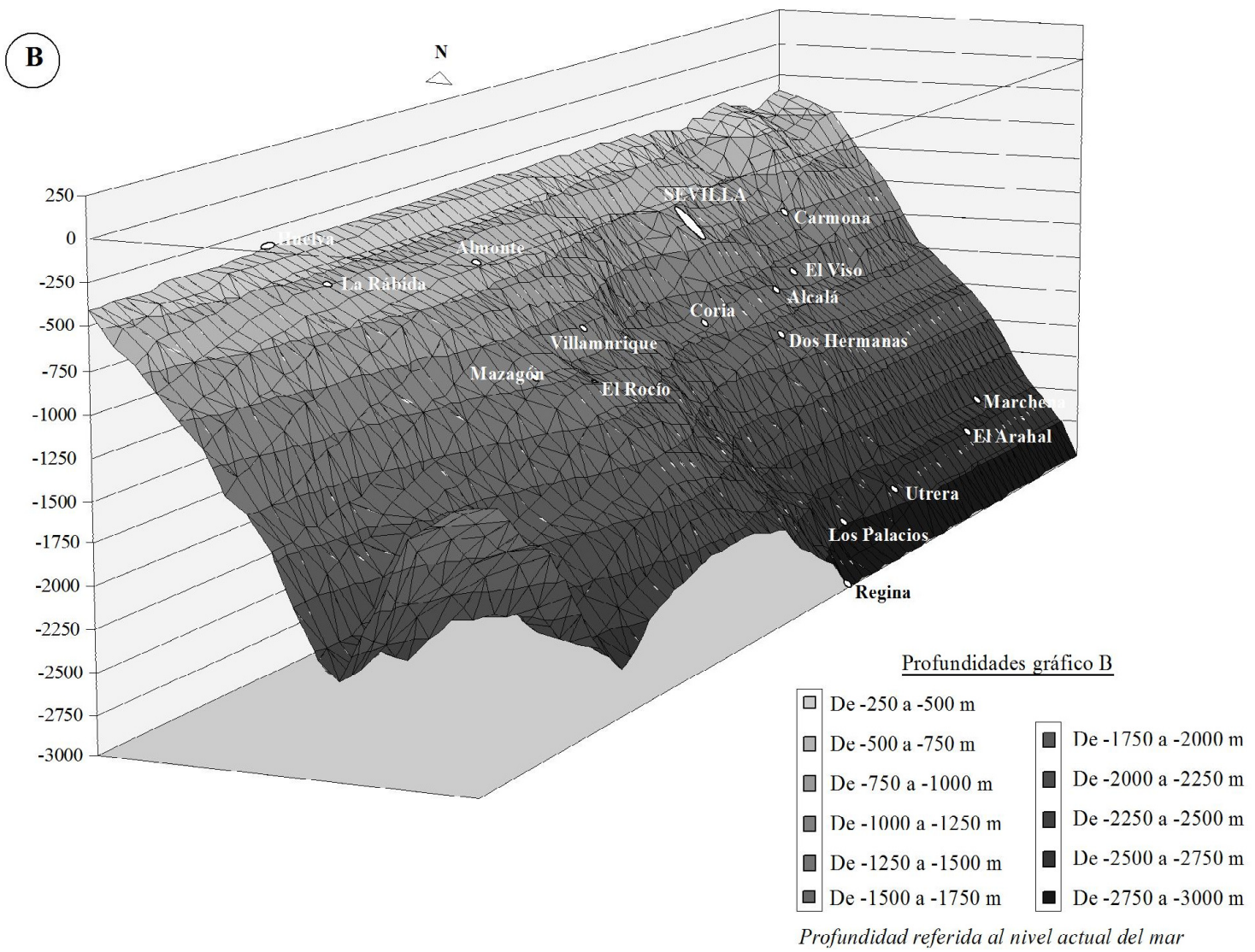

Figura 7.2. Dos imágenes de las isobatas del límite entre las unidades litosísmicas A y B (En torno a 8 Ma) 


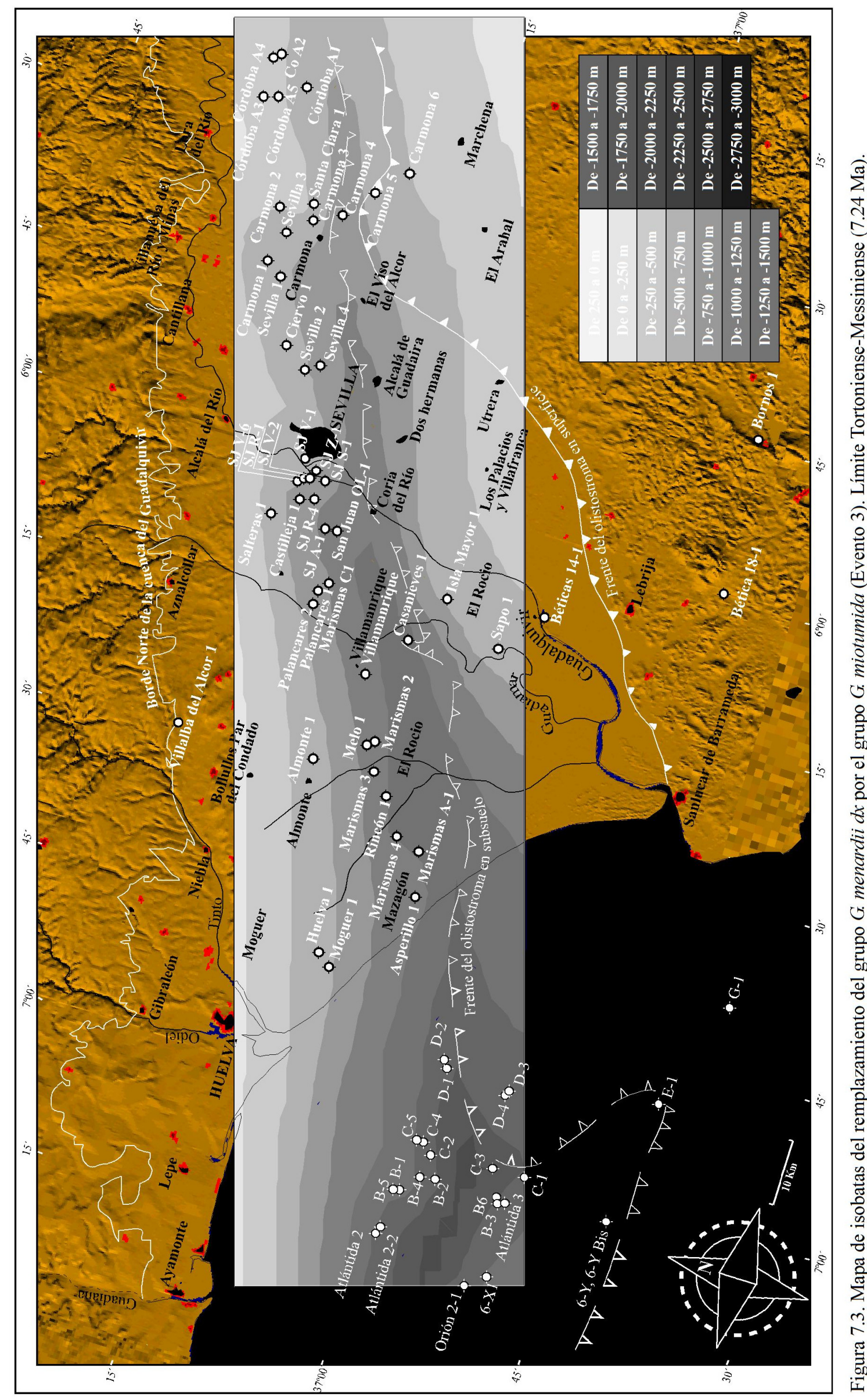



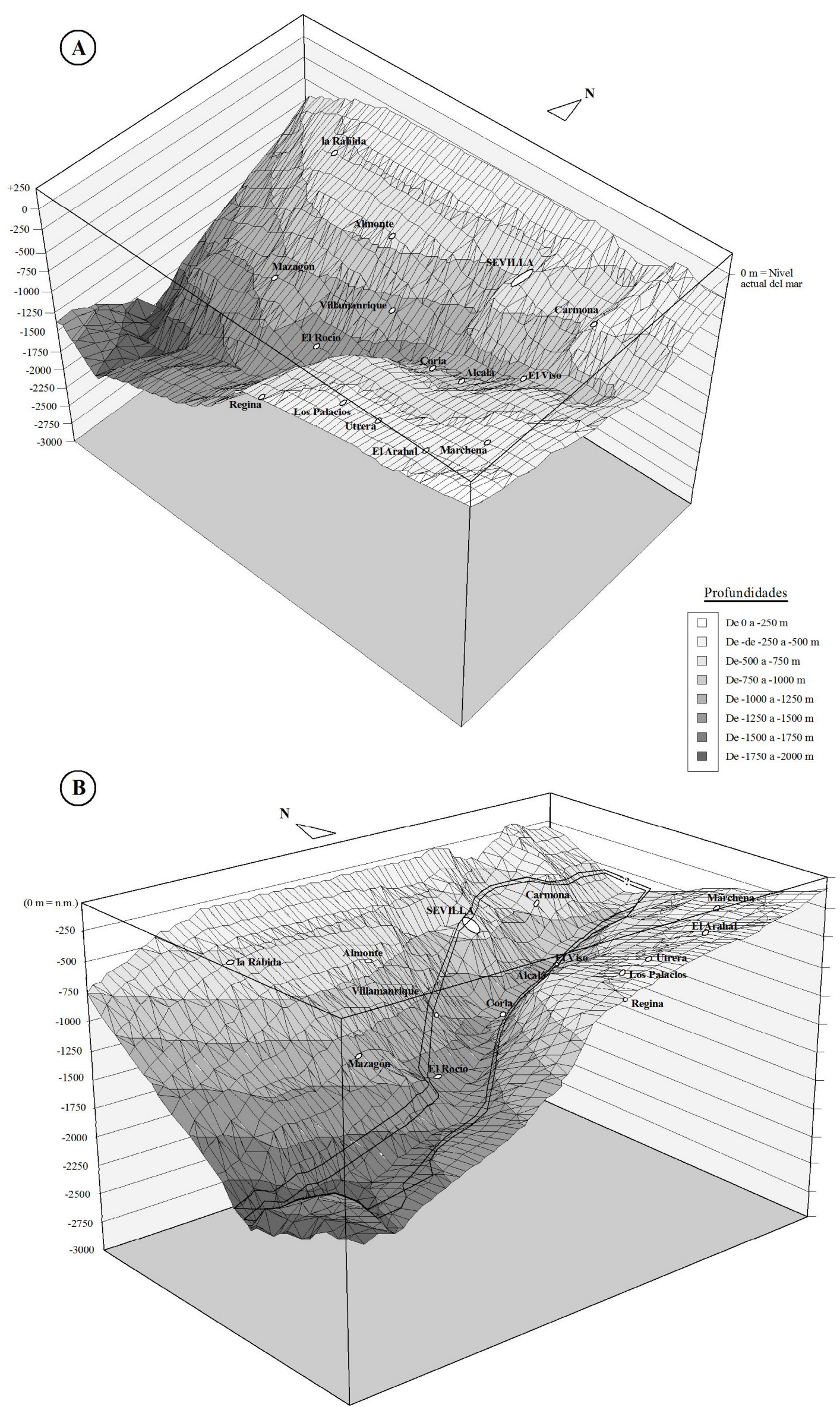

Fig. 7.4. Dos imágenes tridimensionales del mapa de isobatas del evento E3 (7.24 Ma). 


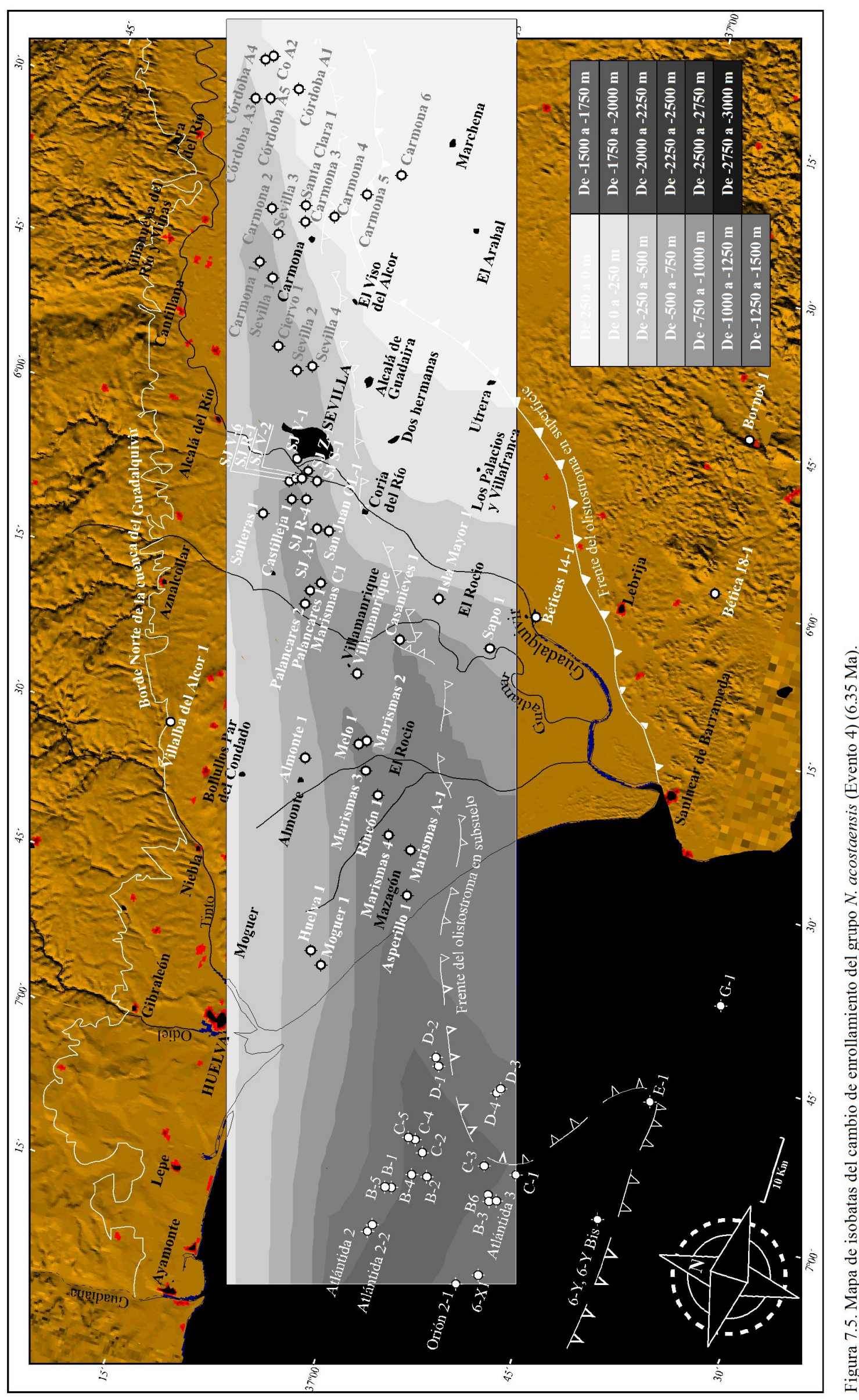


$\underline{\text { Profundidades }}$
망 +250 a $0 \mathrm{~m}$
$\square$ De 0 a $-250 \mathrm{~m}$
$\square \quad$ De -250 a $-500 \mathrm{~m}$
$\square \quad$ De -500 a $-750 \mathrm{~m}$
\begin{tabular}{l|l}
$\square$ & De -750 a $-1000 \mathrm{~m}$ \\
$\square$ & De $-1000 \mathrm{a}-1250 \mathrm{~m}$ \\
$\square$ & De $-1250 \mathrm{a}-1500 \mathrm{~m}$ \\
$\square$ & De $-1500 \mathrm{a}-1750 \mathrm{~m}$
\end{tabular}

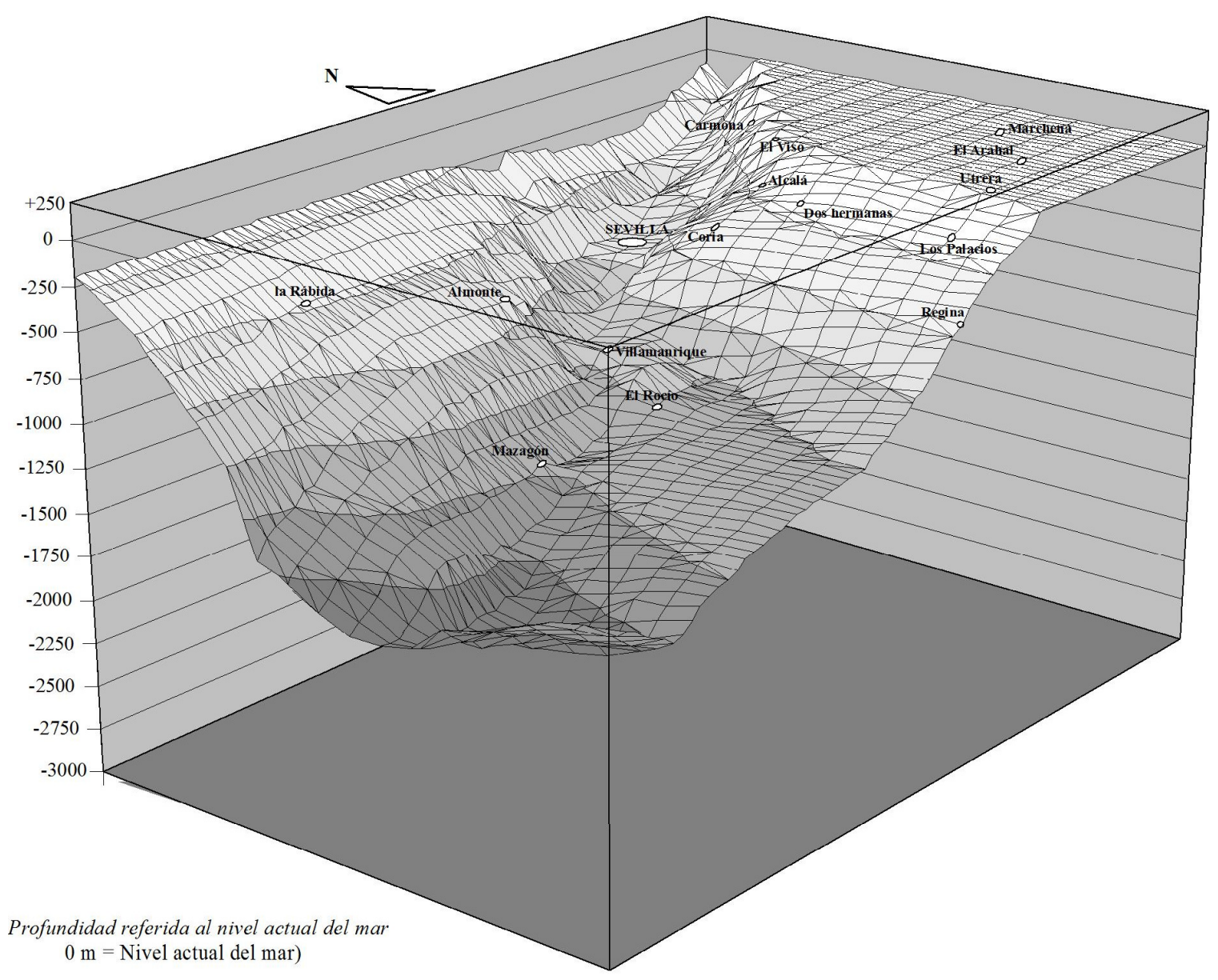

Fig. 7.6. Representación tridimensional del mapa de isobatas correspondiente al evento E4 (6.35 Ma). 


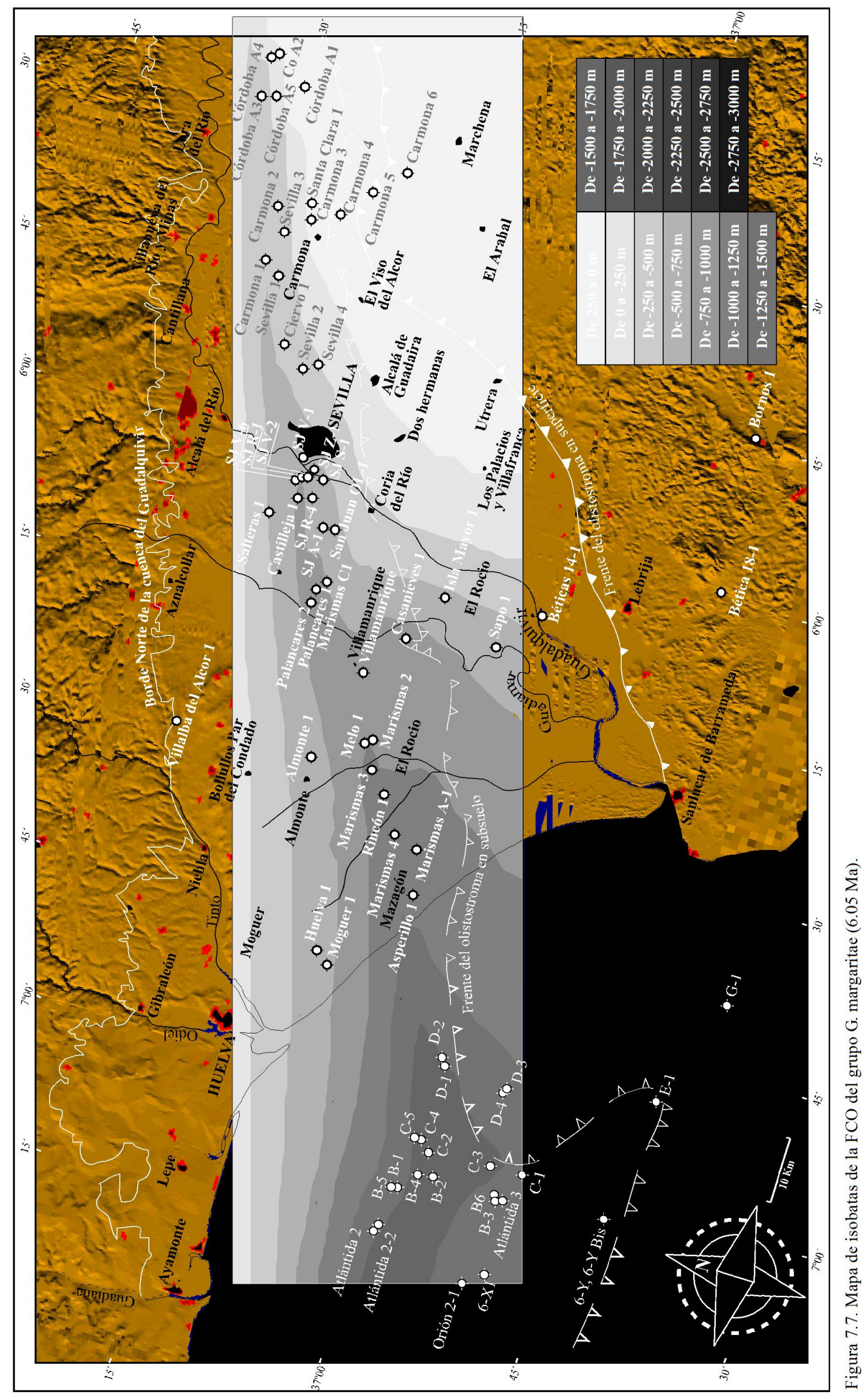




\section{Profundidades}
만 +250 a $0 \mathrm{~m}$
De 0 a $-250 \mathrm{~m}$
De -250 a $-500 \mathrm{~m}$
De -500 a $-750 \mathrm{~m}$
\begin{tabular}{l|l}
$\square$ & De -750 a $-1000 \mathrm{~m}$ \\
$\square$ & De $-1000 \mathrm{a}-1250 \mathrm{~m}$ \\
$\square$ & De $-1250 \mathrm{a}-1500 \mathrm{~m}$ \\
$\square$ & De $-1500 \mathrm{a}-1750 \mathrm{~m}$
\end{tabular}

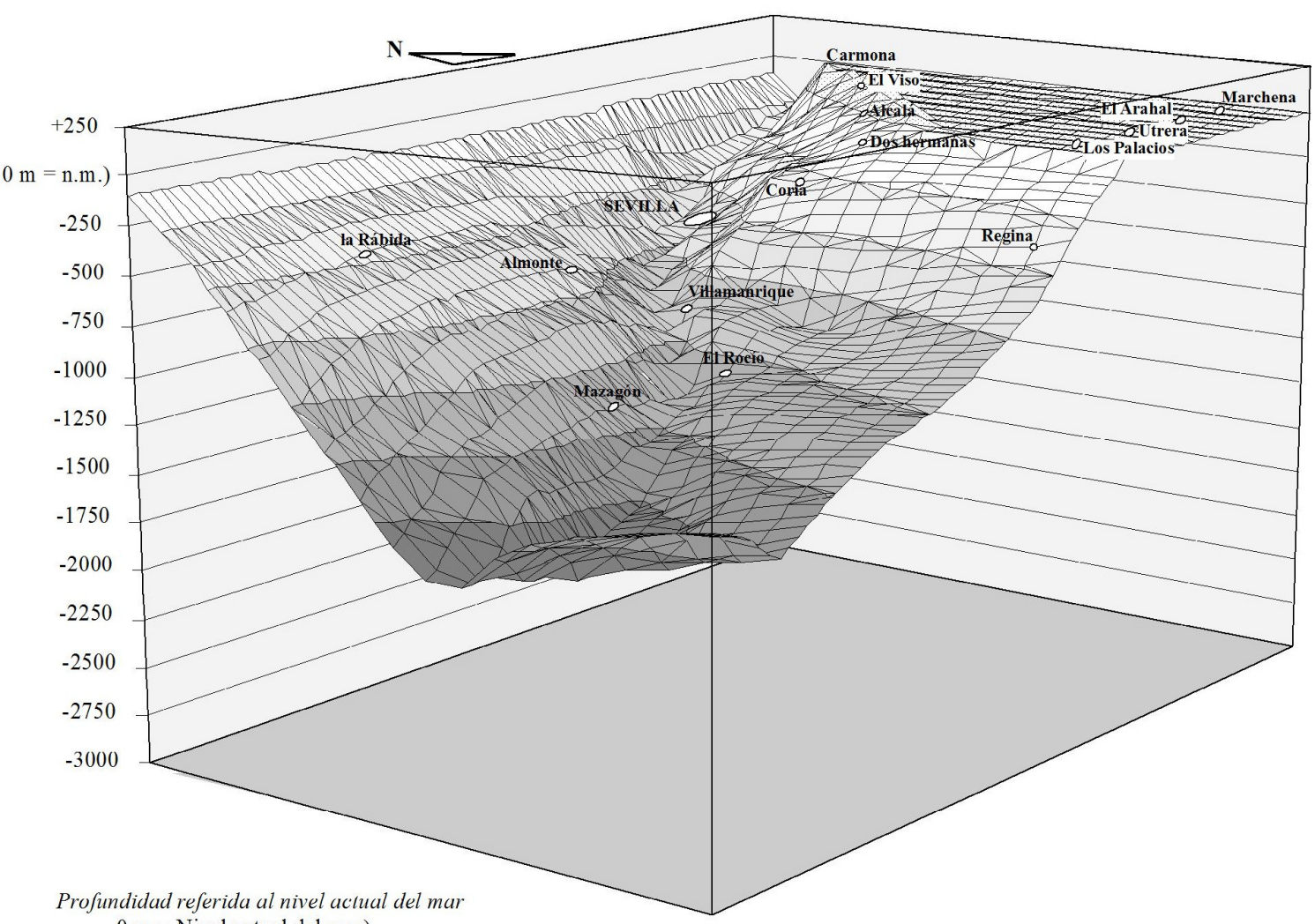

$0 \mathrm{~m}=$ Nivel actual del mar)

Figura 7.8. Representación tridimensional del mapa de isobatas correspondiente a la $F C O$ del grupo de G. margaritae (6.05 Ma). 


\subsection{EL RELLENO SEDIMENTARIO}

La disposición de las unidades litosísmicas y bioestratigráficas propuestas en la Tesis (fig. 7.9) mantiene importantes semejanzas con los primeros modelos tectosedimentarios (Martínez del Olmo, 1984) y con los últimos modelos de secuencias de depósito (Riaza y Martínez del Olmo, 1996; Martínez del Olmo et al., 1996) (fig. 2.6), si bien plantea una nueva concepción del relleno de la cuenca y abre nuevas interrogantes al respecto.

El actual modelo de secuencias de depósito, encuadra la formación "arenas del Guadalquivir" en un contexto de HST al final de una secuencia (Secuencia Bética) que comienza con la transgresión Tortoniense (fig. 2.6). A continuación se registra según este modelo, el depósito de la secuencia Andalucía que presenta depósitos de TST y de HST que incluye a la formación "calcarenita de Carmona". Tras esta secuencia se producirá un descenso eustático de edad intramessiniense, contemporáneo a la Crisis de Salinidad en el Mediterráneo, a consecuencia del cual va a desarrollarse un completo sistema de abanico submarino en el golfo de Cádiz (formación “arenas del Guadiana”) (fig. 2.6).

En función de los resultados obtenidos en esta Tesis, pensamos sin embargo que al menos los primeros cuerpos turbidíticos del golfo de Cádiz (tabulares y de gran extensión lateral), localizados en el área sur de la zona de estudio, presentan una edad sensiblemente inferior a la esperada. Todos los sondeos del área sur del golfo de Cádiz presentan exclusivamente arenas de edad anterior a 6.3-6.34 Ma (edad determinada por la $L O$ del grupo G. miotumida localizada varias decenas de metros por encima de los niveles arenosos). Por lo tanto estos lóbulos turbidíticos son casi 1 Ma anteriores a la discontinuidad intramesiniense. Por otro lado, la edad del reflector propuesto como base erosiva del cañón messiniense en el Guadalquivir (límite entre las unidades litosísmicas C y D) presenta una edad astronómica entre 5.60 Ma y 5.33 Ma (fig. 7.9). Esta datación obtenida gracias al análisis cicloestratigráfico de los sondeos Casanieves-1 y Villamanrique-1 es bastante más moderna que los depósitos turbidíticos del golfo de Cádiz supuestamente relacionados con la misma.

En la figura 7.9 se muestra una correlación tridimensional basada en las unidades litosísmicas establecidas en el capítulo 4. En la parte inferior de la figura aparece un cuadro de equivalencia entre las unidades litosísmicas y bioestratigráficas propuestas en esta Tesis, las secuencias de depósito establecidas por Riaza y Martínez del Olmo (1996) para el Guadalquivir y para el golfo de Cádiz, las secuencias definidas por Sierro et al. (1996) para el Guadalquivir y las unidades litosísmicas propuestas por Maldonado et al. (1999) en el golfo de Cádiz. La figura 7.9 propone un modelo de relleno de la cuenca que 
justifica los resultados micropaleontológicos obtenidos en la Tesis. No obstante el modelo planteado no es definitivo, quedando pendiente establecer una interpretación en base a la estratigrafía secuencial propuesta por Vail et al. (1991) y que contemple los datos micropaleontológicos presentados en este trabajo.

Las unidades litosísmicas A, B, C, D y E descritas en el capítulo 4, coinciden en parte con las secuencias de depósito homónimas definidas por Sierro et al. (1996) en afloramientos de campo del Guadalquivir y fundamentalmente con las 5 secuencias tectosedimentarias de edad equivalente (M1, M2, M3, P1-P2 y PQ) que Maldonado et al. (1999) distinguen en el golfo de Cádiz (fig. 7.9). Por otro lado Riaza y Martínez del Olmo (1996) identifican 4 secuencias de depósito (secuencias Atlántida, Bética, Andalucía y Marismas) en el golfo de Cádiz, aunque con una distribución diferente (fig. 7.9).

En la figura 7.10, se ha representado la secuencia de relleno sedimentario de dos de los perfiles más característicos en la cuenca Guadalquivir-golfo de Cádiz, el primero de ellos en el alto Guadalquivir (perfil $n^{\circ} 1$ ) y el otro en el golfo de Cádiz (perfil $n^{\circ} 8$ ). En la figura se muestra la sucesión de los distintos cuerpos sedimentarios en función de la bioestratigrafía (capítulo 3), así como las principales direcciones de aporte de los sedimentos y contexto tectónico deducidos del análisis de los perfiles sísmicos (capítulo 4).

\subsubsection{Unidad litosísmica A}

En la zona de estudio, la unidad litosísmica A solo aparece en el golfo de Cádiz (figura 7.9), es equivalente a la "secuencia A" definida por Sierro et al. (1996) (de edad Tortoniense inferior a medio), al "Grupo Atlántida" (Suárez et al., 1989, Riaza y Martínez del Olmo, 1996), y a la denominada UTS-1 (Martínez del Olmo, 1984; ITGE, 1990) que consideran de edad Serravalliense 2 - Tortoniense. Comienza hace unos $11 \mathrm{Ma}$ y aflora en campo en la zona más oriental de la cuenca del Guadalquivir, entre Bailén e Iznatoraf. Sierro et al. (1996) indican que comienza en el margen norte con depósitos marinos someros, transgresivos sobre basamento Mesozoico, que rápidamente pasan hacia arriba a limos ricos en foraminíferos planctónicos depositados en un ambiente profundo y cubiertos por margas y arcillas (Sabiote, figura 2.7). La calcarenita basal o los sedimentos terrígenos y las margas representarían los Transgresive System Tract y el Highstand System Tract, mientras que las margas ricas en foraminíferos planctónicos supondría la sección condensada (Posamentier et al., 1988). 


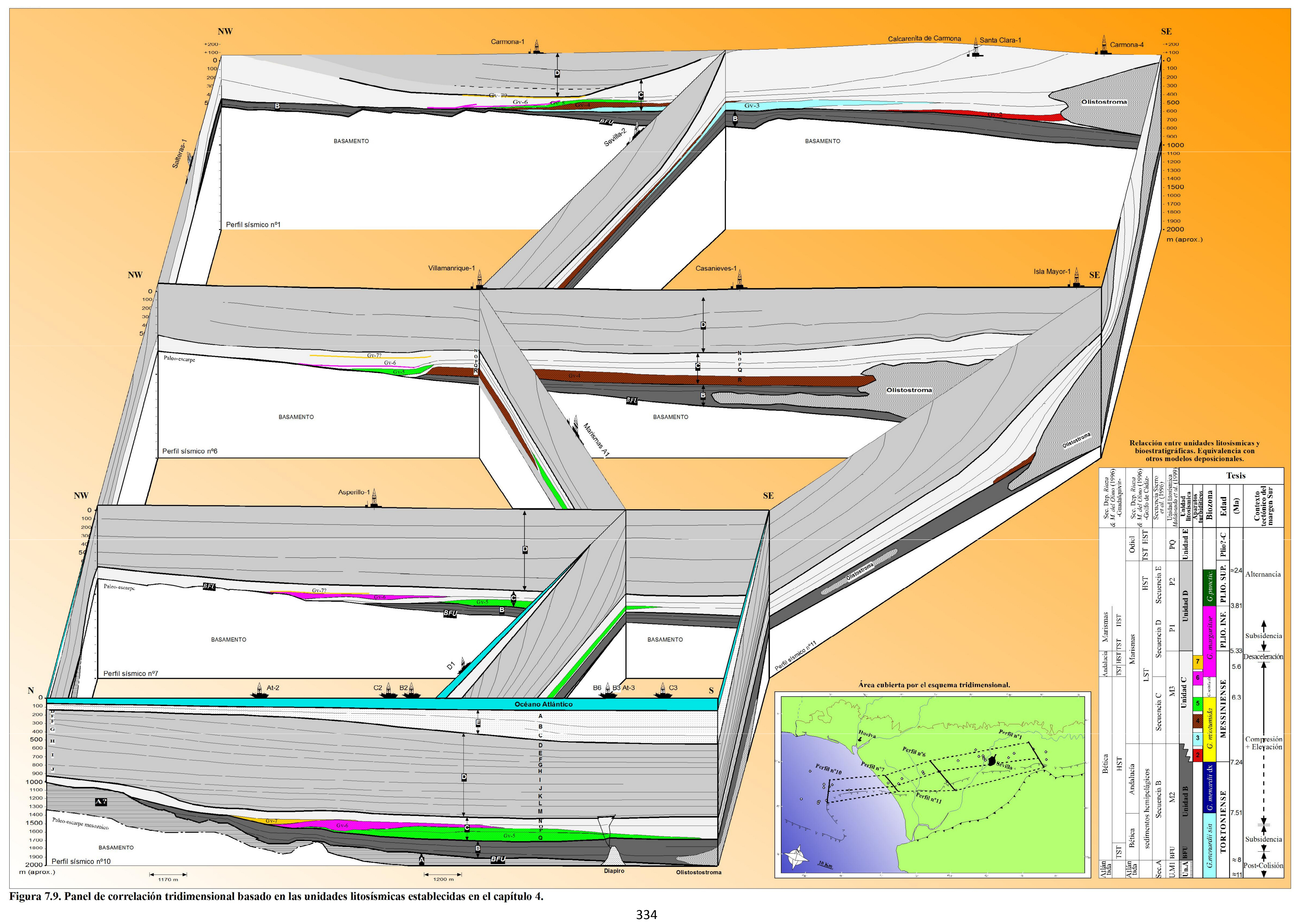




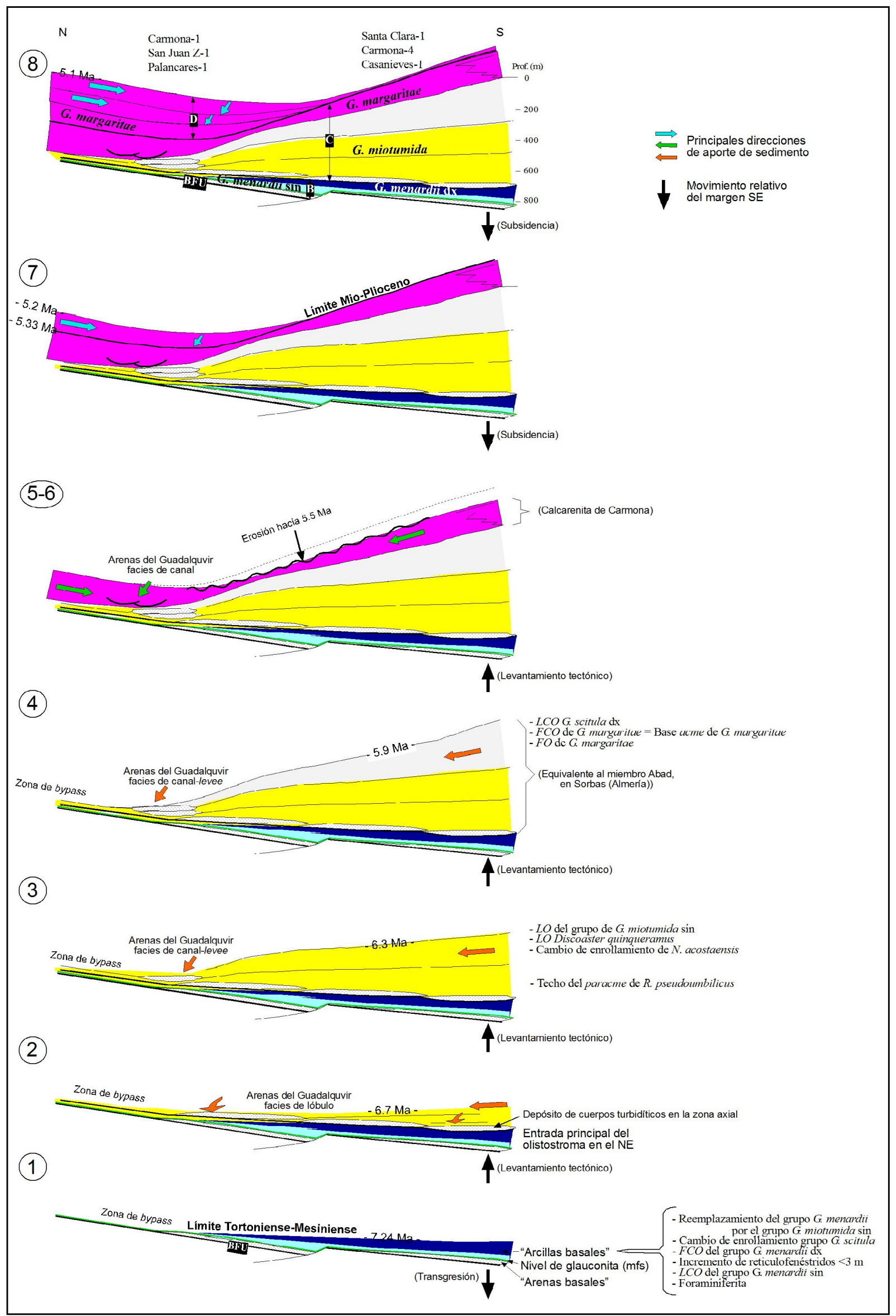

Figura 7.10. En esta página, esquema deposicional y sucesión bioestratigráfica en un corte característico transversal a la cuenca del Guadalquivir (basado en el perfil sismobioestratigráfico $\mathrm{n}^{\circ} 1$ ). En la página siguiente, esquema deposicional de una sección NW-SE en el golfo de Cádiz (basado en el perfil sismobioestratigráfico no 8 ) 


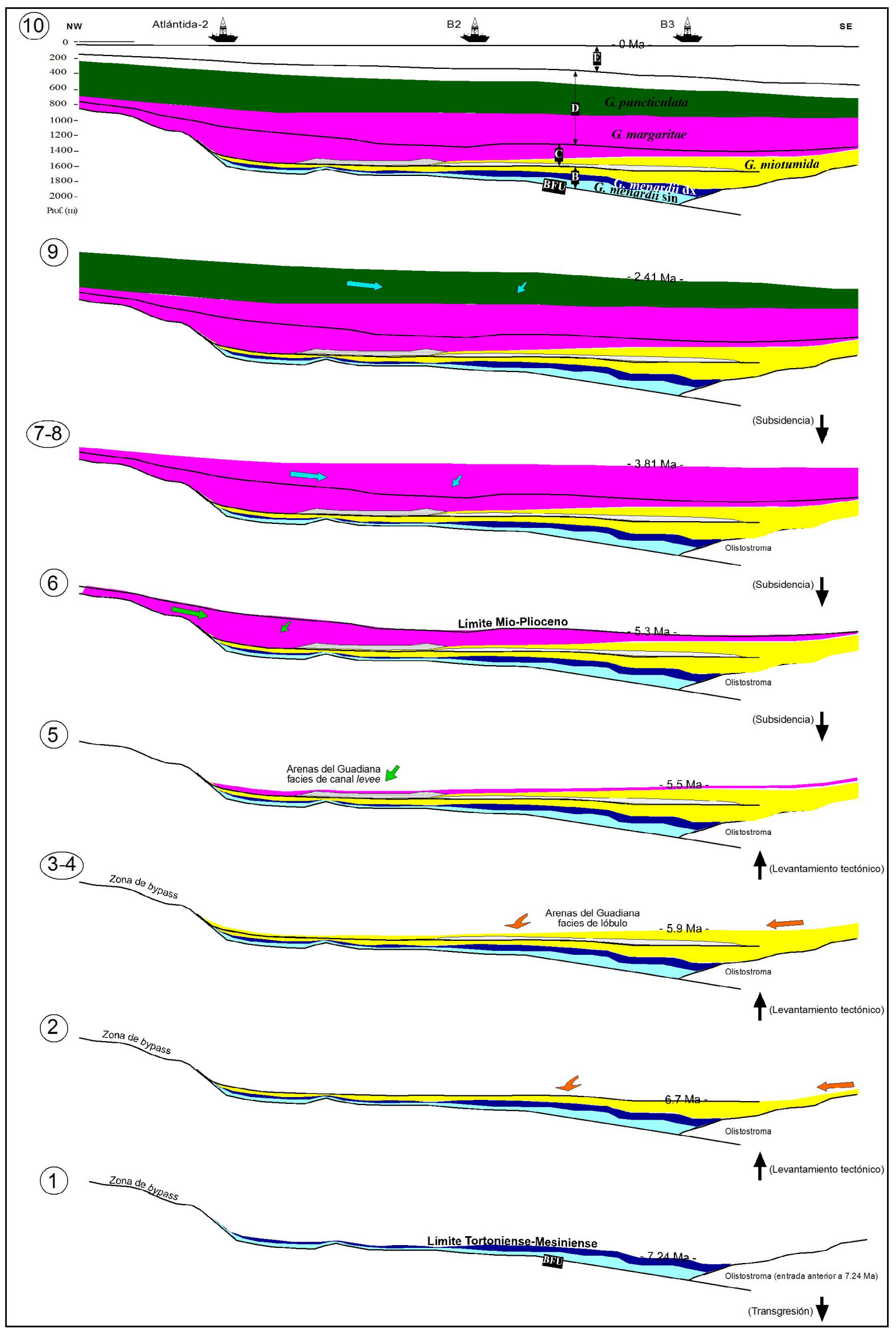




\subsubsection{Unidad litosísmica B}

La unidad litosísmica B (figura 7.9) comienza con arenas transgresivas que se apoyan sobre el basamento de la Meseta y que constituirían un Transgresive System Tract. Anteriores investigaciones a lo largo del borde de la Meseta han permitido reconocer el carácter transgresivo de los depósitos miocenos sobre el Paleozoico (Perconig, 1971). La transgresión corresponde al Tortoniense superior y en general está representada por conglomerados, brechas, calizas y areniscas con Heterostegina (Perconig y Martínez Díaz, 1977) encontrándose también más profundamente al sur (ver sondeo Salteras, apartado 6.1.11.). Sobre ellas aparecen arcillas ricas en foraminíferos y glauconita que constituyen un nivel de condensación interpretado como el nivel de máxima inundación ( $m f s$, maximun flooding surface). Por encima aparecen depósitos hemipelágicos de arcilla con foraminíferos bentónicos profundos y con un alto contenido biogénico que podrían ser interpretados como depósitos progradantes de alto nivel del mar (HST, Higstand System Tract).

Sierro et al. (1996) estiman que entre el depósito de la unidad A y la unidad B se produjo un importante cambio paleogeográfico relacionado con el cierre del paso Norbético, debido al ascenso de las sierras de Cazorla y Segura. En la mitad occidental del fondo de cuenca Bética se produjo una rotación de los depocentros hacia el noroeste y la individualización de una nueva cuenca de foreland, la cuenca del Guadalquivir. El desplazamiento de los depocentros hacia el NW significó la inundación (transgresión) de grandes áreas del foreland emergido donde los nuevos depósitos descansan directamente sobre rocas Paleozoicas y Mesozoicas en la zonas central y occidental de la cuenca. Una migración similar habría acontecido en la cuenca foreland del Rif (Marruecos) (Sierro et al., 1996). En las figuras 7.1 y 7.2 se aprecia la topografía de la cuenca en este momento.

El límite entre las unidades litosísmicas B y C no es isócrono, ya que se ha establecido en función del cambio litológico que supone la incursión de los cuerpos turbidíticos en el fondo de cuenca. En la zona de Carmona-Sevilla, este límite coincide con el emplazamiento del olistostroma que supone una reducción drástica de la cuenca y un desplazamiento de la zona axial hacia el norte. La unidad litosísmica B comprende a la biozona del grupo de G. menardii sin, la biozona del grupo de G. menardii dx y hacia el golfo de Cádiz los primeros metros de la base de la biozona del grupo de G. miotumida. 

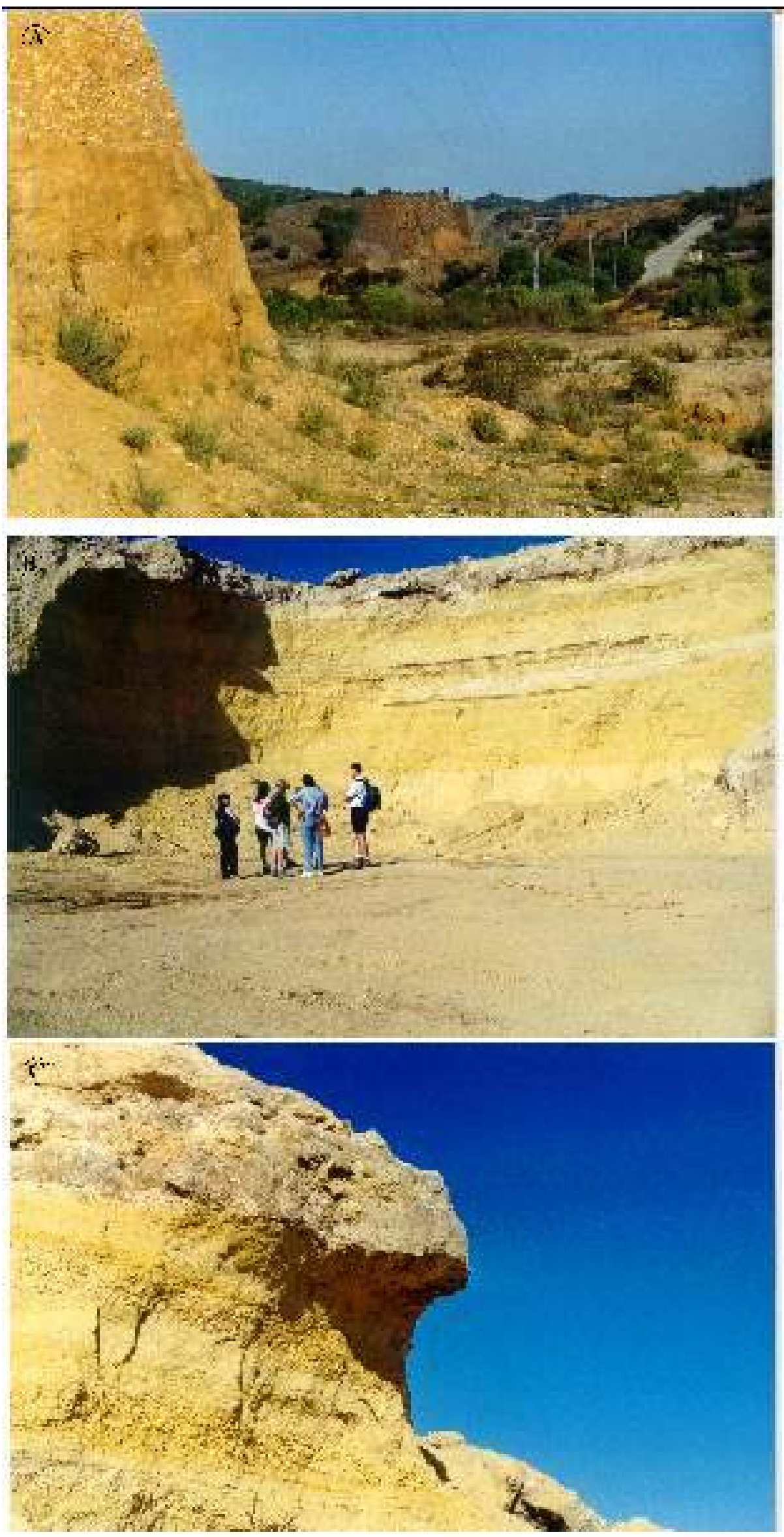

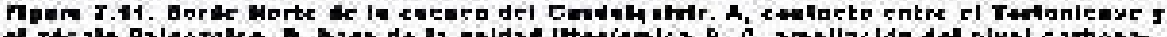

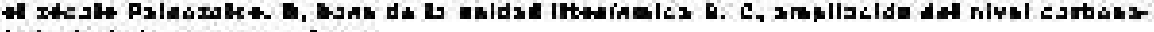
ledo de Io I magre anpertor. 

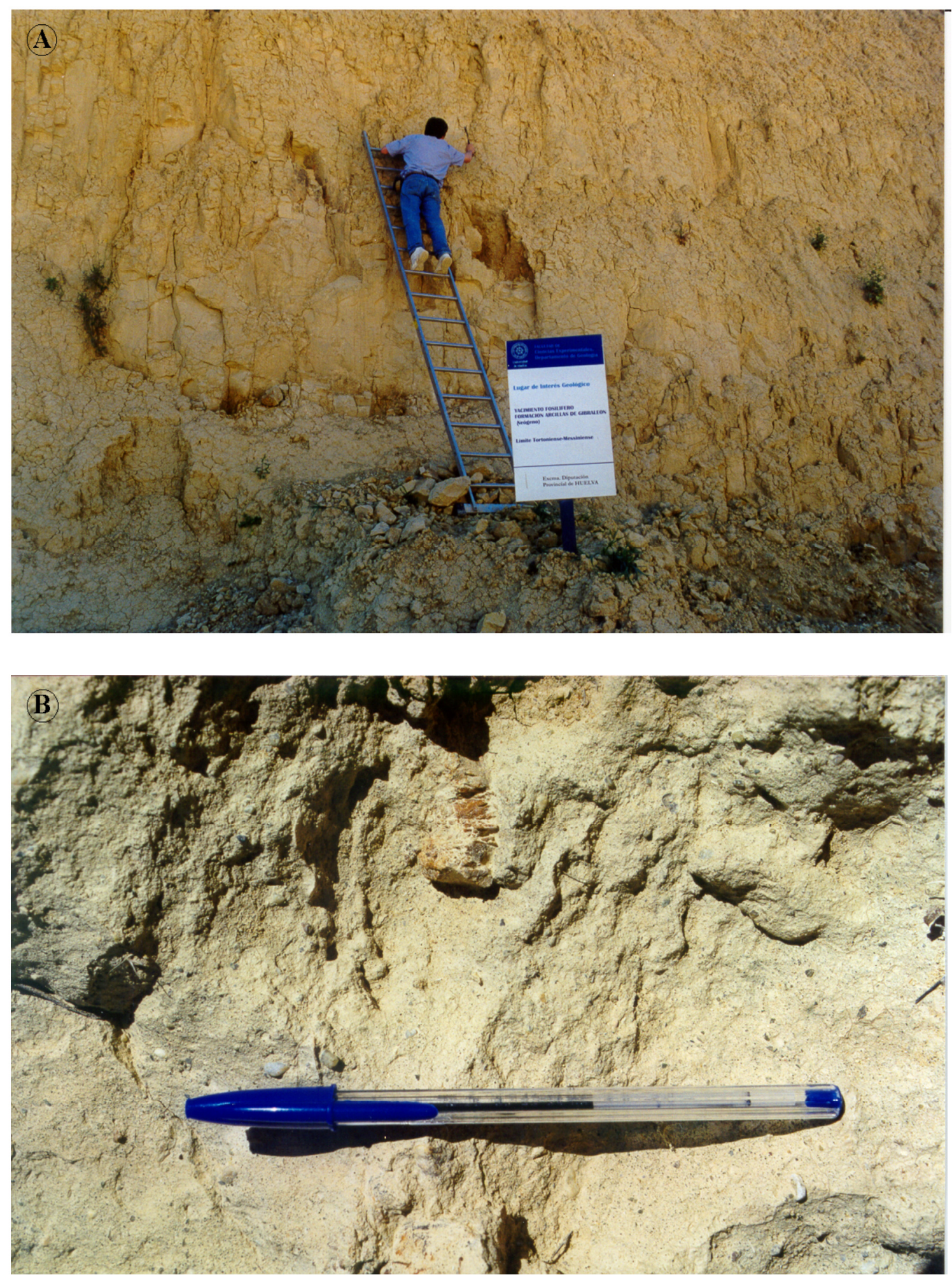

Figura 7.12. En la imagen superior A, formación arcillas de Gibraleón. En la imagen inferior $B$, detalle del nivel de galuconita.

Explicación en el texto. 
El Transgresive Systems Tract de la unidad B estaría representado por las arenas basales y la calcarenita (fig. 7.10). La superficie de máxima inundación ( $m f s$ ), está identificada por la abundante presencia de glauconita en muchos de los sondeos estudiados (Carmona1, Santa Clara-1, San Juan-Z-1, Salteras-1, etc), correspondiendo a la sección condensada que aparece en diversos afloramientos de campo como Montoro y Arroyo Galapagar (Sierro et al., 1996) (fig. 2.7). Esta superficie presentaría una edad próxima a $7.55 \mathrm{Ma}$ coincidiendo con la sección condensada global del Ciclo 3.2 de Haq et al. (1987). El Highstand Systems Tract estaría constituido a continuación por las "margas gris azuladas" que aparecen entre el nivel de glauconita y las "arenas del Guadalquivir".

Las tres imágenes de la figura 7.11 (A, B y C) están tomadas en el norte de la cuenca, en el límite de la cuenca del Guadalquivir con el macizo Hespérico (carretera de Cantillana a Villanueva, Sevilla, coordenadas GPS: N 37 $39^{\prime} 54,9^{\prime \prime}$; W $5^{\circ} 45^{\prime} 2,8^{\prime \prime}$ ) y corresponden a la parte inferior de la unidad B. En la figura 7.11A aparece el contacto entre el Tortoniense de la unidad litosísmica B (en primer plano) y el zócalo Paleozoico (al fondo de la ilustración). En la figura 7.11B observamos una sección de la unidad siliciclástica que aparece en primer plano en la figura 7.11A, cuya organización interna sugiere un sistema deltaico (Drs. Gaspar Alonso y Ángel González com. per.). De edad Tortoniense superior, estas facies son el equivalente proximal a las "arenas basales" detectadas en muchos de los sondeos estudiados (capítulo 6). Tras un nivel rico en Isognomon, el último tramo de esta sección muestra un nivel carbonatado que aparece detallado en la imagen inferior (figura 7.11C). El nivel carbonatado que aparece en la figura 7.11C es equivalente en edad a la formación "calcarenita de Niebla" (Civis et al., 1987, 1994 Borrego y Pendón, 1988; ). Sobre esta calcarenita se encuentra un nivel de glauconita detectado en gran parte de los sondeos estudiados (capítulo 6) que indicaría la máxima transgresión del Tortoniense superior (7.55 Ma).

La figura 7.12 contiene dos imágenes de la unidad B, la primera de ellas (fig. 7.12A) se tomó en una cantera de arcillas de Gibraleón (coordenadas GPS: N $37^{\circ} 22^{\prime}$ 22,0“; W 6 $\left.6^{\circ} 57.05^{\prime}, 8^{\prime \prime}\right)$ donde se atraviesa el Highstand System Tract constituido por las "margas gris azuladas". El cartel está apoyado aproximadamente sobre el nivel de glauconita equivalente al de la figura 7.11C. En torno a los primeros escalones de la escalera se encuentra la $L C O$ del grupo de G. menardii sin, en el centro de la misma se encuentra aproximadamente la $F C O$ del grupo de G. menardii dx, mientras que el Dr. Ángel González trata de limpiar la zona en la que se encuentra el límite TortonienseMessiniense definido por el reemplazamiento de G. menardii dx por formas del grupo de G. miotumida sin (Sierro, 1985). Un detalle del nivel de glauconita (con restos óseos), se muestra en la figura 7.12B. 
Según Sierro et al. (1996) en la parte este de la cuenca (fuera de nuestro área de estudio), la secuencia B comienza con sedimentación turbidítica (Lowstand Systems Tract, probablemente correlacionados con el ciclo 3.2 de Haq et al., 1987) apoyándose sobre las margas profundas de Sabiote de la unidad litosísmica A (Sabiote, Baeza, fig. 2.7). Sin embargo, en las zonas central (Carmona-Sevilla) y occidental (zona de Huelva), estos depósitos turbidíticos no afloran, comenzando la unidad B con el depósito costero transgresivo "arenas basales" en el primer caso y "calcarenita de Niebla" en el segundo, superponiéndose a rocas pre-neógenas en el margen norte.

\subsubsection{Unidad litosísmica C}

La progradación del talud sur de la cuenca durante el depósito de las unidades litosísmicas $\mathrm{B}$ у $\mathrm{C}$, queda bien patente en la secuencia de mapas topográficos de la cuenca para este periodo (figuras 7.2, 7.4 y 7.6). En un contexto fuertemente compresivo, destaca la entrada de la unidad alóctona del Guadalquivir en la cabecera de la cuenca en el límite Tortoniense-Messiniense (7.2 Ma), condicionando el posterior relleno sedimentario de la unidad C. Fernández et al., (1998) en un reciente análisis de secuencias sísmicas del relleno de la cuenca, estudian la configuración de las secuencias depositadas desde el Langhiense superior-Serravalliense al Messiniense. Estos autores indentifican durante este periodo de tiempo 6 secuencias que indican que el relleno se produjo fundamentalmente en dirección NNW, descartando un modelo de progradación E-W durante este periodo (Fernández et al., 1998). No obstante durante el Messiniense la cabecera de la cuenca si avanza hacia el oeste como consecuencia del levantamiento tectónico de las sierras de Segura y Cazorla (Sierro com. per).

El ascenso tectónico del margen sur (fig. 7.9) y de la cabecera de la cuenca en el este, va a generar una secuencia de carácter regresivo, progradante y relacionada con regresiones forzadas en los bordes de la cuenca, desencadenando el comienzo de la unidad litosísmica C. La sedimentación hemipelágica distal de la unidad litosísmica B, va a dar paso a una serie de cuerpos turbidíticos canalizados a lo largo de la cuenca y sucesivamente más jóvenes hacia el noroeste (en la figura 7.9 aparecen coloreados estos aparatos turbidíticos en el interior de la unidad litosísmica C). La unidad C está constituida por cúmulos derivados de la erosión de la plataforma y de las partes altas del talud, así como de materiales procedentes de la descarga de los ríos. Frente al olistostroma se desarrollaron una serie de cuerpos turbidíticos que progradan hacia el fondo de cuenca situado en el golfo de Cádiz. El ascenso del sistema bético y el empuje del olistostroma estimulan una fuerte progradación lateral de modo que los cuerpos turbidíticos aparecen alargados en el sentido del eje de la cuenca, pero dispuestos cada 
uno por encima y a la derecha del precedente (figs. 7.9 y 7.10). Lateralmente, las "margas azules" del Messiniense inferior de Carmona (biozona del grupo de G. miotumida) constituyen el talud sur contemporáneo a los sucesivos lóbulos turbidíticos (fig. 7.9). En el talud norte, el equivalente a la formación "arcillas de Gibraleón” (Civis et al., 1987) constituirían la facies de talud simétrica. Finalmente la calcarenita de Carmona representaría a las facies proximales de topset de esta secuencia regresiva. En cuanto a la bioestratigrafía, la unidad litosísmica $\mathrm{C}$ incluye la mayor parte de la biozona del grupo de G. miotumida y el intervalo messiniense de la biozona del grupo de G. margaritae.

\subsubsection{Depósitos turbidíticos en la cuenca del Guadalquivir-golfo de Cádiz}

La unidad litosísmica $\mathrm{C}$ consiste por lo tanto en una unidad litosísmica de edad Messiniense en la que se desarrollan una serie de lóbulos turbidíticos que progradan por el eje de la cuenca desde la cabecera hasta el golfo de Cádiz. Los lóbulos más antiguos se encuentran frente al olistostroma, para ser progresivamente más modernos hacia el talud norte y el golfo de Cádiz. Por otra parte, Sierro et al., (1996) proponen la equivalencia de estos aparatos turbidíticos con el Ciclo 3.3 de Haq et al. (1987).

Como se muestra en el capítulo 6, los aparatos turbidíticos atravesados en el Guadalquivir por los sondeos Sevilla-2, Casanieves-1, Villamanrique-1, Marismas A-1, se encuentran incluidos en la biozona del grupo de G. miotumida. Por otro lado, los cuerpos atravesados por los sondeos situados sobre el sector central del Guadalquivir (sondeos Carmona-1, San Juan V-6, San Juan R-1, San Juan V2) presentan la base de los niveles de arena sobre la biozona del grupo de G. miotumida, comenzando a techo de estos niveles la biozona del grupo de G. margaritae. Incluso los niveles de arena de los sondeos localizados más al norte, como en Salteras-1, Castilleja-1, Melo-1 y Marismas-4, se encuentran incluidos totalmente en la biozona del grupo de $G$. margaritae. De la misma forma, los cuerpos turbidíticos de los sondeos Orión 2-1, 6x1, B-3, B-6, Atlántida3, C-3 (del sector sur en el golfo de Cádiz) se encuentran ubicados en la biozona del grupo de G. miotumida, mientras que los sondeos del área norte del golfo de Cádiz (sondeos D-1, B-2, C-2, C4) presentan varios lóbulos superpuestos, ubicándose los más modernos en la biozona del grupo de G. margaritae. El último cuerpo turbidítico atravesado se localiza en el sondeo Atlántida-2 (sector noroeste del golfo de Cádiz).

Los cuerpos turbidíticos del área continental fueron profúsamente estudiados por Suárez et al. (1989). Estos autores identifican tres sistemas correspondientes a secuencias de depósito contemporáneas al depósito de la unidad litosísmica C. Uno de carácter siliciclástico ligado al talud norte, otro relacionado con una plataforma carbonatada 
inestable en el sur, y por último un sistema axial, con el complejo turbidítico situado en la parte más profunda de la cuenca (fig. 7.13). Este sistema axial está limitado al norte por una zona de by-pass y/o no sedimentación que lo separa del sistema de depósito norte mientras que al sur limita con el olistostroma.

Esta disposición geométrica implica la coexistencia de tres paleopendientes, siendo la de menor gradiente la axial, E-W. El aporte de sedimentos se puede realizar desde los dos bordes, norte y sur, aunque una vez que los sedimentos llegan al fondo de la cuenca, se mueven en dirección E-W, en el sentido de la pendiente axial. El sistema turbidítico de las "arenas del Guadalquivir", prograda de este a oeste, en el sentido de la pendiente del eje de la cuenca, y estaría formado según Suárez et al. (1989) por al menos seis aparatos turbidíticos completos, que presentan un alto grado de deriva lateral en sentido norte-sur, ya que se encuentran yuxtapuestos en la horizontal.

Suárez et al. (1989) realizan el análisis de las facies sísmicas correspondientes a las arenas del Guadalquivir, identificando y describiendo este sistema turbidítico en base a las morfologías del techo de los cuerpos arenosos. Estos autores describen tres tipos de facies de morfología sísmica que, de proximal a distal, son: facies de canal, facies de canal con levees y facies de lóbulo.

La cartografía y la descripción de los cuerpos turbidíticos sugieren a estos autores que la evolución cíclica del depósito del aparato turbidítico y posterior abandono hasta el siguiente episodio, se repitió más de seis veces durante el Messiniense. Por otro lado, la geometría interna de cada uno de estos aparatos turbidíticos indicaría un downlap de los niveles arenosos de este a oeste y simultáneamente un cierto onlap hacia el norte.

Los aparatos están individualizados por cicatrices, normalmente erosivas, que los separan entre sí. Las cicatrices representan truncaciones de los reflectores asociados a niveles arenosos y siempre buzan hacia el norte. Estas cicatrices están asociadas a contactos canal-canal con levees y canal con levees-lóbulo, mientras que los contactos lóbulo-lóbulo llevan asociadas cicatrices mucho más suaves y planas (Suárez et al., 1989). También en los afloramientos de campo aparecen estas superficies erosivas bajo los canales (Sierro et al., 1996). Dentro de cada uno de los aparatos turbidíticos se registran todos los estadios intermedios de proximal a distal: canales poco desarrollados, canales desarrollados, canales con levees, lóbulos proximales y lóbulos distales. 
NW

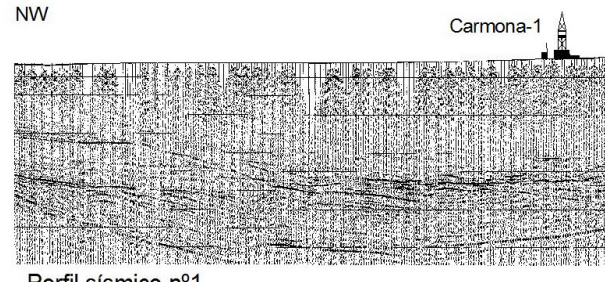

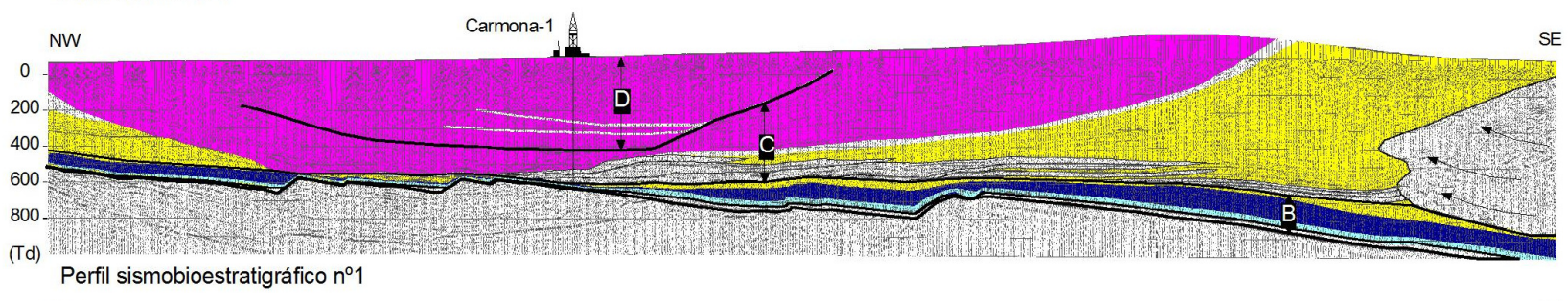
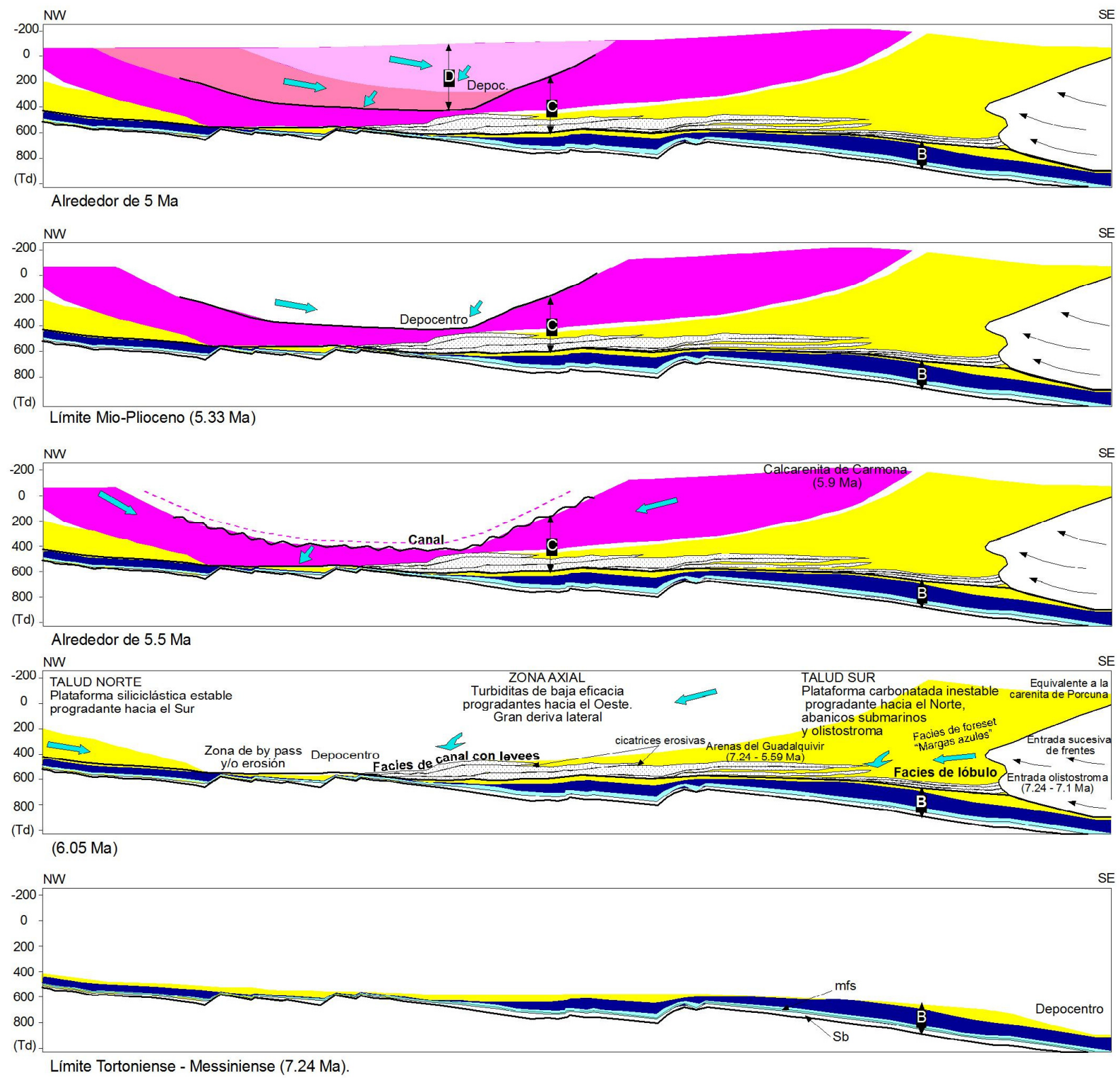

Límite Tortoniense - Messiniense (7.24 Ma)

Figura 7.13. Evolución del relleno sedimentario sobre el perfil sismobioestratigráfico $\mathrm{n}^{0} 1$. Profundidad en milisegundos (TD, tiempo doble).

(Principales direcciones
de aporte de sedimentos)
Formación "Arenas del Guadalquivir"


La edad astronómica de los primeros depósitos turbidíticos atravesados por los sondeos estudiados es de 7.24 Ma y corresponden a la base de las arenas que atraviesa el sondeo Santa Clara-1. Algo más modernas $(7.1 \mathrm{Ma})$ son las arenas atravesadas por el sondeo Casanieves-1 y más al sur, en el golfo de Cádiz, los primeros lóbulos turbidíticos aparecen entre 6.72 y 6.35 Ma. Más tarde, las arenas perforadas en el sondeo Marismas-4 en el Guadalquivir y los tramos arenosos superiores de los sondeos del norte del golfo de Cádiz (D-1, B-2, C-2, C-4...), contienen G. margaritae, por lo que se depositaron en torno a 6.0 Ma, siendo aún más modernas las atravesadas por el sondeo At-2. En este último periodo, hacia la cabecera de la cuenca (entre Sevilla y Carmona) se observan facies de canal, con superficies erosivas bajo los canales (sondeo Carmona-1). Finalmente, en los perfiles sismobioestratigráficos (capítulo 4) podemos observar el solapamiento de los aparatos turbidíticos por una unidad a modo de cuña ligada al talud norte y que proporciona algunos niveles arenosos más modernos (entre 6.0-5.33 Ma).

En la figura 7.14, se puede observar la progresión de los lóbulos turbidíticos de la unidad C. En esta Tesis, la denominación de los diferentes cuerpos turbidíticos sigue la nomenclatura utilizada por Suárez et al. (1989). La distribución de los cuerpos ha sido modificada en función de los resultados micropaleontológicos obtenidos (capítulo 6). Los cambios realizados han supuesto la modificación de los límites de los aparatos turbidíticos (Gv-2 a Gv-6) y fundamentalmente la extensión al golfo de Cádiz del área de influencia de los últimos aparatos (Gv-5 y Gv-6), así como la incorporación de al menos un nuevo aparato turbidítico, Gv-7.

Hacia el final del Tortoniense se produce el ingreso del frente olistostrómico en el Guadalquivir y un espectacular levantamiento de la zona oriental de las Béticas (Sierras de Cazorla y Segura). La elevación del sector oriental provoca el aumento de la energía potencial de los sedimentos de la cabecera de la cuenca. El desarrollo del complejo turbidítico de la cuenca del Guadalquivir-golfo de Cádiz se produce en un contexto compresivo que tuvo lugar a finales del Tortoniense y a lo largo del Messiniense y que propició el progresivo confinamiento de la cuenca del Guadalquivir. La entrada del Olistostroma en el borde sur de la cuenca del Guadalquivir modifica su configuración creando un abrupto borde sur y un fondo de cuenca estrecho en dirección N-S y alargado en dirección E-W. Desde su comienzo, el sistema turbidítico está condicionado por la tectónica regional. La migración lateral de los lóbulos hacia el talud norte, sin duda ha sido condicionada por el levantamiento del edificio bético. Los sucesivos lóbulos pueden estar ligados a pulsos de elevación tectónica durante el Messiniense, pudiendo provocar las cicatrices erosivas que presentan los cuerpos en su base. La configuración interna de los lóbulos, con niveles de arcilla intercalados entre los depósitos de arena, puede estar 
controlada en parte por el régimen climático, que a su vez responde a las variaciones astronómicas (capítulo 5).

El emplazamiento del cuerpo Gv-2 (fig. 7.14A), se produce prácticamente en el límite Tortoniense-Messiniense. Respecto a la distribución de este cuerpo propuesta por Suárez et al. (1989), se ha extendido la facies de lóbulo hasta alcanzar la posición del sondeo Santa Clara-1. En el sondeo Santa Clara-1 (fig. 6.4), este cuerpo comienza inmediatamente después de la desaparición $(L O)$ del grupo de G. menardii dx (7.240 Ma) y termina debajo del techo del paracme de R. pseudoumbilicus (7.112 Ma), de forma que el aparato turbidítico Gv-2 ha sido datado entre 7.240 y $7.112 \mathrm{Ma}$.

El siguiente cuerpo Gv-3 (fig. 7.14A) no se atraviesa directamente por ninguno de los sondeos estudiados. La presencia del aparato Gv-3 en los perfiles sísmicos próximos a Sevilla (capítulo 4) ha obligado a extender el área de influencia de este cuerpo hasta al sur de la capital andaluza. Se ha detectado la influencia distal del cuerpo Gv-3 en los sondeos Carmona-2, Sevilla-2, San Juan Z-1, San Juan V-2, San Juan R-1, Palancares-1, Villamanrique-1, Casanieves-1 y Marismas-1. En todos ellos, este aparato aparece comprendido entre la $F O$ del grupo de G. miotumida (7.240 Ma) y el techo del paracme de $R$. pseudoumbilicus $(7.112 \mathrm{Ma}$ ) por lo que su edad estaría comprendida entre este intervalo de tiempo, siendo posterior a la edad del cuerpo Gv-2.

La distribución del aparato Gv-4 (fig. 7.14B) se ha ajustado así mismo respecto a la posición de los sondeos en los que ha sido atravesado, desde el sondeo Carmona-2 (al este de la zona de estudio), hasta el Marismas-2 (al oeste), pasando bajo la ciudad de Sevilla. Su distribución se ha ajustado al borde del olistostroma en subsuperficie, aunque se extiende probablemente incluso sobre la cuña olistostrómica (como en el caso del sondeo Casanieves-1, fig. 6.17). La datación de este aparato es muy precisa gracias al calibrado astronómico del registro geofísico de los sondeos Villamanrique-1 y Casanieves-1 (fig. 5.15). El análisis cicloestratigráfico sobre estos sondeos proporciona una edad astronómica de 7.1 Ma para la base y 6.8 Ma para el techo de este cuerpo.

El aparato turbidítico Gv-5 (fig. 7.14C) es el que ha sufrido una mayor modificación respecto a la distribución propuesta por Suárez et al. (1989) de modo que se ha adaptado a los resultados micropaleontológicos obtenidos en el golfo de Cádiz. La presencia de niveles de arena en el golfo de Cádiz intercalados en la biozona de $G$. miotumida, así como las secciones transversales de lóbulos de arena observadas en los perfiles sismobioestratigráficos N-S del golfo de Cádiz (capítulo 4), parecen indicar la existencia de una conexión natural con los aparatos turbidíticos ubicados en el bajo Guadalquivir. Una vez en el golfo de Cádiz, la base "plana" del fondo de cuenca ha permitido el desarrollo completo de los lóbulos turbidíticos. 


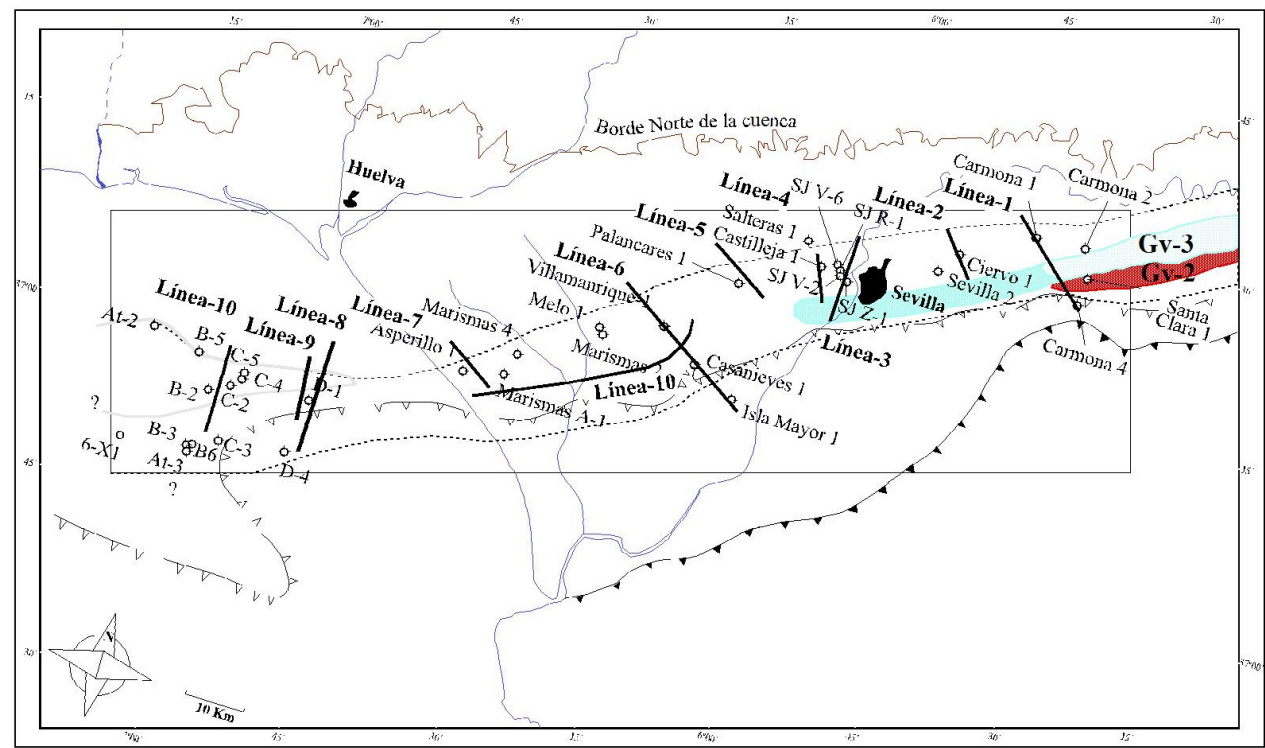

(A) Posición de los perfiles utilizados en la Tesis y emplazamiento de los primeros cuerpos turbidíticos messinienses detectados en el área de estudio, Gv-2 y Gv-3 (entre 7.240 y 7.112 Ma).

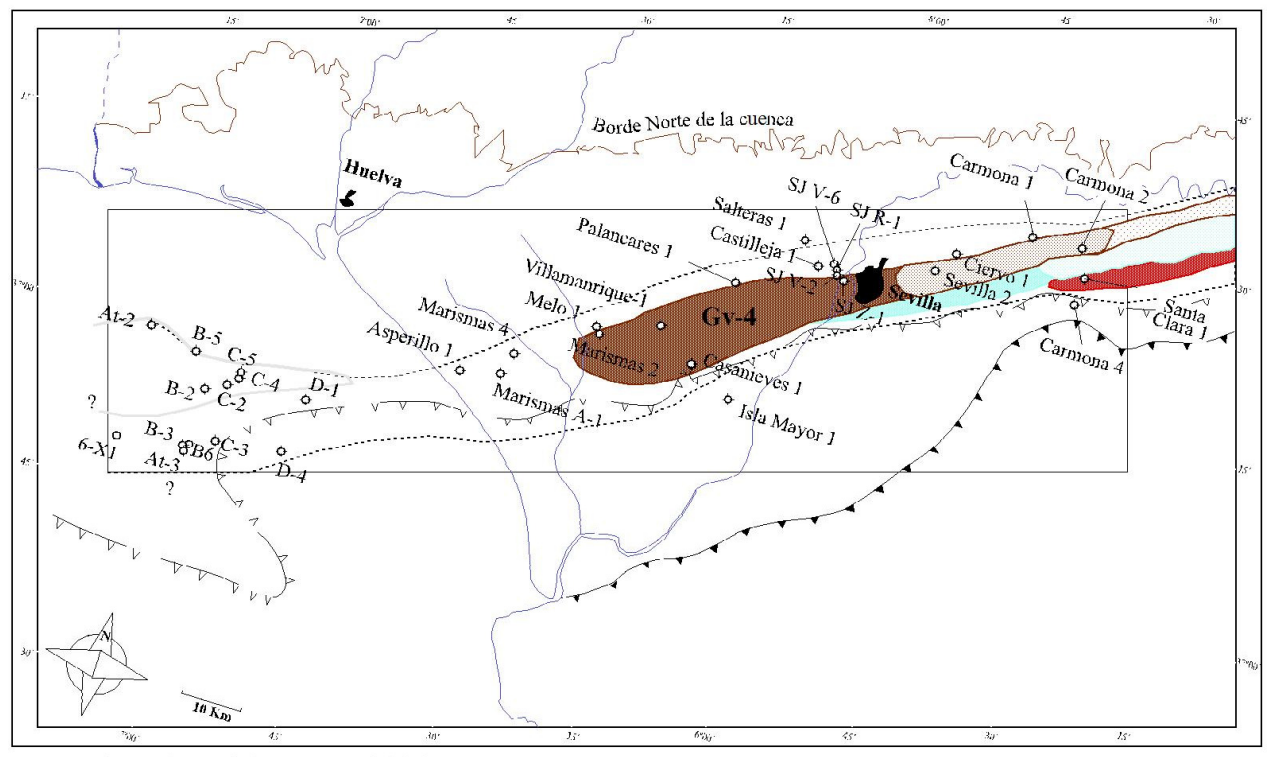

(B) Emplazamiento del cuerpo turbidítico Gv-4, (entre 7.1 y $6.8 \mathrm{Ma}$ ).

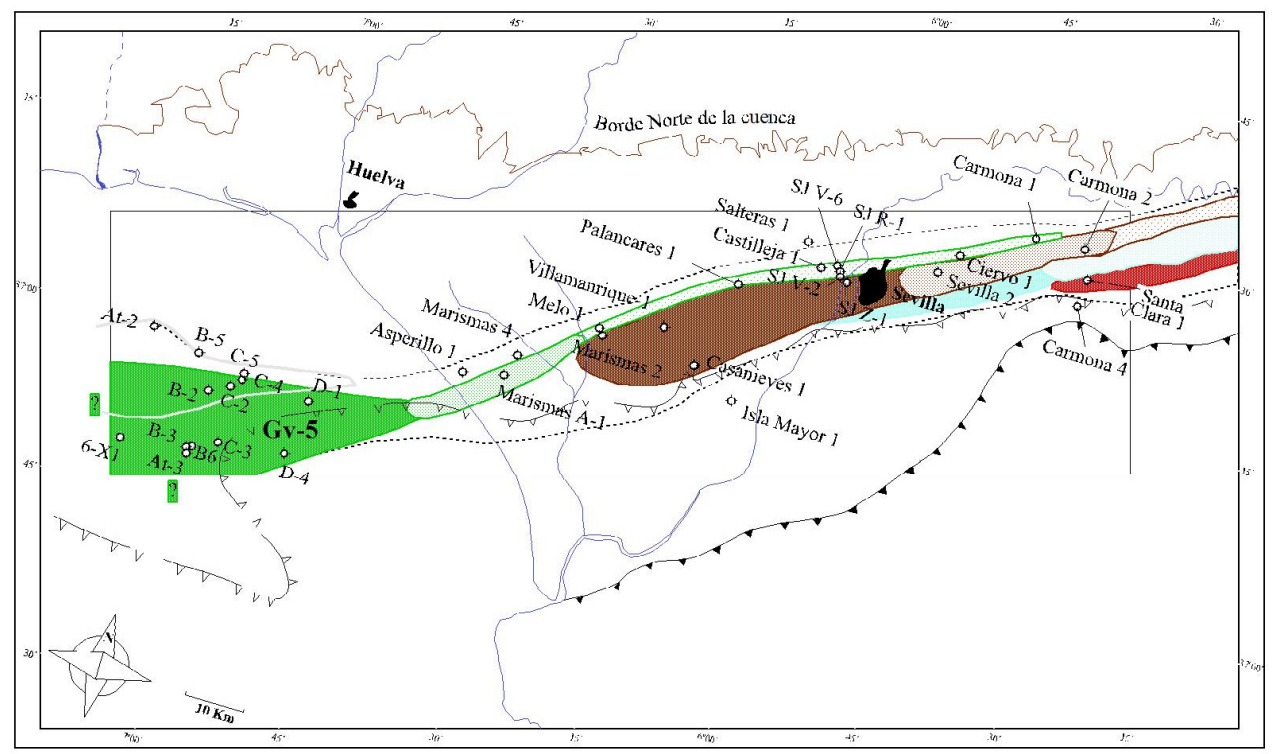

(C) Emplazamiento del cuerpo turbidítico Gv-5 (entre 6.8 y $6.3 \mathrm{Ma}$ ).

Figura 7.14. Aparatos turbidíticos messinienses en la cuenca del Guadalquivir-golfo de Cádiz. 


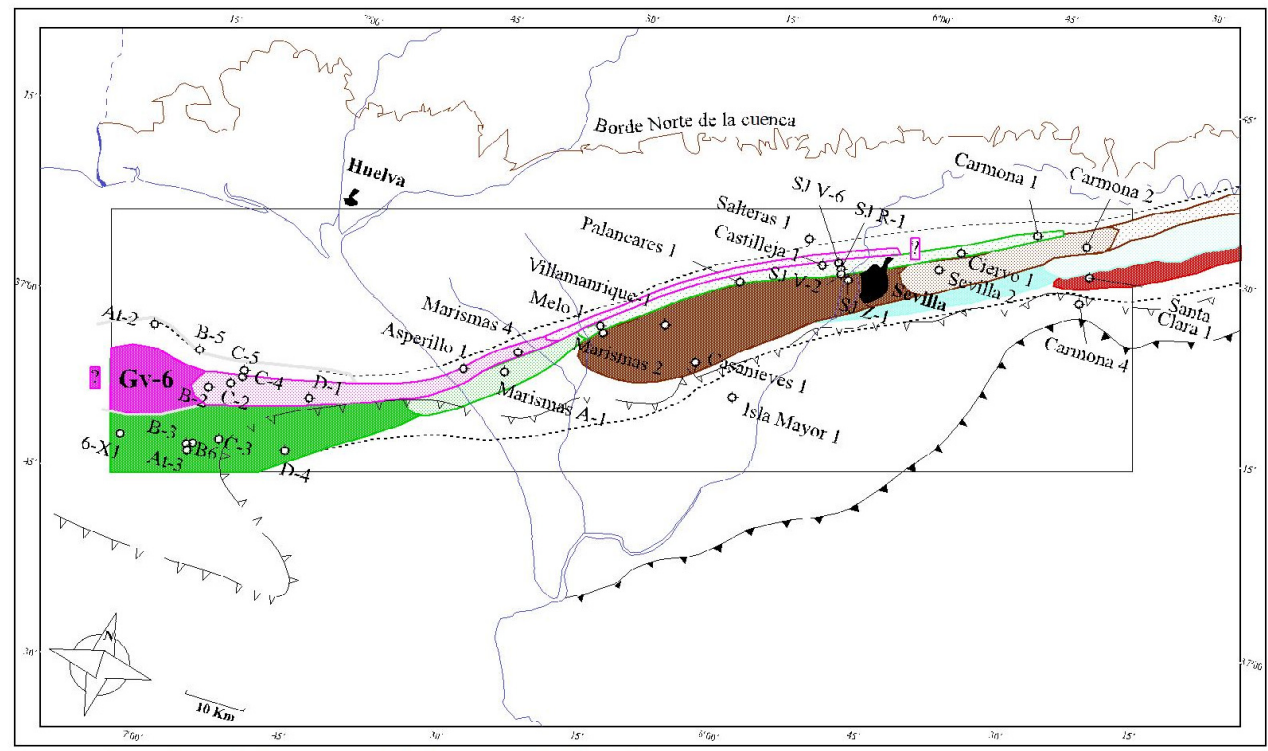

(D) Emplazamiento del cuerpo turbidítico Gv-6 (hacia $6.0 \mathrm{Ma}$ ).

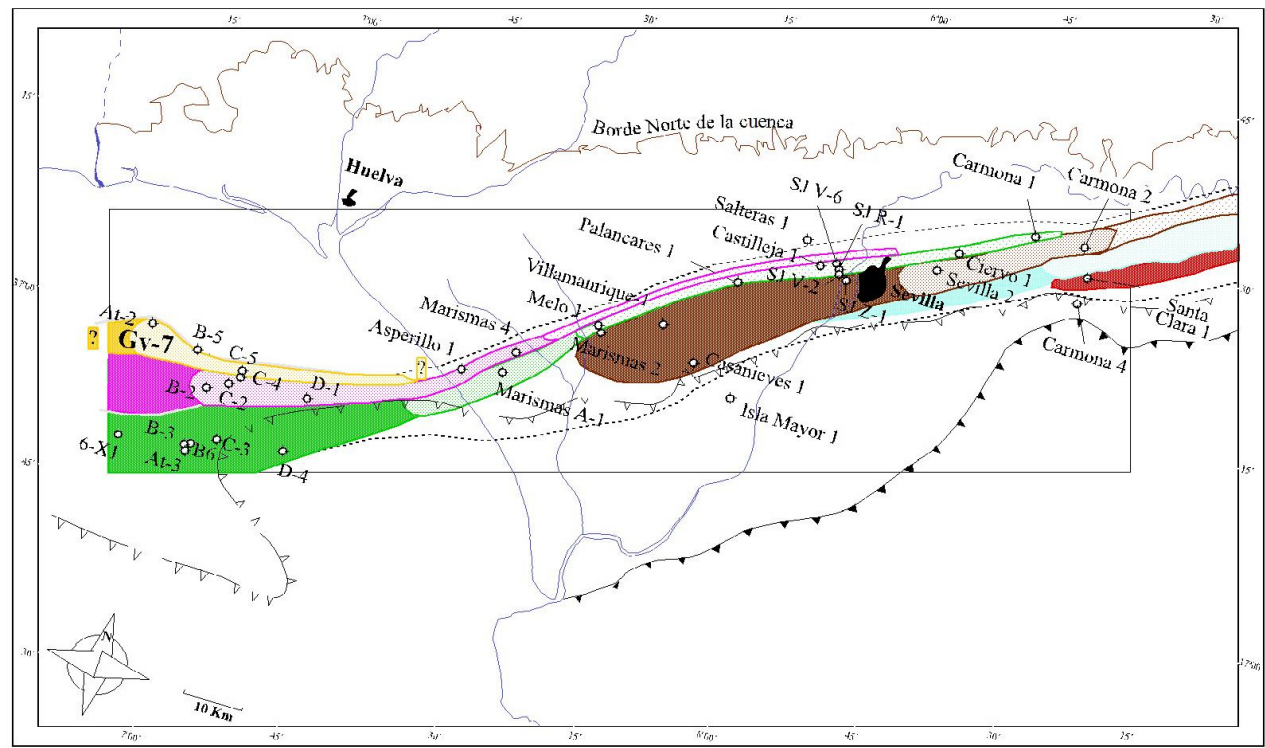

(E) Desarrollo del cuerpo turbidítico Gv-7 (entre 6.0 y $5.33 \mathrm{Ma}$ ).
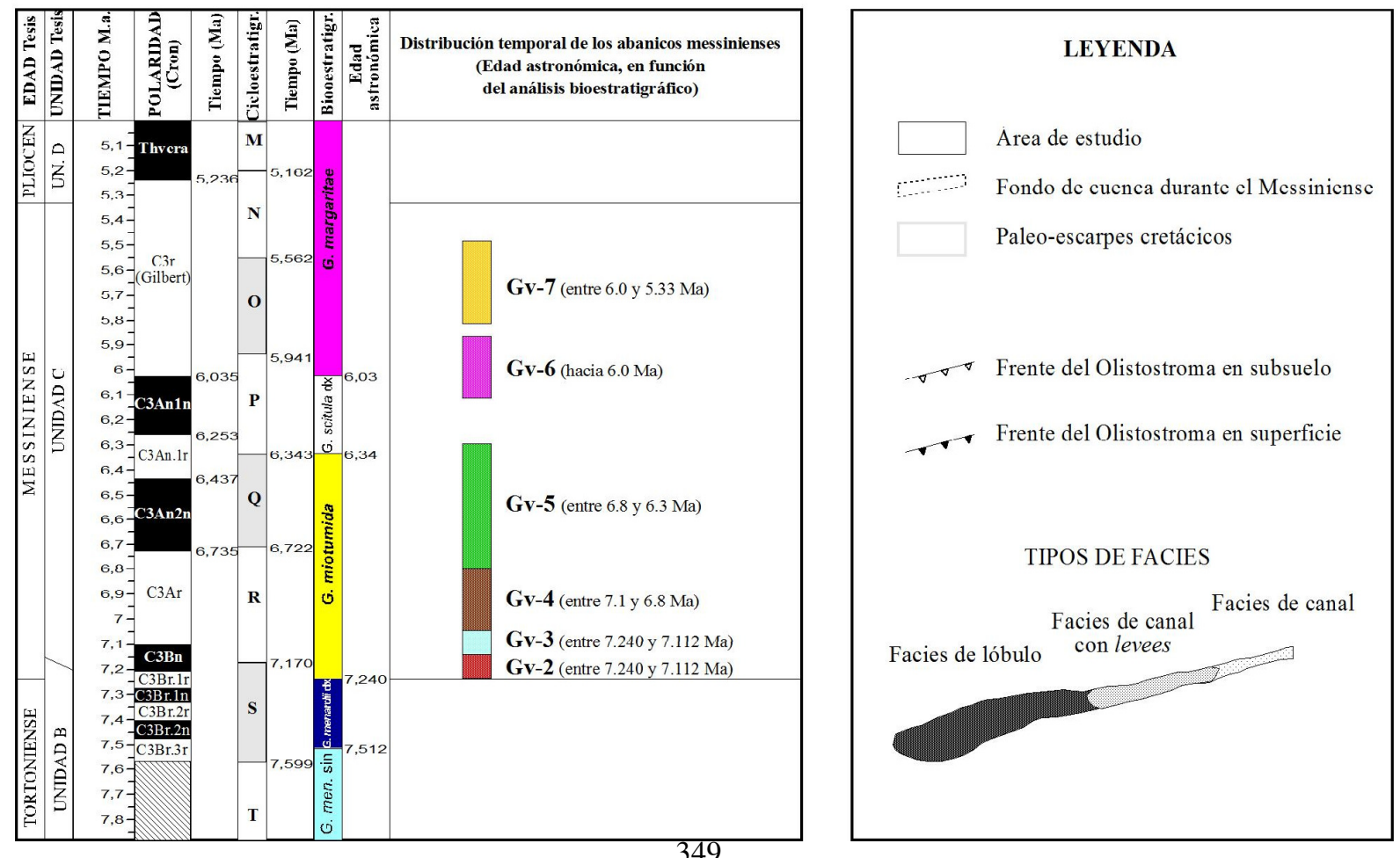
En función de su posición estratigráfica respecto a los aparatos precedentes se ha datado la base del aparato Gv-5 en torno a 6.8 Ma. La datación del techo de este aparato en 6.3 $\mathrm{Ma}$, se ha establecido teniendo en cuenta que inmediatamente encima del mismo, se localiza el cambio de enrollamiento de $N$. acostaensis $(6.35 \mathrm{Ma})$ y la desaparición $(L O)$ del grupo de G. miotumida (6.3 Ma). Por lo tanto se interpreta que el depósito del aparato Gv-5 se produce entre 6.8-6.3 Ma.

Actualmente se considera que existe una desconexión física entre los aparatos turbidíticos del Guadalquivir y los del golfo de Cádiz, sin embargo la ausencia de perfiles sísmicos junto a la línea de costa actual (que separa ambos dominios) no permite ser concluyentes en este sentido (Martínez del Olmo com. per.). Por otro lado se ha constatado en esta Tesis que la edad de los aparatos turbidíticos al sur del golfo de Cádiz es equivalente a la que presenta el aparato Gv-5 en el Guadalquivir. Por lo tanto, aún existiendo una desconexión física, no existe desconexión temporal. En este sentido podría existir una zona de reactivación en torno a la posición de la actual línea de costa, de forma que el aumento de pendiente que se registra en esa zona (perfil sísmico $\mathrm{n}^{\circ} 11 \mathrm{en}$ fig. 4.2) deslice los sedimentos hacia el fondo de cuenca y produzca una aparente zona de desconexión de tipo bypass.

El aparato Gv-6 (fig. 7.14) se ha datado en el área del Guadalquivir en función de las arcillas con abundante $G$. margaritae localizadas bajo los niveles de arena en el sondeo Marismas-4 (fig. 6.21). La presencia del aparato turbidítico sobre la FCO del grupo de G. margaritae en el sondeo Marismas-4 indicaría una edad posterior a $6.05 \mathrm{Ma}$ corroborada por el nivel arenoso con ejemplares de G. margaritae que aparece en la base de Asperillo-1 y por el análisis de los perfiles sismobioestratigráficos. En el perfil sismobioestratigráfico $\mathrm{n}^{\mathrm{o}} 1$ (fig. 4.4) observamos como al norte del sondeo Carmona-1 existen fuertes canalizaciones en la biozona del grupo de $G$. margaritae que probablemente son contemporáneas a este aparato turbidítico. Progresando sobre el cuerpo turbidítico precedente, el aparato Gv-6 alcanza el $\mathrm{N}$ del golfo de Cádiz sobre el área que ocupan los sondeos B2 y C2 (fig. 7.14) en los que también se ha datado este cuerpo en torno a 6.05 Ma.

El aparato Gv-7 (fig. 7.14) se desarrollaría exclusivamente en el golfo de Cádiz, pudiendo estar enraizado con la cicatriz erosiva observada por Martínez del Olmo et al. (1996) en el alto Guadalquivir (fig. 7.15). En función del análisis bioestratigráfico, su edad estaría comprendida entre la $F C O$ del grupo de G. margaritae (6.05 Ma) y el límite Mio-Plioceno (5.33 Ma). No obstante su posición estratigráfica sobre el cuerpo Gv-6 indicaría una edad próxima al límite Mio-Plioceno, probablemente hacia 5.5 Ma. De los 
sondeos estudiados, solo Atlántida-2 y posiblemente el sondeo C4, atraviesan este aparato turbidítico.

Estos son los principales aparatos detectados y sus respectivas dataciones bioestratigráficas, sin descartar no obstante la posibilidad de que exista algún aparato turbidítico posterior o intermedio a los detectados.
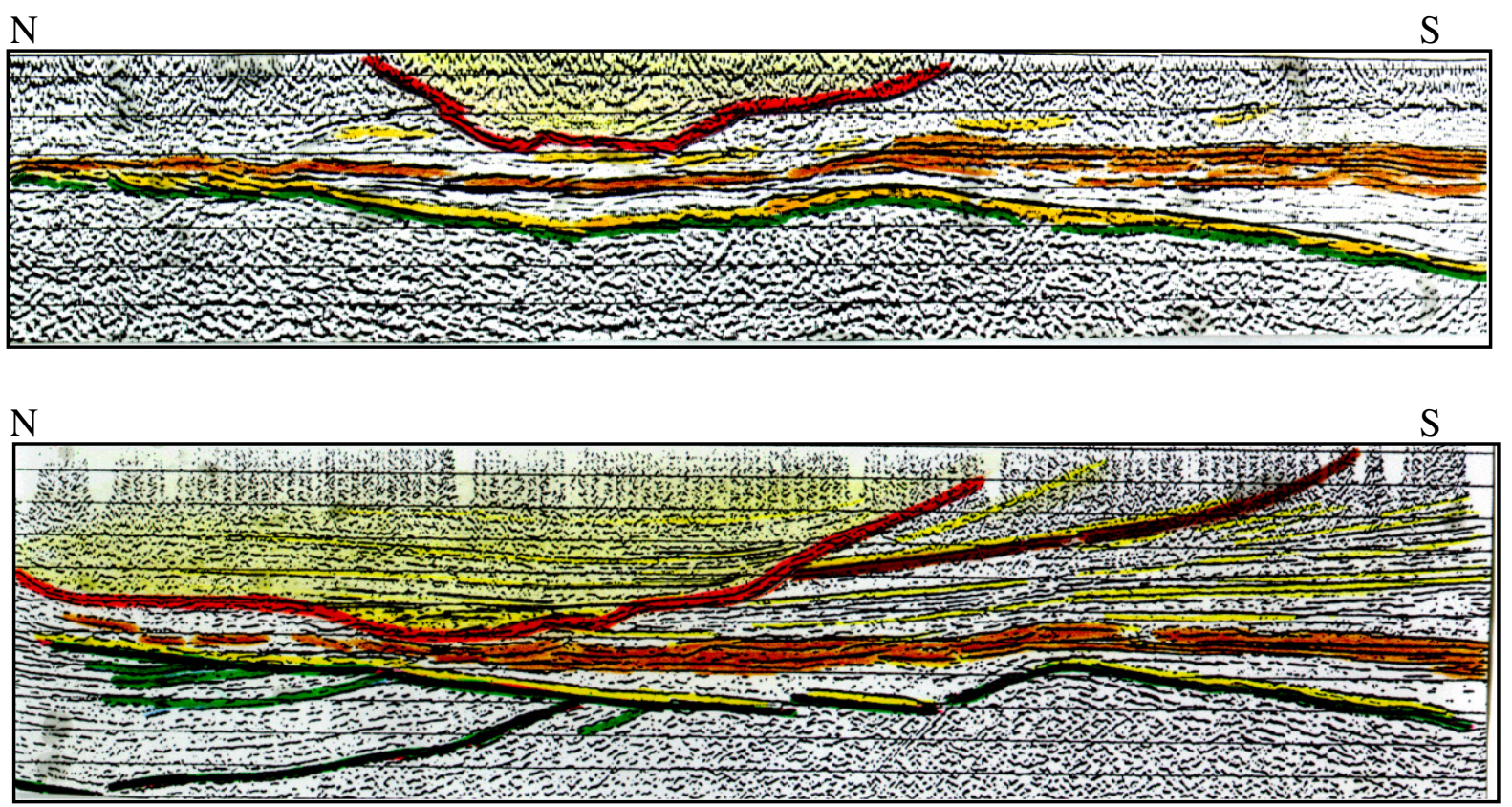

Figura 7.15. Interpretación de 2 líneas sísmicas de dirección $\mathrm{N}-\mathrm{S}$, transversales a la cuenca y localizadas en las inmediaciones de Carmona. En verde zócalo preterciario; en naranja las arenas del Guadalquivir; en rojo erosión del cañón intramessiniense y en amarillo su posterior relleno (Martínez del Olmo, com. per.).

La figura 7.16 muestra un ejemplo de correlación cicloestratigráfica sobre el perfil sísmico $n^{\circ} 10$. Esta figura combina la bioestratigrafía (capítulo 3) y la cicloestratigrafía de los sondeos B2 y C2 (capítulo 5) con el perfil sísmico $\mathrm{n}^{\circ} 10$ (capítulo 4) que posee gran calidad y donde se pueden identificar las unidades cicloestratigráficas de $400 \mathrm{Ka}$. Esta combinación de disciplinas constituye un excelente marco de correlación y datación de los perfiles sísmicos. En la figura 7.16 podemos observar la diferente zonación bioestratigráfica de los cuerpos Gv-5, G-6 y Gv-7, su relación espacial y la edad de los mismos. Gracias al análisis cicloestratigráfico de los sondeos y a la calidad del perfil sismico, se ha proyectado la cicloestratigrafía obtenida en los sondeos B2 y C2 sobre el perfil mostrando las unidades cicloestratigráficas y la datación de las mismas a la derecha de la imagen. En la figura, se incluye además un pequeño esquema resumen con la distri- 


\begin{tabular}{|c|c|c|c|c|c|c|}
\hline рерэ & 0 & des 'olnd & - $\mathrm{NNI}$ "Olרd & ISNヨINISS $\exists W$ & 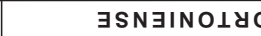 & \\
\hline euozo!g & CII & 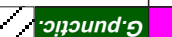 & әерџлеблеи & \begin{tabular}{|l|l|}
$x p$ 's \\
\end{tabular} & хр црдеиәш 'פ & (C/ \\
\hline eग!ms|sol!! ' & $\exists$ un & a pep!̣un & & o peplun & g pep̣un & $\forall$ pep!un \\
\hline
\end{tabular}
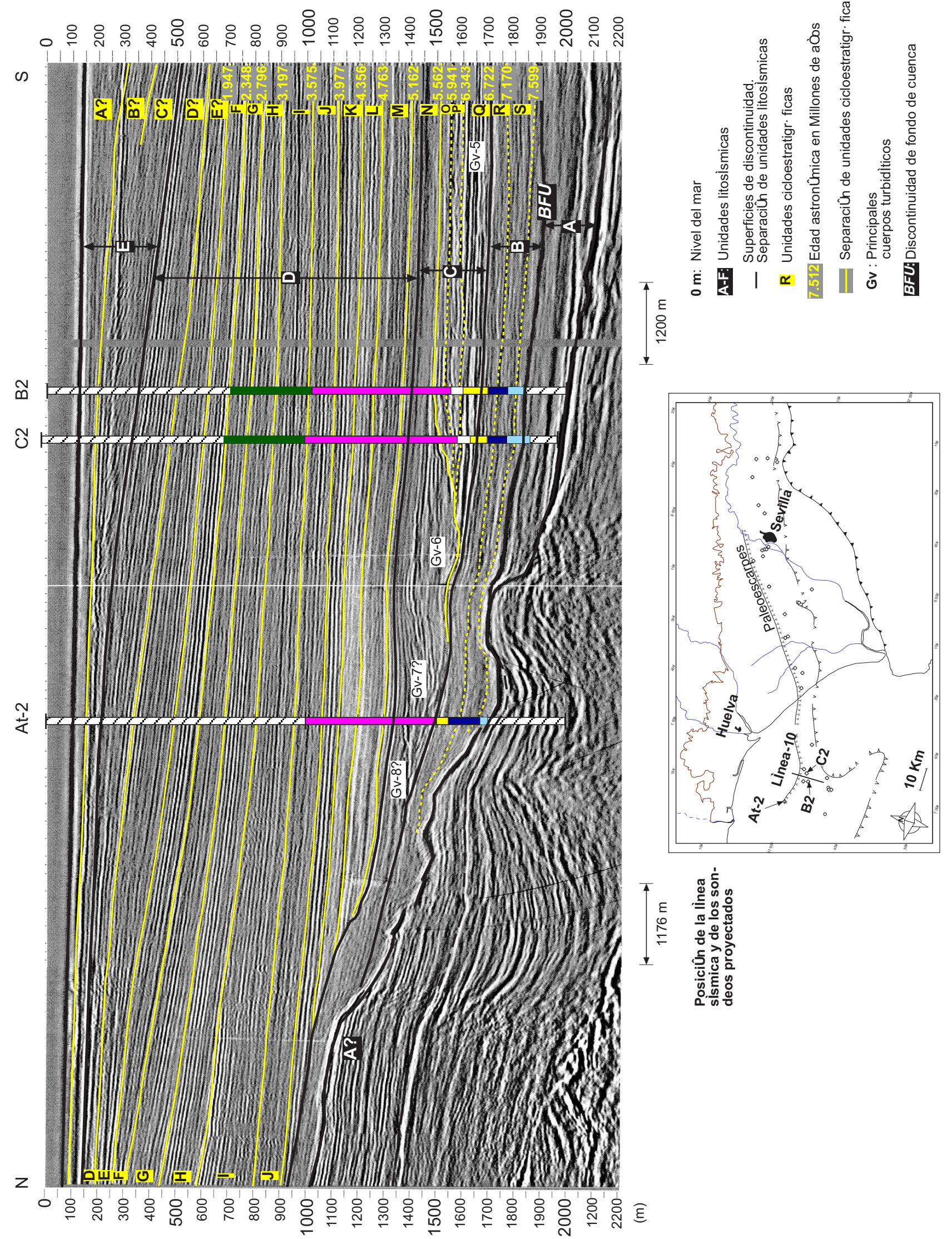

吾) 
bución de la bioestratigrafía, las unidades litosísmicas y la posición de los diferentes cuerpos turbidíticos.

Tal y como reflejan los perfiles simobioestratigráficos (capítulo 4) y los paneles de correlación (fig. 7.9), el cuerpo turbidítico Gv-6 y posibles cuerpos posteriores (Gv-7), podrían ser contemporáneos a la calcarenita de Carmona en facies proximales. Del mismo modo, los primeros aparatos turbidíticos ( $\mathrm{Gv}-2$ a Gv-5) podrían estar relacionados en facies proximales con formaciones equivalentes a la calcarenita de Porcuna.

\subsubsection{Unidad litosísmica $D$}

Después de la potente acumulación de materiales autóctonos y alóctonos fundamentalmente en el margen sur, la cuenca se hunde por el SE entorno al límite MioPlioceno (5.33 Ma) (fig. 7.10). La base de la unidad litosísmica D está definida en función de este acontecimiento detectado sísmicamente por la disposición en downlap de los reflectores inmediatamente superiores y que va a dar lugar a una sección condensada sobre la zona inundada. En el análisis de las muestras estudiadas, este nivel es detectado debido a la presencia concentrada de foraminíferos planctónicos (golfo de Cádiz) y a la rápida sucesión de bioeventos (sondeos Carmona-2, Ciervo-1, San Juan R-1, San Juan V6, San Juan R-1, San Juan V-2...), o por la presencia de glauconita en las muestras de los sondeos (San Juan V-2, Carmona-1). Este nivel podría ser equivalente a un nivel glauconítico similar detectado en aforamientos de campo de la provincia de Huelva y que costituye un tradicional nivel guia en este área (Sierro, 1984; Civis et al., 1987; Sierro et $a l .$, 1996). Este nivel de glauconita podría ser interpretado como una sección condensada depositada durante la superficie de máxima inundación pliocena.

Como consecuencia de esta rápida subida relativa del nivel del mar se produce una transgresión que afecta fundamentalmente al margen sur de la cuenca. El cortejo transgresivo está escasamente desarrollado en el área de estudio y el mejor reflejo lo constituye la superficie terminal de máxima inundación $(m f s)$, en relación con la cual se deposita la sección condensada. A continuación se desarrollaría un potente cortejo sedimentario de alto nivel del mar (highstand systems tract, HST) con dispositivos progradantes (obsérvese el perfil sismobioestratigráfico $\mathrm{n}^{\circ} 11$ de la figura 4.4) y que constituye el grueso de la unidad litosísmica D. Con el nivel del mar en posición elevada se desarrolla un dispositivo progradante en el que se ha registrado la mayor parte de los ciclos sedimentarios de alta frecuencia utilizados en el análisis cicloestratigráfico de los sondeos del golfo de Cádiz (fig. 7.16). 


\subsubsection{Límite Mio-Plioceno}

El estratotipo del límite Mio-Plioceno ha sido recientemente propuesto por Hilgen y Langereis (1993) en la base de la secuencia de Trubi en la sección de Eraclea Minoa (sur de Sicilia) después de que en Capo Rossello, donde Cita (1975) propuso este límite, no pudieran ser obtenidos datos de paleomagnetismo. La proposición de Benson y RakicEl Bied (1996) para definir este límite en la sección del Bou Regreg (Marruecos), coincidiendo con la base del intervalo paleomagnético $\mathrm{C} 3 \mathrm{r}$, es controvertido y está todavía en discusión (Di Stefano, 1998).

Hilgen y Langereis (1993) adelantan que el reconocimiento de este límite en el registro de océano abierto es difícil, debido a la falta de marcadores bioestratigráficos en este nivel. Recientes artículos basados en secciones continentales de Calabria muestran que este límite sucede levemente debajo (cinco ciclos astronómicos) de la base del subcron de Thvera, por debajo de la desaparición $(L O)$ de Triquetrorhabdulus rugosus (Channell et al., 1988; Hilgen y Langereis, 1988). Por consiguiente, este límite tiene una edad de 5.33 Ma (Hilgen, 1991b) localizándose fuera de las secuencias marinas Mediterráneas en la Subzona CN10a de la zonación de Okada y Bukry (1980).

En torno a 5.33 Ma, en la cuenca del Guadalquivir-golfo de Cádiz se produjo un importante cambio en la configuración de la cuenca y en el suministro de sedimentos. En este momento se produce un incremento significativo de la subsidencia del margen sur de la cuenca, de forma que bascula y se inunda. Este fenómeno regional, que debe afectar probablemente a todo el sistema bético es apreciado también por Maldonado et al. (1999) en el área del golfo de Cádiz. Este importante cambio va a producir una fosilización del talud sur de la cuenca del Guadalquivir-golfo de Cádiz (figuras 7.9 y 7.10), que pasará de ostentar la mayor velocidad de sedimentación a conformar una superficie de condensación sobre la que se asentarán en downlap los aportes posteriores que llegan desde el talud norte. Este cambio de tendencia puede observarse en varios de los perfiles sismobioestratigráficos (fig. 4.4). A partir del límite Mio-plioceno, comienza a depositarse la unidad litosísmica D que es regresiva, progradante y se desarrolla en un contexto de alto nivel del mar. Esta unidad refleja un importante aporte de sedimentos desde la cabecera de la cuenca y desde el talud norte. A partir de este momento, comenzará un desplazamiento lateral del depocentro de la cuenca hacia el SE (fig. 4.4), que no cesará hasta nuestros días. Obsérvese la dirección N-S que toma el actual río Guadalquivir por debajo de Sevilla respecto a la dirección general E-W de la cabecera de la cuenca. En el golfo de Cádiz, el depocentro también se desplaza hacia el sur, sobre los sondeos del área meridional (fig. 7.16). Así mismo, en el perfil longitudinal nº 10 (fig. 
4.4) observamos como también avanza rápidamente la cabecera de la cuenca que se desplaza de este a oeste.

Como hemos visto en el capítulo 5, durante el Messiniense es característica la presencia de ciclos astronómicos en las facies hemipelágicas del talud sur de la cuenca (sondeos Casanieves-1 y Villamanrique-1). En el golfo de Cádiz, durante el mismo periodo, la escasa velocidad de sedimentación primero y la sedimentación turbidítica después, van a impedir la identificación de los ciclos astronómicos durante el Messiniense. A partir de $5.33 \mathrm{Ma}$ el hundimiento de la cuenca por el sureste, va a propiciar un desplazamiento del depocentro en este sentido por lo que los sondeos Casanieves-1 y Villamanrique-1 van a volver a situarse en el eje de la cuenca, incorporando materiales más groseros y perdiendo la ciclicidad astronómica característica en el Messiniense (fig. 5.17). Por otro lado el cese de la actividad turbidítica, sustituida por un suministro continuo de materiales finos desde el talud, va a permitir la individualización de ciclos astronómicos en los sedimentos pliocenos del golfo de Cádiz (capítulo 5) (fig. 7.16).

Como muestra la distribución de los depocentros y las elevaciones diapíricas, la sedimentación en el Plioceno inferior en el golfo de Cádiz parece controlada por la actividad diapírica, el colapso extensional del margen y la localización de las elevaciones tectónicas o de las depresiones diapíricas (Maldonado et al., 1999).

El hundimiento de la cuenca se produce fundamentalmente en el talud sur debido al cambio de las condiciones tectónicas del sistema bético y probablemente al reajuste que supone el peso del olistostroma y la potencia de los sedimentos acumulados en este borde durante el Tortoniense y el Messiniense. Sin lugar a dudas el efecto más destacado del reajuste del sistema bético lo constituye la aparición del estrecho en el arco de Gibraltar reanudándose definitivamente las comunicaciones marinas atlánticomediterráneas y ocasionando el final de la Crisis de Salinidad en el Mediterráneo. Al mismo tiempo se desarrollaron algunas cuencas subsidentes costeras en la bahía de Cádiz, Fuengirola, Málaga o Almería.

\subsubsection{Unidad litosísmica $\mathbf{E}$}

La unidad litosísmica E (Plio?-Cuaternario) podría corresponder al depósito de borde de plataforma $(S M W)$ formado tras el cortejo sedimentario de alto nivel del mar relativo, progradante y regresivo que formaba la unidad $\mathrm{D}$. La unidad litosísmica $\mathrm{E}$ sería equivalente a la secuencia Odiel que Riaza y Martínez del Olmo (1996) reconocen en 
varios de los sondeos del golfo de Cádiz mediante el análisis de diagrafías. Así mismo sería equivalente a la unidad litosísmica PQ de Maldonado et al. (1999). Sólo se ha determinado su presencia mediante el análisis de los perfiles sísmicos por lo que no existe un control fiable de la base de la unidad ya que no se ha determinado su bioestratigrafía. Riaza y Martínez del Olmo (1996) incluyen en esta secuencia un cortejo transgresivo y otro de alto nivel del mar (fig. 2.6).

\subsubsection{Posición relativa del nivel del mar}

Como podemos observar en la figura 7.17 el principal relleno de la cuenca lo constituyen fundamentalmente dos grandes unidades regresivas y progradantes (unidades litosísmicas $\mathrm{C}$ y D) separadas por un corto intervalo transgresivo poco desarrollado. La primera de estas unidades desarrolla frontalmente una serie de cuerpos turbidíticos que avanzan con el sistema. Es ilustrativo el hecho de que la potente unidad progradante desarrollada en el Plioceno no presente asociado un sistema turbidítico similar al que existe en el Messiniense. La diferencia entre ambos sistemas regresivos y progradantes está condicionada por la actividad tectónica del sistema bético durante el Tortoniense y especialmente el Messiniense.

- $\quad$ En el caso del Messiniense, la actividad tectónica compresiva viene acompañada de una impresionante elevación de la cabecera de la cuenca en el NE y del ingreso de varios megaelementos olistostrómicos desde las Zonas Externas del sistema bético al sur. Basta recordar que los primeros cuerpos turbidíticos desarrollados en Baeza se encuentran actualmente a más de 700 de altitud sobre el nivel del mar (Sierro com. per.) para estimar la considerable elevación tectónica sufrida por la cabecera de la cuenca durante el Messiniense. La unidad $\mathrm{C}$ es por tanto sinorogénica, contemporánea a la elevación del edificio bético. La enérgica actividad tectónica compresiva provoca sucesivos fenómenos de regresión forzada en los márgenes durante todo el Messiniense. Probablemente cada pulso tectónico significativo desencadena la formación de un aparato turbidítico. La ausencia de subsidencia, la actividad tectónica compresiva y el alto aporte sedimentario caracterizan este periodo.

El final del Mioceno se caracterizó por una regresión generalizada a lo largo de toda la cordillera Bética. Las cuencas béticas orientales localizadas en las Zonas Internas fueron afectadas por la crisis de salinidad mediterránea. Emergió el Subbético y el sector central de la cordillera (ya emergido desde el Tortoniense superior) sufrió una etapa erosiva al tiempo que las cuencas intramontañosas soportaron un potente relleno de depósitos clásticos (Boccaletti, et al., 1987). 


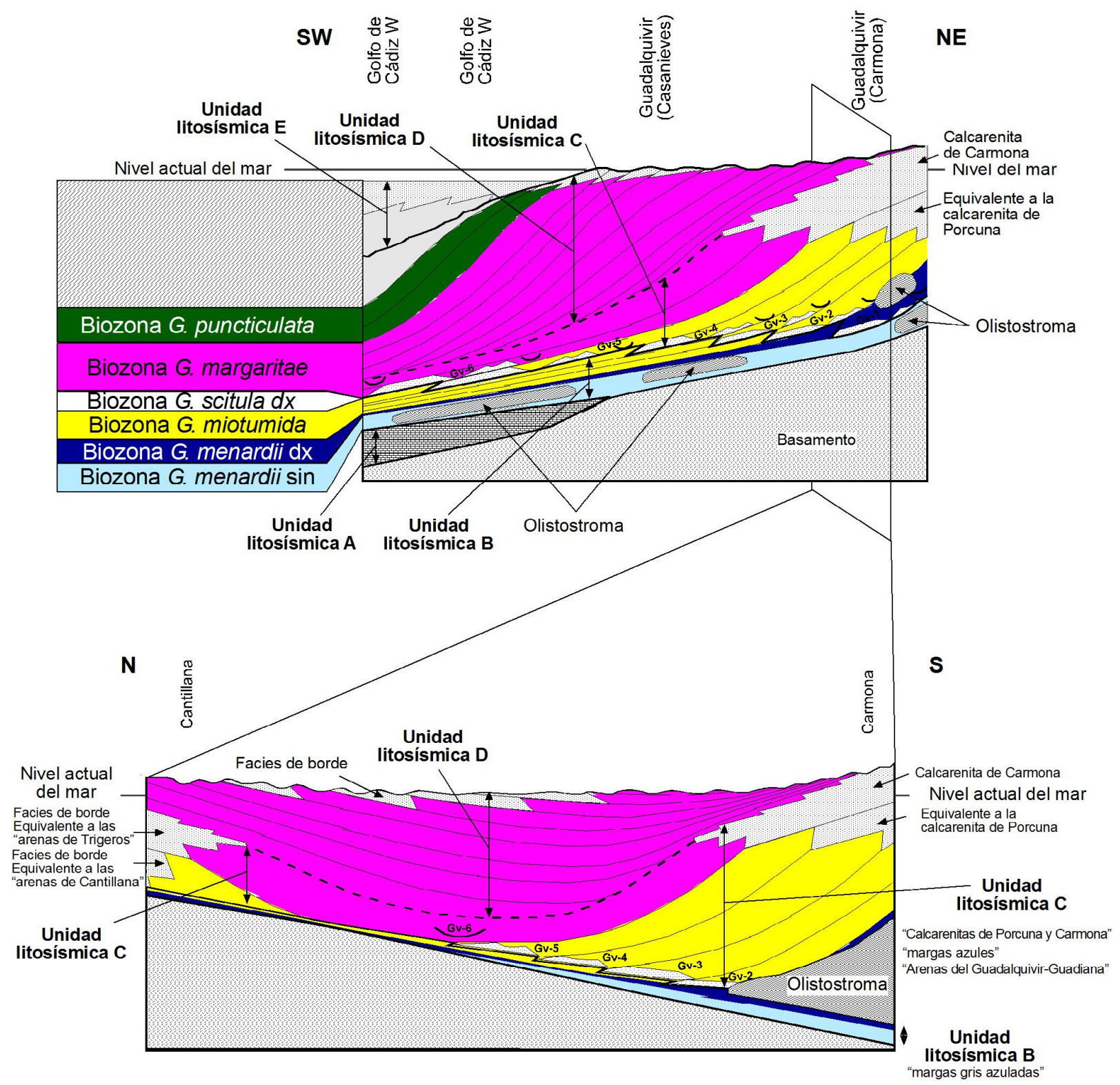

Figura 7.17. Esquema simplificado de la disposición de las unidades litosísmicas en un panel longitudinal al eje de la cuenca (arriba) y perpendicular a la misma (abajo). Las unidades litosísmicas A, B, C y D son sincrónicas, salvo en el intervalo de separación entre las unidades B y C que ha sido establecido en función de la base de los aparatos turbidíticos (ver esquema inferior). Se han representado unicamente 4 de las 5 unidades bioestratigráficas con el fï de simplificar el esquema deposicional. La biozona del grupo $G$. scitula dx representaría una estrecha franja entre las biozonas del grupo $G$ miotumida y $G$ margaritae.

SW

NE

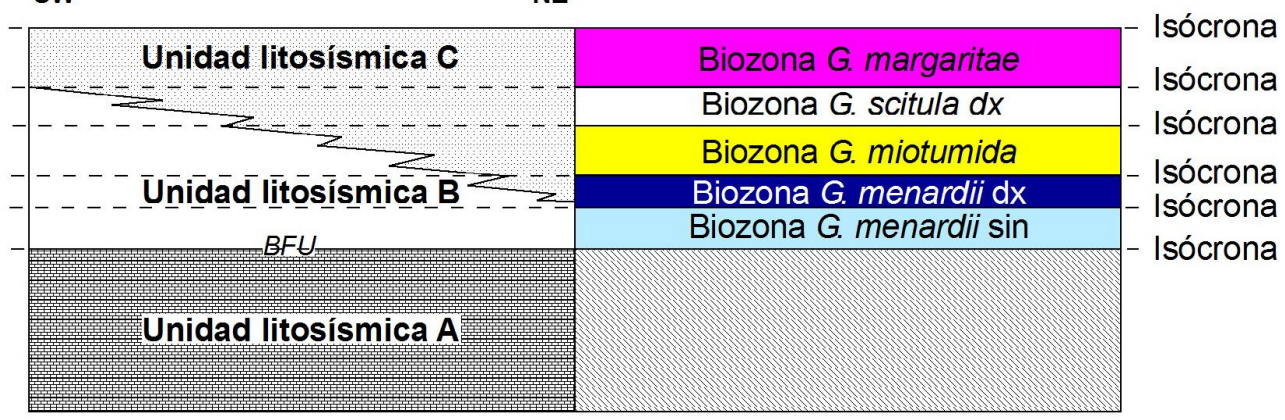

Diferencia entre unidades diacrónicas (unidades litosísmicas) y unidades sincrónicas (biozonas), modificado del Código Estratigráfico norteamericano (NASC, 1983). Las unidades litosísmicas A, B y C son sincrónicas salvo en el sector en el que se produce el cambio de las unidades B y C. 
Los cambios relativos del nivel del mar son fruto de la interrelación de tres factores fundamentales que regulan la sedimentación en un sector e intervalo de tiempo concretos. Estos tres factores son: subsidencia, cambios eustáticos y volumen de sedimentos. Teniendo en cuenta que un aumento de la subsidencia, del nivel del mar y del espesor de los sedimentos representan valores positivos, mientras que en el sentido contrario reflejan valores negativos (Vera 1994). La relación entre ellos es la siguiente:

$$
\begin{gathered}
\text { + Incremento de subsidencia } \\
+ \text { cambio eustático del nivel del mar } \\
\text { - espesor de sedimentos } \\
\text { = cambio relativo del nivel del mar }
\end{gathered}
$$

En el Messiniense la relación anterior es claramente negativa provocada por un ascenso tectónico (subsidencia negativa) y un gran espesor de sedimentos (incluido olistostroma). También se han registrado evidencias de este ascenso tectónico en la cuenca Taza-Guercif en el norte de Marruecos (Krijgsman et al., 1999c). Por lo tanto se obtendría un descenso relativo del nivel del mar durante el depósito de la unidad litosísmica C. La falta de espacio y la fuerte pendiente explicarían la elevada relación longitud / anchura de los aparatos turbidíticos en el Guadalquivir. La reducción de la pendiente y la apertura de la cuenca en el golfo de Cádiz permiten desarrollar finalmente un característico sistema de abanicos submarinos en este área.

- $\quad$ En el límite Mio-Plioceno se invierte la actividad tectónica del margen sur de la cuenca. En la relación anterior se produce un incremento de la subsidencia que origina una subida relativa del nivel del mar.

Al final de la crisis de salinidad, las cuencas béticas orientales fueron afectadas por la transgresión pliocena. Sin embargo el área prebética y gran parte del Subbético no fueron afectados por esta trasgresión. El sector central, ya emergido, se caracterizó por la presencia de cuencas endorreicas que formaron lagos rodeados de abanicos aluviales interdigitados con depósitos lacustres (Boccaletti, et al., 1987).

En la cuenca del Guadalquivir, la transgresión se refleja como subsidencia del margen sur quedando fosilizado este talud. Poco después, la progradación a modo de 
frente deltaico se realiza tanto desde la cabecera como desde el talud norte. Esta situación postorogénica de la unidad $\mathrm{D}$, queda perfectamente reflejada por la disposición de los reflectores internos de esta unidad litosísmica. 


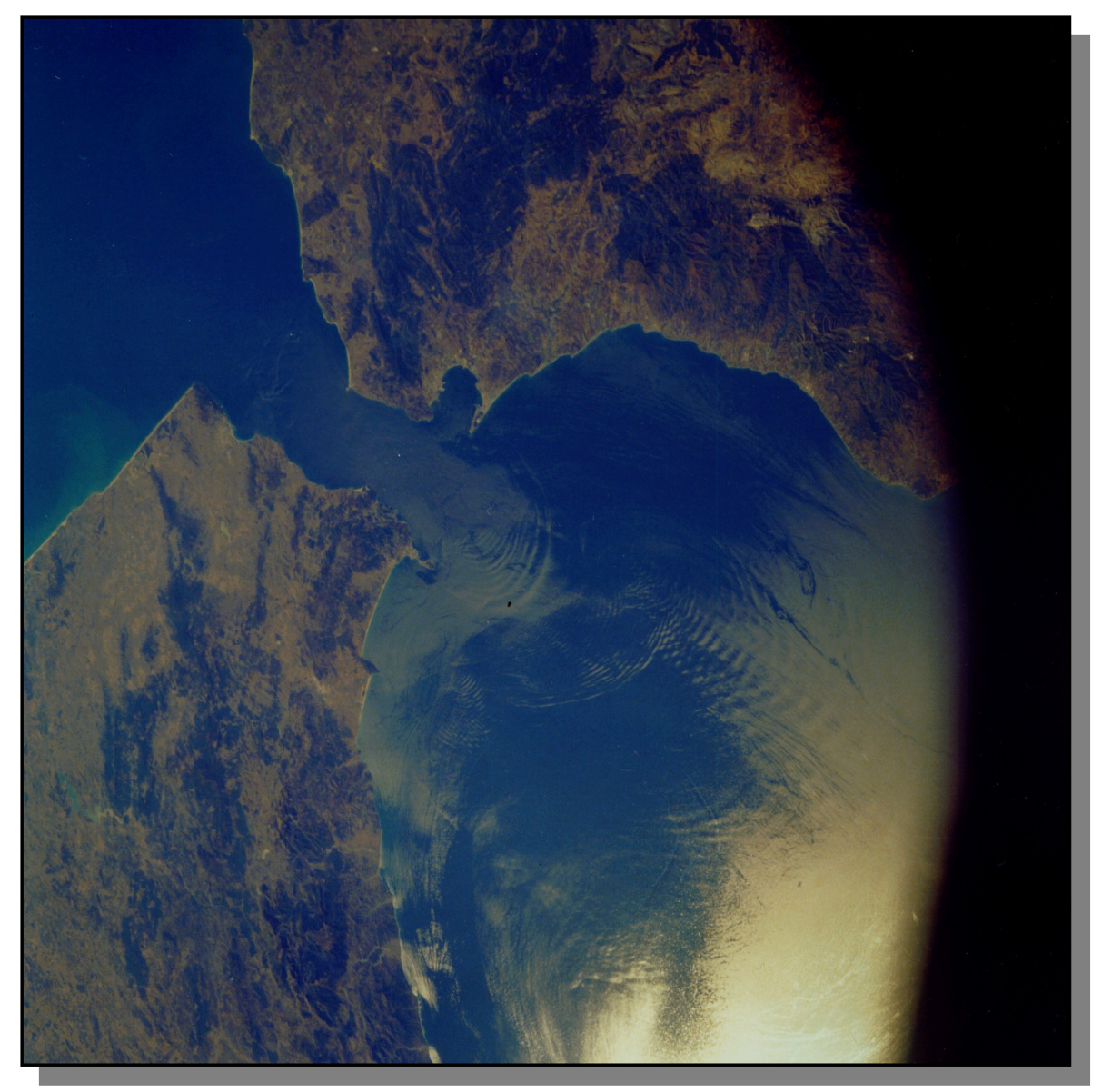

\section{RELACIÓN CON LAS SERIES MEDITERRÁNEAS Y CON LA CRISIS DE SALINIDAD MESSINIENSE}


Página anterior: Imagen del estrecho de Gibraltar desde el espacio con el golfo de Cádiz a la izquierda de la imagen y el mar Mediterráneo a la derecha. Puede observarse la formación de "solitones" como consecuencia del ingreso en el Mediterráneo de la corriente superficial atlántica. 
La precisión alcanzada con el uso de la astrocronología (capítulo 5) nos permite comparar y correlacionar con gran detalle los registros sedimentarios atlánticos y mediterráneos ayudando a comprender la evolución general del área de conexión entre ambas regiones. El análisis detallado de los registros geofísicos en el área del Guadalquivir-golfo de Cádiz sin duda reporta una interesante información sobre la evolución tectónica de la cordillera Bética, evolución que ha condicionado la conexión entre el Atlántico y el Mediterráneo durante el Mio-Plioceno. Discutiremos a continuación cuales son los principales acontecimientos registrados durante el Mioceno superior y Plioceno y como se han manifestado en ambos dominios.

\subsection{LÍMITE TORTONIENSE-MESSINIENSE}

La cuenca del Guadalquivir-golfo de Cádiz y anteriormente la fosa bética constituyó en el Tortoniense inferior uno de los corredores de comunicación entre el Atlántico y el Mediterráneo. Durante el Tortoniense medio y superior la zona oriental de la original fosa bética experimentó una importante elevación tectónica como resultado del levantamiento de las sierras de Cazorla y Segura, donde encontramos sedimentos marinos profundos del Tortoniense inferior a mas de $1500 \mathrm{~m}$ de altura (Sierro com. personal). De forma similar, actualmente en la parte oriental de la cuenca del Guadalquivir aparecen sedimentos marinos profundos del Tortoniense inferior-medio a mas de $1000 \mathrm{~m}$ de altura (por ejemplo en Iznatoraf, Jaén) (Sierro com. personal). También se producen contemporáneamente importantes levantamientos tectónicos en la región de Murcia (cuenca de Fortuna) (Garcés et al, 1998).

A finales del Tortoniense superior existían en la zona de conexión atlánticomediterránea unas condiciones relativamente cálidas y estables. Sin embargo, hacia el límite Tortoniense-Messiniense entre 7.29-7.26 Ma se produce en el Mediterráneo un importante evento paleoceanográfico que afecta sobre todo a la circulación profunda (Kouwenhofen, 2000). En las cuencas profundas del Mediterráneo se produce una primera etapa de circulación restringida en el fondo que provoca la desaparición de numerosas especies de foraminíferos bentónicos característicos del océano abierto (Seidenkraft et al., 1999; Kouwenhofen et al., 1999). Al mismo tiempo se produce un acusado aumento de $\delta^{18} \mathrm{O}$, reflejando un descenso de la temperatura y un incremento de la salinidad, así como un aumento de $\delta^{12} \mathrm{C}$ reflejando condiciones reductoras en el fondo de la cuenca (Kouwenhofen, 2000). El registro isotópico obtenido por Hodell et al. (1994) sobre foraminíferos bentónicos en el noroeste de Marruecos sugiere un significativo enfriamiento en este momento. El comienzo del "evento sifón" (siphon event, influjo de 
aguas frías profundas del Atlántico a través del corredor rifeño) propuesto por Benson et al. (1991) puede ser correlacionado con este enfriamiento. Los registros de manganeso y vanadio indican ambos una reducida ventilación de las aguas profundas Mediterráneas (Kouwenhofen, 2000).

¿Cuando se interrumpe definitivamente la comunicación entre Atlántico y Mediterráneo a través del Guadalquivir? Esta es una cuestión difícil de responder ya que los sedimentos marinos del Mioceno superior y del Plioceno, han sido erosionados en la parte oriental de la cuenca del Guadalquivir y en las áreas de conexión con otras cuencas que probablemente formaban parte del corredor norbético (como la cuenca de Guadix). No obstante, si atendemos a los resultados obtenidos en esta Tesis, podemos precisar que la configuración de la cuenca cambia drásticamente con la entrada de los últimos grandes cuerpos alóctonos desde el Subbético en el fondo de cuenca en torno al limite Tortoniense-Messiniense. Con anterioridad a este evento tectónico la cuenca del Guadalquivir era una fosa que se profundizaba hacia el sur (actualmente al sur de Córdoba y Sevilla los sedimentos marinos del Tortoniense superior se sitúan a casi 3000 $\mathrm{m}$ de profundidad) (fig. 7.1 y 7.2). Sin embargo a partir del limite TortonienseMessiniense (7.24 Ma), la cuenca del Guadalquivir sufre un espectacular cambio en su configuración, cerrándose por el este mientras que se mantiene abierta hacia el Atlántico en el oeste (fig. 7.3 y 7.4). Pensamos que en este momento la conexión del surco del Guadalquivir hacia el este podría estar ya completamente cerrada.

Por lo tanto la edad mas probable del cierre de la conexión Mediterránea a través de la cuenca del Guadalquivir correspondería aproximadamente al limite TortonienseMessininense, con una edad astronómica de 7.240 Ma. Esta datación confirma las estimaciones de otros autores que consideran que el levantamiento tectónico ya había cerrado el corredor bético norte hacia el Tortoniense superior-Messiniense inferior (Weijermars, 1988; Riding et al., 1998; Garcés et al., 1998; Krijgsman et al. 1999b). El cierre se produjo de forma progresiva desde el este y sureste a través de las cuencas intramontañosas béticas como la de Guadix. Esta cuenca del sector central de la cordillera Bética se desconectó del Mediterráneo en el Tortoniense superior y posteriormente del Guadalquivir (Atántico) en el Tortoniense superior-Messiniense en lo que supuso su aislamiento definitivo del mar abierto (Soria et al,.1999).

\subsection{MESSINIENSE PREEVAPORÍTICO}

La progresiva modificación del intercambio de masas de agua con el Atlántico causó importantes cambios paleoceanográficos en el Mediterráneo. Esto quedó reflejado 
en la clásica secuencia messiniense mediterránea, que comienza hace $7.24 \mathrm{Ma}$ con alternancia entre margas homogéneas y sapropeles, pasa mediante depósitos diatomíticos a las evaporitas inferiores (yeso, areniscas evaporíticas y halita), y termina con una superficie erosiva sobre la que se asientan las evaporitas superiores (yeso, margas) y finalmente los depósitos de las facies Lago Mare de ambientes de agua dulce a salobre. Pero vayamos por partes:

En el apartado 7.2.3.1 se dataron mediante edades astronómicas los principales cuerpos turbidíticos de la cuenca del Guadalquivir-golfo de Cádiz. El comienzo de los aparatos turbidíticos en el área de estudio se produce hacia 7.2 Ma, momento en el que ingresa en el fondo de la cuenca el cuerpo Gv-2. La base de este cuerpo turbidítico coincide prácticamente con el ingreso del olistostroma al sur de Carmona (Sevilla) (fig. 6.4D), en lo que pensamos supone el cierre definitivo de la conexión AtlánticoMediterráneo por el estrecho Norbético. Contemporáneamente a los depósitos preevaporíticos en el Mediterráneo, un progresivo levantamiento en la zona bética provoca el depósito de sucesivos cuerpos turbidíticos a lo largo del eje de la cuenca del Guadalquivir-golfo de Cádiz mediante repetidos pulsos tectónicos. En la cuenca del Guadalquivir, durante el Messiniense inferior desde 7,24 Ma hasta 6.35 Ma, se produce una rápida progradación desde el sur, con lo que la cuenca se va estrechando cada vez más y se va somerizando de forma muy marcada. Si observamos la reconstrucción de la figura 7.6 vemos una cuenca que se va somerizando rápidamente por el sureste como resultado del relleno de la cuenca. Sierro et al., (en prensa) observan un importante levantamiento tectónico en la cuenca de Sorbas entre los miembros Abad inferior y Abad superior, hacia 6.8 Ma. Contemporáneamente, en la cuenca del Guadalquivir se registra el depósito del cuerpo turbidítico Gv-5, que alcanza ya el golfo de Cádiz. Entre los cuerpos Gv-2 y Gv-5, se desarrollaron otros dos cuerpos turbidíticos (Gv-3 y Gv-4) en el fondo de cuenca del Guadalquivir, indicando que el levantamiento tectónico se mantuvo durante todo el Messiniense preevaporítico. Los sedimentos que se depositan a partir de este momento en la zona axial de la cuenca en el área de Carmona son relativamente someros. Este proceso de colmatacion se acentuó desde 6.35 a 6,05 Ma (fig.7.8).

Por otro lado en el Mediterráneo esta es una etapa de restricción en la conexión con el Atlántico, lo que provoca la formación de sedimentos diatomíticos primero y finalmente el deposito de las evaporitas inferiores con influencia marina. Las series preevaporíticas de Sorbas, Metochia y Falconara / Gibliscemi, terminan hacia los 5.96 Ma (fig. 5.16) con una zona de transición hasta los yesos (evaporitas inferiores del Mediterráneo). Curiosamente, a partir de este momento, la identificación de la ciclicidad astronómica en el Guadalquivir también se complica debido a la probable intrusión de slumps sobre el sondeo Casanieves-1, que entorpecen el seguimiento de los ciclos (fig. 
5.17). Una elevación tectónica con la consiguiente bajada relativa del nivel del mar, podría explicar tanto el comienzo de las evaporitas por el lado Mediterráneo, como la precipitación de slumps sobre Casanieves-1 y el desarrollo de un sistema de bajo nivel del mar relativo en el Guadalquivir.

La evidencia de actividad tectónica messiniense anterior a la Crisis de Salinidad se ha obtenido en los dos corredores Atlánticos. Existe cierto paralelismo en la evolución la cuenca del Guadalquivir con la cuenca de Taza-Guercif, en el margen sur del corredor rifeño en Marruecos. Este corredor, fue la principal conexión marina entre el Atlántico y el Mediterráneo al menos durante el Messiniense inferior. Krijgsman et al. (1999c) consideran que los últimos sedimentos marinos que aseguran la existencia del corredor rifeño, fueron depositados hace $8 \mathrm{Ma}$ (edad astronómica) y están formados por ciclos de alternancia entre turbiditas y margas controlados por la precesión. Las reconstrucciones de paleoprofundidad indican una rápida somerización del corredor hacia el límite Tortoniense-Messiniense (7.2 Ma) relacionada con una significativa actividad tectónica debida al avance del frente de cabalgamientos estando el corredor rifeño ya entonces severamente restringido (Benson et al., 1991; Krijgsman et al., 1999b; Krijgsman et al. 1999c). El momento exacto del cierre del corredor rifeño es poco preciso ya que grandes complejos de olistostromas cubren los sedimentos marinos más jóvenes en las zonas centrales. Garcés et al. (1998) y Benanmi et al. (1996) estiman que se produjo en 6.1 Ma, $150 \mathrm{Ka}$ antes del depósito de las evaporitas; mientras que Krijgsman et al. (1999c) consideran una edad de 6.0 Ma para este importante momento. La cuenca llegó a emerger hace 6.0 Ma (coincidiendo con una marcada regresión en la cuenca del Guadalquivir), y continuó con sedimentación continental en el Plioceno inferior. Krijgsman et al. (1999c) consideran que la somerización y restricción de la cuenca de Taza-Guercif, causada por la elevación tectónica, repercutió directamente en el comienzo de la Crisis de Salinidad Messiniense. Estos procesos tectónicos obviamente limitaron el intercambio de agua entre el Mediterráneo y el Atlántico durante el Messiniense y precedieron al comienzo de la Crisis de Salinidad. Una pequeña caída glacio-eustática del nivel del mar pudo añadirse a los procesos restrictivos, pero las caídas más importantes (en los estadios isotópicos 22 y 20) se produjeron unos 200 Ka después del comienzo de la Crisis de Salinidad (Hodell et al., 1994; Clauzon et al., 1996; Krijgsman et al., 1999b) por lo que el comienzo de la Crisis de Salinidad pudo ser consecuencia de un evento fundamentalmente tectónico. 


\subsection{MESSINIENSE EVAPORÍTICO}

La Crisis de Salinidad Messiniense es uno de los eventos más catastróficos en la historia geológica. De acuerdo con los modelos originales, durante este episodio se depositaron potentes series evaporíticas en una cuenca mediterránea desecada y aislada del Atlántico. La mayoría de las hipótesis concernientes al inicio de la Crisis de Salinidad Messiniense (MSC) están de acuerdo en que constituye el resultado de una compleja combinación de procesos tectónicos y glacioeustáticos que progresivamente restringieron y finalmente aislaron al Mediterráneo del océano abierto. No obstante, parece evidente que los procesos tectónicos jugaron un papel preponderante en el Messiniense superior.

Krijgsman et al. (1999b) definen la Crisis de Salinidad Messiniense como el intervalo en el que se produce el depósito evaporítico y la sedimentación de las facies Lago Mare en el Mediterráneo antes de la inundación pliocena. Sin embargo todavía existen diferentes opiniones respecto a la datación y al tiempo de duración de la MSC (fig. 8.1). Algunos autores (Hsü et al., 1973; Vai, 1997; Hilgen et al., 1995; Krijgsman et al., 1999b; Krijgsman et al., 1999d) consideran que se trata de un evento isócrono en toda la cuenca, otros (Clauzon et al., 1996; Riding et al., 1998) creen que sucedió en dos etapas y otros proponen una evolución completamente diacrónica (Buttler, 1995). Así mismo existen diferencias a la hora de explicar la causa y el impacto del aislamiento del Mediterráneo. Existen principalmente dos teorías: una de ellas plantea una importante caída glacioeustática, relacionada con el aumento del volumen de hielo. Otra de la que nos hacemos partícipes, propone un levantamiento orogénico acompañado de un deslizamiento gravitacional de grandes mantos complejos en el arco de Gibraltar.

Hasta ahora las correlaciones de los registros de isótopos estables $\left(\delta^{18} \mathrm{O}\right.$ y $\left.\delta^{13} \mathrm{C}\right)$ para la estratigrafía del evento Messiniense, han sido ambiguas debido a la ausencia de una escala de tiempo real para la Crisis de Salinidad Messiniense. El establecimiento de las escalas de tiempo de polaridad astronómicas (APTS) para los últimos $10 \mathrm{Ma}$ proporciona un salto cualitativo en la solución a la controvertida datación de la MSC (Krijgsman et al., 1999b). La cicloestratigrafía y los estudios paleoclimáticos revelaron que los ciclos sedimentarios de las series pre-evaporíticas están principalmente controlados por los cambios del clima mediterráneo inducidos por la precesión (Hilgen et al., 1995; Sprovieri et al., 1996b; Sierro et al., 1999). La cicloestratigrafía empleada por Krijgsman et al. (1999b) muestra que el depósito rítmico de las evaporitas durante la Crisis de Salinidad fue provocado casi exclusivamente por la ciclicidad de los cambios climáticos mediterráneos (inducidos por la precesión) y no son de ninguna forma resultado de los cambios glacioeustáticos del nivel del mar (inducidos en este caso por la oblicuidad). 


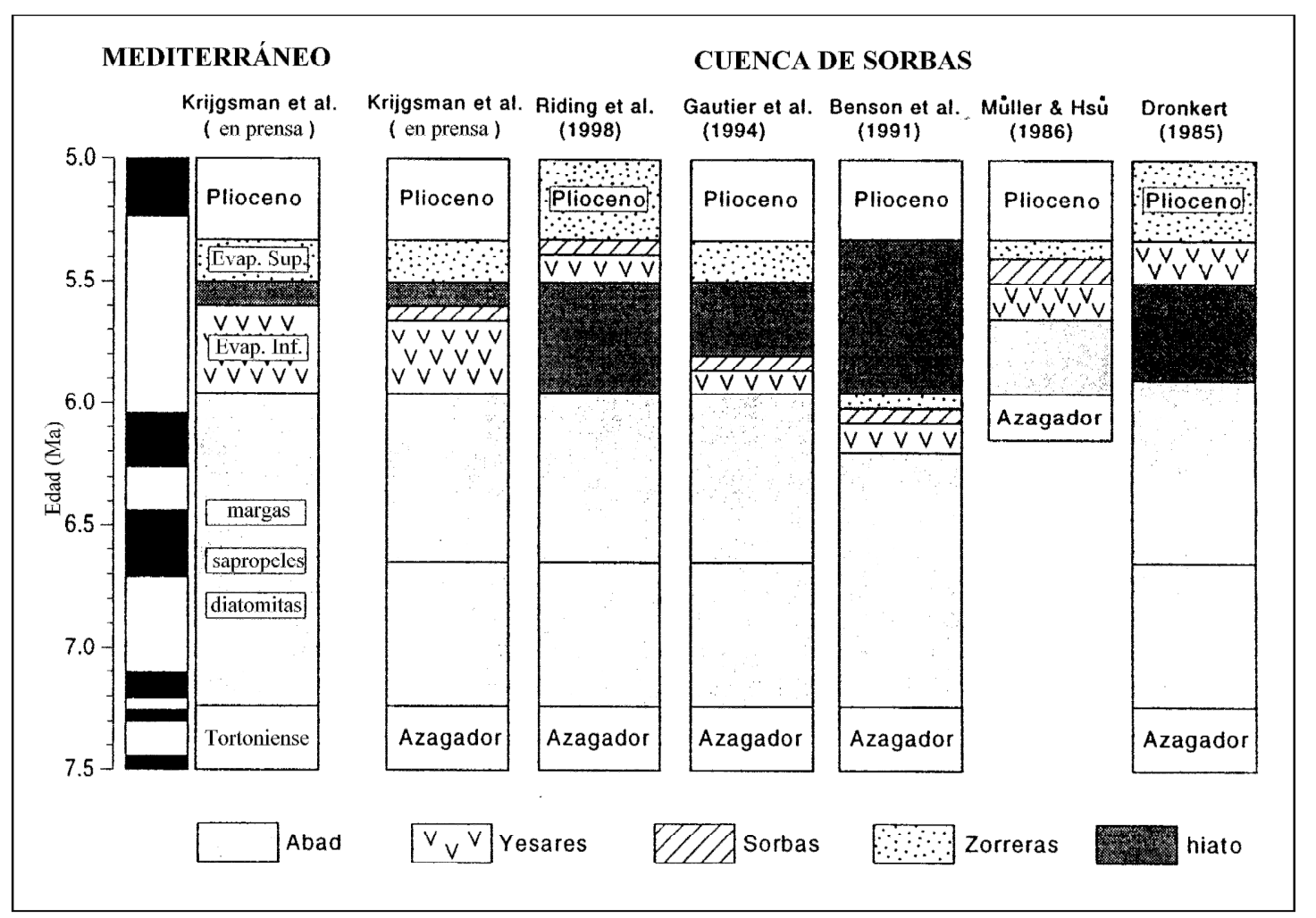

Figura 8.1. Diferentes interpretaciones respecto a la datación y tiempo de duración de la Crisis de Salinidad Messiniense ( modificado de Krijgsman et al., en prensa).

Krijgsman et al. (1999b) consideran así mismo que el origen de la Crisis de Salinidad pudo ser provocado por la actividad tectónica, quizás relacionada con un cambio importante en la velocidad de expansión de las placas tectónicas. Aseguran así mismo que el comienzo de las evaporitas (Evaporitas inferiores) fue isócrono (se produjo en el mismo ciclo sedimentario) en las tres secciones estudiadas por estos autores (Sorbas, al este de las Béticas; Metochia, en la isla de Gavdos-Grecia y la serie de Falconara / Gibliscemi, en la isla de Sicilia-Italia). Esto, según los mismos autores prueba que la $M S C$ es perfectamente isócrona en todo el Mediterráneo, y calculan el comienzo de la Crisis de Salinidad en 5.96 Ma con una duración de 640 Ka. Estiman por tanto, que el depósito de la unidad de las evaporitas inferiores es independiente de las condiciones paleogeográficas y geodinámicas de las cuencas individuales. El aislamiento completo y la posible desecación no se produjo hasta después del depósito de las evaporitas inferiores. Esta circunstancia se produjo entre 5.59 y $5.33 \mathrm{Ma}$, cuando el nivel de las aguas del Mediterráneo cayó más de 1000 metros como evidencian los cañones incisos del Ródano, Ebro, Po y Nilo en los márgenes del Mediterráneo (Krijgsman et al., 1999b). Los mismos autores estiman de forma tentativa la edad de la superficie erosiva localizada 
entre las dos formaciones evaporíticas datándola entre 5.59 y 5.50 Ma. Durante este evento debió suceder la desecación del Mediterráneo y el consiguiente reajuste (rebote) isostático (Krijgsman et al., 1999b). Finalmente, el depósito de la unidad de evaporitas superiores, que solapa las superficies erosivas, tuvo lugar en la zona profunda del Mediterráneo en una cuenca no-marina que formaba un gran Lago Mare (McCulloch, 1989).

Volviendo a la cuenca del Guadalquivir-golfo de Cádiz, Riaza y Martínez del Olmo (1996) caracterizaron una profunda incisión erosiva intramessiniense que se extiende en gran parte paralela al curso del actual río Guadalquivir (fig. 7.15). Este cañón permitía constatar según los autores, que tanto Mediterráneo como Atlántico registraron un descenso eustático de edad Messiniense (Martínez del Olmo et al., 1996). Los mismos autores consideran que dicho descenso eustático y erosión generó un LST con un cortejo de abanico submarino formado por los niveles de arena que aparecen en el golfo de Cádiz y que tradicionalmente se han denominado "arenas del Guadiana". Sin embargo, como hemos visto en el capítulo 7, dicha erosión es posterior a gran parte de las "arenas del Guadiana”.

No obstante, es posible la existencia de una discordancia intramessiniense en la cabecera de la cuenca del Guadalquivir (perfil sismobioestratigráfico $\mathrm{n}^{\circ} 1$ de la figura 4.4 y figura 7.15) tal y como proponen Riaza y Martínez del Olmo (1996). Esta discordancia reflejaría el último pulso tectónico acaecido durante el Messiniense superior y podría coincidir con el evento erosivo detectado en la cuenca mediterránea (5.59-5.3 Ma, Krijgsman et al., 1999b). La caída relativa del nivel del mar, pudo haber quedado reflejada en la cuenca del Guadalquivir mediante superficies de erosión en el talud sur y fondo de cuenca muy próximos al límite Mio-Plioceno. Contemporáneamente al comienzo de la Crisis de Salinidad (MSC) en el Mediterráneo, en el alto Guadalquivir (al norte de Carmona) se detectan en este momento una sucesión de canales erosivos, que pasan por el norte de la ciudad de Sevilla y se encaminan hacia la zona del sondeo Asperillo (fig. 7.9). Por encima de estos canales en los sondeos Carmona-1 y Carmona-2 se ha detectado un nivel de arenas conchíferas seguramente relacionado con la "calcarenita de Carmona" (plataforma carbonatada inestable) y que significaría el máximo regresivo alcanzado en la unidad litosísmica C. Este contexto sedimentario con la calcarenita progradante en el talud sur, canales erosivos en el eje de la cuenca y depósito turbidítico en el bajo Guadalquivir (aparatos Gv-6 o Gv-7), se desarrolla como consecuencia de uno o varios pulsos tectónicos de elevación del margen suroriental de la cuenca entre 6.0 y 5.5 Ma. Cavazza y DeCelles (1998) proponen un interesante modelo tectónico, que incluye un rebote flexural en un frente de acreción, para justificar la génesis de los "fanconglomerados" del Messiniense superior en el sueste de Calabria (sur 
de Italia). Consideran a esta unidad sintectónica, producto de ajustes isostáticos de la cuña orogénica. Seria interesante evaluar un modelo similar como posible génesis de esta discontinuidad en la cuenca del Guadalquivir.

En la figura 7.16, se muestra el perfil sísmico $\mathrm{n}^{\mathrm{o}} 10$ (golfo de Cádiz) y los resultados del análisis bioestratigráfico y cicloestratigráfico de 3 sondeos próximos a esta línea sísmica. En esta figura se puede observar la presencia de al menos un aparato turbidítico (Gv-5) con una edad (6.8-6-3 Ma) al menos 700.000 años anterior a la discordancia intramessiniense en el Mediterráneo (5.52-5.60 Ma; Krijgsman et al., en prensa) e incluso anterior al comienzo de la Crisis de Salinidad Messiniense (5.96 Ma, según Krijgsman et al., en prensa). Queda pendiente determinar si el depósito del aparato turbidítico Gv-6 está relacionado con la discontinuidad intramessiniense o bien es ligeramente anterior, en caso negativo la discordancia observada en la cabecera de la cuenca podría estar relacionada con el depósito del aparato turbidítico Gv-7. Si podemos avanzar que la discordancia intramessiniense en la cuenca del Guadalquivir tendría una edad posterior al evento E6 de foraminíferos planctónicos (6.1 Ma; Sierro, in prep.) y muy probablemente posterior a la $F C O$ del grupo de G. margaritae (6.05 Ma). La discontinuidad del alto Guadalquivir se produjo por lo tanto entre 6.05 y $5.33 \mathrm{Ma}$ (límite Mio-Plioceno).

El ascenso tectónico de los pasos de comunicación Atlántico-Mediterráneo y el consiguiente aislamiento del Mediterráneo desembocaría en el comienzo del depósito de las evaporitas inferiores (Miembro Yesares). Teniendo en cuenta que el comienzo de los depósitos evaporíticos en las cuencas marginales béticas ha sido datado mediante astrobiocronología en 5.96 Ma (Sierro et al. en prensa) al igual que en el resto del Mediterráneo (Krijgsman et al. 1999b), sería lógico pensar que en el contexto compresivo messiniense el ascenso del sector suroriental bético pudo culminar entorno a 6.0 Ma con una significativa restricción de la comunicación entre el océano Atlántico y el mar Mediterráneo. La culminación de la tectónica compresiva en el área Bética pudo desencadenar los depósitos evaporíticos messinienses en el Mediterráneo y en las cuencas marginales Béticas (Sorbas...). Al mismo tiempo, en el Guadalquivir esta elevación tectónica provocaría superficies erosivas en los taludes del sector oriental de la cuenca asociadas a canales en el fondo de cuenca (perfil sismobioestratigráfico $n^{\circ} 1$ ) que posiblemente suministran el depósito del aparato turbidítico Gv-6 y con seguridad los aparatos turbidíticos posteriores en el fondo de cuenca del golfo de Cádiz. 


\subsection{LÍMITE MIO-PLIOCENO. La inundación pliocena.}

El límite Messiniense / Plioceno se expresa de forma diferente en las distintas subcuencas Mediterráneas. En las áreas marginales que están ahora en España, Italia, Chipre y norte de África está marcado frecuentemente por una inconformidad sedimentaria (superficie erosiva, gap o laguna sedimentaria, paleosuelos y/o paso a depósitos continentales durante el Plioceno inferior) (Cita et al., 1978; Pierre et al. 1998). Igual sucede en el mar de Alborán, donde destaca la discordancia angular de la base de los depósitos plio-pleistocenos (que se correlaciona con el techo de las evaporitas messinienses), asentándose sobre este reflector (denominado "reflector M") un fango de nanofósiles calcáreos que refleja la inundación Pliocena (Alonso et al., 1999; ÁlvarezMarrón, 1999).

Al final del Messiniense, después de la Crisis de Salinidad, existían condiciones salobres (con niveles de concentración variables) en cuencas profundas mediterráneas de aguas someras (ambiente conocido como Lago Mare). En un período que probablemente duró unos 1000-2000 años, todo el Mediterráneo se rellena por aguas marinas al comienzo del Plioceno inferior de manera que las condiciones de mar abierto homogéneo se restablecieron en las diferentes cuencas (Pierre et al. 1998). En las partes más internas del Mediterráneo, el límite Messiniense / Plioceno se perforó durante las campañas de Deep Sea Drilling Project (DSDP) y el Ocean Drilling Program (ODP) en los Sites 132, 652,653 , y 654 en la cuenca del Tirreno, Sites 371 y 372 en la cuenca Balear, en los Sites 125 y 374 de la cuenca Jónica, en los Sites 375 y 376 de la cuenca Oriental junto con el Site 968A sobre el flanco del norte del seamount de Eratóstenes, los Site 969A y 969B sobre la dorsal del Mediterráneo, y el Site 378 de la cuenca de Creta. En todos ellos, un cambio litológico significativo caracteriza esta transición, así como cambios en el contenido y mineralogía de los carbonatos, indicando que existieron en ese momento importantes modificaciones paleoambientales en la totalidad del Mediterráneo. Así mismo se produjeron importantes cambios sedimentológicos y paleontológicos. A las arcillas oscuras pobres en carbonato y nanofósiles con fauna salobre característica de los últimos depósitos messinienses, se sobrepusieron arcillas ricas en nanofósiles, de colores claros y ricas en carbonato, cuando las aguas marinas reinvadieron por completo la cuenca (Iaccarino, et al. 1997; Pierre et al. 1998). En el Hole 967 A (Leg 160), los fangos pelágicos y/o las margas hemipelágicas del Zancleiense se sobreponen a la secuencia de breccia carbonatada del Messiniense superior. En este Site, la identificación del límite Mioceno / Plioceno coincide con un cambio en el contenido en calcita inorgánica no marina hacia una típica calcita biogénica característica de un fango pelágico. Después de la Crisis de Salinidad Messiniense, los foraminíferos bentónicos repoblaron paulatinamente el fondo del mar Mediterráneo oriental durante el acme de Sphaeroidi- 


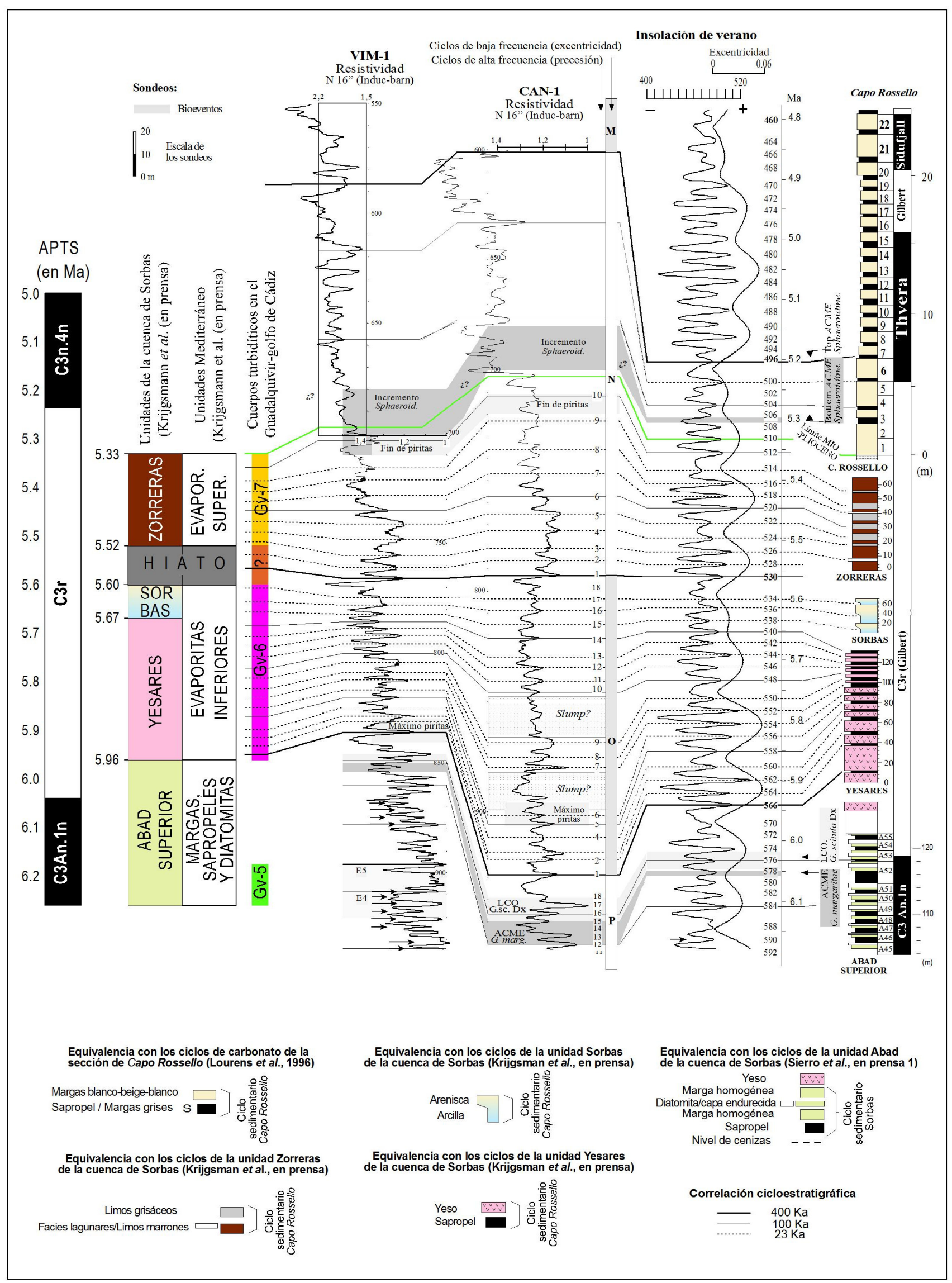

Figura 8.3. Datación y correlación astronómica de los sondeos Villamanrique-1 y Casanieves-1 con las series mediterráneas y con la Crisis de Salinidad messiniense. Datación de la Crisis de salinidad de Krijgsmann et al. (en prensa). Principales eventos de foraminíferos planctónicos, litología, ciclos de carbonato y magnetoestratigrafía de la sección de Capo Rossello tomados de Lourens et al. (1996). 
nellopsis (Biozona MP11). El gradual ingreso de foraminíferos bentónicos típicos del Atlántico profundo coincide con el límite entre las biozonas MP11 y MP12 indicando que se restableció en este intervalo una eficiente conexión entre el océano Atlántico y el Mediterráneo oriental (Spezzaferri et al., 1998).

La MSC finalizó hace 5.33 Ma con la restauración de las condiciones marinas abiertas como se refleja en la base de las secciones sicilianas de Trubi y Capo Rossello (fig. 8.2). El final de la $M S C$ sucede en un momento de descenso general de los valores de $\delta^{18} \mathrm{O}$ Hodell et al. (remitido), pero estos autores encuentran que no coincide con ningún mínimo concreto en la curva de $\delta^{18} \mathrm{O}$. Incluso, apuntan que los valores de $\delta^{18} \mathrm{O}$ en carbonato total (bulk carbonate) fueron más bajos al comienzo del Plioceno, indicando condiciones cálidas-interglaciales. El descenso más prominente en los valores de $\delta^{18} \mathrm{O}$ en foraminíferos bentónicos sucedió hace 5.5 Ma, lo que sugiere que el nivel del mar (fuera del Mediterráneo) comenzó a subir antes de la base del Plioceno. Esto implicaría que probablemente la responsable del final de la Crisis de Salinidad Messiniense fue la tectónica (Hodell et al., remitido). Si bien se han citado algunos trabajos que muestran una posible subida eustática del nivel del mar pliocena (Mckenzie, et al., 1997; Mckenzie, et al. 1999), posteriormente Hodell et al. (remitido) en estudios de alta resolución del Atlántico Norte, no encuentran ninguna evidencia de una subida glacioeustática global en este momento. Consideramos por tanto que la inundación pliocena del Mediterráneo fue consecuencia de un proceso principalmente regional, relacionado con una situación favorable al intercambio de masas de agua en el área de conexión atlántico-mediterránea.

Por otro lado en el Guadalquivir-golfo de Cádiz, para conseguir la datación del reflector sísmico utilizado como límite entre las unidades litosísmicas C y D se han utilizado los perfiles próximos a los sondeos estudiados (figura 4.4, perfiles $n^{\circ} 6 \mathrm{y} \mathrm{n}^{\circ} 10$ ). La datación de este reflector corresponde al ciclo sedimentario N11, que es equivalente al ciclo de insolación ic510 y que presenta una edad de 5.33 Ma (fig. 5.17 y fig. 5.24), correspondiendo por lo tanto al límite Mio-Plioceno. Así mismo, como puede observarse en la figura 8.2, hacia 5.45 Ma se observa un cambio de tendencia en los logs que va a culminar drásticamente en el límite Mio-Plioceno (5.33 Ma). La subsidencia del sector sureste de la cuenca del Guadalquivir, coincide con el límite Mio-Plioceno por lo que el evento tectónico que supuso el comienzo de la unidad litosísmica $\mathrm{D}$, pudo ser el mismo que provocara la restauración de las condiciones marinas abiertas en el Mediterráneo.

Más aún, consideramos que este evento, supone un importante acontecimiento tectónico regional. Maldonado et al. (1996) reconocen en el golfo de Cádiz un importante evento tectónico que denominan "colapso extensional" y en el que estos autores aprecian 
las más altas tasas de subsidencia tectónica en el área. Consideran así mismo que al final del Messiniense y durante el Plioceno inferior la compresión N-S facilitó un régimen transtensional y el desarrollo de cuencas pull-apart y que esta evolución tectónica pudo inducir a la reapertura de la conexión Atlántico-Mediterráneo a través del estrecho de Gibraltar.

La subsidencia del sector suroriental de la cuenca del Guadalquivir-golfo de Cádiz podría coincidir con una individualización de la Bahía de Cádiz (Viguier, 1976) relacionada según este autor con las estructuras diapíricas visibles entre San Fernando y Puerto Real. La subsidencia del sector suroriental, pudo reflejarse en otras cuencas periféricas béticas, no así en el sector central bético, que no se vio afectado por la inundación pliocena prosiguiendo la somerización emprendida en el Messiniense (Rodríguez-Fernández et al., 1984).

En la cuenca del Guadalquivir-golfo de Cádiz, con la subsidencia del sector suroriental se abandona la sedimentación turbidítica que venía desarrollándose en la cuenca durante el Messiniense. Hacia el final del Messiniense, el depocentro de la cuenca del Guadalquivir había alcanzado su posición más occidental. A partir del límite MioPlioceno, el depocentro de la cuenca se desplaza rápidamente hacia el sureste, de modo que los sondeos Casanieves-1 y Villamanrique-1 que durante el Messiniense superior se encontraban en el talud sur, vuelven a ocupar una posición en el eje de la cuenca. El consiguiente incremento en la velocidad de sedimentación, impide la identificación de la ciclicidad astronómica (fig. 8.2) y provoca la desnaturalización de los ciclos astronómicos que venían siguiéndose a lo largo del Messiniense (ver fig. 5.17). Por otra parte, en el golfo de Cádiz la ausencia de la sedimentación turbidítica unido a la llegada de material terrígeno fino arcilloso se traduce en la individualización de los ciclos astronómicos.

Perconig (1964, 1966), en su intento por establecer el término estratigráfico "Andaluciense" para la fase final del Mioceno, considera el techo de la calcarenita de Carmona como el límite Mio-Plioceno del estratotipo propuesto. En función de los perfiles sismobioestratigráficos próximos a Carmona (perfil $n^{\circ} 1$ de la figura 4.4), si continuamos el límite Mio-Plioceno hacia superficie, el reflector límite entre las unidades litosísmicas C y D se coloca ligeramente por encima de la calcarenita de Carmona. Teniendo en cuenta que la base de la unidad litosísmica $\mathrm{C}$ coincide en ese área con el límite Tortoniense-Messiniense, podría establecerse ahora sí una unidad equivalente al estratotipo Messiniense italiano, tal y como propusieron Crescenti et al. (1973) y que correspondería a la unidad litosísmica $\mathrm{C}$, con base en la arenas del Guadalquivir y techo sobre la calcarenita de Carmona. 


\subsection{PLIOCENO}

Como hemos visto en el capítulo 5, la correlación de los ciclos sedimentarios del plioceno inferior registrados en el golfo de Cádiz con las curvas de precesión es directa y muy precisa. La cicloestratigrafía del Plioceno superior se complica en su tramo superior ya que las periodicidades de alta frecuencia ( $3^{\text {er }}$ orden) son propensas a ser enmascaradas por pequeños cambios en la velocidad de sedimentación. Esto debió suceder en el golfo de Cádiz en torno a 2.4-2.6 Ma, momento a partir del cual la ciclicidad de alta frecuencia cede paso a una periodicidad de menor frecuencia. A partir de ese momento se individualizan ciclos más potentes que probablemente corresponden a ciclos de $2^{\circ}$ orden ligados a la frecuencia de excentricidad de $100 \mathrm{Ka}$, si bien la ausencia de bioestratigrafía para este intervalo no permite asegurar esta hipótesis (póster del anexo). Destaca no obstante la coincidencia cronológica de este suceso con la pérdida de ciclicidad observada en las series Mediterráneas.

Aunque no hemos analizado en detalle por qué se produce esta desnaturalización de los ciclos de alta frecuencia, si es cierto que coincide con la intensificación de la glaciación en el hemisferio norte. El Mediterráneo occidental y lógicamente Atlántico adyacente está muy influenciado por las fluctuaciones del clima en el Atlántico Norte (Zahn, et al. 1997, Grafenstein, et al., 1999). Con el comienzo de los grandes ciclos glaciales-interglaciales durante el Pleistoceno, la influencia atlántica probablemente comenzó a variar rítmicamente debido al crecimiento y mengua de la capa de hielo. Esto pudo originar así mismo la pérdida de la ciclicidad de alta frecuencia en el golfo de Cádiz, en favor de los ciclos de frecuencia media (excentricidad de 100.000 años) que estarían reflejando alteraciones climáticas en el Atlántico Norte relacionadas con el crecimiento y retracción del casquete glaciar.

Un cambio paleoceanográfico y climático global ha sido reconocido por numerosos autores en el Atlántico Norte entre 3.2 y 2.4 Ma (Hodell et al., 1983; Leonard et al., 1983; Williams et al., 1985; Vergnaud-Grazzini et al., 1990; Francés, 1992). Se considera que existió un enfriamiento oceánico importante hace 3,2 Ma que coincidiría con un enfriamiento climático y/o al cierre del estrecho de Panamá. Este enfriamiento iría seguido por un deterioro climático que desemboca en una glaciación, cuyo inicio se cifra en 2,6 Ma. Según estos autores desde ese momento la glaciación se intensificó de forma gradual, alcanzando su máximo en 2,4 Ma. 


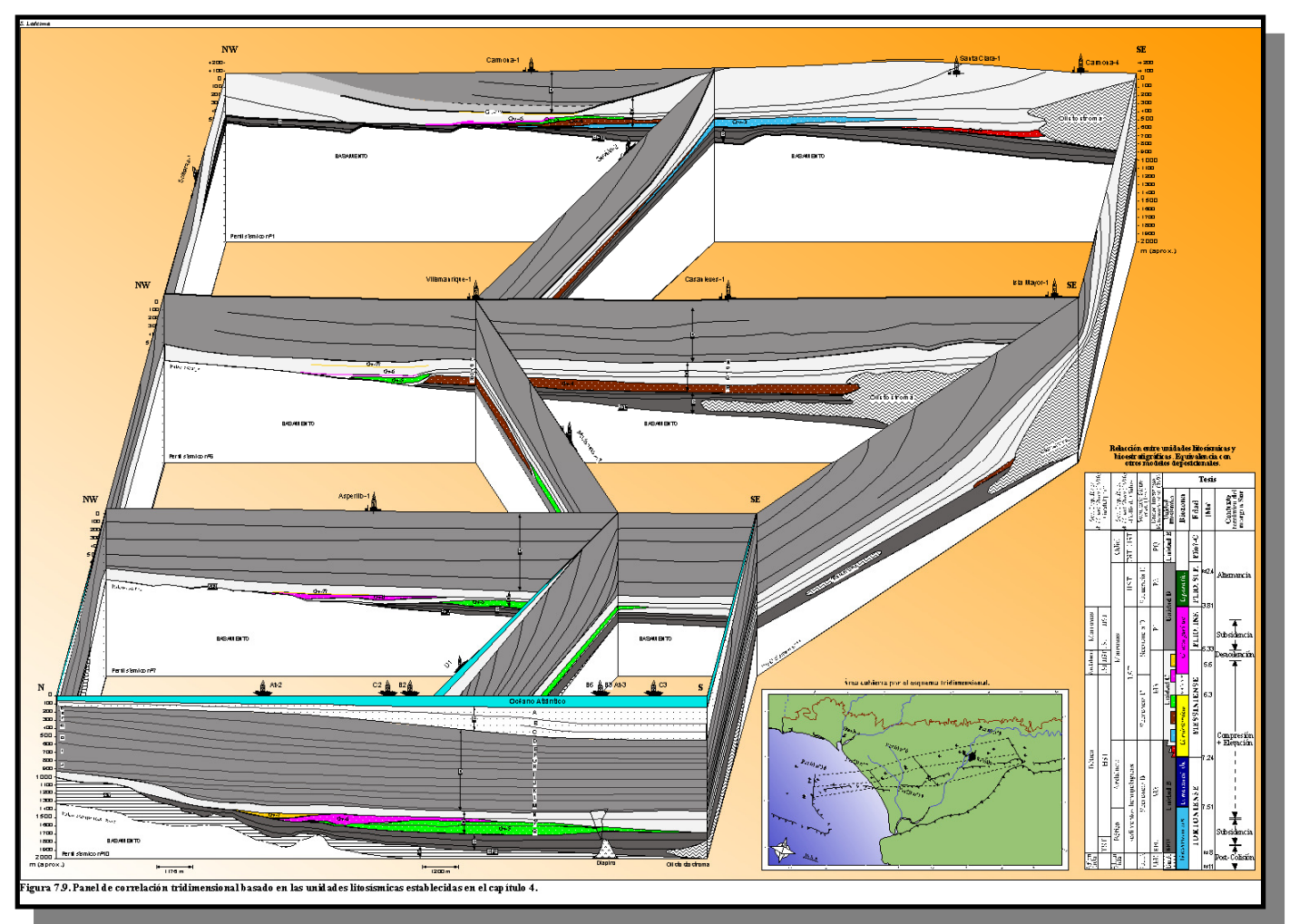

9. CONCLUSIONES 
Página anterior: Reconstrucción del relleno sedimentario de la cuenca en función de los resultados obtenidos (corresponde a la fig. 7.9). 
Se presenta una detallada cronología de la cuenca del Guadalquivir-golfo de Cádiz basada en la combinación de datos bioestratigráficos y cicloestratigráficos, en lo que supone la primera calibración astronómica del relleno sedimentario de esta cuenca MioPliocena.

La bioestratigrafía obtenida en el análisis de 32 sondeos profundos de la cuenca del Guadalquivir-golfo de Cádiz esta basada en 20 bioeventos de plancton calcareo y ha permitido establecer seis unidades bioestratigráficas definidas por eventos de desaparición, que constituyen a su vez unidades cronoestratigráficas. Los nuevos datos micropaleontológicos han permitido localizar los límites Tortoniense-Messiniense y Mioceno-Plioceno conforme a las nuevas escalas astronómicas de tiempo en todos los sondeos analizados. Se presenta también la datación individual de los principales aparatos turbidíticos de la cuenca del Guadalquivir-golfo de Cádiz que son objeto de la exploración de hidrocarburos en el área.

Así mismo, se han identificado cinco unidades litosísmicas desde el Tortoniense superior, basadas en 11 perfiles sismobioestratigráficos. Se ha establecido así mismo la relación de estas unidades litosísmicas con la secuencia de relleno de la cuenca y el emplazamiento del olistostroma.

El reconocimiento en las diagrafías de los sondeos de distintas pautas de repetición de origen astronómico, de la modulación de la precesión por la excentricidad, los patrones de interferencia precesión-oblicuidad y en definitiva las características que definen la curva de insolación, han permitido sintonizar ciclo a ciclo 20 diagrafías (de rayos gamma, velocidad sónica y resistividad) procedentes de 15 sondeos petrolíferos de la cuenca del Guadalquivir-golfo de Cádiz con la curva de insolación de verano (Laskar, 1990). Se ha correlacionado el registro geológico de estos 15 sondeos con la escala astronómica de tiempo, actualmente mucho más precisa que cualquier otro tipo de escala de tiempo geológica. Se han establecido una serie de unidades cicloestratigráficas de carácter astronómico-climático (frecuencias de Milankovitch) que constituyen a su vez unidades cronoestratigráficas de alta resolución. De este modo se ha podido datar y correlacionar con alta resolución el intervalo de tiempo que va desde 7.5 Ma hasta 2.6 Ma.

Los análisis cicloestratigráficos de alta resolución en las diagrafías han revelado la existencia de una correlación regional y global capa a capa con las series de la cuenca de Sorbas (Almería) y de Capo Rossello (Sicilia), que son las secciones de referencia para la escala astronómica de tiempo. Las correlaciones cicloestratigráficas con otras secciones del Mediterráneo son directas y están confirmadas por la bioestratigrafía de alta 
resolución. Además, la cicloestratigrafía de los sondeos del Guadalquivir-golfo de Cádiz ha sido correlacionada con la escala magnetoestratigráfica (APTS) obtenida en estas secciones, lo que ha permitido obtener una secuencia magnetoestratigráfica inferida para los sondeos estudiados. Dentro de las secciones calibradas con la escala astronómica de tiempo, el control de cada punto tiene un error inferior a 20.000 años, que es la duración media de un ciclo de precesión. La calibración ha sido posible gracias a la utilización de la micropaleontología como necesaria verificación de las múltiples posibilidades de correlación estratigráfica proporcionadas por el registro geofísico.

El esquema astrobiocronológico permite establecer una edad astronómica de unos 6.3 Ma para la desaparición del grupo de G. miotumida ( $L O$ del grupo de G. miotumida), ya que esta desaparición sucede inmediatamente después del cambio de enrollamiento de N. acostaensis (6.35 Ma), concretamente al final del ciclo Q17 en los sondeos Casanieves-1 y Villamanrique-1. Por otro lado se propone una edad astronómica de 6.03 Ma para el descenso en la abundancia relativa de las formas dextrógiras del grupo de $G$. scitula ( $L C O$ del grupo de G. scitula dx) localizado inmediatamente por encima de la FCO del grupo de G. margaritae en los sondeos Villamanrique-1 y Casanieves-1.

El estudio cicloestratigráfico que se presenta constituye una de las series correlacionadas con la escala astronómica de tiempo, más larga, contínua y precisa de las existentes actualmente en la bibliografía. Se ha multiplicado la resolución de las correlaciones habituales y al mismo tiempo se ha aumentado la fiabilidad de la correlación al estar apoyada en diferentes criterios (análisis cicloestratigráfico, micropaleontológico y sísmico). El calibrado astronómico de los ciclos sedimentarios proporciona edades exactas para todos los ciclos, bioeventos, o acontecimientos sedimentarios (slumps...) y proporciona una fidedigna datación para futuros estudios en el área estudiada. Esta Tesis trata de demostrar que el análisis de los patrones característicos en la ciclicidad del registro geofísico, acompañados de estudios bioestratigráficos puede ser utilizado para realizar correlaciones globales y para la datación astronómica con errores no mayores de $20 \mathrm{Ka}$ (20.000 años).

En un contexto geológico más amplio y como resumen de la interpretación del modelo sedimentario podemos concretar que el levantamiento tectónico que sufre la cabecera y el margen sur de la cuenca del Guadalquivir en el límite TortonienseMessiniense, pudo desencadenar además del ingreso del olistostroma y del desarrollo de los cuerpos turbidíticos messinienses en el Guadalquivir, el cierre definitivo de la conexión Atlántico-Mediterráneo en el estrecho Norbético. Por otro lado, el pulso tectónico que originó el depósito del cuerpo Gv-6 en el Guadalquivir-golfo de Cádiz, podría coincidir con el comienzo de la crisis de salinidad en el Mediterráneo, mientras 
que posteriores aparatos turbidíticos $(\mathrm{Gv}-7)$ podrían estar relacionados con la discontinuidad intramessiniense observada en el Mediterráneo. En el límite MioPlioceno, el hundimiento parcial del sector sur de la cuenca pudo repercutir en la inundación pliocena del Mediterráneo.

Junto con este ejemplar de la Tesis Doctoral, se presenta un CD-ROM interactivo realizado como complemento de la Tesis y que incluye una versión digital de la misma. El CD-ROM también incluye el programa MICROPALEO-2000, desarrollado paralelemente y como resultado de la Tesis Doctoral. 



\section{BIBLIOGRAFÍA}

Adams, C.G., Gentry, A.W. y Whybrow, P.J. (1983). Dating the terminal Tethys event. Utrecht Micropaleontological Bulletin, 30: 273-298.

Allen, J.R.M., Brandt, U., Brauer, A., Hubberten, H-W., Huntley B., Kellerk, J., Kraml, M., Mackensen A., Mingram, J., Negendank, J.F.W., Nowaczyk N.R., Oberhänsli, H., Watts W.A., Wulf, S., y Zolitschka, B. (1999). Rapid enviromental changes in southern Europe during the last glacial period. Nature, 400, 19 August, 1999, pp:740-743.

Alonso, B., Ercilla, G., Martínez-Ruíz, F., Baraza, J. y Galimont, A. (1999). PliocenePleistocene sedimentary facies at Site 976: Depositional history in the Northwestern Alboran Sea. Zahn, R., Comas, M.C. y Klaus, A. (Eds.). Proceedings of the Ocean Drilling Program, Scientific Results, 161: 57-68

Álvarez-Marrón, J. (1999). Pliocene to Holocene structure of the Eastern Alborán Sea (Western Mediterranean). Zahn, R., Comas, M.C. y Klaus, A. (Eds.). Proceedings of the Ocean Drilling Program, Scientific Results, 161: 345-355

Andrieux, J., Fontboté, J.M. y Mattauer, M., (1971). Sur un modèle explicatif de 1'Arc de Gibraltar. Earth and Planetary Science Letters, 12: 191-198.

Arthur, M.A., Bottjer, D.J., Dean, W.E., Fischer, A.G., Hattin, D.E., Kauffman, E.G., Prat, L.M. y Sscholle, O.A. (1986). Rhithmic bedding in Upper Cretaceous pelagic carbonate sequences: varyng sedimentary response to climatic forcing. Geology, 14: 153-156.

Arthur, M.A. y Dean, W.E. (1991). A Holistic Geochemical Approach to Cyclomania: Examples form Cretaceous Pelagic Limestone Sequences. Einsele el al. (Eds.). Cycles an Events in Stratigraphy: 128-166.

Aziz, H.A., Hilgen, F., Krijgsman, W., Sanz, E. y Calvo, J.P. (en prensa). Astronomical forcing of sedimentary cycles in the Miocene continental Calatayud Basin (NE Spain).

Backmand, J. y Raffi, I. (1997). Calibration of Miocene nannofossil events to orbitally timed cyclostratigraphies from Ceara Rise. Proc. ODP. Sci. Results, 154: 83-99. 
Baker, G. S., (1994). An Examination of Triassic Cyclostratigraphy in the Newark Basin from Shallow Seismic Profiles and Geophysical Logs. Masters Thesis, Lehigh Univesrity, Lehigh, PA: 145 p.

Baraza, J. y Nelson, C.H. (1992): Clasificaciones y dinámica de formas de fondo en el Golfo de Cádiz: implicaciones de la corriente profunda mediterránea en los procesos sedimentarios durante el Pliocuaternario. En: III Congreso Geológico de España, VIII Congreso Latinoamericano de Geología-Simposios, ed. Univ. de Salamanca, 2: 477:486.

Baraza, J., Hampton, M.A., Lee, H.J. y Kayen, R.E. (1989). Utilización del análisis de facies sísmicas para la evaluación de los riesgos potenciales en el talud continental del golfo de Cádiz. XII Congreso Español de Sedimentología. Simposios y Conferencias.

Baraza.J., Ercilla, G. y Nelson, C.H. (1999). Potential geologic hazards on the eastern Gulf of Cadiz slope (SW Spain). Marine Geology, 155: 191-215.

Baringer, M.O. y Price, J.F. (1999). A review of the physical oceanography of the Mediterranean outfow. Marine Geology, 155: 63-82.

Barron, E.J., Arthur, M.A. y Kauffman, E.G. (1985). Cretaceous rhythmic bedding secuences: a plausible link between orbital variations and climate. Earth Planet. Sci. Letters, 72: 327-340.

Beaufort, L. y Aubry, M.P. (1990). Fluctuations in the composition of Late Miocene calcareous Nannofossil assemblages as a response to orbital forcing. Paleoceanography, 5 (6): 845-865.

Bennami, M., Calvo, M., Prévot, M., y Jaeger, J.J. (1996). Magnetostratigraphy and paleontology of Ait Kandoula Basin (High Atlas. Morocco) and the AfricanEuropean late Miocene terrestrial fauna exchanges, Earth Planet. Sci. Lett., 145: 1529.

Benson, R.H. (1995). Is the death of an ocean falling through a stratigraphic crack? Paleoceanography, 10: 1-3. 
Benson, R.H., Rakic-El Bied, K. y Bonanduce, G. (1991). An important current reversal (influx) in the Rifian corridor (Morocco) at the Tortonian-Messinian boundary: the end of Tethys Ocean. Paleoceanography, 6, 1: 164-172.

Benson, R.H., Hodell, D. y Rakic-El Bied, K. (1995). Extending the climatic precession curve back into the late miocene by signature template comparison. Paleoceanography, Vol. 10, $\mathrm{n}^{\mathrm{o}}$ 1: 5-20.

Berger, A., y Loutre, M.F. (1991). Insolation values for the climate of the last 10 m.y. Quat. Sci. Rev., 10: 297-317.

Berger, A. (1984). Accuracy and Frequence Stability of the Earth's orbital elements during the Quaternary. Berger et al. (edts). Milankovitch and Climate. NATO AS/ Series C, $126(1): 3-39$.

Berggren, W.A., Kent, D.V., Flynn, J.J., y van Couvering, J.A. (1985). Cenozoic geochronology. Geological Society of American Bulletin, 96: 1407-1418.

Berggren, W.A., Hilgen, F.J., Langereis, C.G., Kent, D.V., Obradovich, J.D., Raffi, I., Raymo, M.E. y Shackleton, N.J., (1995a). Late Neogene chronology: New perspectives in high-resolution stratigraphy. Geological Society of American Bulletin, 107: 1272-1287.

Berggren, W.A., Kent, D.V., Swisher, III, C.C. y Aubry, M-P. (1995). A revised Cenozoic Geochronology and Chronostratigraphy. SEPM (Society for Sedimentary Geology) Special Publication No. 54: 127-212.

Biju-Duval, B., Letouzey, J. y Montadert, L. (1978). Structure and evolution of the Mediterranean basins. Initial Reports of the Deep Sea Drilling Project, 42: 651-984.

Boccaletti, M., Papani, G., Gelati, R., Rodríguez-Fernández, J., López Garrido, A.C. y Sanz de Galdeano, C. (1987). Neogene-Quaternary sedimentary-tectonic evolution of the Betic Cordillera. Acta Naturalia de l'Ateneo Parmense, vol. 23, $\mathrm{n}^{\circ} 4$ : 179-200.

Boelaert, A. (1998). Variabilité de la circulation de surface et intermédiaire aux moyennes latitudes de l'Atlantique Nord: réponse aux variations lentes et rapides du climat lors 
du dernier cycle glaciaire-interglaciaire. These de Doctorat. Université de Bretagne Occidentale.

Boer, P.L. (1982). Cyclicity and storage of organic matter in Middle Cretaceous pelagic sediments. En: Cyclic and event stratification. Einsele, G. y Seilacher, A. (Eds.). Springer-Verlag, Berlin: 456-465

Borehole Research Group (1999). ODP Logging Manual. Lamont-Doherty Earth Observatory; Rt. 9W; Palisades, NY 10964; USA.

Borrego, J. y Pendón, J.G. (1988). Progradación deltaica tortoniense en el sector de Villanueva del Río y Minas (Provincia de Sevilla). I Congr. Geol. España: 47-50

Bossio, A., El-Bied Rakic, K., Giannelli, L., Mazzei, R., Russo, A. y Salvatorini, G. (1976). Correlation de quelques sections stratigraphiques du Mio-Pliocene de la zone atlantique du Maroc avec les stratotypes de bassin Mediterraneen sur la base des foraminiferes planctoniques, nanoplancton calcarie et ostracodes. Atti. Soc. Tos. Sci. Nat. Mem., 83: 121-137.

Brumsack, H.J. y Wehausen, R. (1997). Orbitally-driven inorganic geochemical variations in Pliocene Eastern Mediterranean sediments. Neogene Mediterranean Paleoceanography, International Conference (Italy): 11.

Broecker, W.S. (1984). Terminations. En Milankovitch and Climate, Berger et al. (eds.). NATO AS/ Series C, 126 (1): 687-698.

Broecker, W.S. (1992). The Glacial World According to Wally. Lamont-Doherty Geological Observatory of Columbia University Palisades, NY (USA).

Butler, R.W.H., Lickorish, W.H., Grasso, M., Pedley, H.M. y Ramberti, L. (1995). Tectonics and sequence stratigraphy in Messinian basins, Sicily: constraints on the initiation and termination of the Mediterranean "salinity crisis". Geol. Soc. Am. Bull, 107: 425-439.

Cachäo, M. (1992). Contribuçao para o estudo quantitativo de polaçöes de Foraminíferos (Aplicabilidade da Analise Factorial). Gaia, Lisboa, 4: 9-20. 
Cachäo, M. (1993). Quantificaçao em Paleoecologia: uma perspectiva de evoluçao. Geonovas, número especial 3: 156-176.

Cande, S.C. y Kent, D.V. (1992). A new geomagnetic polarity time scale for the Late Cretaceous and Cenozoic. Journal of Geophysical Research, 97: 13,917-13,951.

Cande, S.C. y Kent, D.V. (1995). Revised calibration of the geomagnetic polarity time scale for the Late Cretaceous and Cenozoic: Journal of Geophysical Research, 100: 6093-6095.

Castradori, D. (1998). Calcareous nannofossils in the basal Zanclean of the Eastern Mediterranean Sea: Remarks on Palaeoceanography and sapropel formation. Proceedings of the Ocean Drilling Program, Scientific Results, Vol. 160: 113-136.

Cavazza, W. y DeCelles, P. (1998). Upper Messinian siliciclastic rocks in southeastern Calabria (southern Italy): palaeotectonic and eustatic implications for the evolution of the central Mediterranean region. Tectonophysics, 298: 223-241.

Channell, J.E.T., Rio, D. y Thunell, R.C. (1988). Miocene/Pliocene boundary magnetostratigraphy at Capo Spartivento, Calabria, Italy. Geology, 16: 1096-1099.

Cita, M.B. y Ryan, W.B.F. (1978). The Bou Regreg section of the Atlantic coast of Morocco, evidence, timing and significance of a Late Miocene regressive phase. Riv. Ital. Paleont. 84(4): 1051-1082.

Cita, M.B., Ryan, W.B.F. y Kidd, R.B. (1978). Sedimentation rates in Neogene deep-sea sediments from the Mediterranean and geodynamic implications of their changes. Initial Reports of DSDP, 42: 991-1002.

Civis, J., Martinell, J. y Porta, J. (1979). Microfauna del Mioceno terminal de la Rambla de Arejos (Almería). Stvdia Geol., 15: 37-55.

Civis, J., Siero, F.J., González, A., Flores, J.A., Andrés, I., Porta, J. y Valle, Mª.F. (1987). El Neógeno marino de la provincia de Huelva. Antecedentes y definición de las unidades litoestratigráficas. En Civis, J. y Flores, J.A. (Eds.) Paleonotología del Neógeno de Huelva (W. Cuenca del Guadalquivir). Ediciones Universidad de Salamanca. 
Civis, J., Alonso, G., González, A. y Braga J.C. (1994). Sedimentation carbonatee transgressive sur la bordure occidentale du couloir nord-betique pendant le Tortonien superieur (Fm Calcarenita de Niebla, SW de l'Espagne). En, Recifs et plates-formes carbonatees miocenes de Mediterranee-Miocene reefs and carbonate platforms of the Mediterranean. Saint-Martin-J.P., Cornee, J. (editores). Geologie Mediterraneenne, 21 (1-2): 9-18.

Civis, J., González-Delgado, J.A., Larrasoaina, J.C., Sierro, F.J., Alonso-Gavilán, G. y Pais, J. (remitido). A continuous record from the Upper Tortonian-Late Messinian in the Atlantic North Betic Gateway (Spain). The "Huelva" core: event stratigraphy and paleomagnetic calibration. Palaeogeogr. Palaeoclimat. Palaeoecol.

Clauzon, G., Suc, J.P., Gautier, F., Berger, A. y Loutre, M.F. (1996). Alternate interpretation of the Messinian salinity crisis: Controversy resolved?, Geology, 24: 363-366.

Colalongo, M.L., Di Grande A., D’Onofrio, S., Giannelli, K., Iaccarino, S., Mazzei, R., Romeo, M. y Sanvarorini, G. (1979). Stratigraphy of Late Miocene Italian sections straddling the Tortonian-Messinian boundary. Boll. Soc. Pal. Ital. 18(2): 258-302.

Comas, M.C, García-Dueñas, V. y Jurado, M.J. (1992). Neogene tectonic evolution of the Alboran Basin from MCS data. Geo-Marine Letters, 12: 144-149.

Comas, M.C., García-Dueñas, V, Soto, J.I., y Campos, J.I. (1993). An extensional basin developed on a collisional orogen: The Alboran Sea. In: Seranne, M. and Malavielle,J. (eds.). Late Orogenic Extension in Mountain Belts, BRGM Geol. Min. Doc. 219: 4-46.

Cotillon, P. y Rio, M. (1983): Cyclic sedimentation in the Cretaceous of Deep Sea Drilling Proyect Sites 535 and 540 (Gulf of Mexico), 534 (Central Atlantic), and in the Vocontian Basin (France). Init. Rpts. DSDP., 77: 339-376.

Cramp. A., O’Sullivan, G. (1999). Neogene sapropels in the Mediterranean: a review. Marine Geology 153: 11-28.

Crescenti, U., Giannelli, L., Martínez Díaz, C. y Salvatorini, G. (1973). Tentativo di correlazione tra i piani Andalusiano e Messiniano. Atti. Soc. Tosc. Sci. Nat., Mem., Serie A, 80: 17-39 
Dañobeitia, J.J., Bartolomé, R., Checa, A., Maldonado, A. y Slootweg, A.P. (1999). An interpretation of a prominent magnetic anomaly near the boundary between the Eurasian and African plates (Gulf of Cadiz, SW margin of Iberia). Marine Geology, 155: $45-62$

Decourt, J., Zonenshain, L.PI, Ricou. L.E., Zazmin, V.G., Le Pichon, X., Knipper, A.L., Grandjacquet, C., Shotshickov, I.M., Geyssant, J., Lepvrier, C., Perchersky, K.H., Boulin, J., Sibuet, J.C., Savostin, L.A., Sorokthin, Ol, Westphal, M., Bazhenov, M.L., Lauer, J.P., Bijou Duval, B. (1986). Geological evolution of the Tehtys belt from the Atlantic to the Pamirs cince the Lias. Tectonophysics 123: 265-283.

De Visser, J.P., Ebbing, J.H.J., Gudjonsson, L., Hilgen, F.J., Jorissen, F.J., Verhallen, P.J.J.M. y Zevenboom, D. (1989). The origin of rhythmic bedding in the Pliocene Trubi Formation of Sicily, southern Italy. Palaeogeog. Palaeoclimatol. Palaeocol., 69: $45-66$

Di Stefano, E. (1998). Calcareous nannofossil quantitative biostratigraphy of Holes 969E and 963B (Eastern Mediterranean). Proceedings of the Ocean Drilling Program, Scientific Results, Vol. 160: 99-112.

D’Onofrio, S., Giannelli, L., Iaccarino, S., Morlotti, E. Romeo, M., Salvatorini, G., Sampo, M. y Sprovieri, R. (1975). Planktonic foraminifera of the upper Miocene from some italian sections and the problem of the lower boundary of the Messinian. Boll. Soc. Paleo. Ital., 14(2): 177-196.

Eicher, D.L. y Diner, R. (1991). Environmental Factors Controlling Cretaceous Limestone-Marlstone Rhythms. Einsele et al. (Eds.). Cycles an Events in Stratigraphy: 79-93.

Einsele, G. (1982). Limestone-marl cycles (periodites): diagnosis, significance, causes-a review. En: Cyclic and event stratification. Einsele, G. y Seilacher, A. (Edts.). Springer, Berlin: 8-53.

Elberli, G.P., Swart, P.K., Malone, M.J., et al. (1997). ODP Leg 166 - Bahamas Transect Summary of Wireline Logging Results. Proceedings of the Ocean Drilling Program, Initial Reports, Vol. 166. 
Emeis, K-C. y Sakamoto T. (1998). The sapropel theme of leg 160. Proceedings of the Ocean Drilling Program, Scientific Results, Vol. 160: 29-59

Emiliani, C. (1972). Quaternary Paleotemperatures and the duration of the higthtemperature intervals. Science, 178: 348-401.

Emiliani, C. (1978). The cause of the ice ages. Earth Planet. Sci. Letters, 7: 349-352.

Emiliani, C. y Shackleton, N.J. (1974). The Brunhes Epoch: Isotopic paleotemperatures and geochronology. Science 183: 511-514.

Feinberg, H. y Lorez H.G. (1970). Norvelles données stratigraphiques sur le Miocène superieur et le Pliocène de Maroc nord-occidentale. Notes Serv. Geol. Maroc. 30: 2126.

Fernández, M., Berastegui, X., Puig, C., García-Castellanos, D., Jurado M.J., Torne, M., y Banks, C. (1998). Geophysical and geological constraints on the evolution of the Guadalquivir foreland basin, Spain. En: Cenozoic foreland basins of Western Europe. Mascle, A., Puigdefabregas, C., Luterbacher-H.P., Fernández, M. (editores). Geological Society Special Publications, 134: 29-48

Flores, J.A. (1985). Nanoplancton calcáreo del Neógeno del borde noroccidental de la cuenca del Guadalquivir (S.O. de España). Tesis Doctoral, Universidad de Salamanca.

Flores, J.A. y Sierro, F.J. (1987). Calcareous Plankton in Tortonian/Messinian Transition Series of the Northwestern Edge of the Guadalquivir Basin. Abh. Geol. B-A. 39: 6784.

Flores, J.A. y Sierro, F.J. (1989). Calcareous nannoflora and planctonic foraminifera in the Tortonian boundary interval of East Atlantic DSDP sites and their relation to Spanish and Moroccan section. In J. A. Crux \& S. van Heck (Eds.) Nannofossils and their applications: 249-266.

Francés, G. (1992). Foraminíferos bentónicos y paleoceanografía del Plioceno superior en el Atlántico Norte: Incidencia de la glaciación en las comunidades abisales. Tesis Doctoral, Universidad de Salamanca. 
Galán, E., González, I. y Mayoral, E. (1987). Glauconite from the Guadalquivir Basin, Southern Spain. Characterization and origin. VI Meeting of the European Clay Groups: 236-239.

Garcés, M., Krijgsman, W. y Agustí, J. (1998). Chronology of the late Turolian deposits of the Fortuna basin: implications for the Messinian evolution of the eastern Betics. Earth Planet. Sci. Lett., 163: 69-81.

García-Castellanos, D. (1998). Desarrollo de modelos numéricos de flexión litosférica: aplicación a fosas oceánicas y cuencas de antepaís. Tesis Doctoral. Consejo Superior de Investigaciones Científicas (CSIC). Institut de Ciències de la Terra Jaume Almera. Departament de Geofísica.

García-Hernández, M., López-Garrido, A.C., Rivas, P., Sanz de Galdeano, C. y Vera, J.A. (1980). Mesozoic paleogeographic evolution of the External Zones of the Betic Cordillera. Geologie in Mijbow, 59: 155-168.

García-Dueñas, V., Martínez-Martínez, J.M. y Navarro-Vilá, F., (1986). La zona de falla de Torres Cartas, conjunto de fallas normales de bajo ángulo entre NevadoFilábride y Alpujárrides (Sierra Alhamilla, Béticas Orientales). Geogaceta, 1: 17-19.

García-Dueñas, V. y Martínez-Martínez, J.M. (1988). Sobre el adelgazamiento Mioceno del Dominio de Alborán, el despegue extensional se Filabres (Béticas orientales). Geogaceta, 5: 53:55

García-Dueñas, V., Balanyá, J.C. y Martínez-Martínez, J.M. (1992). Miocene extensional detachments in the outcropping basement of the northern Alborán Basin (Betics) and their tectonic implications. Geo. Mar. Lett., 12: 88-95.

García, P. y López, A. (1984). La depresión del Guadalquivir, cuenca de antepaís durante el neógeno: Génesis, evolución y relleno final. I Congreso Español de Geología. Tomo III: 241-252.

García, C., Echánove, A., Arrieta, A. (1998). Gas exploration in southern Spain; a successful AVO/ DHI application. En, AAPG international conference and exhibition; abstracts. AAPG Bulletin. 82; 10, pp 1916. 
García, C., Echánove, A., Arrieta, A. (1999). Aplicación del análisis de la variación de la amplitud con el offset (AVO) en el Guadalquivir (SO de España). Presentación de un nuevo enfoque para el estudio AVO. Libro homenaje a J.Ramírez del Pozo (AGGEP).

Gautier, F., Clauzon, G., Suc, J.P., Cravatte, J. y Violanti, D. (1994). Age et duree de la crise de salinite messinienne. Academid des Sciences. Comptes Rendus, ser. 2, v. 318: 1103-1109.

Glaçon, G.,Gazzini, C.V., Iaccarino, S., Rehault, J.P., Randrianasolo, A., Sierro, F.J., Weavwr, P., Channell, J., Torii, M. y Hawthorne, T. (1990). Planktonic foraminiferal events and stable isotope records in the Upper Miocene, Site 654. Proc. ODP. Sci. Results, 107: 415-427.

Gerlings, L.P.A. (1977). Planktonic foraminifera of the Abad member (Messinian), Turre formation, in the Sorbas basin (Almeria, SE Spain). UNESCO-IGCP. Project $n^{\circ} 96$. Meddinian Correlation. Messinian Seminar $n^{\circ} 3$. Excursion $n^{\circ} 2$, Sorbas: 37-43.

González, A., Vegas, R., Córdoba, D. y Téllez, J. (1992). Arquitectura general de la corteza en el Norte del golfo de Cádiz. III Congreso Geológico de España, VIII Congreso Latinoamericano de Geología-Simposios, ed. Univ. de Salamanca, 2: 506509.

González Donoso, J.M. y Serrano, F. (1977). Bio y cronoestratigrafía de los materiales pre-evaporíticos de Sorbas (provincia de Almería). Messinian Seminar, v. 3, excursion 2 (Sorbas): 69-76.

Grada Sanz, A. (1984). Empleo de métodos eléctricos en la prospección de hidrocarburos. Aplicación a un sector de la cuenca del Guadalquivir. I Congreso Español de Geología, Tomo III: 347-361.

Grafenstein, R., Zahn, R., Tiedemann, R. y Murat, A. (1999). Planktonic $\delta^{18}$ O records at Sites 976 and 977, Alborán Sea; Stratigraphy, forcing, and paleoceanographic implications. Zahn, R., Comas, M.C. y Klaus, A. (Eds.), Proceedings of the Ocean Drilling Program, Scientific Results, Vol. 161: 469-479.

Haq, B.U., Handenbol, J. y Vail, P.R. (1987). Chronology of fluctuating sea levels since the Triassic. Science, 235: 1156-1167. 
Hays, J.D., Imbrie, J. y Shackleton, N.J. (1976). Variations in the Earth's Orbit: Pacemaker of Ices Ages. Science, 194: 1121-1132.

Hilgen, F.J. (1987). Sedimentary rhythms and high resolution chronostratigraphic correlations in the Mediterranean Pliocene. Newsl. Stratigr., 17: 109-127.

Hilgen, F.J. (1991a). Astronomical calibration of Gauss to Matuyama sapropels in the Mediterranean and implication for the Geomagnetic Polarity Time Scale. Earth Planet. Sci. Lett. 104: 226-244.

Hilgen, F.J. (1991b). Extension of the astronomically calibrated (polarity) time scale to the Miocene/Pliocene boundary. Earth Planet. Sci. Lett. 107: 349-368.

Hilgen, F.J. and Langereis, C.G. (1988). The age of the Miocene-Pliocene boundary in the Capo Rossello area (Sicily). Earth Planet. Sci. Lett., 91: 214-222.

Hilgen, F.J. and Langereis, C.G. (1993). A critical re-evaluation of the Miocene/Pliocene boundary as defined in the Mediterranean. Earth Planet. Sci. Lett., 118: 167-179.

Hilgen, F.J., Krijgsman, W., Langereis, C.G., Lourens, L.J., Santarelli, A. y Zachariasse, W.J. (1995) Extending the astronomical (polarity) time scale into the Miocene. Earth Planet Science Letters., 136: 495-510.

Hilgen, F.J., Krijgsman, W., Langereis, C.G., Lourens, L.J. (1997). Breakthrough Made in Dating of the Geological Record. Eos, Vol. 78, No, 28: 288-289.

Hilgen, F.J. y Krijgsman, W. (1999). Cyclostratigraphy and astrochronology of the Tripoli diatomite Formation (pre-evaporite Messinian, Sicily, Italy). Terra Nova (submitted).

Hilgen, F.J., Abdul Aziz, H., Krijgsman, W., Langereis, C.G., Lourens, L.J., Meulenkamp, J.E., Raffi, I., Steenbrink, J., Turco, E., Van Vugt, N., Wijbrans, J.R. y Zachariasse. (1999). Present status of the astronomical (polarity) time-scale for the Mediterranean Late Neogene. The Royal Society, 357: 1931-1947.

Hodell, D.A., Kennett, J.P. y Leonard, K.A. (1983). Climatically induced changes in vertical water mass structure of the Vema Channel during the Pliocene: Evidence 
from Deep Sea Drilling Project holes 516A, 517, and 518. Initial Reports of DSDP, 72: 907-919.

Hodell, D.A., Benson, R.H., Kennett, J.P. y Rakic-El Bied (1989). Stable isotope stratigraphy of Late Miocene-Early Pliocene sequences in Northwest Morocco: the Bou Regreg Section. Paleoceanography 4(4): 467-482.

Hodell, D.A., Benson, R.H., Kent, D.V., Boersma, A. y Rakic-El Bied, K. (1994). Magnetostratigraphic biostratigraphic, and stable isotope stratigraphy of an Upper Miocene drill core from the Salé Briqueterie (northwest Morocco): A high-resolution chronology for the Messinian stage. Paleoceanography, 9: 835-855.

Hodell, M.W., Sierro, F.J. y Raymo, M.E. (remitido). Correlation of Late Miocene-toEarly Pliocene Sequences between the Mediterranean and North Atlantic. Paleoceanography.

Hooper P.W.P. y Weaver, P.P.E. (1987). Paleoceanographic significance of Late Miocene to Early Pliocene planktonic foraminifers at Deep Sea Drilling Project Site 609. Initial Rep. Deep Sea Drill. Poj., 94: 925-934.

Howell, M.W., Thunell, R, C,. Di Stefano, E., Sprovieri, R., Tappa, J. y Sakamoto, T. (1998). Stable Isotope Chronology and Paleoceanographic History of Sites 963 and 964, Eastern Mediterranean Sea. Proceedings of the Ocean Drilling Program, Scientific Results, Vol. 160: 167-190.

Howell, M.W., Rio, D. y Thunell R.C. (1990). Laminated sediments from the Vrica (Calabria, S. Italy): Evidence for Plio-Pleistocene climatic change in the Mediterranean region. Palaeogeog. Palaeoclimatol. Palaeocol., 78:195-216

Hsü, K.J., Cita, M.B. y Ryan, W.B.F. (1972). The origin of the Mediterranean evaporites. Initial Reports of the DSDP, 13: 1203-1231.

Hsü, K.J., Ryan, W.B.F. y Cita, M.B. (1973). Late Miocene desiccation of the Mediterranean. Nature, 242: 240-244.

Hsü, K.J., Montadert, L., Bernoulli, D., Cita, M.B., Erickson, A., Garrison, F.E., Kidd, F.B., Mèlierés, F., Müller, C. y Wright, R. (1977). History of the Mediterranean salinity crisis. Nature, Vol. 267, Nº 5610: 399-403. 
Iaccarino, S., Morlotti, E., Papani, G., Pelosio, G. y Raffi, S. (1975). Litostratigrafia e biostratigrafia di alcune serie neogeniche della provincia de Almeria. Ateneo parmense. Acta Nat., 11: 237-313.

Iaccarino, S. (1985). Mediterranean Miocene and Pliocene Planktonic foraminifera. Bolli, H.M., Saunders, J.B. and Perch-Nielsen, K. (Eds.). Plankton Stratigraphy. Cambridge University Press: 283-314.

Iaccarino, S., Gaboardi, S. y Cita, M.B. (1997). The Miocene/Pliocene boundary in the Western Mediterranean: New data on the timing and significance of the Pliocene transgression after ODP Leg 161. Neogene Mediterranean Paleoceanography, International Conference (Italy): 36

Imbrie, J. (1985). A theoretical framework for the Pleistocene ice ages. Jour. Geol. Soc. London, 142: 417-432.

ITGE (1990). Documentos sobre la geología del subsuelo de España. Tomo 1: Introducción. Guadalquivir-golfo de Cádiz.

Kauffman, E.G. (1986). High resolution event stratigraphy: regional and global Cretaceous Bio-events. En: Global Bio-events (O.H. Walliser, Ed.), Springer-Verlag, Berlin: 279-335.

Kauffman, E.G. (1988). Concepts and Methods of hight-resolution event Stratigraphy. Annu. Rev. Earth Planet. Sci.,16: 605-645.

Kent, D.V., Olsen, P.E., y Witte, W.K. (1995). Late Triassic-Early Jurassic geomagnetic polarity sequence and paleolatitudes from drill cores in the Newark rift basin (Eastern North America). Journal of Geophysical Research, Vol. 100: 1496514998.

Kennett, J.P., y Srinivasan, M.S. (1983). Neogene Planctonic Foraminifera, A Phylogenetic Atlas. Hutchinson Ross Publishing Company, Pennsylvania.

Kouwenhoven, T.J., Seidenkrantz, M.-S. y Van der Zwaan, G.J. (1999). Deep-water changes: The near-synchronous disappearance of a group of benthic foraminifera 
from the late Miocene Mediterranean. Palaeogeography, Palaeoclimatology, Palaeoecology, 152: 259-281.

Kouwenhoven, T.J. (2000). Survival under stress: benthic foraminiferal patterns and Cenozoic biotic crises. Tesis doctoral, Geologica Ultraiectina, $\mathrm{n}^{\circ}$ 186: $206 \mathrm{pp}$.

Krijgsman, W., Hilgen, F, Langereis, C.G. y Zachariasse, W.J. (1994). The age of the Tortonian/Messinian boundary. Earth and Planet. Sci. Letters, 121: 533-547.

Krijgsman, W., Hilgen, F, Langereis, C.G., Santarelli, A., y Zachariasse, W.J. (1995). Late Miocene magnetostratigraphy, biostratigraphy and cyclostratigraphy in the Mediterranean. Earth Planet. Sci. Lett., 136: 475-494.

Krijgsman, W. (1996). Miocene magnetostratigraphy and cyclostratigraphy in the mediterranean: extension of the astronomical polarity time scale. Geologica Utraiectina. Mededelingen van de Facultaeit Utrecht, 141: 207.

Krijgsman, W. (1997). Miocene Magnetoestratigraphy and cyclostatigraphy in the Mediterranean: Extension of the Astronomical Polarity Time Scale. Geological Ultraiectina, 141: 1-207.

Krijgsman, W., Hilgen, F.J., Negri, A., Wijbrans, J.R. y Zachariasse, W.J. (1997). The Monte Casino section (Northern Apennines, Italy): a potential Tortonian/Messinian boundary stratotype?. Palaeogeo. Palaeoclimatol. Palaeoecol., 133: 27-47.

Krijgsman, W., Hilgen, F.J., Marabini, S. y Vai, G.B. (1999a). New paleomagnetic and cyclostratigraphic age constraints on the Messinian of the Nortern Apennines (Vena del Gesso Basin, Italy). Mem. Soc. Geol. It., 54: 25-33

Krijgsman, W, Hilgen, F.J., Raffi, I., Sierro, F.J. y Wilson, D.S. (1999b). Cronology, causes and progression of the Messinian salinity crisis. Nature, vol. 400, August 1999, pp: 652-655.

Krijgsman, W., Langereis, C.G., Zachariasse, W.J., Boccaltetii, M., Moratti, G., Gelati, R., Iaccarino, S., Papani, G., Villa, G. (1999c). Late Neogene evolution of the Taza-Guercif Basin (Rifian Corridor, Morocco) and implications for the Messinian salinity crisis. Marine Geology, 153: 147-160. 
Krijgsman, W., Hilgen, F.J., Marabini, S. y Vai, G.B. (1999d). New paleomagnetic and cyclostratigraphic age constraints on the Messinian of the Northern Apennines (Vena del Gesso Basin, Italy). Mem. Soc. Geol. It., 54: 25-33.

Krijgsman, A.R., Fortuin, A.R., Hilgen, F.J., Roep, Th.B. y Sierro, F.J. (en prensa, 2000). An astrochronology for the Messinian Sorbas Basin (SE Spain). Sedimentary Geology.

Kroon, D., Alexander, I., Little, M., Lourens, L.J., Matthewson, A., Robertson, A.H.F. y Sakamoto, T. (1998). Oxygen isotope and sapropel stratigraphy in the Eastern Mediterranean during the last 3.2 Million Years. Proceedings of the Ocean Drilling Program, Scientific Results, Vol. 160: 181-189.

Kutzbach, J.E., Webb, T. III (1993). Conceptual basis for understanding LateQuaternary Climates. In: Wright Jr., Kutzbach, J.E., Webb, T.III, Ruddiman, W.F., Street-Perrott, F.A., Bartlein, PIJ. (Eds.). Global Climates since the Last Glacial Maximum. University of Minnesota Press, pp. 5-11.

Langereis, C.G. y Hilgen, F.J. (1991). The Rossello composite: A Mediterranean and global reference section for the early to early Late Pliocene. Earth Planet. Sci. Lett., 104:211-225.

Laskar, J. (1990). The chaotic motion of the solar system: A numerical estimate of the size of the chaotic zones. Icarus, 88, 266-291.

Laskar, J., Joutel, F. y Boudin, F. (1993). Orbital, precessional, and insolation quantities for the Earth from -20 Myr to +10 Myr. Astron. Astrophys., 270: 522-533.

Lee, H. y Baraza, J. (1999). Geotechnical characteristics and slope stability in the Gulf of Cadiz. Marine Geology, 155: 173-190.

Leonard, K. A., Williams, D. F. y Thunell, R. C. (1983). Pliocene paleoclimatic and paleoceanographic history of the South Atlantic Ocean: Stable isotopic records from Leg 72 Deep Sea Drilling Project Holes 516 and 517. Initial Reports DSDP, 72: 895906. 
Levy, A., Mathieu, R., Poignant, A., Rosset-Moulinier, M., Ubaldo, M.L. et Lebreiro, S. (1995). Foraminíferes actuels de la Marge Continentale Portugaise-Inventaire et Distribution. Memórias do Instituto Geológico e Mineiro, 32.

López-Galindo, A., Rodero, F. y Maldonado, A. (1999). Surface facies and sediment dispersal patterns; southeastern Gulf of Cadiz, Spanish continental margin. Marine Geology, 155: 83-98

Lourens, L.J., Hilgen, F.J., Raffi, I. y Vergnaud-Grazzini, C. (1996a). Early Pleistocene chronology of the Vrica section (Calabria, Italy). Paleoceanography, 11: 797-812.

Lourens, L.J., Antonarakou, A., Hilgen, F.J., Van Hoof, A.A.M., Vergnaud-Grazzini, C. y Zachariasse, W.J. (1996b). Evaluation of the Plio-Pleistocene astronomical timescale. Paleoceanography, Vol. 11: № 4: 391:413.

Lourens, L.J., Hilgen, F.J. y Raffi, I. (1998). Solving the chronology of the Vrica Section. Proceedings of the Ocean Drilling Program, Scientific Results, Vol. 160: 191-198.

McKenzie, J.A., Spezzaferri, S. e Isern, A. (1997). The Miocene/Pliocene boundary in the Mediterranean and Bahamas; Implications for a global flooding event in the Earliest Pliocene. Neogene Mediterranean Paleoceanography, International Conference (Italy): 36.

Mckenzie, J.A., Spezzaferri, S. e Isern, A. (1999). The Miocene-Pliocene Boundary in the Mediterranean Sea and Bahamas: Implications for a Global Flooding Event in the Earliest Pliocene. Mem. Soc. Geol. It., 54: 93-108.

Maldonado, A. (1992). El mar de Alborán y el Golfo de Cádiz: conexiones AtlánticoMediterráneo. Una introducción. III Congreso Geológico de España, VIII Congreso Latinoamericano de Geología-Simposios, ed. Univ. de Salamanca, 2: 459-466.

Maldonado, A. y Nelson, C.H. (1988). Dos ejemplos de márgenes continentales de la Península Ibérica: el margen del Ebro y el Golfo de Cádiz. Rev. Soc. Geol. de España, 1 (3-4): 317-325. 
Maldonado, A. y Nelson, C.H. (1999). Interaction of tectonic depositional processes that control the evolution of the Iberian Gulf of Cadiz margin. Marine Geology, 155: 217242.

Maldonado, A., Somoza, L. y Pallarés, L. (1999). The Betic orogen and the IberianAfrican boundary in the Gulf of Cadiz: geological evolution (central North Atlantic). Marine Geology, 155: 9-43.

Malanotte-Rizzoli, P., Robinson A.R., Roether W., Manca B., Bergamasco A., Brenner S., Civitarese G., Georgopoulos D., Haley P.J., Kioroglou S., Kontoyannis H., Kress N., Latif M.A., Leslie W.G., Ozsoy E., Ribera d'Alcala M., Salihoglu I., Sansone E. y Theocharis A. (1996). Experiment in Eastern Mediterranean Probes Origin of Deep Water. Earth in Space, Vol. 9, No. 3: 8-10.

Malod, J. y Mougenot, D. (1979). L'histoire géologique néogène du golfe de Cadix. Bull. Soc. géol. France., 5: 603-611.

Manabe, S. y Broccoli, A.J. (1984). Influence of the CLIMAP Ice Sheet on the Climate of a General Circulation Model: Implications for the Milankovitch theory. En: Milankovitch and Climate, Berger et al. (eds.), NATO AS/ Series C, 126 (2): 789799.

Marín Señán, J.M. (1988). Sedimentación detrítica en el borde Norte de la depresión del Guadalquivir (Sector de Villanueva de la Reina, Prov. de Jaén). I Congr. Geol. España: 123-126.

Martín, J.M. y Braga, J.C. (1990). Arrecifes messinienses de Almería. Tipologías de crecimiento, posición estratigráfica y relación con las evaporitas. Geogaceta, 7: 6668.

Matín, J.M. y Braga, J.C. (1994). Messinian events in the Sorbas basin of Southeastern Spain and their implications of the recent history of the Mediterranean. Sediment. Geol. 90: 257-268.

Matín, J.M. y Braga, J.C. (1996). Tectonic signals in the Messinian stratigraphy of the Sorbas basin (Almería, SE Spain). Friend, P., F. and Dabrio, C. (eds). Tertiary basins of Spain, the stratigraphic record of crustal kinematics. Cambridge University Press: 387-391. 
Martínez del Olmo, W. (1984). Modelo tectosedimentario del bajo Guadalquivir. I Congreso Español de Geología. Tomo I: 199-213.

Martínez del Olmo, W., Suárez, J., Serrano, A. and Leret, G. (1986). Los sistemas tubidíticos del Guadalquivir-Golfo de Cádiz: Fms Río Guadiana y Río Guadalquivir. Abstract X Congreso Español de Sedimentología. Barcelona.

Martinez del Olmo, W., Torrescusa, S., Riaza, C., Garcia, C. (1998). Sequence stratigraphy and turbidite reservoir characterization of biogenic gas fields in the Guadalquivir-Golfo de Cadiz Miocene basins, SW Spain. En, AAPG international conference and exhibition; abstracts. AAPG Bulletin. 82; 10, pp 1939.

Martínez del Olmo W., Riaza Molina, C. y Torrescusa Villaverde, S. (1996). Descenso eustático messiniense en una cuenca atlántica. El cañón submarino del Río Guadalquivir. (SW de España). Geogaceta, 20 (1): 138-141.

Martínez-Martínez, J.M. y Azañón, J.M. (1997). Mode of extensional tectonics in the southeastern Betics (SE Spain): Implications for tectonics evolution of the periAlboran orogenic system. Tectonophysics, 16: 205-225.

Meléndez-Hevia, F. y Alvarez de Buergo, E. (1996). Oil and gas resources of the Tertiary basins of Spain. Friend, P., F. and Dabrio, C. (eds). Tertiary basins of Spain, the stratigraphic record of crustal kinematics. Cambridge University Press Cap. G5: 20-25.

McCulloch, M.T. y De Deckker, P. (1989). Sr isotope constraints on the Mediterranean environment at the end of the Messinian salinity crisis. Nature, 342: 62-65.

Montenat, C.H., Bizon, G. and Bizon J.J. (1976). Continuite ou discontinuite de sedimentation marine Mio-Pliocene en Mediterranee occidentale. Inst. Francais $d u$ Petrole Revue, 31: 613-663.

Montenat, C.H. (1996). The Betic Neogene basins: introducción. Friend, P. F. and Dabrio, C. (Editors). Tertiary basins of Spain, the stratigraphic record of crustal kinematics. Cambridge University Press, Cap. S1: 321-322. 
Montenat, C.H. y D'Estevou, P.O. (1996 b). Late Neogene basins evolving in the Eastern Betic transcurrent fault zone: an illustrated review. Friend, P. \& C. J. Dabrio (eds.). Tertiary basins of Spain, the stratigraphic record of crustal kinematics. Cambridge University Press, Cap. S4: 372-386.

Nelson, C.H., Baraza, J., Maldonado, A. (1993). Mediterranean undercurrent sandy contourites, Gulf of Cadiz, Spain. Sediment. Geol. 82, 103-131.

Nelson, C.H. y Maldonado, A. (1999). The Cadiz margin study off Spain: an introduction. Marine Geology, 155: 3-8.

Nelson, C.H., Baraza, J., Maldonado, A., Roderot, F., Escutia, C. y Barber Jr, J.H. (1999). Influence of the Atlantic inflow and Mediterranean outfow currents on Late Quaternary sedimentary facies of the Gulf of Cadiz continental margin. Marine Geology, 155: 99-129

Nijenhuis, I.A., Schenau, S.J., Van der Weijden, C.H., Hilgen, F.J., Lourens, L.J., Zachariasse, W.J., (1996). On the origin of upper Miocene sapropelites. A case study from the Faneromeni section, Crete (Greece). Paleoceanography, 11: 633-645.

Okada, H. and Bukry, D. (1980). Supplementary modifications and introduction of code numbers to the low-latitude coccolith biostratigraphic zonation. Mar. Micropaleonto., 5: 321-325.

Olsen, P.E. y Kent, D.V., (1996). Milankovitch climate forcing in the tropics of Pangea during the Late Triassic. Palaeogeography, Palaeoclimatology, and Palaeoecology, 122:. 1-26.

Olsen, P.E., Kent, D V., Cornet, B., Witte, W.K., y Schlische, R.W. (1996). Highresolution stratigraphy of the Newark rift basin (Early Mesozoic, Eastern North America): Geological Society of America, Vol. 108, nº 1:40-77.

Ott d'Estevou, P. (1980). Evolution dynamique du basin neogène de Sorbas (Cordillères Bétiques Orientales. Espagne). Docum. et Trav. IGAL., 1: 264p.

Perconig, E. (1960). Sur la constitution géologique de l'Andalousie occidentale en particulier du bassin du Guadalquivir. Livre mem. Prof. Fallot, Soc. Geol. France, I: 229-256. 
Perconig, E. (1964). La estratigrafía del Mioceno en Andalucía occidental (España). El límite Oligoceno-Mioceno y la fase terminal marina del Mioceno. C.S.I.C. Cursillos y conferencias, IX: 219-228.

Perconig, E. (1966). Sobre la proposición del nuevo término estratigráfico "andaluciense" para indicar la fase terminal del Mioceno de fácies marina. Inst. Geol. y Minero de España, 91: 13-40.

Peconig, E. (1971). Sobre la edad de la transgresión del Terciario marino en el borde meridional de la meseta. I Congreso Hispano-Luso-Americano de Geología Económica: 309-323.

Perconig, E y Martínez Díaz, C. (1977). Perspectivas petrolíferas de Andalucía Occidental. Boletín Geológico y Minero, nº 88-V: 417-433.

Pierre C., Rouchy, J-M. y Blanc-Valleron M-M. (1998). Sedimentological and stable isotope changes at the messinian/pliocene boundary in the eastern mediterranean (holes 968a, 969a and 969b). Proceedings of the Ocean Drilling Program, Scientific Results, Vol. 160: 3-8

Posamentier, H.W., Jervey, M.T. y Vail, P.R. (1988). Eustatic controls on clastic deposition. I: Conceptual framework. En Sea level changes: an integrated approach. SEPM Spec. Publ., 42: 109-124.

Raffi, I. y Flores, J.A. (1995). Pleistocene through Miocene calcareous nannofossils from easten equatorial Pacific Ocean (Leg 138). Proc. ODP, Sci. Results, 138: 233-286.

Renne, P.R.,Deino, A.L., Walter, R.C., Turrin, B.D., Swisher, C.C., Becker, T.A., Cueris, G.H., Sharp, W.D., y Jaouni, A.R. (1994). Intercalibration of astronomical and radioisotopic time. Geology, 22: 783.

Riaza, C. y Martínez del Olmo, W (1996). Depositional model of the Guadalquivir-Gulf of Cádiz Tertiary basin. Friend, P. F. and Dabrio, C. J. (Editors). Tertiary basins of Spain: the stratigraphic record of crustal kinematics. Cap. S3: 330-338. 
Riding, R, Braga, J.C., Martín, J.M., Sánchez-Almazo, I.M. (1998). Mediterranean Messinian Salinity Crisis: constraints from a coeval marginal basin, Sorbas, southeastern Spain. Marine Geology, 146: 1-20.

Rio, D., Fornaciari, E., y Raffi, I. (1990). Late Oligocene through early Pleistocene calcareous nannofossils from western equatorial Indian Ocean (Leg 115). Proc. ODP, Sci. Results, 115: 175-235.

Ríos, J.M. (1958). Relación de los principales sondeos para investigación de petróleo llevados a cabo en España desde 1939. Not. y Comun. Instit. Geol. Min. Esp., t. 50: 49-73.

Rodero, J., Pallarés, L. y Maldonado, A. (1999). Late Quaternary seismic facies of the Gulf of Cadiz Spanish margin: depositional processes influenced by sea-level change and tectonic controls. Marine Geology, 155: 131-156.

Rodríguez-Fernández, J, Fernández, J., López-Garrido, A.C. y Sanz de Galdeano, C. (1984). The central sector of the betic cordilleras, a realm situated between the Atlantic and Mediterranean domains, during the Upper Miocene. Ann. Geol. Pays Hellen., XXXII: 97-103.

Rögl, F., Steineger, F. y Müller, C. (1978). Middle Miocene salinity crisis and paleogeography of the Parathetys. Initial Reports DSDP, 42: 985-990.

Rohling, E.J. (1994). Review and new aspects concerning the formation of eastern Mediterranean sapropels. Mar. Geol., 122: 1-28.

Rohling, E.J. y Hilgen, F.J. (1991). The eastern Mediterranean climate at times of sapropel formation: a review. Geol. Mijnbouw, 70: 253-264.

Rohling, E., y de Rijk, S. (1999). Holocene Climate Optimum and Last Glacial Maximum in the Mediterranean: the marine oxygen isotope record. Marine Geology, 153:57-75.

Roldan García, F.J. (1988). Implicaciones de materiales triásicos en la depresión del Guadalquivir, cordilleras Béticas (Provincias de Córdoba y Jaén). Congr. Geol. España, 1: 189-192. 
Rossinol-Strick, M. , Nesteroff, V., Olive, P., Vergnaud-Grazzini, C. (1982). After the deluge; Mediterranean stagnation and sapropel formation. Nature 295: 105-110.

Rossignol-Strick, M. (1983). African monsoons, an immediate climatic response to orbital insolation. Nature, 303: 46-49.

Rossinol-Strick, M. (1985). Mediterranean Quaternary sapropels, an immediate response of the African monsoon to variations of insolation. Palaeogeogr., Palaeoclimatol., Palaeoecol. 49: 237-263.

Rossignol-Strick, M. (1987). Rainy periods and bottom water stagnation initiating brine accumulation and metal concentrations, 1. Paleocceanography, 2: 333-360.

Ruddiman, W.F., Raymo, M. y Mc.Intrye, A. (1986). Matuyama 41.000-year cycles: North Atlantic Ocean and northern ice sheets. Earth Planet. Sci. Letters, 80: 117129.

Salvatorini, G. y Cita, M.B. (1979). Miocene Foraminiferal stratigraphy DSDP site 397 (Cape Bojador, North Atlantic). Initial Reports of the Deep Sea Drilling Project, 47 (1): 317-375.

Sartori, R., Torelli, L., Zitellini, N., Peis, D. y Lodolo, E. (1994). Eastern segment of the Azores-Gibraltar line (central-eastern Atlantic): An oceanic plate boundary with diffuse compressional deformation. Geology, 22: 555-558.

Sánchez Almazo, I. M. (1999). Evolución paleoambiental de las cuencas neógenas de Almería en el Messiniense. Tesis Doctoral, Universidad de Granada.

Sanz de Galdeano, C. (1990). Geologic evolution of the Betic Cordilleras in the Western Mediterranean, Miocene to present. Tectonophysics, 172: 107-119.

Sáenz de Galdeano, C. (1983). La neotectónica de las Cordilleras Béticas. Ed. ITGME, Libro Jubilar de J.M. Ríos, Geología de España, 2: 469-485.

Sanz de Galdeano, C.M. y Rodríguez-Fernández, J. (1996). Neogene palaeoceanography of the Betic Cordillera: an attempt at reconstruction. Friend, P. F. and Dabrio, C. (Editors). Tertiary basins of Spain, the stratigraphic record of crustal kinematics. Cambridge University Press Cap. S2: 323-329 
Schenau, S.J., Antonarakou, A., Hilgen, F.J., Lourens, L.J., Nijenhuis, I.A., Van der Weijden, C.H. y Zachariasse, W.J. (1999). Organic rich layers in the Metochia section (Gavdos, Greece): evidence for a single mechanism of sapropel formation during the last 10 My. Marine Geology, 153:117-135.

Schwarzacher, W. y Fischer, A.G. (1982). Limestone-shale bedding and perturvations of the Earth's orbit. En: Cyclic and event stratification. Einsele, G. y Seilacher, A. (Eds.). Springer-Verlag, Berlin: 72-95.

Seidenkrantz, M.-S., Kouwenhoven, T.J., Jorissen, F.J., Shackleton, M.J., y Van der Zwaan, G.J. (1999). Bentic foraminifera as indicators of changing MediterraneanAtlantic water exchange in the late Miocene. Marine Geology, 163.

Shackleton, N.J., Hall, M.A. y Pate, D. (1995). Pliocene stable isotope stratigraphy of ODP site 846, Proc. Ocean Drill. Program Sci. Results, 138, 337-353.

Shackleton, N.J., Crowhurst, S., Hagelberg, T., Pisias, N.G., y Schneider, D.A. (1995b). A new late Neogene time scale: Application to leg 138 sites. Proc. ODP, Sci. Res., 138: 73-101.

Shackleton, N. y Crowhurst, S. (1997). Sediment fluxes based on an orbitally time scale 5Ma to 14 Ma, Site 926. In Shackleton N., Curry, W.B., Richter, C. and Bralower, T.J. (Eds.). Proc. ODP Sci. Results 154:69-82

Sierro, F.J. (1984). Foraminíferos planctónicos y bioestratigrafía del Mioceno superiorplioceno del borde occidental de la cuenca del Guadalquivir (SO de España). Tesis Doctoral. Universidad de Salamanca, 391 pp.

Sierro, F.J. (1985). The replacement of the "Globorotalia menardii" group by the "Globorotalia miotumida" group: An aid to recognizing the Tortonian/Messinian boundary in the Mediterranean and adjacent Atlantic. Marine Micropaleontology, 9: 525-535.

Sierro, F.J. (1986). Estudio sistemático de los foraminíferos planctónicos del Neógeno de la cuenca del Guadalquivir: Género Globorotalia. Studia Geologica Salmanticiensia, XXIII: 121-169. 
Sierro, F.J., González Delgado, J.A., Dabrio, C.J., Flores, J.A. y Civis, J. (1990). The Neogene of the Guadalquivir Basin (SW Spain). En Iberian Neogene Basin, Paleontologia I Evolució, Memòria Especial, n²: 209-250

Sierro, F.J. (1992). Eventoestratigrafía y geometría de cuencas. La cuenca del Guadalquivir. III Congreso Geológico de España y VIII Congreso Latinoamericano de Geología. Salamanca. Tomo I: 217-221.

Sierro, F.J., Flores, J.A., Civis, J., Gonzalez-Delgado, J.A. (1987). New criteria for the correlation of the Andalusian and Messinian stages. Proceed. VIIIth Congress Reg. Medit. Neog. Strat. Budapest Sept.. 1985. Ann Inst. Geol. Publ. Hungar. LXX: 355361.

Sierro, F.J., Flores, J.A., Civis, J, González Delgado, A. (1993). Late miocene globorotaliid event-stratigraphy and biogeography in the NE-Atlantic and Mediterranean. Marine Micropaleontology, 21: 143-168.

Sierro, F.J., Gonzalez Delgado, J.A., Dabrio C.J., Flores, J.A. y Civis, J. (1996). Late Neogene depositional sequences in the foreland basin of Guadalquivir (SW Spain). Friend, P.F. and Dabrio, C.J. (Editors). Tertiary basins of Spain: the stratigraphic record of crustal kinematics. Cap. S4: 339-345.

Sierro, F.J., Flores, J.A. y Baraza, J. (1999a). Late glacial to recent paleoenvironmental changes in the Gulf of Cadiz and formation of sandy contourite layers. Marine Geology, 155: 157-172

Sierro, F.J., Flores, J.A., Zamarreño, I., Vázquez, A., Utrilla, R., Francés, G., Hilgen, F.J. y Krijgsman, W. (1999b). Messinian pre-evaporite saporpels and precessioninduced oscillations in western Mediterranean climate. Marine Geology, 153: 137146.

Sierro, F.J., Ledesma, S., Flores, J.A., Torrescusa, S., Martínez del Olmo, W. (2000). Sonic and gamma ray astrochronology: Cycle to cycle calibration of Atlantic climatic records to Mediterranean sapropels and astronomical oscillations. Geology, nº8: 695698. 
Sierro, F.J., Hilgen, F.J., Krijgsman, W. y Flores, J.A. (en prensa). The Abad composite (SE Spain): A Mediterranean and global reference section for the Messinian. Palaeogeography, palaeoecology, palaeoclimatology.

Somoza, L., Hernández-Molina, F.J., Lobo, F., Andrés, J.R. (1996). Modelo de estratigrafía secuencial de alta resolución de la plataforma continental española del golfo de Cádiz. Geogaceta, 20 (1): 130-133.

Soria, J.M., Fernandez J. y Viseras C. (1999). Late Miocene stratigraphy and palaeogeographic evolution of the intramontane Guadix Basin (central Betic Cordillera, Spain); implications for an Atlantic-Mediterranean connection. Palaeogeography, Palaeoclimatology, Palaeoecology. 151 (4): 255-266.

Spezzaferri S., Cita M.B. y McKenzie J.A. (1998). The miocene/pliocene boundary in the eastern mediterranean:results from sites 967 and 969. Proceedings of the Ocean Drilling Program, Scientific Results, Vol. 160: 9-28

Sprovieri, R., Di Stefano, E. y Sprovieri, M. (1996a). High resolution chronology for Late Miocene Mediterranean stratigraphic events. Riv. Ital. Pal., 102: 77-104.

Sprovieri, R., Di Stefano, E., Caruso, A. y Bonomo, S. (1996b). High resolution stratigraphy in the Messinian Tripoli Formation in Sicily. Paleopelagos, 6:415-435.

Sprovieri, R., Di Stefano, E., Howell, M., Sakamoto, T., Di Stefano, A. y Marino, M. (1998). Integrated calcareous plancton biostratigraphy and cyclostratigraphy at Site 964. Proceedings of the Ocean Drilling Program, Scientific Results, Vol. 160: 155166.

Sprovieri, M., Bellanca, A., Neri, R., Mazzola, S., Bonanno, A., Patti, B. y Sorgente, R. (1999). Astronomical calibration of late Miocene stratigraphic events and analysis of precessionally driven paleoceanographic changes in the Mediterranean basin. Mem. Soc. Geol. It., 54: 7-24.

Srivastava, S.P., Roest, W.R., Kovacs, L.C., Oaekey, G., Lévesque, S., Verhoef, J. y Macnab, R. (1990). Motion of Iberia since Late Jurassic: results from datailed aeromagnetic measurements on the Newfoundland Basin. Tectonophysics, 184: 229260. 
Suárez, J., Martínez del Olmo, W., Serrano, A., Leret Verdú, G. (1989). Estructura del sistema turbidítico de la formación arenas del Guadalquivir, Neógeno del valle del Guadalquivir. Libro homenaje a R. Soler, AGEEP, 123-132.

Schwarzacher, W. (1993). Cycloestratigraphy and the Milankovitch Theory. Elsevier Science Publishers, Developments in Sedimentology, 52: 225 pp.

Thunell, F.C., Locke, S.M., Williams, D.F. (1988). Glacio-eustatic sea-level control on Red Sea salinity. Nature 334: 601-604.

Thunell, R. C., Williams, D.F. (1989). Glacial-Holocene salinity changes in the Mediterranean Sea: hydrographic and depositiona effects. Nature 338: 493-496.

Thunell, R, Rio, D., Sprovieri, R. y Vergnaud-Grazzini, C. (1991). An overview of the post-Messinian paleoenvironmental history of the Western Mediterranean. Paleoceanography, 6:143-164.

Tiedemann R., Sarnthein, M. y Shackleton, N.J. (1994). Astronomic timescale for the Pliocene Atlantic $218^{\circ}$ and dust flux records of Ocean Drilling Program site 659. Paleoceanography 9(4): 619-638.

Tiedemann, R. y Franz, S.O (1997). Deep-water circulation, chemistry and terrigenous sediment supply in the Equatorial Atlantic during the Pliocene, 3.3-2.6 and 5-4.5MA. In: Shackleton, N.J. et al. (Eds.) Proc. ODP Sci. Results, 154:299-318.

Tjalsma, R. C. (1971). Stratigraphy and Foraminifera of the Neogene of the Eastern Guadalquivir Basin (Southern Spain). Utrech Micropal. Bull., 4: 1-161.

Tortella, D., Torné, M. y Pérez-Estaún, A. (1996). Evolución geodinámica del límite de placas entre Eurasia y África en la zona del Banco de Gorringe y Golfo de Cádiz. Geogaceta, 20 (4): 958-961.

Van Os, B.J.H., Lourens, L.J., Hilgen, F.J., De Lange, G.J. y Beaufort L. (1994). The formation of Pliocene sapropels and carbonate cycles in the Mediterranean: Diagenesis, dilution, and productivity. Paleoceanography, 9(4):601-617.

Van de Poel, H.M. (1991). Meddinian stratigraphy of the Nijar basis (SE. Spain) and the origin of its gypsum-ghost limestones. Geologie in Mijnbouw, 70: 215-234. 
Vai, G.B. (1997). Cyclostratigraphic estimate of the Messinian Stage duration. Montanari, A., Odin, G.S., Coccioni, R. (Eds.), Miocene Stratigraphy: An Integrated Approach, Elsevier Science B.V., Amsterdam, 463-476.

Vail, P.R., Mitchum, R.M. y Tompson III, S. (1977). Seismic stratigraphy and global changes of sea level. Part. 4. Global cycles of relative changes of sea level. En: C.E.Payton (Ed.). Seismic Stratigraphy. Amer. Assoc. Petrol. Geol. Mem., 26: 83-97.

Vail, P.R., Colin, J.P., Chene, R.J., Kuchly, J., Mediavilla, F. y Trifilieff, V. (1987). La stratigraphie séquentielle et son application aux corrélations chronostratigraphiques dans le Jurassique du bassin de Paris. Bull. Soc. Geol. France, (8), III: 1301-1321.

Vail, P.R., Audemard, F., Bowman, S.A., Eisner, P.N. Eisner y Pérez-Cruz, C. (1991). The Stratigraphic Signatures of Tectonics, Eustasy and Sedimentology - an Overview. Einsele et al. (Eds.). Cycles and Events in Stratigraphy: 617-659

Vergnaud-Grazzini, C., Saliège, J.F., Urrutiaguer, M.J., Iannace, A. (1990). Oxygen and Carbon isotope stratigraphy of ODP Hole 653A and Site 654: The PliocenePleistocene Glacial history recorded in the Tyrrhenian Basin (West Mediterranean). Proceedings of the Ocean Drilling Program, Scientific Results, Vol. 107: 361-386.

Vázquez, A., Utrilla, R., Zamarreño, I., Sierro, F.J., Flores, J.A., Francés, G. y Barcena, M.A. (en prensa). Precession related sapropelites of the Messinian Sorbas basin (South Spain): Paleoenvironmental significance. Palaeogeog. Palaeoclimatol. Palaeocol.

Veen, J.H., y Postma, G. (1996). Astronomically forced variations in gamma-ray intensity: Late Miocene hemipelagic successions in the eastern Mediterranean basin as a test case. Geology, 24 (1): 15-18.

Vera, J.A. (1986). Las Zonas Externas de las Cordilleras Béticas. En, Geología de España, homenaje a J.M. Ríos. IGME: 218-251.

Vera, J.A. (1988). Evolución de los sistemas de depósito en el margen Ibérico de la Cordillera Bética. Revista de la Sociedad Geológica de España, 1: 373-391.

Vera, J.A. (1994). Estratigrafía. Principios y Métodos. Editorial Rueda, 806 p. 
Vera, J.A. (2000). El Terciario de la Cordillera Bética: Estado actual de conocimientos. Rev. Soc. Geol. España, 13(2): 345-373.

Viguier, C. (1976). Individualisation et évolution structurale de la région de Cadix (Espagne du Sud-Ouest) au Néogène "post-nappe". Bull. Inst. Géol. Bassin Aquitanie, $\mathrm{n}^{\mathrm{o}}$ 20: 107-112.

Völk , H.R. (1967). Zur Geologie und Stratigraphie des Neogen-beckens von Vera, Südostspanien. Ph. D. Thesis. Univ. of Amsterdam, 160p.

Weedon, G.P. (1991). The Spectral Analysis os Stratigraphic Time Series. Einsele et al. (Eds.). Cycles and Events in Stratigraphy: 840-854

Wehausen, R. y Brumsack, H.J. (1998). The formation of Pliocene mediterrenean saporopels: Constraints from high-resolution major and minor element studies. Proceedings of the Ocean Drilling Program, Scientific Results, Vol. 160: 207-217.

Wehausen, R. y Brumsack, H.J. (1999). Cyclic variations in the chemical composition of eastern Mediterranean Pliocene sediments: a key for understanding sapropel formation. Marine Geology, 153: 161-176.

Weijermars, R., Roep, Th.B., Van den Eeckhout, B., Potma, G. y Kleverkaan, K. (1985). Uplift history of a batic fold nappe inferred from Neogene Quaternary sedimentation and tectonics (in sierra Alhamilla and Almeria, Sorbas and Tabernas Basins of the Betic Cordilleras, SE Spain). Geol. Mijn., 64: 379-411.

Weijermars, R. (1988). Neogene tectonics in the Western Mediterranean may have caused the Messinian Salinity Crisis and an associated glacial event. Tectonophysics, 148: 211-219.

Weltje, G. y de Boer, P.L. (1993). Astronomicaly induced paleoclimatic oscillations reflected in Pliocene turbidite deposits on Corfu (Greece): Inplications for the interpretation of higher order cyclicity in ancient turbidite systems. Geology, vol. 21, $n^{\circ}$ 4: 307-310.

Williams, D.F., Thunell, R.C., Hodell, D.A. y Vergnaud-Grazzini, C. (1985). Synthesis of late Cretaceous, Tertiary, and Quaternary stable isotope records of the South 
Atlantic based on Leg 72 DSDP core material. Hsü, K.J. and Weissert, H.J. (Editors). Cambridge Univer. Press. South Atlantic Paleoceanography: 205-241.

Wilson, D.S. (1993). Confirmation of the astronomical calibration of the magnetic polarity time scale from sea-floor spreading rates. Nature, 364: 788.

Winograd et al. (1988). A 250,000 Year Climatic Record from Great Basin Vein Calcite: Implications for Milankovitch Theory. Science, vol. 242, no. 4883: 1275-1280.

Zachariasse, W.J. (1975). Planktonic foraminiferal biostratigraphy of the Late Neogene of Crete (Greece). Utrecht Micropal. Bull., 11.

Zachariasse, W.J. (1979a). The origin of Globorotalia conomiozea in the Mediterranean and the value of its entry level in bioestratigraphic correlations. Ann. Geol. Pays Hellen., Tome hors serie, fasc. III, VIIth International Congress on Mediterranean Neogene, Athens: 1281-1292

Zachariasse, J.W. (1979b). Planktonic foraminifera from section Potamidha1: taxonomic anphiletic aspects of keeled globorotaliids and some paleoenvironmental estimates. Utrecht Micropal. Bull., 21: 129-166.

Zahn, R. (1997). North Atlantic Thermohaline circulation during the Last Glacial Period: Evidence for coupling between meltewater events and convective instability. Geomar Report, $\mathrm{n}^{\circ} 63$.

Zahn, R. Tiedemann, R. y Grafenstein, R. (1997). Plio-Pleistocen; Monsoonal history vs. North Atlanctic oscillation. Neogene Mediterranean Paleoceanography, International Conference (Italy): 94

Zhang, J, Scott, D.B. (1996). Integrated stratigraphy and paleoceanography of the Messinian (latest Miocene) across the North Atlantic Ocean. Marine Micropaleontology 29: 1-36. 



\section{TABLAS DE RESULTADOS CUANTITATIVOS PARCIALES}

Las siguientes tablas recogen los resultados cuantitativos del recuento de foraminíferos planctónicos realizados sobre diversos tramos de los sondeos estudiados. Las representaciones gráficas de estos resultados se encuentran incluidas en las respectivas figuras sintéticas que aparecen en el capítulo 6. 


\section{ATLÁNTIDA-2}

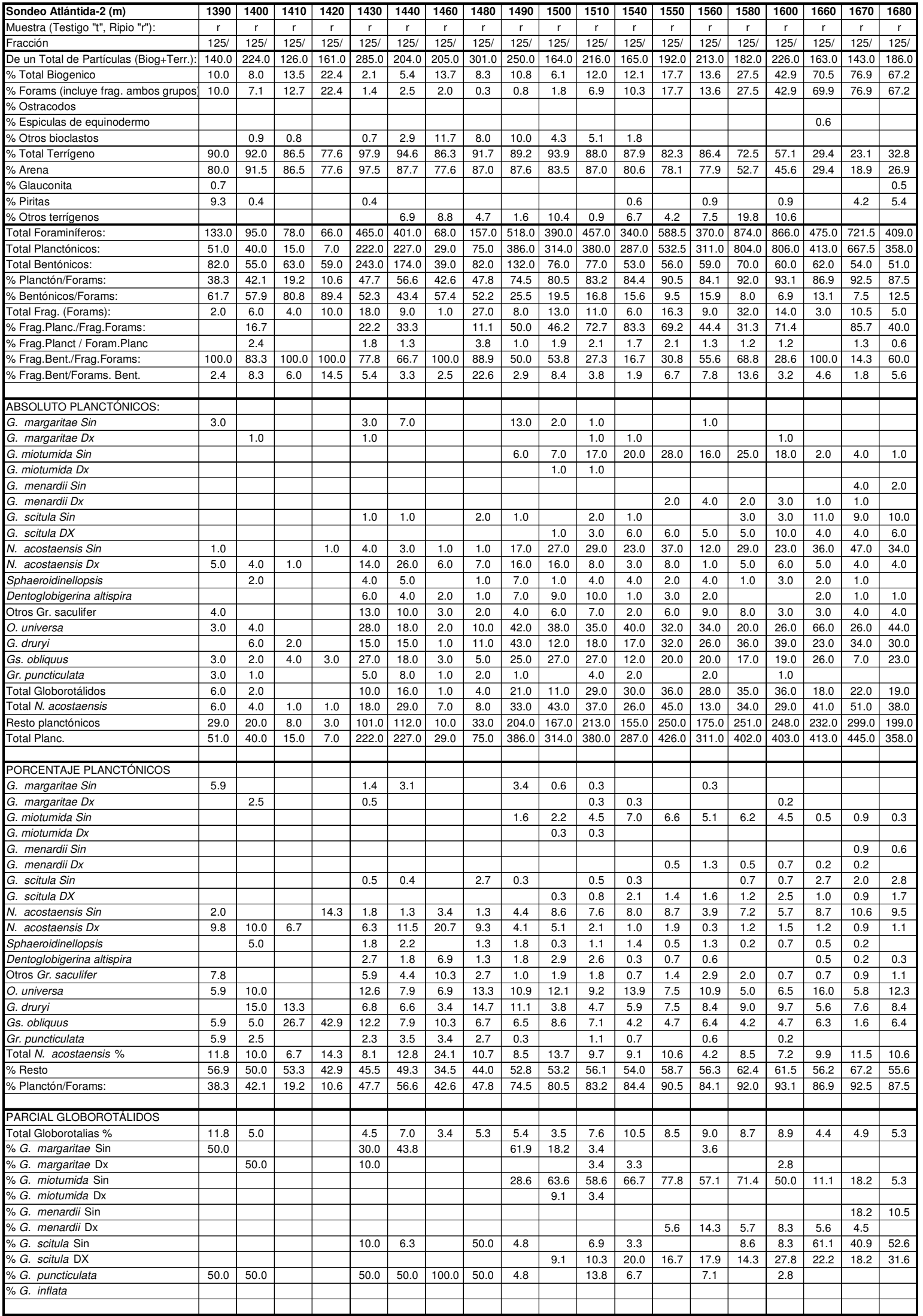


GOLFO DE CÁDIZ - B6

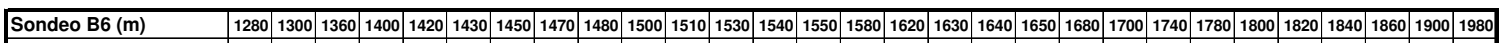
Muestra (Testigo "t", Ripic $\mathrm{r}$

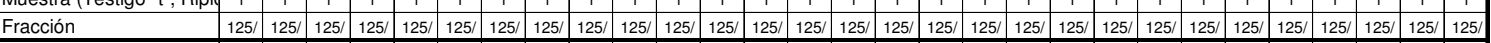

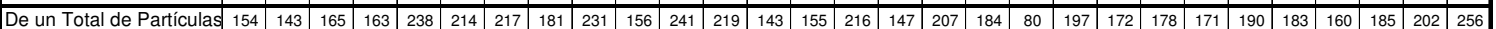

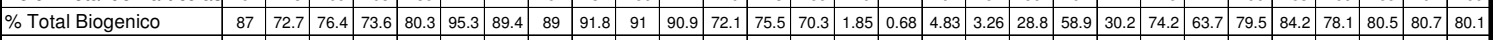

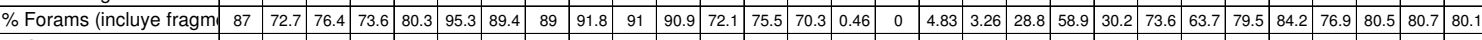
$\%$ Ostracodos

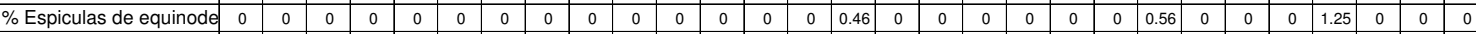
\begin{tabular}{|l|c|c|c|c|c|c|c|c|c|c|c|c|c|c|c|c|c|c|c|c|c|c|c|c|c|c|c|c|c|c|c|c|}
\hline \% Otros bioclastos & 0 & 0 & 0 & 0 & 0 & 0 & 0 & 0 & 0 & 0 & 0 & 0 & 0 & 0 & 0.93 & 0.68 & 0 & 0 & 0 & 0 & 0 & 0 & 0 & 0 & 0 & 0 & 0 & 0 & 0 \\
\hline
\end{tabular}

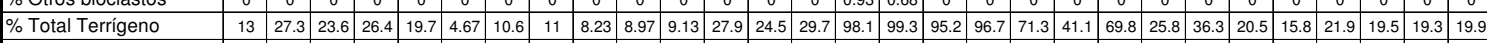

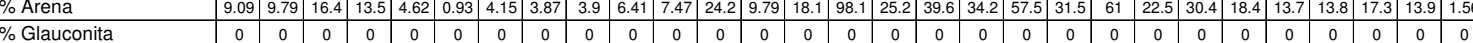

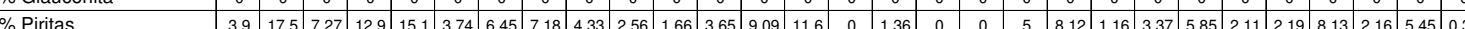
$\%$ Otros terrígenos

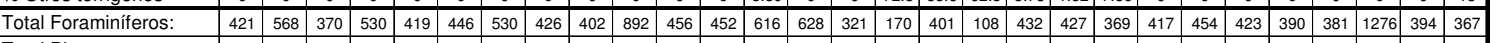

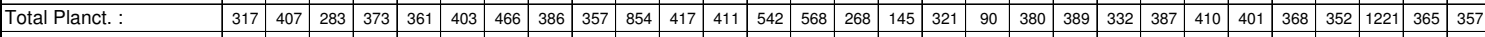

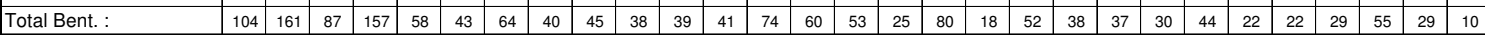

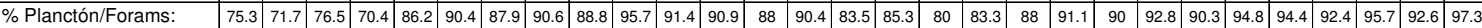

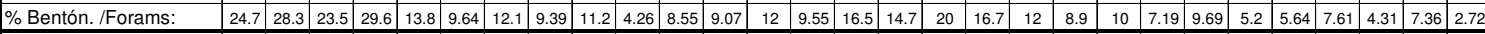

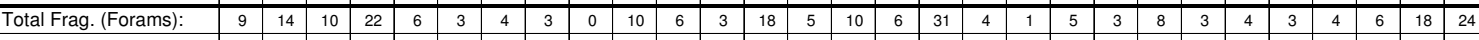
\begin{tabular}{|l|l|l|l|l|l|l|l|l|l|l|l|l|l|l|l|l|l|l|l|l|l|l|l|l|l|l|l|l|l|}
\hline \% Frag. Planc. /Frag. For 55.6 & 28.6 & 50 & 40.9 & 66.7 & 33.3 & 50 & 100 & 0 & 60 & 83.3 & 0 & 66.7 & 60 & 80 & 66.7 & 83.9 & 75 & 100 & 80 & 66.7 & 75 & 66.7 & 75 & 100 & 100 & 0 & 66.7 & 91.7 \\
\hline$\%$
\end{tabular}

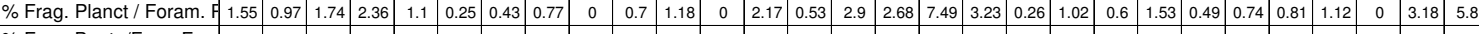

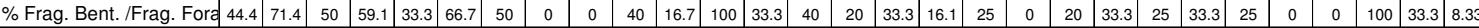
\begin{tabular}{lllllllllllllll|l|l|l|l|l|l|l|l|l|l|l|l|l|l|l|l|l|l} 
\% Frag. Bent/Forams. Be & 3.7 & 5.85 & 5.43 & 7.65 & 3.33 & 4.44 & 3.03 & 0 & 0 & 5 & 2.5 & 6.82 & 7.5 & 3.23 & 3.64 & 7.41 & 5.88 & 5.26 & 0 & 2.56 & 2.63 & 6.25 & 2.22 & 4.35 & 0 & 0 & 3.51 & 17.1 & 16.7 \\
\hline
\end{tabular}

Gr. margaritae Sin

Gr. margaritae $D x$

Gr. miotumi

Gr. menardii Sin

Gr. menardii $D x$

Gr. scitula Sin

Gr. scitula $D X$

N. acostaensis Sin

$N$. acostaensis $D x$

Sphaeroidinellopsis

Dentoglobigerina altispira

Otros Gr. saculifer

O. universa

G. druryi

Gs. obliquus

Gr. puncticulata

Total N. acostaensis

No identificados

Total Planctónicos

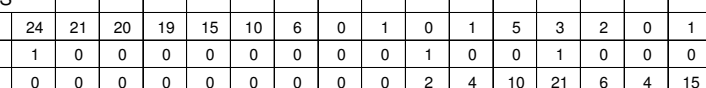

\begin{tabular}{|c|c|c|c|c|c|c|c|c|c|c|c|}
\hline 2 & 1 & 0 & 2 & 1 & 0 & 0 & 0 & 0 & 1 & 0 & 0 \\
\hline 0 & 1 & 0 & 0 & 0 & 0 & 0 & 0 & 0 & 0 & 0 & 0 \\
\hline 2 & 54 & 14 & 22 & 34 & 36 & 31 & 19 & 16 & 12 & 9 & 2 \\
\hline
\end{tabular}

PORCENTAJE PLANCT

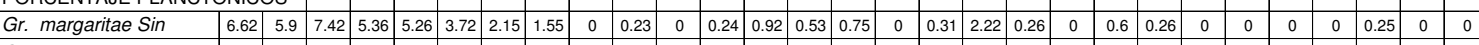
\begin{tabular}{|l|c|c|c|c|c|c|c|c|c|c|c|c|c|c|c|c|c|c|c|c|c|c|c|c|c|c|c|c|c|c|c|c|c|c|c|}
\hline Gr. margaritae $D x$ & 0.32 & 0.25 & 0 & 0 & 0 & 0 & 0 & 0 & 0 & 0 & 0.24 & 0 & 0 & 0.18 & 0 & 0 & 0 & 0 & 0.26 & 0 & 0 & 0 & 0 & 0 & 0 & 0 & 0 & 0 & 0 \\
\hline
\end{tabular}

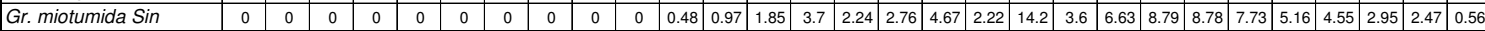

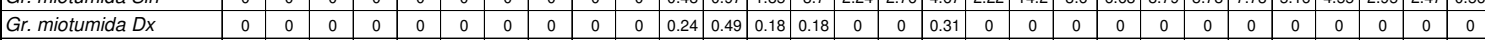

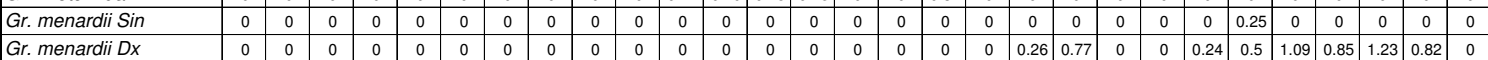

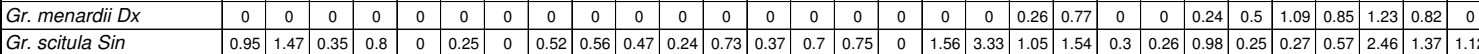

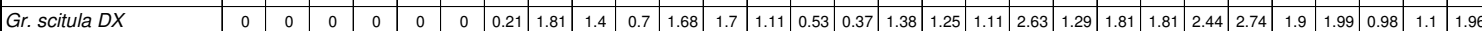

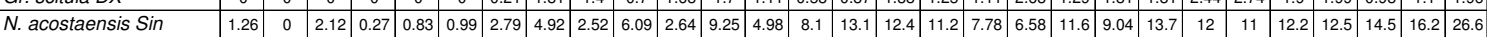

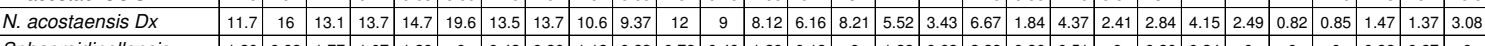

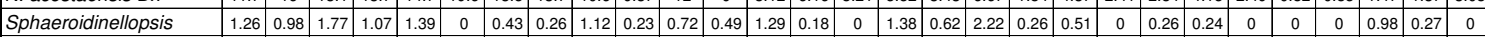

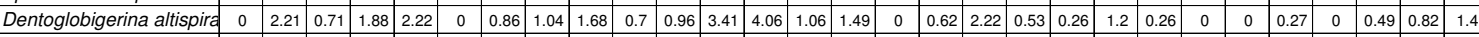

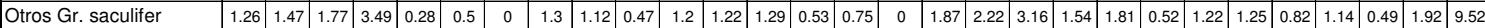

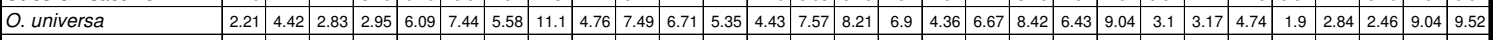

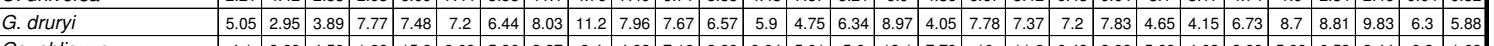

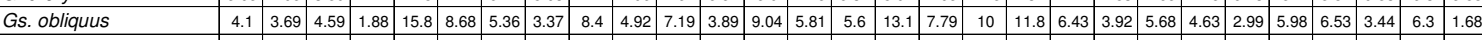

\begin{tabular}{|l|c|c|c|c|c|c|c|c|c|c|c|c|c|c|c|c|c|c|c|c|c|c|c|c|c|c|c|c|c|c|c|c|c|c|}
\hline Gr. puncticulata & 4.73 & 3.44 & 3.18 & 1.88 & 0 & 0.5 & 0.43 & 0.26 & 0 & 0 & 0.96 & 0.49 & 0.74 & 0 & 0 & 0 & 0.31 & 0 & 0.26 & 0.26 & 0.3 & 0 & 0 & 0 & 0 & 0 & 0 & 0 & 0 \\
\hline
\end{tabular}

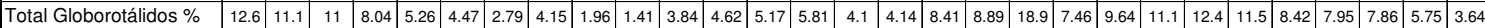

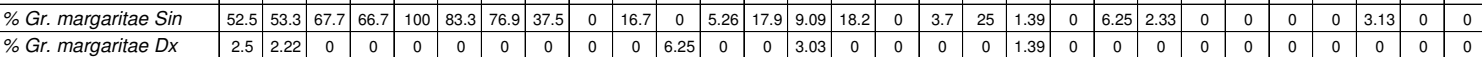

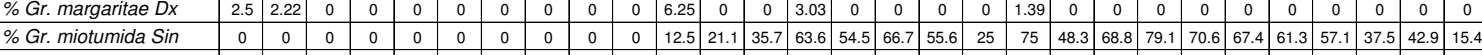

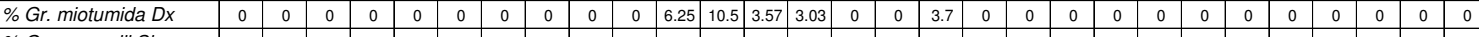

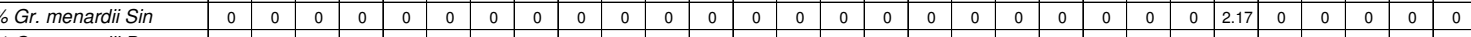

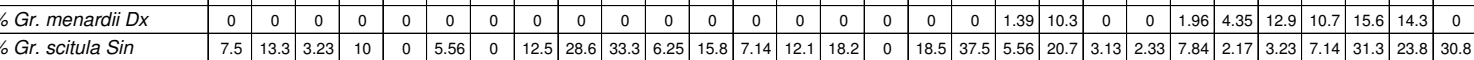

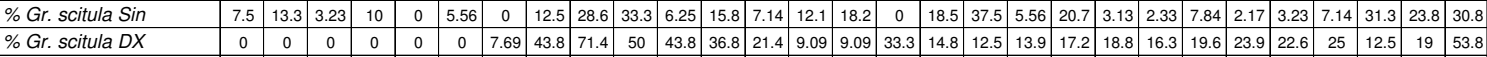

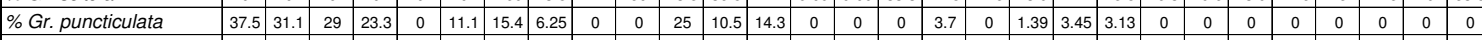
\begin{tabular}{|l|c|c|c|c|c|c|c|c|c|c|c|c|c|c|c|c|c|c|c|c|c|c|c|c|c|c|c|c|c|}
\hline$\%$ Gr. inflata & 0 & 0 & 0 & 0 & 0 & 0 & 0 & 0 & 0 & 0 & 0 & 0 & 0 & 0 & 0 & 0 & 0 & 0 & 0 & 0 & 0 & 0 & 0 & 0 & 0 & 0 & 0 & 0 & 0 \\
\hline
\end{tabular}

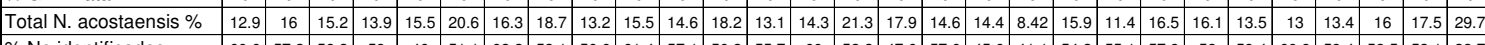

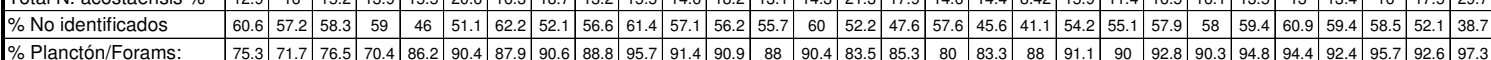




\section{CASANIEVES-1}

\begin{tabular}{|c|c|c|c|c|c|c|c|c|c|c|c|c|c|c|c|c|c|c|}
\hline Sondeo Casanieves-1 $(\mathrm{m})$ & 880 & 890 & 900 & 920 & 940 & 960 & 980 & 997 & 1010 & \begin{tabular}{|c|c|}
1025 \\
\end{tabular} & 1053 & 1097 & 1150 & 1202 & 1251 & 1280 & 1320 & 1340 \\
\hline Muestra (Testigo "t", Ripio "r"): & $\mathrm{r}$ & $\mathrm{r}$ & $\mathrm{r}$ & $\mathrm{r}$ & $\mathrm{r}$ & $\mathrm{r}$ & $\mathrm{r}$ & $\mathrm{r}$ & $\mathrm{r}$ & $\mathrm{r}$ & $\mathrm{t}$ & $\mathrm{r}$ & $\mathrm{t}$ & $\mathrm{r}$ & $\mathrm{t}$ & $\mathrm{r}$ & $r$ & $\mathrm{r}$ \\
\hline Fracción & 125 & 125 & 125 & $125 /$ & 125 & 125 & 125 & 125 & 125 & 125 & $125 /$ & $125 /$ & $125 /$ & $125 /$ & $125 /$ & $125 /$ & $125 /$ & $125 /$ \\
\hline De un Total de Partíc (Biog+Terr.): & 153 & 138 & 135 & 220 & 262 & 144 & 179 & 115 & 117 & 109 & 207 & 260 & \begin{tabular}{|l|l|l|l|l}
196 \\
\end{tabular} & 176 & 193 & 273 & 156 & 154 \\
\hline$\%$ Total Biogenico & 64.71 & 49.28 & 49.63 & 34.09 & 80.15 & 72.92 & 79.89 & 85.22 & 25.64 & 48.62 & 90.343 & 30.77 & 2.55 & 38.64 & 83.94 & 44.69 & 64.74 & 57.79 \\
\hline$\%$ Forams (fragmentos ambos grupos) & 64 & 49 & 50 & 34 & 79 & 73 & 80 & 85 & 26 & 47 & 90 & 31 & 2 & 39 & 84 & 45 & 65 & 58 \\
\hline$\%$ Ostracodos & & & & & & & & & & & & & & & & & & \\
\hline$\%$ Espiculas de equinodermo & & & & & & & & & & & 0 & & 1 & & & & & \\
\hline$\%$ Otros bioclastos & 1 & & & & 1 & & & & & 2 & & & & & & & & \\
\hline$\%$ Total Terrígeno & 35 & 51 & 50 & 66 & 20 & 27 & 20 & 15 & 74 & 51 & 10 & 69 & 97 & 61 & 16 & 55 & 35 & 42 \\
\hline$\%$ Arena & 16 & 30 & 16 & 49 & 15 & 9 & 13 & 6 & 48 & 11 & 10 & 50 & 97 & 58 & 5 & 45 & 31 & 39 \\
\hline$\%$ Glauconita & 1 & & & & & & & & & & & & 1 & 1 & & & & \\
\hline$\%$ Piritas & 18 & 20 & 33 & 17 & 4 & 13 & 5 & 9 & 17 & 17 & & 19 & & 9 & 11 & 10 & 4 & 3 \\
\hline \% Otros terrígenos & 1 & & 2 & & 1 & 6 & 2 & & 9 & 23 & & & & & & & & \\
\hline Total Foraminíferos: & \begin{tabular}{|l|}
567 \\
\end{tabular} & 665 & \begin{tabular}{|l|}
475 \\
\end{tabular} & 530 & 987 & 455 & \begin{tabular}{|l|}
1077 \\
\end{tabular} & 915 & 483 & 505 & 400 & \begin{tabular}{|l|}
441 \\
\end{tabular} & \begin{tabular}{|l|}
105 \\
\end{tabular} & 438 & 402 & 440 & 1056 & 461 \\
\hline Total Planct.: & 476 & 430 & 345 & 336 & 794 & 379 & 932 & 790 & 395 & 400 & 370 & 356 & 69 & 367 & 377 & 375 & 970 & 415 \\
\hline Total Bent.: & 91 & 235 & 130 & 194 & 193 & 76 & \begin{tabular}{|l|}
145 \\
\end{tabular} & 125 & 88 & 105 & 30 & 85 & 36 & 71 & 25 & 65 & 86 & 46 \\
\hline \% Planctón/Forams: & 84 & 65 & 73 & 63 & 80 & 83 & 87 & 86 & 82 & 79 & 93 & 81 & 66 & 84 & 94 & 85 & 92 & 90 \\
\hline \% Bentón./Forams: & 16 & 35 & 27 & 37 & 20 & 17 & 13 & 14 & 18 & 21 & 8 & 19 & 34 & 16 & 6 & 15 & 8 & 10 \\
\hline Total Frag. (Forams): & 12 & 7 & 17 & 25 & 52 & 52 & 70 & 80 & 22 & 66 & 7 & 11 & 26 & 5 & 1 & 1 & 20 & 9 \\
\hline$\%$ Frag.Planc./Frag.Forams: & 58 & 43 & 12 & 64 & 54 & 81 & 60 & 68 & 77 & 64 & 100 & 82 & 73 & 20 & 100 & 100 & 20 & 56 \\
\hline$\%$ Frag.Planct / Foram.Planc & 1 & 1 & 1 & 5 & 3 & 10 & 4 & 6 & 4 & 10 & 2 & 2 & 22 & 0 & 0 & 0 & 0 & 1 \\
\hline$\%$ Frag.Bent./Frag.Forams: & 42 & 57 & 88 & 36 & 46 & 19 & 40 & 33 & 23 & 36 & & 18 & 27 & 80 & & & 80 & 44 \\
\hline$\%$ Frag.Bent/Forams. Bent. & 5 & 2 & 10 & 4 & 6 & 12 & 9 & 9 & 5 & 19 & & 2 & 16 & 5 & & & 9 & 8 \\
\hline ABSOLUTO PLANCTÓNICOS & & & & & & & & & & & & & & & & & & \\
\hline G. margaritae Sin & 9 & 45 & 11 & 5 & 18 & 2 & 3 & 1 & 1 & & & 1 & & 1 & & & & \\
\hline G. margaritae $D x$ & & 1 & 3 & & & & & 1 & 1 & & & & & & & & & \\
\hline G. miotumida Sin & & & & & & & & & & 30 & 47 & 50 & 7 & 28 & & 54 & 66 & 16 \\
\hline G. miotumida $D x$ & & & & & & & & & & 3 & & 2 & & 1 & & 1 & & \\
\hline G. menardii Sin & & & & & & & & & & & & & & & & & & 2 \\
\hline G. menardii $D x$ & & & & & & & & & & & & & & & & & & 39 \\
\hline G. scitula Sin & & 2 & 2 & 6 & 1 & 2 & 4 & 1 & 1 & 2 & & 4 & & 2 & 11 & 6 & 2 & 1 \\
\hline G. scitula $D x$ & 4 & & 1 & & 2 & 1 & 12 & 5 & 3 & 4 & 4 & 4 & & 6 & 20 & 6 & 5 & 6 \\
\hline N. acostaensis Sin & 7 & 4 & 7 & 6 & 28 & 45 & 47 & 12 & 9 & 25 & 38 & 28 & 4 & 25 & 73 & 32 & 35 & 37 \\
\hline N. acostaensis $D x$ & 76 & 41 & 39 & 28 & 50 & 68 & 58 & 63 & 45 & 23 & 3 & 7 & 1 & 4 & 10 & 7 & 3 & 3 \\
\hline Sphaeroidinellopsis & 1 & 3 & 1 & 7 & 5 & 9 & 1 & 4 & 5 & 3 & 3 & 2 & & 3 & & 1 & 1 & 1 \\
\hline Dentoglobigerina altispira & & 5 & & 3 & 1 & 6 & & 11 & 15 & 4 & & 12 & 2 & 3 & 3 & & & \\
\hline Otros Gr. saculifer & & 3 & & 1 & 15 & & 2 & & 4 & 5 & & 3 & 2 & 17 & 1 & 8 & 5 & 4 \\
\hline O. universa & 11 & 32 & 18 & 28 & 39 & 22 & 28 & 21 & 15 & 24 & 32 & 28 & 2 & 27 & 14 & 14 & 2 & 9 \\
\hline G. druryi & 40 & 13 & 3 & 24 & 9 & 61 & 23 & 12 & 15 & 22 & 26 & 25 & 9 & 27 & 18 & 22 & 73 & 86 \\
\hline Gs. obliquus & 10 & 22 & 5 & 35 & 37 & 11 & 15 & 51 & 22 & 22 & 25 & 62 & 11 & 41 & 51 & 27 & 19 & 21 \\
\hline N. pachyderma Sin & & & & & & 1 & & & & & & & & & & & & \\
\hline Total Globorotálidos & 13 & 48 & 17 & 11 & 21 & 5 & 19 & 8 & 6 & 39 & 51 & 61 & 7 & 38 & 31 & 67 & 73 & 64 \\
\hline Total N. acostaensis & 83 & 45 & 46 & 34 & 78 & 113 & 105 & 75 & 54 & 48 & 41 & 35 & 5 & 29 & 83 & 39 & 38 & 40 \\
\hline Resto planctónicos & 318 & 259 & \begin{tabular}{|l|}
255 \\
\end{tabular} & 193 & 192 & 151 & \begin{tabular}{|l|}
273 \\
\end{tabular} & \begin{tabular}{|l|l|}
213 \\
\end{tabular} & 259 & 233 & 192 & \begin{tabular}{|l|}
128 \\
\end{tabular} & 31 & 182 & 176 & 197 & 274 & 190 \\
\hline Total Planctónicos & \begin{tabular}{|l|l}
476 \\
\end{tabular} & 430 & 345 & 336 & 397 & 379 & \begin{tabular}{|l|}
466 \\
\end{tabular} & 395 & 395 & 400 & 370 & 356 & 69 & 367 & 377 & 375 & 485 & 415 \\
\hline & & & & & & & & & & & & & & & & & & \\
\hline PORCENTAJE PLANCTONIICOS & & & & & & & & & & & & & & & & & & \\
\hline G. margaritae Sin & 1.89 & 10.5 & 3.19 & 1.49 & 4.53 & 0.53 & \begin{tabular}{|l|}
0.64 \\
\end{tabular} & 0.25 & 0.25 & & & 0.28 & & 0.27 & & & & \\
\hline G. margaritae $D x$ & & 0.23 & 0.87 & & & & & 0.25 & 0.25 & & & & & & & & & \\
\hline G. miotumida Sin & & & & & & & & & & 7.5 & 12.7 & 14 & 10.1 & 7.63 & & \begin{tabular}{|l|}
14.4 \\
\end{tabular} & 13.6 & 3.86 \\
\hline G. miotumida $D x$ & & & & & & & & & & 0.75 & & 0.56 & & 0.27 & & 0.27 & & \\
\hline G. menardii Sin & & & & & & & & & & & & & & & & & & 0.48 \\
\hline G. menardii $D x$ & & & & & & & & & & & & & & & & & & 9.4 \\
\hline G. scitula Sin & & 0.47 & 0.58 & 1.79 & 0.25 & 0.53 & 0.86 & 0.25 & 0.25 & 0.5 & & 1.12 & & 0.54 & 2.92 & 1.6 & 0.41 & 0.24 \\
\hline G. scitula Dx & 0.84 & & 0.29 & & 0.5 & 0.26 & \begin{tabular}{|l|}
2.58 \\
\end{tabular} & 1.27 & 0.76 & 1 & 1.08 & 1.12 & & 1.63 & 5.31 & 1.6 & 1.03 & 1.45 \\
\hline N. acostaensis Sin & 1.47 & 0.93 & 2.03 & 1.79 & 7.05 & 11.9 & 10.1 & 3.04 & 2.28 & 6.25 & 10.3 & 7.87 & 5.8 & 6.81 & \begin{tabular}{|c|}
19.4 \\
\end{tabular} & 8.53 & 7.22 & 8.92 \\
\hline$N$. acostaensis $D x$ & 16 & 9.53 & 11.3 & 8.33 & 12.6 & \begin{tabular}{|l|}
17.9 \\
\end{tabular} & \begin{tabular}{|l|}
12.4 \\
\end{tabular} & $\begin{array}{ll}15.9 \\
\end{array}$ & 11.4 & 5.75 & \begin{tabular}{|l|}
0.81 \\
\end{tabular} & 1.97 & \begin{tabular}{|l|}
1.45 \\
\end{tabular} & 1.09 & 2.65 & 1.87 & 0.62 & 0.72 \\
\hline Sphaeroidinellopsis & 0.21 & 0.7 & 0.29 & 2.08 & 1.26 & 2.37 & 0.21 & 1.01 & 1.27 & 0.75 & \begin{tabular}{|l|}
0.81 \\
\end{tabular} & 0.56 & & 0.82 & & \begin{tabular}{|l|}
0.27 \\
\end{tabular} & 0.21 & 0.24 \\
\hline Dentoglobigerina altispira & & 1.16 & & \begin{tabular}{|l|}
0.89 \\
\end{tabular} & 0.25 & 1.58 & & 2.78 & 3.8 & 1 & & 3.37 & 2.9 & 0.82 & 0.8 & & & \\
\hline Otros Gr. saculifer & & 0.7 & & 0.3 & 3.78 & & \begin{tabular}{|l|}
0.43 \\
\end{tabular} & & 1.01 & 1.25 & & 0.84 & 2.9 & 4.63 & 0.27 & \begin{tabular}{|l|l|}
2.13 \\
\end{tabular} & 1.03 & 0.96 \\
\hline O. universa & 2.31 & 7.44 & 5.22 & 8.33 & 9.82 & 5.8 & \begin{tabular}{|l|}
6.01 \\
\end{tabular} & 5.32 & 3.8 & 6 & \begin{tabular}{|l|}
8.65 \\
\end{tabular} & 7.87 & 2.9 & 7.36 & 3.71 & \begin{tabular}{|l|}
3.73 \\
\end{tabular} & 0.41 & \begin{tabular}{|l|}
2.17 \\
\end{tabular} \\
\hline G. druryi & 8.4 & 3.02 & 0.87 & 7.14 & 2.27 & 16.1 & \begin{tabular}{|l|}
4.94 \\
\end{tabular} & 3.04 & 3.8 & 5.5 & \begin{tabular}{|l|}
7.03 \\
\end{tabular} & 7.02 & 13 & 7.36 & 4.77 & \begin{tabular}{|l|}
5.87 \\
\end{tabular} & 15.1 & 20.7 \\
\hline Gs. obliquus & 2.1 & 5.12 & 1.45 & 10.4 & 9.32 & 2.9 & 3.22 & 13 & 5.57 & 5.5 & \begin{tabular}{|c|}
6.76 \\
\end{tabular} & \begin{tabular}{|l|}
17.4 \\
\end{tabular} & \begin{tabular}{|l|}
15.9 \\
\end{tabular} & 11.2 & 13.5 & 7.2 & 3.92 & 5.06 \\
\hline N. pachyderma Sin & & & & & & 0.26 & & & & & & & & & & & & \\
\hline Total Globorotálidos \% & \begin{tabular}{|l|}
2.73 \\
\end{tabular} & 11.2 & 4.93 & 3.27 & 5.29 & 1.32 & \begin{tabular}{|l|}
4.08 \\
\end{tabular} & 2.03 & 1.52 & 9.75 & 13.781 & 17.13 & 10.14 & 10.35 & 8.22 & 17.87 & 15.1 & 15.4 \\
\hline$\%$ G. margaritae Sin & 69.2 & 93.8 & 64.7 & 45.5 & 85.7 & 40 & 15.8 & 12.5 & 16.7 & & & 1.64 & & 2.63 & & & & \\
\hline$\%$ G. margaritae Dx & & 2.08 & 17.6 & & & & & 12.5 & 16.7 & & & & & & & & & \\
\hline$\%$ G. miotumida Sin & & & & & & & & & & 76.9 & 92.2 & 82 & 100 & 73.7 & & 80.6 & 90.4 & 25 \\
\hline$\%$ G. miotumida Dx & & & & & & & & & & 7.69 & & 3.28 & & 2.63 & & \begin{tabular}{|l|}
1.49 \\
\end{tabular} & & \\
\hline$\%$ G. menardii Sin & & & & & & & & & & & & & & & & & & 3.13 \\
\hline$\%$ G. menardii Dx & & & & & & & & & & & & & & & & & & 60.9 \\
\hline$\%$ G. scitula $\operatorname{Sin}$ & & 4.17 & \begin{tabular}{|l|}
11.8 \\
\end{tabular} & 54.5 & 4.76 & 40 & 21.1 & 12.5 & 16.7 & 5.13 & & 6.56 & & 5.26 & 35.5 & 8.96 & 2.74 & 1.56 \\
\hline$\%$ G. scitula Dx & 30.8 & & 5.88 & & 9.52 & 20 & 63.2 & 62.5 & 50 & \begin{tabular}{|c|}
10.3 \\
\end{tabular} & 7.84 & 6.56 & & 15.8 & 64.5 & 8.96 & 6.85 & 9.38 \\
\hline$\%$ G. puncticulata & & & & & & & & & & & & & & & & & & \\
\hline$\%$ G. inflata & & & & & & & & & & & & & & & & & & \\
\hline Total Parcial Globorotálidos & 100 & 100 & 100 & 100 & 100 & 100 & 100 & 100 & 100 & 100 & 100 & 100 & 100 & 100 & 100 & 100 & 100 & 100 \\
\hline Total N. acostaensis \% & 17.4 & 10.5 & 13.3 & 10.1 & 19.6 & 29.8 & 22.5 & 19 & 13.7 & 12 & 11.1 & 9.83 & 7.25 & 7.9 & 22 & 10.4 & 7.84 & 9.64 \\
\hline$\%$ Resto planctónicos & 66.8 & 60.2 & 73.9 & 57.4 & 48.4 & 39.8 & 58.6 & 53.9 & 65.6 & 58.3 & 51.9 & 36 & 44.9 & 49.6 & 46.7 & 52.5 & 56.5 & 45.8 \\
\hline \% Planctón/Forams: & 84 & \begin{tabular}{|l|}
64.7 \\
\end{tabular} & 72.6 & 63.4 & 80.4 & 83.3 & 86.5 & 86.3 & 81.8 & \begin{tabular}{|l|}
79.2 \\
\end{tabular} & 92.5 & 80.7 & 65.7 & 83.8 & \begin{tabular}{|l|}
93.8 \\
\end{tabular} & \begin{tabular}{|l|}
85.2 \\
\end{tabular} & 91.9 & 90 \\
\hline
\end{tabular}


GOLFO DE CÁDIZ - D1

\begin{tabular}{|c|c|c|c|c|c|c|c|c|c|c|c|c|c|c|c|}
\hline Sondeo D1 (m) & 1400 & 1410 & 1430 & 1460 & 1470 & 1480 & 1500 & 1520 & 1690 & 1700 & 1740 & 1760 & 1780 & \begin{tabular}{|l|}
1790 \\
\end{tabular} & 1800 \\
\hline Muestra (Testigo "t", Ripio "r"): & $\mathrm{r}$ & $\mathrm{r}$ & $\mathrm{r}$ & $r$ & $\mathrm{r}$ & $r$ & $r$ & $r$ & r & $r$ & $r$ & $\mathrm{r}$ & $\mathrm{r}$ & $\mathrm{r}$ & $r$ \\
\hline Fracción & $125 /$ & $125 /$ & $125 /$ & $125 / 1$ & $125 / 500$ & $125 /$ & $125 /$ & $125 /$ & $125 /$ & $125 /$ & $125 /$ & $125 /$ & $125 /$ & $125 /$ & $125 /$ \\
\hline De un Total de Partículas (Biog+Terr.): & 135 & 227 & 188 & 172 & 148 & 230 & 253 & 248 & 235 & 210 & 203 & 159 & 196 & 188 & 155 \\
\hline$\%$ Total Biogenico & 61.48 & 18.94 & 9.574 & 2.326 & 12.16 & 6.957 & 3.557 & 0.806 & 33.19 & 46.67 & 45.81 & 33.33 & 34.18 & 57.98 & 61.94 \\
\hline$\%$ Forams (incluye fragmentos ambos grupos) & 61.48 & 18.94 & 9.043 & 2.326 & 12.16 & 6.957 & 3.557 & 0.806 & 33.19 & 46.67 & 45.81 & 33.33 & 34.18 & 57.98 & 61.94 \\
\hline$\%$ Ostracodos & 0 & 0 & 0 & 0 & 0 & 0 & 0 & 0 & 0 & 0 & 0 & 0 & 0 & 0 & 0 \\
\hline$\%$ Espículas de equinodermo & 0 & 0 & 0 & 0 & 0 & 0 & 0 & 0 & 0 & 0 & 0 & 0 & 0 & 0 & 0 \\
\hline$\%$ Otros bioclastos & 0 & 0 & 0.532 & 0 & 0 & 0 & 0 & 0 & 0 & 0 & 0 & 0 & 0 & 0 & 0 \\
\hline$\%$ Total Terrígeno & 38.52 & 81.06 & 90.43 & 97.67 & 87.84 & 93.04 & 96.44 & \begin{tabular}{|l|}
99.19 \\
\end{tabular} & 66.81 & 53.33 & 54.19 & 66.67 & 65.82 & \begin{tabular}{|l|}
42.02 \\
\end{tabular} & 38.06 \\
\hline$\%$ Arena & \begin{tabular}{|l|}
19.26 \\
\end{tabular} & \begin{tabular}{|l|}
79.3 \\
\end{tabular} & 88.83 & 96.51 & 87.16 & \begin{tabular}{|l|}
92.17 \\
\end{tabular} & 94.07 & \begin{tabular}{|l|}
99.19 \\
\end{tabular} & 63.83 & 52.38 & 53.69 & \begin{tabular}{|l|}
62.89 \\
\end{tabular} & 65.82 & \begin{tabular}{|l|}
37.77 \\
\end{tabular} & 37.42 \\
\hline \% Glauconita & 0 & 0 & 0 & 0 & 0 & 0 & 0 & 0 & 0.851 & 0 & 0.493 & 0.629 & 0 & 0.532 & 0 \\
\hline$\%$ Piritas & 14.81 & 1.762 & 1.596 & 1.163 & 0.676 & \begin{tabular}{|l|}
0.87 \\
\end{tabular} & 2.372 & 0 & 2.128 & \begin{tabular}{|l|}
0.952 \\
\end{tabular} & 0 & \begin{tabular}{|c|}
3.145 \\
\end{tabular} & 0 & 3.723 & 0.645 \\
\hline$\%$ Otros terrígenos & \begin{tabular}{|l|l|}
4.444 \\
\end{tabular} & 0 & 0 & 0 & 0 & 0 & 0 & 0 & 0 & 0 & 0 & 0 & 0 & 0 & 0 \\
\hline Total Foraminíferos: & 1039 & 435 & 447 & 439 & 976 & 405 & 203 & 261 & 781.4 & 846 & 439 & 526 & 479 & 487 & 393 \\
\hline Total Planct.: & 858 & 360 & 355 & 363 & 906 & 357 & 164 & 209 & 710.4 & 750 & 379 & 471 & 405 & 430 & 362 \\
\hline Total Bent.: & 181 & 75 & 92 & 76 & 70 & 48 & 39 & 52 & 71 & 96 & 60 & 55 & 74 & 57 & 31 \\
\hline$\%$ Planctón/Forams: & 82.58 & 82.76 & 79.42 & 82.69 & 92.83 & 88.15 & 80.79 & 80.08 & 90.91 & 88.65 & 86.33 & 89.54 & 84.55 & 88.3 & 92.11 \\
\hline \% Bentón./Forams: & 17.42 & \begin{tabular}{|l|}
17.24 \\
\end{tabular} & 20.58 & 17.31 & 7.172 & \begin{tabular}{|l|}
11.85 \\
\end{tabular} & 19.21 & 19.92 & \begin{tabular}{|c|}
9.086 \\
\end{tabular} & 11.35 & 13.67 & 10.46 & 15.45 & 11.7 & 7.888 \\
\hline Total Frag. (Forams): & 40 & 5 & 15 & 13 & 26 & 17 & 12 & 18 & 30.4 & 14 & 24 & 10 & 13 & 6 & 10 \\
\hline$\%$ Frag.Planc./Frag.Forams: & 75 & 40 & 60 & 61.54 & 46.15 & 64.71 & 66.67 & 38.89 & 57.89 & 28.57 & 91.67 & 70 & 61.54 & 83.33 & 60 \\
\hline$\%$ Frag.Planct / Foram.Planc & 3.378 & 0.552 & 2.473 & 2.156 & 1.307 & 2.989 & 4.651 & 3.241 & 2.418 & 0.531 & 5.486 & 1.464 & 1.937 & $\mid 1.149$ & 1.63 \\
\hline$\%$ Frag.Bent./Frag.Forams: & 25 & 60 & 40 & 38.46 & 53.85 & 35.29 & 33.33 & 61.11 & 42.11 & 71.43 & 8.333 & 30 & 38.46 & \begin{tabular}{|l|}
16.67 \\
\end{tabular} & 40 \\
\hline$\%$ Frag.Bent/Forams. Bent. & 2.688 & 3.846 & 6.122 & 6.173 & 9.091 & 111.11 & 9.302 & 17.46 & \begin{tabular}{|l|l|}
10.13 \\
\end{tabular} & 4.95 & 3.226 & 5.172 & 6.329 & 1.724 & 11.43 \\
\hline & & & & & & & & & & & & & & & \\
\hline ABSOLUTO PLANCTÓNICOS & & & & & & & & & & & & & & & \\
\hline Gr. margaritae Sin & 14 & 6 & 10 & 7 & 0 & 1 & 1 & 0 & 0 & 0 & 0 & 0 & 0 & 0 & 0 \\
\hline Gr. margaritae $D x$ & 0 & 0 & 0 & 0 & 0 & 0 & 0 & 0 & 0 & 0 & 0 & 0 & 0 & 0 & 0 \\
\hline Gr. miotumida Sin & 0 & 0 & 0 & 1 & 45 & 16 & 3 & 9 & 51 & 22 & 23 & 26 & 15 & 9 & 1 \\
\hline Gr. miotumida $D x$ & 1 & 0 & 0 & 0 & 2 & 0 & 0 & 0 & 3 & 0 & 0 & 0 & 0 & 0 & 0 \\
\hline Gr. menardii Sin & 2 & 0 & 0 & 0 & 0 & 3 & 1 & 0 & 0 & 1 & 0 & 2 & 4 & 1 & 0 \\
\hline Gr. menardii $D x$ & 0 & 0 & 0 & 0 & 0 & 0 & 0 & 0 & 0 & 3 & 1 & 3 & 7 & 31 & 13 \\
\hline Gr. scitula Sin & 1 & 2 & 2 & 0 & 0 & 1 & 1 & 1 & 2 & 2 & 6 & 5 & 4 & 4 & 4 \\
\hline Gr. scitula DX & 3 & 1 & 0 & 1 & 3 & 0 & 0 & 0 & 12 & 7 & 8 & 6 & 7 & 14 & 4 \\
\hline N. acostaensis Sin & 9 & 7 & 5 & 18 & 62 & 35 & 14 & 16 & 45 & 37 & 44 & 47 & 37 & 48 & 55 \\
\hline N. acostaensis $D x$ & 54 & 24 & 31 & 20 & 9 & 10 & 3 & 11 & 7 & 16 & 9 & 13 & 12 & 1 & 7 \\
\hline Sphaeroidinellopsis & 4 & 3 & 3 & 11 & 3 & 1 & 4 & 1 & 1 & 0 & 0 & 1 & 1 & 2 & 2 \\
\hline Dentoglobigerina altispira & 2 & 8 & 4 & 3 & 1 & 1 & 4 & 3 & 0 & 2 & 0 & 0 & 0 & 2 & 0 \\
\hline Otros Gr. saculifer & 3 & 7 & 5 & 9 & 0 & 1 & 4 & 3 & 4 & 1 & 6 & 9 & 8 & 10 & 6 \\
\hline O. universa & 22 & 29 & 78 & 87 & 26 & 50 & 18 & 22 & 29 & 12 & 24 & 26 & 33 & 52 & 14 \\
\hline G. druryi & 18 & 26 & 17 & 25 & 13 & 16 & 14 & 17 & 37 & 22 & 26 & 55 & 22 & 31 & 28 \\
\hline Gs. obliquus & 41 & 39 & 34 & 57 & 39 & 53 & 17 & 20 & 23 & 6 & 37 & 16 & 16 & 16 & 20 \\
\hline N. humerosaSIN & 0 & 0 & 0 & 1 & 0 & 0 & 0 & 0 & 0 & 0 & 0 & 0 & 0 & 0 & 0 \\
\hline N. humerosaDx & 0 & 0 & 0 & 0 & 0 & 0 & 0 & 0 & 0 & 0 & 0 & 1 & 0 & 0 & 0 \\
\hline Gr. puncticulata & 1 & 0 & 0 & 2 & 0 & 0 & 0 & 0 & 0 & 0 & 0 & 0 & 0 & 0 & 0 \\
\hline Total Globorotálidos & 22 & 9 & 12 & 11 & 50 & 21 & 6 & 10 & 68 & 35 & 38 & 42 & 37 & 59 & 22 \\
\hline Total N. acostaensis & 63 & 31 & 36 & 38 & 71 & 45 & 17 & 27 & 52 & 53 & 53 & 60 & 49 & 49 & 62 \\
\hline Resto planctónicos & 254 & 208 & 166 & 121 & 250 & 169 & 80 & 106 & 230 & 244 & 195 & 261 & 239 & 209 & 208 \\
\hline Total Planctónicos & 429 & 360 & 355 & 363 & 453 & 357 & 164 & 209 & 444 & 375 & 379 & 471 & 405 & 430 & 362 \\
\hline PORCENTAJE PLANTÓNICOS & & & & & & & & & & & & & & & \\
\hline Gr. margaritae Sin & 3.263 & 1.667 & 2.817 & 1.928 & 0 & 0.28 & 0.61 & 0 & 0 & 0 & 0 & 0 & 0 & 0 & 0 \\
\hline Gr. margaritae $D x$ & 0 & 0 & 0 & 0 & 0 & 0 & 0 & 0 & 0 & 0 & 0 & 0 & 0 & 0 & 0 \\
\hline Gr. miotumida Sin & 0 & 0 & 0 & 0.275 & 9.934 & \begin{tabular}{|l|l|}
4.482 \\
\end{tabular} & 1.829 & 4.306 & 11.49 & 5.867 & 6.069 & 5.519 & 3.704 & 2.093 & 0.276 \\
\hline Gr. miotumida $D x$ & 0.233 & 0 & 0 & 0 & 0.442 & 0 & 0 & 0 & \begin{tabular}{|l|l|}
0.676 \\
\end{tabular} & 0 & 0 & 0 & 0 & 0 & 0 \\
\hline Gr. menardii Sin & 0.466 & 0 & 0 & 0 & 0 & \begin{tabular}{|l|}
0.84 \\
\end{tabular} & \begin{tabular}{|l|}
0.61 \\
\end{tabular} & 0 & 0 & \begin{tabular}{|l|}
0.267 \\
\end{tabular} & 0 & 0.552 & \begin{tabular}{|l|}
0.988 \\
\end{tabular} & 0.233 & 0 \\
\hline Gr. menardii $D x$ & 0 & 0 & 0 & 0 & 0 & 0 & 0 & 0 & 0 & 0.8 & 0.264 & 0.637 & 1.728 & 7.209 & 3.591 \\
\hline Gr. scitula Sin & 0.233 & 0.556 & 0.563 & 0 & 0 & \begin{tabular}{|l|}
0.28 \\
\end{tabular} & \begin{tabular}{|l|}
0.61 \\
\end{tabular} & \begin{tabular}{|l|}
0.478 \\
\end{tabular} & \begin{tabular}{|l|}
0.45 \\
\end{tabular} & \begin{tabular}{|l|}
0.533 \\
\end{tabular} & 1.583 & 1.062 & \begin{tabular}{|l|}
0.988 \\
\end{tabular} & 0.93 & 1.105 \\
\hline Gr. scitula DX & 0.699 & 0.278 & 0 & 0.275 & 0.662 & 0 & 0 & 0 & 2.703 & \begin{tabular}{|l|}
1.867 \\
\end{tabular} & 2.111 & 1.274 & \begin{tabular}{|l|l|}
1.728 \\
\end{tabular} & 3.256 & 1.105 \\
\hline N. acostaensis Sin & 2.098 & \begin{tabular}{|l|l|}
1.944 \\
\end{tabular} & 1.408 & \begin{tabular}{|l|l|}
4.959 \\
\end{tabular} & 13.69 & \begin{tabular}{|l|}
9.804 \\
\end{tabular} & 8.537 & 7.656 & \begin{tabular}{|l|}
10.14 \\
\end{tabular} & 9.867 & 11.61 & \begin{tabular}{|l|}
9.979 \\
\end{tabular} & 9.136 & \begin{tabular}{|l|}
11.16 \\
\end{tabular} & 15.19 \\
\hline N. acostaensis $D x$ & 12.59 & 6.667 & 8.732 & 5.51 & 1.987 & 2.801 & 1.829 & 5.263 & \begin{tabular}{|c|}
1.577 \\
\end{tabular} & \begin{tabular}{|l|l|}
4.267 \\
\end{tabular} & 2.375 & 2.76 & 2.963 & 0.233 & 1.934 \\
\hline Sphaeroidinellopsis & \begin{tabular}{|l|}
0.932 \\
\end{tabular} & 0.833 & 0.845 & 3.03 & 0.662 & \begin{tabular}{|l|}
0.28 \\
\end{tabular} & 2.439 & 0.478 & 0.225 & 0 & 0 & 0.212 & 0.247 & 0.465 & 0.552 \\
\hline Dentoglobigerina altispira & 0.466 & 2.222 & 1.127 & 0.826 & 0.221 & 0.28 & 2.439 & 1.435 & 0 & 0.533 & 0 & 0 & 0 & 0.465 & 0 \\
\hline Otros Gr. saculifer & 0.699 & 1.944 & 1.408 & 2.479 & 0 & \begin{tabular}{|l|}
0.28 \\
\end{tabular} & 2.439 & 1.435 & 0.901 & 0.267 & 1.583 & \begin{tabular}{|c|}
1.911 \\
\end{tabular} & 1.975 & 2.326 & 1.657 \\
\hline O. universa & 5.128 & 8.056 & 21.97 & 23.97 & 5.74 & \begin{tabular}{|l|}
14.01 \\
\end{tabular} & 10.98 & 10.53 & 6.532 & 3.2 & 6.332 & 5.52 & 8.148 & \begin{tabular}{|l|}
12.09 \\
\end{tabular} & 3.867 \\
\hline G. druryi & 4.196 & 7.222 & 4.789 & \begin{tabular}{|c|}
6.887 \\
\end{tabular} & 2.87 & \begin{tabular}{|l|l}
4.482 \\
\end{tabular} & 8.537 & 8.134 & 8.333 & 5.867 & 6.86 & \begin{tabular}{|c|}
11.68 \\
\end{tabular} & 5.432 & 7.209 & 7.735 \\
\hline Gs. obliquus & 9.557 & 10.83 & 9.577 & 15.7 & 8.609 & 14.85 & 10.37 & 9.569 & 5.18 & 1.6 & 9.763 & 3.39 & 3.951 & 3.721 & 5.525 \\
\hline N. humerosa SIN & 0 & 0 & 0 & 0.275 & 0 & 0 & 0 & 0 & 0 & 0 & 0 & 0 & 0 & 0 & 0 \\
\hline N. humerosa $D x$ & 0 & 0 & 0 & 0 & 0 & 0 & 0 & 0 & 0 & 0 & 0 & 0.212 & 0 & 0 & 0 \\
\hline Gr. puncticulata & 0.233 & 0 & 0 & 0.551 & 0 & 0 & 0 & 0 & 0 & 0 & 0 & 0 & 0 & 0 & 0 \\
\hline Total Globorotálidos \% & 5.128 & 2.5 & 3.38 & 3.03 & 11.04 & \begin{tabular}{|l|l|}
5.882 \\
\end{tabular} & 3.659 & 4.785 & 15.32 & 9.333 & 10.03 & 8.917 & 9.136 & 13.72 & 6.077 \\
\hline$\%$ Gr. margaritae Sin & 63.64 & 66.67 & 83.33 & 63.64 & 0 & \begin{tabular}{|l|}
4.762 \\
\end{tabular} & 16.67 & 0 & 0 & 0 & 0 & 0 & 0 & 0 & 0 \\
\hline$\%$ Gr. margaritae Dx & 0 & 0 & 0 & 0 & 0 & 0 & 0 & 0 & 0 & 0 & 0 & 0 & 0 & 0 & 0 \\
\hline$\%$ Gr. miotumida Sin & 0 & 0 & 0 & 9.091 & 90 & \begin{tabular}{|l|}
76.19 \\
\end{tabular} & 50 & 90 & 75 & 62.86 & 60.53 & 61.9 & 40.54 & 15.25 & 4.545 \\
\hline$\%$ Gr. miotumida Dx & 4.545 & 0 & 0 & 0 & 4 & 0 & 0 & 0 & \begin{tabular}{|c|}
4.412 \\
\end{tabular} & 0 & 0 & 0 & 0 & 0 & 0 \\
\hline$\%$ Gr. menardii Sin & 9.091 & 0 & 0 & 0 & 0 & \begin{tabular}{|l|}
14.29 \\
\end{tabular} & 16.67 & 0 & 0 & 2.857 & 0 & 4.762 & 10.81 & \begin{tabular}{|c|}
1.695 \\
\end{tabular} & 0 \\
\hline$\%$ Gr. menardii Dx & 0 & 0 & 0 & 0 & 0 & 0 & 0 & 0 & 0 & 8.571 & 2.632 & 7.143 & 18.92 & 52.54 & 59.09 \\
\hline$\%$ Gr. scitula Sin & 4.545 & 22.22 & 16.67 & 0 & 0 & \begin{tabular}{|l|}
4.762 \\
\end{tabular} & 16.67 & 10 & 2.941 & \begin{tabular}{|l|l|}
5.714 \\
\end{tabular} & 15.79 & 11.9 & 10.81 & \begin{tabular}{|c|}
6.78 \\
\end{tabular} & 18.18 \\
\hline$\%$ Gr. scitula DX & 13.64 & 11.11 & 0 & 9.091 & 6 & 0 & 0 & 0 & 17.65 & 20 & 21.05 & 14.29 & 18.92 & 23.73 & 18.18 \\
\hline$\%$ Gr. puncticulata & 4.545 & 0 & 0 & 18.18 & 0 & 0 & 0 & 0 & 0 & 0 & 0 & & 0 & 0 & 0 \\
\hline$\%$ Gr. inflata & & 0 & & & & & & & & & 0 & & & 0 & \\
\hline Total N. acostaensis \% & 14.69 & 8.611 & 10.14 & $\mid 10.47$ & 15.67 & 12.61 & 10.37 & 12.92 & $\mid 11.71$ & 14.13 & 13.98 & 12.74 & 12.1 & 11.4 & 17.13 \\
\hline$\%$ Resto planctónicos & 59.21 & 57.78 & 46.76 & 33.33 & 55.19 & \begin{tabular}{|l|}
47.34 \\
\end{tabular} & 48.78 & 50.72 & 51.8 & 65.07 & 51.45 & 55.41 & 59.01 & 48.6 & 57.46 \\
\hline \% Planctón/Forams: & 82.58 & 82.76 & 79.42 & 82.69 & 92.83 & \begin{tabular}{|l|}
88.15 \\
\end{tabular} & 80.79 & 80.08 & 90.91 & 88.65 & 86.33 & 89.54 & 84.55 & \begin{tabular}{|l|}
88.3 \\
\end{tabular} & 92.11 \\
\hline
\end{tabular}




\section{MARISMAS-2}

\begin{tabular}{|c|c|c|c|c|c|c|c|c|c|c|c|c|c|c|c|c|c|c|c|c|c|c|c|c|c|c|c|c|c|c|c|c|c|c|}
\hline \multicolumn{35}{|c|}{440052055658062264666468269470071273076077278479080282088689892} \\
\hline SOLU & & & & & & & & & & & & & & & & & & & & & & & & & & & & & & & & & & \\
\hline i. marge & 4 & 2 & 2 & & $\begin{array}{ll}6 \\
\end{array}$ & & 2 & \begin{tabular}{l|lll}
2 & 5
\end{tabular} & & 3 & & 1 & & 16 & 21 & 3 & 15 & 10 & & 7 & & 8 & 5 & 1 & & & & & 1 & & & & & \\
\hline i. marg & & & & & 1 & & & & & & & & & & & & & & & & 1 & & & & & & & & & & & & & \\
\hline & & & & & & & & & & & & & & & & 4 & 3 & \begin{tabular}{l|l}
3 & 2 \\
\end{tabular} & & & & 11 & 20 & 11 & 9 & $\begin{array}{ll}12 & \\
\end{array}$ & \begin{tabular}{|l|l|}
17 & \\
\end{tabular} & \begin{tabular}{ll|l|l|l|}
13 & \\
\end{tabular} & 36 & 14 & 20 & & 7 & \\
\hline & & & & & & & & & & & & & & & & & \begin{tabular}{l|l}
1 &
\end{tabular} & & & & & & & & & & 1 & & & & 1 & & & \\
\hline & & & & & & & & & & & & & & & & & & & & & & & & 0 & & & & & & & & & & \\
\hline & & & & & & & & & & & & & & & & & & & & & & & & & & & & & 17 & $\mid 19$ & 14 & & & \\
\hline & & & 1 & 2 & & 3 & & 1 & & 1 & & & & & & 3 & 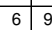 & \begin{tabular}{l|l}
9 & 5 \\
\end{tabular} & & 3 & & 9 & & 7 & & & & & 2 & & & & & \\
\hline Gr.sc & & & & & & & & & & & & & & & \begin{tabular}{l|lll}
1 & 1
\end{tabular} & 11 & 1 & \begin{tabular}{l|ll}
1 & 1 \\
\end{tabular} & 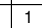 & 2 & & 1 & & & & 4 & & & 4 & 3 & 3 & & & \\
\hline & 4 & 6 & 2 & & 8 & & 2 & 6 & $\begin{array}{llll}5 & 4 \\
\end{array}$ & 4 & 0 & & & & & & & & 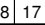 & & 9 & 29 & 32 & 21 & 12 & 17 & 3 & 14 & 60 & & 45 & 2 & & \\
\hline & & & & & & & & 1 & & 0 & & & & & & 3 & & 0 & & & & 21 & 4 & 11 & 6 & 8 & 71 & 10 & 27 & 25 & 37 & 17 & 20 & \\
\hline the & 1 & & & & & & & & & 5 & & & & & & & & \begin{tabular}{l|l}
7 & 6 \\
\end{tabular} & & & & 21 & 18 & & & 2 & & 3 & 2 & 2 & 8 & 6 & & \\
\hline Parcial hion & & & & & & & & & & a & 0 & & & & مa & 19 & 262 & & & & & & & & & & (2) & & & 64 & & & & \\
\hline
\end{tabular}




\section{MARISMAS 4}

\begin{tabular}{|c|c|c|c|c|c|c|c|c|c|c|c|c|c|c|c|}
\hline Sondeo Marismas 4(m) & 860 & 1015 & 1100 & 1121 & 1160 & 1180 & 1202 & 1220 & 1232 & 1241 & 1259 & 1268 & 1280 & 1292 & 1301 \\
\hline Tipo de muestra (Testigo "t", Ripio "r"): & $\mathrm{r}$ & $\mathrm{r}$ & $\mathrm{r}$ & $\mathrm{r}$ & $\mathrm{r}$ & $\mathrm{r}$ & $\mathrm{r}$ & $\mathrm{r}$ & $\mathrm{r}$ & $\mathrm{r}$ & $\mathrm{r}$ & $\mathrm{r}$ & $\mathrm{r}$ & $\mathrm{r}$ & $\mathrm{r}$ \\
\hline Tamiz: & 125 & 125 & 125 & & 125 & 125 & 125 & 125 & 125 & 125 & 125 & 125 & 125 & 125 & 125 \\
\hline De un Total de Partículas (Biog+Terr.): & & & 162 & & 150 & & & & 206 & 114 & 106 & 175 & 174 & 211 & 125 \\
\hline$\%$ Total Biogenico & & & 29.63 & & 16.00 & & & & 18.45 & 11.40 & 15.09 & 13.71 & 12.64 & 27.01 & 38.40 \\
\hline$\%$ Forams (incluye fragmentos ambos grupos) & & & 30 & & 15 & & & & 16 & 11 & 13 & 13 & 12 & 27 & 38 \\
\hline \% Ostracodos & & & & & & & & & & 1 & & & & & \\
\hline \% Espiculas de equinodermo & & & & & & & & & & & 2 & & & & \\
\hline$\%$ Otros bioclastos & & & & & 1 & & & & 2 & & & 1 & 1 & & \\
\hline \% Total Terrígeno & & & 70 & & 84 & & & & 82 & 89 & 85 & 86 & 87 & 73 & 62 \\
\hline$\%$ Arena & & & 42 & & 57 & & & & 60 & 51 & 77 & 71 & 80 & 61 & 24 \\
\hline$\%$ Glauconita & & & & & & & & & & & & & & & \\
\hline \% Piritas & & & 23 & & 18 & & & & 19 & 17 & 8 & 14 & 6 & 8 & 14 \\
\hline$\%$ Otros terrígenos & & & 5 & & 9 & & & & 3 & 21 & & 1 & 1 & 4 & 24 \\
\hline № Total de Forams. en la muestra & 391 & 15 & 606 & 17 & 503 & 12 & 530 & 58 & 533 & 507 & 509 & 565 & 837 & 618 & 663 \\
\hline Total Planct.: & 139 & 15 & 341 & 17 & 503 & 12 & 530 & 58 & 345 & 338 & 312 & 319 & 570 & 478 & 530 \\
\hline Total Bent.: & 252 & & 265 & & & & & & 188 & 169 & 197 & 246 & 267 & 140 & 133 \\
\hline \% Planctón/Forams: & 36 & 100 & 56 & 100 & 100 & 100 & 100 & 100 & 65 & 67 & 61 & 56 & 68 & 77 & 80 \\
\hline \% Bentón./Forams: & 64 & & 44 & & & & & & 35 & 33 & 39 & 44 & 32 & 23 & 20 \\
\hline Frag. (Forams) en la muestra: & & & 10 & & 18 & & & & 24 & 12 & 11 & 26 & 27 & 16 & 17 \\
\hline \% Frag.Planc./Frag.Forams: & & & 10 & & 100 & & & & 26 & 25 & 18 & 46 & 81 & 56 & 45 \\
\hline \% Frag.Planct / Foram.Planc & & & 0 & & 3 & & & & 2 & 1 & 1 & 4 & 4 & 2 & 1 \\
\hline \% Frag.Bent./Frag.Forams: & & & 90 & & & & & & 74 & 75 & 82 & 54 & 19 & 44 & 55 \\
\hline$\%$ Frag.Bent/Forams. Bent. & & & 3 & & & & & & 7 & 5 & 4 & 6 & 3 & 5 & 4 \\
\hline & & & & & & & & & & & & & & & \\
\hline ABSOLUTO PLANCTÓNICOS: & & & & & & & & & & & & & & & \\
\hline Gr. margaritae Sin & 3 & 13 & 18 & 13 & 9 & 7 & 7 & 6 & 9 & 17 & 7 & 5 & 8 & 1 & 2 \\
\hline Gr. margaritae $D x$ & & & & & & & & & & & 1 & & & & \\
\hline Gr.miotumida Sin & & & & & 1 & 3 & & & & & & & & & \\
\hline Gr.miotumida $D x$ & & & & & & & & & & & & & & & \\
\hline Gr. menardii Sin & & & & & & & & & & & 1 & & & 5 & \\
\hline Gr. menardii $D x$ & & & & & & & & & & & & & & 2 & \\
\hline Gr. scitula Sin & 3 & 2 & 2 & 4 & 3 & 1 & 3 & 3 & 5 & 1 & 4 & 1 & 3 & 11 & 1 \\
\hline Gr. scitula $D X$ & & & 1 & & & & 1 & 1 & 2 & 2 & 2 & & 1 & 5 & 6 \\
\hline N. acostaensis Sin & 1 & & 3 & & 7 & 1 & 9 & 24 & 10 & 22 & 14 & 14 & 30 & 43 & 47 \\
\hline N. acostaensis $D x$ & 18 & & 18 & & 44 & & 62 & 24 & 23 & 34 & 19 & 32 & 60 & 29 & 15 \\
\hline Sphaeroidinellopsis & 2 & & 27 & & 18 & & 13 & & 4 & 7 & 13 & 3 & 17 & 5 & 3 \\
\hline Dentoglobigerina altispira & 7 & & 4 & & 4 & & & & 3 & 2 & 5 & 3 & 8 & 7 & 2 \\
\hline Otros Gr.saculifer & 2 & & 6 & & 8 & & 7 & & 9 & 6 & 5 & 7 & 8 & 7 & 3 \\
\hline O.universa & 16 & & 72 & & 115 & & 148 & & 79 & 44 & 83 & 48 & 110 & 83 & 86 \\
\hline G.druryi & 1 & & 7 & & 4 & & 4 & & 8 & 28 & 11 & 8 & 5 & 11 & 10 \\
\hline G.apertura & & & 3 & & & & & & & & & & & & \\
\hline Gs.obliquus & & & 22 & & & & & & 19 & 20 & 39 & 33 & & 15 & 13 \\
\hline Gs.Triloba & & & 3 & & & & & & & & & & & & \\
\hline Gs.immaturus & & & 1 & & & & & & & & & & & & \\
\hline O.bilobata & & & 1 & & & & & & & & & & & & \\
\hline G.nepentes & & & 3 & & 4 & & & & & & & & 1 & 1 & \\
\hline Gs.bulloideus & & & 2 & & & & & & & & & & & & \\
\hline G.falconensis & & & 3 & & & & & & & & & & & & \\
\hline Gs.extremus & & & 13 & & & & & & & & & & & & \\
\hline Total Globorotálidos & 6 & 15 & 21 & 17 & 13 & 11 & 11 & 10 & 16 & 20 & 15 & 6 & 12 & 24 & 9 \\
\hline Total Acostaensis & 19 & & 21 & & 51 & 1 & 71 & 48 & 33 & 56 & 33 & 46 & 90 & 72 & 62 \\
\hline Resto planct. & 86 & & 132 & & 286 & & 276 & & 105 & 155 & 108 & 165 & 319 & 253 & 165 \\
\hline Total Planctónicos & 139 & 15 & 341 & 17 & 503 & 12 & 530 & 58 & 276 & 338 & 312 & 319 & 570 & 478 & 353 \\
\hline PORCENTAJE PLANCTÓNICOS & & & & & & & & & & & & & & & \\
\hline Gr. margaritae Sin & 2.2 & 86.7 & 5.3 & 76.5 & 1.8 & 58.3 & 1.3 & 10.3 & 3.3 & 5.0 & 2.2 & 1.6 & 1.4 & 0.2 & 0.6 \\
\hline Gr. margaritae $D x$ & & & & & & & & & & & 0.3 & & & & \\
\hline Gr.miotumida Sin & & & & & 0.2 & 25.0 & & & & & & & & & \\
\hline Gr.miotumida $D x$ & & & & & & & & & & & & & & & \\
\hline Gr. menardii Sin & & & & & & & & & & & 0.3 & & & 1.0 & \\
\hline Gr. menardii $D x$ & & & & & & & & & & & & & & 0.4 & \\
\hline Gr. scitula Sin & 2.2 & 13.3 & 0.6 & 23.5 & 0.6 & 8.3 & 0.6 & 5.2 & 1.8 & 0.3 & 1.3 & 0.3 & 0.5 & 2.3 & 0.3 \\
\hline Gr. scitula DX & & & 0.3 & & & & 0.2 & 1.7 & 0.7 & 0.6 & 0.6 & & 0.2 & 1.0 & 1.7 \\
\hline N. acostaensis Sin & 0.7 & & 0.9 & & 1.4 & 8.3 & 1.7 & \begin{tabular}{|l|l|}
41.4 &
\end{tabular} & 3.6 & 6.5 & 4.5 & 4.4 & 5.3 & 9.0 & 13.3 \\
\hline N. acostaensis $D x$ & 12.9 & & 5.3 & & 8.7 & & $\mid 11.7$ & \begin{tabular}{|l|l|}
41.4 &
\end{tabular} & 8.3 & 10.1 & 6.1 & 10.0 & 10.5 & 6.1 & 4.2 \\
\hline Sphaeroidinellopsis & 1.4 & & 7.9 & & 3.6 & & 2.5 & & 1.4 & 2.1 & 4.2 & 0.9 & 3.0 & 1.0 & 0.8 \\
\hline Dentoglobigerina altispira & 5.0 & & 1.2 & & 0.8 & & & & 1.1 & 0.6 & 1.6 & 0.9 & 1.4 & 1.5 & 0.6 \\
\hline Otros Gr.saculifer & 1.4 & & 1.8 & & 1.6 & & 1.3 & & 3.3 & 1.8 & 1.6 & 2.2 & 1.4 & 1.5 & 0.8 \\
\hline O.universa & 11.5 & & 21.1 & & 22.9 & & \begin{tabular}{|l|}
27.9 \\
\end{tabular} & & 28.6 & 13.0 & 26.6 & 15.0 & 19.3 & \begin{tabular}{|l|}
17.4 \\
\end{tabular} & 24.4 \\
\hline G.druryi & 0.7 & & 2.1 & & 0.8 & & 0.8 & & 2.9 & 8.3 & 3.5 & 2.5 & 0.9 & 2.3 & 2.8 \\
\hline G.apertura & & & 0.9 & & & & & & & & & & & & \\
\hline Gs.obliquus & & & 6.5 & & & & & & 6.9 & 5.9 & 12.5 & 10.3 & & 3.1 & 3.7 \\
\hline Gs.Triloba & & & 0.9 & & & & & & & & & & & & \\
\hline Gs.immaturus & & & 0.3 & & & & & & & & & & & & \\
\hline O.bilobata & & & 0.3 & & & & & & & & & & & & \\
\hline G.nepentes & & & 0.9 & & 0.8 & & & & & & & & 0.2 & 0.2 & \\
\hline Gs.bulloideus & & & 0.6 & & & & & & & & & & & & \\
\hline G.falconensis & & & 0.9 & & & & & & & & & & & & \\
\hline Gs.extremus & & & 3.8 & & & & & & & & & & & & \\
\hline Total Globorotálidos \% & 4.3 & 100.0 & 6.2 & $\mid 100.0$ & 2.6 & \begin{tabular}{|l|}
91.7 \\
\end{tabular} & 2.1 & 17.2 & 5.8 & 5.9 & 4.8 & 1.9 & 2.1 & 5.0 & 2.5 \\
\hline Total Acostaensis \% & 13.7 & & 6.2 & & \begin{tabular}{|l|}
10.1 \\
\end{tabular} & 8.3 & \begin{tabular}{|l|}
13.4 \\
\end{tabular} & \begin{tabular}{|l|l|}
82.8 & \\
\end{tabular} & 12.0 & 16.6 & \begin{tabular}{|l|}
10.6 \\
\end{tabular} & 14.4 & \begin{tabular}{|l|}
15.8 \\
\end{tabular} & \begin{tabular}{|l|}
15.1 \\
\end{tabular} & \begin{tabular}{|l|}
17.6 \\
\end{tabular} \\
\hline$\%$ Resto planc. & 61.9 & & 38.7 & & \begin{tabular}{|l|}
56.9 \\
\end{tabular} & & 52.1 & & 38.0 & 45.9 & 34.6 & 51.7 & 56.0 & \begin{tabular}{|l|}
52.9 \\
\end{tabular} & 46.7 \\
\hline$\%$ Planctón/Forams: & 35.5 & 100.0 & 56.3 & \begin{tabular}{|l|}
100.0 \\
\end{tabular} & 100.0 & $\mid 100.0$ & 100.0 & \begin{tabular}{|l|}
100.0 \\
\end{tabular} & 64.7 & 66.7 & 61.3 & 56.5 & 68.1 & \begin{tabular}{|l|}
77.3 \\
\end{tabular} & 79.9 \\
\hline
\end{tabular}




\section{SAN JUAN R1}

\begin{tabular}{|c|c|c|c|c|c|c|c|c|c|c|c|c|c|c|c|c|c|c|c|c|c|c|c|}
\hline San Juan R1 (m) & 620 & 640 & 660 & 680 & \begin{tabular}{|l|l}
700 \\
\end{tabular} & 720 & 740 & 760 & 780 & 790 & \begin{tabular}{|l|}
800 \\
\end{tabular} & \begin{tabular}{|l|}
820 \\
\end{tabular} & \begin{tabular}{|l|}
840 \\
\end{tabular} & \begin{tabular}{|l|}
860 \\
\end{tabular} & 880 & \begin{tabular}{|l|}
900 \\
\end{tabular} & \begin{tabular}{|l|}
920 \\
\end{tabular} & \begin{tabular}{|l|}
940 \\
\end{tabular} & \begin{tabular}{|l|}
960 \\
\end{tabular} & \begin{tabular}{|l|}
980 \\
\end{tabular} & 1000 & 1020 & 1040 \\
\hline \multicolumn{24}{|l|}{ ABSOLUTO PLANC. } \\
\hline$D X$ & & & & & & 1 & & 1 & 1 & & & & & & & & & & & 1 & & & \\
\hline miotumidaSIN & 1 & & & & & & & 2 & 4 & 1 & & & & & 1 & & & 2 & & & & & \\
\hline menardiiSIN & & & & & & & & 1 & & & & & & & & 2 & 1 & 1 & & & & & \\
\hline \multicolumn{24}{|l|}{$D X$} \\
\hline scitulaSIN & & 2 & & 1 & 1 & & & & 1 & 6 & 1 & 2 & & 1 & 7 & 3 & 3 & 3 & & 2 & 1 & 3 & \\
\hline$D X$ & 38 & 23 & 34 & 27 & 15 & 29 & 16 & 32 & 28 & 47 & 44 & 50 & 51 & 22 & 19 & 24 & 11 & 19 & 7 & 14 & 3 & 1 & \\
\hline Sphaeroid. & 4 & 12 & 1 & 2 & & 3 & 9 & 3 & 1 & 4 & 1 & 4 & 3 & 1 & 2 & 3 & 1 & & & & 1 & & \\
\hline Dentoglob. & 6 & 19 & 1 & 4 & 2 & 8 & 4 & 1 & 6 & 7 & 4 & 3 & 5 & & 1 & 1 & 1 & & & & & & \\
\hline Saculifer & 3 & 10 & 5 & 3 & 2 & & & 1 & & & 1 & 3 & 5 & 3 & 2 & 1 & 1 & 3 & & 2 & 1 & 2 & 1 \\
\hline Orbulina & 21 & 39 & 33 & 20 & 4 & 15 & 13 & 13 & 11 & 16 & 25 & 24 & 48 & 38 & 31 & 28 & 12 & 15 & 4 & 4 & 1 & 5 & \\
\hline Druryi & 2 & 9 & 1 & 1 & 1 & 1 & 1 & & & & 4 & 2 & 5 & 3 & 2 & 1 & 9 & 3 & 4 & 2 & & 1 & \\
\hline Parcial Globort. & 10 & 5 & 2 & 3 & 4 & 6 & 15 & 12 & 20 & 29 & 8 & 10 & 8 & 6 & 15 & 6 & 8 & 11 & & 6 & 1 & 3 & \\
\hline margaritaeSIN & 3.8 & 0.7 & 0.7 & 0.5 & 2.1 & 1.4 & 5.8 & \begin{tabular}{|l|l|}
3.8 & \\
\end{tabular} & 5.6 & 5.9 & 1.3 & 1.8 & 0.3 & & 0.6 & & & & & & & & \\
\hline$D X$ & & & & & & 0.5 & & 0.5 & 0.4 & & & & & & & & & & & 0.9 & & & \\
\hline miotumidaSIN & 0.5 & & & & & & & 1.0 & 1.7 & 0.3 & & & & & \begin{tabular}{|l|}
0.3 \\
\end{tabular} & & & \begin{tabular}{|l|l|}
0.7 \\
\end{tabular} & & & & & \\
\hline$D X$ & & & & & & & & & & & & & & \begin{tabular}{|l|l|}
0.3 \\
\end{tabular} & & & & & & 0.9 & & & \\
\hline menardiiSIN & & & & & & & & 0.5 & & & & & & & & 0.8 & 0.5 & \begin{tabular}{|l|l|}
0.4 \\
\end{tabular} & & & & & \\
\hline \multicolumn{24}{|l|}{$D X$} \\
\hline scitulaSIN & & 0.7 & & 0.5 & 0.7 & & & & 0.4 & 1.6 & 0.3 & 0.6 & & \begin{tabular}{|l|l|}
0.3 \\
\end{tabular} & \begin{tabular}{|l|}
2.0 \\
\end{tabular} & 1.3 & \begin{tabular}{|c|}
1.5 \\
\end{tabular} & \begin{tabular}{|l|}
1.1 \\
\end{tabular} & & 1.8 & 1.8 & 8.3 & \\
\hline$D X$ & \begin{tabular}{l|}
0.5 \\
\end{tabular} & 0.3 & & 0.5 & & \begin{tabular}{l|l}
0.9 \\
\end{tabular} & & & 0.4 & & 1.0 & 0.6 & 2.3 & \begin{tabular}{|l|}
1.2 \\
\end{tabular} & \begin{tabular}{|l|}
1.4 \\
\end{tabular} & \begin{tabular}{|l|}
0.4 \\
\end{tabular} & \begin{tabular}{|l|}
1.9 \\
\end{tabular} & 1.9 & & \begin{tabular}{|l|}
1.8 \\
\end{tabular} & & & \\
\hline acostaensisSIN & 1.9 & 3.3 & 3.5 & 2.9 & 2.1 & 0.9 & 2.7 & \begin{tabular}{|l|}
1.9 \\
\end{tabular} & & 1.1 & 1.7 & 0.6 & 1.7 & \begin{tabular}{|l|}
8.2 \\
\end{tabular} & \begin{tabular}{|l|}
7.8 \\
\end{tabular} & 8.1 & \begin{tabular}{|l|l|}
7.3 \\
\end{tabular} & 4.9 & 1.3 & 7.2 & 5.5 & 5.6 & \\
\hline$D X$ & 17.9 & 7.5 & \begin{tabular}{|c|}
11.8 \\
\end{tabular} & \begin{tabular}{|l|}
13.0 \\
\end{tabular} & 10.7 & 13.3 & 6.2 & \begin{tabular}{|l|}
15.2 \\
\end{tabular} & 12.0 & 12.6 & \begin{tabular}{|l|}
14.6 \\
\end{tabular} & 15.2 & \begin{tabular}{|l|}
16.8 \\
\end{tabular} & \begin{tabular}{|l|l}
6.6 \\
\end{tabular} & \begin{tabular}{|l|}
5.3 \\
\end{tabular} & 10.2 & \begin{tabular}{|l|l|}
5.3 \\
\end{tabular} & \begin{tabular}{|l|}
7.1 \\
\end{tabular} & 9.2 & 12.6 & 5.5 & 2.8 & \\
\hline Sphaeroid. & \begin{tabular}{l|l|}
1.9 \\
\end{tabular} & 3.9 & 0.3 & \begin{tabular}{|l|}
1.0 \\
\end{tabular} & & \begin{tabular}{|l|}
1.4 \\
\end{tabular} & 3.5 & \begin{tabular}{|l|}
1.4 \\
\end{tabular} & 0.4 & 1.1 & \begin{tabular}{|l|}
0.3 \\
\end{tabular} & 1.2 & 1.0 & \begin{tabular}{|l|}
0.3 \\
\end{tabular} & \begin{tabular}{|l|}
0.6 \\
\end{tabular} & \begin{tabular}{|l|}
1.3 \\
\end{tabular} & \begin{tabular}{|l|}
0.5 \\
\end{tabular} & & & & 1.8 & & \\
\hline Dentoglob. & 2.8 & 6.2 & 0.3 & 1.9 & 1.4 & \begin{tabular}{|l|}
3.7 \\
\end{tabular} & 1.5 & \begin{tabular}{|l|}
0.5 \\
\end{tabular} & 2.6 & 1.9 & 1.3 & 0.9 & \begin{tabular}{|l|}
1.7 \\
\end{tabular} & & \begin{tabular}{|l|}
0.3 \\
\end{tabular} & \begin{tabular}{|l|}
0.4 \\
\end{tabular} & \begin{tabular}{|l|}
0.5 \\
\end{tabular} & & & & & & \\
\hline Saculifer & 1.4 & 3.3 & \begin{tabular}{|l|}
1.7 \\
\end{tabular} & 1.4 & 1.4 & & & \begin{tabular}{|l|}
0.5 \\
\end{tabular} & & & \begin{tabular}{|l|}
0.3 \\
\end{tabular} & 0.9 & 1.7 & \begin{tabular}{|l|}
0.9 \\
\end{tabular} & \begin{tabular}{|l|}
0.6 \\
\end{tabular} & \begin{tabular}{|l|}
0.4 \\
\end{tabular} & \begin{tabular}{|l|}
0.5 \\
\end{tabular} & \begin{tabular}{|l|}
1.1 \\
\end{tabular} & & 1.8 & 1.8 & 5.6 & 33.3 \\
\hline Orbulina & 9.9 & 12.8 & 11.5 & \begin{tabular}{|l|}
9.6 \\
\end{tabular} & 2.9 & 6.9 & 5.0 & \begin{tabular}{|l|}
6.2 \\
\end{tabular} & \begin{tabular}{|l|}
4.7 \\
\end{tabular} & 4.3 & \begin{tabular}{|l|}
8.3 \\
\end{tabular} & 7.3 & 15.8 & \begin{tabular}{|l|}
11.5 \\
\end{tabular} & \begin{tabular}{|l|}
8.7 \\
\end{tabular} & \begin{tabular}{|l|}
11.9 \\
\end{tabular} & \begin{tabular}{|l|}
5.8 \\
\end{tabular} & \begin{tabular}{|l|}
5.6 \\
\end{tabular} & 5.3 & 3.6 & 1.8 & 13.9 & \\
\hline miotumidaSIN & 10 & & & & & & & 25 & 20 & 3.45 & & & & & 6.67 & & & 18.2 & & & & & \\
\hline$D X$ & & & & & & & & & & & & & & 16.7 & & & & & & 16.7 & & & \\
\hline menardiiSIN & & & & & & & & & & & & & & & & 33.3 & 12.5 & 9.09 & & & & & \\
\hline$D X$ & & & & & & & & & & & & & & & & & & & & & & & \\
\hline scitulaSIN & & 40 & & 33.3 & 25 & & & & 5 & 20.7 & 12.5 & 20 & & \begin{tabular}{|l|}
16.7 \\
\end{tabular} & 46.7 & 50 & 37.5 & \begin{tabular}{|l|}
27.3 \\
\end{tabular} & & 33.3 & 100 & 100 & \\
\hline$D X$ & 10 & 20 & & 33.3 & & 33.3 & & & 5 & & 37.5 & 20 & 87.5 & 66.7 & 33.3 & $\mid 16.7$ & 50 & 45.5 & & 33.3 & & & \\
\hline \%Globorotálidos & 4.72 & 1.64 & \begin{tabular}{|l|}
0.7 \\
\end{tabular} & 1.44 & 2.86 & 2.75 & 5.77 & 5.71 & 8.55 & 7.8 & 2.66 & 3.04 & 2.64 & 1.81 & 4.19 & 2.54 & 3.88 & \begin{tabular}{|l|l}
4.1 \\
\end{tabular} & & 5.41 & \begin{tabular}{|l|}
1.82 \\
\end{tabular} & 8.33 & \\
\hline
\end{tabular}




\section{SAN JUAN V-2}

\begin{tabular}{|c|c|c|c|c|c|c|c|c|c|c|c|c|c|c|c|c|c|c|c|c|c|c|c|c|}
\hline Sondeo San Juan V-2 (m) & \begin{tabular}{|l|}
240 \\
\end{tabular} & 260 & 280 & \begin{tabular}{|l|l|}
300 \\
\end{tabular} & 320 & 340 & 360 & 380 & 400 & 420 & 460 & 520 & 540 & 680 & 720 & 740 & 760 & 780 & 800 & 820 & 820 & 840 & 860 & 880 \\
\hline \multicolumn{25}{|l|}{ ABSOLUTO PLANCTÓNICOS: } \\
\hline Gr. margaritae Sin & 7 & 3 & 9 & 3 & 8 & 12 & 1 & & 3 & 5 & 3 & 2 & 1 & 6 & 17 & 5 & 9 & 2 & 4 & & & 5 & 1 & 3 \\
\hline Gr. margaritae $D x$ & & & & 1 & & & & & & & & & & & & & & & & & & & & \\
\hline Gr.miotumida Sin & & & & & 2 & & & & & & & & & & & 2 & 2 & 4 & & 1 & & & & \\
\hline Gr.miotumida $D x$ & & & & & & & & & & 1 & & & & & & 1 & & & & & & & & \\
\hline Gr. menardii Sin & & & & & & & & & & & & & & & & & & & & 1 & & 1 & & \\
\hline Gr. menardii $D x$ & & & & & & & & & & & & & & & & 1 & & 2 & & & & & & \\
\hline Gr. scitula Sin & 2 & 1 & & 3 & 3 & 2 & & & & 1 & & & & & & 1 & 1 & 2 & 3 & 6 & & 5 & & \\
\hline Gr. scitula $D X$ & & 1 & & & 2 & 1 & & & & & 1 & & & & 1 & 3 & & 2 & 1 & & & 1 & & \\
\hline N. acostaensis Sin & 23 & 27 & 11 & 8 & 23 & 9 & 3 & 6 & 5 & 9 & 2 & 5 & 14 & 3 & 6 & 13 & 4 & 19 & 12 & 23 & 6 & 28 & & \\
\hline N. acostaensis $D x$ & 36 & 21 & 27 & 38 & 56 & 46 & 14 & 23 & 24 & 26 & 10 & 21 & 29 & 8 & 12 & 15 & 15 & 27 & 22 & 28 & 8 & 39 & & \\
\hline Sphaeroidinellopsis & & & 2 & & 1 & 2 & & 1 & & 2 & & 5 & & 1 & 8 & 1 & 2 & & 1 & 1 & 1 & 1 & & \\
\hline Dentoglobigerina altispira & & & 5 & 1 & 6 & 5 & 1 & 2 & 2 & 4 & 3 & 8 & 4 & 2 & 3 & 5 & 20 & 1 & 4 & 6 & 2 & 1 & & \\
\hline Grupo Gs.saculifer & & 7 & 1 & 3 & 4 & 8 & 5 & 12 & 16 & 6 & 12 & & 3 & 1 & 3 & 2 & 2 & 1 & & 5 & 5 & 2 & 2 & 1 \\
\hline O.universa & 15 & 9 & 15 & 26 & 18 & 17 & 18 & 9 & 16 & 7 & 11 & 14 & 11 & 7 & 21 & 19 & 28 & 13 & 24 & 16 & 12 & 16 & 9 & 2 \\
\hline Gg. (Zg.) druryi & 1 & & & & 3 & & & 2 & & & 2 & & 3 & 2 & 12 & 6 & 3 & 2 & & 3 & & 4 & 1 & \\
\hline Parcial Globort. & 9 & 5 & 9 & 7 & 15 & 15 & 1 & & 3 & 7 & 4 & 2 & 1 & 6 & 18 & 13 & 12 & 12 & 8 & 8 & & 12 & 1 & 3 \\
\hline Resto de planc. & 132 & 168 & 125 & 159 & 186 & 244 & 152 & \begin{tabular}{|l|l|l|l|l|}
127 \\
\end{tabular} & 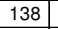 & 109 & 123 & 160 & 120 & 128 & 163 & 124 & 93 & 173 & 105 & \begin{tabular}{|l|l|l|l|l|l}
178 \\
\end{tabular} & 57 & 215 & 19 & 7 \\
\hline TOTAL Planc. & 216 & 237 & 195 & 242 & 312 & 346 & 194 & 182 & 204 & 170 & 167 & 215 & 185 & 158 & 246 & 198 & 179 & 248 & 176 & 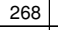 & 91 & 318 & 32 & 13 \\
\hline \multirow{2}{*}{\multicolumn{25}{|c|}{ PORCENTAJE PLANCTÓNICOS }} \\
\hline & & & & & & & & & & & & & & & & & & & & & & & & \\
\hline$\%$ Gr. margaritae Sin & \begin{tabular}{|l|}
3.24 \\
\end{tabular} & 1.27 & 4.62 & \begin{tabular}{|l|}
1.24 \\
\end{tabular} & 2.56 & 3.47 & 0.52 & & \begin{tabular}{|l|l|}
1.47 \\
\end{tabular} & 2.94 & 1.8 & 0.93 & 0.54 & 3.8 & \begin{tabular}{|l|l|}
6.91 \\
\end{tabular} & 2.53 & 5.03 & \begin{tabular}{|l|l|}
0.81 & - \\
\end{tabular} & 2.27 & & & 1.57 & 3.13 & 23.1 \\
\hline$\%$ Gr. margaritae $D x$ & & & & 0.41 & & & & & & & & & & & & & & & & & & & & \\
\hline$\%$ Gr.miotumida Sin & & & & & 0.64 & & & & & & & & & & & 1.01 & 1.12 & 1.61 & & \begin{tabular}{|l|l|l|l}
0.37 \\
\end{tabular} & & & & \\
\hline$\%$ Gr.miotumida $D x$ & & & & & & & & & & 0.59 & & & & & & 0.51 & & & & & & & & \\
\hline$\%$ Gr. menardii Sin & & & & & & & & & & & & & & & & & & & & \begin{tabular}{|l|l|l|}
0.37 \\
\end{tabular} & & 0.31 & & \\
\hline$\%$ Gr. menardii $D x$ & & & & & & & & & & & & & & & & 0.51 & & 0.81 & & & & & & \\
\hline$\%$ Gr. scitula Sin & 0.93 & 0.42 & & 1.24 & 0.96 & 0.58 & & & & 0.59 & & & & & & 0.51 & 0.56 & 0.81 & 1.7 & 2.24 & & 1.57 & & \\
\hline$\%$ Gr. scitula $D X$ & & 0.42 & & & 0.64 & 0.29 & & & & & 0.6 & & & & 0.41 & 1.52 & & 0.81 & 0.57 & & & 0.31 & & \\
\hline$\%$ N. acostaensis Sin & 10.6 & 11.4 & 5.64 & 3.31 & 7.37 & 2.6 & 1.55 & \begin{tabular}{|l|l|l|l|}
3.3 \\
\end{tabular} & 2.45 & 5.29 & 1.2 & 2.33 & 7.57 & 1.9 & 2.44 & 6.57 & 2.23 & 7.66 & 6.82 & \begin{tabular}{|l|l|}
8.58 \\
\end{tabular} & 6.59 & 8.81 & & \\
\hline$\% N$. acostaensis $D x$ & \begin{tabular}{|l|}
16.7 \\
\end{tabular} & 8.86 & 13.8 & \begin{tabular}{|l|}
15.7 \\
\end{tabular} & 17.9 & 13.3 & 7.22 & 12.6 & 11.8 & 15.3 & 5.99 & 9.77 & 15.7 & 5.06 & \begin{tabular}{|l|l|l|}
4.88 \\
\end{tabular} & 7.58 & 8.38 & 10.9 & 12.5 & \begin{tabular}{|l|l|}
10.4 \\
\end{tabular} & 8.79 & 12.3 & & \\
\hline$\%$ Sphaeroidinellopsis & & & 1.03 & & 0.32 & 0.58 & & 0.55 & & 1.18 & & \begin{tabular}{|l|l|l}
2.33 \\
\end{tabular} & & 0.63 & \begin{tabular}{|c|}
3.25 \\
\end{tabular} & 0.51 & 1.12 & & 0.57 & 0.37 & \begin{tabular}{|l|}
1.1 \\
\end{tabular} & 0.31 & & \\
\hline \% Dentoglobigerina altispira & & & 2.56 & 0.41 & 1.92 & 1.45 & 0.52 & 1.1 & 0.98 & 2.35 & 1.8 & \begin{tabular}{|l|l|}
3.72 \\
\end{tabular} & 2.16 & 1.27 & 1.22 & 2.53 & 11.2 & \begin{tabular}{|l|l|}
0.4 \\
\end{tabular} & 2.27 & \begin{tabular}{|l|l|}
2.24 \\
\end{tabular} & 2.2 & 0.31 & & \\
\hline \% Grupo Gs.saculifer & & 2.95 & 0.51 & \begin{tabular}{|l|}
1.24 \\
\end{tabular} & 1.28 & 2.31 & 2.58 & \begin{tabular}{|l|l|}
6.59 \\
\end{tabular} & \begin{tabular}{|l|}
7.84 \\
\end{tabular} & 3.53 & 7.19 & & 1.62 & 0.63 & \begin{tabular}{|l|}
1.22 \\
\end{tabular} & 1.01 & 1.12 & \begin{tabular}{|l|l|}
0.4 \\
\end{tabular} & & \begin{tabular}{|l|}
1.87 \\
\end{tabular} & \begin{tabular}{|l|}
5.49 \\
\end{tabular} & 0.63 & 6.25 & 7.69 \\
\hline$\%$ O.universa & 6.94 & 3.8 & 7.69 & \begin{tabular}{|l|}
10.7 \\
\end{tabular} & 5.77 & 4.91 & 9.28 & 4.95 & 7.84 & 4.12 & 6.59 & 6.51 & 5.95 & 4.43 & 8.54 & 9.6 & 15.6 & 5.24 & 13.6 & \begin{tabular}{|l|l|}
5.97 \\
\end{tabular} & \begin{tabular}{|l|}
13.2 \\
\end{tabular} & 5.03 & 28.1 & 15.4 \\
\hline \% Gg. (Zg.) druryi & 0.46 & & & & 0.96 & & & 1.1 & & & 1.2 & & 1.62 & 1.27 & \begin{tabular}{|l|l|}
4.88 \\
\end{tabular} & 3.03 & 1.68 & 0.81 & & \begin{tabular}{|l|l|}
1.12 \\
\end{tabular} & & \begin{tabular}{|l|}
1.26 \\
\end{tabular} & 3.13 & \\
\hline \% Globorotálidos & \begin{tabular}{|l|l|}
4.17 \\
\end{tabular} & 2.11 & 4.62 & 2.89 & 4.81 & 4.34 & 0.52 & & \begin{tabular}{|l|l|}
1.47 \\
\end{tabular} & 4.12 & 2.4 & \begin{tabular}{|l|l|}
0.93 \\
\end{tabular} & 0.54 & 3.8 & \begin{tabular}{|l|l|}
7.32 \\
\end{tabular} & 6.57 & 6.7 & \begin{tabular}{|l|}
4.84 \\
\end{tabular} & 4.55 & \begin{tabular}{|l|l|}
2.99 \\
\end{tabular} & & 3.77 & 3.13 & 23.1 \\
\hline$\%$ N. acostaensis & 27.3 & 20.3 & 19.5 & 19 & 25.3 & 15.9 & 8.76 & \begin{tabular}{|l|}
15.9 \\
\end{tabular} & 14.2 & 20.6 & 7.19 & 12.1 & 23.2 & 6.96 & 7.32 & 14.1 & 10.6 & 18.5 & 19.3 & 19 & 15.4 & 21.1 & & \\
\hline$\%$ Resto: & 61.1 & 70.9 & 64.1 & 65.7 & 59.6 & 70.5 & 78.4 & 69.8 & 67.6 & 64.1 & 73.7 & \begin{tabular}{|l|l|}
74.4 \\
\end{tabular} & 64.9 & 81 & \begin{tabular}{|l|}
66.3 \\
\end{tabular} & 62.6 & 52 & \begin{tabular}{|c|}
69.8 \\
\end{tabular} & 59.7 & \begin{tabular}{|l|l|}
66.4 & - \\
\end{tabular} & \begin{tabular}{|l|}
62.6 \\
\end{tabular} & 67.6 & 59.4 & 53.8 \\
\hline$\%$ Plan / foram & 39 & 33.7 & 34.2 & 40.9 & 38.7 & 39.5 & 29.3 & 44.7 & 32.6 & 36.8 & 40 & 45.4 & 36.9 & 43.4 & 49.9 & 57.9 & 51.4 & 61.8 & 36.4 & 100 & 21.2 & 39.1 & 12 & 22.4 \\
\hline \multicolumn{25}{|l|}{ PARCIAL Globorotálidos } \\
\hline$\%$ Gr. margaritae Sin & \begin{tabular}{|l|}
77.8 \\
\end{tabular} & 60 & 100 & \begin{tabular}{|l|}
42.9 \\
\end{tabular} & 53.3 & 80 & 100 & & \begin{tabular}{|l|l|}
100 \\
\end{tabular} & 71.4 & 75 & \begin{tabular}{|l|l|}
100 \\
\end{tabular} & 100 & 100 & 94.4 & 38.5 & 75 & \begin{tabular}{|l|}
16.7 \\
\end{tabular} & 50 & & & 41.7 & 100 & 100 \\
\hline$\%$ Gr. margaritae $D x$ & & & & \begin{tabular}{|l|}
14.3 \\
\end{tabular} & & & & & & & & & & & & & & & & & & & & \\
\hline$\%$ Gr.miotumida Sin & & & & & 13.3 & & & & & & & & & & & 15.4 & 16.7 & 33.3 & & \begin{tabular}{|l|}
12.5 \\
\end{tabular} & & & & \\
\hline \% Gr.miotumida $D x$ & & & & & & & & & & 14.3 & & & & & & 7.69 & & & & & & & & \\
\hline$\%$ Gr. menardii Sin & & & & & & & & & & & & & & & & & & & & \begin{tabular}{|l|l|l|}
12.5 \\
\end{tabular} & & 8.33 & & \\
\hline$\%$ Gr. menardii $D x$ & & & & & & & & & & & & & & & & 7.69 & & \begin{tabular}{|l|}
16.7 \\
\end{tabular} & & & & & & \\
\hline$\%$ Gr. scitula Sin & 22.2 & 20 & & 42.9 & 20 & 13.3 & & & & 14.3 & & & & & & 7.69 & 8.33 & \begin{tabular}{|c|}
16.7 \\
\end{tabular} & 37.5 & 75 & & 41.7 & & \\
\hline$\%$ Gr. scitula DX & & 20 & & & 13.3 & 6.67 & & & & & 25 & & & & \begin{tabular}{|l|l}
5.56 \\
\end{tabular} & 23.1 & & \begin{tabular}{|l|}
16.7 \\
\end{tabular} & 12.5 & & & 8.33 & & \\
\hline \% Globorotálidos & \begin{tabular}{|l|}
4.17 \\
\end{tabular} & 2.11 & 4.62 & \begin{tabular}{|l|}
2.89 \\
\end{tabular} & 4.81 & 4.34 & 0.52 & & \begin{tabular}{|l|l|}
1.47 & \\
\end{tabular} & 4.12 & 2.4 & \begin{tabular}{|l|l|l|l|l|}
0.93 \\
\end{tabular} & 0.54 & 3.8 & \begin{tabular}{|l|l|}
7.32 & -1 \\
\end{tabular} & 6.57 & 6.7 & 4.84 & 4.55 & \begin{tabular}{|l|}
2.99 \\
\end{tabular} & & 3.77 & 3.13 & 23.1 \\
\hline
\end{tabular}


SONDEO: SANTA CLARA-1

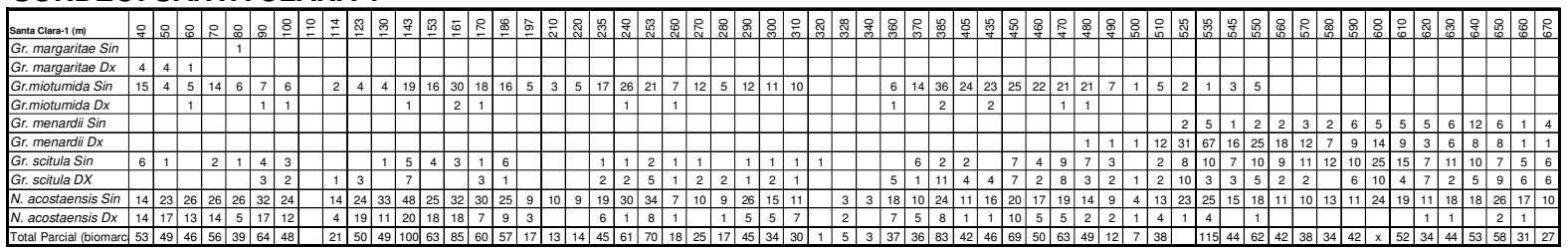




\section{MATRICES DE LA TOPOGRAFÍA DE LA CUENCA DURANTE EL TORTONIENSE-MESSINIENSE}

Las matrices se muestran sobre el mapa de la cuenca reflejando cada valor, la profundidad media del área circundante (unos $2 \mathrm{Km}^{2}$ ). La primera de las matrices (tabla 1) corresponde al comienzo de la transgresión del Tortoniense superior (equivalente en Guadalquivir a las "arenas basales") (Edad 8-7.5 Ma?). La segunda matriz (tabla 2), está elaborada a partir de las profundidades a las que se encuentra el evento E3 (reemplazamiento del grupo de G. menardii dx por G. miotumida hace $7.24 \mathrm{Ma}$ ) en los sondeos estudiados, teniendo en cuenta también los afloramientos de campo en los que aparece dicho evento. Corresponde al límite Tortoniense-Messiniense. La localización del cambio de enrollamiento de $N$. acostaensis (6.35 Ma) en la práctica totalidad de sondeos analizados, ha permitido elaborar la tercera matriz de datos (tabla 3 ) en función de la cual se han elaborado los mapas de isobatas correspondientes a este evento. El último de los eventos utilizados en esta reconstrucción ha sido la primera aparición común $(F C O)$ del grupo de G. margaritae (6.05 Ma), que constituye otro de los eventos mejor representados en el arena estudiada. Este evento ha permitido elaborar una matriz que aparece en la figura (tabla 4), en la que se ha basado el correspondiente mapa de isobatas (capítulo 7). 


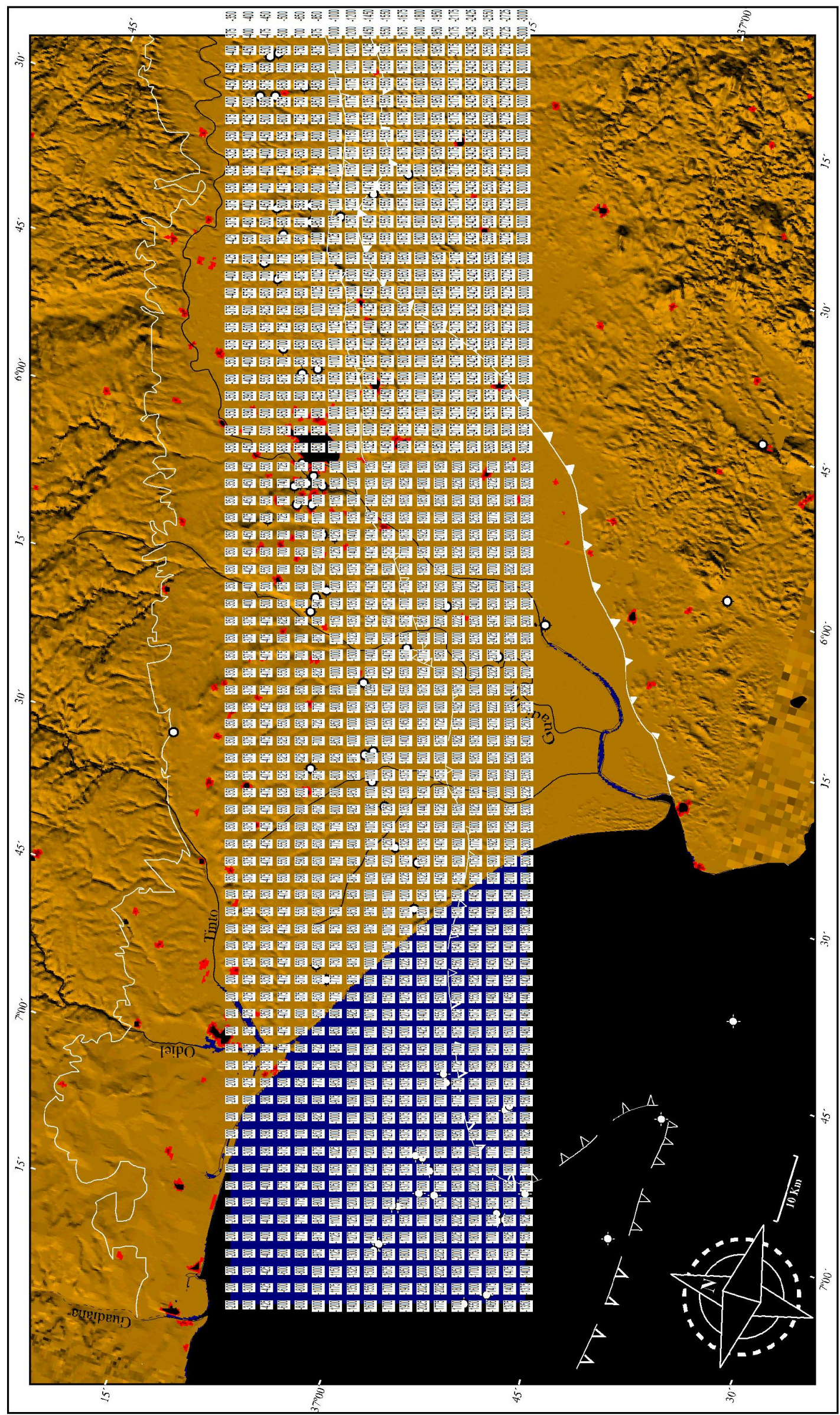

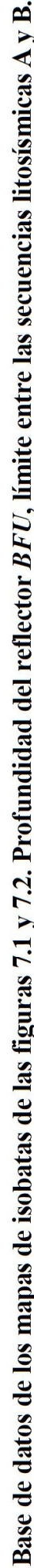




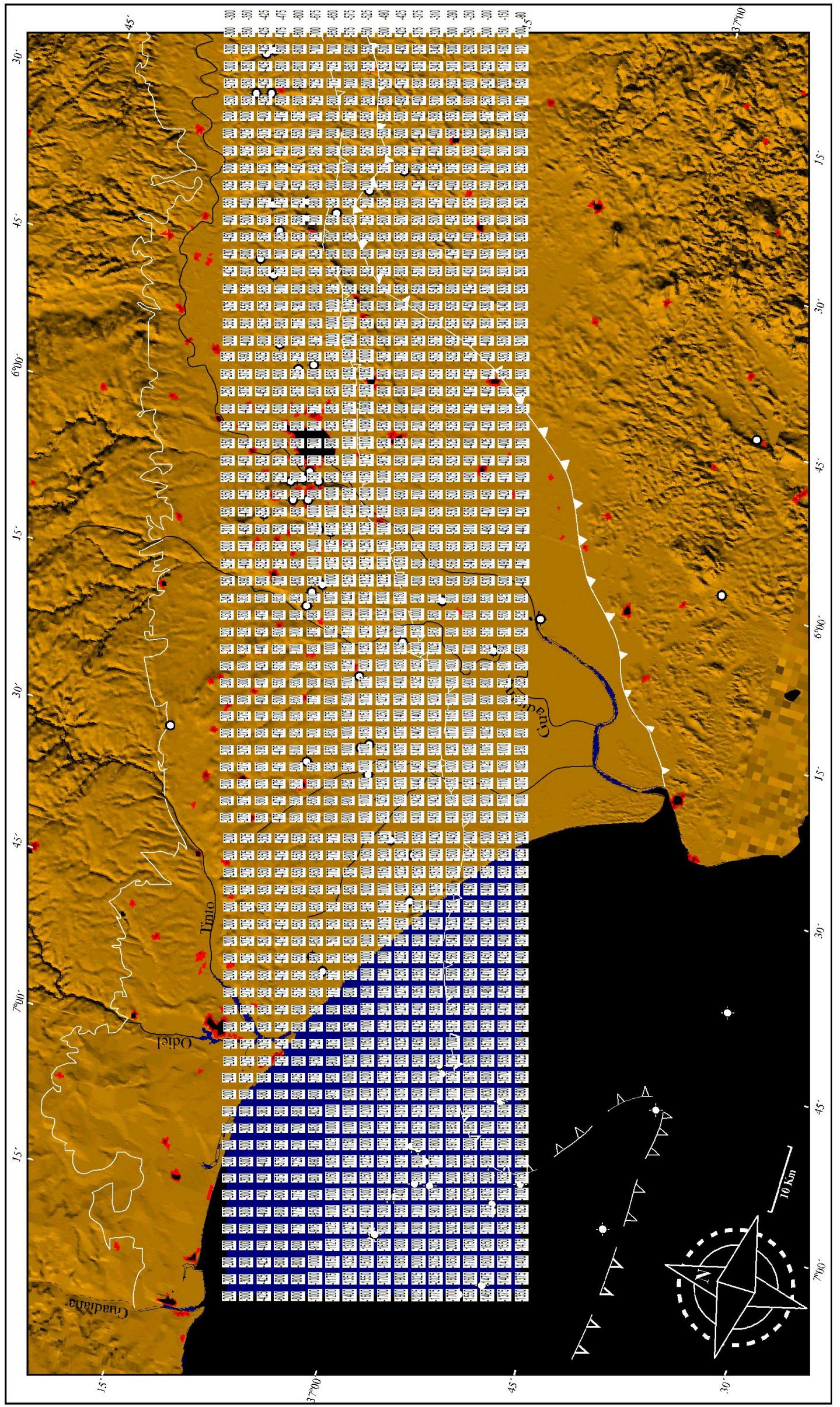

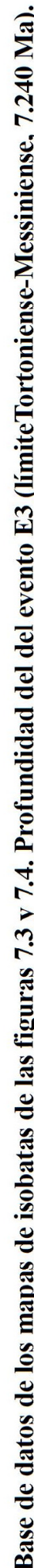




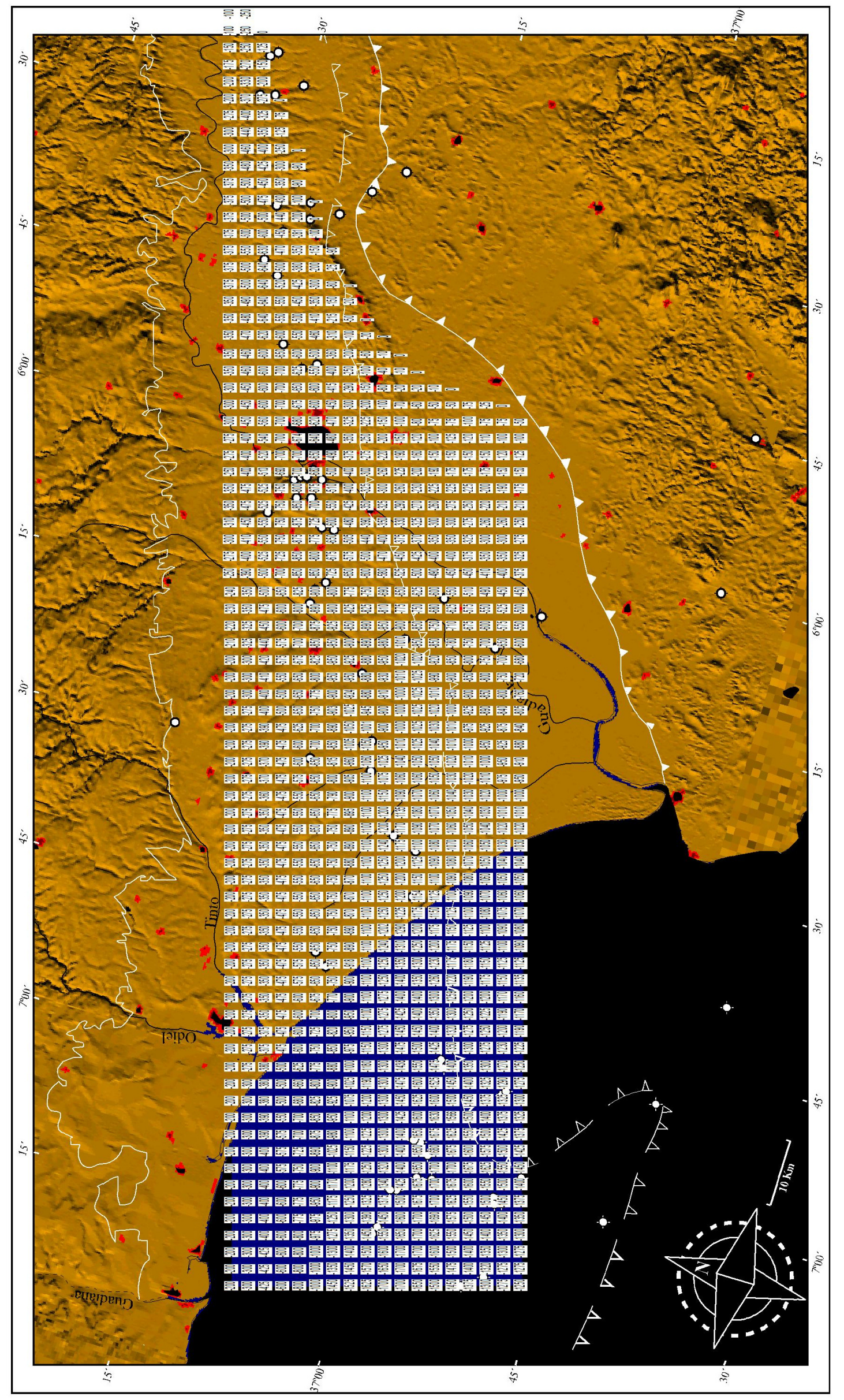

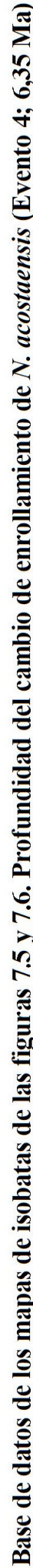




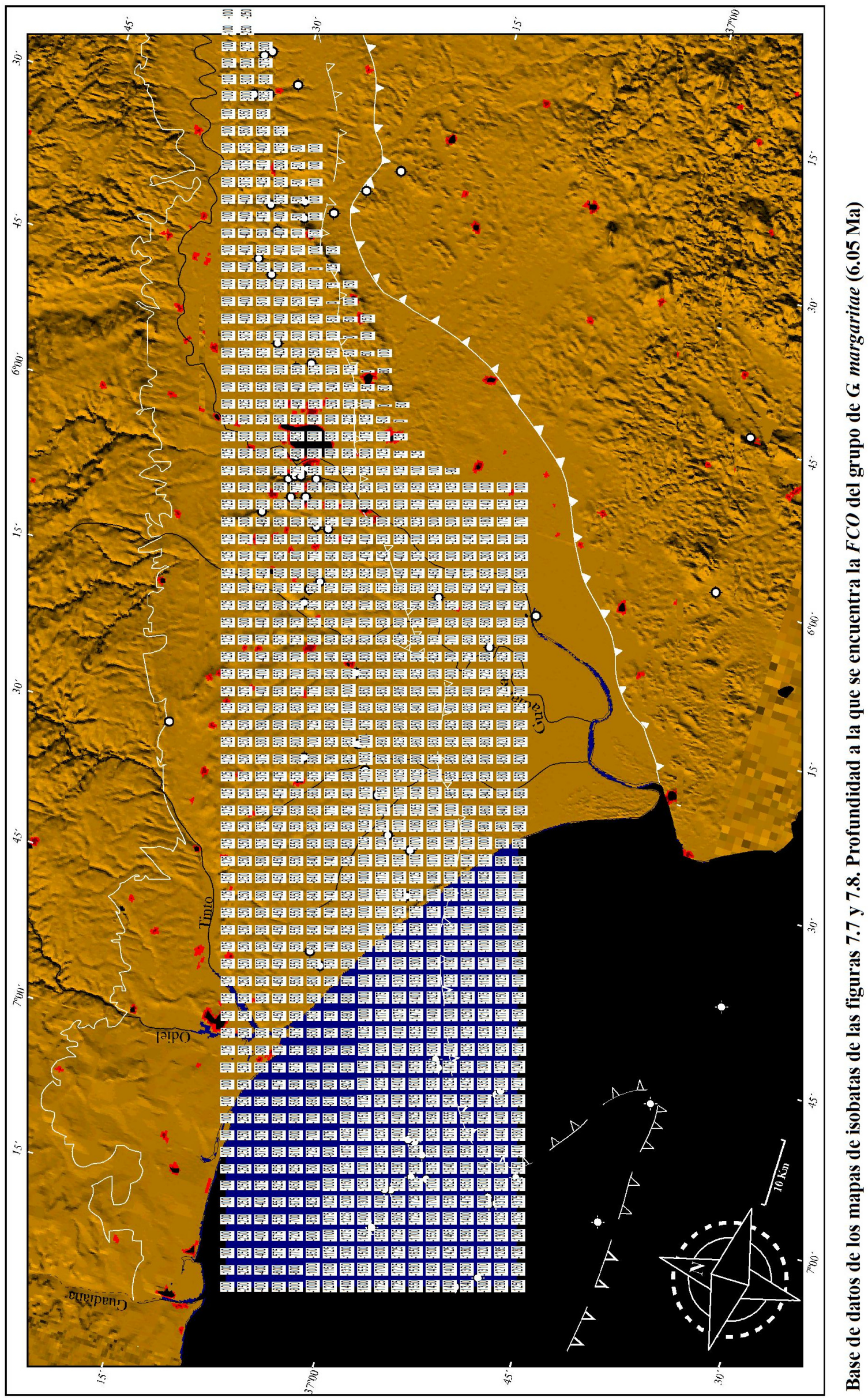




\section{MICROPALEO-2000, TÉCNICAS INFORMÁTICAS DE APOYO}

\section{Requisitos y configuración del sistema}

MICROPALEO-2000, es una aplicación programada mediante Visual Basic, que trabaja sobre una hoja de calculo Microsoft Excel (versión 8.0 o superior). Una vez completada la base de datos de un sondeo, podemos utilizar directamente la capacidad que ofrece Microsoft Excel para crear gráficos y representaciones de los datos obtenidos. Trabajar con un número elevado de fotografías y controles como es el caso de MICROPALEO-2000, consume abundantes recursos del sistema, de modo que necesitaremos un ordenador con unas características mínimas para trabajar con comodidad. Un monitor de gran formato es muy recomendable ya que nuestro campo de trabajo será mayor.

\section{Requerimientos de software:}

Windows 95, 98, Me. Windows NT.

Microsoft Excel 97/2000

\section{Equipo mínimo:}

CPU: Pentium 100 (mínimo).

Puede trabajar directamente desde el CD-ROM o cargar el archivo en su disco duro. Para ejecutarlo directamente desde el CD-ROM es recomendable una unidad de lectora de al menos 16x.

Tarjeta de video VGA 256 colores.

\section{Equipo recomendado:}

MICROPALEO-2000 se ha evaluado satisfactoriamente en sistemas con las siguientes características: Ordenador PC compatible con procesador Pentium 200 MMX, 64 Mb de memoria RAM y 4 Mb de memoria de vídeo. Resolución de 1024 x 768, a color de alta densidad (16 bits).

Cualquier configuración superior proporcionará buenos resultados. Configuraciones inferiores pueden traducirse en una ralentización de las operaciones. 


\section{Instrucciones de instalación}

Para trabajar directamente desde el CD-ROM, introducir el CD-ROM en la unidad correspondiente. Si tiene habilitada la función de autoarranque del $\mathrm{CD}$, se ejecutará automáticamente la presentación de la Tesis. Desde la pantalla de presentación podemos acceder directamente al programa Micropaleo-2000. También podemos buscar en el CDROM el archivo "Microp" y copiarlo en el disco duro del ordenador. Pulsando dos veces sobre "Microp" ejecutaremos la aplicación.

\section{Configuración del programa}

Es conveniente adecuar el programa a las condiciones propias de cada ordenador. Con un poco de práctica, el recuento de individuos puede llegar a ser en algunos momentos superior a 1 individuo / segundo. Si la configuración de nuestra computadora no es suficientemente potente, podemos recurrir a algunos trucos a fin de incrementar su rendimiento. Para que el recuento de individuos se produzca con mayor rapidez podemos agilizar el trabajo del procesador y de la tarjeta gráfica del ordenador si disminuimos la cantidad de colores con los que trabajan. Si trabajamos habitualmente con "color auténtico (32 bits)", podemos reducir la configuración de la pantalla a "color auténtico (24 bits)" a "color de alta densidad (16 bits)" o excepcionalmente a "256 colores", notaremos de este modo un notable incremento en la velocidad de procesado. Así mismo si fuera necesario, podemos disminuir la resolución gráfica a 800 x 600 (configuración mínima recomendada) para reducir el trabajo de nuestro ordenador. Si a pesar de ello conseguimos superar al ordenador, no es necesario que paremos el recuento. Podemos seguir contabilizando otros individuos ya que el ordenador utilizará su memoria RAM para seguir trabajando con los datos en un segundo plano.

Al ejecutar el programa, este arrancará Microsoft Excel y a continuación mostrará una pantalla de presentación (fig. A1). En la pantalla de presentación de MICROPALEO2000 pulsar sobre la imagen (vista de la torre de perforación del sondeo Santa Clara-1). Aparecerá a continuación una pantalla con gran cantidad de fotografías de foraminíferos (fig. A2). Sobre esta pantalla realizaremos las principales operaciones.

Junto a los habituales comandos de Excel, Micropaleo-2000 incorpora los menús: Comenzar, Ir a..., Ver..., $\underline{\text { Nuevo, Terminar. }}$

Al ejecutar Micropaleo-2000, es posible que Microsoft Excel pida nuestra confirmación para abrir el documento, ya que contiene macros. Debemos contestar afirmativamente para que el programa funcione correctamente. 


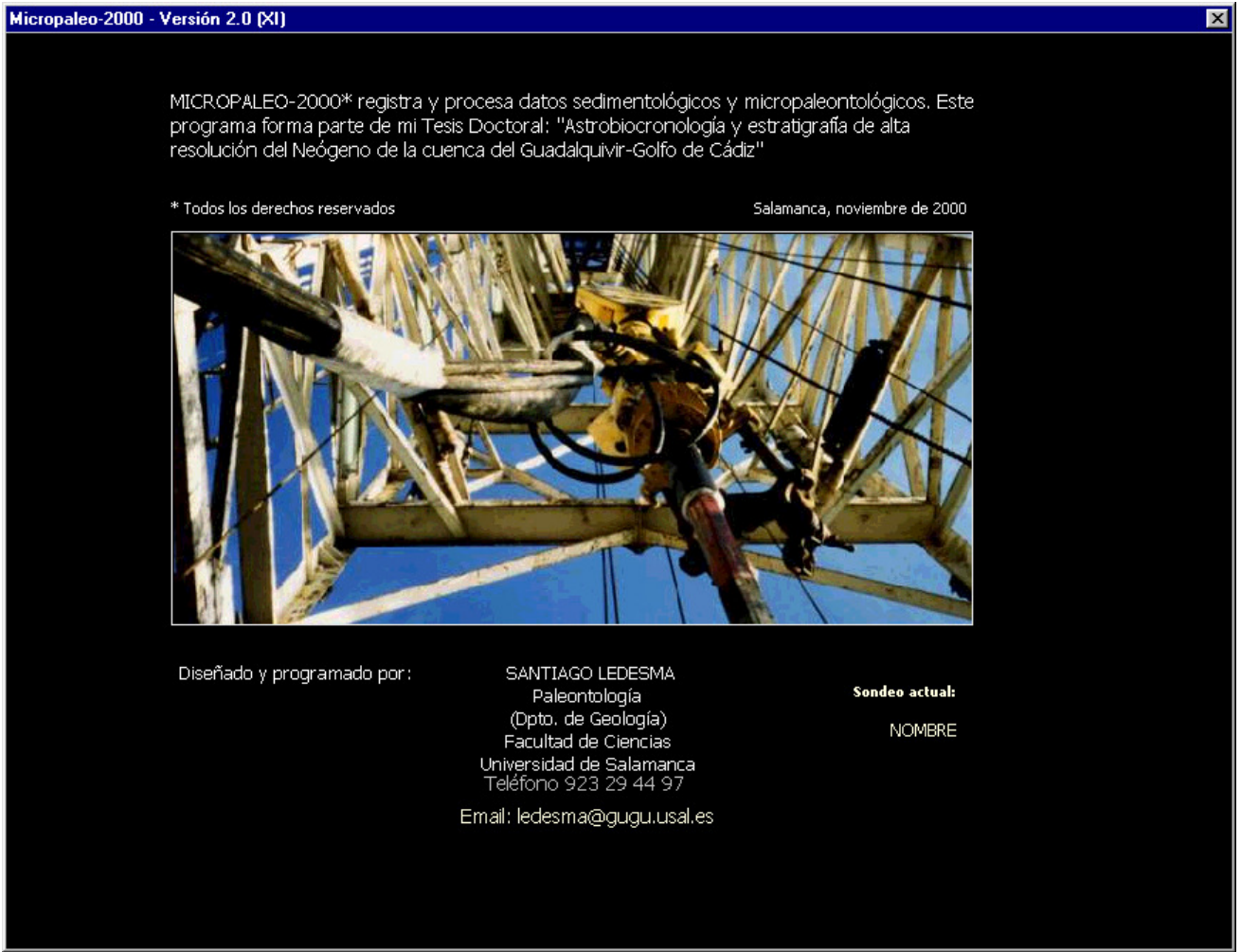

Figura A1. Pantalla de presentación del programa "Micropaleo-2000"

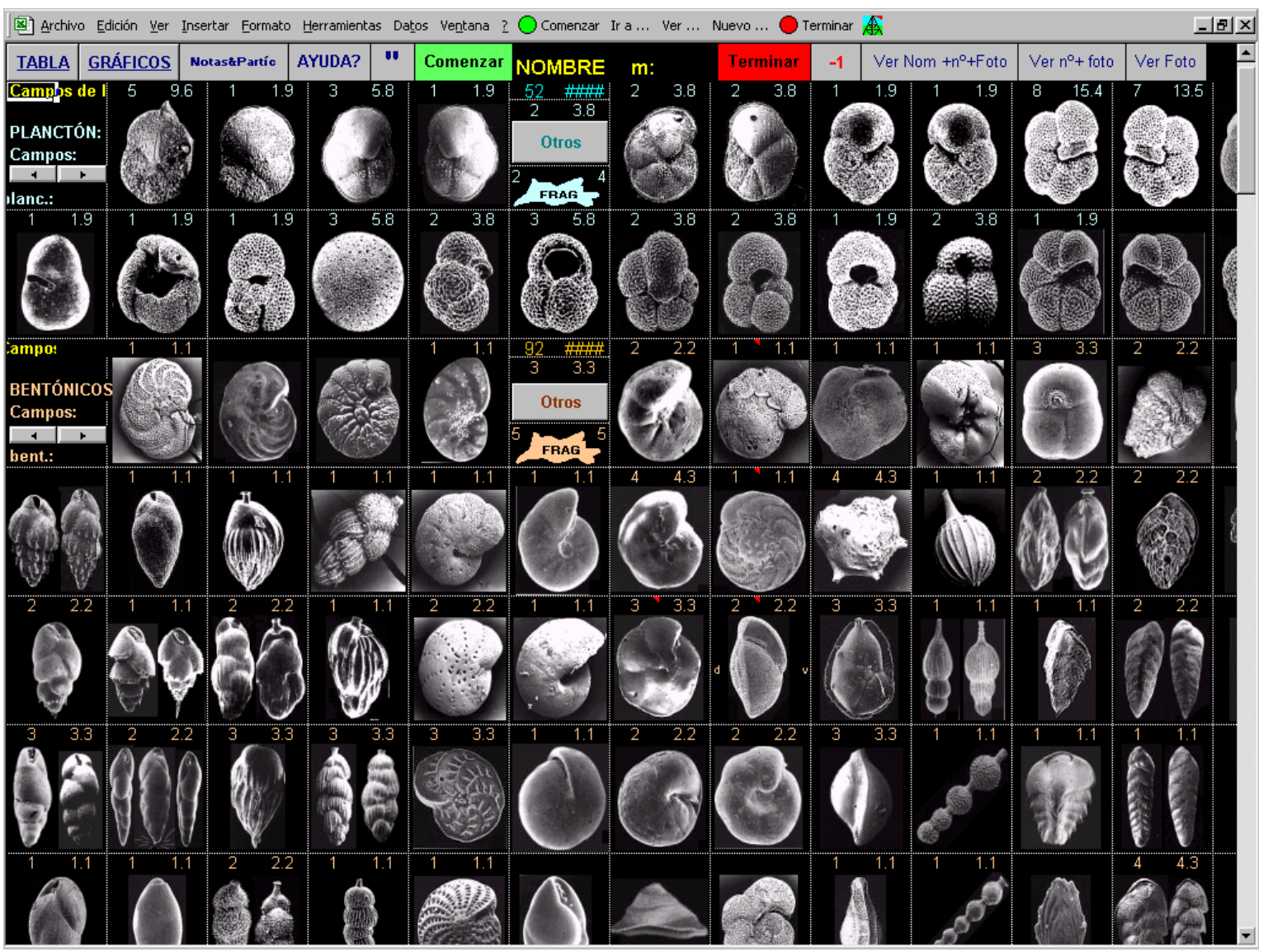

Figura A2. Pantalla principal de recuento de foraminíferos. 


\section{Trabajar con Micropaleo-2000}

\section{Un nuevo sondeo}

Junto a la tradicional barra de herreminentas de Microsoft Excel, aparecerá una serie de nuevos comandos. Para comenzar a trabajar con un nuevo sondeo, debemos pulsar sobre el comando: Nuevo / $\underline{\text { Sondeo }}$. En el cuadro de dialogo que aparece a continuación deberemos escribir el nombre del sondeo. Pulsando en Aceptar se actualizaran todos los contadores a 0 y a partir de ese momento se denominara el sondeo con el nombre que hayamos introducido.

\section{Una nueva muestra}

Cuando queramos iniciar el análisis de una muestra pulsaremos sobre el comando Comenzar (en verde). Un mensaje de aviso nos pide nuestra confirmación para borrar los datos existentes y actualizar los contadores. Después de confirmar la operación, el programa nos mostrará un cuadro de diálogo en el que se solicita la profundidad de la muestra y el rango del sedimento (los tamices utilizados). Después deberemos indicar si se trata de una muestra tipo cutting (ripio) o bien de una muestra procedente de un testigo. En este último caso el programa nos pedirá a continuación el peso (en gramos) de la muestra inicial, así como el peso de la fracción tamizada y el número de campos (unidades de superficie) que presenta la fracción. En el cuadro de dialogo que aparecerá a continuación realizaremos el recuento de partículas.

\section{Recuento de partículas}

El recuento de partículas (fig. A3) está basado en un recuento visual de las diferentes partículas que componen la muestra. Aparecerán en pantalla una serie de controles: "Forams" (Foraminíferos), "Ostrácodos", "Espículas de equinodermo" y "Otros bioclastos" en un primer apartado denominado "Bioclastos". Debajo, en el apartado "Terrígenos" aparecen los controles para contabilizar las partículas de "Arena", "Glauconita", "Pirita" o de "Otros terrígenos" que aparezcan en la muestra. Pulsando sobre cualquiera de los contadores sumaremos una unidad en la casilla correspondiente sumando así mismo una unidad al contador global de partículas que aparece a la derecha. Con estos datos el programa calcula los porcentajes relativos de los diferentes tipos de partículas que componen la muestra. Estos porcentajes aparecerán en la columna correspondiente a la muestra, una vez concluido el recuento de foraminíferos. 
En el apartado "Notas Muestra", podemos introducir un comentario o descripción de la muestra y en el apartado "Notas Foraminíferos" podemos añadir comentarios respecto al estado de conservación, retrabajado, etc. Los comentarios que hayamos introducido sobre la muestra y los foraminíferos, serán incorporados a modo de texto en la base de datos de cada muestra.

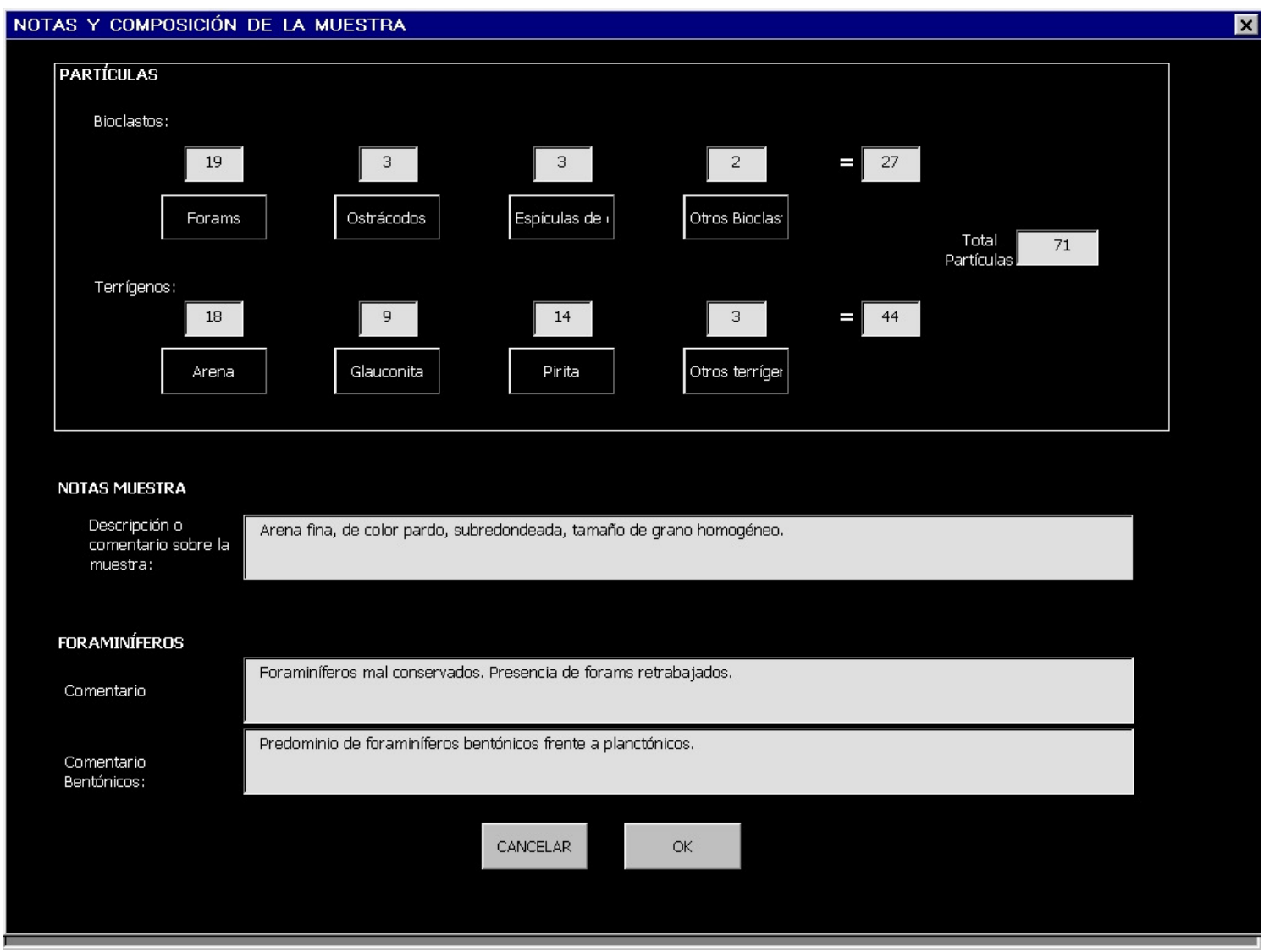

Figura A3. Pantalla principal del recuento de partículas.

\section{Recuento de foraminíferos}

Una vez rellenada total o parcialmente la sección anterior, se procede al chequeo de los foraminíferos (fig. A2). Para contabilizar un individuo solo deberemos pulsar sobre la fotografía correspondiente.

La hoja del chequeo está compuesta de dos partes. En la parte superior aparecen los foraminíferos planctónicos que se encuentran ordenados para facilitar la identificación visual, agrupados por formas similares, grupos o familias. Por ejemplo, los globorotálidos se encuentran en la primera fila, y las especies en las cuales es importante la determinación 
del sentido de enrollamiento, se encuentra colocadas por parejas. Debajo de los foraminíferos planctónicos, y diferenciados por el color de los bordes, se encuentran los foraminíferos bentónicos. En este grupo también se han distribuido los foraminíferos según la familia o grupo a la que pertenecen (a la izquierda pueden observarse ordenados verticalmente, bulimínidos, uvigerínidos...) o en función de morfologías similares.

En el comando "Otros" iremos sumando los ejemplares no determinados, que no obstante se incorporarán al numero de foraminíferos observados. El numero de fragmentos de foraminíferos planctónicos o bentónicos puede ser interesante en algunas ocasiones, como por ejemplo si queremos trabajar con índices de facturación y determinar grados de disolución, etc., podemos contabilizar los fragmentos procedentes de ambos grupos pulsando en el botón "Frac." respectivo.

Si en cualquiera de las ocasiones nos hemos equivocado al pulsar sobre cualquiera de las imágenes-contadores, podemos rectificar rápidamente si pulsamos sobre el comando “-1" de modo que se restara 1 en la casilla sobre la que nos encontremos en ese momento. Podemos hacerlo también manualmente mediante el teclado.

Cada vez que pulsamos sobre un pulsador, el programa realiza los siguientes cambios: Suma un individuo en la casilla izquierda correspondiente a la imagen-pulsador sobre la que hallamos presionado (esta celda contabiliza el numero absoluto de individuos identificados), suma 1 individuo en el contador general de foraminíferos planctónicos o bentónicos, según el grupo al que pertenezca, y suma una unidad en el computo global de individuos contabilizados. Al mismo tiempo y teniendo en cuenta estos datos, calcula los porcentajes para los nuevos valores absolutos que acabamos de generar. Calcula entonces el porcentaje de dicha especie, genero o grupo respecto al total de foraminíferos planctónicos o bentónicos (según el caso) y así mismo incrementa el porcentaje del grupo al que pertenezca (plancton / bentos) respecto al total de foraminíferos (100\%). En el caso de los globorotálidos calcula así mismo el porcentaje de la especie seleccionada respecto al total de globorotálidos; este calculo será utilizado posteriormente para determinar la posición de algunos de los eventos utilizados en esta Tesis.

En general es importante alcanzar un numero determinado de individuos para que nuestras interpretaciones sean correctas. Si estudiamos ambos grupos (planctónicos y bentónicos) observaremos que en ocasiones, mientras rápidamente contabilizamos los suficientes individuos de uno de los grupos, del otro, apenas hemos identificado unos pocos ejemplares. Para solucionar este problema debemos introducir por separado el numero de campos o filas de la batea (en definitiva unidades de superficie) en las que hemos realizado el recuento. Así por ejemplo, en el caso de haber alcanzado un numero suficiente de planctónicos, podremos seguir contando bentónicos hasta alcanzar el numero 
conveniente. Al final del recuento, introduciremos el numero de áreas utilizadas en el recuento de planctónicos y el numero de áreas utilizadas en el recuento de bentónicos, para que el programa considere la abundancia relativa de cada uno de estos grupos. En el extremo superior izquierda de cada grupo aparece una celda para introducir el numero de áreas de cada grupo. Podemos ayudarnos de las flechas que aparecen debajo para incrementar o disminuir en una unidad el numero de campos utilizados para cada grupo.

Finalmente, una vez completados nuestros objetivos en la observación de la muestra pulsaremos sobre el comando "Terminar" con el objeto de que el programa fije los resultados. Si hemos olvidado alguno de los datos necesarios para el cálculo, el programa nos reclamará la información antes de realizar todos los cálculos y fijar los resultados de la muestra.

\section{Complementos}

En cualquier momento podemos volver sobre el recuento de partículas si queremos completar la información introducida al iniciar el estudio de la muestra, o si queremos anotar un comentario, alguna peculiaridad, o cualquier tipo de anotación. Para ello deberemos pulsar sobre el comando Ver / Notas\&Partículas.

Pulsando sobre el comando Ver / Ayuda obtendremos un resumen de cómo trabajar con el programa (fig. A4). Cuando necesite hacer una pausa en el análisis de una muestra puede pulsar sobre Ver / Pausa; dejando una nota, le servirá de referencia para retomar el recuento.

Aunque existen una serie de vistas predeterminadas en el comando "Ver". Existen varios modelos de visualizar el área de trabajo. En ocasiones necesitaremos chequear tanto foraminíferos planctónicos como bentónicos, otras veces trabajaremos solo con los foraminíferos planctónicos, o solo con los bentónicos. Podemos precisar nuestra forma de trabajar pulsando sobre los siguientes comandos:

El comando Ver / Texto $+\mathrm{n}^{\circ}+$ foto, permite observar además de las imágenes, las celdas en las que aparece el numero y porcentaje de individuos identificados así como el nombre de la especie, genero o grupo correspondiente. Sobre el nombre correspondiente a algunas imágenes aparece un pequeño triángulo rojo; en este caso, si colocamos sobre él el puntero del ratón, aparecerá un comentario sobre la especie correspondiente, generalmente orientado a conseguir su identificación y diferenciación de formas similares. Para alternar rápidamente entre el recuento de foraminíferos planctónicos y foraminíferos bentónicos podemos utilizar las teclas "Av Pág" y "Ret Pág" del teclado. 


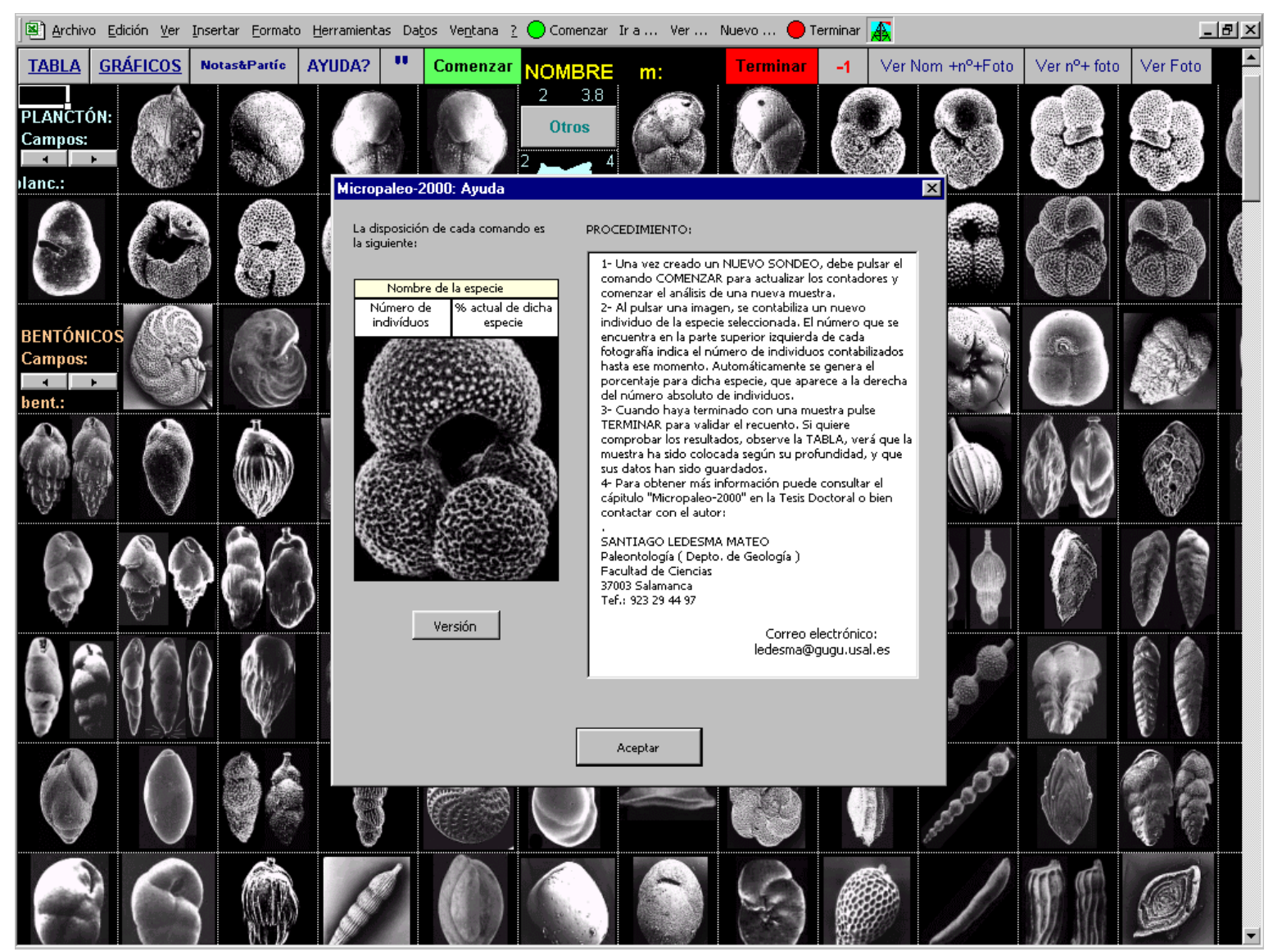

Figura A4. Pulsando la ayuda obtenemos instrucciones sobre las principales operaciones.

El comando $\underline{\mathrm{Ver} / \mathrm{n}^{\circ}+\text { foto, }}$, oculta las celdas correspondientes a los nombres de los foraminíferos, de forma que solo observamos la imagen y los contadores, pero permite observar mayor número de fotografías que del modo anterior.

El comando Ver / $\underline{\text { foto: }}$ Mostrara el mayor numero posible de pulsadores (fotografías) tanto de foraminíferos planctónicos como bentónicos (fig.A5). No serán visibles las casillas en las que aparecen el numero y porcentaje relativo de los individuos contabilizados, y tampoco el nombre de la especie, genero o grupo al que pertenezca la imagen-contador. Sin embargo esta opción, una vez que estemos familiarizados con los foraminíferos que aparecen en nuestras muestras, es la que ofrece el mayor área de trabajo posible. No obstante, en cualquiera de los casos podemos modificar la cantidad de controles visibles. Para ello, seleccionaremos el área concreta que queremos visualizar y pulsaremos sobre el comando de la barra de herramientas de Excel: Ver / Zoom... eligiendo la opción Ajustar la selección a la ventana. 
También podemos observar en cualquier momento la base de datos del sondeo que estamos creando, deberemos pulsar en ese caso el comando Ir a... / Tabla (fig.A6). Aparece una hoja de cálculo en la que se irán colocando ordenadamente los análisis micropaleontológicos de las muestras que vayamos introduciendo. Los valores de la muestra que se está estudiando en ese momento aparecerán provisionalmente en la primera columna por la izquierda. Para acceder a una hoja de cálculo vacía donde poder pegar los resultados y trabajar con ellos mediante gráficos, podemos pulsar sobre el comando Ir a / Gráficos. Para volver al recuento de foraminíferos en la muestra pulsaremos Ir a / Chequeo.

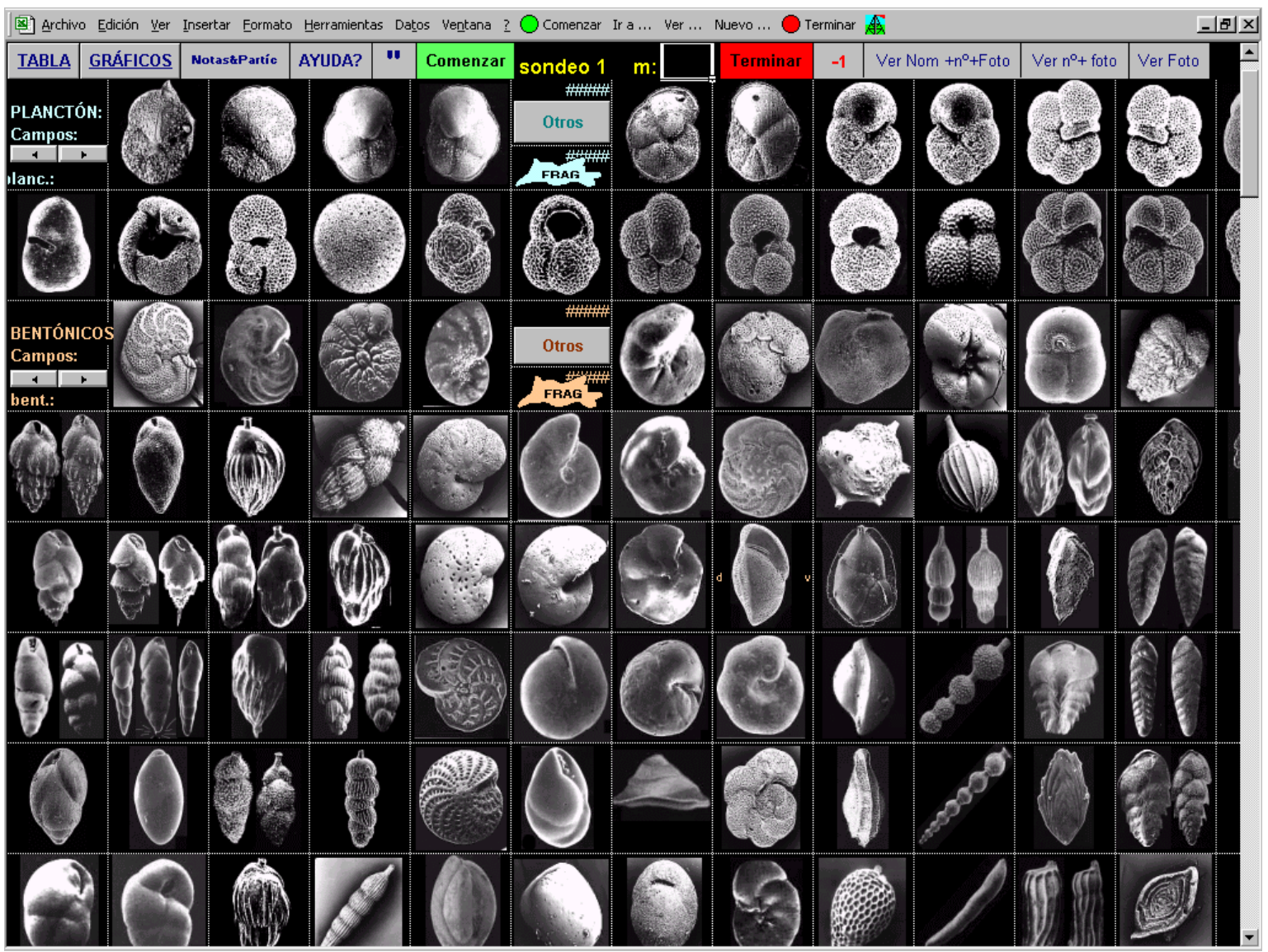

Figura A5. En la pantalla principal podemos trabajar con 92 especies diferentes al mismo tiempo .

\section{Base de datos}

Con toda la información que vamos introduciendo, el programa genera una base de datos de cada sondeo (ver figura A6) en la que coloca ordenadamente las muestras de izquierda a derecha en función de su profundidad creciente. El ordenamiento en 
profundidad se realiza indistintamente del orden en el que haya sido introducido el análisis de cada muestra. Por este motivo, siempre podremos volver al programa para incorporar por ejemplo el análisis de muestras intermedias.

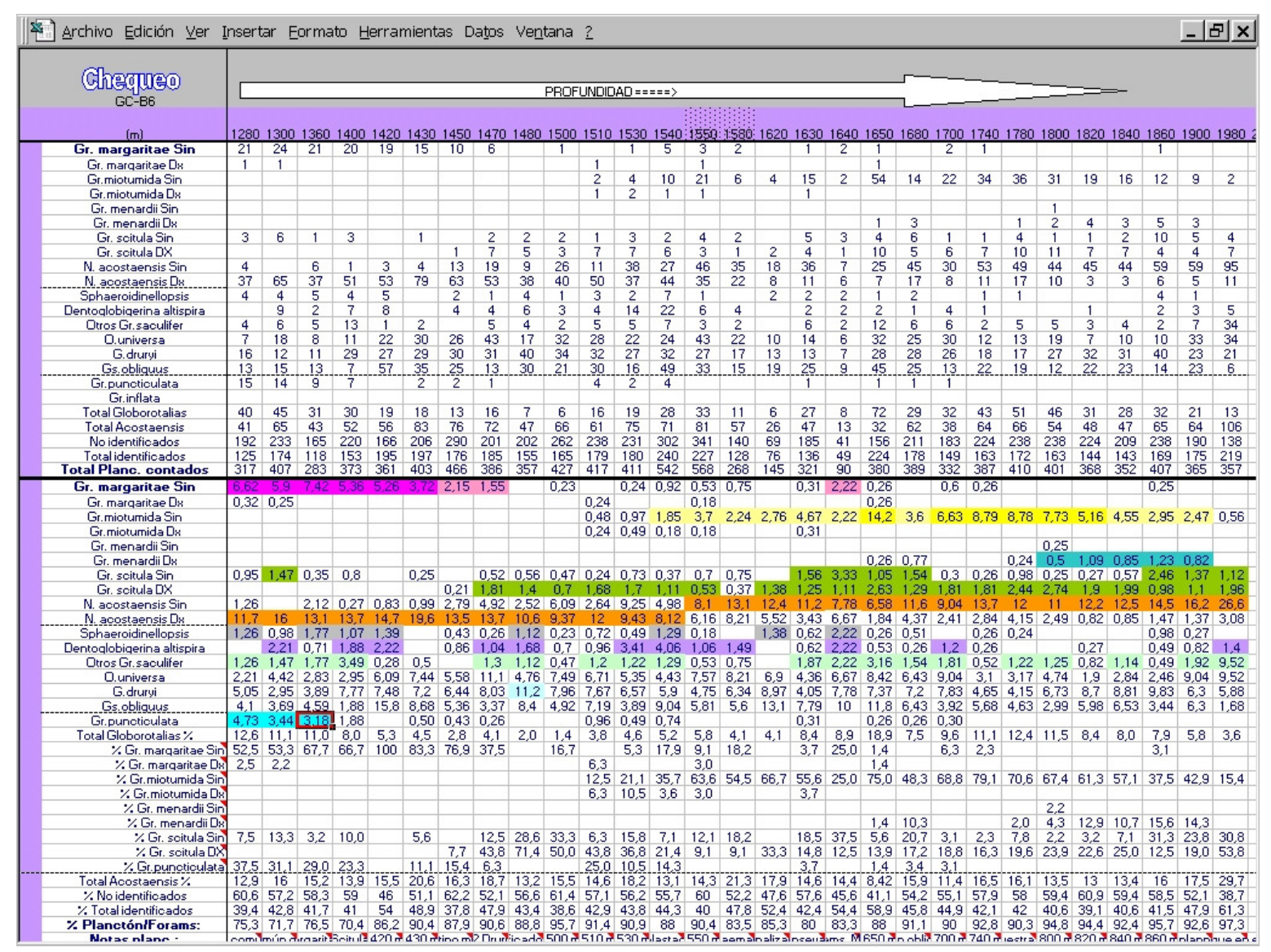

Figura A6. Base de datos creada en el sondeo B6.

En esta tabla, se irán colocando todos los valores y los resultados de los cálculos realizados por MICROPALEO-2000 mientras realizamos el chequeo. Cuando terminemos el chequeo de todas las muestras, resultará una base de datos similar a la que aparece en la figura A6. En esta tabla aparecerán todos los datos que hayamos introducido directamente durante los cuestionarios o mediante el recuento, pero además contendrá datos indirectos como son los distintos cálculos porcentuales. El programa estudia los valores absolutos obtenidos y genera nueva información con los valores proporcionados resaltando mediante colores los hechos mas significativos para calcular la edad de la muestra en función de la bioestratigrafía propuesta en la Tesis Doctoral (capítulo 3). Si está accediendo al programa desde el CD-ROM, puede consultar el resto de Tesis desde el comando Ir a.../Tesis. 
Entre otras notas, en la base de datos del sondeo aparecerán el peso de la muestra, la fracción analizada, comentarios, porcentaje de las partículas que componen la muestra, relación planctónicos / bentónicos de los foraminíferos que componen cada muestra, una relación de los fragmentos según su procedencia, etc.

En el caso de las muestras procedentes de testigos se añaden nuevos cálculos basados en el peso de la muestra. Para realizar estos cálculos será necesario haber introducido previamente el peso de la muestra y el numero de áreas total que ocupaba la muestra. De esta forma se obtienen los fragmentos de cada grupo por gramo de sedimento, los foraminíferos por gramo de sedimento, así como los foraminíferos planctónicos y los foraminíferos bentónicos por gramo de sedimento.

\section{Gráficos}

Una vez completada la base de datos del sondeo, con las muestra que hayamos utilizado, podemos realizar cualquiera de los gráficos y representaciones que permite Microsoft Excel. Podemos trabajar directamente desde la tabla que acabamos de crear, o copiar los datos y trasladarlos a una hoja de cálculo en blanco donde trabajar con los resultados obtenidos. Pulsaremos en este ultimo caso sobre el comando Ir a... / Gráficos para acceder a una hoja en blanco donde podemos construir y almacenar cualquier tipo de representación gráfica. 


\section{GLOSARIO}

Glosario de términos utilizados. Recopilación basada en Vera (1994), en el glosario de términos del Instituto Mexicano del Petróleo (http://www.imp.mx/) y en el manual de logging de ODP (Borehole Research Group, 1999) entre otras fuentes. Los diferentes terminos técnicos que aparecen en la Tesis están basados en las siguientes definiciones:

Acreción (accretion): Aumento de volumen gradual de un cuerpo sedimentario.

Acreción lateral (lateral accretion): Aumento de volumen gradual de un cuerpo sedimentario en sentido perpendicular a la dirección de las corrientes.

Analyseries (Macintosh Program Performs Time-Series Analysis): Programa informático para Macintosh que permite realizar el análisis espectral de una serie temporal. Para obtener más información acerca de este programa puede consultarse la dirección de internet: http://www.agu.org/eos_elec

Análisis de facies sísmicas (seismic facies analysis): Metodología que consiste en la descripción e interpretación estratigráfica y sedimentaria a partir de las características geométricas de las reflexiones que constituyen la secuencia sísmica.

Análisis de Fourier (Fourier analisys): El matemático francés Jean-Baptiste Joseph Fourier demostró, en 1807, que la curva de casi cualquier función podía representarse con el grado de aproximación que se deseara superponiendo curvas sinusoidales y cosinusoidales de diversas fases, amplitudes y frecuencias; este proceso constituye la llamada síntesis de Fourier. En el proceso inverso se descompone una curva compleja en ondas sinusoidales y cosinusoidales simples: la amplitud y la fase de cada componente de frecuencia se eligen de manera que la suma de las ondas dé la mejor aproximación posible a la curva medida. El resultado de un análisis de Fourier suele representarse en forma espectral dando la amplitud total en función de la frecuencia o del período. Se utiliza el análisis espectral para examinar la distribución de las frecuencia de las oscilaciones periódicas.

Análisis de secuencias sísmicas (seismic sequence analysis): Metodología que consiste en la subdivisión de la sección sísmica en conjuntos de depósitos limitados por superficies de discontinuidad y que comprende grupos de reflexiones más o menos concordantes y de características similares.

Análisis espectral (spectral analysis): Es la representación gráfica del resultado de un análisis de Fourier.

Afelio (Aphelion): El punto más lejano al Sol en la órbita de cualquier cuerpo celeste que gire alrededor de la estrella.

Agua Atlántica Modificada (Modified Atlantic Water; MAW): se trata de una masa de agua superficial atlántica confinada a los 150 metros superiores. Es ligera y fría. 
Agua Intermedia Levantina (Levantine Intermediate Water; LIW): Es una masa de agua mediterránea intermedia que ocupa el lecho entre 300 y 500 metros; es cálida y muy salada.

Agua Profunda Noratlántica (North Atlantic Deep Water; NADW): Es una masa de agua originaria del Atlántico Norte. Esta masa de agua invade la mayor parte de la cuenca Atlántica. Se origina en el mar de Noruega-Groenlandia y se compone de una mezcla de diversas masas de agua superficiales e intermedias: La Norwegian Sea Overflow Water (NSOW), la Labrador Sea Water (LSW) y la Mediterranean Sea Overflow Water $(M O W)$. En terminos generales se puede considerar unas caracteristicas propias de $\mathrm{T}=2,5^{\circ} \mathrm{C} ; \mathrm{S}=34 \%$, Tolmazin, 1985 (En Francés, 1992). La $N A D W$ circula hacia el Sur por todo el Atlántico profundo hasta que es captada por la Corriente Circumpolar Antártica. En el Mediterráneo, se encuentra a unos 200 metros por debajo de la masa de agua Intermedia Levantina. Se trata de agua más fría y menos salada que la masa de agua Intermedia Levantina. Pero es más cálida y salada que la masa de agua Superficial Atlántica y que la Atlántica Modificada.

Agua Profunda del Mediterráneo Occidental (Western Mediterranean Deep Water; WMDW): Masa de agua densa y profunda confinada en el Mediterráneo occidental. Está separada de la EMDW por el umbral de Malta-Sicilia.

Agua Profunda del Mediterráneo Oriental (Eastern Mediterranean Deep Water; EMDW): Masa de agua densa y profunda confinada en el Mediterráneo oriental. Está separada de la $W M D W$ por el umbral de Malta-Sicilia.

Agua de Salida del Mediterráneo (Mediterranean Outflow Water; MOW): El flujo de agua del Mediterráneo que se desplaza hacia el Atlántico es consecuencia del exceso de evaporación en la cuenca Mediterránea. El balance salino del Mediterráneo se mantiene por un sistema de flujo con estrada de agua superficial atlántica y salida de aguas porfundas mediterráneas a través del extrehcho de Gibraltar (284 m de profundidad).

Agua Superficial Atlántica (North Atlantic Central Water; NACW): En la parte atlántica del estrecho de Gibraltar, es la masa de agua más superficial.

$\boldsymbol{A P I}$ : unidad estandard de medida de rayos gamma, establecida por el American Petroleum Institute.

APTS, escala de tiempo de polaridad astronómica (Astronomical Polarity Time Scales): Se trata de la escala magnetoestratigráfica calibrada mediante cicloestratigrafía astronómica.

Basamento (basement): Complejo indiferenciado de rocas infrayacentes a aquellas que tienen interés en una región. 
Bioestratigrafía (Bioestratigraphy): Estudio y organización de los estratos basándose en su contenido fósil. Ciencia intermedia entre la Estratigrafía y la Paleontología que se ocupa del estudio de la distribución temporal de los fósiles en el seno del registro estratigráfico.

Bioevento (bioevent): Acontecimiento biológico extraordinario detectado en el registro estratigráfico por cambios notables en el contenido paleontológico.

Biozona (biozone): Forma abreviada y de uso común del término zona bioestratigráfica que se aplica a cualquier tipo de unidad bioestratigráfica.

BCF, BPC o BN PC: Billón (10 9) pies cúbicos (pc), unidad de medida.

BP (Before Present): Unidad de tiempo en años antes de 1950.

Cambio relativo del nivel del mar (relative change of sea level): Fenómeno (alocíclico o autocíclico) de levantamiento y/o hundimiento del fondo marino y/o del nivel del mar, que queda reflejado en las secciones estratigráficas con secuencias de somerización, con secuencias de profundización o con discontinuidades.

Campo de gas (Gasfield): Un campo o grupo de yacimientos de hidrocarburos que contienen gas natural y cantidades insignificantes de aceite.

Circulación termohalina (thermohaline circulation): La circulación termohalina está inducida por el aumento de densidad de las aguas superficiales. Inmediatamente se produce su hundimiento creándose nuevas masas de agua intermedias y dejando sitio a masas de agua menos densas. Este proceso recibe el nombre de circulación termohalina y es el motor de la dinámica profunda. El aumento de densidad se lleva a cabo bien por evaporación superficial (Mediterráneo) o por procesos de convección invernal y de congelación (regiones subpolares y polares).

Compañía Multinacional (Multi-national company - MNC): Una compañía con inversiones y actividades operativas en muchos países alrededor del mundo.

Complejo de canales y diques (levee channel complex, lcc): sistema de depósito diferenciado dentro del cortejo de la cuña de nivel bajo y caracterizado por el dominio de turbiditas terrígenas delgadas intercaladas en sedimentos hemipelágicos y por la presencia de canales y diques.

Complejo progradante (prograding complex, pgc): sistema de depósito diferenciado dentro del cortejo de la cuña de nivel bajo y caracterizado por el dominio de la geometría sigmoidad de las capas.

Cortejo sedimentario (systems tract): Conjunto de sistemas de depósito contemporáneos y formados bajo unas mismas condiciones del nivel del mar. 
Cortejo de abanico submarino (lowstand fan systems tract, LSF): Tipo de cortejo sedimentario de nivel de mar bajo, constituido por los redepósitos derivados de la erosión de la plataforma y de las partes altas del talud, que forman un abanico submarino con depósitos turbidíticos.

Cortejo de borde de plataforma (shelf-margin wedge systems tract, SMW): Conjunto de sistemas de depósito acumulados sobre la plataforma continental externa y el talud, formados por cuerpos regresivos de configuración sigmoidal. También denominado "Cuña de borde de plataforma".

Cortejo de nivel alto (highstand systems tract, HST): Conjunto de materiales depositados cuando el nivel relativo del mar está alto y caracterizado, generalmente, por dispositivos progradantes.

Cortejo de nivel bajo (lowstand systems tract, LST): Nombre genérico para el conjunto de sistemas de depósito formados en una fase de nivel relativo del mar bajo. Con frecuencia se divide en: cortejo de abanico submarino ( $L S F$, lowstand fan systems tract) y cuña de nivel bajo ( $L S W$, lowstand wedge systems tract).

Cortejo transgresivo (transgressive systems tract, TST): Conjunto de parasecuencias retrogradantes desarrolladas durante el ascenso relativo del nivel del mar.

Composite Logs: Gráfico compuesto de información procedente de varias diagrafías. Combinan, generalmente a escala 1/500, dos diagrafías con una interpretación litológica del sondeo, en la cual se indican los muros y techos de las formaciones y se describe la litología de las mismas.

Concesión (Concession): Una determinada área concedida a una compañía para la exploración de aceite y/o gas bajo términos y condiciones especificadas, y por un período de tiempo fijo.

Core: Sección de un Hole (sondeo)

Crisis de Salinidad Messiniense (Messinian Salinity Crisis, MSC): A finales del Messiniense se produjo una situación paleoceanográfica sin igual a lo largo de la historia geológica, el aislamiento y desecación del mar Mediterráneo. Este episodio es conocido como “Crisis de Salinidad”.

Cronozona de polaridad (polarity chronozone): Unidad cronoestratigráfica definida a partir de la polaridad del magnetismo remanente.

Cron de polaridad (polarity chron): Unidad geocronológica correspondiente a la cronozona de polaridad magnética.

Cuenca de antepaís (foreland basin): Cuenca sedimentaria subsidente localizada entre el frente de una cordillera plegada y el creatón adyacente originada con posterioridad a la formación de la cadena orogénica. También se utiliza en un sentido más amplio incluyendo, además, la cuenca remanente.

Cuenca remanente (remanent basin ó foredeep basin): Cuenca sedimentaria que se individualiza en el frente de una cadena orogénica durante el tiempo de su formación. 
Cuña de nivel bajo (Lowstand wedge systems tract, $L S W$ ): Cortejo de nivel bajo con forma de cuña formado por sistemas de depósito regresivos y en el que se suele deferenciar: los rellenos de canales, el complejo de canales-diques y el complejo progradante.

Deep Sea Drilling Project (DSDP): Proyecto de investigación, desarrollado desde 1968 a 1983, consistente en la realización de sondeos de testigo contínuo, desde el buque oceanográfico Glomar Challenger, en áreas seleccionadas de los océanos con el fin de avanzar en el conocimiento de la Geología.

Depocentro (depocenter): Área o lugar de una cuenca sedimentaria en la que una unidad estratigráfica concreta alcanza el máximo espesor.

Descenso relativo del nivel del mar (relative fall of sea level): Fenómeno de elevación del fondo marino o hundimiento del nivel del mar, que queda reflejado en las secciones estratigráficas con secuencias de somerización o con discontinuidades.

Diagrafía ( $\log o$ well $\log$ ): Gráfico en el que se representa los valores de una medida contínua de alguna propiedad físisca, obtenidos directamente sobre las paredes de un sondeo. Una diagrafía es el registro continuo de las variaciones de una propiedad física de las rocas atravesadas por un sondeo en función de la profundidad. Para ello se introduce hasta el fondo del sondeo (sin entubar) una sonda, o equipo de medida, conectado con la superficie mediante un cable. Esta sonda realiza mediciones continuas de la propiedad física seleccionada al mismo tiempo que se asciende (fig. 1.4B). Se utilizan dos tipos de sondas: la más simple es una que va suspendida por un cable y que se coloca en el centro del pozo (fig. 1.4B.e) y la otra más compleja es aquella en la que una vez introducida la sonda en el fondo del pozo se abre un dispositivo flexible de manera que el emisor (A en figura 1.4B.d) y receptor (B en figura 1.4B.d) de ondas van apoyados sobre las propias paredes ganando fiabilidad en la medida

Discontinuidad (discontinuity): 1-Relación estratigráfica entre dos materiales superpuestos entre cuyo depósito ha mediado una interrupción sedimentaria reconocible. 2-Relación entre dos unidades estratigráficas entre las que se detecte una laguna estratigráfica (hiato) medible.

Downlap (biselamiento basal): Relación geométrica en bisel de la base de una unidad litosísmica.

DT : (Delta Time). Unidad de tiempo en pies (ft) por segundo. DT (Short Spacing Transit Time (10'-8' spacing; $\mu \mathrm{sec} / \mathrm{ft})$ ): intervalo de tiempo del trayecto de la onda de sonido en microsegundos por pie para la pareja receptora próxima. DTL (Long Spacing Transit Time (12'-10' spacing; $\mu \mathrm{sec} / \mathrm{ft}$ )): Intervalo de tiempo del trayecto de la onda de sonido en microsegundos por pie para la pareja receptora lejana.

Evaluación de impacto ambiental (Environmental Impact Assessment, EIA): Evaluación del impacto de una instalación o actividad sobre el medio ambiente que la rodea, realizada antes de que el trabajo sobre 
esa actividad haya comenzado. El estudio base original, parte clave de este proceso, describe las condiciones originales.

Estadio de nivel alto (highstand): Etapas en las que, en la cuenca sedimentaria, el nivel relativo del mar está alto.

Estadio de nivel bajo (lowstand): Etapas en las que, en la cuenca sedimentaria, el nivel relativo del mar está bajo.

Facies sísmica (seismic facies): Conjunto de propiedades observables en un perfil sísmico que permite diferenciar volúmenes rocosos (unidades litosísmicas).

Falla (Fault-Faulting): Una estructura geológica que consiste de una fractura en la roca, a lo largo de la cual ha habido un perceptible deslizamiento.

Foredeep basin (cuenca remanente): Antefosa. Parte más profunda de una cuenca foreland. Ver cuenca remanente.

Foreland basin (cuenca de antepaís): Ver cuenca de antepaís.

\section{GAS:}

Gas Natural (Natural gas): a).- Una mezcla de hidrocarburos, generalmente gaseosos presentes en forma natural en estructuras subterráneas. El gas natural consiste principalmente de metano (80\%) y proporciones significativas de etano, propano y butano. Habrá siempre alguna cantidad de condensado y/o aceite asociado con el gas. b).- El término también es usado para designar el gas tratado que se abastece a la industria y a los usuarios comerciales y domésticos y tiene una calidad específica.

Gas pobre o gas seco (Lean gas or dry gas).: Gas con relativamente pocos hidrocarburos diferentes al metano. El poder calorífico es típicamente alrededor de 1,000 Btu/pié cúbico estándar, a menos que esté presente una proporción significativa de gases que no sean hidrocarburos.

Gas rico (Rich gas): Gas predominantemente con metano, pero con una proporción relativamente alta de otros hidrocarburos. Muchos de estos hidrocarburos normalmente se separan como líquidos del gas natural.

Gas seco (Dry gas): a).- Lo mismo que gas pobre, que no contiene hidrocarburos que se licuen a temperatura y presión ambiente. b).- Gas que no contiene vapor de agua, gas "sin agua".

GPS (Global Positioning System): Sistema de Posicionamiento Global (http://www.gpsworld.com/).

Hardground (Fondo endurecido) Superficie estratigráfica caracterizada por costras de Fe y Mn, perforaciones, concreciones, etc. originada durante una interrupción sedimentaria en el fondo marino. 
Hiato (Hiatus): 1- Ruptura o interrupción de la continuidad del registro estratigráfico debida a la ausencia de materiales estratificados que en condiciones normales deberían estar presentes pero que faltan o por no haberse depositado o por haberse erosionado antes del depósito de la unidad suprayacente. Sinónimo, laguna estratigráfica.

Hidrocarburo (Hydrocarbon): Cualquier compuesto o mezcla de compuestos, sólido, líquido o gas que contiene carbono e hidrógeno (p. ej. : carbón, aceite crudo y gas natural).

Hidrógeno (Hydrogen): El más ligero de todos los gases, presente principalmente, combinado con oxígeno, en el agua. El hidrógeno se combina con el carbono para formar una enorme variedad de hidrocarburos gaseosos, líquidos y sólidos.

Highstand: Ver estadio de nivel alto.

Highstand systems tract, HST. Ver Cortejo de nivel alto.

Hole: Sondeo (nomenclatura utilizada por $O D P$ ).

ka: Miles de años.

Radiación solar incidente (insolation, INcident SOLar radiATION): Cantidad de energía solar recibida en un lugar, en un momento determinado.

Isobata (Isodepth): Línea o superficie que en un mapa batimétrico, une los puntos de igual profundidad.

Isocrona (isochrone): Línea o superficie que une los puntos de igual edad.

Lago Mare: Denominación que se aplica a las facies características que se depositaron en el Mediterráneo y que presentan un ambiente con características intermedias entre lacustres y marinas. En general domina el carácter salóbre.

Laguna estratigráfica: Ver hiato

Leg: Campaña oceanográfica (nomenclatura utilizada por $O D P$ )

Levantamiento sismológico (Seismic survey): Método para establecer la estructura subterránea detallada mediante la detección y medición de ondas acústicas que refleja el impacto sobre los diferentes estratos de roca. Se le emplea para localizar estructuras potencialmente contenedores de aceite o gas antes de perforar. El procesado datos moderno permite la generación de imágenes de tres dimensiones de estas estructuras subterráneas.

Lodo de perforación (Drilling $m u d$ ): Una mezcla de arcillas, agua y productos químicos utilizada en las operaciones de perforación para lubricar y enfriar la barrena, para elevar hasta la superficie el material que va cortando la barrena, para evitar el colapso de las paredes del pozo y para mantener 
bajo control el flujo ascendente del aceite ó del gas. Circula de forma continua hacia abajo por la tubería de perforación y hacia arriba hasta la superficie por el espacio entre la tubería de perforación y la pared del pozo.

Log: Ver diagrafía.

Lowstand: Ver estadio de nivel bajo.

Lowstand systems tract, LST: Ver Cortejo de nivel bajo.

Ma: Millones de años

Metano (Methane - CH4): La mas pequeña de las moléculas de los hidrocarburos, con un átomo de carbono y cuatro átomos de hidrógeno. Es el componente principal del gas natural, pero también está presente en las capas de carbón, y es producido por la descomposición de restos los vegetales y animales. Es un gas ligero, sin color, sin olor e inflamable bajo condiciones normales. El metano es el primer miembro en la serie de los alcanos (parafinas). A presión atmosférica se licúa a $-162^{\circ} \mathrm{C}$.

Milankovitch, Milutin: Astrónomo yugoslavo (1879-1958) que demostró la periodicidad de las variaciones orbitales de la Tierra con respecto al Sol. Formalizó la hipótesis de que los ciclos glaciales fueron originados por cambios en la órbita terrestre (1920). Muchas de las secuencas sedimentarias muestran ciclicidades con el mismo origen. En su honor, su nombre se utiliza para denominar tanto a los ciclos climáticos inducidos astronómicamente, como al registro estratigráfico de los mismos.

Ocean Drilling Program, ODP: Programa de investigación internacional, de sondeos oceánicos, continuación del Deep Sea Drilling Project a partir de 1984.

Offlap (solapamiento retractivo): Término usado en estratigrafía sísmica para denominar dispositivos de estratos progradante. Progresivo desplazamiento hacia el interior de la cuenca de las terminaciones de las unidades estratigráficas. Antónimo: solapamiento expansivo, onlap.

Offshore: Denominación habitual utilizada para referirse a un área de exploración-producción localizada mar adentro.

Olistostroma (olistostrome): Material alóctono que se emplazó en la cuenca del Guadalquivir proviniente del Sur, de los mantos béticos que están formando en ese momento la nueva cadena montañosa.

Onlap (solapamiento expansivo): Relación basal discordante en la cual los estratos van terminando progresivamente al chocar con la superficie basal inclinada. Antónimo: solapamiento retractivo, offlap.

Onshore: Denominación habitual utilizada al referirse a un área de exploración-producción localizada en tierra. 
Operador (Operator): Compañía, organización o persona con autoridad legal para perforar pozos y extraer hidrocarburos. Puede emplearse un contratista de perforación para llevar a cabo la perforación en sí. El operador es con frecuencia parte de un consorcio y actúa a nombre de este.

Perihelio (Perihelion): El punto más cercano al Sol en la órbita de cualquier cuerpo celeste que se mueva alredor de esta estrella.

Petróleo (Petroleum): Nombre genérico para hidrocarburos, incluyendo petróleo crudo, gas natural y líquidos del gas natural. En ocasiones contiene impurezas, como azufre y nitrógeno. El nombre se deriva del latín, oleum, presente en forma natural en rocas, petra.

Plataforma (Platform): Estructura fija o flotante, costa afuera, desde la cual se perforan pozos. Las plataformas de perforación pueden convertirse en plataformas de producción una vez que los pozos entren en producción.

Pozo (Well): Agujero perforado en la roca desde la superficie de un yacimiento a efecto de explorar o extraer aceite o gas.

Pozo de exploración o de prueba (Wildcat well): Pozo exploratorio perforado sin conocimiento detallado de la estructura rocosa subyacente.

Registro sónico (Sonic log): Un registro del tiempo que toma una onda acústica (sonido) para viajar cierta distancia a través de formaciones geológicas. También es llamado registro acústico. Unidad de medida, DT, Delta Time, velocidad estimada en microsegundos por pie, $\mu \mathrm{s} / \mathrm{f}$.

Regresión (regression): Movimiento de la línea de costa hacia mar adentro.

Regresión forzada (forced regression): cuando en una región tiene lugar un levantamiento brusco por factores tectónicos, emergen amplias zonas marinas que sufren una erosión continental.

Reservas (Reserves): Ver: reservas probadas, reservas probables, reservas posibles y reservas recuperables.

Reservas posibles (Posible reserves): Estimación de reservas de aceite o gas en base a datos geológicos o de ingeniería, de áreas no perforadas o no probadas.

Reservas probables (Probable reserves): Estimación de las reservas de aceite y/o gas en base a estructuras penetradas, pero requiriendo confirmación más avanzada para poderlas clasificar como reservas probadas.

Reservas probadas (Proven reserves): La cantidad de aceite y gas que se estima recuperable de campos conocidos, bajo condiciones económicas y operativas existentes.

Reservas recuperables (Recoverable reserves): La proporción de hidrocarburos que se puede recuperar de un yacimiento empleando técnicas existentes.

Sapropel (sapropel): Son capas de sedimento oscuras, orgánicas, ricas en materia orgánica, que pueden alcanzar $30 \mathrm{~cm}$ de potencia. Se han encontrado principalmente al Sur de Italia, Sicilia y en Creta. 
Fueron depositados hace más de 5 Ma y se cree reflejan distintos cambios en el clima mediterráneo y en la producción orgánica del mar Mediterráneo.

Sarta de perforación (Drill string): Tuberías de acero de aproximadamente 10 metros de largo que se unen para formar un tubo desde la barrena de perforación hasta la plataforma de perforación. El conjunto se gira para llevar a cabo la operación de perforación y también sirve de conducto para el lodo de perforación.

Sección condensada (condensed section): En materioales pelágicos suponen niveles de mínima tasa de sedimentación depositados en los umbrales, frecuentemente asociados con fondos endurecidos y superficies de omisión.

Secuencia (sequence): 1- Módulo distinguible en una sucesión estratigráfica cuyos términos litológicos están dispuestos de manera ordenada y previsible. 2- Forma simplificada de nombrar una secuencia de depósito.

Secuencia de depósito (depositional sequence): Parte de una sucesión estratigráfica relativamente concordante de estratos genéticamente relacionados y cuyo techo y muro son discontinuidades o continuidades correlativas. Se trata de una unidad estratigráfica híbrida, en parte limitada por discontinuidades y en parte unidades cronoestratigráficas.

Secuencia sísmica (seismic sequence): Un conjunto de reflectores continuos en el espacio y en el tiempo genéticamente relacionados, que están limitados en su base y en su techo por discontinuidades, o por sus continuidades correlativas.

Site: Estación/Emplazamiento. Lugar en el que se posiciona el barco para extraer uno o varios sondeos en una campaña oceanográfica (nomenclatura utilizada por $O D P$ ).

Sísmica de reflexión (reflection seismic lines): La sísmica de reflexión es un método geofísico basado en la emisión, recepción y registro, desde superficie, de ondas acústicas con características de frecuencia, amplitud y forma ajustadas a la penetración y a la resolución que se desea obtener. Los registros proporcionan información acerca de las propiedades físicas y la estructura (o geometría) de los materiales del subsuelo, mostrando además las profundidades a las que se encuentran las superficies que separan materiales de distintas características sísmicas. Las profundidades de estas superficies se obtienen midiendo automáticamente los tiempos empleados por las ondas en su camino de ida y vuelta ( $D T$ ó TD, tiempo doble: ida y vuelta) desde el momento de la emisión inicial hasta la recepción y registro finales, de las ondas reflejadas en ellas.

Sistema de depósito (depositional system): Cuerpo tridimensional de litofacies genéticamente relacionadas depositadas en un mismo medio sedimentaio.

Solsticio (solstice): Momento del año en el que el sol incide directamente sobre el trópico de Cáncer (solsticio de verano), o sobre el trópico de Capricornio (solsticio de invierno). 
Sonic log: Ver Registro sónico.

STARPAC: Programa informático para realizar análisis estadísticos que permite entre otros desarrollar la demodulación compleja. Puede obtenerse más información sobre este programa en la dirección de internet: http://www.scd.ucar.edu/softlib/STARPAC.html

Subida relativa del nivel del mar (relative rise of sea level): Fenómeno de hundimiento del fondo marino o de elevación del nivel del mar, que queda reflejado en las series estratigráficas con secuencias de profundización.

Subsidencia (subsidence): Hundimiento de una cuenca sedimentaria (o de un sector de la misma) simultáneo al depósito.

Superficie de máxima inundación (maximum flooding surface, $m f s$ ): Superficie que marca el techo de un cortejo transgresivo y el inicio de un cortejo de nivel alto.

Superficie transgresiva (transgresive surface, $t s$ ): Superficie reconocida en una sección estratigráfica que marca el inicio de un episodio transgresivo. Superficie que marca el límite entre el cortejo de nivel del mar bajo y el corteno transgresivo.

Systems tract: Ver cortejo sedimentario.

Toplap (biselamiento somital): Relación geométrica en bisel del techo de una unidad litosísmica.

Torre de perforación (Derrick): Estructura de acero montada sobre la boca del pozo para soportar la tubería de perforación y otros equipos que son descendidos y elevados durante las operaciones de perforación.

Trampa (Trap): Estructura geológica en la cual se acumulan hidrocarburos para formar un campo de aceite o gas. Ver también: Trampa estratigráfica.

Trampa estratigráfica (Stratigraphic trap): Trampa de hidrocarburos formada durante la sedimentación y en la cual los hidrocarburos fueron encapsulados como resultado del cambio de roca de porosa a no porosa. Si la trampa es debida al plegamiento o falla de los estratos de roca se denomina trampa estructural.

Transgresión (transgression): Movimiento tierra adentro de la línea de costa. Antónimo, regresión.

Transgressive systems tract, TST: Ver Cortejo transgresivo.

Unidad bioestratigráfica (bioestratigraphic unit): Volumen de materiales diferenciado por su contenido paleontológico.

Unidad cicloestratigráfica (cyclostratigraphic unit): Conjunto de materiales del registro estratigráfico de una región que representan una etapa o un periodo histórico en la evolución de una cuenca, que están delimitadas por sendas discontinuidades estratigráficas o por inflexiones en la polaridad 
evolutiva, y que puede tener su origen en factores orogénicos, epirogénico, eustáticos, sedimentarios, ecológicos o climáticos.

Unidad cronoestratigráfica (chronostratigraphic unit): Volumen de materiales diferenciado por su edad.

Unidad de depósito (depositional unit): Conjunto de materiales depositados bajo unas mismas condiciones sedimentarias.

Unidad estratigráfica (stratigraphic unit): Nombre genérico que se utiliza para denominar a los volúmenes de rocas diferenciados a partir de cualquiera de sus propiedades.

Unidad litosísmica (seismic facies unit): Unidad estratigráfica deducida a partir de datos procedentes de la sísmica de reflexión.

Unidad magnetoestratigráfica (magnetoestratigraphic unit): Unidad estratigráfica delimitada por tener diferentes algunas de las propiedades del magnetismo remanente.

Unidad tectosedimentaria (tectosedimentary unit, UTS): Unidad estratigráfica cuya evolución en la vertical y la horizontal viene caracterizada por una determinada polaridad sedimentaria y tectónica genéticamente relacionada. Término afín, secuencia de depósito.

Yacimiento (Reservoir): Acumulación de aceite y/o gas en una roca porosa tal como una arenisca. Un yacimiento petrolífero normalmente contiene tres fluidos (aceite, gas y agua) que se separan en secciones distintas debido a sus gravedades variantes. El gas siendo el más ligero ocupa la parte superior del yacimiento, el aceite la parte intermedia y el agua la parte inferior.

Yacimiento de hidrocarburos (Hydrocarbone Reservoir).- Es la porción de una trampa geológica que contiene hidrocarburos, la cual se comporta como un sistema intercomunicado hidráulicamente. Los hidrocarburos ocupan los poros de la roca almacenante, quedan confinados por una roca impermeable en la parte superior e inicialmente se encuentran a alta presión y temperatura, debido a la profundidad del yacimiento.

Zona bioestratigráfica (bioestratigraphic zone): Término general utilizado para las unidades bioestratigráficas. Sinónimo de biozona.

Zona eufótica (euphotic zone): Parte del océano en la que llega la luz solar permitiendo la fotosíntesis. Usualmente se extiende hasta los 60 o $70 \mathrm{~m}$ de profundidad. 


\section{ABREVIATURAS}

Se han utilizado las siguientes abreviaturas:

Acme: Incremento significativo de una especie.

API: unidad estandard de medida de rayos gamma, establecida por el American Petroleum Institute

APTS: Astronomical Polarity Time Scales.

Escala de Tiempo de Polaridad Astronómica.

At: Atlántida (sondeo)

BFU:basal foredeep unconformity, reflector sísmico que representa la discordancia basal de fondo de cuenca en el golfo de Cádiz

(Maldonado et al., 1999)

com. per.: Comentario personal.

DSDP: Deep Sea Drilling Program (programa de perforación del océano profundo, antecesor de $O D P$ )

DT: double time, tiempo de transito de una onda compresiva a través de la formación, medida en microsegundos por pie ( $\mu \mathrm{s} / \mathrm{f})$.

dx: formas dextrorsas, dextrógiras, aquellas en las que el crecimiento de su concha se produce hacia la derecha, en el sentido de las agujas del reloj.

en prep.: en preparación

FCO: First Common Occurrence, primera aparición común-abundante de una especie, genero o grupo.

$\boldsymbol{F O}$ : First Occurrence, primera aparición de una especie, genero o grupo. Equivalente a"biohorizonte de primera aparición" (Vera, 1994).

GC: Golfo de Cádiz

Gg: Globigerina

$\boldsymbol{G}$ : Globorotalia

GR: Gamma Ray (API Units), rayos gamma (unidades API)
Gs: Globigerinoides

en prensa: en prensa

ITGE: Instituto Tecnológico GeoMinero de España

mfs: maximun flooding surface. Ver "superficie de máxima inundación" en Glosario.

LCO: Last Common Occurrence última aparición común-abundante-regular de una especie, genero o grupo.

LO: Last Occurrence, última aparición de una especie, genero o grupo. Equivalente a"biohorizonte de última presencia" (Vera, 1994).

Ma-2, Ma-4: Marismas 2 y 4 (sondeos)

Ma: Millones de años

mbsf: meters below sea floor, metros bajo el fondo marino

MOW: Mediterranean Outflow Water. Masa de agua de salida del Mediterráneo

N.: Neogloboquadrina

MSC: Messinian Salinity Crisis, Crisis de

Salinidad Messiniense.

n.m.: nivel del mar

ODP: Ocean Drilling Program (Programa de Perforación Oceánico)

Palc: Palancares (sondeo)

paracme: Dentro de una biozona, reducción significativa de la especie que la define.

Rep. Ex.: Información de Repsol Exploración

Sec: Secuencia (de secuencia de depósito)

Sev: Sevilla (sondeo) 
sin: formas sinistrorsas, levógiras, aquellas

formas en las que el crecimiento de su concha se produce hacia la izquierda, en el sentido opuesto a las agujas del reloj.

SJ: San Juan (sondeo)

Tl /T. lateral: Testigo lateral ts: (transgresive surface) superficies transgresivas que se reflejan porque son los primeros depósitos sedimentados después de un tiempo de bajo nivel del mar (LST, Lowstand Systems Tract) 


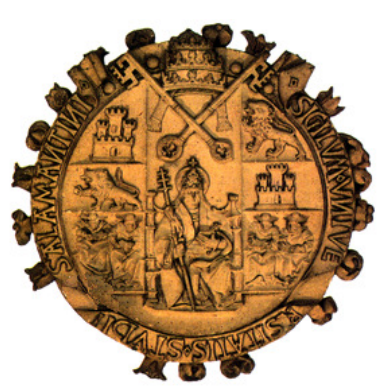

DEPARTAMENTO DE GEOLOGÍA - UNIVERSIDAD DE SALAMANCA

Santiago Ledesma (correo electrónico): ledesma@gugu.usal.es 